KATIA YAGUIU

\title{
MODELO PARA O DIMENSIONAMENTO DE UMA FROTA DE CONTÊINERES PARA UMA EMPRESA DE NAVEGAÇÃO
}

Dissertação apresentada à Escola Politécnica da Universidade de São Paulo para a obtenção do Título de Mestre em Engenharia, junto ao Departame nto de Engenharia Naval e Oceânica. 
KATIA YAGUIU

\section{MODELO PARA O DIMENSIONAMENTO DE UMA FROTA DE CONTÊINERES PARA UMA EMPRESA DE NAVEGAÇÃO}

Dissertação apresentada à Escola Politécnica da Universidade de São Paulo para a obtenção do Título de Mestre em Engenharia, junto ao Departamento de Engenharia Naval e Oceânica.

Área de Concentração:

Engenharia Naval e Oceânica

Orientador:

Professor Dr. Marco Antonio Brinati

São Paulo

2006 


\section{FICHA CATALOGRÁFICA}

Yaguiu, Katia

Modelo para o dimensionamento de uma frota de contêineres para uma empresa de navegação. São Paulo, 2006.

$167 p$.

Dissertação (Mestrado) - Escola Politécnica da Universidade de São Paulo. Departamento de Engenharia Naval e Oceânica.

1. Programação Linear 2. Contêineres 3. Dimensionamento

I. Universidade de São Paulo. Escola Politécnica. Departamento de Engenharia Naval e Oceânica II. T 
À minha família, em especial, meus pais e à minha irmã Andréa, por todo apoio e carinho. 


\section{AGRADECIMENTOS}

Ao mestre, conselheiro, orientador e principalmente amigo Prof. Dr. Marco Antonio Brinati, por ter acreditado e me dado confiança na condução e concretização deste trabalho.

Aos meus amigos Eng ${ }^{\circ}$. Celso Mitsuo Hino e Eng. Antonio Augusto Russo pela amizade, companheirismo e apoio dado em todos os momentos que precisei. Sou eternamente grata a vocês.

Ao Prof. Hugo Tsugunobu Yoshida Yoshizaki pelo apoio que me auxiliou em momento decisivos.

A Lânia, Sandra, César, Adenilson, Max, Damares por toda ajuda que sempre me foi dispensada.

Aos demais amigos que sempre fizeram parte da minha história, desde a graduação, e que me apoiaram durante a elaboração do trabalho.

A CAPES, pelo suporte financeiro para a realização desta pesquisa. 
"Conte-me e eu esqueço.

Mostre-me e eu apenas me lembro.

Envolva-me e eu compreendo."

(Confúcio) 


\section{RESUMO}

Para uma empresa de navegação, ma nter uma frota grande de contêineres próprios poderia gerar custos desnecessários para manutenção dos estoques destes contêineres; contudo, se a frota de contêineres próprios for pequena, poderia resultar em um número grande de contêineres arrendados a curto prazo.

Assim, nesta dissertação desenvolve-se um modelo de programação linear capaz de estimar a frota ótima de contêineres próprios e alugados, que envolve a dificuldade da tomada de decisão em um comércio extremamente desequilibrado.

A revisão bibliográfica apresenta poucas publicações que tratam do tema proposto. O trabalho desenvolvido por Imai e Rivera (2001) é examinado por ser mais semelhante ao tema proposto para esta dissertação. Por tratarem do dimensionamento de frota de contêineres para dois portos e não admitirem aleatoriedades nos tempos de movimentação terrestre de contêineres outros procedimentos foram examinados.

Para tentar solucionar o problema de dimensionamento de frota de contêineres próprios para a empresa de navegação dois métodos são analisados: modelo de simulação probabilística e modelo de programação linear. O modelo de simulação é desenvolvido para um problema pequeno. Conforme a ampliação deste modelo e o aumento do número de variáveis, o modelo de simulação passou a ser difícil de ser controlado, pois a mudança dos valores destas variáveis se tornaria muito difícil.

O modelo de programação linear é desenvolvido com base nas características e definições adotadas para o modelo de simulação. Este modelo matemático incorpora as aleatoriedades existentes nos processos terrestres, de acordo com as hipóteses adotadas. Este modelo permite auxiliar o planejador a tomar decisões estratégicas, com relação ao tamanho da frota de contêineres necessários para atender a demanda de transporte ao longo do horizonte de planejamento, e operacionais, por apresentar o fluxo de transporte de contêineres vazios entre portos, bem como a quantidade de contêineres alugados, se necessários, para realizar as operações emergenciais associadas a picos de demanda ao longo do período de planejamento.

Para testar a consistência do modelo, cenários hipotéticos foram gerados. Por meio dos resultados obtidos para estes cenários, mostra-se a relação do custo dos contêineres alugados e do custo do transporte de contêineres próprios vazios sobre o tamanho da frota de contêineres próprios. 


\begin{abstract}
For a carrier, provide a large fleet of owned containers could generate unnecessary costs for maintenance of their inventories; however, if the fleet of owned containers is small, it might result in a large number of short-term leased containers.

Thus, it is developed a linear programming model capable to determine the optimal fleet size of owned and leased containers that involves the difficulty of decision-making in an extremely unbalanced trade.

The literature survey presents few publications that deal with the considered subject. The work developed for Imai and Rivera (2001) is examined by being more similar to the subject considered in this project. For dealing with the container fleet sizing for two ports and not admitting stochastic travel times inland of containers other procedures are examined.

To solve the problem of own container fleet sizing for the carriers two methods are analyzed: probabilistic simulation model and linear programming model. The simulation model is developed for a small problem. As the growing of this model and the increase of the number of variables, the simulation model becomes difficult to control, because the change of the values of these variables would become very hard.

The linear programming model is developed on the basis of the characteristics and definitions adopted for the simulation model. This mathematical model incorporates the existing stochastic inland times, in accordance with the adopted hypotheses. This model allows to assist the planner to make strategical decisions, with regard to the size of the fleet of containers necessary to attempt the demand of transport throughout the planning horizon, and operational, for presenting the flow of empty containers between ports, as well as the amount of leased containers, if necessary, to carry through the special operations associated the peaks of demand throughout the period of planning.

To test the consistency of the model, hypothetical scenes had been generated. By the results gotten for these scenes, it is showed the relation of the cost of leases containers and the cost of the transport of empty owned containers above the owned container fleet size.
\end{abstract}




\section{LISTA DE FIGURAS}

Figura 1-1 - Movimentação de contêineres na costa leste da América Latina ..........................................................6

Figura 2-1- Fluxograma do Processo de Modelagem ...................................................................................................14

Figura 2-2-Sistema estudado por Turnquist e Jordan .................................................................................................16

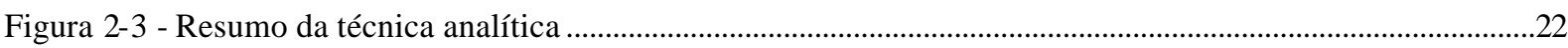

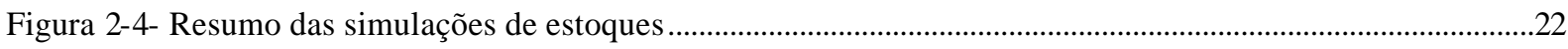

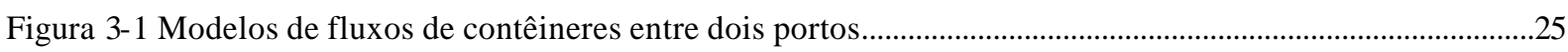

Figura 3-2 Conservação dos Fluxos de Contêineres nos Portos ...............................................................................29

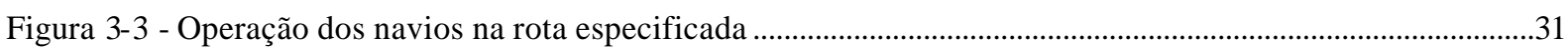

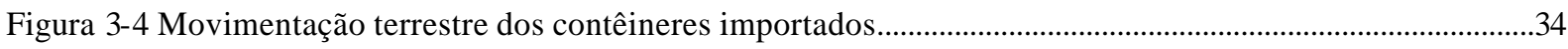

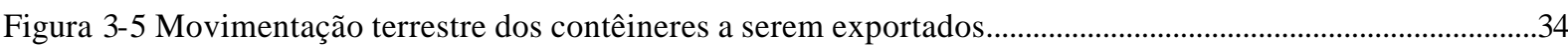

Figura 3-6 Gráfico referente à evolução do estoque no porto 1 .....................................................................................36

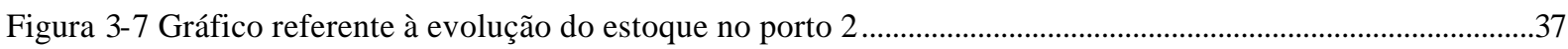

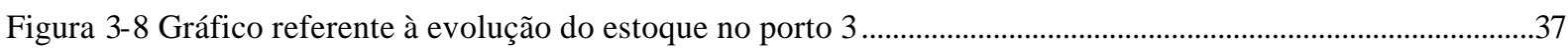

Figura 4-1 Rota genérica para a definição do modelo de programação linear ..........................................................50

Figura 4-2 Importação de contêineres cheios e vazios pelo porto ................................................................................51

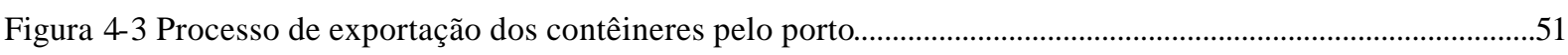

Figura 5-1 Definição da rota considerada e da posição dos navios no início do horizonte de planejamento ...........73

Figura 5-2 Freqüência relativa do tempo de retorno dos contêineres para o Cenário - Base.....................................77

Figura 5-3 Variação da freqüência relativa para o grupo de cenários $B$.......................................................................81

Figura 5-4 Variação da demanda de contêineres cheios importados em cada porto no sentido sul ..........................85

Figura 5-5 Variação da demanda de contêineres cheios importados em cada porto no sentido norte .......................85

Figura 5-6 Variação da demanda de contêineres cheios exportados em cada porto no sentido sul...........................86

Figura 5-7 Variação da demanda de contêineres cheios exportados em cada porto no sentido norte......................86

Figura 0-1 Modelos de fluxos de contêineres entre dois portos.................................................................................95

Figura 0-2 Conservação dos Fluxos de Contêineres nos Portos ................................................................................99

Figura 0-3 Fluxograma referente à logica de operação dos navios .............................................................104

Figura 0-4 Fluxograma referente ao processo de descarregamento dos contêineres cheios ................................106

Figura 0-5 Fluxograma referente ao processo dos contêineres vazios...........................................................107 


\section{LISTA DE TABELAS}

Tabela 1-1 Estimativa do fluxo de carga para as maiores rotas de comércio (em milhões de TEU's) 3

Tabela 3-1 - Quantidade de contêineres cheios nos navios no início da simulação e os contêineres movimentados nos portos

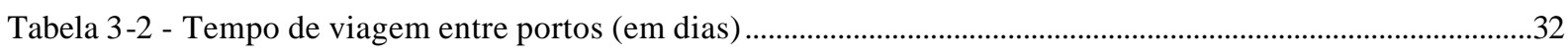

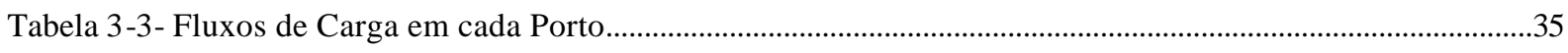

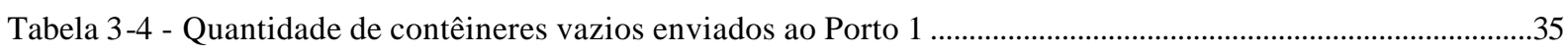

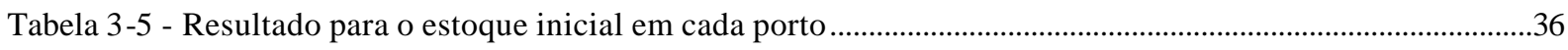

Tabela 3-6 - Resultado para o estoque inicial em cada porto por meio do modelo matemático ................................44

Tabela 3-7 Resultados obtidos para os modelos de simulação e de programação linear...........................................44

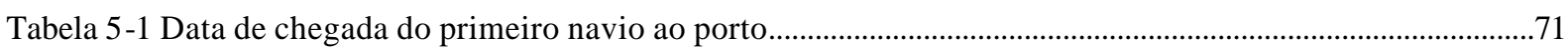

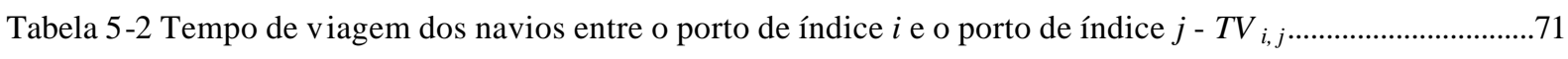

Tabela 5-3 Tempo restante para a chegada de cada navio a cada porto na primeira viagem.....................................72

Tabela 5-4 Significado dos trechos para a rota considerada............................................................................................72

Tabela 5-5 Contêineres existentes nos navios - do porto de índice $i$ para o porto de índice $j$ - em cada trecho da

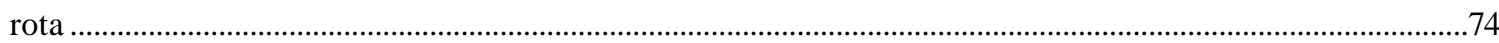

Tabela 5-6 Demanda de contêineres cheios exportados em cada porto nos sentidos sul e norte para o caso da

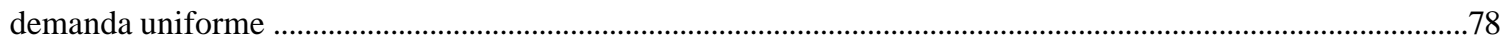

Tabela 5-7 Demanda de contêineres cheios importados em cada porto nos sentidos sul e norte para o caso da demanda uniforme .78

Tabela 5-8 Transporte de contêineres vazios entre cada par de portos e em cada sentido da rota............................79

Tabela 5-9 Resultados obtidos para os cenários $A$ com variação do tempo de retorno dos contêineres .................80

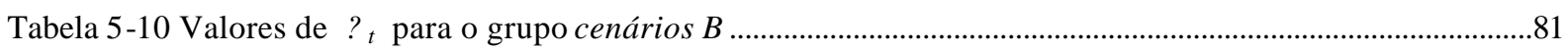

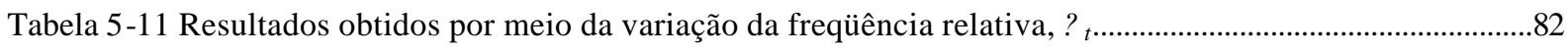

Tabela 5-12 Descrição das alterações do grupo de cenários $C$...................................................................................82

Tabela 5-13 Resultados obtidos para os cenários do grupo $C$..............................................................................83

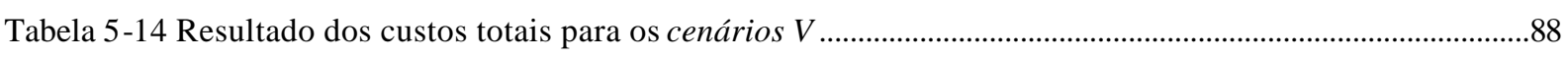

Tabela 5-15 - Tamanho da frota própria variando-se o custo de leasing ........................................................................8

Tabela 5-16 Resultados obtidos para a variação do custo do transporte de contêineres vazios .................................90

Tabela 5-17 Tamanho da frota própria variando o custo do transporte de contêineres vazios...................................90 


\section{SUMÁRIO}

\section{LISTA DE FIGURAS}

LISTA DE TABELAS

CAPÍTULO 1 - O TRANSPORTE MARÍTIMO DE CONTÊINERES E O PROBLEMA DE

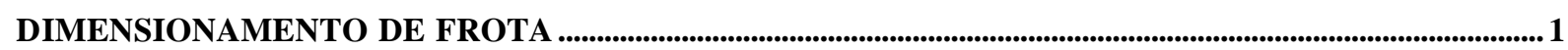

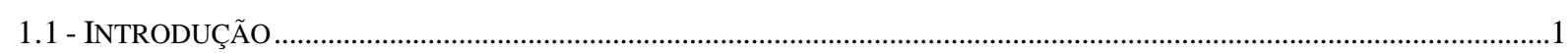

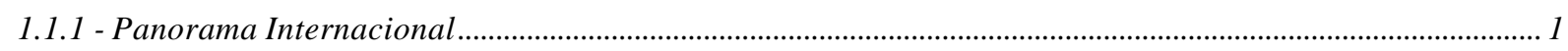

1.1.2 - Rotas Internacionais de Comércio ......................................................................................................... 3

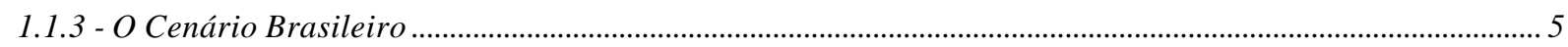

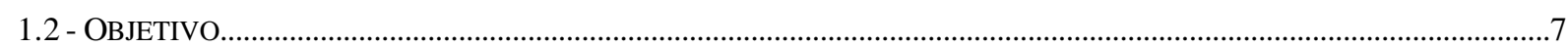

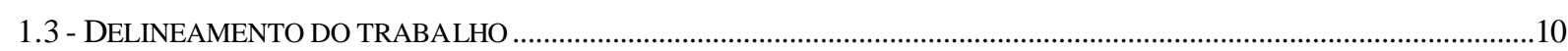

CAPÍTULO 2 - REVISÃO BIBLIOGRÁFICA.................................................................................................11

2.1 - MODELOS DE DIMENSIONAMENTO DE FROTA DE CONTÊINERES ...............................................................................11

2.2 - MODELOS DE DIMENSIONAMENTO DE FROTA DE VEÍCULOS …………………………………………………….......16

2.3 - MODELOS PARA ADMINISTRAÇÃO DE VEÍCULOS E CONTÊINERES VAZIOS...............................................................18

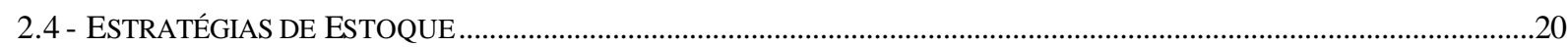

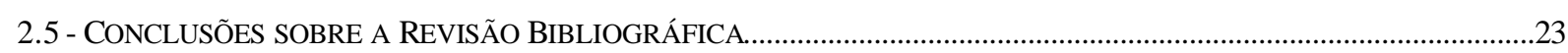

\section{CAPÍTULO 3 - MÉTODOS PARA RESOLUÇÃO DO PROBLEMA DE DIMENSIONAMENTO DA} FROTA DE CONTÊINERES ..........................................................................................................................24

3.1 - PROCEDIMENTOS PROPOST OS POR IMAI E RIVERA (2001) …………………………………………………………......24

3.1.1 - Descrição dos procedimentos propostos por Imai e Rivera (2001) ................................................................25

3.2 - MODELO DE SIMULAÇ̃̃O P ARA UM PROBLEMA PEQUENO DE DIMENSIONAMENTO DE FROTA.................................30

3.2.1 - A Operação dos navios................................................................................................................................

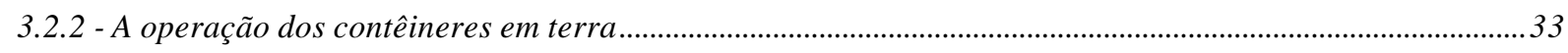

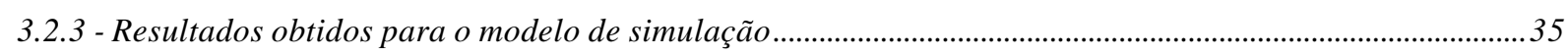

3.3 - MODELO DE PROGRAMAÇÃO LINEAR PARA UM PROBLEMA PEQUENO DE DIMENSIONAMENTO DE FROTA...........38

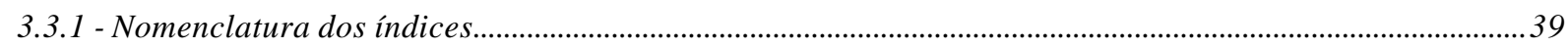

3.3.2 - Nomenclatura dos parâmetros......................................................................................................... 39

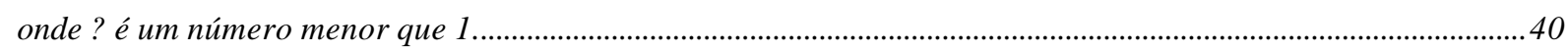

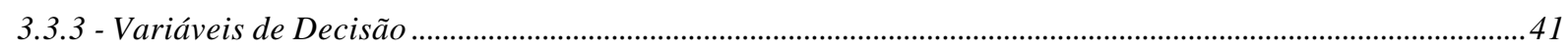

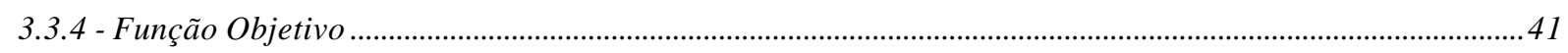

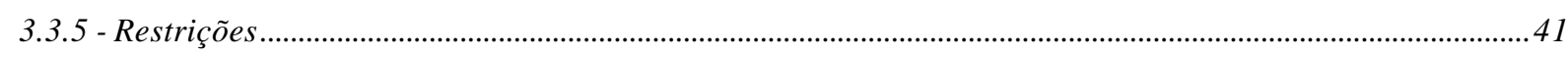

3.3.6 - Resultados obtidos para o modelo de programação linear ……………………………………………………...4

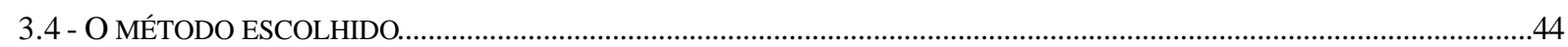




\section{CAPÍTULO 4 - DESCRIÇÃO E MODELAGEM PROPOSTA PARA O PROBLEMA DE}

DIMENSIONAMENTO DA FROTA DE CONTÊINERES .............................................................................................46

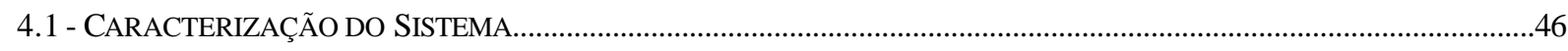

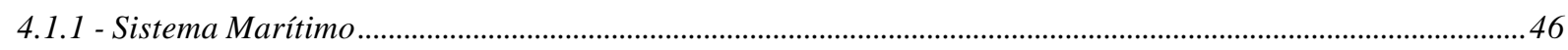

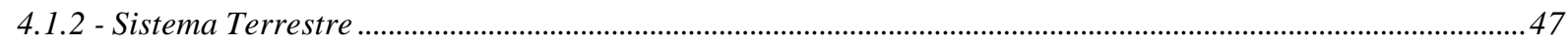

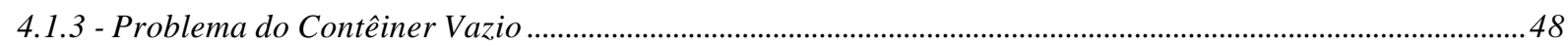

4.2 - DESCRIÇÃO DO SISTEMA DE TRANSPORTE A SER MODELADO................................................................................49

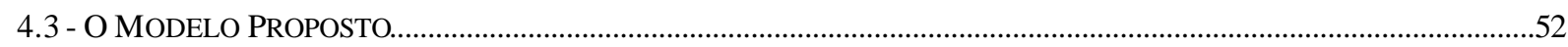

4.3.1 - Nomenclatura dos índices ....................................................................................................................5

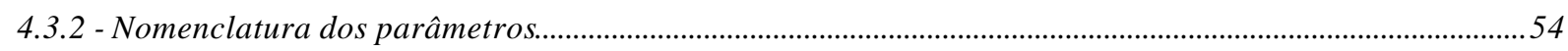

4.3.3 - Variáveis de Decisão …………………………………………………………………………………...59

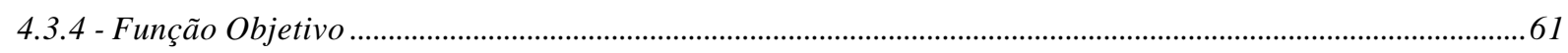

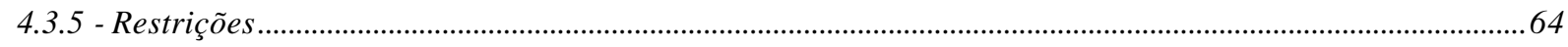

4.4 - VARIANTES PARA O MODELO DE PROGRAMAÇÃo LINEAR PROPOSTO......................................................................68

CAPÍTUlO 5 - APLICAÇõeS dO MODELO DE PROGRAMAÇÃo LINEAR PARA O ESTUDO DE

CASO.......................................................................................................................................................................................70

5.1 - DEFINIÇÃO DOS PARÂMET ROS UTILIZADOS PARA A GERAÇÃO DE TODOS OS CENÁRIOS.........................................70

5.2 - DEMANDA UNIFORME AO LONGO DO HORIZONTE DE PLANEJAMENTO_....................................................................75

5.2.1 - Dimensionamento da frota de contêineres próprios para demanda uniforme ao longo do tempo...............75

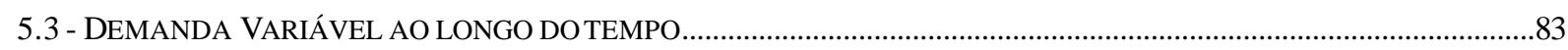

CAPÍTULO 6 - CONSIDERAÇÕES FINAIS..................................................................................................91

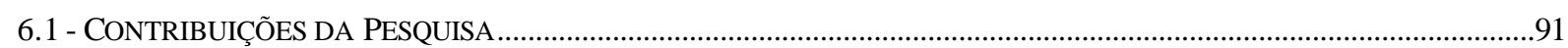

6.2 - LiMITAÇÕES E SUGESTÕES DE CONTINUIDADE DA PESQUISA ...................................................................................92

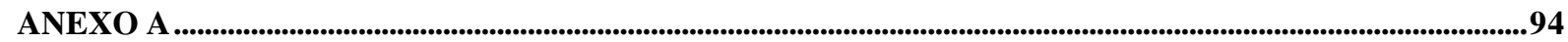

ANEXO B ........................................................................................................................................102

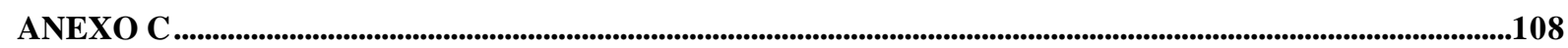

ANEXO D .........................................................................................................................................127

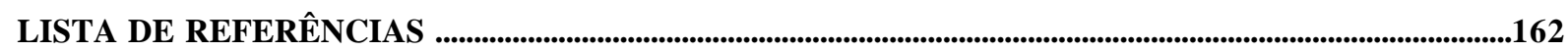




\section{CAPÍTULO 1 - O TRANSPORTE MARÍTIMO DE}

\section{CONTÊINERES E O PROBLEMA DE DIMENSIONAMENTO}

\section{DE FROTA}

Neste capítulo descrevem-se as condições atuais dos mercados internacional e brasileiro. Ainda, uma breve descrição do problema de dimensionamento da frota de contêineres para uma empresa de navegação é apresentada.

\section{1 - Introdução}

\subsection{1 - Panorama Internacional}

A introdução de contêineres para o transporte marítimo de cargas, a partir da década de 1960, modificou a operação tanto das empresas de navegação quanto das áreas portuárias. Nos portos, a principal modificação foi a redução da quantidade de mão-de-obra necessária para o manuseio de cargas e para as operações de embarque e desembarque. $\mathrm{O}$ acondicionamento das cargas nos contêineres pode ser descentralizado e realizado na origem 
DIMENSIONAMENTO DE FROTA

das mercadorias, nas fábricas, ou por meio de serviços especializados, dentro ou fora das áreas dos portos. Como resultado, o tempo necessário para transportar as cargas dentro do porto e embarcá- las nos navios foi reduzido.

O transporte internacional de carga geral tem sido realizado por poucas empresas que vêm dominando, através de fusões e associações, o transporte de contêineres. Essas grandes transportadoras globais deixaram de oferecer transporte porto-a-porto, passando a oferecer serviços porta-a-porta, utilizando sofisticados serviços de logística. Durante os últimos anos, as grandes transportadoras globais (mega carriers) passaram a ser proprietárias de portos centralizadores, de terminais, de imensas frotas mercantes (muitas vezes superiores a toda frota brasileira), de ferrovias etc.

A necessidade de manutenção de uma freqüência regular de navios em determinados portos torna as empresas vulneráveis às oscilações da demanda por transportes. Como os navios não têm usos alternativos que não seja o transporte de contêineres, existe pouca flexibilidade no curto prazo para ajustes da oferta quando ocorrem reduções da demanda. Além disso, o tempo entre a assinatura de um contrato de construção de um novo navio e sua efetiva entrada em operação pode levar de dois a três anos, o que também dificulta a resposta das empresas a mudanças no mercado de transporte.

A administração das frotas de contêineres também é complicada pelos desequilíbrios dos fluxos de comércio, que em geral têm maior densidade de cargas em um sentido, obrigando o reposicionamento dos contêineres vazios para as regiões exportadoras. Outro fator relevante é a existência da descontinuidade na oferta de transporte marítimo, pois cada navio adicionado às frotas representa um aumento relativamente grande da capacidade de transporte, enquanto o crescimento da demanda pode acontecer de forma progressiva. Uma empresa de navegação operando a plena capacidade, a fim de atender a um pequeno aumento 
DIMENSIONAMENTO DE FROTA

da demanda, teria de adquirir outro navio que, durante algum tempo, ficaria em grande parte ocioso.

Diante dessas complexidades da administração da oferta de serviços de transporte de contêineres, as empresas de navegação buscam realizar arranjos cooperativos entre elas para a operação conjunta das frotas e a repartição de espaço nos navios.

\subsection{2 - Rotas Internacionais de Comércio}

Os contêineres fluem ao longo das rotas leste-oeste (transpacífico, Europa-leste e transatlântica), norte-sul e das rotas regionais. A principal rota de transporte do comércio internacional é a leste-oeste, que interliga Ásia, América do Norte e Europa Ocidental, por onde são transportados cerca de $44 \%$ da carga mundial e utilizados $60 \%$ da frota mundial de navios porta-contêineres, além da maioria dos navios com mais de dois mil TEUs.

A Tabela 1-1 abaixo apresenta as estimativas dos fluxos de carga conteinerizada para as três maiores rotas leste-oeste.

Tabela 1-1 Estimativa do fluxo de carga para as maiores rotas de comércio (em milhões de TEU’s)

\begin{tabular}{lcccccc}
\hline \multirow{2}{*}{ Year } & \multicolumn{2}{c}{ Trans-Pacific } & \multicolumn{2}{c}{ Europe-Asia } & \multicolumn{2}{c}{ Transatlantic } \\
\cline { 2 - 7 } & Asia-USA & USA-Asia & $\begin{array}{c}\text { Europe- } \\
\text { Asia }\end{array}$ & $\begin{array}{c}\text { Asia- } \\
\text { Europe }\end{array}$ & USA-Europe Europe-USA \\
\hline $\mathbf{2 0 0 2}$ & 8.81 & 3.90 & 3.94 & 6.13 & 1.50 & 2.59 \\
$\mathbf{2 0 0 3}$ & 10.19 & 4.12 & 4.00 & 7.06 & 1.58 & 2.56 \\
$\%$ change & 15.7 & 5.6 & 1.5 & 15.2 & 5.3 & -1.0 \\
\hline
\end{tabular}

Fonte: UNCTAD (2003)

Na maior rota leste-oeste, a transpacífica, estima-se que o fluxo total tenha alcançado 14,3 milhões de TEU's em 2003, de acordo com a previsão da UNCTAD (2003). O fluxo de contêineres no sentido Ásia - América do Norte alcançou 10,1 milhões de TEU's, enquanto 
DIMENSIONAMENTO DE FROTA

que no sentido oposto o fluxo era menor que a metade, cerca de 4,2 milhões de TEU's. Como conseqüência, o desequilíbrio contínuo dos fluxos de contêineres e o reposicionamento de contêineres vazios tornaram-se o principal interesse para as transportadoras. Na rota ÁsiaEuropa, estimou-se um carregamento de 11 milhões de TEU's durante 2003. Outra vez, houve um desequilíbrio entre os fluxos no sentido ocidental, originários da Ásia, que alcançou 7 milhões de TEU's, e no sentido oriental, que foram estimados para totalizar 4 milhões de TEU's. Entretanto, este desequilíbrio do fluxo era menos expressivo do que aquele que existia através do Pacífico. Na rota transatlântica, Europa - América do Norte, a menor das rotas leste-oeste, o fluxo de contêineres estimado foi de 4,6 milhões de TEU's, sendo que da Europa para a América do Norte alcançoutse 2,9 milhões de TEU’s e no sentido oposto eram quase 1,7 milhões de TEU's. O fluxo de tráfego total nestas três rotas leste-oeste alcançou quase 30 milhões de TEU's, com o reposicionamento de contêineres vazios sendo uma característica importante em todas elas.

As rotas norte-sul, que transportam cerca de $22 \%$ da carga mundial, estão articuladas em torno dos principais centros de produção e de consumo da Europa e da América do Norte, ligando estes centros aos países em desenvolvimento. Ainda segundo a UNCTAD, em 2003, acreditava-se que as rotas norte-sul carregaram até 16 milhões de TEU's. Os fluxos de contêineres nas rotas que ligavam a Europa à África e à Oceania alcançaram 0,7 e 0,6 milhão de TEU's, respectivamente. Os fluxos foram distribuídos quase uniformemente entre os sentidos norte-sul. Os fluxos de contêineres entre a Europa e a América Central e América do Sul eram quase quatro vezes maior, cerca de 2,5 milhões de TEU's, sendo que no sentido sul os fluxos totalizaram menos de 1 milhão de TEU’s, gerando também um desequilíbrio. Os fluxos entre a América do Norte e América Central e do Sul foram maiores, aproximadamente 3 milhões de TEU's, com um desequilíbrio similar, sendo que os fluxos no sentido sul foram 
DIMENSIONAMENTO DE FROTA

estimados em 1,3 milhão de TEU's. Os fluxos de contêineres entre a Ásia e a Oceania alcançaram 1,7 milhão de TEU’s.

As rotas regionais, que transportam cargas a pequenas distâncias, são responsáveis pela movimentação de $34 \%$ da carga mundial. Estimou-se que para a maior rota regional, a intra-Ásia, o fluxo de contêineres tenha sido de 17 milhões de TEU’s em 2003.

A movimentação de contêineres na América do Sul corresponde a $4 \%$ da movimentação mundial. O Brasil encontra-se em uma rota internacional de comércio marítimo com baixa densidade de cargas, quando comparada com as rotas principais, o que resulta em maiores custos do transporte marítimo do comércio exterior brasileiro.

\subsection{3 - O Cenário Brasileiro}

O Brasil é o principal movimentador de contêineres na costa leste da América Latina. Em 2002, segundo o Anuário Estatístico Portuário, a movimentação de contêineres nos portos brasileiros (2,9 milhões de TEU's) correspondeu a 24\% da movimentação de contêineres na costa leste da América Latina e a 53\% da movimentação de contêineres na costa leste da América do Sul (ver Figura 1-1 ).

Os portos da região Sudeste do Brasil foram responsáveis, em 2002, por quase 50\% da movimentação total de contêineres nos portos brasileiros, sendo que somente a participação do porto de Santos foi de $36 \%$. A região Sul respondeu por $38 \%$ da movimentação e as regiões Nordeste e Norte por $9 \%$ e 5\%, respectivamente. 


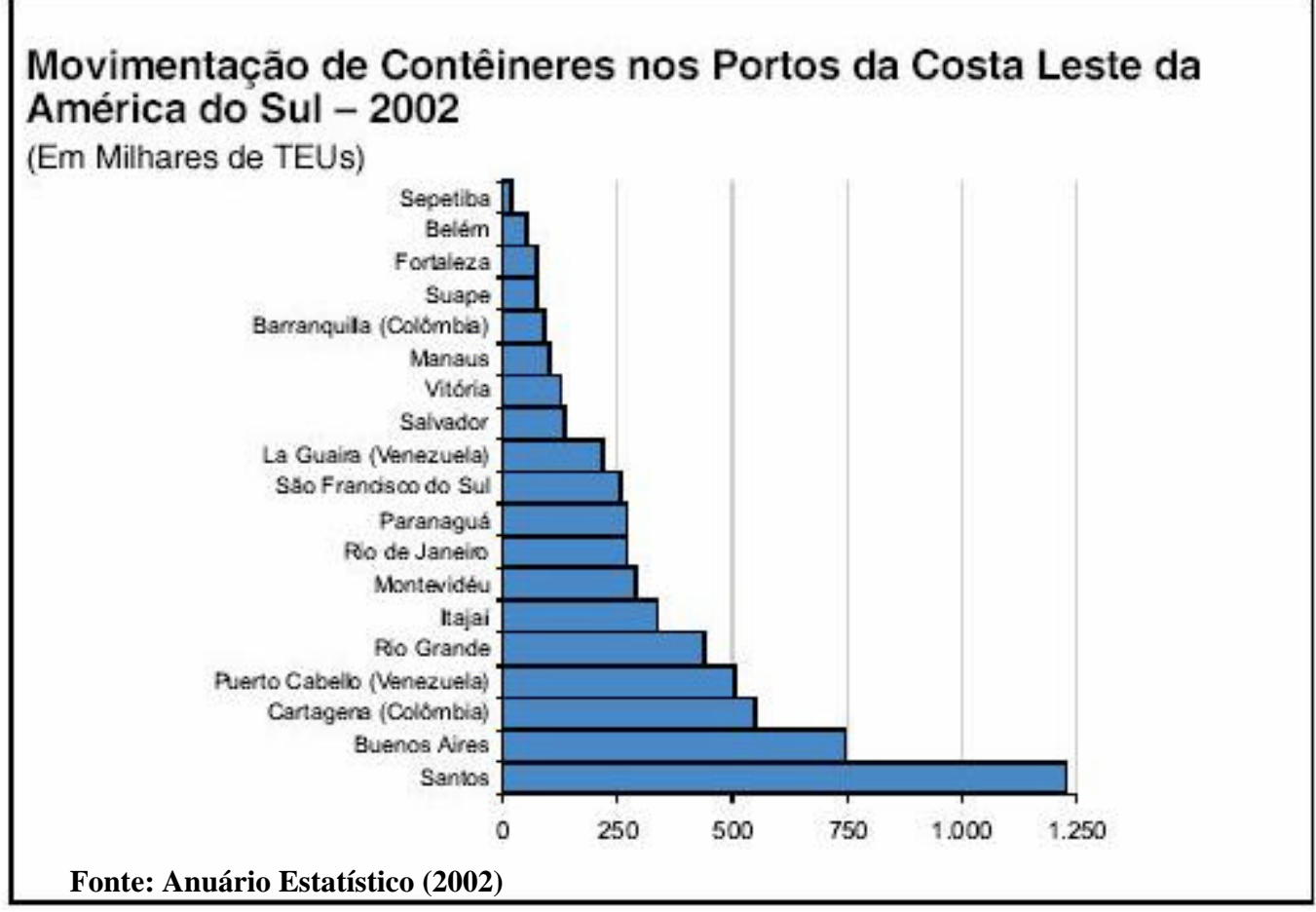

Figura 1-1 - Movimentação de contêineres na costa leste da América Latina

A demanda por transporte de contêineres é concentrada na região entre os portos do Rio de Janeiro e de Buenos Aires, que, numa distância de 1.141 milhas marítimas, engloba $68 \%$ da movimentação de contêineres na costa leste da América do Sul. Os portos localizados no trecho de 3.284 milhas marítimas entre Rio de Janeiro e Manaus, por outro lado, respondem por apenas $7 \%$ dos contêineres movimentados na costa leste da América do Sul.

Entre 1999 e 2003, a movimentação de contêineres nos portos do país dobrou e, no primeiro semestre de 2004, sua procura estava aquecida a ponto de causar falta de contêine res para embarques de cargas de exportação. Tem contribuído para o aumento da demanda por contêineres, além da expansão das exportações, a crescente eficiência dos terminais portuários. Tanto a navegação quanto os portos passaram por profundas modificações na década de 1990, com a transferência das operações portuárias das companhias docas estatais para operadores privados e a liberalização da navegação de longo curso. Os resultados dessas transformações foram a redução de custos de transportes e o aumento de sua eficiência. Entre 
DIMENSIONAMENTO DE FROTA

1989 e 2000, os custos de fretes de importação como proporção do valor das mercadorias importadas diminuiu de $9 \%$ para $4,7 \%$.

Como resultado da redução de custos portuários e do aumento da eficiência dos terminais, o transporte de contêineres pela navegação de cabotagem tem apresentado forte crescimento. A oferta atual desse tipo de serviço, no entanto, acontece nas rotas de longas distâncias, como, por exemplo, entre Santos e Manaus. Quanto maior a distância, maior a vantagem de custos da cabotagem frente ao transporte rodoviário, o que leva as empresas de navegação a concentrar sua limitada oferta de serviços nessas rotas.

Atualmente, já não basta oferecer bons serviços portuários. É preciso viabilizar a implantação de sistemas de logística de abrangência global, no interior dos quais os portos brasileiros funcionem como um eficiente elo da corrente.

\section{2 - Objetivo}

Devido ao aumento das atividades de comércio globais, a indústria de transporte marítimo tem crescido continuamente durante a última década. Em particular, o setor de serviço regular altamente conteinerizado é aquele que vem crescendo mais rapidamente. Atualmente, $80 \%$ dos navios do setor de serviço regular na rota transpacífica são navios celulares, e quase todos os navios novos são construídos para fazer parte desta categoria. Um dos assuntos mais importantes e difíceis é dimensionar o tamanho da frota de contêineres próprios e o da frota de contêineres arrendados a longo prazo.

Em geral, técnicas eficientes de planejamento são importantes não somente para questões estratégicas, mas, também para a tomada de decisão operacional. No primeiro grupo estão a definição da roteirização do navio associada à escolha de portos e problemas de 
DIMENSIONAMENTO DE FROTA

dimensionamento da frota de contêineres. Problemas de tamanho da frota de contêineres decidem o número de contêineres requeridos para atender demandas futuras de transporte, enquanto problemas de administração da frota de contêineres alocam contêineres vazios a remessas subseqüentes e decidem pelo arrendamento de contêineres a curto prazo devido a uma escassez de contêineres vazios.

Se as transportadoras proverem uma frota grande de contêineres próprios, então elas normalmente têm um fardo pequeno de movimentos de contêineres vazios. Por outro lado, quando a frota de contêineres próprios for pequena, poderia resultar em um número grande de contêineres arrendados a curto prazo. Em resumo, há uma relação íntima importante entre problemas de administração da frota e tamanho da frota. Apesar de tais interações importantes entre estratégia e operação, é mais conveniente separar os problemas do ponto de vista prático. Tamanho da frota é planejamento a longo prazo, enquanto administração da frota é relacionada ao planejamento a curto prazo. Há alguns estudos relacionados ao tamanho da frota em outros meios de transporte como aéreo, férreo e rodoviário. Porém, nenhum estudo foi encontrado para o tamanho da frota de contêineres.

Modelos de tamanho de frota normalmente tratam do seguinte problema: dada a demanda para viagens carregadas (número de viagens que deixam cada nó da rede) e as características de cada viagem (comprimento, incerteza, etc), qual é o número ótimo de veículos necessários para satisfazer demandas com respeito a algum critério.

Um efeito potencial importante de uma melhor distribuição de veículos vazios é permitir reduções de tamanho de frota sem degradar a qualidade do serviço. A maioria dos papers existentes relativos ao tamanho de frota está relacionada com investigações de administração de frota; os modelos desenvolvidos compartilham semelhanças entre o problema de tamanho de frota para contêineres marítimos e para outros meios de transporte 
DIMENSIONAMENTO DE FROTA

como o aéreo, férreo e rodoviário. Porém, poucos tratam de características específicas do tamanho de frota para contêineres marítimos.

A proposta deste trabalho é desenvolver um modelo matemático determinístico e de simulação capazes de estimar a frota ótima de contêineres, próprios ou alugados, que envolve a dificuldade da tomada de decisão em um comércio extremamente desequilibrado sob o ponto de vista de uma empresa de navegação.

É desejável que se possa contar com um modelo generalizado, capaz de propiciar uma análise operacional da frota de contêineres. Para isso, poderiam ser variados: as demandas, as características de cada viagem, tais como duração, distância, os tipos de contêineres envolvidos, além dos principais parâmetros deste sistema de transporte, tais como:

a. Número de contêineres em cada navio;

b. Tempo do contêiner em terra;

c. Disponibilidade do contêiner;

d. Estoque de contêineres nos portos;

e. Desbalanceamento do sistema (importação/exportação).

De posse do modelo, das características de demanda de uma carga (origem, destino, volumes, etc.), das características operacionais e dos parâmetros de custo envolvidos, será possível simular a operação deste sistema, aproximando-se de uma condição real de operação, visando tornar o dimensionamento o mais realista possível. 
DIMENSIONAMENTO DE FROTA

\section{3 - Delineamento do trabalho}

Neste capítulo foram apresentadas as principais características dos cenários internacional e brasileiro, bem como uma breve descrição do problema a ser abordado e o objetivo desta dissertação.

O capítulo 2 dedica-se à revisão bibliográfica sobre temas relacionados ao assunto a ser estudado.

No capítulo 3, examinam-se alguns métodos para a resolução do problema de dimensionamento da frota de contêineres, justificando, assim, o procedimento escolhido.

O capítulo 4 apresenta uma descrição detalhada do problema, o modelo de programação linear proposto, assim como as principais premissas adotadas.

No capítulo 5, demonstra-se a aplicação do modelo desenvolvido para o estudo de caso. Descrevem-se, também, as simplificações adotadas e os resultados obtidos com os cenários gerados para este modelo.

O capítulo 6 apresenta as considerações finais do presente trabalho fazendo uma análise crítica do modelo de programação linear proposto para a resolução do problema estudado, bem como sugestões para trabalhos futuros. 


\section{CAPÍTULO 2 - REVISÃO BIBLIOGRÁFICA}

A bibliografia apresenta poucas referências específicas para o caso do tamanho da frota de contêineres. Alguns trabalhos encontrados relacionam o tamanho da frota para os meios de transporte como o aéreo (aviões), rodoviário (carros, caminhões) e marítimo (navios). As publicações mais recentes relacionadas ao transporte de contêineres ou tratam do problema do contêiner vazio ou relatam as condições do mercado e as tendências do setor. Assim sendo, praticamente inexistem estudos que tratam das características específicas e de soluções para o tema proposto. A seguir, faz-se uma breve revisão bibliográfica de alguns trabalhos.

\section{1 - Modelos de dimensionamento de frota de contêineres}

Imai e Rivera (2001) trataram do problema de tamanho de frota para contêineres refrigerados. Para estes autores, um dos assuntos mais difíceis e importantes era determinar o tamanho da frota de contêineres próprios associados ao leasing de contêineres a longo prazo. Eles discutiram um modelo analítico para determinar o tamanho da frota de contêineres próprios do tipo dry para um comércio relativamente balanceado. Em seguida, estenderam 
este modelo para a determinação do tamanho da frota para contêineres refrigerados para um mercado extremamente desbalanceado. Por último, desenvolveram um modelo de simulação numa situação mais real do comércio para determinar a melhor composição de uma frota de contêineres refrigerados incluindo próprios e alugados.

Para o primeiro modelo analítico, os autores desenvolveram uma formulação para determinar o tamanho da frota admitindo as seguintes hipóteses:

i. Contêineres carregados são entregues aos clientes tão logo cheguem ao porto de destino;

ii. Os contêineres vazios são mandados de volta ao porto de origem tão logo eles retornem dos clientes de importação;

iii. Tempo médio de carregamento e descarregamento;

iv. Dada uma quantidade de carga anual, admite-se a quantidade média de carga por viagem;

v. Tempo de porto dos navios é nulo.

Os modelos analíticos são para o caso de rotas com apenas dois portos, ou seja, Origem-Destino. Além disso, adotou-se uma demanda constante ao longo do horizonte de planejamento.

Para o modelo de simulação proposto, pretendeu-se determinar uma composição de uma frota de contêineres refrigerados contendo tanto contêineres próprios como alugados. Além de todas as hipóteses adotadas para os modelos analíticos, admitiram-se interações prédeterminadas de contêineres vazios para uma rota com múltiplos portos.

Gao (1994), por sua vez, desenvolveu um modelo matemático capaz de tratar com a compra, arrendamento, estoque e alocação dos contêineres de forma a alcançar soluções de custo mínimo para ambas decisões de investimento de capital (tamanho do estoque de contêiner) e decisões operacionais de rotina (alocação de contêineres vazios) sujeitos a uma 
variedade de serviços. Para isto, ele analisou o processo de desequilíbrio dos fluxos de contêineres importados e exportados, o qual seria gerado pela "auto-produção" de contêineres vazios, ou seja, quando os contêineres cheios, após entregues aos clientes de importação, retornam ao porto como contêineres vazios.

O autor caracterizou o problema como sendo um serviço de navegação regular consistindo de um feeder e uma rede de navegação de transbordo, que possui $\mathrm{N}$ diferentes portos permitindo $\mathrm{M}$ diferentes rotas. As rotas de navegação e os tempos de passagem dos navios nos portos eram fixos, determinísticos. Assim, dados os fluxos de carga, a programação de navegação, o tempo de retorno do contêiner cheio em cada porto, pretendeuse estimar, para um dado período de tempo no futuro, $t$ ? $t+T$ : (1) quantos contêineres deveriam ser armazenados em cada porto para qualquer tempo dado; (2) quantos contêineres deveriam ser empregados no total durante este período; e (3) como o operador deveria manipulá-los para alcançar os custos mínimos ou os lucros máximos.

Para auxiliar a resolução do problema, algumas hipóteses foram adotadas:

a. Os fluxos de carga, ou seja, as movimentações de carga de entrada e saída em cada porto durante todo o período previsto, eram conhecidos no início;

b. As demandas de carga deveriam ser satisfeitas devido às penalidades serem muito altas;

c. Os contêineres cheios retornavam a uma taxa constante em todos os portos. Notase que o autor utilizou o termo "tempo de retorno dos contêineres cheios" como sendo o tempo que o contêiner leva para ser transportado até o cliente de importação, desovado e retornar vazio até o depósito da empresa de navegação junto ao porto para ser reutilizado;

d. Para simplificação, todos os contêineres foram tratados como sendo de $20^{\prime}$ do tipo dry. 
Além disto, algumas medidas foram tomadas para manipular os contêineres a fim de minimizar os custos:

i. Manter os contêineres vazios em um porto para algum futuro arranjo;

ii. Reposicionar os contêineres vazios para outros portos sob as limitações de espaço dos navios, considerando também as diferenças entre os fluxos de contêineres nos portos;

iii. Alugar ou devolver alguns contêineres sob as limitações do mercado de leasing no porto.

O processo foi, então, dividido em dois estágios, Figura 2-1. No primeiro estágio, analisou-se o comportamento da auto-produção dos contêineres e, então, calculou-se o desequilíbrio existente entre a oferta e demanda por contêineres em cada porto da rede. No segundo estágio, desenvolveu-se um modelo de programação linear para corrigir este desequilíbrio através do custo mínimo.

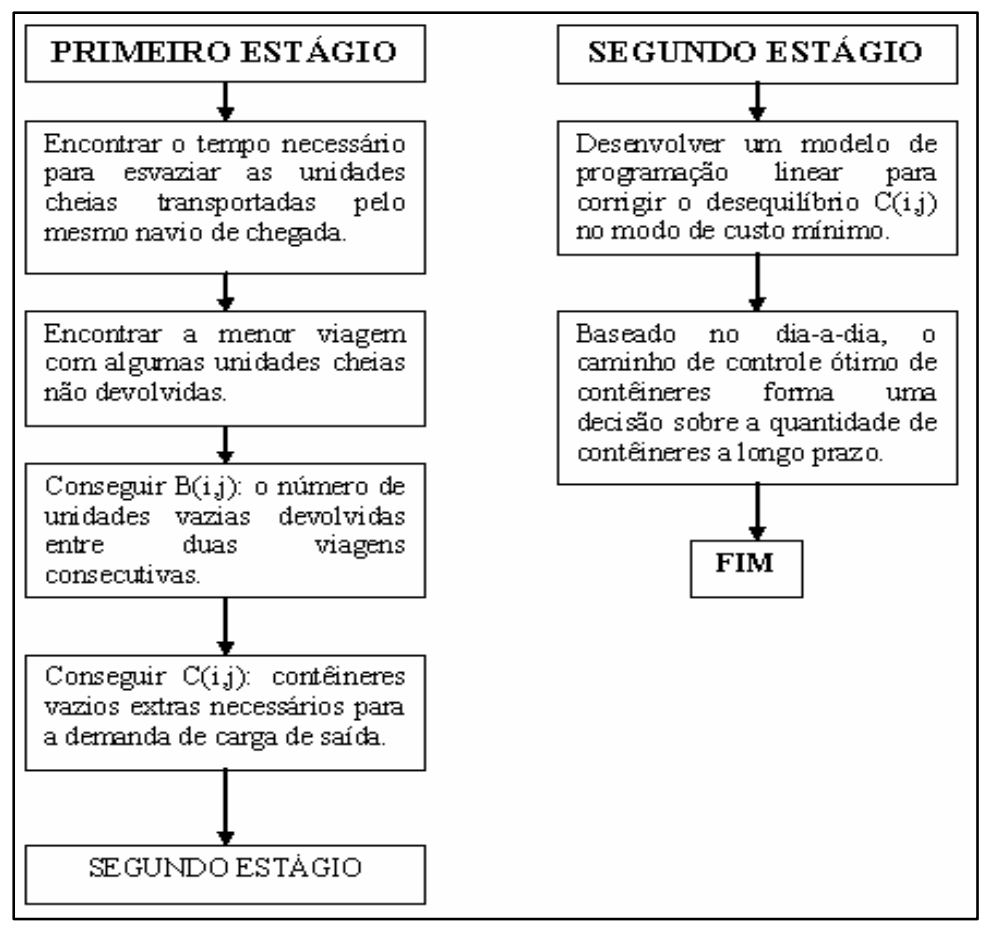

Figura 2-1- Fluxograma do Processo de Modelagem 
Turnquist e Jordan (1986) procuraram determinar o tamanho da frota para um único tipo de contêiner usado para transportar peças de uma fábrica até várias montadoras. A Figura 2-2 ilustra este sistema.

Para a formulação do modelo, os autores adotaram algumas hipóteses:

(1) a produção das peças era um ciclo arbitrário, porém determinístico;

(2) o tamanho do lote para transporte era fixo e pequeno comparado com o número de peças produzidas em um ciclo de produção;

(3) os transportes eram freqüentes, no mínimo, diários.

Quando os tempos de viagem forem certos e o ciclo de produção for fixo, caracterizando um problema completamente determinístico, a solução óbvia para o problema de tamanho de frota é somente ter contêineres necessários para acomodar a produção específica e as programações dos navios. Contudo, quando os tempos de viagem dos contêineres são incertos, há uma probabilidade de que o carregamento atrase, causando uma falta de contêineres. Assim, o que este modelo propõe é uma solução do seguinte tipo: "se a probabilidade de esgotamento dos contêineres não for maior do que x, a frota requerida será y".

No caso do modelo determinístico, os contêineres ou estavam na fábrica ou nas montadoras ou estavam em trânsito. Então, para determinar o tamanho da frota, foram analisados os números de contêineres em cada estágio. 


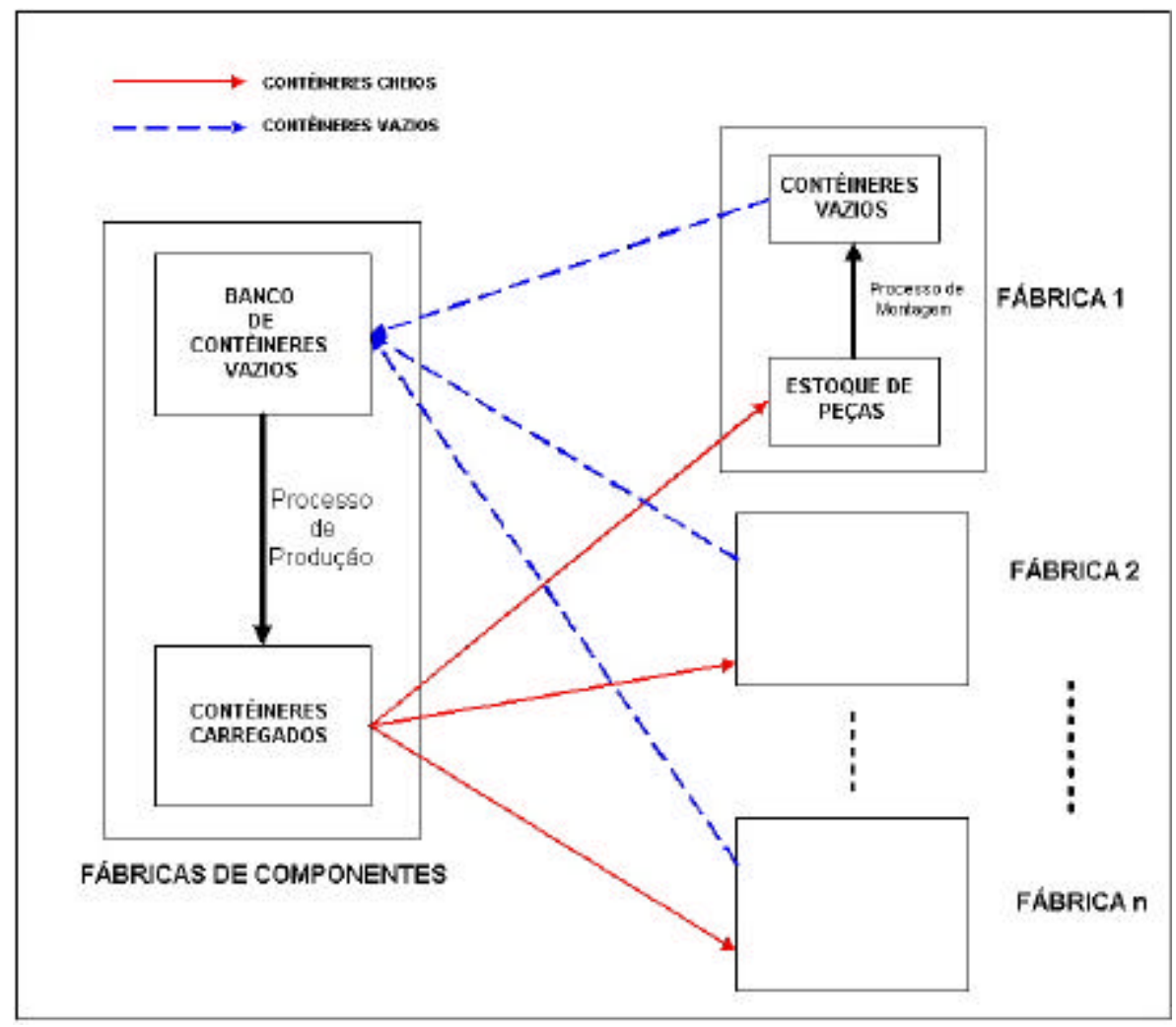

Figura 2-2-Sistema estudado por Turnquist e Jordan

\section{2 - Modelos de dimensionamento de frota de veículos}

Apesar de tratarem de dimensionamento de frota, os modelos que quantificam a frota de contêineres e os que dimensionam a frota de veículos são diferentes, principalmente, no que diz respeito ao arrendamento de contêineres a longo prazo e à aleatoriedade dos tempos de trânsito dos contêineres em terra, ou seja, desde sua chegada até o seu retorno ao porto.

Gertsbach e Gurevich (1977) desenvolveram um modelo para a determinação de uma frota ótima de veículos para terminais específicos de partida e chegada, isto é, para tempos de partida e de chegada fixos (uma variante determinística). O modelo era dependente do teorema da coincidência entre a função déficit total e o tamanho da frota de veículos, e a solução obtida foi generalizada para uma programação periódica. A função déficit para cada 
estação foi definida como a diferença entre os números de partidas e chegadas de veículos dentro do intervalo de tempo em consideração. Assim, o tamanho da frota era igual à soma dos valores máximos das funções déficit total para todos os terminais.

Sherali e Tuncbilek (1997) objetivaram desenvolver modelos práticos de tamanho de frota para as indústrias automobilísticas e ferrovias, relacionados com o problema de transporte de automóveis através de vagões ferroviários. Foram investigados e comparados modelos de tamanho de frota estocásticos e dinâmicos. A proposta do modelo dinâmico era baseada em uma representação da rede no espaço-tempo, no qual cada local de origem e destino em cada dia do horizonte de planejamento foi representado por um nó distinto. A solução deste problema foi feita através da decomposição do processo de solução em uma seqüência de subproblemas da rede espaço-tempo. Foram apresentados, também, modelos estáticos mais simples na qual suas calibrações foram examinadas para produzir resultados que fossem compatíveis com os do modelo dinâmico. Um caso-base foi rodado para se comparar os modelos dinâmico e estático. O resultado encontrado pelo modelo estático foi muito próximo do valor da frota ótima encontrada pelo modelo dinâmico.

Fagerholt (1999) realizou um trabalho baseado num problema real que envolveu o desenvolvimento de um sistema para o transporte de carga a partir de vários portos produtores da costa Norueguesa até os mercados na Europa e nos Estados Unidos. O sistema foi dividido em duas partes: a primeira parte consistiu no transporte da carga dos portos produtores até um porto principal, e a segunda, que transportaria a carga deste porto principal até os mercados. $\mathrm{O}$ objetivo deste trabalho era desenvolver uma frota ótima de navios para a primeira parte, chamado de sistema alimentador, e designar rotas semanais coerentes para os navios da frota. Para achar o tamanho da frota ótima, levourse em consideração os custos fixos (aluguel dos navios) e operacionais dos navios. A solução do problema foi dividida em três fases. Na fase 1, todas as rotas simples possíveis foram geradas para o navio de maior tamanho. Na fase 2, 
as rotas simples geradas foram combinadas em rotas múltiplas. Na fase 3, através da resolução de um problema set partitioning, encontrou-se a frota ótima e as rotas coerentes para esta frota.

\section{3 - Modelos para administração de veículos e contêineres vazios}

Além dos problemas descritos acima, alguns pesquisadores realizaram investigações no que concerne à alocação e distribuição de veículos e recipientes vazios. Um efeito potencial importante de uma melhor distribuição de unidades vazias é permitir reduções de tamanho de frota sem degradar a qualidade do serviço.

Mendiratta e Turnquist (1982) realizaram uma tentativa bem sucedida de construção de um modelo geral de controle do estoque de carros vazios para uma rede ferroviária inteira. Segundo os autores, a falta de coordenação entre as decisões tomadas centralizadas para a ferrovia inteira e as decisões tomadas localmente em terminais individuais era a principal razão para os problemas de distribuição de carros vazios. Conseqüentemente, o modelo incorporou a interação de submodelos - o modelo da rede e o modelo do terminal - cada um representando as atividades realizadas no nível correspondente no sistema da ferrovia: a tomada de decisão central estava relacionada com as movimentações sobre a rede total ferroviária, enquanto que as decisões de tamanho de estoque eram tomadas em cada terminal individual ferroviário. Assim, as decisões eram tomadas em cada nível (corporativo e terminal), enquanto que a coordenação entre os dois níveis dependia de um mecanismo de preço. O objetivo do sistema era maximizar os lucros para a ferrovia sujeito a restrições impostas pela disponibilidade de carros vazios, demandas por carros vazios e requisições institucionais. A fim de se alcançar a otimalidade do sistema, houve uma troca interativa de 
informação entre o modelo da rede e o modelo do terminal. O modelo da rede determinou os preços de transferência interna para os carros vazios, que foram, então, introduzidos no modelo do terminal; o modelo do terminal usou estes preços para determinar os pedidos de liberação dos carros. Estes pedidos e liberações foram introduzidos de volta no modelo da rede para o recálculo dos preços de transferência. As interações continuaram até que os resultados dos dois modelos fossem consistentes e que os preços de transferência interna entre os dois modelos refletissem o custo de oportunidade dos carros.

Glickman e Sherali (1985) objetivaram achar a distribuição ótima de carros vazios pertencentes a mais de uma empresa a partir de diferentes pontos de vista. Para isto, um conjunto de modelos foi desenvolvido. Sob o foco do sistema, o primeiro modelo foi desenvolvido, cujo dbjetivo era minimizar o custo total de distribuição e intercâmbio dos carros vazios entre empresas. Assim, determinou-se a solução ótima para um modelo que satisfazia a demanda sem considerar os lucros relativos para cada empresa. Usando o custo mínimo total associado como uma referência, um segundo modelo foi desenvolvido, aperfeiçoando o balanço dos lucros relativos entre as empresas de acordo com um critério determinado que permaneça dentro de um limite especificado pelo ótimo do primeiro modelo. Sob o foco da companhia, um terceiro modelo minimiza o custo total considerando os lucros que a distribuição e o intercâmbio de carros daria para cada empresa. A comparação das soluções dos modelos permitiu uma estimativa dos custos de reunir os objetivos de cada empresa.

Crainic et al. (1993) propuseram modelos para a alocação de contêineres vazios em um sistema de transporte e distribuição por terra, levando-se em consideração a dependência do espaço e do tempo dos eventos e as incertezas de oferta e demanda do sistema. Além disso, foram consideradas também as características operacionais, tais como: as substituições entre 
os tipos de contêineres, as relações entre companhias do mesmo ramo, importações e exportações e grande equilíbrio dos fluxos. Foram desenvolvidos dois modelos determinísticos, um para um só tipo de contêiner e outro para o caso de vários tipos de contêineres, ou seja, onde substituições parciais eram permitidas. Em seguida, desenvolveurse um modelo estocástico para o caso de um só tipo de contêiner, levando-se em consideração a aleatoriedade da maioria dos parâmetros. Este trabalho foi um dos pioneiros a tratar da alocação do contêiner vazio em terra.

Chong et al. (2001) realizaram uma análise computacional dos efeitos do horizonte de planejamento no controle de contêineres vazios para redes de transporte multimodal. Foram considerados os modais rodoviário, ferroviário e fluvial. Desenvolveu-se um modelo de programação linear no qual sua estrutura básica era uma adaptação do modelo determinístico para um único tipo de contêiner aplicado por Crainic et al. (1993). Discutiu-se o efeito do comprimento do horizonte de planejamento sobre o estoque inicial de contêineres em cada pólo, o número de pólos no sistema e o modal de transporte utilizado. Concluiu-se que maiores horizontes de planejamento permitem um melhor controle do contêiner, uma vez que os planos de distribuição eram realizados antecipadamente. Além disso, eles incentivaram o uso dos modais mais lentos e mais baratos, como as chatas.

\section{4 - Estratégias de Estoque}

O estoque de segurança ameniza as variações e incertezas de curto prazo, tanto para a demanda quanto para o tempo de realocação dos contêineres. É necessário que haja um cuidadoso planejamento na determinação do estoque de segurança, a fim de não se obter contêineres vazios em excesso e, conseqüentemente, maiores custos. 
Segundo Bowersox e Closs (2001), as decisões relacionadas à análise de estoques concentram-se na determinação dos melhores parâmetros de gerenciamento de estoques para atingir níveis de serviço desejados com os menores investimentos. A análise pode ser realizada periodicamente, até mesmo diariamente, com o objetivo de tornar os parâmetros mais sensíveis a, por exemplo, alterações da demanda ou tempo de ciclo das operações.

Ainda segundo os autores, há dois tipos de técnicas para realizar a análise do estoque: as técnicas analíticas e as de simulação.

As técnicas analíticas utilizam relações funcionais para determinar os parâmetros ideais de estoque e níveis de serviço desejados. A Figura 2-3 ilustra o conceito de da técnica analítica para estoques. Esta técnica baseia-se em hipóteses sobre o sistema logístico e sobre as probabilidades relativas às características da demanda e do ciclo de operações. A vantagem da técnica analítica para estoque é a possibilidade de determinar diretamente os melhores parâmetros de estoques, com base em hipóteses do ambiente operacional. Porém, são de limitada exatidão quando estas hipóteses não são bem parametrizadas ou coerentes com a realidade. Isto se deve ao fato da maioria das técnicas analíticas considerarem uma distribuição normal para a demanda e os ciclos de atividades, sendo que há grandes chances de que o perfil da demanda real e o ciclo de atividades tenham outras distribuições. 


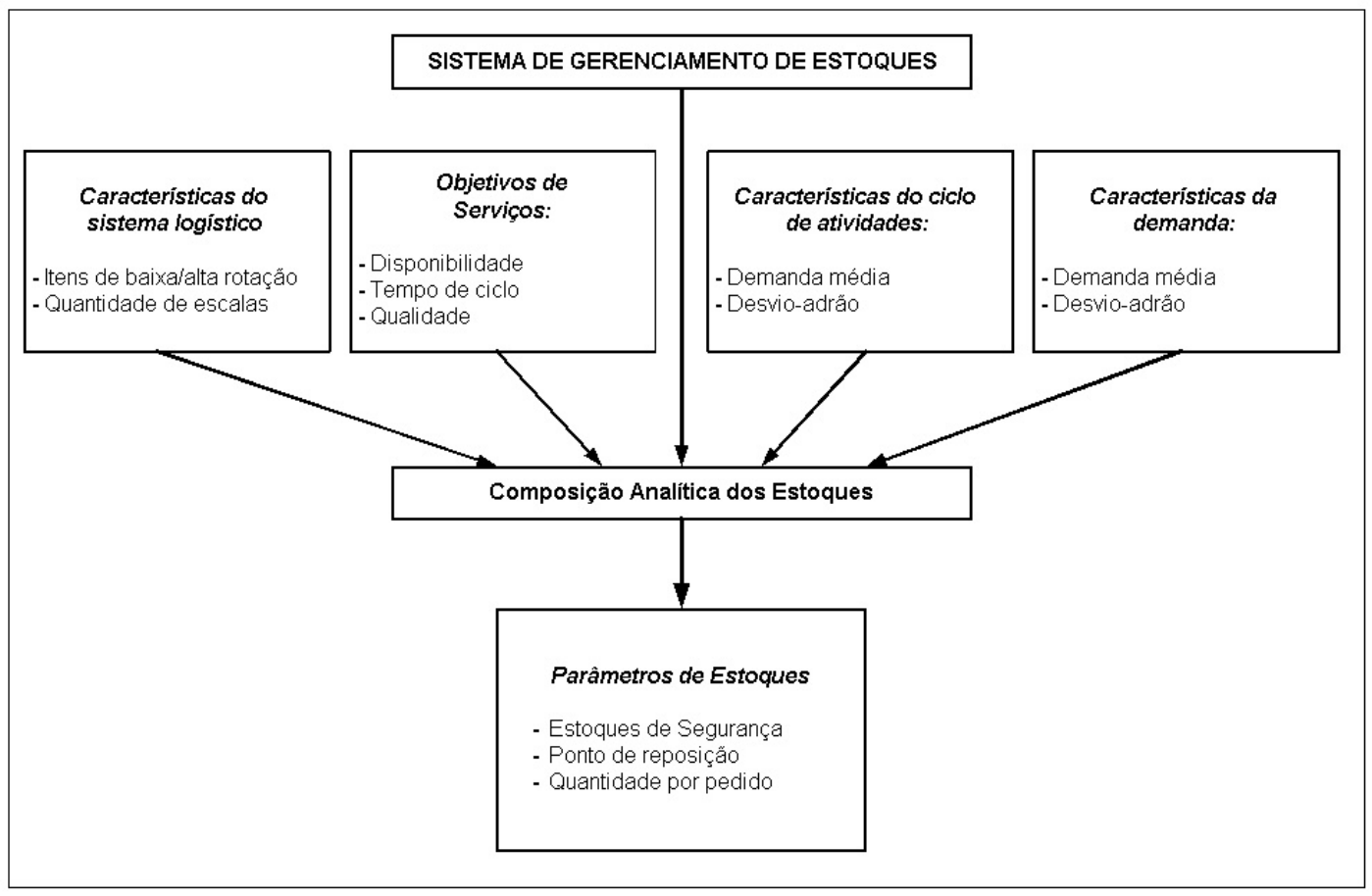

Figura 2-3 - Resumo da técnica analítica

A simulação de estoques cria um modelo matemático e probabilístico de um ambiente operacional logístico já existente, ilustrado pela Figura 2-4. As principais saídas da simulação são as características de nível de serviço e de operação dos estoques no ambiente experimentado. Para cada situação específica, o desempenho é avaliado pela simulação e, se os objetivos desejados não forem atingidos, os parâmetros devem ser alterados e deve ser simulado um novo ambiente.

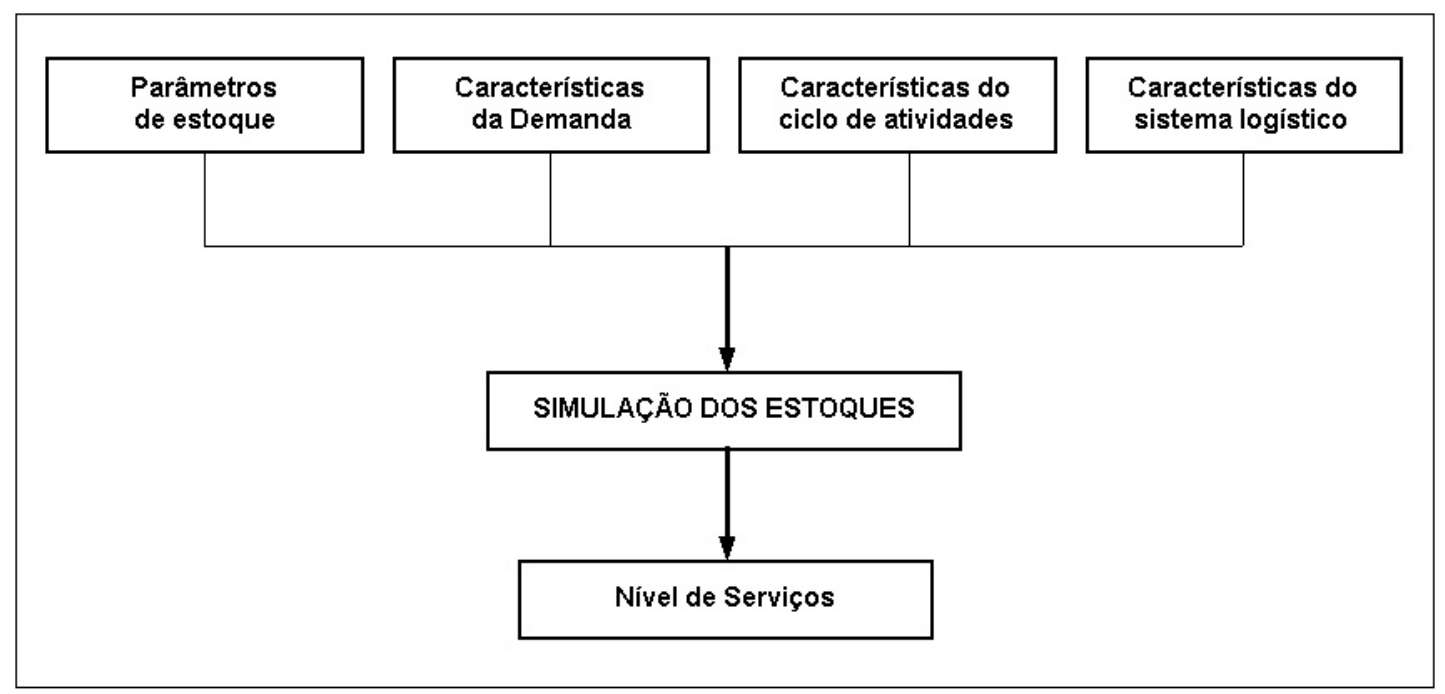

Figura 2-4- Resumo das simulações de estoques 


\section{5 - Conclusões sobre a Revisão Bibliográfica}

Na pesquisa bibliográfica efetuada, foram encontrados poucos trabalhos que tratam diretamente do tema proposto. A maioria dos trabalhos encontrados trata ou do problema de reposicionamento de contêineres vazios ou do tamanho da frota de veículos de transporte. Em ambos os casos, nenhum procedimento relevante para o dimensionamento da frota de contêineres foi encontrado.

O trabalho de Imai e Rivera (2001) foi o que mais se aproximou dos objetivos desta dissertação. Contudo, eles simplificaram os modelos propostos, adotando hipóteses pouco coerentes com a realidade do sistema de transporte de contêineres refrigerados e, conseqüentemente, desviando-se do problema real de dimensionamento de frota de contêineres.

A fim de identificar as hipóteses adotadas por Imai e Rivera (2001) e tentar utilizar, neste estudo, algum dos métodos propostos por eles, realizar-se-á um detalhamento maior daquele trabalho, como poderá ser visto no capítulo 3 . 


\section{CAPÍTULO 3 - MÉTODOS PARA RESOLUÇÃO DO PROBLEMA DE DIMENSIONAMENTO DA FROTA DE CONTÊINERES}

Este capítulo dedica-se a discutir alguns métodos para a resolução do problema proposto neste trabalho. Primeiramente, mostra-se um detalhamento maior do trabalho escrito por Imai e Rivera (2001). Em seguida, foram estudadas duas técnicas com o intuito de encontrar o método mais apropriado à resolução do problema de dimensionamento de frota de contêineres para uma empresa de navegação, concluindo-se o capítulo com a justificativa da escolha de uma delas.

\section{1 - Procedimentos propostos por Imai e Rivera (2001)}

Nesta seção serão descritos os procedimentos propostos por Imai e Rivera (2001) para o problema do dimensionamento da frota de contêineres. Para não tornar esta seção muito extensa, apenas as principais equações dos modelos propostos pelos autores serão apresentadas. A modelagem completa apresentada pelos autores poderá ser vista mais detalhadamente no apêndice A. 
FROTA DE CONTÊINERES

\subsection{1 - Descrição dos procedimentos propostos por Imai e Rivera (2001)}

Imai e Rivera (2001) discutem três modelos para tratar o problema do dimensionamento da frota de contêineres. Um modelo analítico é primeiro discutido para determinar o tamanho ótimo de uma frota de contêiner próprio do tipo dry em um mercado relativamente balanceado. Em seguida, este modelo é modificado para determinar o tamanho da frota de contêineres refrigerados em um comércio extremamente desbalanceado. Desenvolveram também um modelo de simulação que será apresentado posteriormente.

Para isto, eles consideram o fluxo de contêineres entre dois portos, $P$ e $S$. Para o primeiro caso, eles admitem que há um fluxo de carga maior partindo do porto $P$ para o porto S. Os autores adotam, também, dois tipos de fluxos de contêineres entre estes portos: o fluxo do modelo (A), representado na Figura 3-1 pelos trechos (1) - (2) - (3) - (4) - (5) - (6), e o fluxo de modelo (B), representado pelos trechos (1) - (7) - (8) - (9).

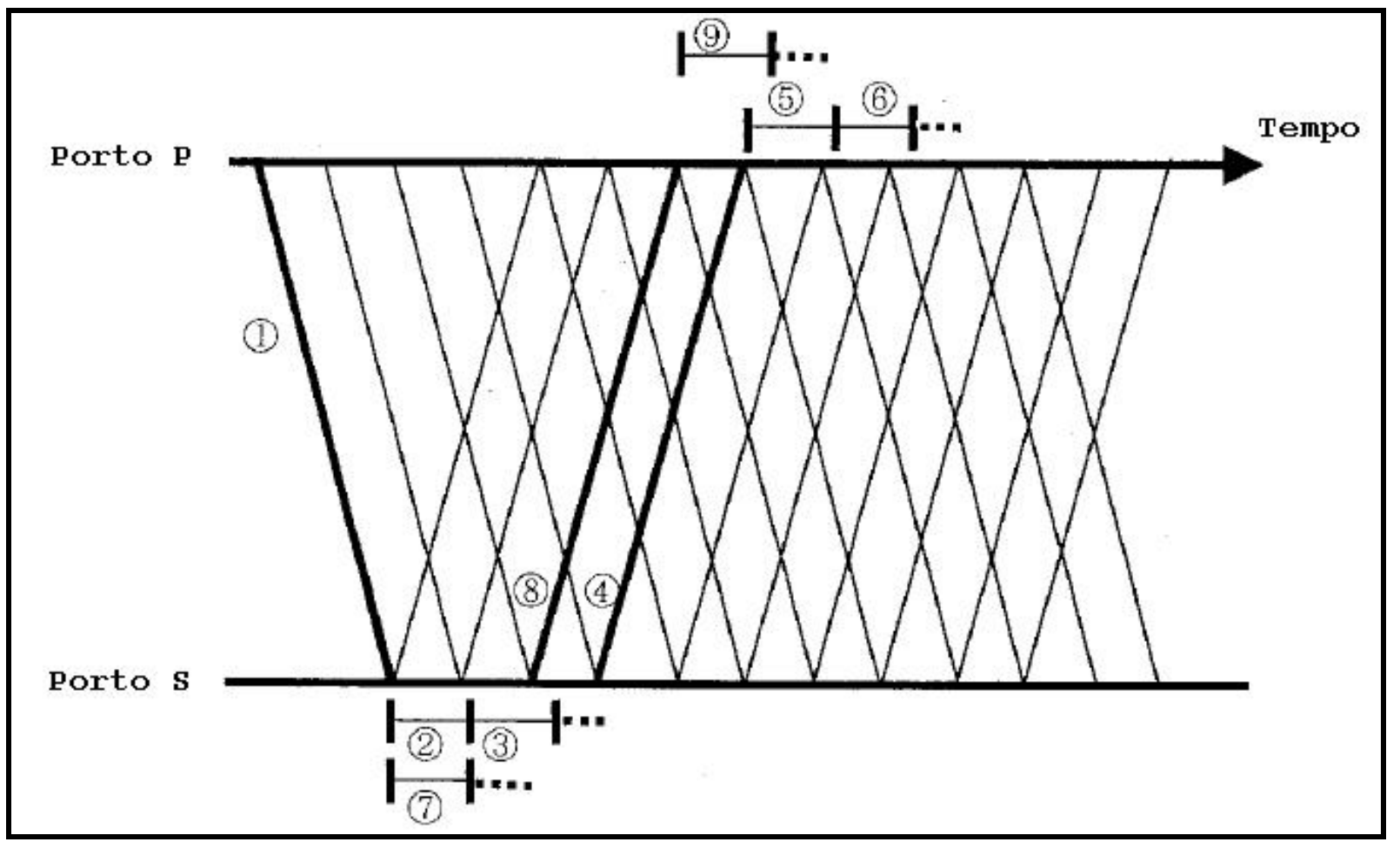

Fonte: Imai, A., Rivera, F.(2001)

Figura 3-1 Modelos de fluxos de contêineres entre dois portos 
FROTA DE CONTÊINERES

Para o modelo (A), no trecho (1), os contêineres cheios são transportados do porto $P$ até o porto $S$; no trecho (2), eles são levados até o cliente de importação, onde são desovados, retornando em seguida para o terminal de contêineres vazios no porto $S$; no trecho (3), os contêineres são encaminhados para os clientes de exportação que os devolvem ao porto $S$ como contêineres cheios. Estes contêineres cheios aguardam a próxima passagem do navio pelo porto; no trecho (4), eles são transportados até o porto $P$; no trecho (5), os contêineres cheios são encaminhados até os clientes de importação, que os devolvem ao porto como contêineres vazios. No trecho (6), estes contêineres vazios são enviados até os clientes de exportação, retornando ao porto como contêineres cheios e aguardam a passagem do próximo navio, reiniciando o ciclo.

Para o modelo (B), no trecho (1), os contêineres cheios partem do porto $P$; no trecho (7), eles são encaminhados para os clientes de importação do porto $S$, retornando como contêineres vazios a este porto. Aguardam a passagem do próximo navio; no trecho (8), os contêineres são transportados vazios de volta para o porto $P$; no trecho (9), eles são remetidos aos clientes de exportação para devolvê-los como contêineres cheios ao porto. Estes contêineres aguardam a passagem do próximo navio para o porto $S$, reiniciando o ciclo.

Os tempos de viagem redonda de um contêiner do modelo (A), trechos (1) a (6), $T_{a}^{\dagger}$, e do modelo (B), trechos (1), (7) a (9), $T_{b}^{t}$, são dados como segue:

$$
\begin{aligned}
& T_{a}^{t}=2 \cdot\left(T^{c}+m \cdot T^{i}\right) \\
& T_{b}^{t}=2 \cdot\left(T^{c}+n \cdot T^{i}\right)
\end{aligned}
$$

onde $T^{c}$ é o tempo de viagem de $P$ para $S$ (ou vice-versa); $T^{i}$ é o intervalo entre passagens dos navios no porto $P$ ou $S$ (em dias); $m$ é a quantidade de passagens de navios no porto $P$ enquanto os contêineres estiverem percorrendo os trechos (5) e (6), ou a quantidade de passagens de navios no porto $S$ enquanto os contêineres estiverem percorrendo os trechos (2) 
FROTA DE CONTÊINERES

e (3); $n$ é o número de navios que passam pelo porto $P$ enquanto os contêineres trafegam pelo trecho (9), ou número de navios que passam pelo porto $S$ enquanto os contêineres trafegam pelo trecho (7). Os valores de $m$ e $n$ devem ser inteiros que satisfaçam as restrições (3.3) e (3.4), respectivamente.

$$
\begin{aligned}
& (m-1) \cdot T^{i}<2 \cdot T^{d} \leq m \cdot T^{i} \\
& (n-1) \cdot T^{i}<2 \cdot T^{d} \leq n \cdot T^{i}
\end{aligned}
$$

onde $T^{d}$ é o tempo de viagem do contêiner saindo do porto, indo a um cliente no interior da região e retornando ao mesmo porto de onde partiu.

Após deduzirem os tempos dos processos do transporte terrestre dos contêineres, e algumas outras equações que podem ser vistas no apêndice, os autores puderam equacionar a fórmula, $C$, que define o tamanho da frota de contêineres próprios do tipo dry, para o caso onde há dois portos em um mercado relativamente balanceado:

$$
C=\frac{2}{Y} \cdot\left\{N_{P} \cdot\left(T^{c}+n \cdot T^{i}\right)+N_{S} \cdot(m-n) \cdot T^{i}\right\}
$$

onde $N_{P}$ e $N_{S}$ são os volumes de carga anual de $P$ para $S$ e de $S$ para $P$, e $Y$ é o número de dias de um ano (365 dias).

Para o segundo caso, no qual deseja-se determinar o tamanho da frota de contêineres refrigerados em um mercado extremamente desbalanceado, além das hipóteses acima adotadas, considera-se que o tempo de retorno dos contêineres na região do porto $P$ seja diferente do tempo de retorno dos contêineres na região do porto $S$. Sendo um mercado desbalanceado, os autores admitem que apenas o fluxo do modelo (B) seja levado em consideração.

Realizando as substituições necessárias, tal como explicado no apêndice, tem-se que o volume de contêiner necessário, $C$, para este caso, é definido como segue: 
FROTA DE CONTÊINERES

$$
C=\frac{N_{P}}{Y} \cdot\left\{T^{c}+\left(n_{P}+n_{S}\right) \cdot T^{i}\right\}
$$

onde $n_{P}$ é o número de navios que passam pelo porto $P$ enquanto um contêiner está em trânsito na região atendida pelo porto $P$. Analogamente, $n_{S}$ é válido para o porto $S$. Os valores de $n_{P}$ e $n_{S}$ devem satisfazer as seguintes restrições, respectivamente.

$$
\begin{aligned}
& \left(n_{P}-1\right) \cdot T^{i}<T_{P}^{d} \leq n_{P} \cdot T^{i} \\
& \left(n_{S}-1\right) \cdot T^{i}<T_{S}^{d} \leq n_{S} \cdot T^{i}
\end{aligned}
$$

onde $T_{P}^{d}$ e $T_{S}^{d}$ são os tempos de viagem redonda de um contêiner no interior da região dos portos $P$ e $S$, respectivamente.

Os autores desenvolveram este modelo para o caso de uma rota com dois portos. Eles afirmam que, para o caso de uma rota com multi-portos, o tamanho da frota total para este mercado seria a soma do volume de contêineres dado pela equação (3.6).

Além dos dois modelos acima propostos, Imai e Rivera (2001) também desenvolveram um modelo de simulação determinística, envolvendo multi-portos, que assume, além das hipóteses anteriormente discutidas, interações pré-determinadas para os movimentos de contêineres vazios. Eles consideram que os fluxos de contêineres estão em uma rede tempoespaço (Figura 3-2), no qual os nós correspondem aos portos de origem e destino dos contêineres cheios e vazios, enquanto os arcos representam as viagens.

A Figura 3-2(a) mostra uma conservação do fluxo de contêiner vazio em um porto de origem, enquanto que a Figura 3-2(b) ilustra esta conservação em um porto de destino, onde:

- $\quad E_{i}^{t} \ldots$ é o volume de contêiner que retorna ao porto $i$ a partir dos portos de destino $j$ em um tempo $t$

- $F_{i}^{t} \ldots$ é o volume total de contêiner que parte do porto $i$ para os próximos carregamentos no tempo $t$; 
- $\quad S_{i}^{t} \ldots$ é o volume total de contêiner estocado disponível no porto $i$ no tempo $t$;

- $G_{j}^{t} \ldots$ é o volume total de contêiner que retorna ao porto $j$ no tempo $t$ vindos dos clientes de importação; e

- $\quad H_{j}^{t} \ldots$ é o volume total de contêiner que retorna ao porto de origem a partir do porto $j$ no tempo $t$.

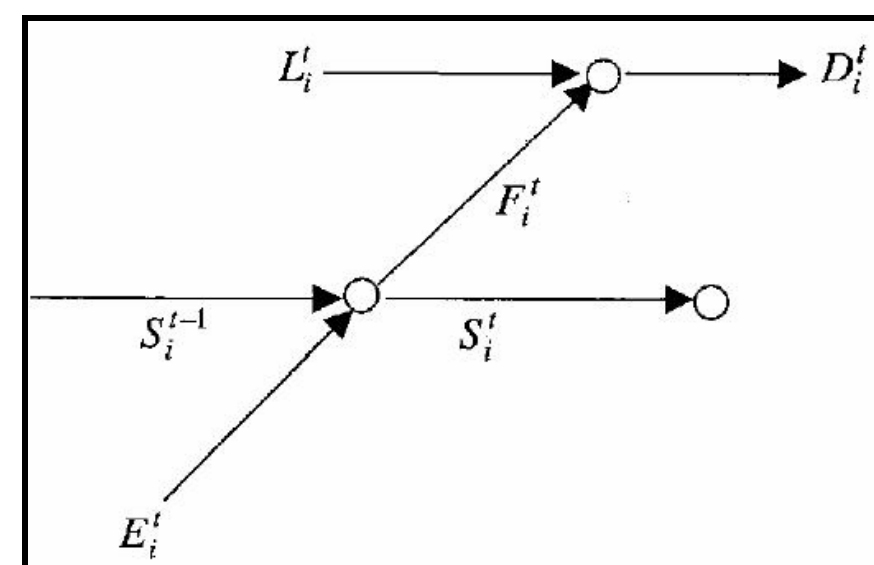

(a) Porto de Origem i

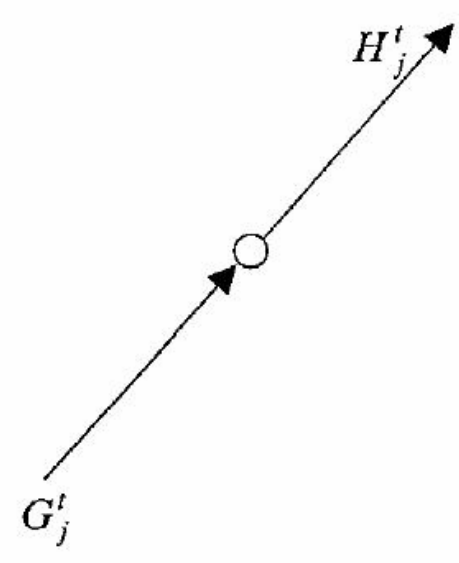

(b) Porto de Destino j

Fonte: Imai, A., Rivera, F.(2001)

Figura 3-2 Conservação dos Fluxos de Contêineres nos Portos

Adotando a hipótese da conservação de fluxo para o porto de origem $i$ e para o porto de destino $j$, os autores obtiveram uma relação para $H_{j}^{t}$ e $E_{i}^{t}$, melhor detalhada no apêndice. Esta relação é representada pelas equações (3.9) e (3.10), onde $X_{i j}^{t}$ é o volume de contêiner vazio próprio que parte do porto $j$ no tempo $t$, levando $B$ dias (que corresponde a $T^{c}$ ) para chegar ao porto de origem $i$ no tempo $v$.

$$
\begin{gathered}
H_{j}^{t}=\sum_{i} X_{i j}^{t} \\
E_{i}^{v}=\left.\sum_{j} X_{i j}^{t}\right|_{\{t \mid t=v-\beta\}}
\end{gathered}
$$

Sabendo-se que a determinação dos valores $X_{i j}^{t}$ afetaria o uso dos contêineres, isto implica que $X_{i j}^{t}$ deveria ser uma variável de decisão. Por isto, segundo os autores, o modelo de simulação proposto é reduzido a um problema de programação matemática cuja resolução é 
FROTA DE CONTÊINERES

difícil. Assim, adotaram uma estratégia de distribuição de vazio baseado em experiências de uma particular companhia de navegação.

\section{2 - Modelo de simulação para um problema pequeno de dimensionamento de frota}

Após examinar o trabalho de Imai e Rivera (2001), surgiu a necessidade de explorar outras linhas de pesquisa para a resolução do problema de dimensionamento da frota de contêineres. Decidiu-se utilizar o esquema básico de Imai e Rivera (2001) para o movimento do contêiner entre o porto ? cliente de importação ? terminal e entre terminal ? cliente de exportação ? porto, porém os tempos de movimentação dos contêineres em terra foram adotados como variáveis aleatórias, que é mais condizente com a realidade. Por isso, pensouse primeiro no desenvolvimento de um modelo de simulação probabilística.

A simulação tem que ter como objetivo a descrição do comportamento de sistemas; a construção de teorias ou hipóteses que explicam o comportamento observado; o uso do modelo para prever um comportamento futuro (efeitos produzidos por mudanças no sistema ou na sua forma de operar).

A seguir será apresentado o modelo de simulação para o dimensionamento de frota de contêineres, bem como seu funcionamento básico e principais características funcionais. Uma descrição detalhada do modelo codificado em linguagem Arena ${ }^{\circledR}$ pode ser encontrada no apêndice B. Para isto, um cenário inicial de operação foi adotado, descrito ao longo da seção. O modelo de simulação pode ser dividido em dois blocos: a operação dos navios e a operação dos contêineres em terra. 


\subsection{1 - A Operação dos navios}

Admite-se que uma empresa de navegação possui 3 navios operando em 3 portos, tal como mostra a Figura 3-3. Cada navio chega no porto de destino em uma data prédeterminada. Este instante de chegada caracteriza as janelas de tempo (intervalo de tempo reservado para a chegada do navio ao porto), comuns, atualmente, para navios que operam em um serviço regular; isto é, possuem rotas e portos fixos de passagem. Os navios, no início desta simulação, carregam uma certa quantidade de contêineres cheios e os descarregam nos portos conforme a Tabela 3-1.

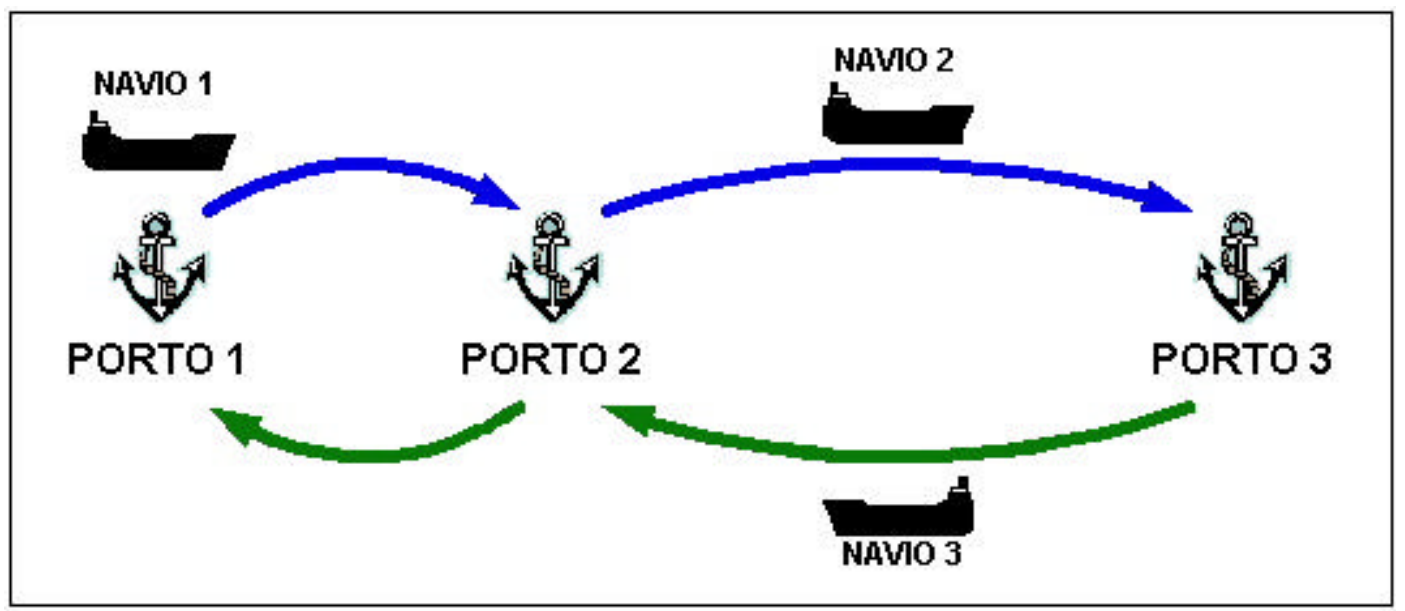

Figura 3-3 - Operação dos navios na rota especificada

Tabela 3-1 - Quantidade de contêineres cheios nos navios no início da simulação e os contêineres movimentados nos portos

\begin{tabular}{|c|c|c|}
\hline Navio 1 & Navio 2 & Navio 3 \\
\hline 625 & 880 & 750 \\
\hline
\end{tabular}

\begin{tabular}{|c|c|c|c|c|c|}
\hline & \multicolumn{4}{|c|}{ Importação } \\
\hline & & Porto 1 & Porto 2 & Porto 3 & Total \\
\hline \multirow{4}{*}{ 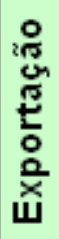 } & Porto 1 & - & 350 & 480 & 830 \\
\hline & Porto 2 & 300 & - & 400 & 700 \\
\hline & Porto 3 & 325 & 425 & - & 750 \\
\hline & Total & 625 & 775 & 880 & \\
\hline
\end{tabular}


FROTA DE CONTÊINERES

Depois de atracado, o navio descarrega estes contêineres e carrega outros cheios. Devido ao desequilíbrio do fluxo de contêineres, haverá a necessidade dos navios também carregarem contêineres vazios para outros portos. A permanência do navio no porto será determinística e estará relacionada com a quantidade de contêineres carregados e descarregados.

Determinourse, no início da simulação, que os navios estariam dispostos no sistema conforme a Figura 3-3, ou seja, um navio chegando ao porto 1, outro navio entre os portos 2 e 3 e o terceiro navio entre os portos 3 e 2 (no sentido inverso ao segundo navio). Ainda, visualizando esta figura, observa-se que os navios seguem através da seguinte rota: porto 1 porto 2 - porto 3 - porto 2 - porto 1 . Deste modo, o porto 2 é visitado pelos navios nos dois sentidos da rota.

Após a operação de carga e descarga no porto, o navio segue para o próximo porto. Os tempos de viagem entre portos são determinísticos, de acordo com a Tabela 3-2. A frequiência dos navios nos portos depende do tempo de viagem redonda da rota e da quantidade de navios que realiza esta mesma rota. Para este caso, o tempo que cada navio leva para percorrer esta rota, identificada pela Figura 3-3, é de 30 dias. Deste modo, o intervalo entre passagens dos navios nos portos 10 dias. Convém lembrar que a aleatoriedade dos processos ficou concentrada exclusivamente nas movimentações terrestres dos contêineres.

Tabela 3-2 - Tempo de viagem entre portos (em dias)

\begin{tabular}{|l|r|r|r|}
\cline { 2 - 4 } \multicolumn{1}{c|}{} & Porto 1 & Porto 2 & Porto 3 \\
\hline Porto 1 & - & 5 & 15 \\
\hline Porto 2 & 5 & - & 10 \\
\hline Porto 3 & 15 & 10 & - \\
\hline
\end{tabular}




\subsection{2 - A operação dos contêineres em terra}

Os contêineres cheios, descarregados dos navios, são enviados aos clientes de importação. Estes desovam os contêineres e os enviam vazios ao depósito de contêineres da empresa junto ao porto, doravante chamado apenas de depósito de vazios. Admite-se que os tempos de trânsito dos contêineres entre o porto ? cliente de importação ? depósito de vazios e entre o depósito de vazios? cliente de exportação ? porto, Figura 3-4 e Figura 3-5, variam segundo uma distribuição triangular $[5,10,15]$ dias. Os contêineres vazios que foram importados de outros portos, os que retornaram vazios dos clientes de importação e os que serão destinados aos clientes de exportação ou a outros portos permanecem em uma área comum destinada a todos os contêineres vazios no depósito de vazios.

Os contêineres cheios que foram importados pelos clientes, quando retornam vazios ao depósito de vazios, passam por uma vistoria que determina se o contêiner necessitará ou não de reparos. Ambos os casos, os contêineres passarão por uma limpeza, antes de chegar até o pátio de contêineres vazios. Se o contêiner necessitar de reparos, ele entra numa "oficina" onde aguardará um tempo até se tornar disponível novamente.

Sabendo-se, a priori, o schedule dos navios (quando opera num serviço regular) e a quantidade de contêineres cheios exportada em cada porto, admitiu-se um fluxo diário uniforme de contêineres vazios dos terminais até os clientes de exportação, de modo que ao retornarem ao porto como contêineres cheios, estes possam atender toda a demanda de transporte sem que nenhum navio parta sem a demanda prevista. 
FROTA DE CONTÊINERES

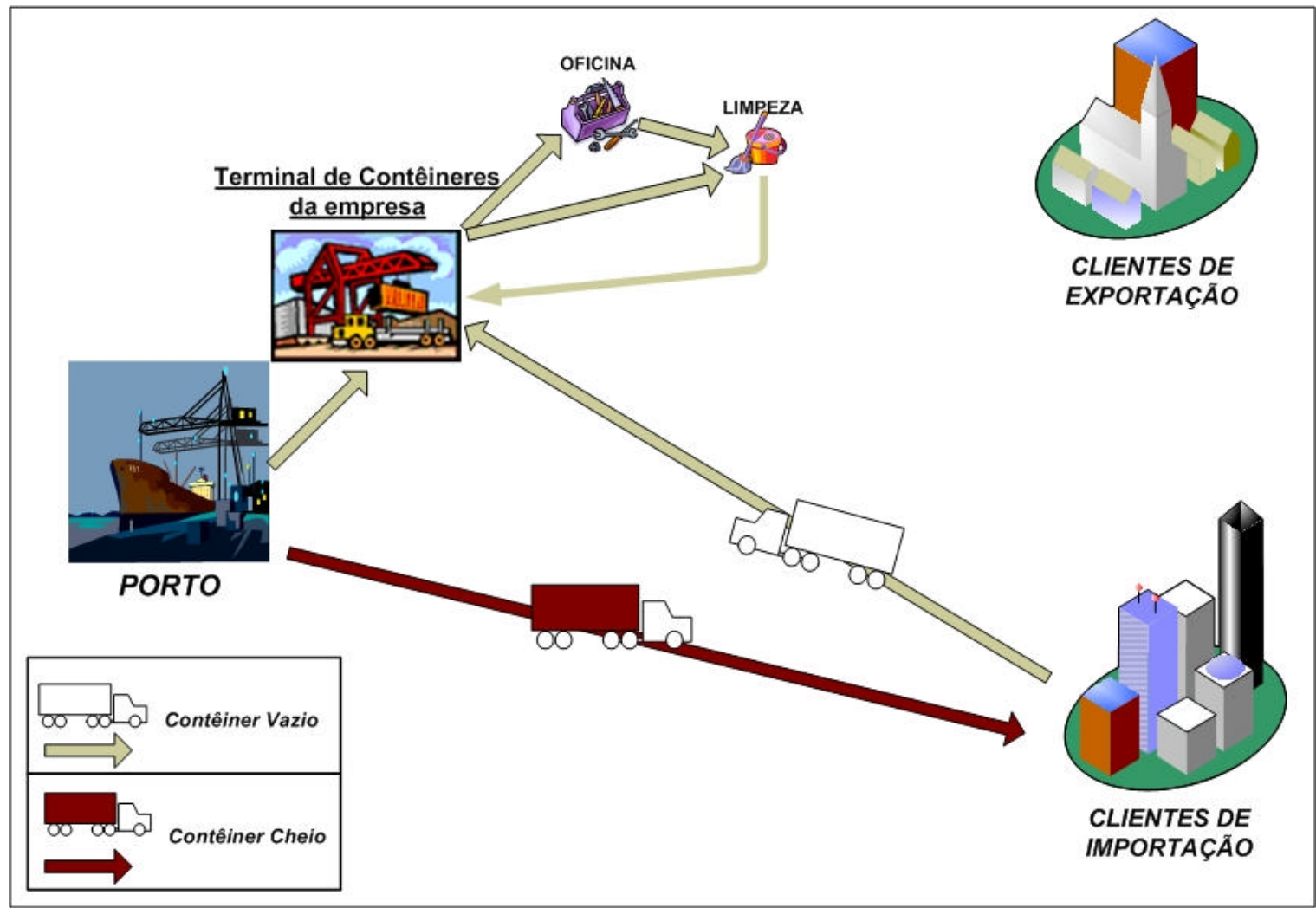

Figura 3-4 Movimentação terrestre dos contêineres importados

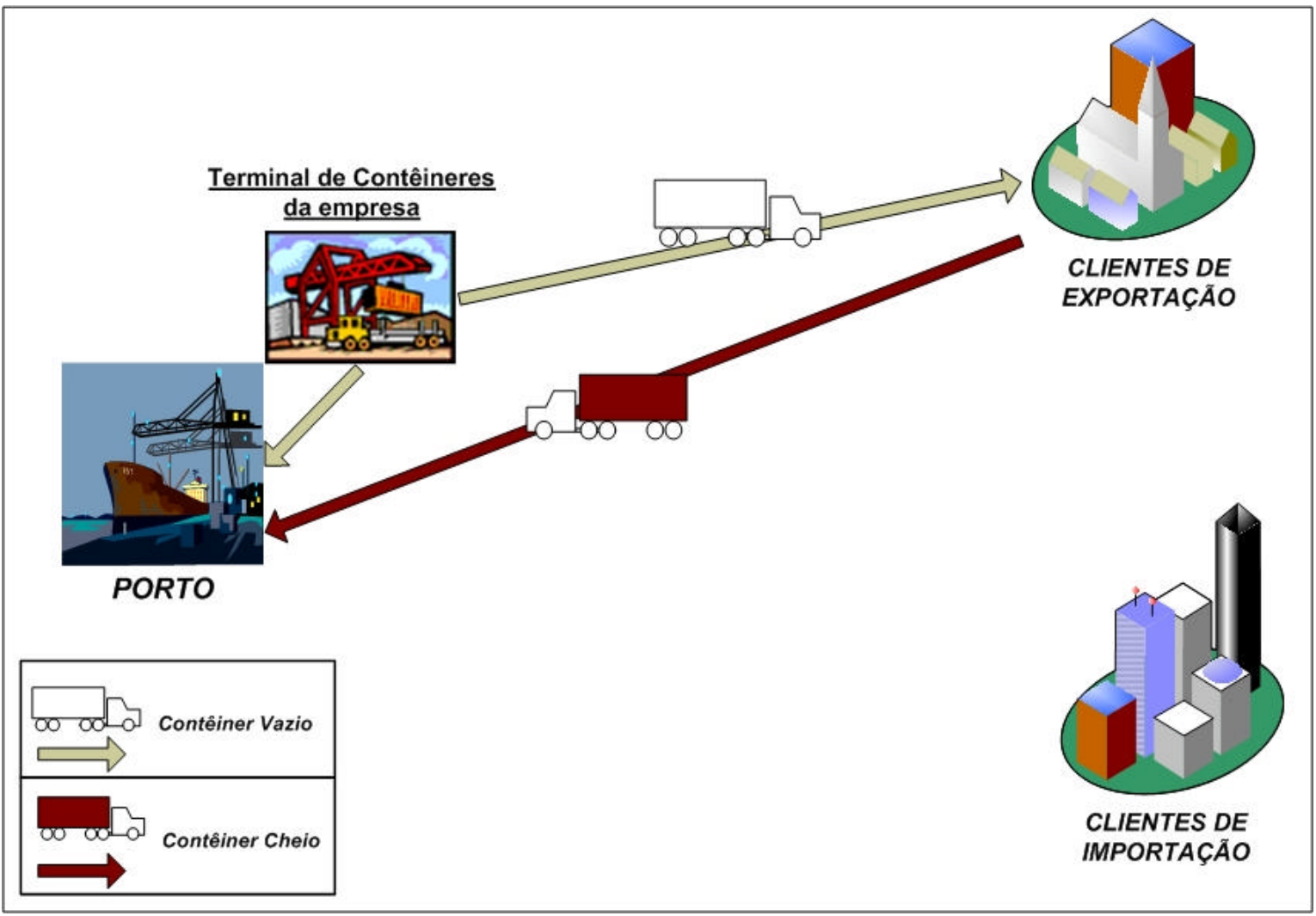

Figura 3-5 Movimentação terrestre dos contêineres a serem exportados 


\subsection{3 - Resultados obtidos para o modelo de simulação}

O cenário descrito nos itens 3.2.1 - e 3.2.2 - foi implementado no software Arena ${ }^{\circledR}$, gerando os resultados detalhados a seguir. Nota-se, na Tabela 3-3, que somente há necessidade de envio de contêineres vazios para o porto 1, pois a quantidade de contêineres cheios exportada é maior do que a quantidade de contêineres cheios importada. Analogamente para os outros portos, caso o número de contêineres cheios exportados seja maior que o número de contêineres cheios importados, este porto deverá receber a diferença dessas quantidades em contêineres vazios. Caso contrário, o porto exportará contêineres vazios (verificar a Tabela 3-4).

Tabela 3-3- Fluxos de Carga em cada Porto

\begin{tabular}{|l|c|c|}
\cline { 2 - 3 } \multicolumn{1}{c|}{} & \multicolumn{2}{c|}{ FLUXO DE CARGA } \\
\cline { 2 - 3 } \multicolumn{1}{c|}{} & Contêineres Cheios Importados & Contêineres Cheios Exportados \\
\hline Porto 1 & 625 & 830 \\
\hline Porto 2 & 775 & 700 \\
\hline Porto 3 & 880 & 750 \\
\hline
\end{tabular}

Tabela 3-4 - Quantidade de contêineres vazios enviados ao Porto 1

\begin{tabular}{|l|r|}
\cline { 2 - 2 } \multicolumn{1}{c|}{} & \multicolumn{2}{c|}{ Contêineres Vazios } \\
\cline { 2 - 3 } \multicolumn{1}{c|}{} & Porto 1 \\
\hline Porto 2 & 75 \\
\hline Porto 3 & 130 \\
\hline
\end{tabular}

O principal resultado deste cenário é a quantidade de contêineres, cheios e vazios, que se deve ter no estoque inicial de cada porto. O modelo foi processado algumas vezes, mudando-se os estoques iniciais de cheios e vazios nos portos até se chegar a uma configuração que conseguia atender toda a demanda sem manter níveis elevados de estoque de contêineres vazios nos portos. Os estoques de contêineres iniciais em cada porto pode ser visto na Tabela 3-5. 
FROTA DE CONTÊINERES

Tabela 3-5 - Resultado para o estoque inicial em cada porto

\begin{tabular}{|l|r|r|}
\cline { 2 - 3 } \multicolumn{1}{c|}{} & \multicolumn{2}{c|}{ ESTOQUE MICIAL } \\
\cline { 2 - 3 } \multicolumn{1}{c|}{ Contèiner Cheio } & Contêiner Vazio \\
\hline Porto 1 & 1180 & 1000 \\
\hline Porto 2 & 1075 & 1105 \\
\hline Porto 3 & 910 & 1430 \\
\hline
\end{tabular}

Logo, a frota total de contêineres para este cenário simulado é dada pela soma dos estoques iniciais de contêineres cheios e vazios em cada porto, Tabela 3-5, e da quantidade de contêineres cheios existentes nos navios no início da simulação, Tabela 3-1. O resultado é uma frota total de 8.955 contêineres.

Além disso, verifica-se, por meio da Figura 3-6, Figura 3-7 e Figura 3-8 abaixo, a evolução da carga nos portos e em trânsito nos clientes de importação e de exportação. Apesar de o estoque de contêineres vazios ter chegado ao valor zero em alguns portos, nenhum navio percorreu qualquer trajeto sem a demanda de carga prevista.

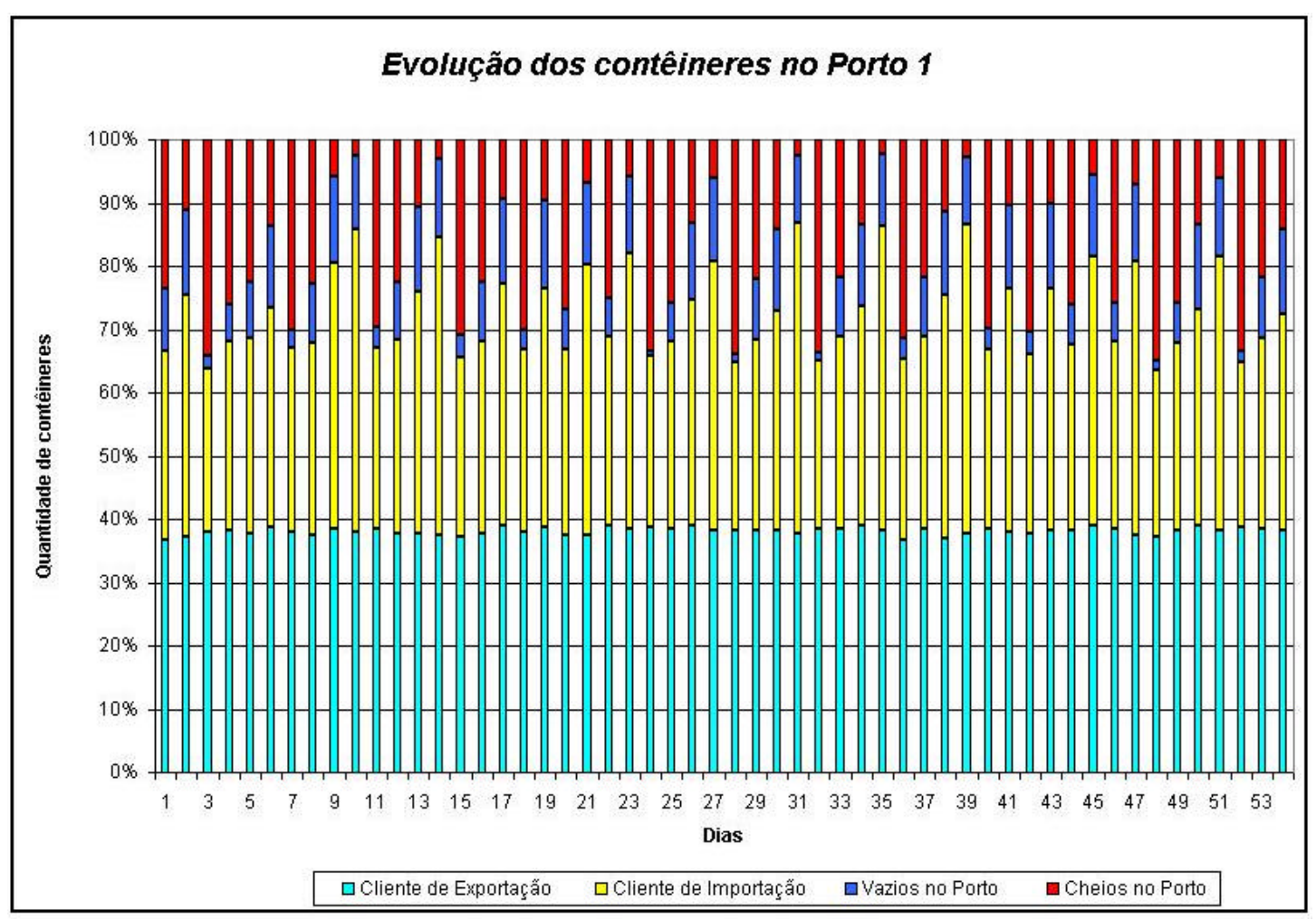

Figura 3-6 Gráfico referente à evolução do estoque no porto 1 
FROTA DE CONTÊINERES

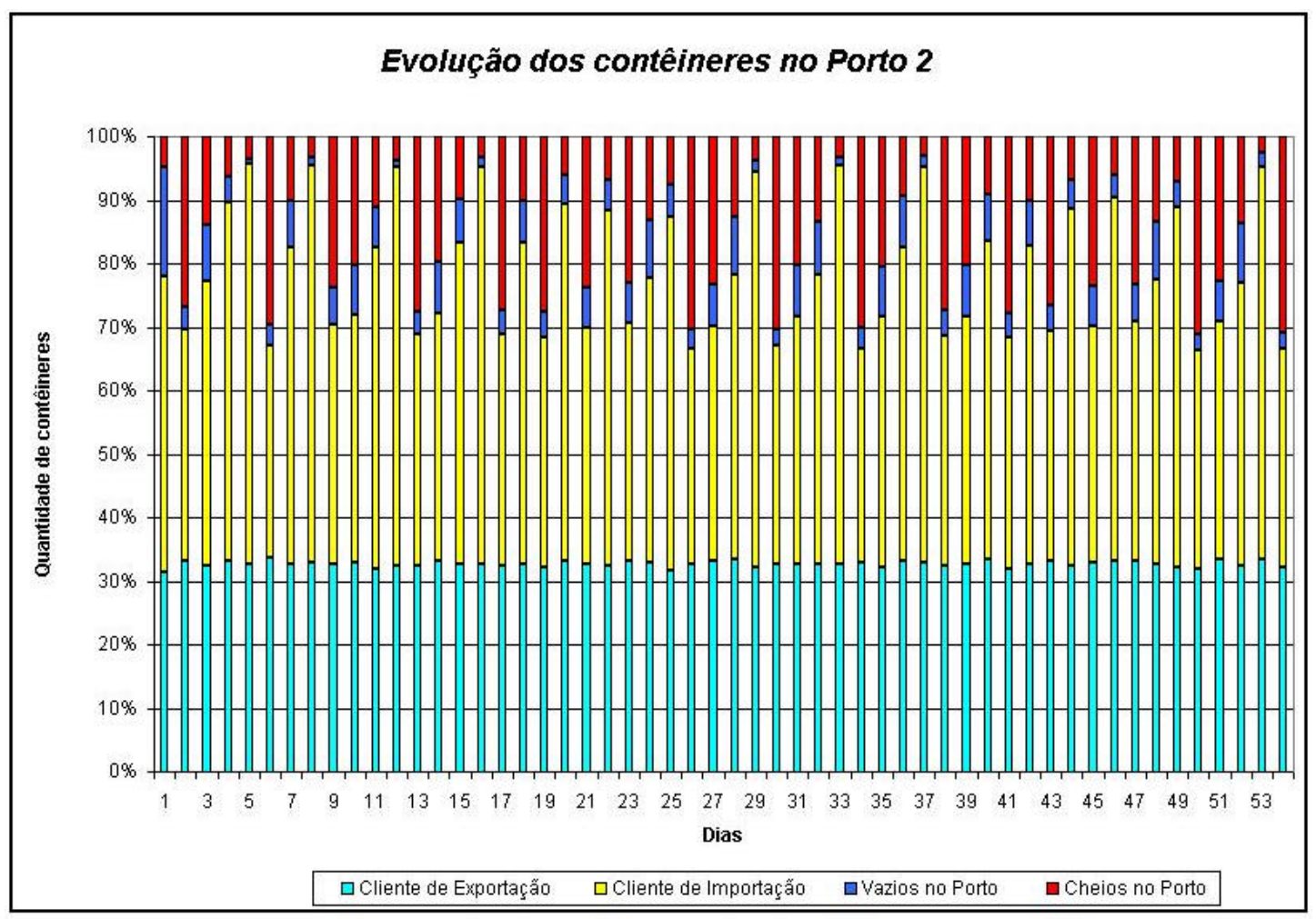

Figura 3-7 Gráfico referente à evolução do estoque no porto 2

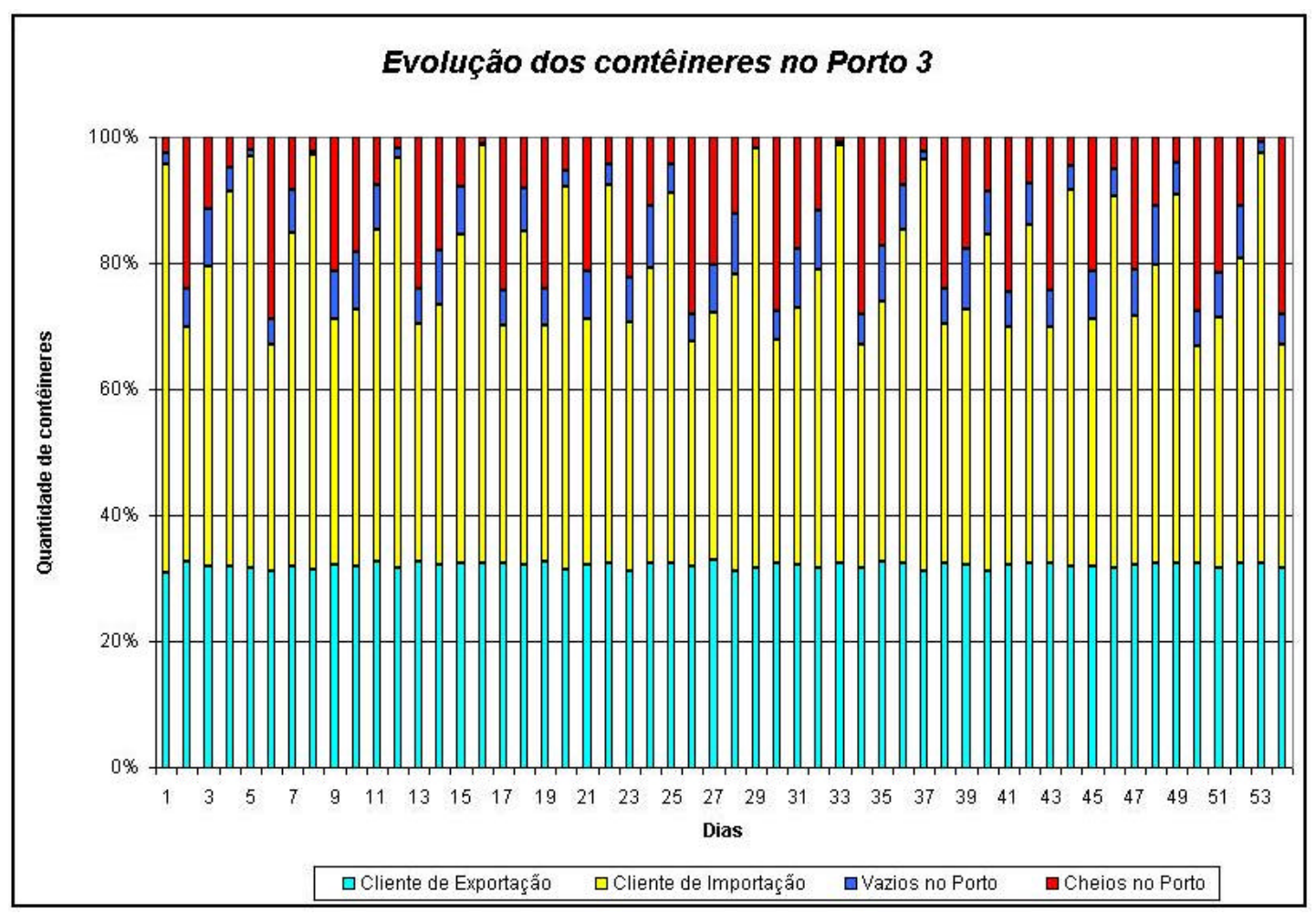

Figura 3-8 Gráfico referente à evolução do estoque no porto 3

Este modelo de simulação atendeu satisfatoriamente às restrições impostas e forneceu resultados compatíveis para o problema de dimensionamento de frota de contêineres. Devido 
FROTA DE CONTÊINERES

ao fato de haver poucas variáveis para controlar, foi, relativamente, simples alterá-las até conseguir obter os valores próximos do ótimo para cada estoque em cada porto.

Com a necessidade de ampliação do modelo, ou seja, a agregação de mais portos e maior número de navios, há também um aumento do número de variáveis a serem controladas. Sendo muitas variáveis, alterá-las e controlá-las para alcançar um resultado próximo da frota ótima tornar-se-ia muito difícil.

Portanto, uma outra solução para resolver o problema de dimensionamento de frota de contêineres, seria a construção de um modelo de programação linear que pudesse incorporar, de alguma forma, as características aleatórias dos tempos de movimentação dos contêineres em terra.

\section{3 - Modelo de programação linear para um problema pequeno de dimensionamento de frota}

Com a finalidade de desenvolver um método alternativo ao de simulação, que pudesse ser aplicado a rotas mais complexas, com maior número de navios, desenvolveurse um modelo de programação linear específico para o mesmo problema descrito na seção anterior. Para este modelo de programação linear, consideroutse que os tempos dos navios nos portos foram incluídos nos tempos de viagem. 
FROTA DE CONTÊINERES

\subsection{1 - Nomenclatura dos índices}

Os seguintes índices serão utilizados para o desenvolvimento do modelo matemático proposto neste trabalho:

- $\quad i$... para representar os portos;

- $\quad$... para indicar o período de tempo.

Relativos aos conjuntos de índices:

- $\quad$ I ... para representar o conjunto de todos portos;

- $T$... para indicar o conjunto com todos os períodos de tempo dentro do horizonte de planejamento.

\subsection{2 - Nomenclatura dos parâmetros}

Os parâmetros utilizados no modelo matemáticos estão descritos a seguir:

Relativos à Demanda:

- $\quad D_{i} \ldots$ quantidade de contêineres cheios exportados pelo porto de índice $i$;

- $\quad Q_{i} \ldots$ quantidade de contêineres cheios importados pelo porto de índice $i$;

- $S_{i \ldots}$ diferença entre a quantidade de contêineres cheios importados e cheios exportados pelo porto de índice $i$ :

$$
S_{i}=Q_{i}-D_{i}
$$

Se $S_{i}$ for maior que zero, significa que haverá contêineres vazios sendo exportados pelo porto de índice $i$. Caso contrário, $S_{i}$ menor que zero, $\left(-S_{i}\right)$ indicará a quantidade de contêineres vazios que devem ser importados pelo porto de índice $i$. 
FROTA DE CONTÊINERES

Relativo aos navios:

- $\quad F$... freqüência de passagens dos navios nos portos.

Relativos aos contêineres:

- $\quad \alpha_{t-t_{k}} \ldots$ função que define a frequiência relativa de retorno, no período de tempo de índice $t$, ao depósito de vazios dos contêineres encaminhados cheios do porto ao cliente de importação, no período de tempo de índice $t_{k}$;

- $\quad \beta_{t-\tau_{k}} \ldots$ função que define a freqüência relativa de retorno ao porto, no período de tempo de índice $t$, dos contêineres que foram encaminhados do depósito de vazios ao cliente de exportação, no período de tempo de índice $t_{k}$,

Estas duas funções, $\alpha_{t-t_{k}}$ e $\beta_{t-\tau_{k}}$, representam, respectivamente, as aleatoriedades dos tempos dos contêineres em trânsito entre o porto ? cliente de importação ? depósito de vazios e entre o depósito de vazios ? cliente de exportação ? porto, tal como descrito para o modelo de simulação. Naquele caso, no modelo de simulação, adotou-se para estes tempos uma distribuição triangular $[5,10,15]$ dias.

Relativo ao estoque de contêineres:

- $E M I N_{i, ~}$... estoque mínimo de contêineres vazios no depósito de vazios junto ao porto de índice $i$ para qualquer período de tempo de índice $t$. Pode ser interpretado como estoque de segurança e definido como uma fração da demanda de contêineres cheios exportados pelo porto de índice $i$ :

$$
\operatorname{EMIN}_{i, t}=\gamma \cdot D_{i}
$$

onde ? é um número menor que 1. 
FROTA DE CONTÊINERES

\subsection{3 - Variáveis de Decisão}

As seguintes variáveis de decisões compõem o modelo matemático proposto:

Relativo ao sistema todo:

- $\quad E T$... quantidade total de contêineres, cheios e vazios, estocados no porto de índice $i$ no início do horizonte de planejamento.

Relativos ao estoque de contêineres:

- $\quad E C_{i, t} \ldots$ quantidade de contêineres cheios estocados no porto de índice $i$ no período de tempo de índice $t$;

- $E V_{i, t \ldots}$ quantidade de contêineres vazios estocados no depósito de vazios junto ao porto de índice $i$ no período de tempo de índice $t$.

\subsection{4 - Função Objetivo}

A função objetivo a ser minimizada é a soma dos contêineres cheios e vazios estocados no portos do sistema no início do horizonte de planejamento.

$$
E T=\sum_{i \in I}\left(E C_{i,(t=1)}+E V_{i,(t=1)}\right)
$$

\subsection{5 - Restrições}

A seguir mostram-se, de forma genérica, as restrições deste modelo de programação linear. Expressões mais detalhadas para estas restrições serão apresentadas no capítulo 4. 
FROTA DE CONTÊINERES

(A) Atendimentó da demand_anda de_contêeineres cheions:

$$
E C_{i, t} \geq D_{i} \quad \forall i \in I, \forall t \in T^{\prime}
$$

onde $T^{\prime}$ representa o conjunto dos instantes de passagem do navio pelo porto de índice $i$.

Esta restrição garante que, nos instantes em que há passagem de navio pelo porto de índice $i$, a demanda de transporte de contêineres sempre será atendida.

(B) Attendimento da demanda de contêineres vazios:

$$
\begin{gathered}
E V_{i, t} \geq S_{i} \quad \forall i \in I, \forall t \in T^{\prime} \\
S_{i} \geq 0
\end{gathered}
$$

onde $T^{\prime}$ representa o conjunto dos instantes de passagem do navio pelo porto de índice $i$.

Caso haja excesso de contêineres vazios no porto de índice $i, S_{i}=0$, devido ao desbalanceamento do fluxo de contêineres, estes $S_{i}$ contêineres vazios serão exportados para outros portos no instante da passagem do navio.

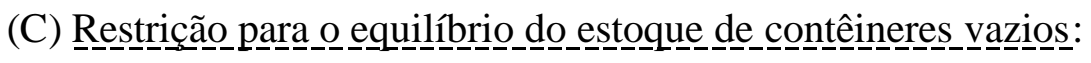

$$
\begin{array}{cc}
E V_{i, t}=E V_{i, t^{\prime}=(t-1)}-\frac{D_{i}}{F}+\alpha_{t-t_{k}} \cdot Q_{i}-S_{i} & \forall i \in I, \forall t \in T^{\prime} \\
E V_{i, t}=E V_{i, t^{\prime}=(t-1)}-\frac{D_{i}}{F}+\alpha_{t-t_{k}} \cdot Q_{i}+S_{i} & S_{i} \geq 0 \\
E V_{i, t}=E V_{i, t^{\prime}=(t-1)}-\frac{D_{i}}{F}+\alpha_{t-t_{k}} \cdot Q_{i} & \forall i \in I, \forall t \in T^{\prime} \\
& S_{i} \leq 0 \\
& \forall i \in I, \forall t \notin T^{\prime}
\end{array}
$$

onde $T^{\prime}$ representa o conjunto dos instantes de passagem do navio pelo porto de índice $i$;

- $\quad E V_{i, t^{\prime}=(t-l)} \ldots$ representa o estoque de contêineres vazios no porto de índice $i$ no período de tempo anterior ao período de tempo de índice $t$; 
FROTA DE CONTÊINERES

- $\frac{D_{i}}{F} \ldots$ representa a saída diária uniforme de contêineres vazios para os clientes de exportação; e

- $\quad \alpha_{t-t_{k}} \cdot Q_{i} \ldots$ representa os contêineres vazios, no período de tempo de índice $t$, que foram encaminhados aos clientes de importação, no período de tempo de índice $t_{k}$.

(D) Restrições para _o estogue de conontêineres cheioios:

$$
\begin{array}{cl}
E C_{i, t}=E C_{i, t^{\prime}=(t-1)}+\beta_{t-\tau_{k}} *\left(\frac{D_{i}}{F}\right)-D_{i} & \forall i \in I, \forall t \in T^{\prime} \\
E C_{i, t}=E C_{i, t^{\prime}=(t-1)}+\beta_{t-\tau_{k}} *\left(\frac{D_{i}}{F}\right) & \forall i \in I, \forall t \notin T^{\prime}
\end{array}
$$

onde $T^{\prime}$ representa o conjunto dos instantes de passagem do navio pelo porto de índice $i$.

- $E C_{i, t^{\prime}=(t-l)} \cdots$ representa o estoque de contêineres cheios para exportação no porto de índice $i$ no período de tempo anterior ao período de tempo de índice $t$; e

- $\quad \beta_{t-\tau_{k}} \cdot\left(\frac{D_{i}}{F}\right) \ldots$ é o número de contêineres cheios que retorna dos clientes de exportação, no período de tempo de índice $t$.

\subsection{6 - Resultados obtidos para o modelo de programação linear}

Este modelo matemático foi desenvolvido em programação linear com variáveis reais e foi implementado utilizando-se como linguagem de manipulação algébrica o GAMS 2.50 e o CPLEX 7.0, como solver. 
Considerando os mesmos parâmetros descritos para o modelo de simulação e a utilização de um estoque mínimo de contêineres vazios (estoque de segurança), determinou-se que a frota total necessária para operar naqueles três portos era de 8.378 contêineres, contando com os contêineres nos navios no início do horizonte de planejamento.

Verificourse, então, que os resultados obtidos pelo modelo matemático estavam bem próximos dos resultados do modelo de simulação, Tabela 3-7, com uma diferença de, aproximadamente, $6,44 \%$ do primeiro modelo. Convém lembrar que a simulação não é uma ferramenta de otimização.

Tabela 3-6 - Resultado para o estoque inicial em cada porto por meio do modelo matemático

\begin{tabular}{|l|c|c|}
\cline { 2 - 3 } \multicolumn{1}{c|}{} & \multicolumn{2}{c|}{ ESTOQUE WOCIAL } \\
\cline { 2 - 3 } \multicolumn{1}{c|}{} & Contêineres Cheios & Contêineres Vazios \\
\hline Porto 1 & $\mathbf{1 1 5 6}$ & $\mathbf{8 9 5}$ \\
\hline Porto 2 & $\mathbf{1 3 2 7}$ & $\mathbf{6 0 8}$ \\
\hline Porto 3 & $\mathbf{1 4 2 1}$ & $\mathbf{7 1 6}$ \\
\hline
\end{tabular}

Tabela 3-7 Resultados obtidos para os modelos de simulação e de programação linear

\begin{tabular}{|r|r|}
\hline \multicolumn{2}{|c|}{ TAMANHO DA FROTA } \\
\hline Simulaçào & Prog. Linear \\
\hline 8.955 & 8.378 \\
\hline
\end{tabular}

\section{4 - O método escolhido}

Conforme descrito inicialmente neste capítulo, optou-se por analisar e refazer os procedimentos propostos pelos autores Imai e Rivera (2001). Os procedimentos realizados pelos autores para o dimensionamento da frota de contêineres foram aplicados para pares de portos e com os tempos de movimentação terrestre dos contêineres sendo determinísticos.

Pelo fato desta dissertação tratar do problema de dimensionamento de frota de contêineres para multi-portos e tempos de movimentação terrestre dos contêineres sendo 
FROTA DE CONTÊINERES

probabilísticos, dois outros métodos foram examinados para a resolução do mesmo: modelos de simulação e programação matemática. Foi elaborado um modelo de simulação para um problema pequeno. Este modelo foi importante para a compreensão dos processos do transporte dos contêineres em sua totalidade.

Com o desencadeamento deste trabalho, verificou-se que o modelo de simulação tornar-se-ia pouco prático, uma vez que, devido ao aumento do número de variáveis, para cada cenário simulado, despender-se-ia muito tempo para realizar as alterações dos valores das variáveis contidas no modelo.

Deste modo, desenvolveu-se, em correspondência ao modelo de simulação, um modelo de programação linear que incorporou as aleatoriedades dos tempos de movimentação terrestre dos contêineres.

O capítulo 4 apresenta a ampliação deste modelo matemático e propõe novas equações e uma nova abordagem para a função objetivo. 


\section{CAPÍTULO 4 - DESCRIÇÃO E MODELAGEM PROPOSTA PARA O PROBLEMA DE DIMENSIONAMENTO DA FROTA DE CONTÊINERES}

Neste capítulo descrevem-se os processos envolvidos no transporte internacional da carga conteinerizada, caracterizando os principais fatores que afetam o dimensionamento da frota de contêineres de uma empresa de navegação destinada a atender uma dada demanda de transporte. Em seguida, o método proposto para a resolução deste problema, sob o ponto de vista da empresa de navegação, é apresentado, assim como as principais hipóteses adotadas.

\section{1 - Caracterização do Sistema}

\subsection{1 - Sistema Marítimo}

Basicamente, o transporte marítimo pode ser dividido em dois setores bastante diferentes na sua organização e forma de atuação:

- Segmento Liner, ou de linhas regulares - caracteriza-se por operar em rotas fixas, com frequiências e portos de passagem regulares. Transporta principalmente carga geral unitizada; 
DIMENSIONAMENTO DA FROTA DE CONTÊINERES

- Segmento Tramp, ou de navios sem linha ou rota fixa - É um serviço não regular, é a mais velha forma de serviço prestada ainda muito importante.

Em uma dada rota de navegação, a quantidade de navios que trafegam por esta rota depende tanto do tempo de viagem redonda, ou seja, quanto tempo o navio demora para percorrer todos os portos da rota até voltar ao porto inicial, quanto da freqüência das passagens dos navios nos portos.

Cada navio, operando em linhas regulares (segmento liner), quando chega ao porto, deverá atracar em um berço que esteja disponível. Caso contrário, deverá aguardar em uma fila até que o berço seja liberado. Após atracado, inicia-se o processo de descarregamento dos contêineres dos navios. Primeiro, os contêineres vazios e depois os cheios de importação. Em seguida, tem-se o processo de carregamento dos contêineres nos navios; desta vez, primeiro são carregados os contêineres cheios e, após, os contêineres vazios de exportação.

Os navios partem dos portos tão logo acabem os processos de descarregamento e carregamento dos contêineres, uma vez que os mesmos devem cumprir uma janela de tempo imposta pelo terminal do porto no qual está atracado. O navio, então, viaja para o próximo porto, carregando os contêineres destinados tanto para o próximo quanto para os subseqüentes portos da rota.

\subsection{2 - Sistema Terrestre}

Os terminais dos portos possuem três áreas distintas: uma área destinada aos contêineres cheios resultantes dos navios no processo de importação, um espaço para os 
DIMENSIONAMENTO DA FROTA DE CONTÊINERES

contêineres cheios que serão exportados e uma terceira área que estará reservada aos contêineres vazios, sejam eles de importação ou de exportação.

Os contêineres cheios importados seguem para sua respectiva área, partindo em seguida para os clientes que os importaram, doravante denominados clientes de importação. Após serem esvaziados por estes clientes, os contêineres retornam ao depósito de vazios da empresa junto ao porto para serem vistoriados. Todos eles passam um processo de limpeza, sendo que alguns acabam necessitando de reparos também. Em seguida, estes contêineres ficam estocados na área destinada aos contêineres vazios.

Tão logo sejam requisitados pelos clientes que irão exportar suas cargas, de agora em diante denominados clientes de exportação, os contêineres partem para os clientes para serem estufados, retornando ao porto para serem embarcados na data da próxima escala do navio da empresa. Estes contêineres cheios, quando retornam ao porto, aguardam na área de exportação seguindo a regra de first in first out, ou seja, os primeiros contêineres que chegaram serão aqueles que embarcarão primeiro no navio. Caso não haja mais espaço disponível no navio, os contêineres restantes aguardam nesta área até a passagem do próximo navio.

Os contêineres vazios que permanecem no depósito de vazios da empresa tanto podem servir de estoque para os próximos clientes de exportação, quanto podem ser reposicionados para outros portos a fim de suprir as demandas existentes naqueles portos.

\subsection{3 - Problema do Contêiner Vazio}

Os contêineres vazios surgem quando há um desequilíbrio entre os fluxos de importação e exportação. Isto ocasiona um acúmulo de contêineres vazios em algumas regiões, enquanto em outras há falta de contêineres. 
DIMENSIONAMENTO DA FROTA DE CONTÊINERES

Para satisfazer a demanda de contêineres vazios, podem ser utilizados alguns recursos tais como, o reposicionamento dos contêineres vazios excedentes em alguns portos e/ou o aluguel de contêineres de outras empresas. A decisão entre reposicionar um contêiner vazio ou o leasing (aluguel) de contêiner de outra empresa leva em conta os custos de reposicionamento do contêiner vazio e do leasing bem como a própria viabilidade dessas operações.

Essencialmente, a estimativa do número de contêineres vazios necessários depende da previsão de demanda de cada porto, que geralmente varia ao longo do tempo, do estoque de vazios e do tempo de retorno dos contêineres que trouxeram carga na importação. A realocação dos contêineres vazios também dependerá do espaço vazio dos navios.

Devido a estas incertezas, faz-se necessária a utilização de estoques de segurança em cada porto para que não haja a perda do transporte da carga para outras empresas, mesmo aumentando os custos de se manter estoques de contêineres vazios e a diminuição do espaço reservado no terminal para os contêineres cheios.

\section{2 - Descrição do sistema de transporte a ser modelado}

O sistema modelado para o dimensionamento da frota de contêineres pode ser, sinteticamente, descrito da seguinte forma:

i. Tomando-se como base uma rota específica, tal como citada no trabalho de Imai e Rivera (2001), um navio chega a um dado porto com uma determinada quantidade de contêineres cheios e vazios. Devido ao desequilíbrio do fluxo de contêineres, haverá a necessidade de alguns navios carregarem contêineres vazios para outros portos;

ii. O navio descarrega parte destes contêineres e carrega outros; 
iii. O navio, assim, segue para o próximo porto. A freqüência dos navios nos portos depende do tempo de viagem redonda da rota e da quantidade de navios da empresa que realiza esta mesma rota, Figura 4-1;

iv. Os contêineres cheios, descarregados dos navios, são enviados aos clientes de importação. Estes desovam os contêineres e os enviam vazios ao depósito de vazios da empresa junto ao porto, Figura 4-2;

v. Os contêineres vazios que foram importados de outros portos, os que retornaram vazios dos clientes de importação e os que serão destinados aos clientes de exportação ou a outros portos permanecem no depósito de vazios da empresa junto ao porto;

vi. Sabendo-se, a priori, o schedule dos navios e a quantidade de contêineres exportada em cada porto, é necessário que haja um fluxo diário uniforme de contêineres vazios, próprios e alugados, dos terminais até os clientes de exportação, a fim de que nenhum navio parta sem a demanda prevista. Estes contêineres vazios são enviados aos clientes de exportação de onde retornam ao porto como contêineres cheios. Estes contêineres cheios aguardam, então, a passagem do próximo navio, Figura 4-3.

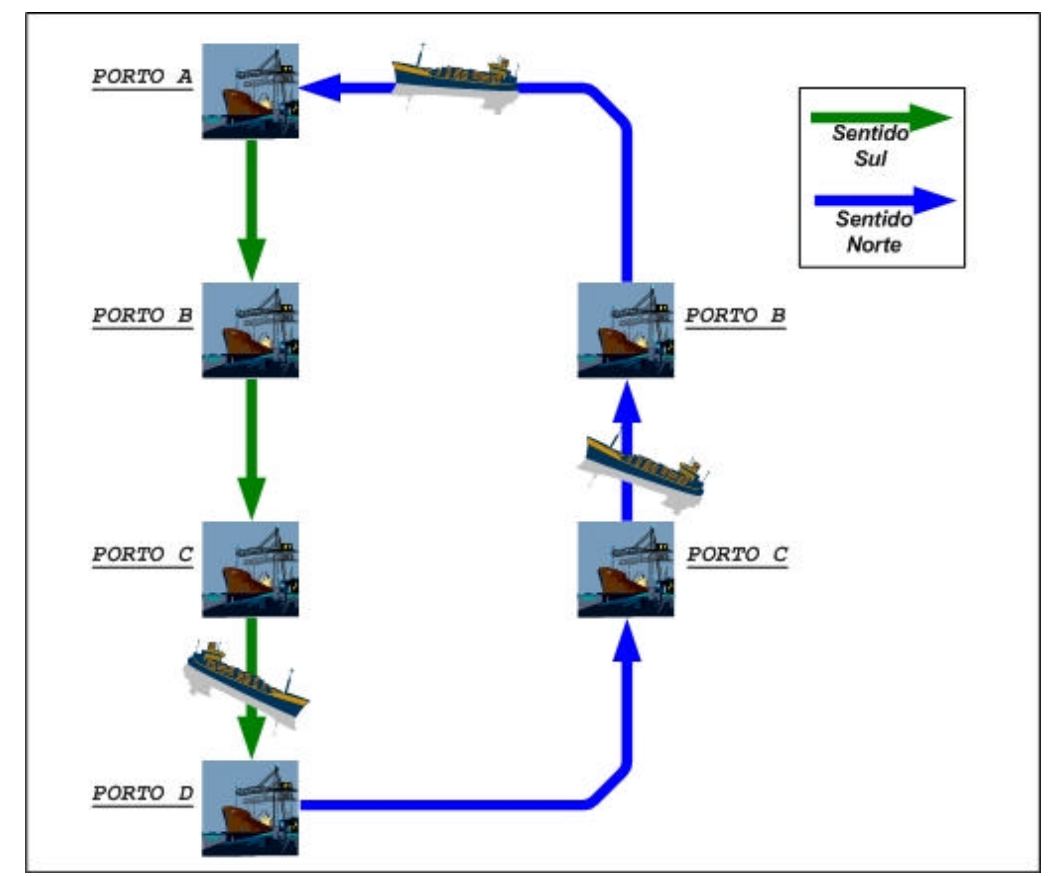

Figura 4-1 Rota genérica para a definição do modelo de programação linear 
DIMENSIONAMENTO DA FROTA DE CONTÊINERES

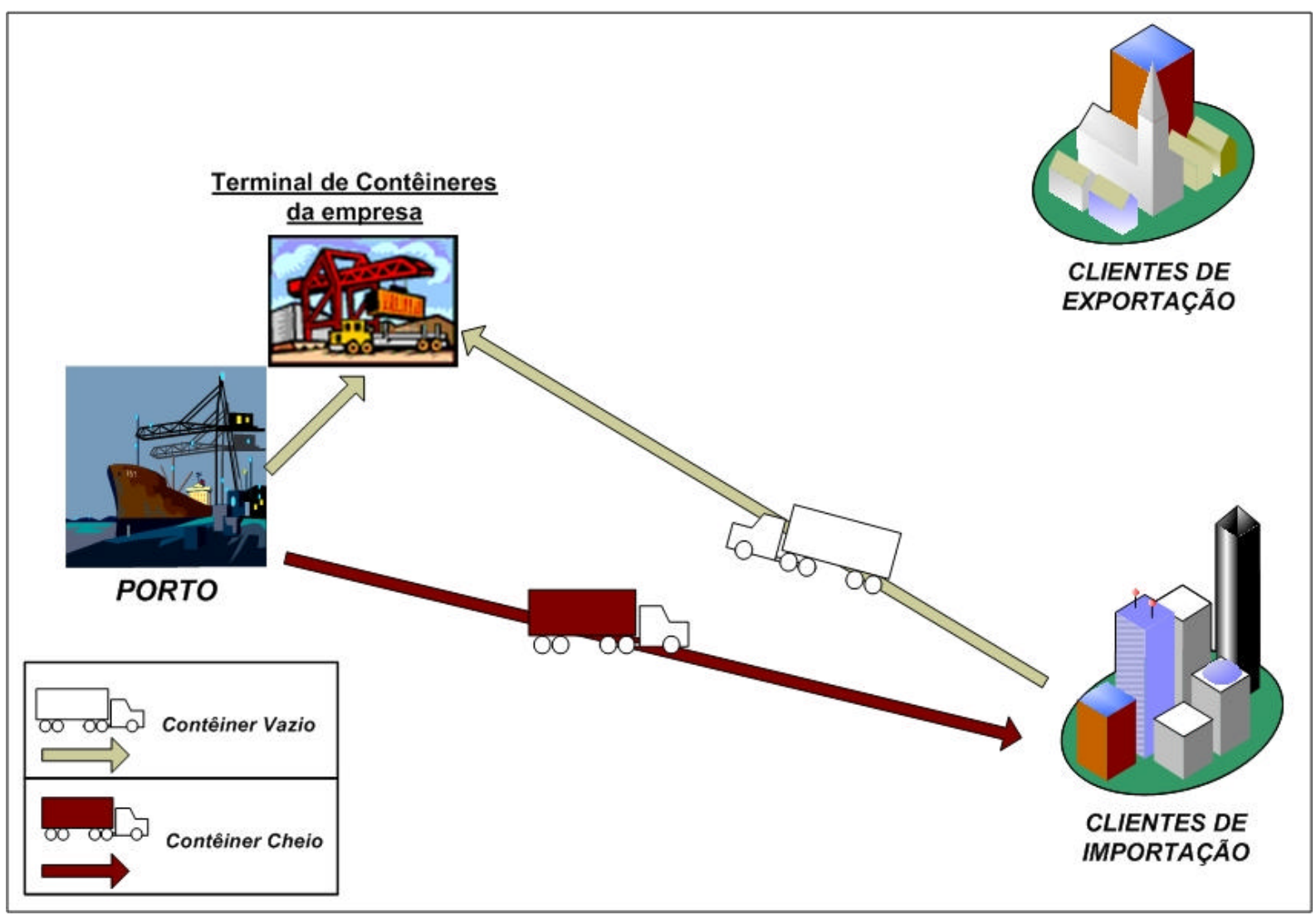

Figura 4-2 Importação de contêineres cheios e vazios pelo porto

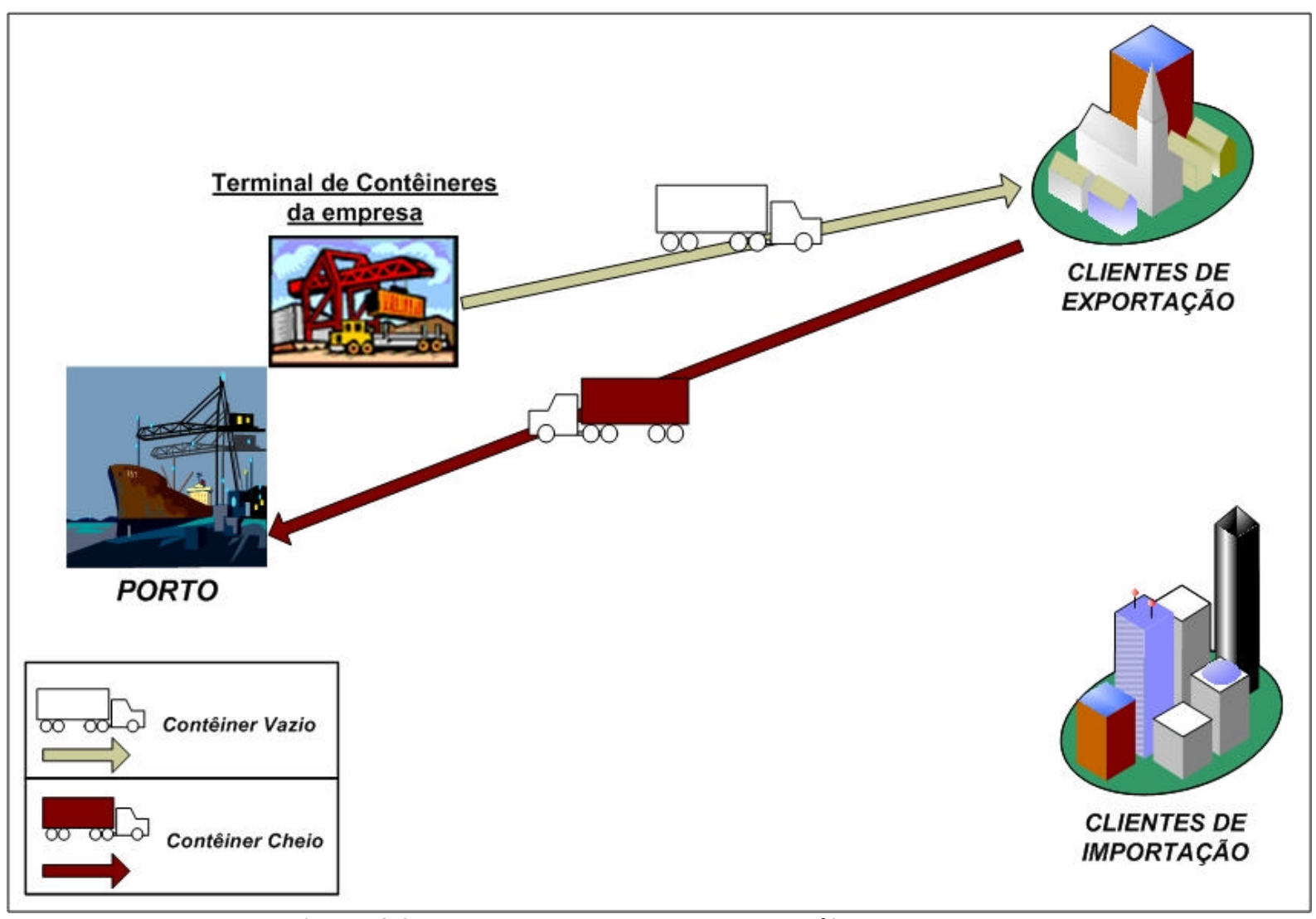

Figura 4-3 Processo de exportação dos contêineres pelo porto 
DIMENSIONAMENTO DA FROTA DE CONTÊINERES

Sendo assim, este modelo procurará obter a solução ótima para o custo total do sistema analisado, sob o ponto de vista da empresa de navegação, resultando na melhor composição da quantidade de contêineres próprios e alugados para um dado horizonte de planejamento sob o ponto de vista de uma empresa de navegação. Por se tratar de um problema complexo - principalmente devido à variabilidade da demanda de contêineres ao longo do tempo, à aleatoriedade existente nos tempos de movimentação terrestre dos contêineres e ao problema de fluxo ou desbalanceamento da carga - fez-se necessário adotar algumas simplificações ao modelar o sistema real.

\section{3 - O Modelo Proposto}

As premissas adotadas para a elaboração do modelo matemático são semelhantes as do modelo de simulação, ou seja, os navios pertencentes à empresa de navegação deverão respeitar as janelas de tempo para a sua chegada ao porto e, além disso, toda a aleatoriedade estará concentrada no transporte terrestre dos contêineres. Admite-se, também, que a frota de contêineres seja composta por um único tipo de contêiner. Porém, em lugar da distribuição probabilística do tempo de retorno dos contêineres utilizada na simulação, para o modelo de programação linear tem-se uma freqüência relativa dos tempos de devolução dos contêineres. Mais precisamente, se num dado dia $t, N$ contêineres cheios são enviados do porto aos clientes de importação, então o depósito de vazios da empresa de navegação receberá de volta os correspondentes contêineres vazios no intervalo de tempo $\left[t+t_{\min }, t+t_{\max }\right]$, doravante chamado de intervalo de tempo de retorno dos vazios, de modo que o número de contêineres recebidos num dia $\mathrm{t}, t+t_{\text {min }}=\mathrm{t}=t+t_{\text {max }}$, seja igual a $? N$, em que $?=\mathrm{P}\left[(\mathrm{t}-t)<t_{\text {retorno }}=(\mathrm{t}-t\right.$ $+1)]$ 
DIMENSIONAMENTO DA FROTA DE CONTÊINERES

Uma representação semelhante é adotada para modelar o retorno ao porto, carregados, de $N$ contêineres vazios encaminhados no dia $t$ aos clientes de exportação. Trata-se de uma aproximação da realidade, pois ?N não é necessariamente inteiro, que é bastante aceitável para modelos de planejamento.

\subsection{1 - Nomenclatura dos índices}

Os seguintes índices serão utilizados para o desenvolvimento do modelo matemático proposto neste trabalho:

- $\quad i, j \ldots$ para representar os portos, tanto de origem quanto de destino;

- $\quad n$... para representar os navios da empresa que atendem os portos na rota;

- $\quad$ tr ... para indicar o trecho da rota;

- $\quad t$... para indicar o período de tempo, que será discretizado em dias;

- $p_{t} \ldots$ para representar a passage m do navio pelo porto, no período de tempo de índice $t$.

Relativos aos conjuntos de índices:

* I, J ... para representar o conjunto de todos os portos, tanto de origem quanto de destino;

* $\quad N$... para representar o conjunto de todos os navios da empresa que atendem a todos os portos na rota determinada;

* TR ... para representar o conjunto de todos os trechos pertencentes à rota analisada;

* T ... para indicar o conjunto com todos os períodos de tempo dentro do horizonte de planejamento; 
DIMENSIONAMENTO DA FROTA DE CONTÊINERES

* $\quad P_{T} \ldots$ representa o conjunto de todas as passagens dos navios pelo porto, durante o horizonte de planejamento.

\subsection{2 - Nomenclatura dos parâmetros}

Relativos aos custos:

* $\quad C P$... custo unitário diário dos contêineres próprios;

* $\quad F_{i, j} \ldots$ frete diário para o aluguel (leasing) de um contêiner vazio que será utilizado para o transporte de carga de um exportador da região do porto de índice $i$ para um importador da região do porto de índice $j$. Admite-se, para tornar o modelo mais genérico, que esse parâmetro depende da oferta/demanda de contêineres vazios nas regiões dos portos de índice $i$ e $j$;

* $\quad C V_{i, j} \ldots$ custo unitário para o transporte de um contêiner próprio vazio entre os portos de índices $i$ e $j$;

* $C C C_{i} \ldots$ custo unitário diário para a carga armazenada no contêiner no porto de índice $i$. Este custo representa uma "penalidade" para o contêiner cheio que ficar estocado no porto.

Relativos às embarcações:

* $\quad N Q \ldots$ número de navios da empresa designados para a rota considerada;

* TVR ... tempo de viagem redonda, ou seja, tempo que um navio leva para executar um ciclo de operações na rota;

* IN ... intervalo de tempo entre as passagens dos navios da empresa pelo porto. Considera-se que este intervalo será o mesmo para todos os portos pertencentes à rota 
considerada. No caso de portos em que há passagem nos dois sentidos, IN é o intervalo entre passagens consecutivas no mesmo sentido;

* TS ${ }_{i} \ldots$ dia da primeira chegada do navio, no sentido sul da viagem, ao porto de índice $i$ dentro do horizonte de planejamento considerado;

* $T N_{i} \ldots$ dia da primeira chegada do navio, no sentido norte da viagem, ao porto de índice $i$ dentro do horizonte de planejamento considerado;

* $\quad T V_{i, j} \ldots$ tempo de viagem do navio entre o porto de índice $i$ e o porto de índice $j$. Para o caso dos portos que forem visitados pelo navio nos dois sentidos da rota, este tempo refere-se ao tempo de viagem do navio entre estes portos no mesmo sentido em que o navio está trafegando;

* TF $i, n \ldots$ intervalo de tempo até o navio de índice $n$ chegar ao porto de índice $i$ na primeira viagem do horizonte de planejamento;

* TRS $t r, i, j \ldots$ parâmetro binário que assume o valor igual a 1 se, no trecho da viagem no sentido sul, há no navio carga do porto de índice $i$ destinada ao porto de índice $j$;

* $T R N_{t r, i, j} \ldots$ parâmetro binário que assume o valor igual a 1 se, no trecho da viagem no sentido norte, há no navio carga do porto de índice $i$ destinada ao porto de índice $j$;

* $\operatorname{ENPS}_{i, n} \ldots$ quantidade de contêineres próprios cheios existentes no navio de índice $n$, no início do horizonte de planejamento, que serão desembarcados no porto de índice $i$, no trecho sul da viagem;

* $E N P N_{i, n} \ldots$ quantidade de contêineres próprios cheios existentes no navio de índice $n$, no início do horizonte de planejamento, que serão desembarcados no porto de índice $i$, no trecho norte da viagem; 
DIMENSIONAMENTO DA FROTA DE CONTÊINERES

* ENLS $S_{i, n} \ldots$ quantidade de contêineres alugados cheios existentes no navio de índice $n$, no início do horizonte de planejamento, que serão desembarcados no porto de índice $i$, no trecho sul da viagem;

* ENLN $i, n \ldots$ quantidade de contêineres alugados cheios existentes no navio de índice $n$, no início do horizonte de planejamento, que serão desembarcados no porto de índice $i$, no trecho norte da viagem;

* YS $i, t \ldots$ parâmetro binário que assume valor igual a 1 quando há passagem de um navio, no sentido sul, pelo porto de índice $i$, no período de tempo de índice $t$; e 0 , caso contrário;

* YN ${ }_{i, t} \ldots$ parâmetro binário que assume valor igual a 1 quando há passagem de um navio, no sentido norte, pelo porto de índice $i$, no período de tempo de índice $t$; e 0 , caso contrário.

Relativos às demandas:

* DS $i, j, t \ldots$ demanda de transporte de contêineres cheios do porto de índice $i$ para o porto de índice $j$, tal que o período de tempo de índice $t$ seja um dia de passagem do navio, no porto de índice $i$, no sentido sul;

* $D N_{i, j, t} \ldots$ demanda de transporte de contêineres cheios do porto de índice $i$ para o porto de índice $j$, tal que o período de tempo de índice $t$ seja um dia de passagem do navio, no porto de índice $i$, no sentido norte;

* $\quad D S N_{i, n} \ldots$ quantidade de contêineres cheios contidos no navio de índice $n$, no início do horizonte de planejamento, que serão descarregados mo porto de índice $i$ no trecho sul da viagem; 
DIMENSIONAMENTO DA FROTA DE CONTÊINERES

* $D N N_{i, n} \ldots$ quantidade de contêineres cheios contidos no navio de índice $n$, no início do horizonte de planejamento, que serão descarregados no porto de índice $i$ no trecho norte da viagem;

Relativos às capacidades:

* $C L$ i, $t$... disponibilidade de contêineres vazios no porto de índice $i$, no período de tempo de índice $t$, para uma operação de leasing;

* $\quad C V E_{i, t} \ldots$ quantidade de contêineres próprios vazios excedentes no porto de índice $i$, no período de tempo de índice $t$, que poderiam ser reposicionados para outros portos. Pode-se dizer que esta oferta de contêineres vazios será a diferença entre a quantidade de contêineres próprios cheios importados e exportados.

$$
\begin{aligned}
& \forall i \in I, \forall t \in T, t=\left\{0,1,2, \ldots, t_{\text {max }}\right\} \\
& \left.C V E_{i, t}=\sum_{j \in J}\left(\begin{array}{l}
\left(D S_{j, i, t^{\prime}}+D N_{j, i, t^{\prime \prime}}\right)- \\
\left(D S_{i, j, t l^{\prime}}+D N_{i, j, t l^{\prime}}\right)
\end{array}\right) \quad \begin{array}{l}
t^{\prime}=\left\{T S_{i}+p_{t} \cdot I N-T V_{j, i}, p_{t}=0,1, \ldots, p_{t_{\max }}\right\}, \\
t^{\prime \prime}=\left\{T N_{i}+p_{t} \cdot I N-T V_{j, i}, p_{t}=0,1, \ldots, p_{t_{\max }}\right\}, \\
t l^{\prime}=\left\{T S_{i}+p_{t} \cdot I N, p_{t}=0,1, \ldots, p_{t_{\max }}\right\},
\end{array}\right\} \\
& t l^{\prime \prime}=\left\{T N_{i}+p_{t} \cdot I N, p_{t}=0,1, \ldots, p_{t_{\max }}\right\} \text {. }
\end{aligned}
$$

* CN ... capacidade em TEU's dos navios que operam na rota determinada;

* EMIN ${ }_{i, t} \ldots$ estoque mínimo de contêineres próprios vazios para o porto de índice $i$, no período de tempo de índice $t$. Pode ser interpretado como estoque de segurança e definido como uma fração da demanda de contêineres cheios exportados pelo porto de índice $i$, tanto no sentido sul quanto no sentido norte:

$$
\operatorname{EMIN}_{i, t}=\gamma \cdot \sum_{j}^{J}\left(D S_{i, j, t}+D N_{i, j, t}\right) \quad \forall i \in I, \forall t \in T .
$$

onde ? é um escalar menor que 1. 
DIMENSIONAMENTO DA FROTA DE CONTÊINERES

Relativos ao retorno de contêineres vazios:

* $\quad \alpha_{i, t-t_{k}} \ldots$ freqüência relativa do tempo de retorno, no período de tempo de índice $t$, dos contêineres cheios encaminhados do porto de índice $i$ ao cliente de importação, no período de tempo de índice $t_{k}, T M I N V_{i}=\left(t-t_{k}\right)=T M A X V_{i}$;

* $\quad \beta_{i, t-\tau_{k}} \ldots$ freqüência relativa do tempo de retorno, no período de tempo de índice $t$, dos contêineres vazios encaminhados do depósito de vazios da empresa junto ao porto de índice $i$ ao cliente de exportação, no período de tempo de índice $t_{k}$,

$\operatorname{TMINC}_{i}=\left(t-t_{k}\right)=T M A X C_{i}$

* TMINV ${ }_{i} \ldots$ intervalo de tempo mínimo, contado a partir do instante de chegada do contêiner cheio de importação ao porto de índice $i$, para que o contêiner vazio retorne ao depósito de vazios da empresa de navegação;

* TMAXV ${ }_{i} \ldots$ intervalo de tempo máximo, contado a partir do instante de chegada do contêiner cheio de importação ao porto de índice $i$, para que o contêiner vazio retorne ao depósito de vazios da empresa de navegação;

* TMV ${ }_{i}$... intervalo de tempo médio, contado a partir do instante de chegada do contêiner cheio de importação ao porto de índice $i$, para que o contêiner vazio retorne ao depósito de vazios da empresa de navegação: $T M V_{i}=\frac{T M I N V_{i}+T M A X V_{i}}{2}$

* TMINC ${ }_{i}$... intervalo de tempo mínimo, contado a partir do instante da saída do contêiner vazio do depósito de vazios da empresa, para que o contêiner cheio de exportação chegue ao porto de índice $i$;

* TMAXC ${ }_{i}$... intervalo de tempo máximo, contado a partir do instante da saída do contêiner vazio do depósito de vazios da empresa, para que o contêiner cheio de exportação chegue ao porto de índice $i$; 
DIMENSIONAMENTO DA FROTA DE CONTÊINERES

* TMC ${ }_{i} \ldots$ intervalo de tempo médio, contado a partir do instante da saída do contêiner vazio do depósito de vazios da empresa, para que o contêiner cheio de exportação chegue ao porto de índice $i: T M C_{i}=\frac{T_{M I N C_{i}}+T M A X C_{i}}{2}$

\subsection{3 - Variáveis de Decisão}

As seguintes variáveis de decisões compõem o modelo matemático proposto:

Relativas ao sistema todo:

* $\quad C T$... custo total do sistema avaliado;

Relativas ao estoque de contêineres:

* EPC $i, j, t \ldots$ quantidade de contêineres próprios cheios estocados no porto de índice $i$, no período de tempo de índice $t$, e que serão transportados ao porto de índice $j$;

* ELC $i, j, t \ldots$ quantidade de contêineres alugados cheios estocados no porto de índice $i$, no período de tempo de índice $t$, e que serão transportados ao porto de índice $j$;

* $E V_{i, t \ldots}$ quantidade de contêineres próprios vazios estocados no depósito de vazios da empresa de navegação junto ao porto de índice $i$ no período de tempo de índice $t$;

Relativa s à movimentação de contêineres cheios e vazios, próprios ou alugados:

* $Q E V_{i, j, t} \ldots$ quantidade de contêineres próprions vazios que serão enviados, no período de tempo de índice $t$, aos clientes de exportação para remeterem seus carregamentos do porto de índice $i$ ao porto de índice $j$; 
DIMENSIONAMENTO DA FROTA DE CONTÊINERES

* $\quad L E V_{i, j, t} \ldots$ quantidade de contêineres alugados vazios que serão enviados, no período de tempo de índice $t$, aos clientes de exportação para remeterem seus carregamentos do porto de índice $i$ ao porto de índice $j$;

* SES ${ }_{i, j, t} \ldots$ quantidade de contêineres próprios vazios exportados pelo porto de índice $i$ para o porto de índice $j$, tal que o período de tempo de índice $t$ seja um dia de passagem do navio no sentido sul;

* SEN $i, j, t \ldots$ quantidade de contêineres próprios vazios exportados pelo porto de índice $i$ para o porto de índice $j$, tal que o período de tempo de índice $t$ seja um dia de passagem do navio no sentido norte;

* EPS $i, j, t \ldots$ fluxo de contêineres próprios cheios que serão embarcados no porto de índice $i$ para o porto de índice $j$, tal que o período de tempo de índice $t$ seja um dia de passagem do navio no sentido sul;

* EPN $i, j, t \ldots$ fluxo de contêineres próprios cheios que serão embarcados no porto de índice $i$ para o porto de índice $j$, tal que o período de tempo de índice $t$ seja um dia de passagem do navio no sentido norte;

* ELS ${ }_{i, j}, t \ldots$ fluxo de contêineres alugados cheios que serão embarcados no porto de índice $i$ para o porto de índice $j$, tal que o período de tempo de índice $t$ seja um dia de passagem do navio no sentido sul;

* $E L N ~ i, j, t$... fluxo de contêineres alugados cheios que serão embarcados no porto de índice $i$ para o porto de índice $j$, tal que o período de tempo de índice $t$ seja um dia de passagem do navio no sentido norte;

* $R V_{i, n, t} \ldots$ quantidade de contêineres próprios vazios que retornam ao depósito de vazios da empresa junto ao porto de índice $i$, no período de tempo de índice $t$, provenientes da viagem inicial do navio de índice $n$, no horizonte de planejamento; 
DIMENSIONAMENTO DA FROTA DE CONTÊINERES

* $R R V$ i, $t \ldots$ quantidade de contêineres próprios vazios que retornam ao depósito de vazios da empresa de navegação junto ao porto de índice $i$, no período de tempo de índice $t$, provenientes do processo de importação de contêineres cheios.

Relativas às embarcações:

* QNS $i, t \ldots$ quantidade de contêineres existentes dentro do navio após partir do porto de índice $i$, no período de tempo de índice $t$, no sentido sul;

* $Q N N_{i, t} \ldots$ quantidade de contêineres existentes dentro do navio após partir do porto de índice $i$, no período de tempo de índice $t$, no sentido norte.

\subsection{4 - Função Objetivo}

A função objetivo para este problema é a soma dos custos variáveis decorrentes das decisões referentes ao tamanho da frota própria, ao aluguel de contêineres e ao reposicionamento de contêineres vazios, utilizando navios da frota, durante o brizonte de planejamento considerado. Admite-se que a frota própria não se modifica ao longo do horizonte de planejamento, de modo que o seu custo decorre de seu tamanho no início do horizonte de planejamento.

Para efeito da modelagem e com o intuito de não depender de muitas informações do período anterior, admite-se que, no início do horizonte de planejamento, os contêineres da frota própria estejam numa das três situações:

i. embarcados nos navios da frota;

ii. cheios, aguardando embarque nos portos; e

iii. vazios nos terminais da empresa de navegação junto aos portos. 
DIMENSIONAMENTO DA FROTA DE CONTÊINERES

Admite-se conhecida a quantidade de contêineres embarcados, de tal forma que a decisão sobre o dimensionamento da frota própria diz respeito somente à soma das parcelas dos itens (ii) e (iii) acima. Desde que não faz sentido estocar contêineres cheios nos portos além dos necessários para atender as demandas das próximas viagens, impõe-se, na função objetivo, uma penalidade para a quantidade de contêineres cheios nos portos. O fator de penalização poderia representar o custo diário de capital da carga acondicionada em contêineres.

Admite-se que os contêineres são alugados para atender a demanda de transporte para uma única viagem. Isto é, na falta de contêineres vazios da frota própria no depósito de vazios da empresa de navegação junto ao porto de índice $i$ para atender a demanda de transporte para o porto de índice $j$, a empresa faz o leasing de um contêiner vazio e o envia ao cliente de exportação; depois de estufado, o contêiner cheio é encaminhado ao porto de índice $i$, para embarque em um navio da frota com destino ao porto de índice $j$. Após o descarregamento no porto de índice $j$, o contêiner é enviado ao cliente de importação, desovado e encaminhado ao depósito de vazios da empresa para devolução à firma locadora. $\mathrm{O}$ custo de leasing desse contêiner é o produto de um custo diário pelo tempo total de utilização do contêiner. Para efeito da modelagem, admite-se que esse tempo total é a soma do tempo e viagem entre os portos de índices $i$ e $j$ e dos tempos médios dos trechos terrestres.

$\mathrm{O}$ custo de reposicionamento de um contêiner vazio entre os portos de índices $i$ e $j$ corresponde aos custos de seu carregamento no porto de índice $i$ e de seu descarregamento no porto de índice $j$.

Assim,

$$
C T=C_{1}+C_{2}+C_{3}+C_{4}
$$

onde: 
* $C_{l} \quad \ldots$ é a parcela relativa ao custo da frota própria durante o horizonte de planejamento;

$$
C_{I}=\left(\sum_{i \in I} \sum_{j \in J}\left(E P C_{i, j,(t=0)}\right)+\sum_{i \in I}\left(E V_{i,(t=0)}\right)\right) * C P^{*} T
$$

* $C_{2} \ldots$ é a parcela relativa ao aluguel de contêineres. Isto quer dizer, são todos os contêineres alugados no porto de índice $i$ que são enviados ao porto de índice $j$, tanto no sentido sul quanto no sentido norte, multiplicados pelo intervalo de tempo médio entre o aluguel do contêiner e o porto de índice $i\left(T M C_{i}\right)$ e no porto de índice $j\left(T M V_{j}\right)$ mais o tempo de viagem entre estes porto $\left(T V_{i, j}\right)$. Estas parcelas são multiplicadas pelo custo diário para o contêiner alugado;

$$
C_{2}=\left(\begin{array}{l}
\sum_{i \in I} \sum_{j \in J} \sum_{t \in T}\left(E L S_{i, j, t}\right) *\left(T V_{i, j}+T M C_{i}+T M V_{j}\right) * F_{i, j}+ \\
\sum_{i \in I} \sum_{j \in J} \sum_{t \in T}\left(E L N_{i, j, t}\right) *\left(T V_{i, j}+T M C_{i}+T M V_{j}\right) * F_{i, j}
\end{array}\right)
$$

* $\quad C_{3} \ldots$ é a parcela do custo referente ao transporte de contêineres próprios vazios entre os portos de índices $i$ e $j$, tanto no sentido sul quanto no norte;

$$
C_{3}=\sum_{i \in I} \sum_{j \in J} \sum_{t \in T}\left(C V_{i, j} *\left(S E S_{i, j, t}+S E N_{i, j, t}\right)\right)
$$

* $\quad C_{4} \ldots$ é a parcela relativa ao custo associado à permanência dos contêineres cheios no porto;

$$
C_{4}=\sum_{i \in I} \sum_{j \in J} \sum_{t \in T} E P C_{i, j, t} * C C C_{i}+\sum_{i \in I} \sum_{j \in J} \sum_{t \in T} E L C_{i, j, t} *\left(F_{i, j}+C C C_{i}\right)
$$




\subsection{5 - Restrições}

A. Atendimento da Demanda de Exportação dos Portos no sentido sul

$$
\begin{array}{ll}
\left(E P S_{i, j, t}+E L S_{i, j, t}\right)=D S_{i, j, t} & \forall i \in I, \forall j \in J, t \in T, t=\left\{0,1,2, \ldots, t_{\text {max }}\right\} \\
t & =\left\{T S_{i}+p_{t} \cdot I N, p_{t}=0,1, \ldots, p_{t_{\max }}\right\}
\end{array}
$$

Esta restrição garante que a soma dos contêineres cheios, próprios e/ou alugados, embarcados no sentido sul, deverá ser exatamente igual à demanda de exportação do porto de índice $i$ para o porto de índice $j$, no correspondente sentido da viagem, no instante da passagem do navio naquele porto.

B. Atendimento da Demanda de Exportação dos Portos no sentido norte

$$
\begin{array}{ll}
\left(E P N_{i, j, t}+E L N_{i, j, t}\right)=D N_{i, j, t} & \forall i \in I, \forall j \in J, t \in T, t=\left\{0,1,2, \ldots, t_{\max }\right\} \\
& t=\left\{T N_{i}+p_{t} \cdot I N, p_{t}=0,1, \ldots, p_{t_{\max }}\right\}
\end{array}
$$

Esta restrição é semelhante à restrição (4.8), porém ela é válida para o sentido norte.

C. Restricião para o estoque mínimo de contêineres próprios vazios

$$
E P V_{i, t} \geq E M I N_{i, t} \quad \forall i \in I, \forall t \in T
$$

Esta restrição garante que a quantidade de contêineres próprios vazios no estoque não deve ser inferior ao estoque mínimo, mencionado no item 4.3.2 - .

D. Restrição para a saída diária de contêneres vazios para os clientes de exportaçãa

$$
\left(Q E V_{i, j, t}+L E V_{i, j, t}\right)=\frac{\left(D S_{i, j, t^{\prime}}+D N_{i, j, t^{\prime \prime}}\right)}{I N} \quad \begin{aligned}
& \forall i \in I, \forall j \in J, \forall t \in T, t=\left\{0,1,2, \ldots, t_{\max }\right\} \\
& t^{\prime}=\left\{T S_{i}+p_{t} \cdot I N, p_{t}=0,1, \ldots, p_{t_{\max }}\right\} \\
& t^{\prime \prime}=\left\{T N_{i}+p_{t} \cdot I N, p_{t}=0,1, \ldots, p_{t_{\max }}\right\}
\end{aligned}
$$


DIMENSIONAMENTO DA FROTA DE CONTÊINERES

Devido à dificuldade de estabelecer a quantidade de contêineres vazios que cada cliente de exportação necessitaria em um determinado tempo, decidiu-se fixar um fluxo uniforme de saída diário de contêineres vazios para o conjunto destes clientes, levando-se em consideração a sua demanda de exportação para os dois sentidos, sul e norte, e, também, o intervalo entre passagens dos navios pelo porto onde os mesmos clientes encontram-se. Para testar o efeito que esta parcela possa ter sobre a função objetivo, pretende-se deixar esta restrição ilimitada superiormente $(=)$, ou seja, fazer com que o modelo decida qual deverá ser a quantidade de contêineres vazios a ser enviada, por dia, aos clientes de exportação em vista da demanda a ser transportada do porto de índice $i$ para o porto de índice $j$.

E. Restrição para a capacidade máxima de leasing de contêineres vazios:

$$
\sum_{j \in J} L E V_{i, j, t} \leq C L_{i, t}
$$

Devido às limitações do mercado e ao seu desbalanceamento, entende-se que em cada porto haja uma restrição em relação à quantidade de contêineres vazios disponíveis para leasing em cada período. Esta restrição indica, portanto, que o número de contêineres a serem arrendados não deva ultrapassar o limite de cada porto de índice $i$, para cada período de tempo de índice $t$.

F. Restrição para a capacidade máxima de contêineres próprios vazios transportados:

$$
\begin{aligned}
& \sum_{j \in J}\left(S E S_{i, j, t^{\prime}}+S E N_{i, j, t^{\prime \prime}}\right) \leq C V E_{i, t} \quad \forall i \in I \mid C V E_{i, t}>0, \forall j \in J, \forall t \in T, t=\left\{0,1,2, \ldots, t_{\max }\right\} \\
& t^{\prime}=\left\{T S_{i}+p_{t} \cdot I N, p_{t}=0,1, \ldots, p_{t_{\max }}\right\} \\
& t^{\prime \prime}=\left\{T N_{i}+p_{t} \cdot I N, p_{t}=0,1, \ldots, p_{t_{\max }}\right\}
\end{aligned}
$$

Devido ao desbalanceamento do mercado, alguns portos podem importar mais contêineres cheios do que exportam. Isto gera um acúmulo de contêineres vazios nestes portos 
DIMENSIONAMENTO DA FROTA DE CONTÊINERES

e a falta destes em outros portos. A restrição (4.13) garante que a quantidade de contêineres vazios transportados do porto de índice $i$ para todos os outros portos não ultrapasse a quantidade de contêineres próprios vazios que o porto de índice $i$ possa disponibilizar.

G. Restrição para determinar a quantidade de contêineres próprios vazios que retornam ao depósito de vazios do porto de índice $i$ no período de tempo de índice t provenientes dos contêineres cheios já embarcados nos navios da frota com destino ao porto de índice $i$ no início do horizonte de planejamento:

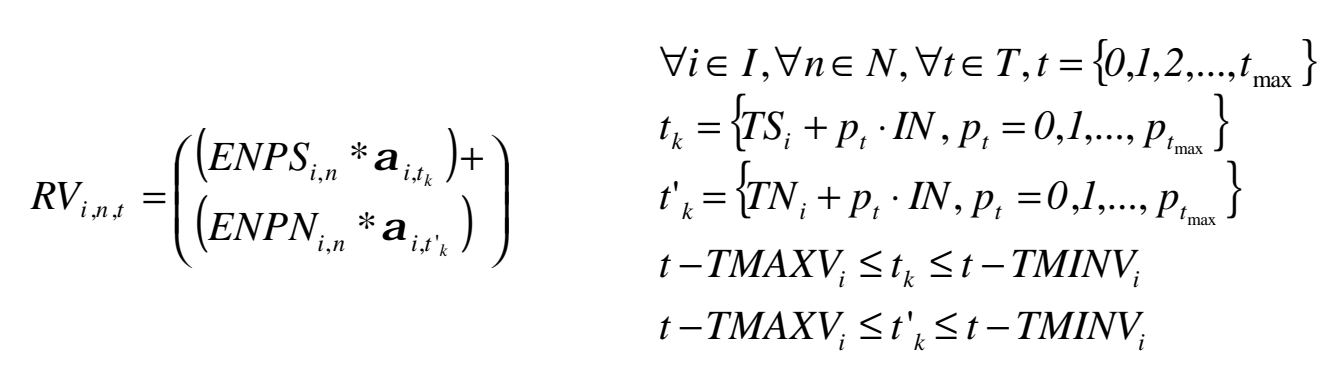

H. Restrição para determinar a quantidade de contêineres próprios vazios que retornam ao depósito de vazios do porto de índice $i$ provenientes dos contêneres cheios embarcados nos navios da frota com destino ao porto de índice $i$ durante o horizonte de planejamento:

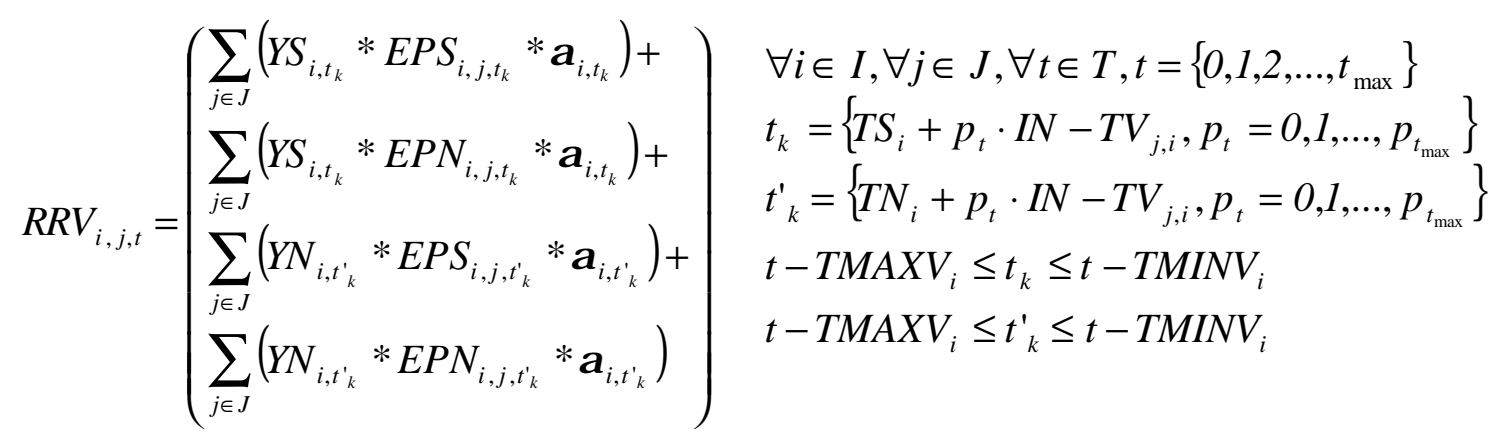


I. Equilíbrio do Estoque de Contêineres Próprios Vazios nos Terminais:

$$
E P V_{i, t}=\left(\begin{array}{ll}
\left.E P V_{i, t^{\prime}}-\sum_{j \in J} Q E V_{i, j, t}+\sum_{n \in N} R V_{i, n f}+R R V_{i, t}-\right) \\
Y S_{i, t_{k}} * \sum_{j \in J} S E S_{i, j t_{k}}-Y N_{i, t_{d}} * \sum_{j \in J} S E N_{i, j, t_{d}}+ \\
Y S_{i, t_{k}} * \sum_{j \in J} S E S_{j, i f_{k}^{\prime}}+Y N_{i, t_{d}} * \sum_{j \in J} S E N_{j, i, t_{d}^{\prime}}
\end{array}\right) \begin{aligned}
& \forall i \in I, \forall t, t^{\prime} \in T, t=\left\{0,1,2, \ldots, t_{\max }\right\} \\
& t^{\prime}=t-1 \\
& t_{k}=\left\{T S_{i}+p_{t} \cdot I N, p_{t}=0,1, \ldots, p_{t_{\max }}\right\}, \\
& t^{\prime}{ }_{k}=\left\{T S_{i}+p_{t} \cdot I N-T V_{j, i}, p_{t}=0,1, \ldots, p_{t_{\max }}\right\}, \\
& t_{d}=\left\{T N_{i}+p_{t} \cdot I N, p_{t}=0,1, \ldots, p_{t_{\max }}\right\}, \\
& t_{d}^{\prime}=\left\{T N_{i}+p_{t} \cdot I N-T V_{j, i}, p_{t}=0,1, \ldots, p_{t_{\max }}\right\},
\end{aligned},
$$

J. Equilíbrio do Estoque de Contêineres Próprios Cheios nos Portos:

$$
E P C_{i, j, t}=\left(\begin{array}{ll}
E P C_{i, j, t^{\prime}}-\sum_{\tau_{k}=t-T M A X C_{i}}^{t-T M I N C}\left(Q V_{i, j, t} * \beta_{i, \tau_{k}}\right)- \\
Y S_{i, t} * E P S_{i, j, t}-Y N_{i, t} * E P N_{i, j, t}
\end{array}\right) \quad \begin{aligned}
& \forall i \in I, \forall j \in J, \forall t, t^{\prime} \in T \\
& t^{\prime}=t-1,
\end{aligned}
$$

K. Equilíbrio do Estoque de Contêineres Cheios Alugados nos Portos:

$$
E L C_{i, j, t}=\left(\begin{array}{ll}
E L C_{i, j, t^{\prime}}-\sum_{\tau_{k}=t-T M A X G}^{t-T M I N G}\left(L E V_{i, j, t} * \beta_{i, \tau_{k}}\right)- \\
Y S_{i, t} * E L S_{i, j, t}-Y N_{i, t} * E L N_{i, j, t}
\end{array}\right) \quad \begin{aligned}
& \forall i \in I, \forall j \in J, \forall t, t^{\prime} \in T, \\
& t^{\prime}=t-1
\end{aligned}
$$

L. Contêineres existentes nos navios no sentido sul na saída do porto de índice $i$

$$
Q N S_{i, t}=\left(\begin{array}{l}
\sum_{\substack{i^{\prime} \in I \\
i^{\prime} \neq i}} \sum_{j \in J}\left(\begin{array}{l}
E P S_{i^{\prime}, j, t_{d}} * T R S_{T R, j, i^{\prime}}+ \\
E P N_{i^{\prime}, j, t_{d}} * T R S_{T R, j, i^{\prime}}+ \\
E L S_{i^{\prime}, j, t_{d}} * T R S_{T R, j, i^{\prime}}+ \\
E L N_{i^{\prime}, j, t_{d}} * T R S_{T R, j, i^{\prime}}+ \\
S E S_{i^{\prime}, j, t_{d}} * T R S_{T R, j, i^{\prime}}+ \\
S E N_{i^{\prime}, j, t_{d}} * T R S_{T R, j, i^{\prime}}
\end{array}\right)+ \\
\sum_{j \in J}\left(E P S_{i, j, t}+E L S_{i, j, t}+S E S_{i, j, t}\right)
\end{array}\right) \quad \begin{aligned}
& \\
& t_{d}=\left\{T S_{i}+p_{t} \cdot I N-T V_{j, i}, p_{t}=0,1, \ldots, p_{t_{\max }}\right\}
\end{aligned}
$$


M. Contêineres existentes nos navios no sentido norte na saída do porto de índice $i$

$$
Q N N_{i, t}=\left(\begin{array}{c}
\sum_{i^{\prime} \in I} \sum_{j \in J}\left(\begin{array}{l}
E P S_{i^{\prime}, j, t_{d}} * T R N_{T R, j, i^{\prime}}+ \\
E P N_{i^{\prime}, j, t_{d}} * T R N_{T R, j, i^{\prime}}+ \\
E L S_{i^{\prime}, j, t_{d}} * T R N_{T R, j, i^{\prime}}+ \\
E L N_{i^{\prime}, j, t_{d}} * T R N_{T R, j, i^{\prime}}+ \\
S E S_{i^{\prime}, j, t_{d}} * T R N_{T R, j, i^{\prime}}+ \\
S E N_{i^{\prime}, j, t_{d}} * T R N_{T R, j, i^{\prime}}
\end{array}\right)+ \\
\sum_{j \in J}\left(E P N_{i, j, t}+E L N_{i, j, t}+S E N_{i, j, t}\right)
\end{array}\right)+\begin{aligned}
& \forall i \in I, \forall j \in J, \forall t \in T, t=\left\{0,1,2, \ldots, t_{\max }\right\} \\
& t_{d}=\left\{T N_{i}+p_{t} \cdot I N-T V_{j, i}, p_{t}=0,1, \ldots, p_{t_{\max }}\right\}
\end{aligned}
$$

N. Capacidade máxima de contêineres dentro das embarcacõos no sentido sul

$$
Q N S_{i, t} \leq C N \quad \forall i \in I, \forall t \in T
$$

O. Capacidade máxima de contêineres dentro das embarcações no sentido norte

$$
Q N N_{i, t} \leq C N \quad \forall i \in I, \forall t \in T
$$

\section{4 - Variantes para o Modelo de Programação Linear Proposto}

Conforme visto no item 4.3.4 - , por meio deste modelo matemático, pretende-se obter a melhor composição da frota de contêineres próprios e alugados minimizando o custo total do sistema analisado. No entanto, a função objetivo deste problema pode ser alterada dependendo das características do sistema que estão sendo levadas em consideração. Por exemplo, caso a demanda de contêineres nos portos seja uniforme ao longo do tempo e mantendo-se os custos dos contêineres próprios e alugados iguais, pode-se reduzir a função de mérito apenas à minimização da frota de contêineres próprios, cheios e vazios, no início do 
DIMENSIONAMENTO DA FROTA DE CONTÊINERES

horizonte de planejamento. Esta última função de mérito também pode ser válida caso a demanda de contêineres seja variável e com os custos dos contêineres próprios e arrendados permanecendo iguais.

Estas variantes do Modelo de Programação Linear apresentado neste capítulo serão examinadas na seção a seguir. 


\section{CAPÍTULO 5 - APLICAÇÕES DO MODELO DE PROGRAMAÇÃO LINEAR PARA O ESTUDO DE CASO}

Este capítulo apresenta os cenários gerados e seus resultados para a verificação do comportamento do modelo de programação linear desenvolvido no capítulo 4 para o dimensionamento de uma frota de contêineres, envolvendo contêineres próprios e alugados.

Devido à dificuldade de obtenção de dados reais para um estudo de caso real, os parâmetros de entrada do modelo expostos neste capítulo são fictícios. Contudo, a idéia central, que é analisar o tamanho da frota de contêineres, não é prejudicada.

\section{1 - Definição dos parâmetros utilizados para a geração de todos os cenários}

Considerando uma frota de navios porta-contêineres homogênea e um único tipo de contêiner de 20', para todos os cenários gerados para a verificação da consistência do modelo proposto, os parâmetros abaixo não serão alterados:

- $\quad N=7$ navios;

- Número de TEU's nos navios = 2500 TEU’s;

- $\quad T V R=70$ dias; 
CASO

- $\quad I N=10$ dias;

- Horizonte de Planjemento $(t)=370$ dias;

- Dia da chegada do primeiro navio aos portos, Tabela 5-1.

Semelhante à hipótese adotada para o modelo de simulação, supôs-se que os navios estariam distribuídos ao longo da rota no início do horizonte de planejamento, de acordo com a Figura 5-1, e tal que o dia da chegada do primeiro navio a cada porto obedecesse à Tabela 5-1. Além disso, dada a posição inicial do navio e o tempo de viagem entre portos, Tabela 5-2, pôde-se calcular o tempo que cada navio levaria para chegar a cada porto em sua primeira viagem, Tabela 5-3. Convém observar que, para os casos em que há dupla passagem, o tempo de viagem se refere ao trecho mais curto de viagem entre o par de portos.

Tabela 5-1 Data de chegada do primeiro navio ao porto

\begin{tabular}{|c|c|c|}
\cline { 2 - 3 } \multicolumn{1}{c|}{} & $\begin{array}{c}\text { Dia da chegada do primeiro navio ao } \\
\text { porto no sentido sul - Ts }\end{array}$ & $\begin{array}{c}\text { Dia da chegada do primeiro navio ao } \\
\text { porto no sentido norte - TN }\end{array}$ \\
\hline PORTO_1 & 1 & 1 \\
\hline PORTO_2 & 6 & - \\
\hline PORTO_3 & 2 & 1 \\
\hline PORTO_4 & 6 & - \\
\hline PORTO_5 & 1 & 3 \\
\hline PORTO_6 & 5 & - \\
\hline PORTO_7 & 1 & - \\
\hline PORTO_8 & 6 & 6 \\
\hline
\end{tabular}

Tabela 5-2 Tempo de viagem dos navios entre o porto de índice $i$ e o porto de índice $j-T V_{i, j}$

\begin{tabular}{|c|c|c|c|c|c|c|c|c|}
\hline & \multicolumn{3}{|c|}{ Tempo de viagem dos } & navios ex & \multicolumn{4}{|c|}{ itre os portos $i$ e $j-T V_{i, j}$} \\
\hline & PORTO 1 & PORTO 2 & PORTO 3 & & PORTO 5 & PORTO 6 & PORTO 7 & PORTO 8 \\
\hline PORTO_ 1 & 0.0 & 5.0 & 11.0 & 15.0 & 20.0 & 24.0 & 30.0 & 35.0 \\
\hline PORTO_ 2 & 65.0 & 0.0 & 6.0 & 10.0 & 15.0 & 19.0 & 25.0 & 30.0 \\
\hline PORTO_ 3 & 10.0 & 15.0 & 0.0 & 4.0 & 9.0 & 13.0 & 19.0 & 24.0 \\
\hline PORTO 4 & 55.0 & 60.0 & 45.0 & 0.0 & 5.0 & 9.0 & 15.0 & 20.0 \\
\hline PORTO_ 5 & 18.0 & 23.0 & 8.0 & 33.0 & 0.0 & 4.0 & 10.0 & 15.0 \\
\hline PORTO_ 6 & 46.0 & 51.0 & 36.0 & 61.0 & 28.0 & 0.0 & 6.0 & 11.0 \\
\hline PORTO 7 & 40.0 & 45.0 & 30.0 & 55.0 & 22.0 & 64.0 & 0.0 & 5.0 \\
\hline PORTO 8 & 35.0 & 40.0 & 25.0 & 50.0 & 17.0 & 59.0 & 65.0 & 0.0 \\
\hline
\end{tabular}


CASO

Tabela 5-3 Tempo restante para a chegada de cada navio a cada porto na primeira viagem

\begin{tabular}{|l|r|r|r|r|r|r|r|}
\hline \multicolumn{1}{|c|}{ Tempo que falta paYa o navio chegar ao porto na primeira viagem } \\
\hline & \multicolumn{1}{|c|}{ NO1 } & \multicolumn{1}{c|}{ NO2 } & \multicolumn{1}{c|}{ No3 } & \multicolumn{1}{c|}{ NO4 } & NO5 & No6 & \multicolumn{1}{c|}{ No7 } \\
\hline PORTO_1 & 1.0 & 61.0 & 51.0 & 41.0 & 31.0 & 21.0 & 11.0 \\
\hline PORTO_2 & 6.0 & 66.0 & 56.0 & 46.0 & 36.0 & 26.0 & 16.0 \\
\hline PORTO_3 & 12.0 & 2.0 & 41.0 & 31.0 & 21.0 & 11.0 & 1.0 \\
\hline PORTO_4 & 16.0 & 6.0 & 66.0 & 56.0 & 46.0 & 36.0 & 26.0 \\
\hline PORTO_5 & 21.0 & 11.0 & 1.0 & 23.0 & 13.0 & 3.0 & 31.0 \\
\hline PORTO_6 & 25.0 & 15.0 & 5.0 & 65.0 & 55.0 & 45.0 & 35.0 \\
\hline PORTO_7 & 31.0 & 21.0 & 11.0 & 1.0 & 61.0 & 51.0 & 41.0 \\
\hline PORTO_8 & 36.0 & 26.0 & 16.0 & 6.0 & 66.0 & 56.0 & 46.0 \\
\hline
\end{tabular}

A Tabela 5-4 mostra a divisão da rota do navio em trechos e a Tabela 5-5 mostra, para cada um dos trechos da rota, os pares origem-destino dos contêineres a bordo do navio. Como exemplo, no trecho sul TRS_1, entre o porto 1 e o porto 2, estão a bordo os contêineres exportados pelo porto 1 para os portos $2,3,4,5,6,7$ e 8 ; os contêineres exportados pelo porto 3 para o porto 2; os contêineres exportados pelo porto 4 para o porto 2; os contêineres exportados pelo porto 5 para os portos 2 e 4; os contêineres exportados pelo porto 6 para os portos 2 e 4; os contêineres exportados pelo porto 7 para os portos 2, 4 e 6 e os contêineres exportados pelo porto 8 para os portos 2, 4, 6 e 7 .

Tabela 5-4 Significado dos trechos para a rota considerada

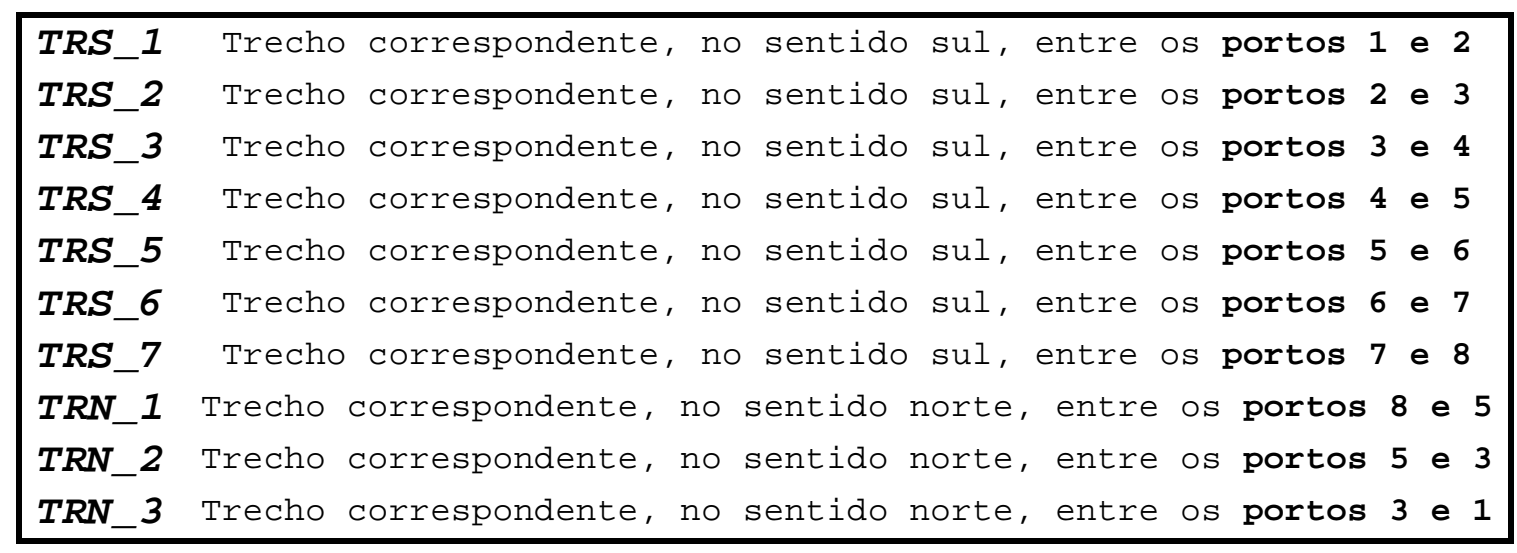


CASO

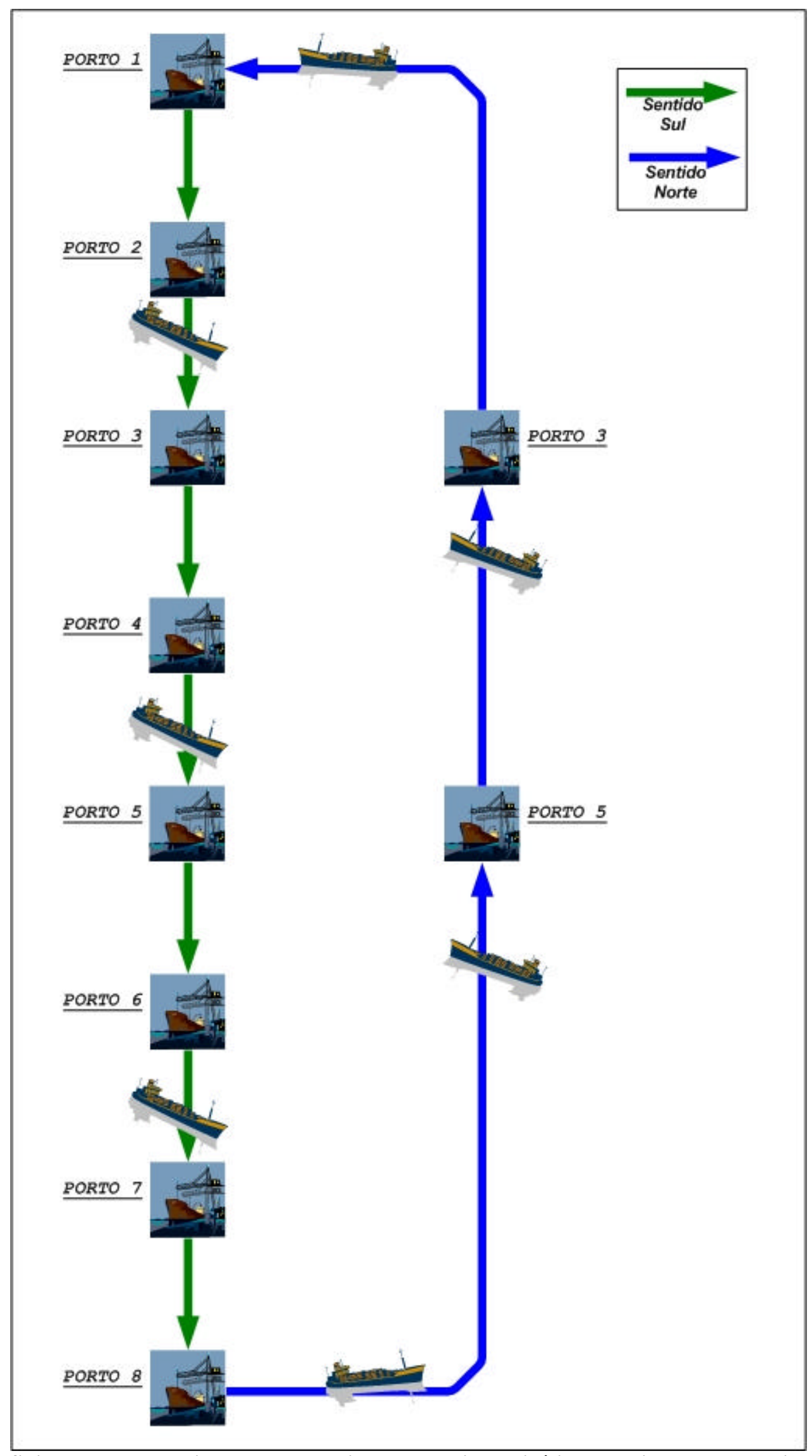

Figura 5-1 Definição da rota considerada e da posição dos navios no início do horizonte de planejamento 
Tabela 5-5 Contêineres existentes nos navios - do porto de índice $i$ para o porto de índice $j$ - em cada trecho da rota

\begin{tabular}{|c|c|c|c|c|c|c|c|c|c|}
\hline TRS 1 & TRS 2 & TRS 3 & TRS 4 & TRS 5 & TRS 6 & IRS 7 & TRA 1 & TRH 2 & TRA 3 \\
\hline PORTO_1.PORTO_2 & PORTO_1.PORTO_3 & PORTO_1.PORTO_4 & PORTO_1.PORTO_5 & PORTO_1.PORTO_6 & PORTO_1.PORTO_? & PORTO_1.PORTO_8 & PORTO_2.PORTO_1 & PORTO_2.PORTO_1 & PORTO_2.PORTO_1 \\
\hline PORTO_1.PORTO_3 & PORTO_1.PORTO_4 & PORTO_1.PORTO_S & PORTO_1.PORTO_6 & PORTO_1.PORTO_? & PORTO_1.PORTO_8 & PORTO_2.PORTO_1 & PORTO_4, PORTO_1 & PORTO_4. PORTO_1 & PORTO_3.PORTO_1 \\
\hline PORTO_1. PORTO_ 4 & PORTO_1.PORTO_S & PORTO_1.PORTO_6 & PORTO_1.PORTO_? & PORTO_1.PORTO_8 & PORTO_2.PORTO_1 & PORTO_2.PORTO_8 & PORTO_4.PORTO_2 & PORTO_4.PORTO_2 & PORTO_3, PORTO_2 \\
\hline PORTO_1.PORTO_S & PORTO_1.PORTO_6 & PORTO_1.PORTO_? & PORTO_1.PORTO_8 & PORTO_2.PORTO_1 & PORTO_2.PORTO_? & PORTO_3.PORTO_8 & PORTO_4.PORTO_ 3 & PORTO_4.PORTO_ 3 & PORTO_4.PORTO_ 1 \\
\hline PORTO_1.PORTO_6 & PORTO_1. PORTO 7 & PORTO_1.PORTO_8 & PORTO_2.PORTO_1 & PORTO_2.PORTO_6 & PORTO_2.PORTO_8 & PORTO_4.PORTO_1 & PORTO_6.PORTO_1 & PORTO_5.PORTO_1 & PORTO_4.PORTO_2 \\
\hline PORTO_1.PORTO_? & PORTO_1.PORTO_8 & PORTO_2.PORTO_1 & PORTO_2.PORTO_5 & PORTO_2.PORTO_7 & PORTO_3.PORTO_? & PORTO_4.PORTO_2 & PORTO_6.PORTO_2 & PORTO_5.PORTO_2 & PORTO_S.PORTO_1 \\
\hline PORTO_1.PORTO_8 & PORTO_2.PORTO_1 & PORTO_2.PORTO_4 & PORTO_2,PORTO_6 & PORTO_2,PORTO_8 & PORTO_3.PORTO_8 & PORTO_4.PORTO_3 & PORTO_6.PORTO_3 & PORTO_S.PORTO_3 & PORTO_S.PORTO_2 \\
\hline PORTO_3.PORTO_2 & PORTO_2.PORTO_3 & PORTO_2.PORTO_S & PORTO_2,PORTO_7 & PORTO_3,PORTO_6 & PORTO_4.PORTO_1 & PORTO_4.PORTO_8 & PORTO_6.PORTO_4 & PORTO_S.PORTO_4 & PORTO_5.PORTO_ 4 \\
\hline PORTO_4.PORTO_2 & PORTO_2.PORTO_4 & PORTO_2.PORTO_6 & PORTO_2, PORTO 8 & PORTO_3.PORTO_? & PORTO_4.PORTO_2 & PORTO_5.PORTO_ 8 & PORTO_6.PORTO_5 & PORTO_6.PORTO_1 & PORTO_6.PORTO_ 1 \\
\hline PORTO_5.PORTO_2 & PORTO_2.PORTO_5 & PORTO_2.PORTO_? & PORTO_3.PORTO_5 & PORTO_3.PORTO_8 & PORTO_4.PORTO_3 & PORTO_6.PORTO_1 & PORTO_7.PORTO_1 & PORTO_6.PORTO_2 & PORTO_6.PORTO_2 \\
\hline PORTO_5.PORTO_4 & PORTO_2.PORTO_6 & PORTO_2.PORTO_8 & PORTO_3.PORTO_6 & PORTO_4.PORTO_1 & PORTO_4.PORTO_? & PORTO_6.PORTO_2 & PORTO_7.PORTO_2 & PORTO_6.PORTO_3 & PORTO_6.PORTO_4 \\
\hline PORTO_6.PORTO_2 & PORTO_2.PORTO_7 & PORTO_3.PORTO_4 & PORTO_3.PORTO_? & PORTO_4.PORTO_2 & PORTO_4.PORTO_8 & PORTO_6.PORTO_3 & PORTO_7.PORTO_3 & PORTO_6.PORTO_4 & PORTO_7.PORTO_1 \\
\hline PORTO_6.PORTO_4 & PORTO_2. PORTO_ 8 & PORTO_3.PORTO_S & PORTO_3.PORTO_8 & PORTO_4.PORTO_3 & PORTO_S.PORTO_? & PORTO_6.PORTO_ 4 & PORTO_7.PORTO_4 & PORTO_7.PORTO_1 & PORTO_7.PORTO_2 \\
\hline PORTO_7.PORTO_2 & PORTO_S.PPORTO_ 4 & PORTO_3.PORTO 6 & PORTO_4.PORTO_ 1 & PORTO_4.PORTO_6 & PORTO_S.PORTO 8 & PORTO_6.PORTO_5 & PORTO_7.PORTO_S & PORTO_7.PORTO_2 & PORTO_7.PORTO_4 \\
\hline PORTO_7.PORTO_4 & PORTO_6.PORTO_4 & PORTO_3.PORTO_? & PORTO_4.PORTO_2 & PORTO_4.PORTO_? & PORTO_6.PORTO_1 & PORTO_6.PORTO_8 & PORTO_7.PORTO_6 & PORTO_7.PORTO_3 & PORTO_7.PORTO_ 6 \\
\hline PORTO_7.PORTO_6 & PORTO_7.PORTO_4 & PORTO_3.PORTO_8 & PORTO_4.PORTO_3 & PORTO_4.PORTO_8 & PORTO_6.PORTO_2 & PORTO_7.PORTO_1 & PORTO_8.PORTO_1 & PORTO_7.PORTO_4 & PORTO_8.PORTO_1 \\
\hline PORTO_8.PORTO_2 & PORTO_7.PORTO_6 & PORTO_5.PORTO_4 & PORTO_4.PORTO_5 & PORTO_5.PORTO_6 & PORTO_6.PORTO_3 & PORTO_7.PORTO_2 & PORTO_8.PORTO_2 & PORTO_7.PORTO_6 & PORTO_8.PORTO_2 \\
\hline PORTO_8.PORTO_4 & PORTO_8.PORTO_ 4 & PORTO_6.PORTO 4 & PORTO_4.PORTO_6 & PORTO_5.PORTO_? & PORTO_6.PORTO_4 & PORTO_7.PORTO_3 & PORTO_8.PORTO_3 & PORTO_8.PORTO_1 & PORTO_8.PORTO_4 \\
\hline PORTO_8.PORTO_6 & PORTO_8.PORTO_6 & PORTO_7.PORTO_A & PORTO_4.PORTO_? & PORTO_5.PORTO_8 & PORTO_6.PORTO_5 & PORTO_7.PORTO_ 4 & PORTO_8.PORTO_4 & PORTO_8.PORTO_2 & PORTO_8.PORTO_6 \\
\hline \multirow[t]{4}{*}{ PORTO 8.PORTO ? } & PORTO 8. PORTO ? & PORTO_7.PORTO_6 & PORTO_4.PORTO_8 & PORTO_7.PORTO_6 & PORTO_6.PORTO_? & PORTO_7.PORTO_5 & PORTO_8.PORTO_5 & PORTO_8.PORTO_3 & PORTO 8.PORTO ? \\
\hline & & PORTO_8.PORTO_4 & PORTO_7.PORTO_6 & PORTO_8.PORTO_6 & PORTO_6.PORTO_8 & PORTO_7.PORTO_6 & PORTO_8.PORTO_6 & PORTO_8.PORTO_4 & \\
\hline & & PORTO_8.PORTO_6 & PORTO_8.PORTO_6 & PORTO B. PORTO ? & PORTO_8.PORTO? & PORTO_7.PORTO_ 8 & PORTO_8.PORTO? & PORTO_8.PORTO_6 & \\
\hline & & PORTO 8.PORTO 7 & PORTO 8. PORTO ? & & & & & PORTO 8. PORTO? & \\
\hline
\end{tabular}


CASO

\section{2 - Demanda Uniforme ao longo do horizonte de planejamento}

Uma das possibilidades para avaliar a coerência dos resultados gerados pelo modelo matemático desenvolvido seria dimensionar uma frota de contêineres que atenderá uma demanda uniforme em todos os portos ao longo do horizonte de planejamento e calcular algum indicador de desempenho, tal como o tamanho da frota de contêineres pelo número de TEU's transportados pelos navios da empresa em uma viagem redonda. Pode-se dizer que este indicador revela a quantidade de contêineres em terra necessária para cada TEU dos navios da frota.

Neste caso, somente é considerada a frota de contêineres próprios, pois os contêineres alugados, como são contratados, para este modelo, por viagem, geralmente atendem a demandas de pico (ou sazonais) devido ao seu custo ser elevado em relação aos contêineres da frota própria. Devido ao desbalanceamento entre os fluxos de importação e exportação, admitiu-se que a oferta de contêineres vazios seria a diferença entre a quantidade de contêineres próprios cheios importados e exportados pelo porto.

O problema recai na minimização da frota de contêineres próprios para atender toda a demanda ao longo do horizonte de planejamento.

\subsection{1 - Dimensionamento da frota de contêineres próprios para demanda uniforme ao longo do tempo}

Para o caso em que a demanda de transporte é uniforme ao longo do horizonte de planejamento para todos os pares de portos, foi examinado o efeito da variação do intervalo de tempo que os contêineres permanecem em terra sobre o tamanho ótimo da frota de 
CASO

contêineres, mantidos constantes os tempos de viagem e o número de navios da frota. Na falta de informações específicas sobre o intervalo de tempo entre o descarregamento de um contêiner cheio num porto e o seu retorno vazio do cliente de importação ao depósito de vazios e sobre o intervalo de tempo entre a saída de um contêiner vazio do depósito de vazios para um cliente de exportação e seu retorno cheio ao porto, admitiu-se uma mesma distribuição para esses dois intervalos de tempo aplicáveis a todos os portos da rota, designado por ? ${ }_{t}$ (correspondente à $\alpha_{i, t_{k}}$ e à $\beta_{i, \tau_{k}}$ da seção 4.3.2 -

Essa distribuição é definida pelos seguintes parâmetros:

- $T_{M I N}{ }_{i} \ldots$ intervalo de tempo mínimo, contado a partir do instante de chegada do contêiner cheio de importação ao porto de índice $i$, para que o contêiner vazio retorne ao depósito de vazios da empresa de navegação; ou a partir do instante da saída do contêiner vazio do depósito de vazios da empresa, para que o contêiner cheio de exportação chegue ao porto de índice $i$.

- TMAX $_{i}$... intervalo de tempo máximo, contado a partir do instante de chegada do contêiner cheio de importação ao porto de índice $i$, para que o contêiner vazio retorne ao depósito de vazios da empresa de navegação; ou a partir do instante da saída do contêiner vazio do depósito de vazios da empresa, para que o contêiner cheio de exportação chegue ao porto de índice $i$.

- $\quad{ }_{t} \ldots$ freqüência relativa do intervalo de tempo $t$, contado a partir do instante de chegada do contêiner cheio de importação ao porto de índice $i$, para que o contêiner vazio retorne ao depósito de vazios da empresa de navegação; ou a partir do instante de saída do contêiner vazio do depósito de vazios da empresa de navegação, para que o contêiner cheio de exportação retorne ao porto de índice $i$; e tal que $\operatorname{TMIN}_{i} \leq \tau \leq T M A X_{i}$. 
CASO

Segundo informações de profissionais que trabalham com o transporte de cargas conteinerizadas, a distribuição mais apropriada para taxa de retorno dos contêineres seria a de uma função triangular.

Admitiu-se, então, um cenário-base com as seguintes características:

- $\operatorname{TMIN}_{i}=7$ dias;

- $\operatorname{TMAX}_{\mathrm{i}}=17$ dias;

- Moda para o intervalo de tempo de retorno dos contêineres de 12 dias;

- $?{ }_{t}=$ ver Figura 5-2;

A demanda de exportação de contêineres entre cada par de portos, em cada sentido de navegação é mostrada na Tabela 5-6. Na Tabela 5-7, mostra-se a demanda total de importação de cada porto em cada sentido da rota. O transporte dos contêineres vazios entre cada par de portos, em cada sentido da rota, será realizado conforme a Tabela 5-8.

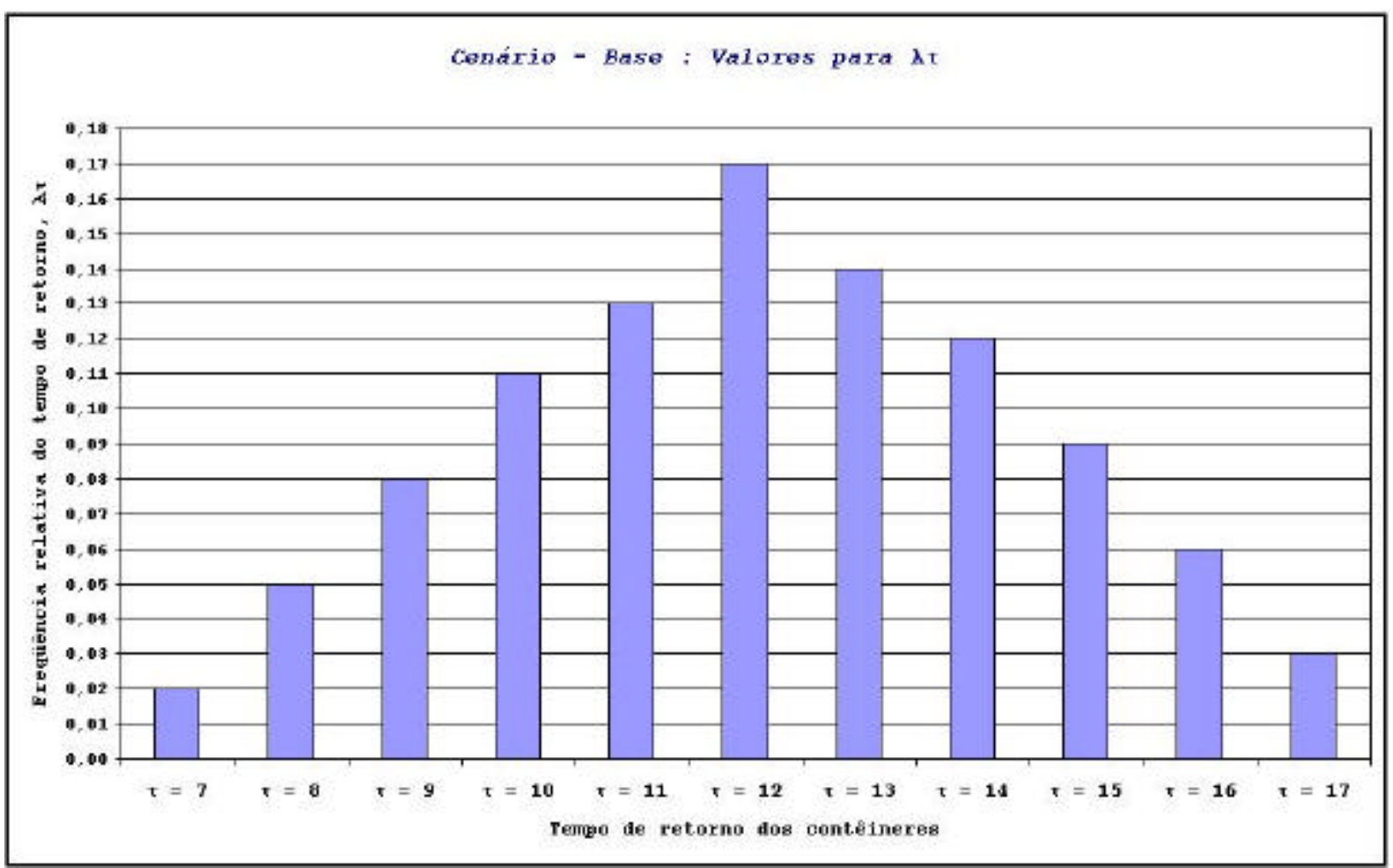

Figura 5-2 Freqüência relativa do tempo de retorno dos contêineres para o Cenário - Base 
CASO

Tabela 5-6 Demanda de contêineres cheios exportados em cada porto nos sentidos sul e norte para o caso da demanda uniforme

\begin{tabular}{|c|c|c|c|c|c|c|c|c|c|}
\hline \multicolumn{10}{|c|}{ CONTEEINERES CHEIOS EXPORTADOS } \\
\hline & \multicolumn{8}{|c|}{ SENTIDO SUL } & \multirow[b]{2}{*}{ TOTAL } \\
\hline & porto1 & porto2 & porto3 & \begin{tabular}{|l|l} 
porto 4 & r
\end{tabular} & porto5 & porto6 & porto7 & porto8 & \\
\hline porto1 & 0 & 90 & 140 & 80 & 160 & 100 & \begin{tabular}{|r|}
80 \\
\end{tabular} & \begin{tabular}{|r|}
80 \\
\end{tabular} & 730 \\
\hline porto2 & 70 & 0 & 130 & 80 & 180 & 80 & 80 & 80 & 700 \\
\hline porto3 & 0 & 0 & 0 & 90 & 140 & 120 & 110 & 120 & 580 \\
\hline porto 4 & 70 & 80 & 150 & 0 & 130 & 90 & 70 & 80 & 670 \\
\hline porto5 & 0 & 0 & 0 & 마 & 0 & 80 & 100 & 90 & 270 \\
\hline porto 6 & 80 & 80 & 100 & 80 & 120 & 0 & 70 & 70 & 600 \\
\hline porto7 & 110 & 80 & 140 & 100 & 180 & 90 & 0 & 90 & 790 \\
\hline \multirow[t]{3}{*}{ portos } & 0 & 마 & 0 & o & 0 & 0 & 믜 & 의 & $\mathbf{0}$ \\
\hline & \multicolumn{8}{|c|}{ SEHTIDO HORTE } & \\
\hline & porto 1 & porto2 & porto3 & \begin{tabular}{|l|l} 
porto 4 \\
\end{tabular} & porto5 & porto 6 & porto7 & porto8 & TOTAL \\
\hline porto1 & 0 & 0 & 0 & 可 & 0 & 0 & 0 & o & $\mathbf{0}$ \\
\hline porto 2 & 0 & 미 & o & 0 & 0 & 0 & 이 & 이 & $\mathbf{0}$ \\
\hline porto3 & 100 & 90 & 0 & 0 & 0 & 0 & 0 & 마 & 190 \\
\hline porto 4 & 0 & 0 & 0 & 0 & 0 & 0 & 0 & 의 & $\mathbf{0}$ \\
\hline porto5 & 120 & 110 & 130 & 90 & 0 & 0 & 0 & 의 & 450 \\
\hline porto 6 & 0 & o & 0 & 0 & 0 & 0 & 만 & 마 & $\mathbf{0}$ \\
\hline porto? & 0 & 0 & 0 & 0 & 0 & 0 & 0 & 可 & 0 \\
\hline porto8 & 80 & 70 & 150 & 110 & 160 & 90 & 90 & 이 & 750 \\
\hline
\end{tabular}

Tabela 5-7 Demanda de contêineres cheios importados em cada porto nos sentidos sul e norte para o caso da demanda uniforme

\begin{tabular}{|c|c|c|c|c|c|c|c|}
\hline \multicolumn{8}{|c|}{ CONIEEINERES CHEIOS INPORTADOS } \\
\hline \multicolumn{8}{|c|}{ SEHT IDO SUL } \\
\hline porto1 & porto2 & porto3 & porto4 & porto5 & porto6 & porto7 & porto8 \\
\hline \begin{tabular}{|r}
0 \\
\end{tabular} & 600 & 270 & 630 & 610 & 650 & 600 & 610 \\
\hline \multicolumn{8}{|c|}{ SEHTIDO HORTE } \\
\hline porto1 & porto2 & porto3 & porto4 & porto5 & porto 6 & porto7 & porto8 \\
\hline $\begin{array}{r}630 \\
\end{array}$ & 0 & 670 & 0 & 460 & 마 & $\begin{array}{r}0 \\
\end{array}$ & \begin{tabular}{|r|}
0 \\
\end{tabular} \\
\hline
\end{tabular}


CASO

Tabela 5-8 Transporte de contêineres vazios entre cada par de portos e em cada sentido da rota

\begin{tabular}{|c|c|c|c|c|c|c|c|c|c|}
\hline \multicolumn{10}{|c|}{ CONTËINERES VAZIOS EXPORTADOS } \\
\hline & \multicolumn{8}{|c|}{ SENTIDO SUL } & \\
\hline & porto1 & porto2 & porto3 & porto4 & porto5 & porto6 & porto7 & porto8 & TOTAL \\
\hline porto1 & - & - & - & - & - & - & - & - & - \\
\hline porto2 & - & - & - & - & - & - & - & - & - \\
\hline porto3 & - & - & - & 40 & - & - & 30 & - & 70 \\
\hline porto 4 & - & - & - & - & - & - & - & - & - \\
\hline porto5 & - & - & - & - & - & - & 110 & 140 & 250 \\
\hline porto 6 & - & - & - & - & - & - & 50 & - & 50 \\
\hline porto7 & - & - & - & - & - & - & - & - & - \\
\hline \multirow[t]{3}{*}{ porto8 } & - & - & - & - & - & - & - & - & - \\
\hline & \multicolumn{8}{|c|}{ SENTIDO HORTE } & \\
\hline & porto1 & porto2 & porto3 & porto 4 & porto5 & porto 6 & porto7 & porto8 & TOTAL \\
\hline porto1 & - & - & - & - & - & - & - & - & - \\
\hline porto2 & - & - & - & - & - & - & - & - & - \\
\hline porto3 & 100 & - & - & - & - & - & - & - & 100 \\
\hline porto 4 & - & - & - & - & - & - & - & - & - \\
\hline porto 5 & - & 100 & - & - & - & - & - & - & 100 \\
\hline porto 6 & - & - & - & - & - & - & - & - & - \\
\hline porto 7 & - & - & - & - & - & - & - & - & - \\
\hline porto8 & - & - & - & - & - & - & - & - & - \\
\hline
\end{tabular}

Para este cenário - base, o tamanho obtido para a frota ótima foi de $\mathbf{3 3 . 3 6 5}$ contêineres, incluindo os contêineres embarcados nos instante inicial. De acordo com a Tabela 5-5 e Tabela 5-6 e com a Figura 5-1, admitiu-se que havia 15.560 contêineres nos navios no início do horizonte de planejamento.

A seguir foi examinado o efeito da alteração no tempo médio de retorno, mantendo-se a mesma amplitude do intervalo de tempo de retorno e as mesmas freqüências relativas de cada classe. Os resultados obtidos, cenários A, são apresentados na Tabela 5-9. 
CASO

Tabela 5-9 Resultados obtidos para os cenários $A$ com variação do tempo de retorno dos contêineres

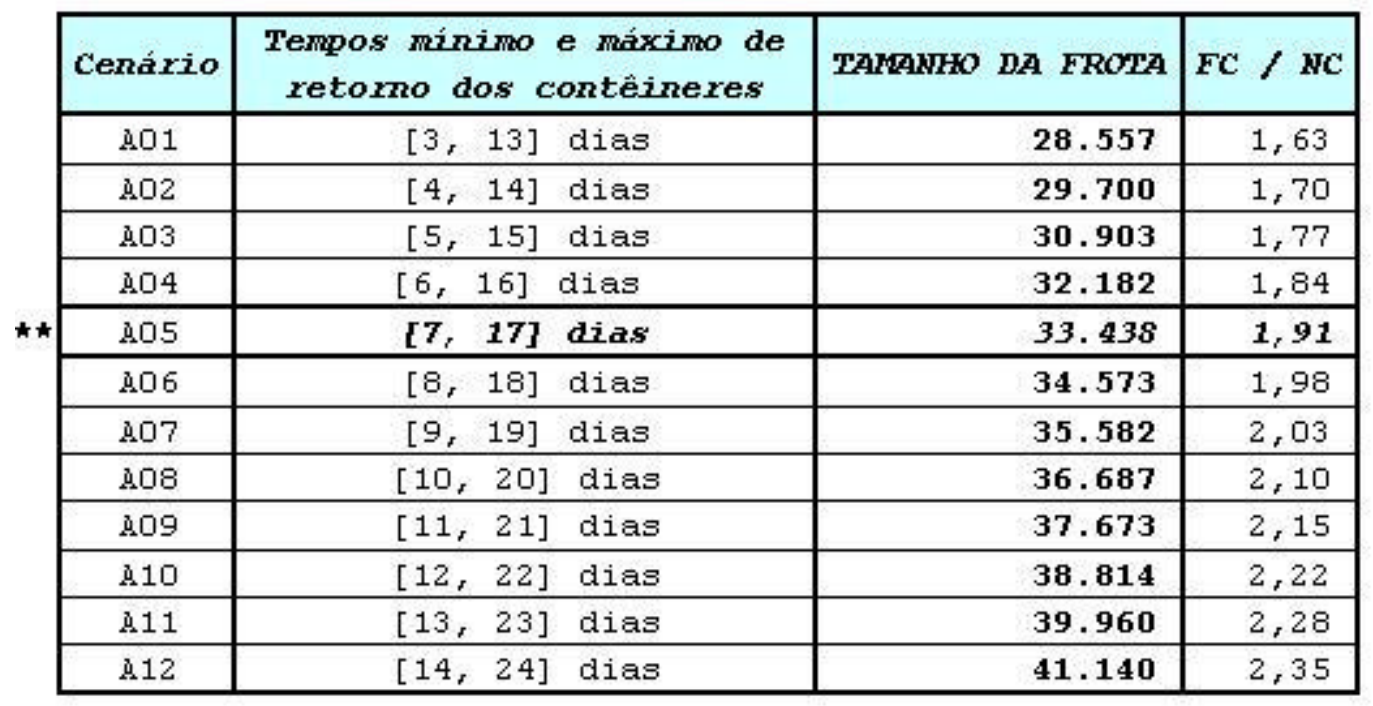

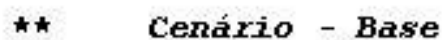

A Tabela 5-9 mostra como o tamanho da frota é afetado pela variação do tempo de retorno dos contêineres. Comparando-se os resultados obtidos para o tamanho da frota de contêineres $(F C)$ nos cenários $A$ com o número de TEU's transportados pelos navios da frota numa viagem redonda $(N C)$, observa-se o aumento deste indicador de desempenho conforme o aumento dos tempos de retorno dos contêineres.

Em seguida, os valores da frequiência de retorno dos contêineres, ? ${ }_{t}$, foram alterados de acordo com a Tabela 5-10, Figura 5-3, gerando-se o grupo de cenários B; exceto no caso B01, foi mantida a mesma faixa de variação do tempo de retorno. Os resultados obtidos para estes cenários, são mostrados na Tabela 5-11. 
Tabela 5-10 Valores de ? ${ }_{t}$ para o grupo cenários $B$

\begin{tabular}{|c|c|c|c|c|c|c|c|c|c|c|c|}
\hline & \multicolumn{11}{|c|}{ CENÁRIOS } \\
\hline & $B 01$ (Pico) & $B 02$ & $B 03$ & $B 04$ & $B 05$ & $B 06$ & $B 07$ & Bos & $B 09$ & $B 10$ & B11 (Uniforme) \\
\hline$\lambda \tau_{1}$ & 0,00 & 0,01 & 0,02 & 0,03 & 0,04 & 0,05 & 0,06 & 0,07 & 0,08 & 0,09 & 0,09 \\
\hline$\lambda \tau_{2}$ & 0,00 & 0,01 & 0,02 & 0,03 & 0,04 & 0,05 & 0,06 & 0,07 & 0,08 & 0,09 & 0,09 \\
\hline$\lambda \tau_{3}$ & 0,00 & 0,01 & 0,02 & 0,03 & 0,04 & 0,05 & 0,06 & 0,07 & 0,08 & 0,09 & 0,09 \\
\hline$\lambda \tau_{4}$ & 0,00 & 0,01 & 0,02 & 0,03 & 0,04 & 0,05 & 0,06 & 0,07 & 0,08 & 0,09 & 0,09 \\
\hline$\lambda \tau_{5}$ & 0,00 & 0,01 & 0,02 & 0,03 & 0,04 & 0,05 & 0,06 & 0,07 & 0,08 & 0,09 & 0,09 \\
\hline$\lambda \tau_{6}$ & 1,00 & 0,90 & 0,80 & 0,70 & 0,60 & 0,50 & 0,40 & 0,30 & 0,20 & 0,10 & 0,09 \\
\hline$\lambda \tau_{7}$ & 0,00 & 0,01 & 0,02 & 0,03 & 0,04 & 0,05 & 0,06 & 0,07 & 0,08 & 0,09 & 0,09 \\
\hline$\lambda \tau_{s}$ & 0,00 & 0,01 & 0,02 & 0,03 & 0,04 & 0,05 & 0,06 & 0,07 & 0,08 & 0,09 & 0,09 \\
\hline$\lambda \tau_{g}$ & 0,00 & 0,01 & 0,02 & 0,03 & 0,04 & 0,05 & 0,06 & 0,07 & 0,08 & 0,09 & 0,09 \\
\hline$\lambda \tau_{10}$ & 0,00 & 0,01 & 0,02 & 0,03 & 0,04 & 0,05 & 0,06 & 0,07 & 0,08 & 0,09 & 0,09 \\
\hline$\lambda \tau_{11}$ & 0,00 & 0,01 & 0,02 & 0,03 & 0,04 & 0,05 & 0,06 & 0,07 & 0,08 & 0,09 & 0,09 \\
\hline
\end{tabular}

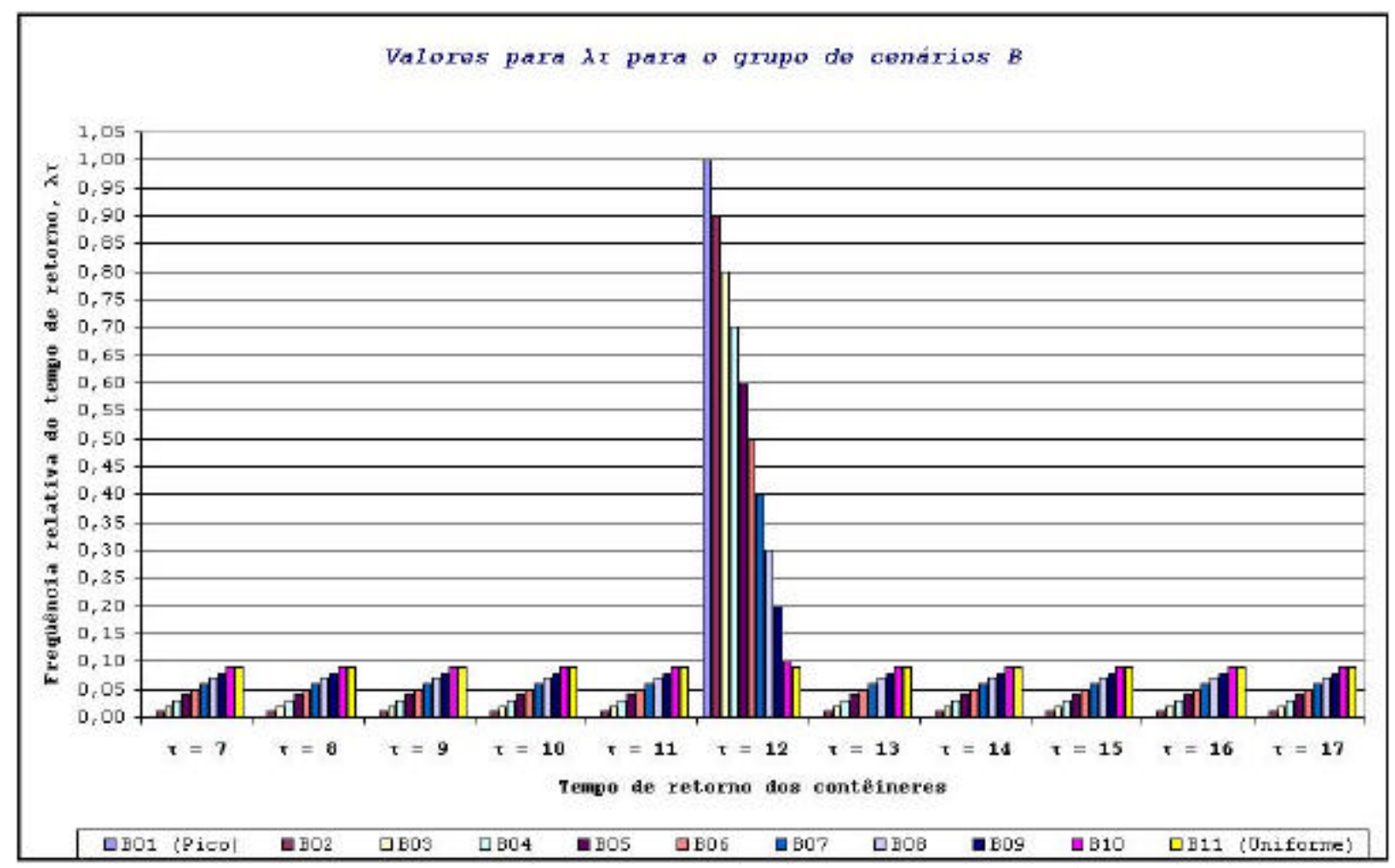

Figura 5-3 Variação da freqüência relativa para o grupo de cenários $B$ 
CASO

Tabela 5-11 Resultados obtidos por meio da variação da freqüência relativa, ${ }_{t}$

\begin{tabular}{|c|c|c|c|c|}
\hline Cenário & [todos os cenários com & 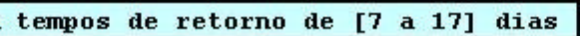 & TAMANHO DA FROTA & $F C / N C$ \\
\hline 801 & & $100 \%$ no tempo 12 (pico) & 34.753 & 1,99 \\
\hline $\mathrm{B02}$ & {$[0.01 \quad 17$} & 7 a 11$), 0.90(12), 0.01$ (13 a 17) $]$ & 34.493 & 1,97 \\
\hline$B 03$ & {$[0.02 \quad 17$} & 7 a 11$), 0.80(12), 0.02 \quad(13$ a 17$)]$ & 34.242 & 1,96 \\
\hline 804 & {$[0.03 \quad 17$} & 7 a 11$), 0.70(12), 0.03 \quad(13$ a 17$)]$ & 33.992 & 1,94 \\
\hline$B 05$ & {$[0.04 \quad 17$} & 7 a 11$), 0.60(12), 0.04(13$ a 17$)]$ & 33.754 & 1,93 \\
\hline$B 06$ & {$[0.05 \quad 17$} & 7 a 11), $0.50 \quad(12), 0.05$ (13 a 17) $]$ & 33.528 & 1,92 \\
\hline Bo7 & {$[0.06 \quad 17$} & 7 a 11$), 0.40 \quad(12), 0.06 \quad(13$ a 17$)]$ & 33.302 & 1,90 \\
\hline B08 & {$[0.07 \quad 17$} & 7 a 11) $, 0.30(12), 0.07$ (13 a 17) ] & 33.079 & 1,89 \\
\hline 809 & {$[0.08 \quad 17$} & 7 a 11) $, 0.20(12), 0.08 \quad(13$ a 17) $]$ & 32.872 & 1,88 \\
\hline 810 & {$[0.09 \quad 17$} & 7 a 11$), 0.10(12), 0.09(13$ a 17$)]$ & 32.754 & 1,87 \\
\hline$B 11$ & & distribuição uniforme & 32.744 & 1,87 \\
\hline
\end{tabular}

Variando-se a distribuição de frequiência relativas ? ${ }_{t}$, pôde-se observar que o tamanho da frota diminui à medida que a taxa de retorno dos contêineres ao porto, vindos do processo de importação ou exportação, vai tornando-se constante. Isto significa que o efeito favorável do aumento da freqüência relativa dos tempos de retorno mais baixos é maior, neste caso, que o efeito negativo do aumento da freqüência relativa dos tempos de retorno mais altos.

Além destes cenários, um terceiro grupo foi rodado abrangendo as possibilidades de alterações nos parâmetros. Modificoutse tanto o parâmetro ? ${ }_{t}$, quanto o tempo de retorno dos contêineres ao porto. A descrição destas alterações pode ser vista na Tabela 5-12.

Tabela 5-12 Descrição das alterações do grupo de cenários $C$

\begin{tabular}{|c|c|c|c|}
\cline { 2 - 4 } \multicolumn{1}{c|}{} & \multicolumn{3}{c|}{ Cenários } \\
\cline { 2 - 4 } \multicolumn{1}{c|}{} & Te1 & C02 & C03 \\
\cline { 2 - 4 } \multicolumn{1}{c|}{} & {$[8,12,16]$ dias } & {$[9,12,15]$ dias } & {$[10,12,14]$ dias } \\
\hline$\lambda_{t 1}$ & - & - & - \\
\hline$\lambda_{t 2}$ & 0.03 & - & - \\
\hline$\lambda_{t 3}$ & 0.06 & 0.05 & - \\
\hline$\lambda_{t 4}$ & 0.12 & 0.13 & 0.11 \\
\hline$\lambda_{t 5}$ & 0.18 & 0.19 & 0.21 \\
\hline$\lambda_{t 6}$ & 0.22 & 0.26 & 0.36 \\
\hline$\lambda_{t 7}$ & 0.18 & 0.19 & 0.21 \\
\hline$\lambda_{t 8}$ & 0.12 & 0.13 & 0.11 \\
\hline$\lambda_{t 9}$ & 0.06 & 0.05 & - \\
\hline$\lambda_{t 10}$ & 0.03 & - & - \\
\hline$\lambda_{t 11}$ & - & - & - \\
\hline
\end{tabular}


CASO

Tabela 5-13 Resultados obtidos para os cenários do grupo $C$

\begin{tabular}{|c|c|r|r|}
\hline Cenário & Tempo de retorno dos contêineres & TAMANHO DA FROTA & FC / NC \\
\hline C01 & {$[8,12,16]$ dias } & $\mathbf{3 3 . 5 6 4}$ & 1,92 \\
\hline C02 & {$[9,12,15]$ dias } & $\mathbf{3 3 . 7 7 0}$ & 1,93 \\
\hline C03 & {$[10,12,14]$ dias } & $\mathbf{3 4 . 0 7 2}$ & 1,95 \\
\hline
\end{tabular}

Mantendo-se a mesma moda para o intervalo de tempo de retorno dos contêineres do Cenário - Base e alterando-se o TMIN $i$ e o TMAX $i$, verifica-se, Tabela 5-13, que quanto mais concentrado for o retorno destes contêineres ao porto, mais contêineres serão necessários para compor a frota. Isto se deve ao fato de que os contêineres permanecem muito tempo retidos pelos clientes de importação (ou exportação), o que ocasiona num baixo número de contêineres vazios que estariam disponíveis para a exportação. Observa-se, então, que o efeito favorável de reduzir o tempo mínimo de retorno supera o efeito negativo de aumentar o tempo de retorno dos csontêineres.

Após analisados alguns cenários para o dimensionamento da frota de contêineres próprios para uma demanda constante ao longo do horizonte de planejamento, partiu-se para a geração de cenários um pouco mais realistas, ou seja, com a variação da demanda (sazonalidade) ao longo do tempo.

\section{3 - Demanda Variável ao longo do tempo}

É de conhecimento geral que o comércio mundial é caracterizado por demandas sazonais e pelo desequilíbrio de fluxos de contêineres entre regiões.

Considerando-se uma demanda variável ao longo do horizonte de planejamento e o desbalanceamento do fluxo de contêineres entre portos, alguns cenários foram gerados com intuito de analisar o modelo proposto. 
CASO

Como mencionado anteriormente, os contêineres arrendados são alugados por viagem, geralmente para atender as demandas de pico. Assim, pretende-se analisar qual será a melhor composição da frota de contêineres próprios e alugados para atender a uma demanda sazonal durante o horizonte de planejamento. Além disso, pretende-se avaliar qual é o impacto do transporte de contêineres vazios sobre o aluguel de contêineres.

Em virtude da dificuldade em se obter dados reais de mercado, uma das formas para analisar a influência da demanda variável, do aluguel de contêineres e do transporte de contêineres vazios entre portos sobre a frota de contêineres próprios da empresa, foi quantificar os custos de leasing como sendo uma fração dos custos dos contêineres próprios: $C L_{i, j}=\varphi * C P$, tal que $\varphi \geq 1$

A Figura 5-4, a Figura 5-5, a Figura 5-6 e a Figura 5-7 mostram a variação sazonal das demandas globais de importação e de exportação de cada porto em cada escala de navio, ao logo do horizonte de planejamento; o comportamento sazonal da variação da demanda de exportação/importação é o mesmo para cada par de portos. 


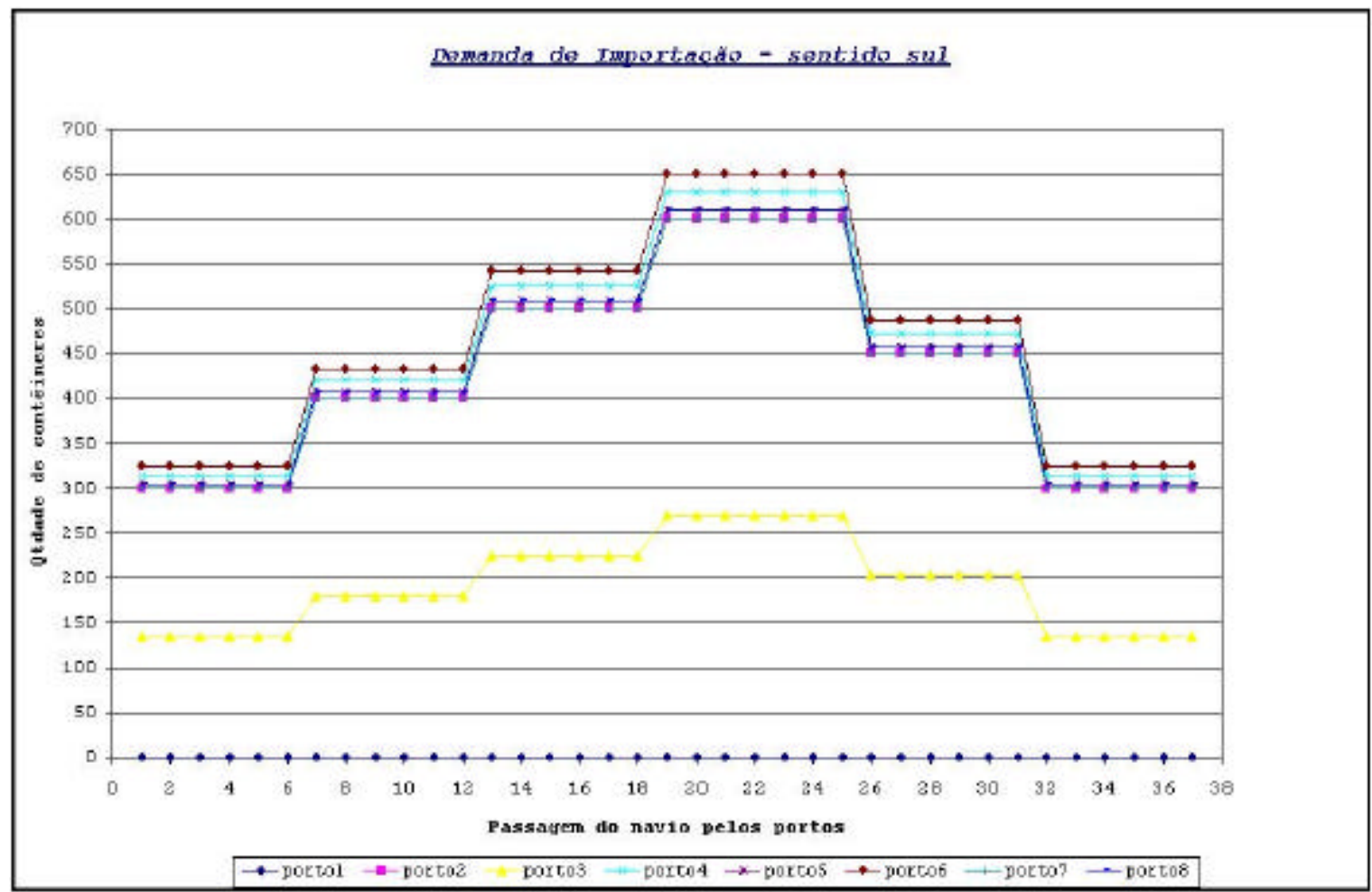

Figura 5-4 Variação da demanda de contêineres cheios importados em cada porto no sentido sul

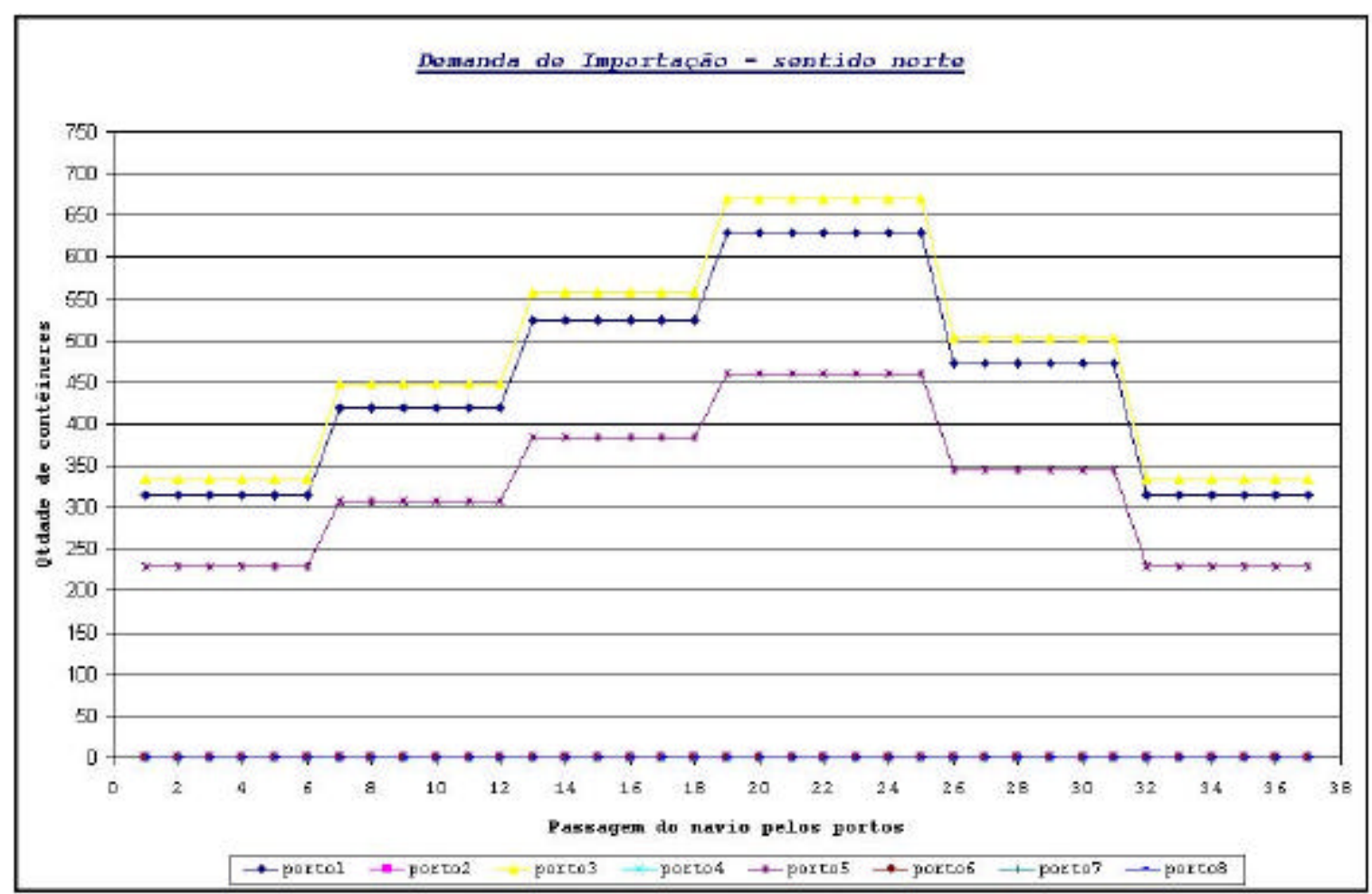

Figura 5-5 Variação da demanda de contêineres cheios importados em cada porto no sentido norte 
CASO

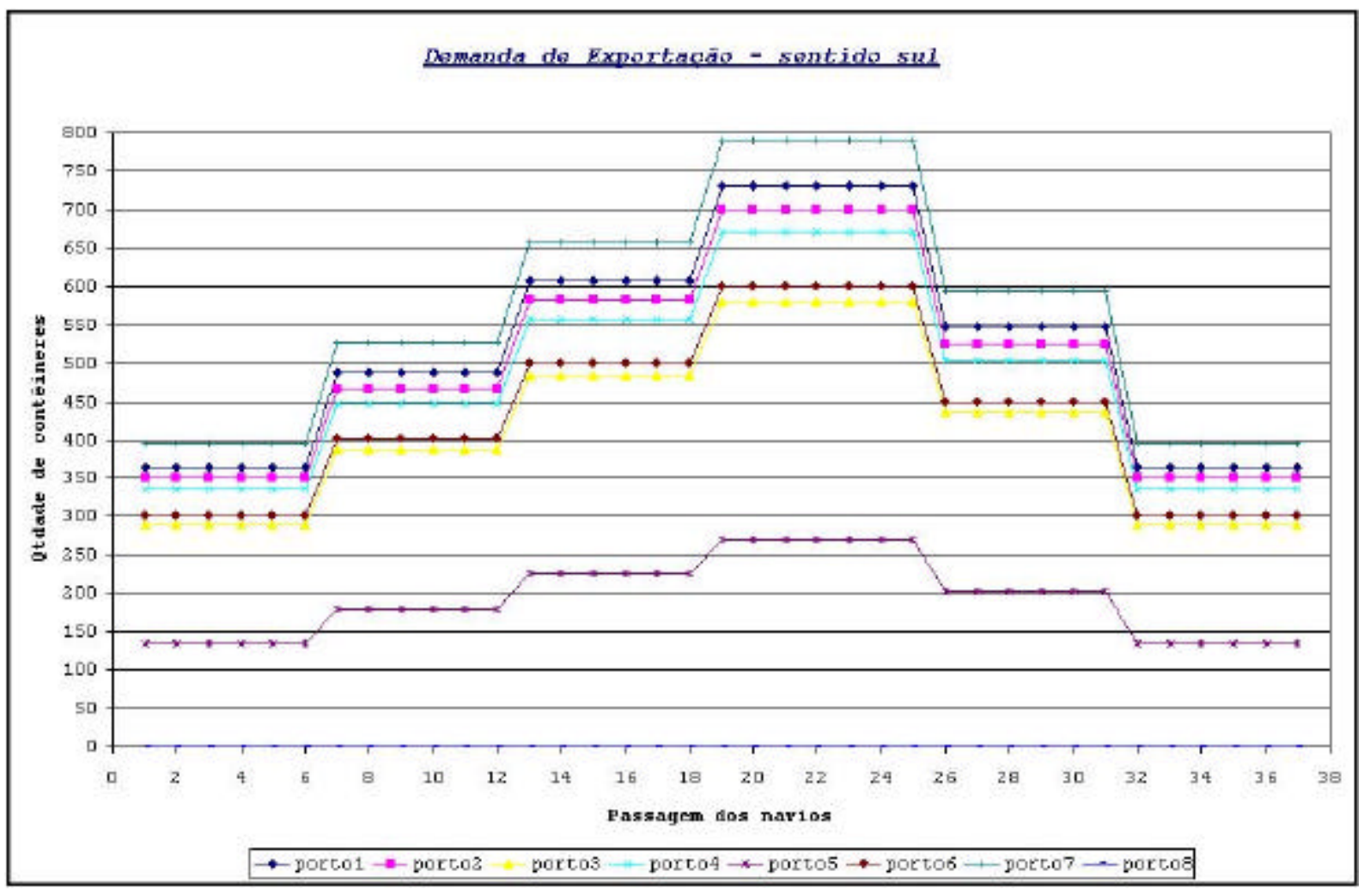

Figura 5-6 Variação da demanda de contêineres cheios exportados em cada porto no sentido sul

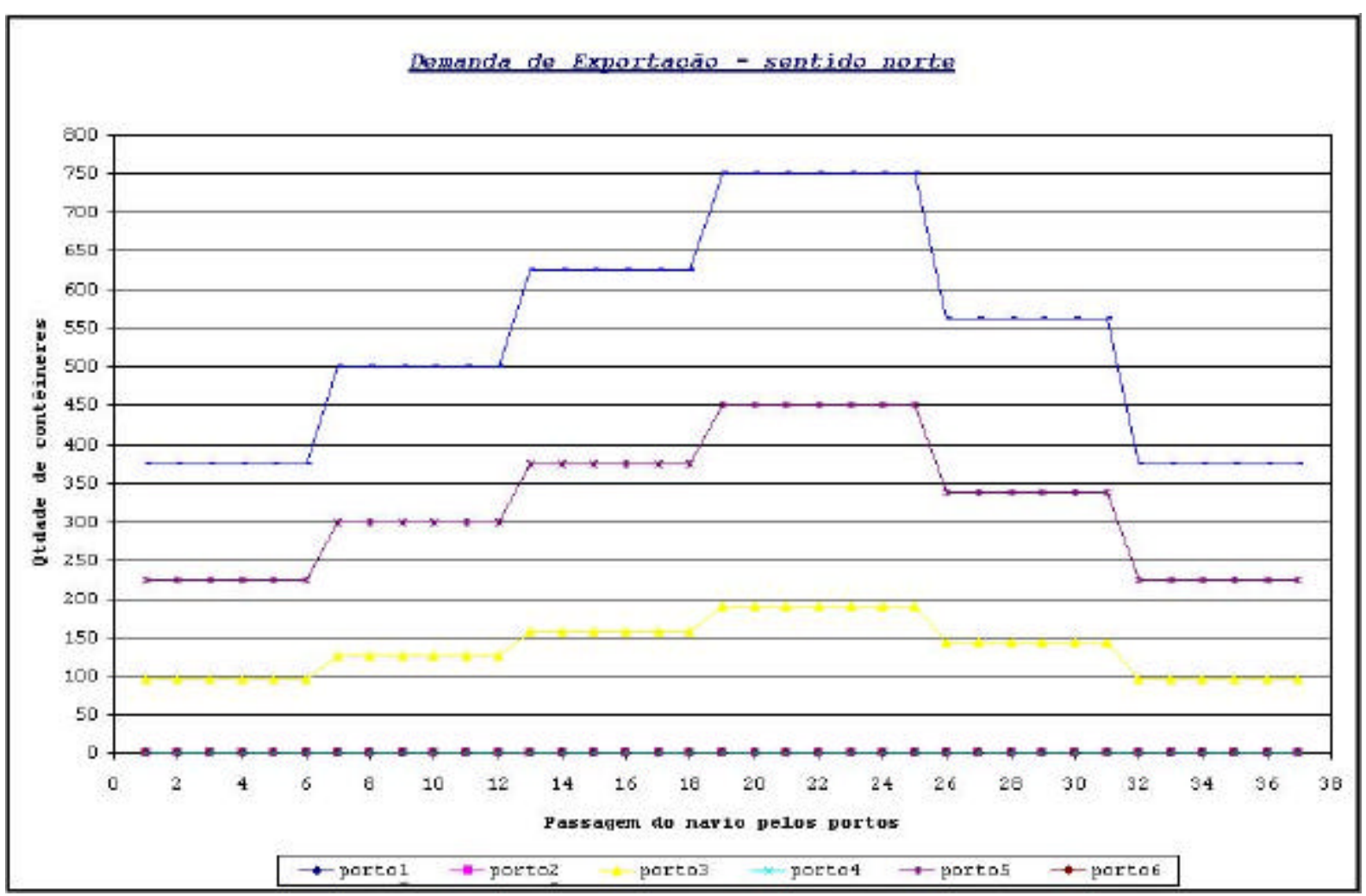

Figura 5-7 Variação da demanda de contêineres cheios exportados em cada porto no sentido norte 
CASO

Para analisar o impacto de uma demanda variável, ao longo do horizonte de planejamento, sobre o tamanho da frota de contêineres próprios de uma empresa de navegação considerando a possibilidade do aluguel de contêineres de outras empresas, dois grupos de cenários foram gerados.

Propôs-se a geração de cenários utilizando as mesmas características adotadas para o cenário - base para o caso da demanda uniforme, tais como, os mesmos tempos, [7, 12, 17] dias, e a mesma distribuição de frequiência de retorno dos contêineres, ? $t$. Além disso, o custo do contêiner próprio foi estimado com um valor unitário, $C P=1$.

Utilizando a relação mencionada anteriormente, $C L_{i, j}=\varphi^{*} C P$, tal que $\varphi \geq 1$, variou-se o valor de $f$, cenários $V \_01 a V_{\_} 14$, de modo a identificar para quais valores o aluguel de contêineres seria uma boa opção. Adotou-se em todos os cenários o mesmo custo para o transporte de contêineres vazios entre os portos da rota. Ainda, analisourse a influência da restrição (4.11) sobre o tamanho da frota de contêineres próprios equerida para cada cenário.

Os resultados dos cenários $V \_01 a V_{-} 14$ estão sintetizados na Tabela 5-14 e Tabela 5-15. A Tabela 5-14 mostra os resultados para o custo do sistema analisado, variando-se o custo de leasing, $C L$, e mantendo-se os demais custos, sendo $C P$ o custo do contêiner próprio e $C V$ o custo de transporte de contêiner próprio vazio entre dois portos. A coluna SAIDA_VAZ indica a relação da restrição (4.11) utilizada, onde $E$ significa a relação de igualdade da equação (4.11) e $G$ para identificar que esta restrição está ilimitada superiormente. 
Tabela 5-14 Resultado dos custos totais para os cenários $V$

\begin{tabular}{|l|c|c|c|c|c|r|r|}
\cline { 2 - 8 } \multicolumn{1}{c|}{} & SAIDA VAZ & CP & \multicolumn{1}{c|}{ CL } & CV & \multicolumn{1}{c|}{ CTCP } & \multicolumn{1}{c|}{ CTCL } & \multicolumn{1}{c|}{ CTTCV } \\
\hline V_01 & E & 1,00 & $\mathbf{2 , 0 0}$ & $\mathbf{0 , 2 0}$ & $6.911 .420,53$ & $2.095 .019,02$ & $4.165,86$ \\
\hline V_02 & G & 1,00 & $\mathbf{2 , 0 0}$ & $\mathbf{0 , 2 0}$ & $6.430 .944,84$ & $2.276 .705,49$ & $4.276,62$ \\
\hline V_03 & E & 1,00 & $\mathbf{4 , 0 0}$ & $\mathbf{0 , 2 0}$ & $9.083 .155,91$ & $1.318 .478,62$ & $2.762,53$ \\
\hline V_04 & G & 1,00 & $\mathbf{4 , 0 0}$ & $\mathbf{0 , 2 0}$ & $8.713 .822,71$ & $1.516 .051,56$ & $2.905,72$ \\
\hline V_05 & E & 1,00 & $\mathbf{6 , 0 0}$ & $\mathbf{0 , 2 0}$ & $10.136 .074,12$ & $596.221,30$ & $2.167,15$ \\
\hline V_06 & G & 1,00 & $\mathbf{6 , 0 0}$ & $\mathbf{0 , 2 0}$ & $9.988 .012,00$ & $596.343,12$ & $2.187,16$ \\
\hline V_07 & E & 1,00 & $\mathbf{8 , 0 0}$ & $\mathbf{0 , 2 0}$ & $10.459 .566,35$ & $405.415,31$ & $2.156,37$ \\
\hline V_08 & G & 1,00 & $\mathbf{8 , 0 0}$ & $\mathbf{0 , 2 0}$ & $10.311 .625,06$ & $405.415,31$ & $2.178,60$ \\
\hline V_09 & E & 1,00 & $\mathbf{9 , 0 0}$ & $\mathbf{0 , 2 0}$ & $10.634 .160,23$ & $275.342,81$ & $2.150,58$ \\
\hline V_10 & G & 1,00 & $\mathbf{9 , 0 0}$ & $\mathbf{0 , 2 0}$ & $10.486 .218,93$ & $275.342,81$ & $2.172,80$ \\
\hline V_11 & E & 1,00 & $\mathbf{9 , 5 0}$ & $\mathbf{0 , 2 0}$ & $10.889 .248,83$ & $27.609,38$ & $2.086,46$ \\
\hline V_12 & G & 1,00 & $\mathbf{9 , 5 0}$ & $\mathbf{0 , 2 0}$ & $10.741 .307,53$ & $27.609,38$ & $2.108,68$ \\
\hline V_13 & E & 1,00 & $\mathbf{1 0 , 0 0}$ & $\mathbf{0 , 2 0}$ & $10.917 .073,83$ & - & $2.048,50$ \\
\hline V_14 & G & 1,00 & $\mathbf{1 0 , 0 0}$ & $\mathbf{0 , 2 0}$ & $10.769 .132,53$ & & $2.070,72$ \\
\hline
\end{tabular}

onde:

- CTCP representa o custo total da frota de contêineres próprios, ao final do horizonte de planejamento;

- CTCL representa o custo gerado pelo aluguel de contêineres ao longo do horizonte de planejamento; e

- CTTCV representa o custo total do transporte de contêineres próprios vazios entre portos, ao longo do horizonte de planejamento.

Tabela 5-15 - Tamanho da frota própria variando-se o custo de leasing

\begin{tabular}{|c|c|c|c|c|c|c|c|c|c|}
\hline & SAIDA VAZ & CP & CL & $\mathrm{CV}$ & ECCP & ECVP & EMBL & T.VAZIOS & ET \\
\hline V_ 01 & $E$ & 1,00 & 2,00 & 0,20 & 7.171 & 4.009 & 17.789 & 10.415 & 18.629 \\
\hline $\mathrm{V} \quad 02$ & G & 1,00 & 2,00 & 0,20 & 3.657 & 6.227 & 19.466 & 10.692 & 17.334 \\
\hline $\mathrm{V} \quad 03$ & $\mathrm{E}$ & 1,00 & 4,00 & 0,20 & 7.989 & 9.044 & 6.876 & 6.906 & 24.483 \\
\hline $\mathrm{V} \quad 04$ & G & 1,00 & 4,00 & 0,20 & 4.215 & 11.822 & 7.774 & 7.264 & 23.487 \\
\hline V_ 05 & $\mathrm{E}$ & 1,00 & 6,00 & 0,20 & 8.084 & 11.787 & 2.160 & 5.418 & 27.321 \\
\hline $\mathrm{V} \quad 06$ & G & 1,00 & 6,00 & 0,20 & 4.310 & 15.162 & 2.161 & 5.468 & 26.922 \\
\hline V_ 07 & $\mathrm{E}$ & 1,00 & 8,00 & 0,20 & 8.084 & 12.659 & 1.233 & 5.391 & 28.193 \\
\hline $\mathrm{V} \quad 08$ & G & 1,00 & 8,00 & 0,20 & 4.310 & 16.034 & 1.233 & 5.446 & 27.794 \\
\hline V_ 09 & $\mathrm{E}$ & 1,00 & 9,00 & 0,20 & 8.084 & 13.129 & 763 & 5.376 & 28.664 \\
\hline $\mathrm{V} \quad 10$ & G & 1,00 & 9,00 & 0,20 & 4.310 & 16.504 & 763 & 5.432 & 28.265 \\
\hline V_ 11 & $\mathrm{E}$ & 1,00 & 9,50 & 0,20 & 8.084 & 13.817 & 75 & 5.216 & 29.351 \\
\hline $\mathrm{V} \quad 12$ & G & 1,00 & 9,50 & 0,20 & 4.310 & 17.192 & 75 & 5.272 & 28.952 \\
\hline $\mathrm{V} \quad 13$ & $\mathrm{E}$ & 1,00 & 10,00 & 0,20 & 8.084 & 13.892 & - & 5.121 & 29.426 \\
\hline $\mathrm{V} \quad 14$ & G & 1,00 & 10,00 & 0,20 & 4.310 & 17.267 & - & 5.177 & 29.027 \\
\hline
\end{tabular}

onde:

- ECCP indica a quantidade de contêineres próprios cheios nos portos, no início do horizonte de planejamento, necessária para atender toda a demanda de transporte; 
CASO

- ECVP indica a quantidade de contêineres próprios vazios nos terminais dos portos, no início do horizonte de planejamento;

- $E M B L$ representa a quantidade total de contêineres alugados transportados ao longo do horizonte de planejamento;

- T.VAZIOS indica o número total de contêineres próprios vazios que foram reposicionados entre os portos ao longo do horizonte de planejamento; e

- ET representa o tamanho ótimo da frota de contêineres próprios, incluindo os contêineres existentes no navio no início do horizonte de planejamento.

Observa-se que, quando se permite que o modelo decida a quantidade de contêineres vazios que serão enviados por dia aos clientes de exportação, ou seja, quando se utiliza a restrição (4.11) na forma =, o tamanho da frota própria é reduzida com o aumento do leasing de contêineres e reduz-se o estoque de contêineres cheios nos portos, no início do processo. Diante da hipótese adotada com relação às condições iniciais, isto é, não há contêineres em trâns ito terrestre no início do horizonte de planejamento, a restrição (4.11) na forma = obriga a que o estoque inicial de contêineres cheios seja muito alta.

Analisando-se os custos de leasing, verifica-se que para valores de $f$ iguais ou acima de 10, cenários $V_{-} 13$ e $V_{-} 14$, o aluguel de contêineres não seria mais realizado, indicando, para este caso, um tamanho de frota ótima de $\mathbf{2 9 . 4 2 6}$ contêineres próprios e de $\mathbf{2 9 . 0 2 7}$ contêineres próprios, para os cenários $V_{-} 13$ e $V_{-} 14$, respectivamente.

O outro cenário gerado refere-se à influência do custo do transporte de contêineres próprios vazios sobre o a decisão do aluguel de contêineres. Utilizando-se as mesmas premissas adotadas para os cenários $V$, fixou-se o valor de $f$ em 4 , de modo que houvesse o aluguel de contêineres, tal como visto na Tabela 5-15. Variando-se o custo do transporte de contêineres próprios vazios até se igualar ao valor do custo do aluguel de contêineres, 
CASO

observa-se, por meio da Tabela 5-16 e da Tabela 5-17, que o custo do transporte de contêineres próprios vazios praticamente tem pouca influência sobre a decisão de aluguel de contêineres e sobre o tamanho total da frota de contêineres próprios.

Tabela 5-16 Resultados obtidos para a variação do custo do transporte de contêineres vazios

\begin{tabular}{|l|c|c|c|c|c|c|c|}
\cline { 2 - 8 } \multicolumn{1}{c|}{} & SAIDA VAZ & CDCP & CDCL & CTCV & CTCP & CTCL & CTTCV \\
\hline E_01 & E & 1,00 & $\mathbf{4 , 0 0}$ & $\mathbf{1 , 0 0}$ & $9.131 .313,95$ & $1.270 .577,71$ & $13.447,36$ \\
\hline E_02 & G & 1,00 & $\mathbf{4 , 0 0}$ & $\mathbf{1 , 0 0}$ & $8.774 .462,48$ & $1.455 .653,58$ & $14.173,43$ \\
\hline E_03 & E & 1,00 & $\mathbf{4 , 0 0}$ & $\mathbf{2 , 0 0}$ & $9.152 .609,59$ & $1.249 .680,05$ & $26.380,27$ \\
\hline E_04 & G & 1,00 & $\mathbf{4 , 0 0}$ & $\mathbf{2 , 0 0}$ & $8.790 .565,63$ & $1.439 .863,55$ & $27.941,16$ \\
\hline E_05 & E & 1,00 & $\mathbf{4 , 0 0}$ & $\mathbf{3 , 0 0}$ & $9.189 .588,92$ & $1.213 .765,29$ & $38.317,87$ \\
\hline E_06 & G & 1,00 & $\mathbf{4 , 0 0}$ & $\mathbf{3 , 0 0}$ & $8.837 .177,30$ & $1.394 .059,08$ & $40.973,25$ \\
\hline E_07 & E & 1,00 & $\mathbf{4 , 0 0}$ & $\mathbf{4 , 0 0}$ & $9.204 .969,87$ & $1.199 .161,09$ & $50.189,02$ \\
\hline E_08 & G & 1,00 & $\mathbf{4 , 0 0}$ & $\mathbf{4 , 0 0}$ & $8.844 .381,20$ & $1.387 .337,34$ & $54.096,99$ \\
\hline
\end{tabular}

Tabela 5-17 Tamanho da frota própria variando o custo do transporte de contêineres vazios

\begin{tabular}{|l|c|c|r|r|r|r|r|r|c|}
\cline { 2 - 10 } \multicolumn{1}{c|}{} & SAIDA VAZ & CDCP & \multicolumn{1}{c|}{ CDCL } & \multicolumn{1}{c|}{ CTCV } & \multicolumn{1}{c|}{ ECCP } & \multicolumn{1}{c|}{ ECVP } & \multicolumn{1}{c|}{ EMABL } & SES+SEU & ET \\
\hline E_01 & E & 1,00 & $\mathbf{4 , 0 0}$ & $\mathbf{1 , 0 0}$ & 7.989 & 9.174 & 6.605 & 6.724 & 24.613 \\
\hline E_02 & G & 1,00 & $\mathbf{4 , 0 0}$ & $\mathbf{1 , 0 0}$ & 4.215 & 11.986 & 7.450 & 7.087 & 23.651 \\
\hline E_03 & E & 1,00 & $\mathbf{4 , 0 0}$ & $\mathbf{2 , 0 0}$ & 7.989 & 9.231 & 6.479 & 6.595 & 24.670 \\
\hline E_04 & G & 1,00 & $\mathbf{4 , 0 0}$ & $\mathbf{2 , 0 0}$ & 4.215 & 12.029 & 7.343 & 6.985 & 23.694 \\
\hline E_05 & E & 1,00 & $\mathbf{4 , 0 0}$ & $\mathbf{3 , 0 0}$ & 7.989 & 9.331 & 7.083 & 6.386 & 24.770 \\
\hline E_06 & G & 1,00 & $\mathbf{4 , 0 0}$ & $\mathbf{3 , 0 0}$ & 4.215 & 12.155 & 6.266 & 6.829 & 23.820 \\
\hline E_07 & E & 1,00 & $\mathbf{4 , 0 0}$ & $\mathbf{4 , 0 0}$ & 7.989 & 9.372 & 7.043 & 6.274 & 24.811 \\
\hline E_08 & G & 1,00 & $\mathbf{4 , 0 0}$ & $\mathbf{4 , 0 0}$ & 4.215 & 12.174 & 6.180 & 6.762 & 23.839 \\
\hline
\end{tabular}




\section{CAPÍTULO 6 - CONSIDERAÇÕES FINAIS}

Neste capítulo mostram-se as principais contribuições apresentadas por esta pesquisa, fazendo-se uma análise crítica do modelo de programação linear proposto para a resolução do problema estudado, bem como sugestões para trabalhos futuros.

\section{1 - Contribuições da Pesquisa}

Esta pesquisa tratou do problema de dimensionamento da frota de contêineres sob o ponto de vista de uma empresa de navegação.

A revisão bibliográfica apresentou poucas publicações que tratassem das características específicas e de soluções para o tema proposto. A referência bibliográfica que mais se aproximou deste estudo foi o trabalho desenvolvido por Imai e Rivera (2001). Eles desenvolveram métodos para o dimensionamento de frota de contêineres considerando pares de portos. Admitiram, também, que não havia aleatoriedade nos tempos de porto e nos tempos de movimentação terrestre dos contêineres. Apesar de terem relatado que a programação matemática desenvolvida por eles poderia ser aplicada para rotas mais complexas, multiportos, não foi empregada em seu estudo de caso. 
Para tentar solucionar o problema proposto dois métodos foram analisados: modelo de simulação probabilística e modelo de programação linear. $\mathrm{O}$ modelo de simulação desenvolvido para uma rota com apenas três portos atendia bem os requisitos e as restrições. Conforme a ampliação do modelo e o aumento do número de variáveis, o modelo de simulação passou a ser difícil de ser controlado, pois a mudança dos valores destas variáveis requereria muito tempo.

O modelo de programação linear foi desenvolvido com base nas características e definições adotadas para o modelo de simulação. Este modelo matemático incorporou bem as aleatoriedades existentes nos processos terrestres, de acordo com as hipóteses adotadas.

O modelo proposto permite auxiliar o planejador nas tomadas das decisões estratégicas com relação ao tamanho da frota de contêineres necessários para atender a demanda de transporte ao longo do horizonte de planejamento.

Este modelo foi aplicado em estudo de caso hipotético, em que a solução gerada apresentou características tanto estratégicas quanto operacionais. Estratégicas no sentido de apresentar um dimensionamento da frota de contêineres próprios no início do horizonte de planejamento, sem necessitar de muitas informações a respeito do período anterior. Operacionais no sentido de apresentar o fluxo de transporte de contêineres vazios entre portos, bem como a quantidade de contêineres alugados, se necessários, para realizar as operações emergenciais associadas a picos de demanda ao longo do período de planejamento.

\section{2 - Limitações e Sugestões de Continuidade da Pesquisa}

Devido à falta de informações reais, não foi possível aplicar o modelo a condições reais de mercado. Além disso, este modelo tratou de dimensionar, para uma frota de navios 
homogênea, a quantidade de contêineres necessária para atender a uma demanda de transporte para apenas um único tipo de contêiner.

Assim, é possível imple mentar melhorias no modelo de programação linear proposto para o dimensionamento da frota de contêineres, tais como a complementação do modelo para ser aplicado para vários tipos de contêineres. Um outro ponto importante para a melhoria do modelo seria a obtenção de dados reais para aplicação de um estudo de caso real.

Uma outra sugestão para um estudo futuro seria alterar as condições iniciais referentes à movimentação terrestre dos contêineres. No caso desta dissertação, admitiu-se que, no início do horizonte de planejamento que não havia contêineres em trânsito terrestre. Isto pode ter afetado os resultados obtidos para os cenários gerados. 


\section{ANEXO A}

\section{ESTUDO DOS MÉTODOS PROPOSTOS POR IMAI E RIVERA (2001)}

Imai e Rivera (2001) discutem três modelos para tratar o problema do dimensionamento da frota de contêineres. Um modelo analítico é primeiro discutido para determinar o tamanho ótimo de uma frota própria de contêiner do tipo dry em um mercado relativamente balanceado. Em seguida, este modelo é modificado para determinar o tamanho da frota de contêineres refrigerados em um comércio extremamente desbalanceado. Desenvolveram também um modelo de simulação que será apresentado posteriormente.

Para isto, eles consideram o fluxo de contêineres entre dois portos, $P$ e $S$. Para o primeiro caso, eles admitem que há um fluxo de carga maior partindo do porto $P$ para o porto $S$. Os autores adotam, também, dois tipos de fluxos de contêineres entre estes portos: o fluxo do modelo (A), representado na Figura 0-1 pelos trechos (1) - (2) - (3) - (4) - (5) - (6), e o fluxo de modelo (B), representado pelos trechos $(1)-(7)-(8)-(9)$. 


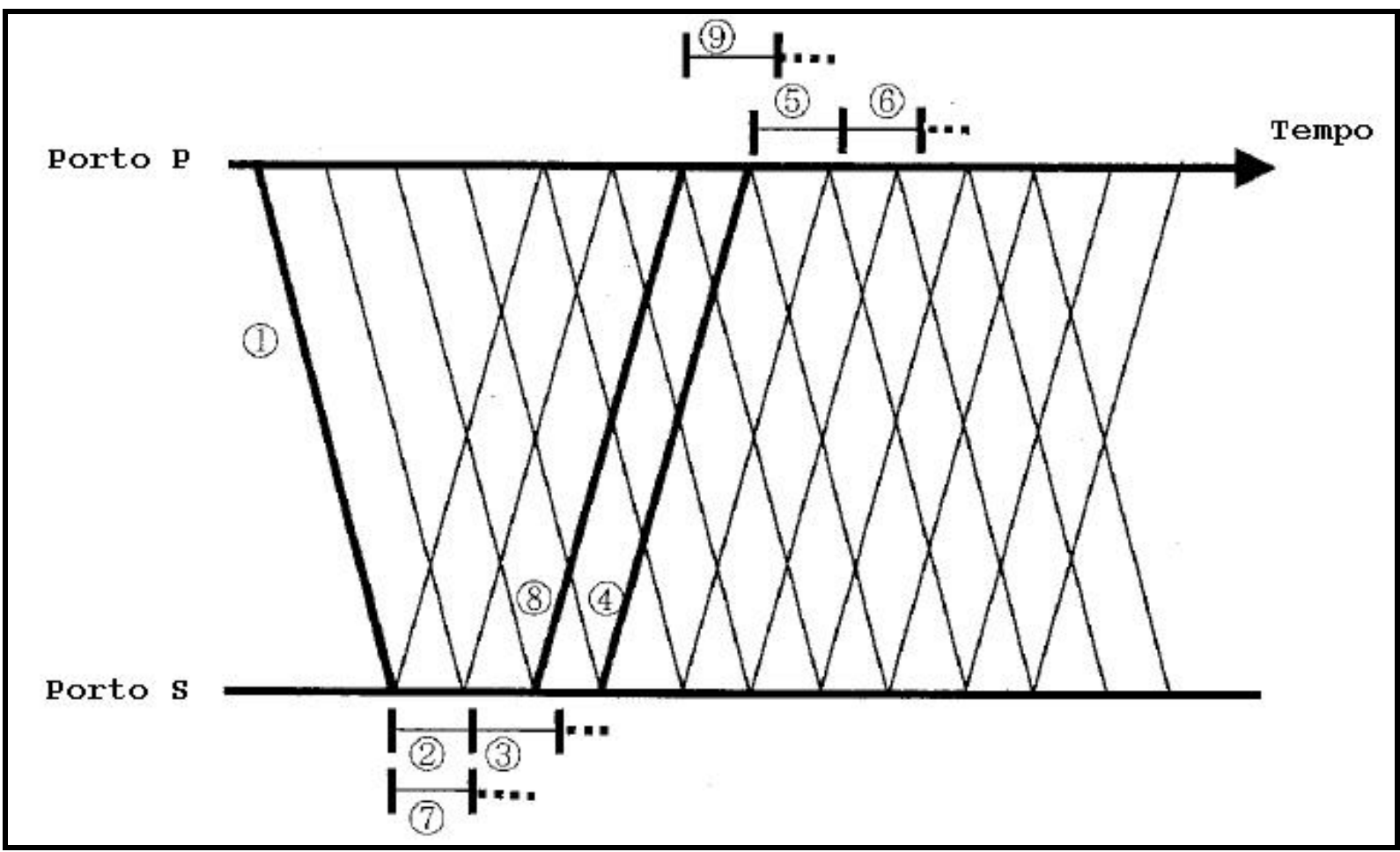

Fonte: Imai, A., Rivera, F.(2001)

Figura 0-1 Modelos de fluxos de contêineres entre dois portos

Para o modelo (A), no trecho (1), os contêineres cheios são transportados do porto $P$ até o porto $S$; no trecho (2), eles são levados até o cliente de importação, onde são desovados, retornando em seguida para o terminal de contêineres vazios no porto $S$; no trecho (3), os contêineres são encaminhados para os clientes de exportação que os devolvem ao porto $S$ como contêineres cheios. Estes contêineres cheios aguardam a próxima passagem do navio pelo porto; no trecho (4), eles são transportados até o porto $P$; no trecho (5), os contêineres cheios são encaminhados até os clientes de importação, que os devolvem ao porto como contêineres vazios. No trecho (6), estes contêineres vazios são enviados até os clientes de exportação, retornando ao porto como contêineres cheios e aguardam a passagem do próximo navio, reiniciando o ciclo.

Para o modelo (B), no trecho (1), os contêineres cheios partem do porto $P$; no trecho (7), eles são encaminhados para os clientes de importação do porto $S$, retornando como contêineres vazios a este porto. Aguardam a passagem do próximo navio; no trecho (8), os contêineres são transportados vazios de volta para o porto $P$; no trecho (9), eles são remetidos 
aos clientes de exportação para devolvê-los como contêineres cheios ao porto. Estes contêineres aguardam a passagem do próximo navio para o porto $S$, reiniciando o ciclo.

Os tempos de viagem redonda de um contêiner do modelo (A), trechos (1) a (6), $T_{a}^{t}$, e do modelo (B), trechos (1), (7) a (9), $T_{b}^{t}$, são dados como segue:

$$
\begin{aligned}
& T_{a}^{t}=2 \cdot\left(T^{c}+m \cdot T^{i}\right) \\
& T_{b}^{t}=2 \cdot\left(T^{c}+n \cdot T^{i}\right)
\end{aligned}
$$

onde $T^{c}$ é o tempo de viagem de $P$ para $S$ (ou vice-versa); $T^{i}$ é o intervalo entre passagens dos navios no porto $P$ ou $S$ (em dias); $m$ é a quantidade de passagens de navios no porto $P$ enquanto os contêineres estiverem percorrendo os trechos (5) e (6), ou a quantidade de passagens de navios no porto $S$ enquanto os contêineres estiverem percorrendo os trechos (2) e (3); $n$ é o número de navios que passam pelo porto $P$ enquanto os contêineres trafegam pelo trecho (9), ou número de navios que passam pelo porto $S$ enquanto os contêineres trafegam pelo trecho (7). Os valores de $m$ e $n$ devem ser inteiros que satisfaçam as restrições (3) e (4), respectivamente.

$$
\begin{aligned}
& (m-1) \cdot T^{i}<2 \cdot T^{d} \leq m \cdot T^{i} \\
& (n-1) \cdot T^{i}<2 \cdot T^{d} \leq n \cdot T^{i}
\end{aligned}
$$

onde $T^{d}$ é o tempo de viagem redonda de ida e volta para um porto via um cliente.

Deixando $F_{a}$ e $F_{b}$ serem o número de navios que passam pelo porto $P$ durante $T_{a}^{t}$ e $T_{b}^{t}$, respectivamente, tem-se:

$$
\begin{gathered}
F_{a}=\frac{T_{a}^{t}}{T^{i}} \\
F_{b}=\frac{T_{b}^{t}}{T^{i}}
\end{gathered}
$$

Os volumes de carga de uma viagem partindo do porto $P$ para o porto $S, D_{P}$, e do porto $S$ para o porto $P, D_{S}$, são dados pelas equações (7) e (8), respectivamente. 


$$
\begin{aligned}
& D_{P}=\frac{T^{i} \cdot N_{P}}{Y} \\
& D_{S}=\frac{T^{i} \cdot N_{S}}{Y}
\end{aligned}
$$

onde $N_{P}$ e $N_{S}$ são os volumes de carga anual de $P$ para $S$ e de $S$ para $P$, e $Y$ é o número de dias de um ano (365 dias).

O volume de contêiner, $C_{b}$, necessário para a primeira das $F_{b}$-ésimas viagens originárias a partir do porto $P$ é igual ao volume de carga transportado para o porto $S$ durante aquelas viagens. A partir de (2), (6) e (7), isto é dado pela equação (9).

$$
C_{b}=D_{P} \cdot F_{b}=\frac{2 \cdot N_{P}}{Y} \cdot\left(T^{c}+n \cdot T^{i}\right)
$$

$C_{a}$, o volume de carga necessário para viagens $F_{b}+1$ para $F_{a}$, é igual ao volume de carga transportado para o porto $P$, pois os contêineres vazios excedentes no porto $S$ são transferidos para o porto $P$. Assim, $C_{a}$ é dado pela equação (10).

$$
C_{a}=D_{S} \cdot\left(F_{a}-F_{b}\right)=\frac{2 \cdot N_{S}}{Y} \cdot(m-n) \cdot T^{i}
$$

A partir de (9) e (10), o tamanho da frota de contêineres próprios $C$ pode ser definido pela equação (11).

$$
C=C_{a}+C_{b}=\frac{2}{Y} \cdot\left\{N_{P} \cdot\left(T^{c}+n \cdot T^{i}\right)+N_{S} \cdot(m-n) \cdot T^{i}\right\}
$$

Se o volume de carga transferido do porto $P$ para o porto $S$ for igual àquele de $S$ para $P$, quer dizer $N=N_{P}=N_{S}$, então $C$ pode ser definido pela equação (12).

$$
C=\frac{2 \cdot N}{Y} \cdot\left(T^{c}+m \cdot T^{i}\right)
$$

Para o segundo caso, no qual deseja-se determinar o tamanho da frota de contêineres refrigerados em um mercado extremamente desbalanceado, além das hipóteses acima assumidas, considera-se que o tempo de retorno dos contêineres na região do porto $P$ seja 
diferente do tempo de retorno dos contêineres na região do porto $S$. Sendo um mercado desbalanceado, os autores admitem que apenas o fluxo do modelo (B) seja levado em consideração.

Assim, substituindo $2 n$ na equação (2) por $\left(n_{P}+n_{S}\right)$, o tempo de viagem redonda, $T^{t}$, de um contêiner indo e voltando para o porto $P$ após carregamento em $S$ é dado como o seguinte:

$$
T^{t}=2 \cdot T^{c}+\left(n_{P}+n_{S}\right) \cdot T^{i}
$$

onde $n_{P}$ é o número de navios que passam pelo porto $P$ enquanto um contêiner está em trânsito da região atendida pelo porto $P$. Analogamente, $n_{S}$ é válido para o porto $S$.

Assim, $n_{P}$ e $n_{S}$ devem satisfazer as seguintes restrições, respectivamente.

$$
\begin{aligned}
& \left(n_{P}-1\right) \cdot T^{i}<T_{P}^{d} \leq n_{P} \cdot T^{i} \\
& \left(n_{S}-1\right) \cdot T^{i}<T_{S}^{d} \leq n_{S} \cdot T^{i}
\end{aligned}
$$

onde $T^{d}{ }_{P}$ e $T_{S}^{d}$ são os tempos de viagem redonda de um contêiner no interior da região dos portos $P$ e $S$, respectivamente.

Portanto, o volume de contêiner necessário, $C$, corresponde a $C_{b}$ no caso anterior; é definido como segue:

$$
C=\frac{N_{P}}{Y} \cdot\left\{T^{c}+\left(n_{P}+n_{S}\right) \cdot T^{i}\right\}
$$

Os autores desenvolveram este modelo para o caso de uma rota com dois portos. Eles afirmam que para o caso de uma rota com multi-portos o tamanho da frota total para este mercado seria a soma do volume de contêineres dado pela equação (16).

Além dos dois modelos acima propostos, Imai e Rivera (2001) também desenvolveram um modelo de simulação, envolvendo multi-portos, que assume, além das hipóteses anteriormente discutidas, interações pré-determinadas para os movimentos de contêineres vazios. Eles consideram que os fluxos de contêineres estão em uma rede tempo-espaço 
(Figura 0-2), no qual os nós correspondem aos portos de origem e destino dos contêineres cheios e vazios, enquanto os arcos representam as viagens.

A Figura 0-2(a) mostra uma conservação do fluxo de contêiner vazio em um porto de origem, enquanto que a Figura 0-2(b) ilustra esta conservação em um porto de destino, onde:

- $\quad E_{i}^{t} \ldots$ é o volume de contêiner que retorna ao porto $i$ a partir dos portos de destino $j$ em um tempo $t$;

- $F_{i}^{t} \ldots$ é o volume total de contêiner que parte do porto $i$ para os próximos carregamentos no tempo $t$;

- $\quad S_{i}^{t} \ldots$ é o volume total de contêiner estocado disponível no porto $i$ no tempo $t$;

- $G_{j}^{t} \ldots$ é o volume total de contêiner que retorna ao porto $j$ no tempo $t$ vindos dos clientes de importação; e

- $\quad H_{j}^{t} \ldots$ é o volume total de contêiner que retorna ao porto de origem a partir do porto $j$ no tempo $t$.

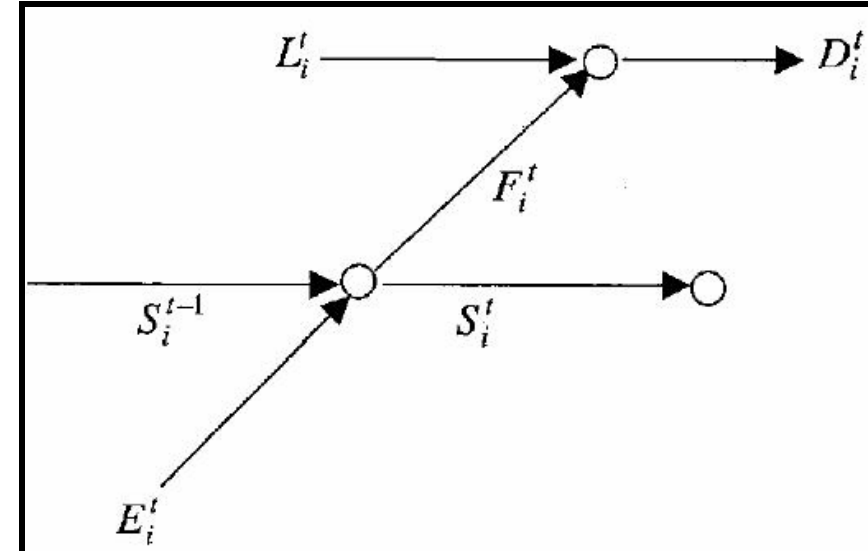

(a) Porto de Origem i

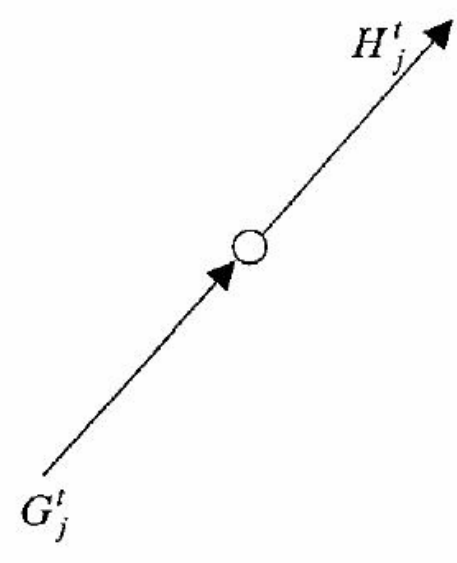

(b) Porto de Destino j

Fonte: Imai, A., Rivera, F.(2001)

Figura 0-2 Conservação dos Fluxos de Contêineres nos Portos

As conservações dos fluxos em um porto de origem $i$ e em um porto de destino $j$ são dadas pelas equações (17) e (18), respectivamente.

$$
S_{i}^{t}+F_{i}^{t}=S_{i}^{t-1}+E_{i}^{t}
$$




$$
G_{j}^{t}=H_{j}^{t}
$$

Em caso de falta de contêiner próprio, arrendam-se contêineres para abastecer toda a demanda de carga no porto $i$. Então, a seguinte relação é válida onde $D_{i}^{t}$ e $L_{i}^{t}$ são respectivamente os volumes totais de demanda de carga e de contêineres arrendados no porto $i$ no tempo $t$.

$$
F_{i}^{t}+L_{i}^{t}=D_{i}^{t}
$$

Sendo $F_{i}^{t}$ o número total de contêineres próprios para novos carregamentos e $G_{j}^{t}$ a soma dos contêineres vazios que retornam ao porto $j$ resultantes do processo de importação deste porto, há uma relação entre $F_{i}^{t}$ e $G_{j}^{t}$ na qual é dada pelas seguintes equações:

$$
\begin{gathered}
F_{i}^{t}=\sum_{j} Y_{i j}^{t} \\
G_{j}^{u}=\left.\sum_{i} Y_{i j}^{t}\right|_{\{t \mid t=u-\alpha\}}
\end{gathered}
$$

onde $Y_{i j}^{t}$ é o volume de contêiner próprio que é enviado ao cliente de exportação a partir do porto $i$ no tempo $t$ com destino ao porto $j$, levando a dias para retornar vazio ao porto $j$ no tempo $u$ após a entrega do carregamento. O tempo decorrido a depende de um par de origem e destino.

Adotando-se que alocam-se tantos contêineres próprios para os carregamentos quanto possíveis, o valor de $Y_{i j}^{t}$ é automaticamente determinado a partir dos volumes da demanda de carga dados e os contêineres próprios disponíveis.

Há também uma relação entre $H_{j}^{t}$ e $E_{i}^{t}$. Esta relação é representada pelas seguintes equações, onde $X_{i j}^{t}$ é o volume de contêiner vazio próprio que parte do porto $j$ no tempo $t$, levando $\beta$ dias (que corresponde a $T^{c}$ ) para chegar ao porto de origem $i$ no tempo $v$.

$$
H_{j}^{t}=\sum_{i} X_{i j}^{t}
$$




$$
E_{i}^{v}=\left.\sum_{j} X_{i j}^{t}\right|_{\{t \mid k=v-\beta\}}
$$

Sabendo-se que a determinação dos valores $X_{i j}^{t}$, afetaria o uso dos contêineres, sito implica que $X_{i j}^{t}$ deveria ser uma variável de decisão. Por isto, segundo os autores, o modelo de simulação proposto é reduzido a um problema de programação matemática sendo difícil resolver. Assim, adotaram uma estratégia de distribuição de vazio baseado em experiências de uma particular companhia de navegação. 


\section{ANEXO B}

\section{MODELO DE SIMULAÇÃO}

\section{INTRODUÇÃO}

No início da simulação é feita uma leitura dos parâmetros utilizados durante a execução do modelo, ais como quantidade de contêineres para importação e exportação, capacidade dos navios, tempos de carregamento e descarregamento, demanda entre portos e a sequiência de portos de uma dada viagem para cada navio.

São definidas também no início da simulação as quantidades exportadas de um determinado porto para os demais portos existentes.

\section{CRIAÇÃO DE NAVIOS}

São criados 3 navios que irão percorrer a rota entre os 3 portos existentes no modelo. Cada navio tem sua capacidade definida.

\section{A LÓGICA DOS NAVIOS (CARGA E DESCARGA)}

Quando o navio chega ao porto, as cargas destinadas a este porto vindas dos demais são somadas para termos a quantidade total a ser descarregada. Neste momento os contêineres 
são descarregados um a um na lógica de descarregamento inclusa no modelo enquanto o navio aguarda este tempo de descarga para em seguida ser carregado.

O navio seguirá seu processo verificando se existem contêineres suficientes a serem embarcados, verificando-se a demanda dos contêineres que serão exportados do porto em questão para os demais portos. Caso a disponibilidade seja suficiente para entregar bda quantidade para os demais portos, o navio receberá atributos com a quantidade total que será exportada para cada porto da sequiência. Caso não haja quantidade suficiente de contêineres disponíveis para embarque, será embarcada toda quantidade disponível no porto, sendo 44\% do total a ser embarcado para o porto seguinte e o restante para os demais no caso do porto 1 ser a origem e $42 \%$ caso o porto 3 seja a origem. Caso o navio esteja no porto 2 (porto intermediário da seqüência) toda carga disponível até o limite da quantidade desejada ou até o limite da quantidade disponível será embarcada para o porto seguinte.

Na seqüência o navio tem um tempo para ser carregado, solicita os contêineres a serem embarcados e tem seu tempo de saída marcado para a criação de estatísticas. Neste momento são atualizadas variáveis e atributos que indicam o porto seguinte e o navio segue viagem. Neste mesmo instante o navio envia um comando para que os contêineres cheios disponíveis no porto sejam operados e carregados, determinando assim o tempo de carregamento do navio.

De forma aleatória, os contêineres vazios existentes em cada porto são liberados por um sinal dado pelos navios, de forma que tais contêineres serão operados e transformados em contêineres cheios para exportação. 


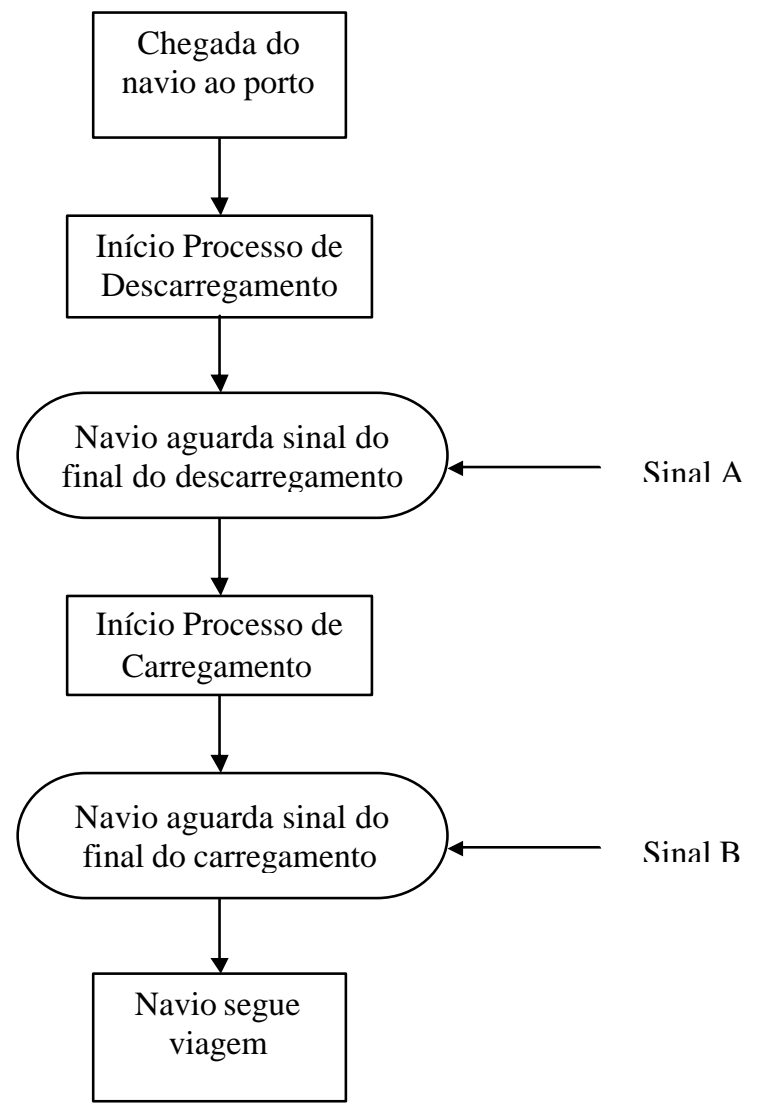

Figura 0-3 Fluxograma referente à logica de operação dos navios

\section{A LÓGICA DOS CONTÊINERES (DESCARREGAMENTO E CARREGAMENTO OS NAVIOS)}

Quando um navio chega ao porto, ele tem sua quantidade a ser descarregada medida e tal quantidade será operada no porto. Cada contêiner tem seu tempo de operação de descarga, e quando o último contêiner é operado, o tempo total de descarga é marcado para compor as estatísticas de descarregamento de cada navio.

Cada porto tem seu valor médio de avarias nos contêineres operados. Caso o contêiner não sofra avaria, ele passa por um processo de limpeza e é disponibilizado como contêiner vazio pronto para ser operado, isto é, ser carregado e transformado em contêiner cheio disponível para exportação. Caso ele sofra avaria, ele terá um atraso maior para voltar ao 
sistema já que além da limpeza deverá sofrer reparos e será disponibilizado para ser carregado. O índice médio de avarias utilizado é de $7 \%$.

Os contêineres vazios ficam aguardando numa fila específica aguardando uma ordem para serem operados.

Quando a ordem de carregamento é dada pelo modelo, o contêiner para pelo processo de ser transformado em contêiner cheio. Esse processo pode ser definido de forma específica em cada porto, tendo para cada local um tempo médio de reparo, limpeza e carga de contêiner.

Ao final do processo anterior, temos uma fila de contêineres cheios e prontos para serem embarcados. Eles ficam aguardando o comando do navio para serem embarcados pelos sistemas portuários, quer podem ter características específicas para cada porto como tempo médio de operação e quantidade de recursos para carregamento de navios. Quando o último contêiner a ser embarcado é operado pelo sistema de carregamento de navios do porto, ele marca tempos de operação para a criação das estatísticas de tempo médio de carga do navio.

Para cada porto temos uma quantidade média de reposição de contêineres vazios, que são disponibilizados antes do processo de carregamento dos contêineres, isto é, de serem transformados em contêineres cheios disponíveis para serem embarcados. 


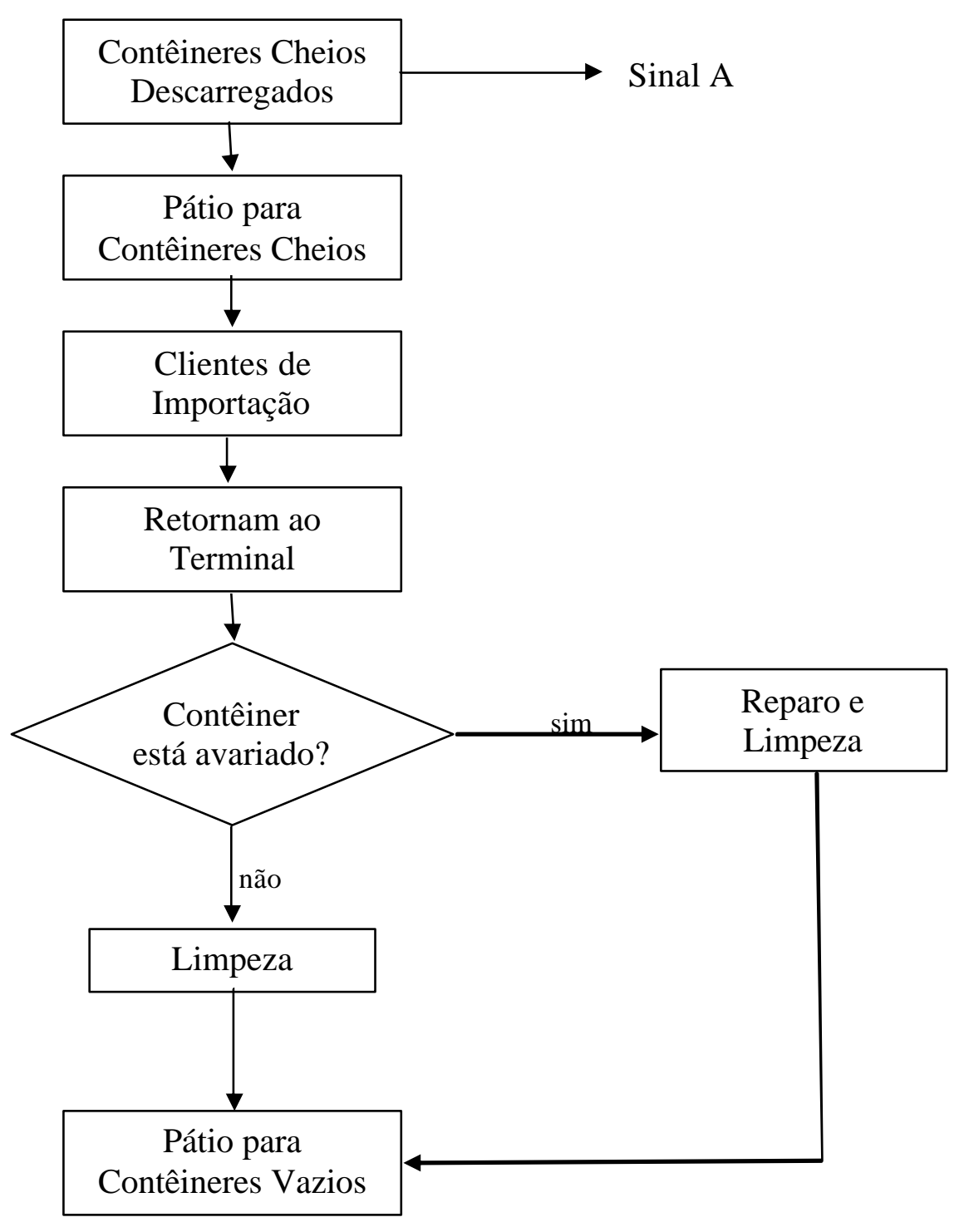

Figura 0-4 Fluxograma referente ao processo de descarregamento dos contêineres cheios 


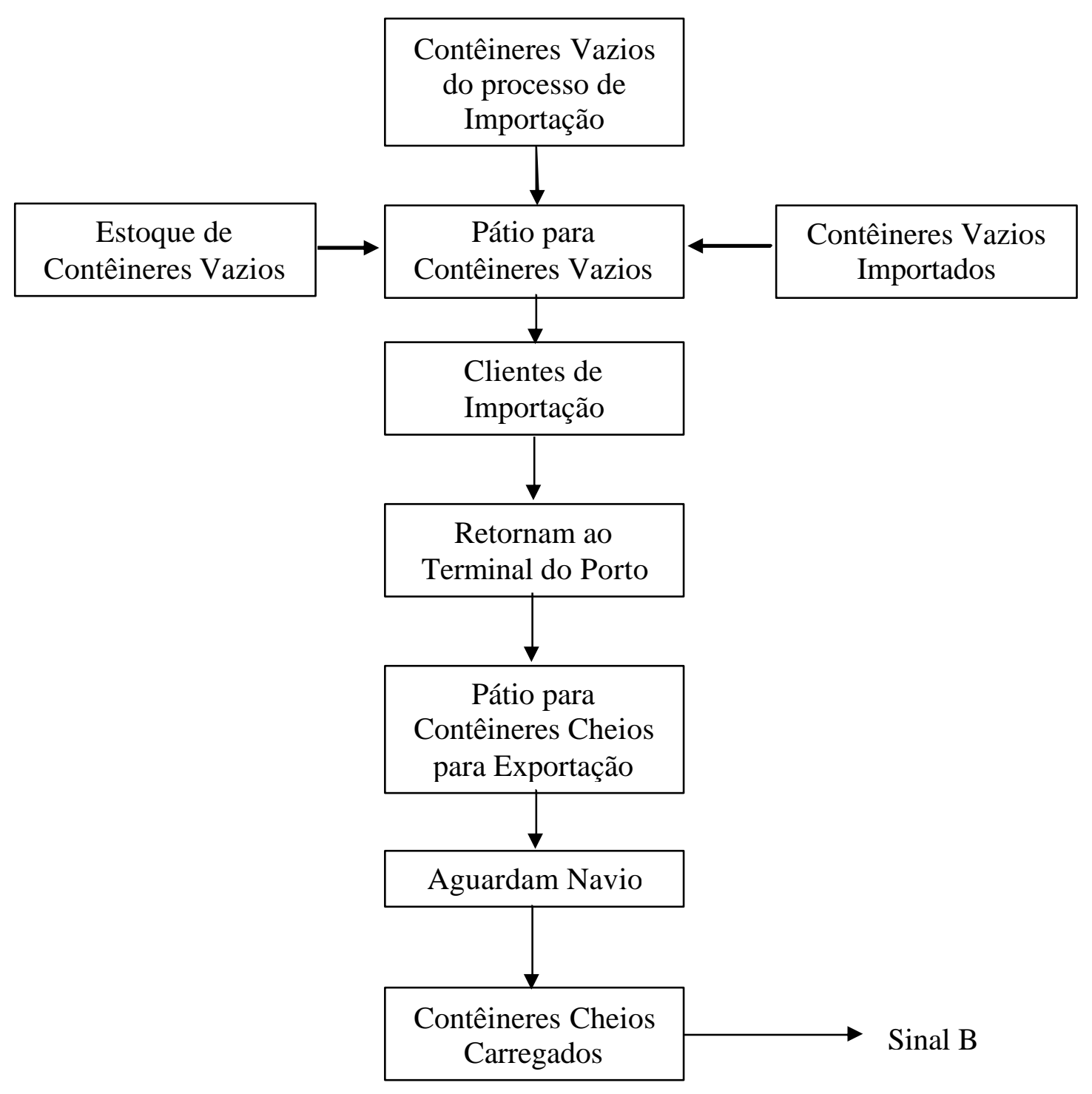

Figura 0-5 Fluxograma referente ao processo dos contêineres vazios 


\section{ANEXO C}

\section{LISTAGEM DO PROGRAMA REFERENTE AO CENÁRIO $V$ _01}

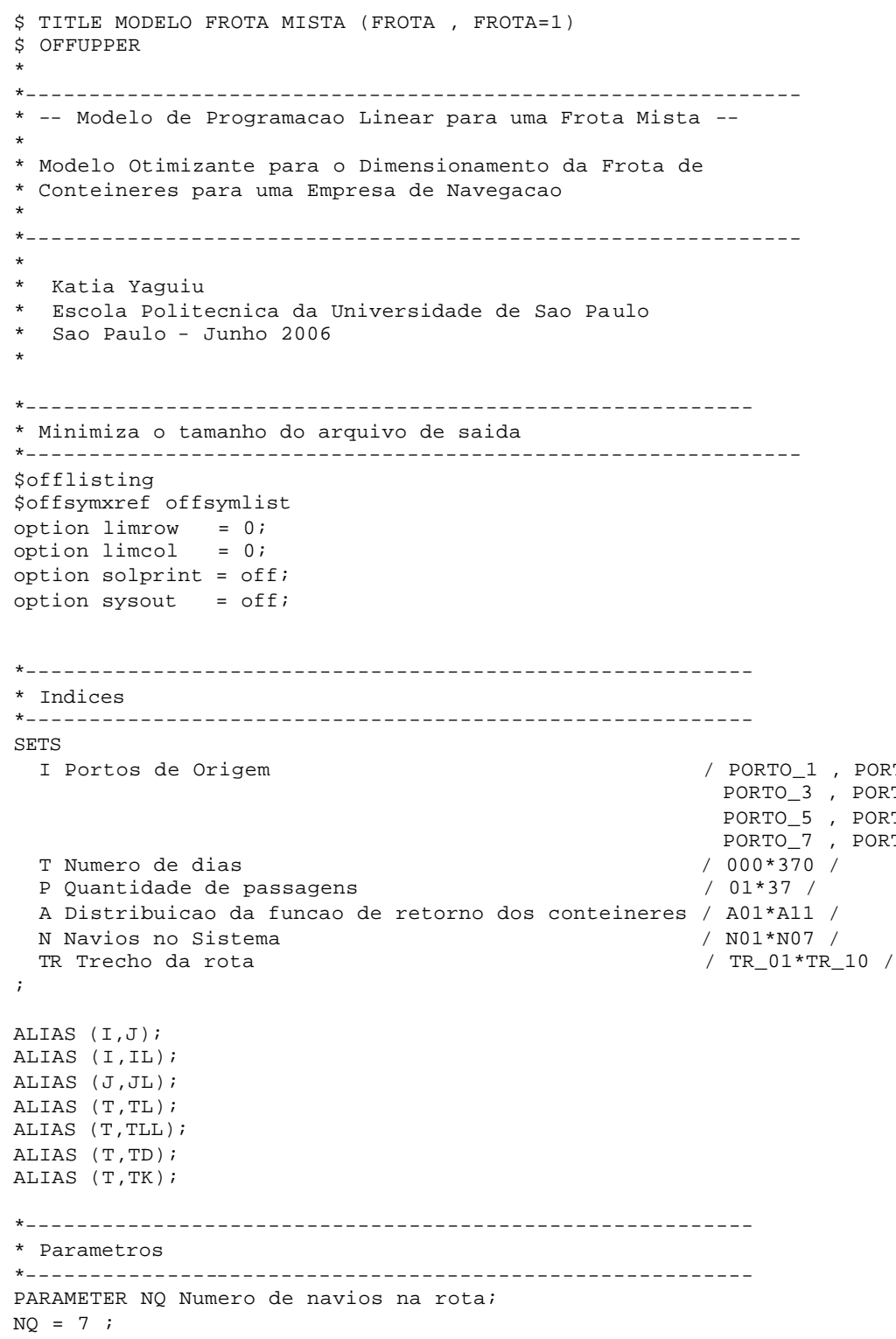


PARAMETER TVR Tempo de viagem redonda (em dias); $\mathrm{TVR}=70$

PARAMETER IN Intervalo entre passagens dos navios nos portos;

$\mathrm{IN}=\mathrm{TVR} / \mathrm{NQ}$;

PARAMETER TMIN(I) Tempo minimo de retorno dos conteineres (em dias);

TMIN ('PORTO_1') $=007$;

TMIN ('PORTO_2') = 007 ;

TMIN ('PORTO_3') $=007$;

TMIN ('PORTO_4') $=007$;

TMIN ('PORTO_5') $=007$;

TMIN ('PORTO_6') $=007$;

TMIN ('PORTO_7') $=007$;

TMIN ('PORTO_8') $=007$;

PARAMETER TMAX(I) Tempo maximo de retorno dos conteineres (em dias);

TMAX ('PORTO_1') $=017$;

TMAX ('PORTO_2') $=017$;

TMAX ('PORTO_3') $=017$;

TMAX ('PORTO_4') $=017$;

$\operatorname{TMAX}($ 'PORTO_5') $=017$;

TMAX ('PORTO_6') $=017$;

TMAX ('PORTO_7') $=017$;

TMAX ('PORTO_8') $=017$;

PARAMETER TS(I) Dia da chegada do primeiro navio ao porto i no sentido sul; TS ('PORTO_1') = 001 ;

TS ('PORTO 2') $=006$

TS ('PORTO_3') = 002 ,

TS ('PORTO_4') $=006$;

TS ('PORTO_5') = 001 ;

TS ('PORTO_6') $=005$;

TS ('PORTO_7') $=001$;

TS ('PORTO_8') = 006 ;

PARAMETER TN(I) Dia de chegada do primeiro navio ao porto i no sentido norte; TN ('PORTO_1') $=001$;

TN ('PORTO_3') $=001$;

TN ('PORTO_5') $=003$;

TN ('PORTO_8') = 006 ;

TABLE TV(I,J) Tempo de viagem entre os portos

$\begin{array}{lllllllll} & \text { PORTO_1 } & \text { PORTO_2 } & \text { PORTO_3 } & \text { PORTO_4 } & \text { PORTO_5 } & \text { PORTO_6 } & \text { PORTO_7 } & \text { PORTO_8 } \\ \text { PORTO_1 } & 0.0 & 5.0 & 11.0 & 15.0 & 20.0 & 24.0 & 30.0 & 35.0 \\ \text { PORTO_2 } & 65.0 & 0.0 & 6.0 & 10.0 & 15.0 & 19.0 & 25.0 & 30.0 \\ \text { PORTO_3 } & 10.0 & 15.0 & 0.0 & 4.0 & 9.0 & 13.0 & 19.0 & 24.0 \\ \text { PORTO_4 } & 55.0 & 60.0 & 45.0 & 0.0 & 5.0 & 9.0 & 15.0 & 20.0 \\ \text { PORTO_5 } & 18.0 & 23.0 & 8.0 & 33.0 & 0.0 & 4.0 & 10.0 & 15.0 \\ \text { PORTO_6 } & 46.0 & 51.0 & 36.0 & 61.0 & 28.0 & 0.0 & 6.0 & 11.0 \\ \text { PORTO_7 } & 40.0 & 45.0 & 30.0 & 55.0 & 22.0 & 64.0 & 0.0 & 5.0 \\ \text { PORTO_8 } & 35.0 & 40.0 & 25.0 & 50.0 & 17.0 & 59.0 & 65.0 & 0.0 \\ \text { i } & & & & & & & & \end{array}$

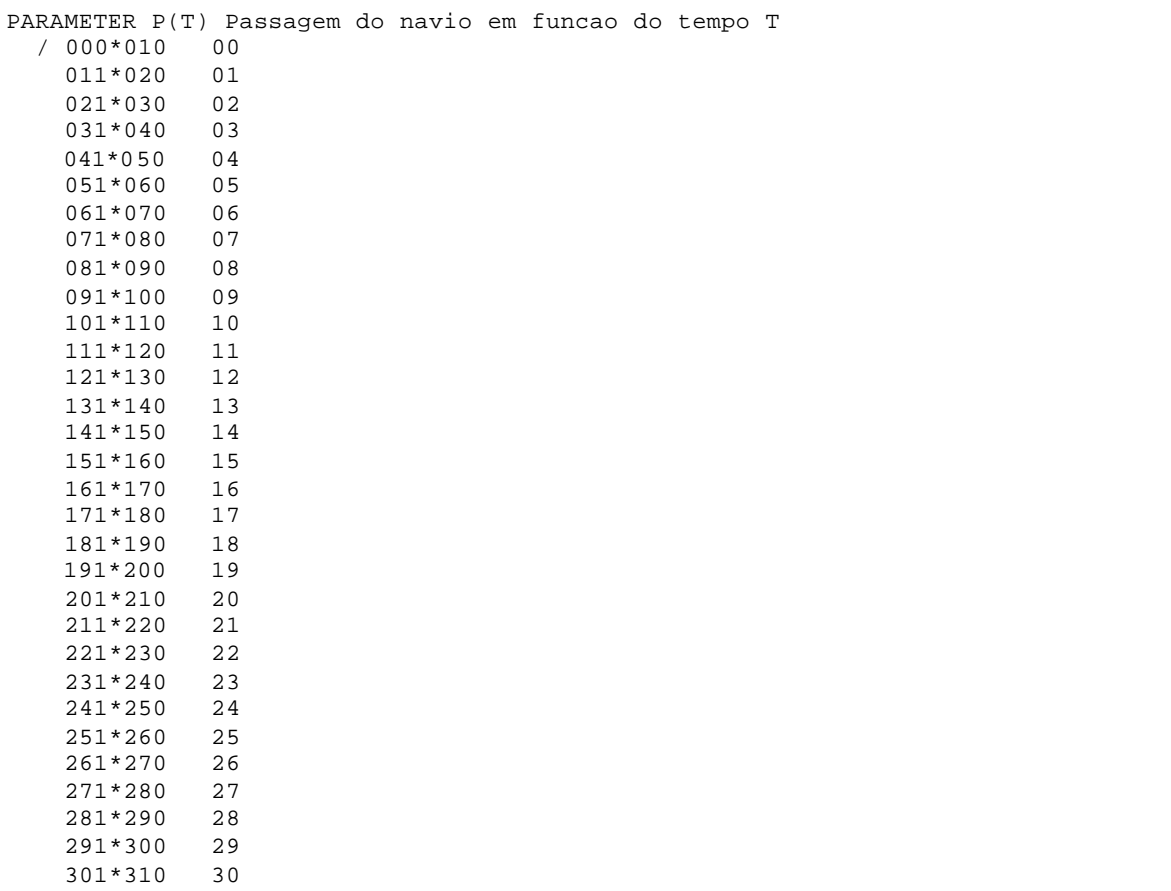




$\begin{array}{ll}311 * 320 & 31 \\ 321 * 330 & 32 \\ 331 * 340 & 33 \\ 341 * 350 & 34 \\ 351 * 360 & 35 \\ 361 * 370 & 36\end{array}$

\begin{tabular}{llllllllll} 
TABLE & LAMB $($ A, I $)$ & Taxa de & retorno dos & \multicolumn{2}{l}{ conteineres aos portos } \\
A01 & PORTO_1 & PORTO_2 & PORTO_3 & PORTO_4 & PORTO_5 & PORTO_6 & PORTO_7 & PORTO_8 \\
A01 & 0.02 & 0.02 & 0.02 & 0.02 & 0.02 & 0.02 & 0.02 & 0.02 \\
A02 & 0.05 & 0.05 & 0.05 & 0.05 & 0.05 & 0.05 & 0.05 & 0.05 \\
A03 & 0.08 & 0.08 & 0.08 & 0.08 & 0.08 & 0.08 & 0.08 & 0.08 \\
A04 & 0.11 & 0.11 & 0.11 & 0.11 & 0.11 & 0.11 & 0.11 & 0.11 \\
A05 & 0.13 & 0.13 & 0.13 & 0.13 & 0.13 & 0.13 & 0.13 & 0.13 \\
A06 & 0.17 & 0.17 & 0.17 & 0.17 & 0.17 & 0.17 & 0.17 & 0.17 \\
A07 & 0.14 & 0.14 & 0.14 & 0.14 & 0.14 & 0.14 & 0.14 & 0.14 \\
A08 & 0.12 & 0.12 & 0.12 & 0.12 & 0.12 & 0.12 & 0.12 & 0.12 \\
A09 & 0.09 & 0.09 & 0.09 & 0.09 & 0.09 & 0.09 & 0.09 & 0.09 \\
A10 & 0.06 & 0.06 & 0.06 & 0.06 & 0.06 & 0.06 & 0.06 & 0.06 \\
A11 & 0.03 & 0.03 & 0.03 & 0.03 & 0.03 & 0.03 & 0.03 & 0.03
\end{tabular}

TABLE DS (I, J, T) Demanda de conteineres cheios no sentido sul

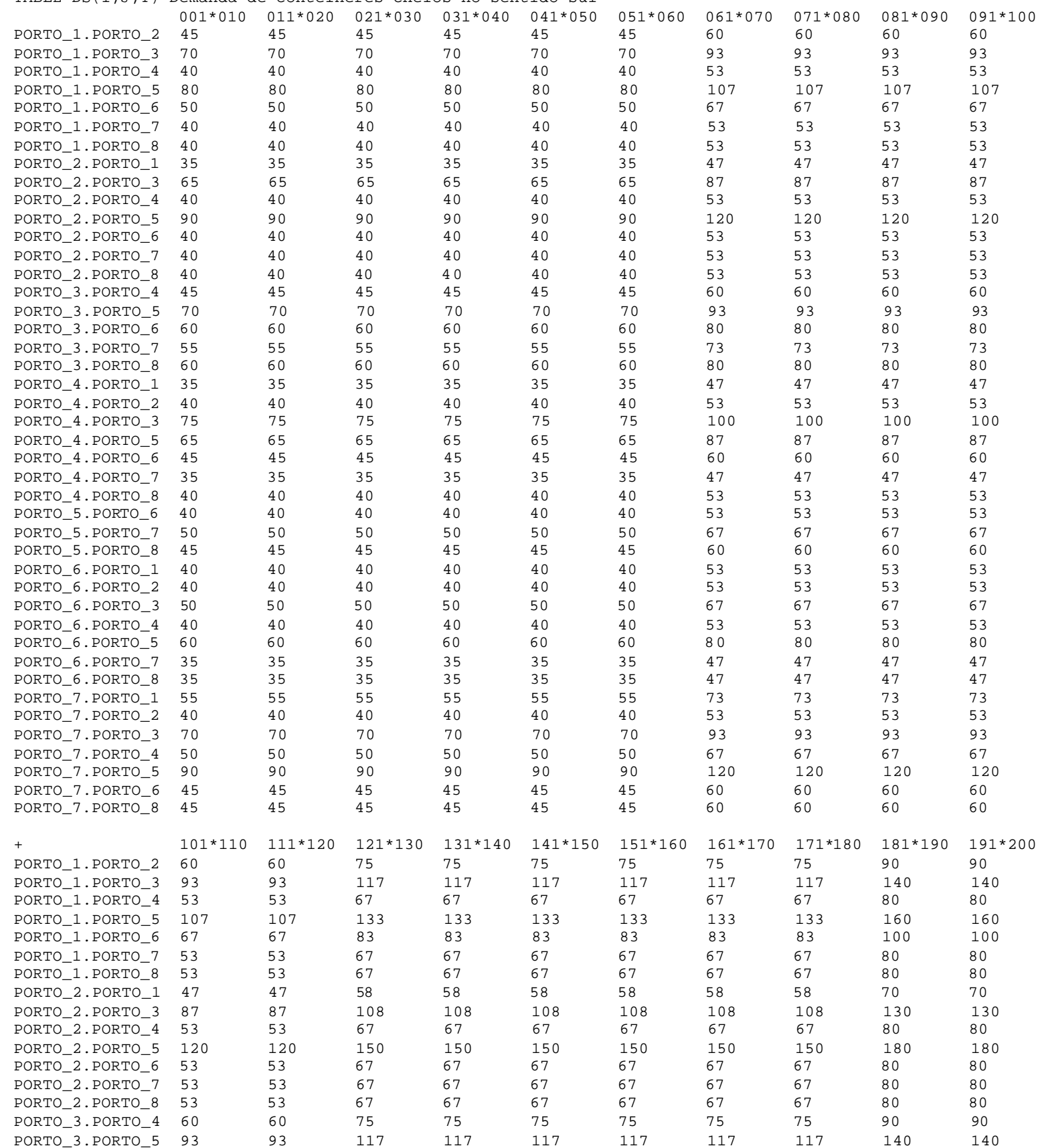




\begin{tabular}{|c|c|c|c|c|c|c|c|c|c|c|}
\hline PORTO_3.PORTO_6 & 80 & 80 & 100 & 100 & 100 & 100 & 100 & 100 & 120 & 120 \\
\hline PORTO_3.PORTO_7 & 73 & 73 & 92 & 92 & 92 & 92 & 92 & 92 & 110 & 110 \\
\hline PORTO_3.PORTO_8 & 80 & 80 & 100 & 100 & 100 & 100 & 100 & 100 & 120 & 120 \\
\hline PORTO_4.PORTO_1 & 47 & 47 & 58 & 58 & 58 & 58 & 58 & 58 & 70 & 70 \\
\hline PORTO_4.PORTO_2 & 53 & 53 & 67 & 67 & 67 & 67 & 67 & 67 & 80 & 80 \\
\hline PORTO_4.PORTO_3 & 100 & 100 & 125 & 125 & 125 & 125 & 125 & 125 & 150 & 150 \\
\hline PORTO_4.PORTO_5 & 87 & 87 & 108 & 108 & 108 & 108 & 108 & 108 & 130 & 130 \\
\hline PORTO_4.PORTO_6 & 60 & 60 & 75 & 75 & 75 & 75 & 75 & 75 & 90 & 90 \\
\hline PORTO_4.PORTO_7 & 47 & 47 & 58 & 58 & 58 & 58 & 58 & 58 & 70 & 70 \\
\hline PORTO_4.PORTO_8 & 53 & 53 & 67 & 67 & 67 & 67 & 67 & 67 & 80 & 80 \\
\hline PORTO_5.PORTO_6 & 53 & 53 & 67 & 67 & 67 & 67 & 67 & 67 & 80 & 80 \\
\hline PORTO_5.PORTO_7 & 67 & 67 & 83 & 83 & 83 & 83 & 83 & 83 & 100 & 100 \\
\hline PORTO_5.PORTO_8 & 60 & 60 & 75 & 75 & 75 & 75 & 75 & 75 & 90 & 90 \\
\hline PORTO_6.PORTO_1 & 53 & 53 & 67 & 67 & 67 & 67 & 67 & 67 & 80 & 80 \\
\hline PORTO_6.PORTO_2 & 53 & 53 & 67 & 67 & 67 & 67 & 67 & 67 & 80 & 80 \\
\hline PORTO_6.PORTO_3 & 67 & 67 & 83 & 83 & 83 & 83 & 83 & 83 & 100 & 100 \\
\hline PORTO_6.PORTO_4 & 53 & 53 & 67 & 67 & 67 & 67 & 67 & 67 & 80 & 80 \\
\hline PORTO_6.PORTO_5 & 80 & 80 & 100 & 100 & 100 & 100 & 100 & 100 & 120 & 120 \\
\hline PORTO_6.PORTO_7 & 47 & 47 & 58 & 58 & 58 & 58 & 58 & 58 & 70 & 70 \\
\hline PORTO_6.PORTO_8 & 47 & 47 & 58 & 58 & 58 & 58 & 58 & 58 & 70 & 70 \\
\hline PORTO_7.PORTO_1 & 73 & 73 & 92 & 92 & 92 & 92 & 92 & 92 & 110 & 110 \\
\hline PORTO_7.PORTO_2 & 53 & 53 & 67 & 67 & 67 & 67 & 67 & 67 & 80 & 80 \\
\hline PORTO_7.PORTO_3 & 93 & 93 & 117 & 117 & 117 & 117 & 117 & 117 & 140 & 140 \\
\hline PORTO_7.PORTO_4 & 67 & 67 & 83 & 83 & 83 & 83 & 83 & 83 & 100 & 100 \\
\hline PORTO_7.PORTO_5 & 120 & 120 & 150 & 150 & 150 & 150 & 150 & 150 & 180 & 180 \\
\hline PORTO_7.PORTO_6 & 60 & 60 & 75 & 75 & 75 & 75 & 75 & 75 & 90 & 90 \\
\hline PORTO_7.PORTO_8 & 60 & 60 & 75 & 75 & 75 & 75 & 75 & 75 & 90 & 90 \\
\hline+ & $201 * 210$ & $211 * 220$ & $221 * 230$ & $231 * 240$ & $241 * 250$ & $251 * 260$ & $261 * 270$ & $271 * 280$ & $281 * 290$ & $291 * 300$ \\
\hline PORTO_1.PORTO_2 & 90 & 90 & 90 & 90 & 90 & 68 & 68 & 68 & 68 & 68 \\
\hline PORTO_1.PORTO_3 & 140 & 140 & 140 & 140 & 140 & 105 & 105 & 105 & 105 & 105 \\
\hline PORTO_1.PORTO_4 & 80 & 80 & 80 & 80 & 80 & 60 & 60 & 60 & 60 & 60 \\
\hline PORTO_1.PORTO_5 & 160 & 160 & 160 & 160 & 160 & 120 & 120 & 120 & 120 & 120 \\
\hline PORTO_1.PORTO_6 & 100 & 100 & 100 & 100 & 100 & 75 & 75 & 75 & 75 & 75 \\
\hline PORTO_1.PORTO_7 & 80 & 80 & 80 & 80 & 80 & 60 & 60 & 60 & 60 & 60 \\
\hline PORTO_1.PORTO_8 & 80 & 80 & 80 & 80 & 80 & 60 & 60 & 60 & 60 & 60 \\
\hline PORTO_2.PORTO_1 & 70 & 70 & 70 & 70 & 70 & 53 & 53 & 53 & 53 & 53 \\
\hline PORTO_2.PORTO_3 & 130 & 130 & 130 & 130 & 130 & 98 & 98 & 98 & 98 & 98 \\
\hline PORTO_2.PORTO_4 & 80 & 80 & 80 & 80 & 80 & 60 & 60 & 60 & 60 & 60 \\
\hline PORTO_2.PORTO_5 & 180 & 180 & 180 & 180 & 180 & 135 & 135 & 135 & 135 & 135 \\
\hline PORTO_2.PORTO_6 & 80 & 80 & 80 & 80 & 80 & 60 & 60 & 60 & 60 & 60 \\
\hline PORTO_2.PORTO_7 & 80 & 80 & 80 & 80 & 80 & 60 & 60 & 60 & 60 & 60 \\
\hline PORTO_2.PORTO_8 & 80 & 80 & 80 & 80 & 80 & 60 & 60 & 60 & 60 & 60 \\
\hline PORTO_3.PORTO_4 & 90 & 90 & 90 & 90 & 90 & 68 & 68 & 68 & 68 & 68 \\
\hline PORTO_3.PORTO_5 & 140 & 140 & 140 & 140 & 140 & 105 & 105 & 105 & 105 & 105 \\
\hline PORTO_3.PORTO_6 & 120 & 120 & 120 & 120 & 120 & 90 & 90 & 90 & 90 & 90 \\
\hline PORTO_3.PORTO_7 & 110 & 110 & 110 & 110 & 110 & 83 & 83 & 83 & 83 & 83 \\
\hline PORTO_3.PORTO_8 & 120 & 120 & 120 & 120 & 120 & 90 & 90 & 90 & 90 & 90 \\
\hline PORTO_4.PORTO_1 & 70 & 70 & 70 & 70 & 70 & 53 & 53 & 53 & 53 & 53 \\
\hline PORTO_4.PORTO_2 & 80 & 80 & 80 & 80 & 80 & 60 & 60 & 60 & 60 & 60 \\
\hline PORTO_4.PORTO_3 & 150 & 150 & 150 & 150 & 150 & 113 & 113 & 113 & 113 & 113 \\
\hline PORTO_4.PORTO_5 & 130 & 130 & 130 & 130 & 130 & 98 & 98 & 98 & 98 & 98 \\
\hline PORTO_4.PORTO_6 & 90 & 90 & 90 & 90 & 90 & 68 & 68 & 68 & 68 & 68 \\
\hline PORTO_4.PORTO_7 & 70 & 70 & 70 & 70 & 70 & 53 & 53 & 53 & 53 & 53 \\
\hline PORTO_4.PORTO_8 & 80 & 80 & 80 & 80 & 80 & 60 & 60 & 60 & 60 & 60 \\
\hline PORTO_5.PORTO_6 & 80 & 80 & 80 & 80 & 80 & 60 & 60 & 60 & 60 & 60 \\
\hline PORTO_5.PORTO_7 & 100 & 100 & 100 & 100 & 100 & 75 & 75 & 75 & 75 & 75 \\
\hline PORTO_5.PORTO_8 & 90 & 90 & 90 & 90 & 90 & 68 & 68 & 68 & 68 & 68 \\
\hline PORTO_6.PORTO_1 & 80 & 80 & 80 & 80 & 80 & 60 & 60 & 60 & 60 & 60 \\
\hline PORTO_6.PORTO_2 & 80 & 80 & 80 & 80 & 80 & 60 & 60 & 60 & 60 & 60 \\
\hline PORTO_6.PORTO_3 & 100 & 100 & 100 & 100 & 100 & 75 & 75 & 75 & 75 & 75 \\
\hline PORTO_6.PORTO_4 & 80 & 80 & 80 & 80 & 80 & 60 & 60 & 60 & 60 & 60 \\
\hline PORTO_6.PORTO_5 & 120 & 120 & 120 & 120 & 120 & 90 & 90 & 90 & 90 & 90 \\
\hline PORTO_6.PORTO_7 & 70 & 70 & 70 & 70 & 70 & 53 & 53 & 53 & 53 & 53 \\
\hline PORTO_6.PORTO_8 & 70 & 70 & 70 & 70 & 70 & 53 & 53 & 53 & 53 & 53 \\
\hline PORTO_7.PORTO_1 & 110 & 110 & 110 & 110 & 110 & 83 & 83 & 83 & 83 & 83 \\
\hline PORTO_7.PORTO_2 & 80 & 80 & 80 & 80 & 80 & 60 & 60 & 60 & 60 & 60 \\
\hline PORTO_7.PORTO_3 & 140 & 140 & 140 & 140 & 140 & 105 & 105 & 105 & 105 & 105 \\
\hline PORTO_7.PORTO_4 & 100 & 100 & 100 & 100 & 100 & 75 & 75 & 75 & 75 & 75 \\
\hline PORTO_7.PORTO_5 & 180 & 180 & 180 & 180 & 180 & 135 & 135 & 135 & 135 & 135 \\
\hline PORTO_7.PORTO_6 & 90 & 90 & 90 & 90 & 90 & 68 & 68 & 68 & 68 & 68 \\
\hline PORTO_7.PORTO_8 & 90 & 90 & 90 & 90 & 90 & 68 & 68 & 68 & 68 & 68 \\
\hline+ & $301 * 310$ & $311 * 320$ & $321 * 330$ & $331 * 340$ & $341 * 350$ & $351 * 360$ & $361 * 370$ & & & \\
\hline PORTO_1.PORTO_2 & 68 & 45 & 45 & 45 & 45 & 45 & 45 & & & \\
\hline PORTO_1.PORTO_3 & 105 & 70 & 70 & 70 & 70 & 70 & 70 & & & \\
\hline PORTO_1.PORTO_4 & 60 & 40 & 40 & 40 & 40 & 40 & 40 & & & \\
\hline PORTO_1.PORTO_5 & 120 & 80 & 80 & 80 & 80 & 80 & 80 & & & \\
\hline PORTO_1.PORTO_6 & 75 & 50 & 50 & 50 & 50 & 50 & 50 & & & \\
\hline PORTO_1.PORTO_7 & 60 & 40 & 40 & 40 & 40 & 40 & 40 & & & \\
\hline PORTO_1.PORTO_8 & 60 & 40 & 40 & 40 & 40 & 40 & 40 & & & \\
\hline PORTO_2.PORTO_1 & 53 & 35 & 35 & 35 & 35 & 35 & 35 & & & \\
\hline PORTO_2.PORTO_3 & 98 & 65 & 65 & 65 & 65 & 65 & 65 & & & \\
\hline PORTO_2.PORTO_4 & 60 & 40 & 40 & 40 & 40 & 40 & 40 & & & \\
\hline PORTO_2.PORTO_5 & 135 & 90 & 90 & 90 & 90 & 90 & 90 & & & \\
\hline PORTO_2.PORTO_6 & 60 & 40 & 40 & 40 & 40 & 40 & 40 & & & \\
\hline
\end{tabular}




$\begin{array}{llllllll}\text { PORTO_2.PORTO_7 } & 60 & 40 & 40 & 40 & 40 & 40 & 40 \\ \text { PORTO_2.PORTO_8 } & 60 & 40 & 40 & 40 & 40 & 40 & 40 \\ \text { PORTO_3.PORTO_4 } & 68 & 45 & 45 & 45 & 45 & 45 & 45 \\ \text { PORTO_3.PORTO_5 } & 105 & 70 & 70 & 70 & 70 & 70 & 70 \\ \text { PORTO_3.PORTO_6 } & 90 & 60 & 60 & 60 & 60 & 60 & 60 \\ \text { PORTO_3.PORTO_7 } & 83 & 55 & 55 & 55 & 55 & 55 & 55 \\ \text { PORTO_3.PORTO_8 } & 90 & 60 & 60 & 60 & 60 & 60 & 60 \\ \text { PORTO_4.PORTO_1 } & 53 & 35 & 35 & 35 & 35 & 35 & 35 \\ \text { PORTO_4.PORTO_2 } & 60 & 40 & 40 & 40 & 40 & 40 & 40 \\ \text { PORTO_4.PORTO_3 } & 113 & 75 & 75 & 75 & 75 & 75 & 75 \\ \text { PORTO_4.PORTO_5 } & 98 & 65 & 65 & 65 & 65 & 65 & 65 \\ \text { PORTO_4.PORTO_6 } & 68 & 45 & 45 & 45 & 45 & 45 & 45 \\ \text { PORTO_4.PORTO_7 } & 53 & 35 & 35 & 35 & 35 & 35 & 35 \\ \text { PORTO_4.PORTO_8 } & 60 & 40 & 40 & 40 & 40 & 40 & 40 \\ \text { PORTO_5.PORTO_6 } & 60 & 40 & 40 & 40 & 40 & 40 & 40 \\ \text { PORTO_5.PORTO_7 } & 75 & 50 & 50 & 50 & 50 & 50 & 50 \\ \text { PORTO_5.PORTO_8 } & 68 & 45 & 45 & 45 & 45 & 45 & 45 \\ \text { PORTO_6.PORTO_1 } & 60 & 40 & 40 & 40 & 40 & 40 & 40 \\ \text { PORTO_6.PORTO_2 } & 60 & 40 & 40 & 40 & 40 & 40 & 40 \\ \text { PORTO_6.PORTO_3 } & 75 & 50 & 50 & 50 & 50 & 50 & 50 \\ \text { PORTO_6.PORTO_4 } & 60 & 40 & 40 & 40 & 40 & 40 & 40 \\ \text { PORTO_6.PORTO_5 } & 90 & 60 & 60 & 60 & 60 & 60 & 60 \\ \text { PORTO_6.PORTO_7 } & 53 & 35 & 35 & 35 & 35 & 35 & 35 \\ \text { PORTO_6.PORTO_8 } & 53 & 35 & 35 & 35 & 35 & 35 & 35 \\ \text { PORTO_7.PORTO_1 } & 83 & 55 & 55 & 55 & 55 & 55 & 55 \\ \text { PORTO_7.PORTO_2 } & 60 & 40 & 40 & 40 & 40 & 40 & 40 \\ \text { PORTO_7.PORTO_3 } & 105 & 70 & 70 & 70 & 70 & 70 & 70 \\ \text { PORTO_7.PORTO_4 } & 75 & 50 & 50 & 50 & 50 & 50 & 50 \\ \text { PORTO_7.PORTO_5 } & 135 & 90 & 90 & 90 & 90 & 90 & 90 \\ \text { PORTO_7.PORTO_6 } & 68 & 45 & 45 & 45 & 45 & 45 & 45 \\ \text { PORTO_7.PORTO_8 } & 68 & 45 & 45 & 45 & 45 & 45 & 45 \\ \text {; } & & & & & & & \end{array}$

TABLE DN $(I, J, T)$ Demanda de conteineres cheios no sentido norte

\begin{tabular}{|c|c|c|c|c|c|c|c|c|c|c|}
\hline & $001 * 010$ & $011 * 020$ & $021 * 030$ & $031 * 040$ & $041 * 050$ & $051 * 060$ & $061 * 070$ & $071 * 080$ & $081 * 090$ & $091 * 100$ \\
\hline PORTO_3.PORTO_2 & 45 & 45 & 45 & 45 & 45 & 45 & 60 & 60 & 60 & 60 \\
\hline PORTO_5.PORTO_1 & 60 & 60 & 60 & 60 & 60 & 60 & 80 & 80 & 80 & 80 \\
\hline PORTO_5.PORTO_2 & 55 & 55 & 55 & 55 & 55 & 55 & 73 & 73 & 73 & 73 \\
\hline PORTO_5.PORTO_4 & 45 & 45 & 45 & 45 & 45 & 45 & 60 & 60 & 60 & 60 \\
\hline PORTO_8.PORTO_1 & 40 & 40 & 40 & 40 & 40 & 40 & 53 & 53 & 53 & 53 \\
\hline PORTO_8.PORTO_2 & 35 & 35 & 35 & 35 & 35 & 35 & 47 & 47 & 47 & 47 \\
\hline PORTO_8.PORTO_5 & 80 & 80 & 80 & 80 & 80 & 80 & 107 & 107 & 107 & 107 \\
\hline PORTO_8.PORTO_6 & 45 & 45 & 45 & 45 & 45 & 45 & 60 & 60 & 60 & 60 \\
\hline PORTO_8.PORTO_7 & 45 & 45 & 45 & 45 & 45 & 45 & 60 & 60 & 60 & 60 \\
\hline+ & $101 * 110$ & $111 * 120$ & $121 * 130$ & $131 * 140$ & $141 * 150$ & $151 * 160$ & $161 * 170$ & $171 * 180$ & $181 * 190$ & $191 * 200$ \\
\hline PORTO_3.PORTO_1 & 67 & 67 & 83 & 83 & 83 & 83 & 83 & 83 & 100 & 100 \\
\hline PORTO_3.PORTO_2 & 60 & 60 & 75 & 75 & 75 & 75 & 75 & 75 & 90 & 90 \\
\hline PORTO_8.PORTO_2 & 47 & 47 & 58 & 58 & 58 & 58 & 58 & 58 & 70 & 70 \\
\hline PORTO_8.PORTO_3 & 100 & 100 & 125 & 125 & 125 & 125 & 125 & 125 & 150 & 150 \\
\hline PORTO_8.PORTO_4 & 73 & 73 & 92 & 92 & 92 & 92 & 92 & 92 & 110 & 110 \\
\hline PORTO_8.PORTO_5 & 107 & 107 & 133 & 133 & 133 & 133 & 133 & 133 & 160 & 160 \\
\hline PORTO_8.PORTO_6 & 60 & 60 & 75 & 75 & 75 & 75 & 75 & 75 & 90 & 90 \\
\hline PORTO_8.PORTO_7 & 60 & 60 & 75 & 75 & 75 & 75 & 75 & 75 & 90 & 90 \\
\hline+ & $201 * 210$ & $211 * 220$ & $221 * 230$ & $231 * 240$ & $241 * 250$ & $251 * 260$ & $261 * 270$ & $271 \star 280$ & $281 * 290$ & $291 * 300$ \\
\hline PORTO_3.PORTO_1 & 100 & 100 & 100 & 100 & 100 & 75 & 75 & 75 & 75 & 75 \\
\hline PORTO_3.PORTO_2 & 90 & 90 & 90 & 90 & 90 & 68 & 68 & 68 & 68 & 68 \\
\hline PORTO_5.PORTO_1 & 120 & 120 & 120 & 120 & 120 & 90 & 90 & 90 & 90 & 90 \\
\hline PORTO_5.PORTO_2 & 110 & 110 & 110 & 110 & 110 & 83 & 83 & 83 & 83 & 83 \\
\hline PORTO_5.PORTO_3 & 130 & 130 & 130 & 130 & 130 & 98 & 98 & 98 & 98 & 98 \\
\hline+ & $301 * 310$ & $311 * 320$ & $321 * 330$ & $331 * 340$ & $341 * 350$ & $351 * 360$ & $361 * 370$ & & & \\
\hline PORTO_3.PORTO_1 & 75 & 50 & 50 & 50 & 50 & 50 & 50 & & & \\
\hline PORTO_3.PORTO_2 & 68 & 45 & 45 & 45 & 45 & 45 & 45 & & & \\
\hline PORTO_5.PORTO_1 & 90 & 60 & 60 & 60 & 60 & 60 & 60 & & & \\
\hline PORTO_5.PORTO_2 & 83 & 55 & 55 & 55 & 55 & 55 & 55 & & & \\
\hline PORTO_5.PORTO_3 & 98 & 65 & 65 & 65 & 65 & 65 & 65 & & & \\
\hline PORTO 5.PORTO 4 & 68 & 45 & 45 & 45 & 45 & 45 & 45 & & & \\
\hline
\end{tabular}




$\begin{array}{llllllll}\text { PORTO_8.PORTO_1 } & 60 & 40 & 40 & 40 & 40 & 40 & 40 \\ \text { PORTO_8.PORTO_2 } & 53 & 35 & 35 & 35 & 35 & 35 & 35 \\ \text { PORTO_8.PORTO_3 } & 113 & 75 & 75 & 75 & 75 & 75 & 75 \\ \text { PORTO_8.PORTO_4 } & 83 & 55 & 55 & 55 & 55 & 55 & 55 \\ \text { PORTO_8.PORTO_5 } & 120 & 80 & 80 & 80 & 80 & 80 & 80 \\ \text { PORTO_8.PORTO_6 } & 68 & 45 & 45 & 45 & 45 & 45 & 45 \\ \text { PORTO_8.PORTO_7 } & 68 & 45 & 45 & 45 & 45 & 45 & 45 \\ \text { P } & & & & & & \end{array}$

;

TABLE TF(I,N) Tempo do primeiro navio chegar ao porto na primeira viagem

$\begin{array}{llllllll} & \text { N01 } & \text { N02 } & \text { N03 } & \text { N04 } & \text { N05 } & \text { N06 } & \text { N07 } \\ \text { PORTO_1 } & 1 & 61 & 51 & 41 & 31 & 21 & 11 \\ \text { PORTO_2 } & 6 & 66 & 56 & 46 & 36 & 26 & 16 \\ \text { PORTO_3 } & 12 & 2 & 41 & 31 & 21 & 11 & 1 \\ \text { PORTO_4 } & 16 & 6 & 66 & 56 & 46 & 36 & 26 \\ \text { PORTO_5 } & 21 & 11 & 1 & 23 & 13 & 3 & 31 \\ \text { PORTO_6 } & 25 & 15 & 5 & 65 & 55 & 45 & 35 \\ \text { PORTO_7 } & 31 & 21 & 11 & 1 & 61 & 51 & 41 \\ \text { PORTO_8 } & 36 & 26 & 16 & 6 & 66 & 56 & 46\end{array}$

TABLE DSN(I,N) Demanda de cada navio no tempo inicial carga - SUL

$\begin{array}{llllllll} & \text { N01 } & \text { N02 } & \text { N03 } & \text { N04 } & \text { N05 } & \text { N06 } & \text { N07 } \\ \text { PORTO_1 } & 165 & 35 & 70 & 110 & 165 & 165 & 165 \\ \text { PORTO_2 } & 120 & 0 & 40 & 80 & 120 & 120 & 120 \\ \text { PORTO_3 } & 0 & 135 & 75 & 125 & 195 & 195 & 195 \\ \text { PORTO_4 } & 90 & 170 & 0 & 40 & 90 & 90 & 90 \\ \text { PORTO_5 } & 0 & 170 & 305 & 60 & 150 & 150 & 0 \\ \text { PORTO_6 } & 45 & 135 & 240 & 0 & 45 & 45 & 45 \\ \text { PORTO_7 } & 0 & 80 & 170 & 255 & 0 & 0 & 0 \\ \text { PORTO_8 } & 0 & 80 & 180 & 260 & 0 & 0 & 0\end{array}$

;

TABLE DNN(I,N) Demanda de cada navio no tempo inicial carga - NORTE

$\begin{array}{llllllll} & \text { N01 } & \text { N02 } & \text { N03 } & \text { N04 } & \text { N05 } & \text { N06 } & \text { N07 } \\ \text { PORTO_1 } & 150 & 0 & 0 & 0 & 40 & 40 & 100 \\ \text { PORTO_2 } & 135 & 0 & 0 & 0 & 35 & 35 & 90 \\ \text { PORTO_3 } & 0 & 0 & 0 & 0 & 75 & 75 & 140 \\ \text { PORTO_4 } & 100 & 100 & 0 & 0 & 55 & 55 & 100 \\ \text { PORTO_5 } & 0 & 0 & 0 & 0 & 80 & 80 & 0 \\ \text { PORTO_6 } & 45 & 45 & 45 & 0 & 45 & 45 & 45 \\ \text { PORTO_7 } & 45 & 45 & 45 & 45 & 45 & 45 & 45 \\ \text { PORTO_8 } & 0 & 0 & 0 & 0 & 0 & 0 & 0\end{array}$

PARAMETER TUPS(I,T) Ultima passagem de um navio pelo Porto I no sentido sul; LOOP (I\$ ( ORD (I) NE 8 ),

LOOP $(T$,

IF $((\mathrm{ORD}(\mathrm{T}) \mathrm{GE} \mathrm{TS}(\mathrm{I})+\mathrm{P}(\mathrm{T}) * \mathrm{IN}+1)$

$\operatorname{TUPS}(I, T)=T S(I)+P(T) * I N$

ELSE

$I F((T S(I)+(P(T)-1) * I N \quad L T 0)$ $\operatorname{TUPS}(I, T)=\operatorname{TS}(I)$

ELSE

)

$\operatorname{TUPS}(I, T)=\operatorname{TS}(I)+(P(T)-1) * I N ;$

$$
\text { ) i }
$$

PARAMETER TUPN(I,T) Ultima passagem de um navio pelo Porto I no sentido norte; LOOP (I\$( (ORD (I) EQ 3) OR (ORD (I) EQ 5) OR (ORD (I) EQ 8)),

PARAMETER TPROXS(I,T) Proxima passagem de um navio pelo Porto I no sentido sul; LOOP $(T$,

LOOP ( I,

$I F((O R D(T) \quad L T T S(I)+P(T) * I N+1)$ $\operatorname{TPROXS}(I, T)=\mathrm{TS}(I)+P(T) * I N$; 


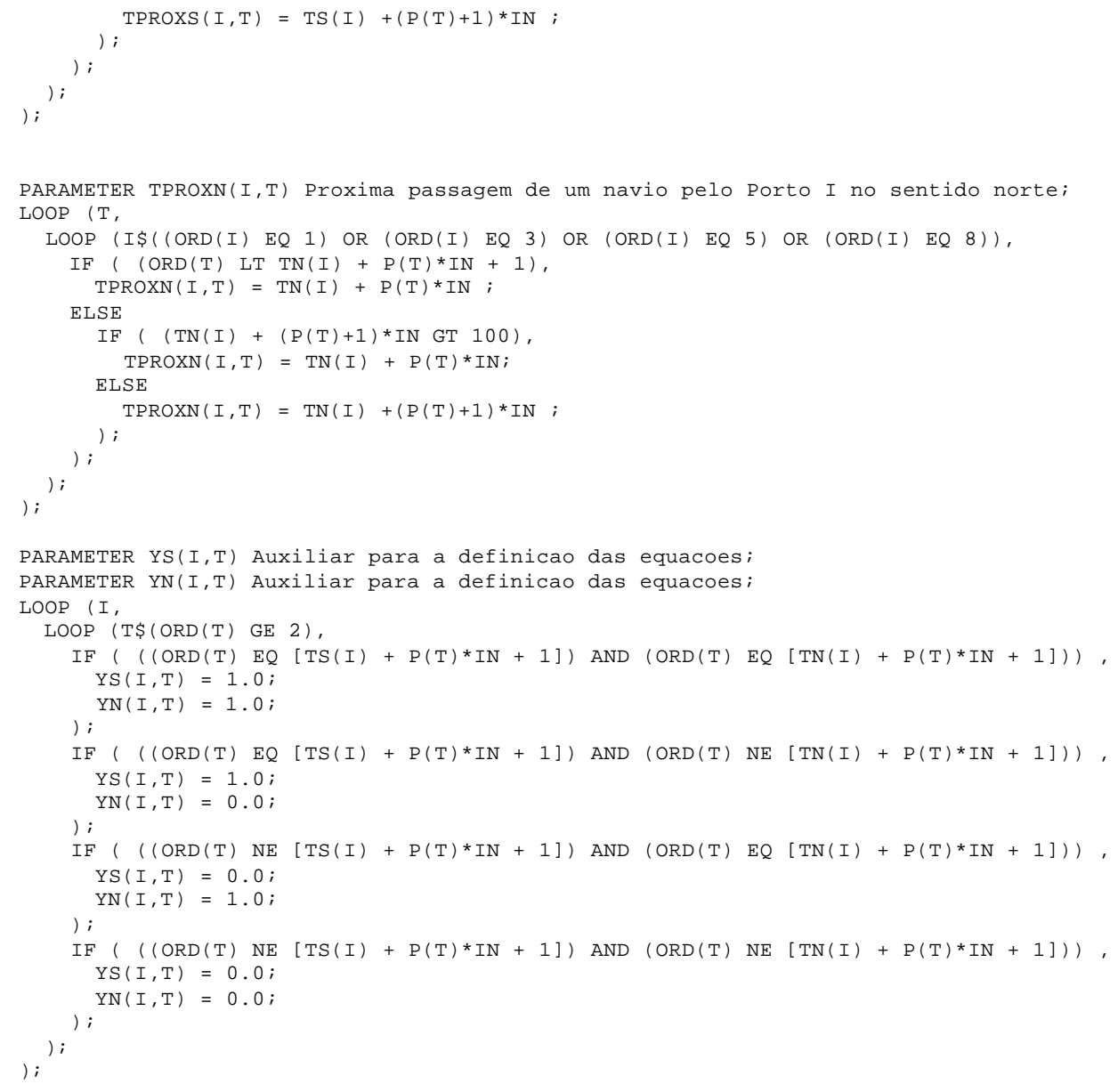




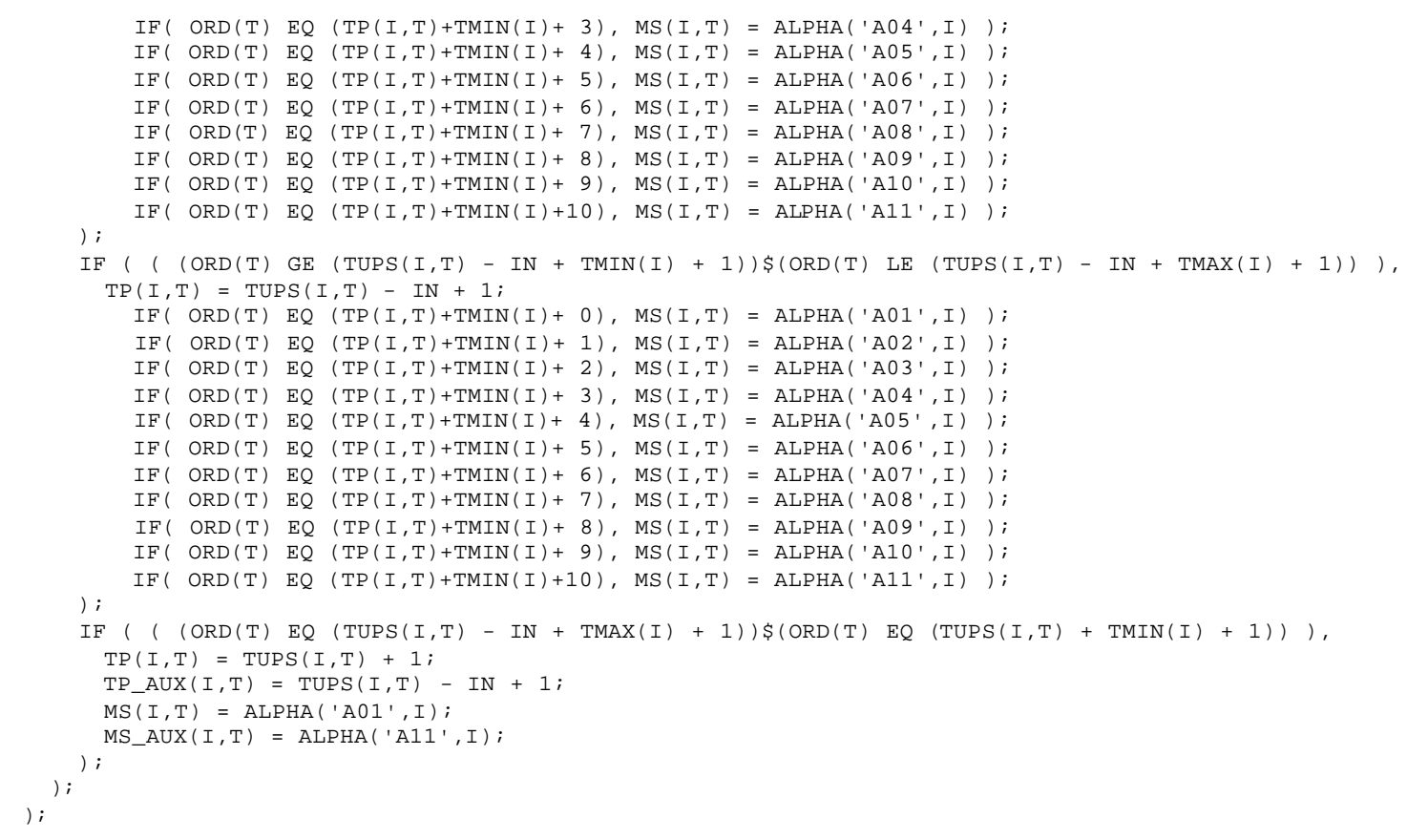

PARAMETER MN(I,T) Multiplicador que define a chegada dos conteineres vazios ao Estoque; PARAMETER MN_AUX(I,T) Multiplicador que define a chegada dos conteineres vazios ao Estoque; PARAMETER TG(I,T); PARAMETER TG_AUX $(I, T)$;

LOOP (I,

LOOP $(T$,

IF ( $(\mathrm{ORD}(\mathrm{T}) \operatorname{LT}(\operatorname{TUPN}(I, T)+\operatorname{TMIN}(I)+1))$,

IF $(\operatorname{TUPN}(I, T)-I N)$ LE 0 ,

$\operatorname{TG}(I, T)=\operatorname{TUPN}(\mathrm{I}, \mathrm{T})+1$;

$\operatorname{IF}\left(\operatorname{ORD}(T) \quad \mathrm{EQ}(\mathrm{TG}(I, T)+\operatorname{TMIN}(I)+0), \operatorname{MN}(I, T)=\operatorname{ALPHA}\left({ }^{\prime} \mathrm{A} 01^{\prime}, I\right)\right)$; $\operatorname{IF}(\operatorname{ORD}(T) \quad \mathrm{EQ}(\mathrm{TG}(I, T)+\operatorname{TMIN}(I)+1), \operatorname{MN}(I, T)=\operatorname{ALPHA}(' A 02 ', I))$; $\operatorname{IF}\left(\operatorname{ORD}(T) \mathrm{EQ}(\mathrm{TG}(I, T)+\operatorname{TMIN}(I)+2), \operatorname{MN}(I, T)=\operatorname{ALPHA}\left({ }^{\prime} \mathrm{A} 03^{\prime}, I\right)\right)$; $\operatorname{IF}\left(\mathrm{ORD}(\mathrm{T}) \mathrm{EQ}(\mathrm{TG}(\mathrm{I}, \mathrm{T})+\mathrm{TMIN}(\mathrm{I})+3), \mathrm{MN}(\mathrm{I}, \mathrm{T})=\operatorname{ALPHA}\left({ }^{\prime} \mathrm{A} 04,, \mathrm{I}\right)\right)$; $\operatorname{IF}\left(\operatorname{ORD}(\mathrm{T}) \mathrm{EQ}(\mathrm{TG}(I, T)+\operatorname{TMIN}(I)+4), \operatorname{MN}(I, T)=\operatorname{ALPHA}\left({ }^{\prime} A 05^{\prime}, I\right)\right)$; $\operatorname{IF}(\operatorname{ORD}(T) \quad \mathrm{EQ}(\mathrm{TG}(I, T)+\operatorname{TMIN}(I)+5), \operatorname{MN}(I, T)=\operatorname{ALPHA}(' A 06 ', I))$ IF ( ORD (T) EQ (TG(I,T) +TMIN $(I)+6), \operatorname{MN}(I, T)=\operatorname{ALPHA}(' A 07 ', I))$; $\operatorname{IF}\left(\operatorname{ORD}(T) \mathrm{EQ}(\mathrm{TG}(I, T)+\operatorname{TMIN}(I)+7), \operatorname{MN}(I, T)=\operatorname{ALPHA}\left(' A 08^{\prime}, I\right)\right)$; $\operatorname{IF}\left(\mathrm{ORD}(\mathrm{T}) \mathrm{EQ}(\mathrm{TG}(\mathrm{I}, \mathrm{T})+\operatorname{TMIN}(\mathrm{I})+8), \mathrm{MN}(\mathrm{I}, \mathrm{T})=\operatorname{ALPHA}\left({ }^{\prime} A 09 ', \mathrm{I}\right)\right)$; $\operatorname{IF}\left(\operatorname{ORD}(\mathrm{T}) \mathrm{EQ}(\mathrm{TG}(\mathrm{I}, \mathrm{T})+\operatorname{TMIN}(\mathrm{I})+9), \operatorname{MN}(\mathrm{I}, \mathrm{T})=\operatorname{ALPHA}\left({ }^{\prime} \mathrm{A} 10^{\prime}, \mathrm{I}\right)\right)$; $\operatorname{IF}\left(\operatorname{ORD}(T) \mathrm{EQ}(\mathrm{TG}(I, T)+\operatorname{TMIN}(I)+10), \operatorname{MN}(I, T)=\operatorname{ALPHA}\left({ }^{\prime} \mathrm{A} 11^{\prime}, I\right)\right)$; ELSE

$\mathrm{TG}(\mathrm{I}, \mathrm{T})=\operatorname{TUPN}(\mathrm{I}, \mathrm{T})-\mathrm{IN}+1 ;$

$\operatorname{IF}\left(\operatorname{ORD}(\mathrm{T}) \mathrm{EQ}(\mathrm{TG}(I, T)+\operatorname{TMIN}(I)+0), \operatorname{MN}(I, T)=\operatorname{ALPHA}\left({ }^{\prime} \mathrm{A} 01^{\prime}, I\right)\right)$; $\operatorname{IF}\left(\operatorname{ORD}(T) \mathrm{EQ}(\mathrm{TG}(I, T)+\operatorname{TMIN}(I)+1), \operatorname{MN}(I, T)=\operatorname{ALPHA}\left({ }^{\prime} \mathrm{T} 02^{\prime}, I\right)\right)$; $\operatorname{IF}\left(\mathrm{ORD}(\mathrm{T}) \mathrm{EQ}(\mathrm{TG}(I, \mathrm{~T})+\operatorname{TMIN}(I)+2), \mathrm{MN}(I, T)=\operatorname{ALPHA}\left({ }^{\prime} \mathrm{A} 03^{\prime}, I\right)\right)$ $\operatorname{IF}\left(\operatorname{ORD}(T) \mathrm{EQ}(\mathrm{TG}(I, T)+\operatorname{TMIN}(I)+3), \operatorname{MN}(I, T)=\operatorname{ALPHA}\left({ }^{\prime} A 04 ', I\right)\right)$; $\operatorname{IF}\left(\mathrm{ORD}(\mathrm{T}) \mathrm{EQ}(\mathrm{TG}(\mathrm{I}, \mathrm{T})+\operatorname{TMIN}(\mathrm{I})+4), \mathrm{MN}(\mathrm{I}, \mathrm{T})=\operatorname{ALPHA}\left({ }^{\prime} \mathrm{A} 05^{\prime}, \mathrm{I}\right)\right)$; $\operatorname{IF}\left(\operatorname{ORD}(\mathrm{T}) \mathrm{EQ}(\mathrm{TG}(\mathrm{I}, \mathrm{T})+\mathrm{TMIN}(\mathrm{I})+5), \operatorname{MN}(\mathrm{I}, \mathrm{T})=\operatorname{ALPHA}\left({ }^{\prime} \mathrm{A} 06^{\prime}, \mathrm{I}\right)\right)$; $\operatorname{IF}\left(\operatorname{ORD}(T)\right.$ EQ $\left.(\mathrm{TG}(I, T)+\operatorname{TMIN}(I)+6), \operatorname{MN}(I, T)=\operatorname{ALPHA}\left({ }^{\prime} \mathrm{A} 07^{\prime}, I\right)\right)$; $\operatorname{IF}(\operatorname{ORD}(T) \quad \mathrm{EQ}(\mathrm{TG}(I, T)+\operatorname{TMIN}(I)+7), \operatorname{MN}(I, T)=A L P H A(' A 08 ', I))$ $\operatorname{IF}\left(\operatorname{ORD}(T) \mathrm{EQ}(\mathrm{TG}(I, T)+\operatorname{TMIN}(I)+8), \operatorname{MN}(I, T)=\operatorname{ALPHA}\left({ }^{\prime} \mathrm{AO} 9 ', I\right)\right)$; $\operatorname{IF}\left(\operatorname{ORD}(\mathrm{T}) \mathrm{EQ}(\mathrm{TG}(\mathrm{I}, \mathrm{T})+\mathrm{TMIN}(\mathrm{I})+9), \mathrm{MN}(\mathrm{I}, \mathrm{T})=\operatorname{ALPHA}\left({ }^{\prime} \mathrm{A} 10^{\prime}, \mathrm{I}\right)\right)$; ) $\operatorname{IF}\left(\operatorname{ORD}(\mathrm{T}) \mathrm{EQ}(\mathrm{TG}(\mathrm{I}, \mathrm{T})+\operatorname{TMIN}(\mathrm{I})+10), \operatorname{MN}(\mathrm{I}, \mathrm{T})=\operatorname{ALPHA}\left({ }^{\prime} \mathrm{A} 11^{\prime}, \mathrm{I}\right)\right)$;

$\operatorname{IF}((\operatorname{ORD}(\mathrm{T}) \mathrm{GE}(\operatorname{TUPN}(I, T)+\operatorname{TMIN}(I)+1)) \$(\mathrm{ORD}(\mathrm{T}) \operatorname{LE}(\operatorname{TUPN}(I, T)+\operatorname{TMAX}(I)+1)))$, $\mathrm{TG}(\mathrm{I}, \mathrm{T})=\operatorname{TUPN}(\mathrm{I}, \mathrm{T})+1$

$\operatorname{IF}(\operatorname{ORD}(T) \operatorname{EQ}(\mathrm{TG}(I, T)+\operatorname{TMIN}(I)+0), \operatorname{MN}(I, T)=\operatorname{ALPHA}(' A 01 ', I))$;

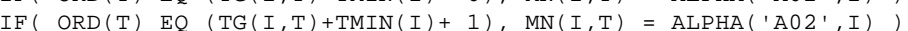
$\operatorname{IF}(\operatorname{ORD}(T)$ EQ $(T G(I, T)+\operatorname{TMIN}(I)+2), \operatorname{MN}(I, T)=\operatorname{ALPHA}(' A 03 ', I))$; $\operatorname{IF}\left(\operatorname{ORD}(\mathrm{T}) \mathrm{EQ}(\mathrm{TG}(I, T)+\operatorname{TMIN}(I)+3), \operatorname{MN}(I, T)=\operatorname{ALPHA}\left({ }^{\prime} \mathrm{A} 04,, I\right)\right)$;

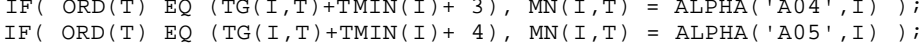
$\operatorname{IF}\left(\operatorname{ORD}(T) \mathrm{EQ}(\mathrm{TG}(I, T)+\operatorname{TMIN}(I)+5), \operatorname{MN}(I, T)=\operatorname{ALPHA}\left({ }^{\prime} A 06^{\prime}, I\right)\right)$; $\operatorname{IF}\left(\operatorname{ORD}(T) \mathrm{EQ}(\mathrm{TG}(I, T)+\operatorname{TMIN}(I)+6), \operatorname{MN}(I, T)=\operatorname{ALPHA}\left({ }^{\prime} \mathrm{A} 07^{\prime}, I\right)\right)$ IF ( ORD (T) EQ (TG (I,T) +TMIN (I) + 7), MN (I,T) = ALPHA ('A08', I) ); $\operatorname{IF}\left(\operatorname{ORD}(T) \mathrm{EQ}(\mathrm{TG}(I, T)+\operatorname{TMIN}(I)+8), \operatorname{MN}(I, T)=\operatorname{ALPHA}\left({ }^{\prime} \mathrm{A} 09^{\prime}, I\right)\right)$, $\operatorname{IF}\left(\operatorname{ORD}(T) \mathrm{EQ}(\mathrm{TG}(I, T)+\operatorname{TMIN}(I)+9), \operatorname{MN}(I, T)=\operatorname{ALPHA}\left({ }^{\prime} \mathrm{A} 10^{\prime}, I\right)\right)$; )$;$ $\operatorname{IF}\left(\operatorname{ORD}(T) \operatorname{EQ}(\mathrm{TG}(I, T)+\operatorname{TMIN}(I)+10), \operatorname{MN}(I, T)=\operatorname{ALPHA}\left({ }^{\prime} \mathrm{A} 11\right.\right.$ ', I $\left.)\right)$;

IF ( ( ORD (T) GE (TUPN (I, T) - IN + TMIN (I) + 1))\$(ORD (T) LE (TUPN (I, T) - IN + TMAX (I) + 1)) ) $T G(I, T)=\operatorname{TUPN}(I, T)-I N+1$

$\operatorname{IF}\left(\operatorname{ORD}(T) \mathrm{EQ}(\mathrm{TG}(I, T)+\operatorname{TMIN}(I)+0), \operatorname{MN}(I, T)=\operatorname{ALPHA}\left({ }^{\prime} \mathrm{A} 01^{\prime}, I\right)\right)$; $\operatorname{IF}\left(\operatorname{ORD}(T) \mathrm{EQ}(\mathrm{TG}(I, T)+\operatorname{TMIN}(I)+1), \operatorname{MN}(I, T)=\operatorname{ALPHA}\left({ }^{\prime} \mathrm{A} 02^{\prime}, I\right)\right)$; 


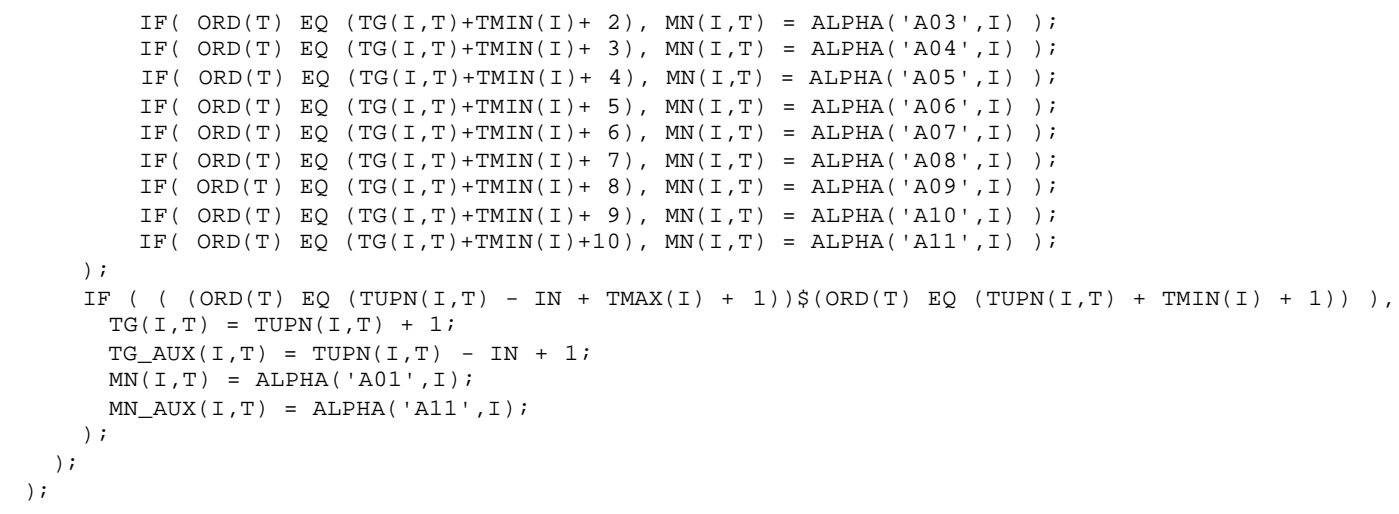

PARAMETER MULT(I, T, TLL) Multiplicador que define a chegada dos conteineres cheios ao Estoque; $\operatorname{MULT}(I, T, T L L) \$(O R D(T) \quad E Q \quad[O R D(T L L)+T M I N(I)+10])=\operatorname{ALPHA}(' A 11$ ', I); $\operatorname{MULT}(I, T, T L L) \$(O R D(T)$ EQ $[O R D(T L L)+T M I N(I)+9])=\operatorname{ALPHA}(' A 10 ', I)$ $\operatorname{MULT}(I, T, T L L) \$(O R D(T) \quad E Q[O R D(T L L)+T M I N(I)+8])=A L P H A(' A 09 ', I)$; $\operatorname{MULT}(I, T, T L L) \$(O R D(T) \quad E O[O R D(T L L)+T M I N(I)+7])=\operatorname{ALPHA}(' A 08$ ', I) $\operatorname{MULT}(I, T, T L L) \$(O R D(T) \quad E Q[O R D(T L L)+T M I N(I)+6])=\operatorname{ALPHA}(' A 07 ', I)$; $\operatorname{MULT}(I, T, T L L) \$(O R D(T)$ EQ $[O R D(T L L)+T M I N(I)+5])=\operatorname{ALPHA}(' A 06 ', I)$ $\operatorname{MULT}(I, T, T L L) \$(O R D(T) \quad E Q \quad[O R D(T L L)+T M I N(I)+4])=\operatorname{ALPHA}\left(' A 05^{\prime}, I\right)$ $\operatorname{MULT}(I, T, T L L) \$(O R D(T)$ EQ [ORD (TLL) +TMIN (I) + 3]) = ALPHA ('A04', I); $\operatorname{MULT}(I, T, T L L) \$(O R D(T) \quad E Q \quad$ ORD $(T L L)+T M I N(I)+2])=\operatorname{ALPHA}\left(' A 03^{\prime}, I\right)$. $\operatorname{MULT}(I, T, T L L) \$(O R D(T) \quad E Q[O R D(T L L)+T M I N(I)+1])=\operatorname{ALPHA}\left(' A 02^{\prime}, I\right)$; $\operatorname{MULT}(I, T, T L L) \$(O R D(T)$ EQ $[O R D(T L L)+T M I N(I) \quad])=\operatorname{ALPHA}(' A 01 ', I)$;

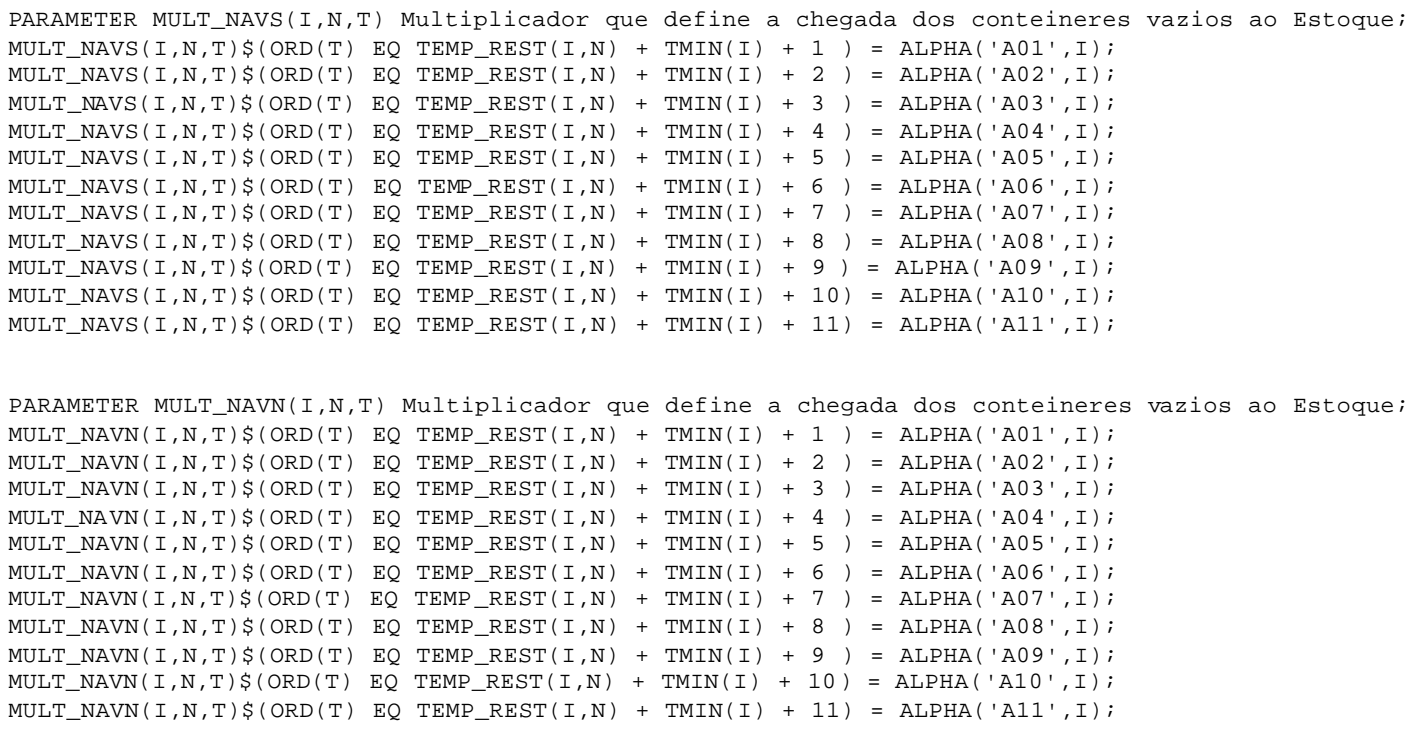

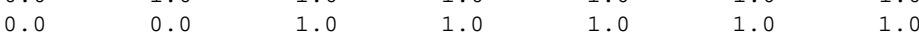




\begin{tabular}{|c|c|c|c|c|c|c|c|}
\hline PORTO_2.PORTO_3 & 0.0 & 0.0 & 0.0 & 0.0 & 0.0 & 0.0 & 0.0 \\
\hline PORTO_2.PORTO_4 & 0.0 & 0.0 & 1.0 & 0.0 & 0.0 & 0.0 & 0.0 \\
\hline PORTO_2.PORTO_5 & 0.0 & 0.0 & 1.0 & 1.0 & 0.0 & 0.0 & 0.0 \\
\hline PORTO_2.PORTO_6 & 0.0 & 0.0 & 1.0 & 1.0 & 1.0 & 0.0 & 0.0 \\
\hline PORTO_2.PORTO_7 & 0.0 & 0.0 & 1.0 & 1.0 & 1.0 & 1.0 & 0.0 \\
\hline PORTO_2.PORTO_8 & 0.0 & 0.0 & 1.0 & 1.0 & 1.0 & 1.0 & 1.0 \\
\hline PORTO_3.PORTO_1 & 0.0 & 0.0 & 0.0 & 0.0 & 0.0 & 0.0 & 0.0 \\
\hline PORTO_3.PORTO_2 & 1.0 & 0.0 & 0.0 & 0.0 & 0.0 & 0.0 & 0.0 \\
\hline PORTO_3.PORTO_4 & 0.0 & 0.0 & 0.0 & 0.0 & 0.0 & 0.0 & 0.0 \\
\hline PORTO_3.PORTO_5 & 0.0 & 0.0 & 0.0 & 1.0 & 0.0 & 0.0 & 0.0 \\
\hline PORTO_3.PORTO_6 & 0.0 & 0.0 & 0.0 & 1.0 & 1.0 & 0.0 & 0.0 \\
\hline PORTO_3.PORTO_7 & 0.0 & 0.0 & 0.0 & 1.0 & 1.0 & 1.0 & 0.0 \\
\hline PORTO_3.PORTO_8 & 0.0 & 0.0 & 0.0 & 1.0 & 1.0 & 1.0 & 1.0 \\
\hline PORTO_4.PORTO_1 & 0.0 & 0.0 & 0.0 & 0.0 & 1.0 & 1.0 & 1.0 \\
\hline PORTO_4.PORTO_2 & 1.0 & 0.0 & 0.0 & 0.0 & 1.0 & 1.0 & 1.0 \\
\hline PORTO_4.PORTO_3 & 0.0 & 0.0 & 0.0 & 0.0 & 1.0 & 1.0 & 1.0 \\
\hline PORTO_4.PORTO_5 & 0.0 & 0.0 & 0.0 & 0.0 & 0.0 & 0.0 & 0.0 \\
\hline PORTO_4.PORTO_6 & 0.0 & 0.0 & 0.0 & 0.0 & 1.0 & 0.0 & 0.0 \\
\hline PORTO_4.PORTO_7 & 0.0 & 0.0 & 0.0 & 0.0 & 1.0 & 1.0 & 0.0 \\
\hline PORTO_4.PORTO_8 & 0.0 & 0.0 & 0.0 & 0.0 & 1.0 & 1.0 & 1.0 \\
\hline PORTO_5.PORTO_1 & 0.0 & 0.0 & 0.0 & 0.0 & 0.0 & 0.0 & 0.0 \\
\hline PORTO_5.PORTO_2 & 1.0 & 0.0 & 0.0 & 0.0 & 0.0 & 0.0 & 0.0 \\
\hline PORTO_5.PORTO_3 & 0.0 & 0.0 & 0.0 & 0.0 & 0.0 & 0.0 & 0.0 \\
\hline PORTO_5.PORTO_4 & 1.0 & 1.0 & 1.0 & 0.0 & 0.0 & 0.0 & 0.0 \\
\hline PORTO_5.PORTO_6 & 0.0 & 0.0 & 0.0 & 0.0 & 0.0 & 0.0 & 0.0 \\
\hline PORTO_5.PORTO_7 & 0.0 & 0.0 & 0.0 & 0.0 & 0.0 & 1.0 & 0.0 \\
\hline PORTO_5.PORTO_8 & 0.0 & 0.0 & 0.0 & 0.0 & 0.0 & 1.0 & 1.0 \\
\hline PORTO_6.PORTO_1 & 0.0 & 0.0 & 0.0 & 0.0 & 0.0 & 0.0 & 1.0 \\
\hline PORTO_6.PORTO_2 & 1.0 & 0.0 & 0.0 & 0.0 & 0.0 & 0.0 & 1.0 \\
\hline PORTO_6.PORTO_3 & 0.0 & 0.0 & 0.0 & 0.0 & 0.0 & 0.0 & 1.0 \\
\hline PORTO_6.PORTO_4 & 1.0 & 1.0 & 1.0 & 0.0 & 0.0 & 0.0 & 1.0 \\
\hline PORTO_6.PORTO_5 & 0.0 & 0.0 & 0.0 & 0.0 & 0.0 & 0.0 & 1.0 \\
\hline PORTO_6.PORTO_7 & 0.0 & 0.0 & 0.0 & 0.0 & 0.0 & 0.0 & 0.0 \\
\hline PORTO_6.PORTO_8 & 0.0 & 0.0 & 0.0 & 0.0 & 0.0 & 0.0 & 1.0 \\
\hline PORTO_7.PORTO_1 & 0.0 & 0.0 & 0.0 & 0.0 & 0.0 & 0.0 & 0.0 \\
\hline PORTO_7.PORTO_2 & 1.0 & 0.0 & 0.0 & 0.0 & 0.0 & 0.0 & 0.0 \\
\hline PORTO_7.PORTO_3 & 0.0 & 0.0 & 0.0 & 0.0 & 0.0 & 0.0 & 0.0 \\
\hline PORTO_7.PORTO_4 & 1.0 & 1.0 & 1.0 & 0.0 & 0.0 & 0.0 & 0.0 \\
\hline PORTO_7.PORTO_5 & 0.0 & 0.0 & 0.0 & 0.0 & 0.0 & 0.0 & 0.0 \\
\hline PORTO_7.PORTO_6 & 1.0 & 1.0 & 1.0 & 1.0 & 1.0 & 0.0 & 0.0 \\
\hline PORTO_7.PORTO_8 & 0.0 & 0.0 & 0.0 & 0.0 & 0.0 & 0.0 & 0.0 \\
\hline PORTO_8.PORTO_1 & 0.0 & 0.0 & 0.0 & 0.0 & 0.0 & 0.0 & 0.0 \\
\hline PORTO_8.PORTO_2 & 1.0 & 0.0 & 0.0 & 0.0 & 0.0 & 0.0 & 0.0 \\
\hline PORTO_8.PORTO_3 & 0.0 & 0.0 & 0.0 & 0.0 & 0.0 & 0.0 & 0.0 \\
\hline PORTO_8.PORTO_4 & 1.0 & 1.0 & 1.0 & 0.0 & 0.0 & 0.0 & 0.0 \\
\hline PORTO_8.PORTO_5 & 0.0 & 0.0 & 0.0 & 0.0 & 0.0 & 0.0 & 0.0 \\
\hline PORTO_8.PORTO_6 & 1.0 & 1.0 & 1.0 & 1.0 & 1.0 & 0.0 & 0.0 \\
\hline PORTO_8.PORTO_7 & 1.0 & 1.0 & 1.0 & 1.0 & 1.0 & 1.0 & 0.0 \\
\hline
\end{tabular}

TABLE TRN(IL, J, I) Cargas contidas nos navios no sentido norte PORTO_8 PORTO_5 PORTO_3

$\begin{array}{llll} & & & \\ \text { PORTO_1.PORTO_2 } & 0.0 & 0.0 & 0.0\end{array}$

PORTO_1.PORTO_3 $0.0 \quad 0.0 \quad 0.0$

$\begin{array}{llll}\text { PORTO_1.PORTO_4 } & 0.0 & 0.0 & 0.0\end{array}$

PORTO_1.PORTO_5 $0.0 \quad 0.0 \quad 0.0$

PORTO_1.PORTO_6 $0.0 \quad 0.0 \quad 0.0$

$\begin{array}{llll}\text { PORTO_1.PORTO_7 } & 0.0 & 0.0 & 0.0\end{array}$

$\begin{array}{llll}\text { PORTO_1.PORTO_8 } & 0.0 & 0.0 & 0.0\end{array}$

PORTO_2.PORTO_1 $1.0 \quad 1.0 \quad 1.0$

PORTO_2.PORTO_3 $0.0 \quad 0.0 \quad 0.0$

PORTO_2.PORTO_4 $30.0 \quad 0.0 \quad 0.0$

PORTO_2.PORTO_6 $0.0 \quad 0.0 \quad 0.0$

$\begin{array}{llll}\text { PORTO_2.PORTO_7 } & 0.0 & 0.0 & 0.0\end{array}$

PORTO_2.PORTO_8 $0.0 \quad 0.0 \quad 0.0$

PORTO_3.PORTO_1 $0.0 \quad 0.0 \quad 0.0$

$\begin{array}{llll}\text { PORTO_3.PORTO_2 } & 0.0 & 0.0 & 0.0\end{array}$

$\begin{array}{llll}\text { PORTO_3.PORTO_4 } & 0.0 & 0.0 & 0.0\end{array}$

$\begin{array}{llll}\text { PORTO_3.PORTO_5 } & 0.0 & 0.0 & 0.0\end{array}$

PORTO_3.PORTO_6 $0.0 \quad 0.0 \quad 0.0$

$\begin{array}{llll}\text { PORTO_3.PORTO_7 } & 0.0 & 0.0 & 0.0\end{array}$

$\begin{array}{llll}\text { PORTO_3.PORTO_8 } & 0.0 & 0.0 & 0.0\end{array}$

PORTO_4.PORTO_1 $1.0 \quad 1.0 \quad 1.0$

PORTO_4.PORTO_2 $1.0 \quad 1.0 \quad 1.0$

$\begin{array}{llll}\text { PORTO_4.PORTO_3 } & 1.0 & 1.0 & 0.0 \\ \text { PORTO_4.PORTO_5 } & 0.0 & 0.0 & 0.0\end{array}$

$\begin{array}{llll}\text { PORTO_4.PORTO_6 } & 0.0 & 0.0 & 0.0\end{array}$

$\begin{array}{llll}\text { PORTO_4.PORTO_7 } & 0.0 & 0.0 & 0.0\end{array}$

PORTO_4.PORTO_8 $0.0 \quad 0.0 \quad 0.0$

$\begin{array}{llll}\text { PORTO_5.PORTO_1 } & 0.0 & 0.0 & 1.0 \\ \text { PORTO55.PORTO_2 } & 0.0 & 0.0 & 1.0\end{array}$

$\begin{array}{llll}\text { PORTO_5.PORTO_3 } & 0.0 & 0.0 & 0.0\end{array}$

PORTO_5.PORTO_4 $0.0 \quad 0.0 \quad 1.0$

PORTO_5.PORTO_6 $0.0 \quad 0.0 \quad 000$

PORTO_5.PORTO_7

$0.0 \quad 0.0$

0.0 


$\begin{array}{llll}\text { PORTO_5.PORTO_8 } & 0.0 & 0.0 & 0.0 \\ \text { PORTO_6.PORTO_1 } & 1.0 & 1.0 & 1.0 \\ \text { PORTO_6.PORTO_2 } & 1.0 & 1.0 & 1.0 \\ \text { PORTO_6.PORTO_3 } & 1.0 & 1.0 & 0.0 \\ \text { PORTO_6.PORTO_4 } & 1.0 & 1.0 & 1.0 \\ \text { PORTO_6.PORTO_5 } & 1.0 & 0.0 & 0.0 \\ \text { PORTO_6.PORTO_7 } & 0.0 & 0.0 & 0.0 \\ \text { PORTO_6.PORTO_8 } & 0.0 & 0.0 & 0.0 \\ \text { PORTO_7.PORTO_1 } & 1.0 & 1.0 & 1.0 \\ \text { PORTO_7.PORTO_2 } & 1.0 & 1.0 & 1.0 \\ \text { PORTO_7.PORTO_3 } & 1.0 & 1.0 & 0.0 \\ \text { PORTO_7.PORTO_4 } & 1.0 & 1.0 & 1.0 \\ \text { PORTO_7.PORTO_5 } & 1.0 & 0.0 & 0.0 \\ \text { PORTO_7.PORTO_6 } & 1.0 & 1.0 & 1.0 \\ \text { PORTO_7.PORTO_8 } & 0.0 & 0.0 & 0.0 \\ \text { PORTO_8.PORTO_1 } & 0.0 & 1.0 & 1.0 \\ \text { PORTO_8.PORTO_2 } & 0.0 & 1.0 & 1.0 \\ \text { PORTO_8.PORTO_3 } & 0.0 & 1.0 & 0.0 \\ \text { PORTO_8.PORTO_4 } & 0.0 & 1.0 & 1.0 \\ \text { PORTO_8.PORTO_5 } & 0.0 & 0.0 & 0.0 \\ \text { PORTO_8.PORTO_6 } & 0.0 & 1.0 & 1.0 \\ \text { PORTO_8.PORTO_7 } & 0.0 & 1.0 & 1.0 \\ \text {; } & & & \end{array}$

PARAMETER CP Custo diario de manutencao do conteiner proprio; $\mathrm{CP}=1.0$;

PARAMETER CL $(I, J)$ Custo diario do conteiner alugado; $\mathrm{CL}(\mathrm{I}, \mathrm{J})=2.0 * \mathrm{~F}(\mathrm{I}, \mathrm{J})$

PARAMETER CV $(I, J)$ Custo do transporte do conteiner vazio do Porto I para o Porto J; $\mathrm{CV}(\mathrm{I}, \mathrm{J})=0.2$;

PARAMETER CCC(I) Custo diario da carga armazenada no conteiner no porto I; $\operatorname{CCC}(I)=50.0$;

PARAMETER CN

$\mathrm{CN}=2500$;

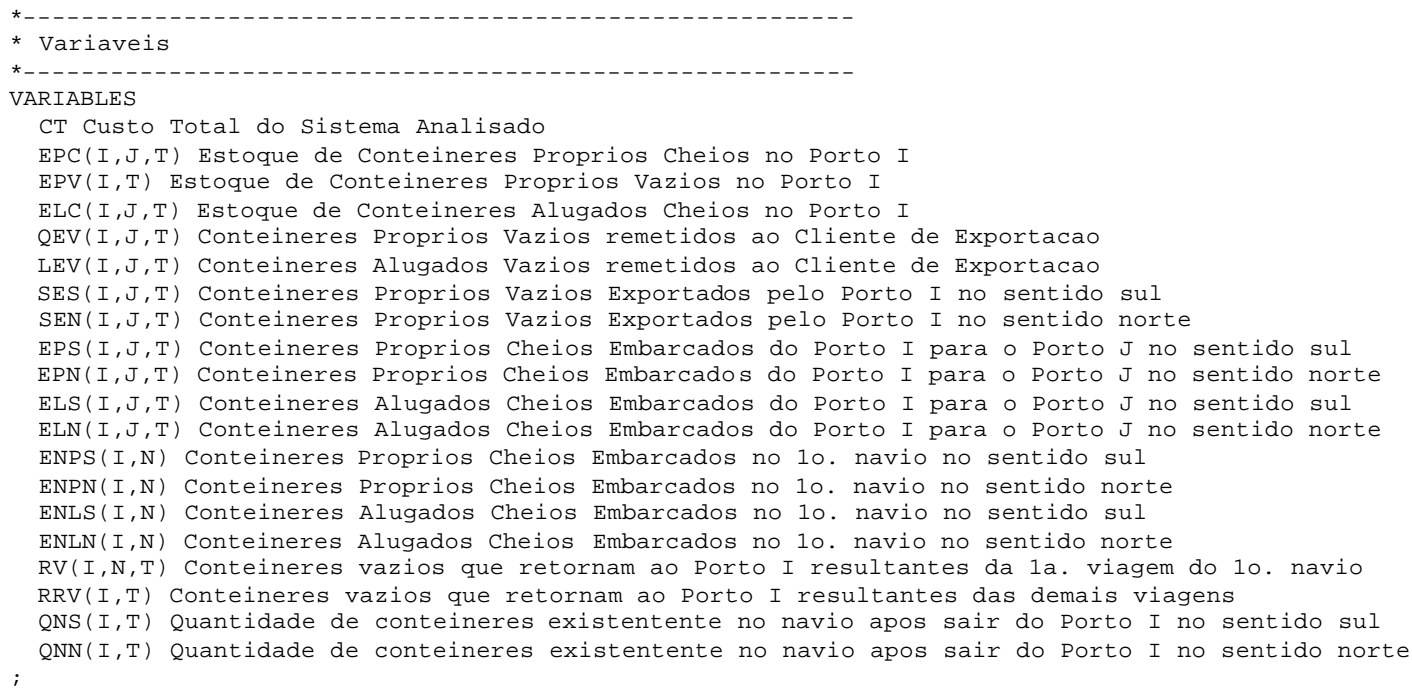

POSITIVE VARIABLES

$\operatorname{EPC}(I, J, T), \operatorname{EPV}(I, T), \operatorname{ELC}(I, J, T), \operatorname{QEV}(I, J, T), \operatorname{LEV}(I, J, T)$,

$\operatorname{EPS}(I, J, T), \operatorname{EPN}(I, J, T), \operatorname{SES}(I, J, T), \operatorname{SEN}(I, J, T)$,

$\operatorname{ELS}(I, J, T), \operatorname{ELN}(I, J, T), \operatorname{ENPS}(I, N), \operatorname{ENPN}(I, N)$,

$\operatorname{ENLS}(I, N), \operatorname{ENLN}(I, N), \operatorname{RV}(I, N, T), \operatorname{RRV}(I, T)$,

$\operatorname{QNS}(I, T), \operatorname{QNN}(I, T)$

FREE VARIABLE CT

* Equacoes
* EQUATIONS
OBJETIVO
EST_MIN $(I, T)$
SAIDA_VAZ_EXP $(I, J, T)$
CAP_MAX_LEASING $(I, T)$

CAP_MAX_EXP_VAZIO(I,TL,TLL, X) 


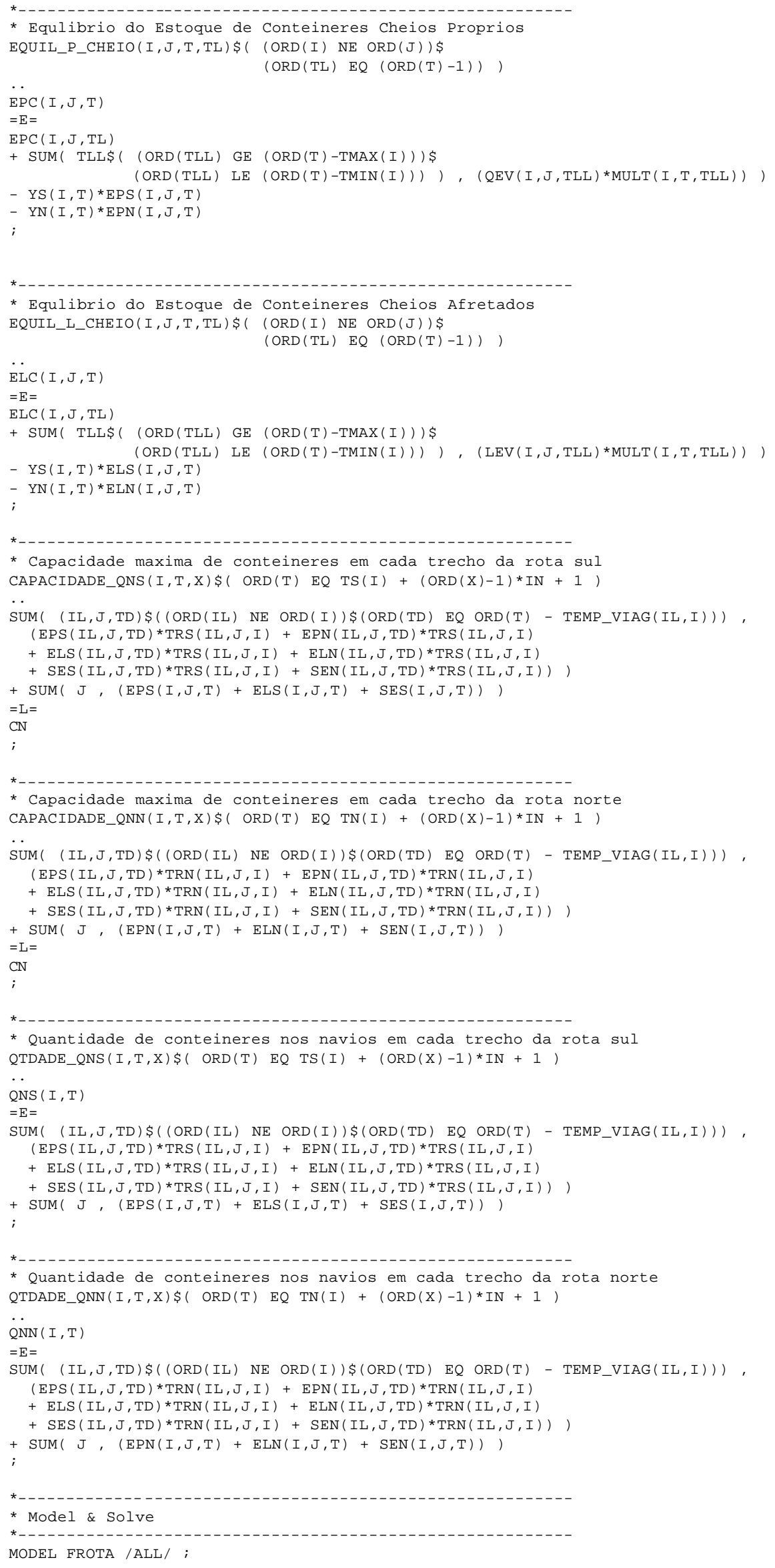




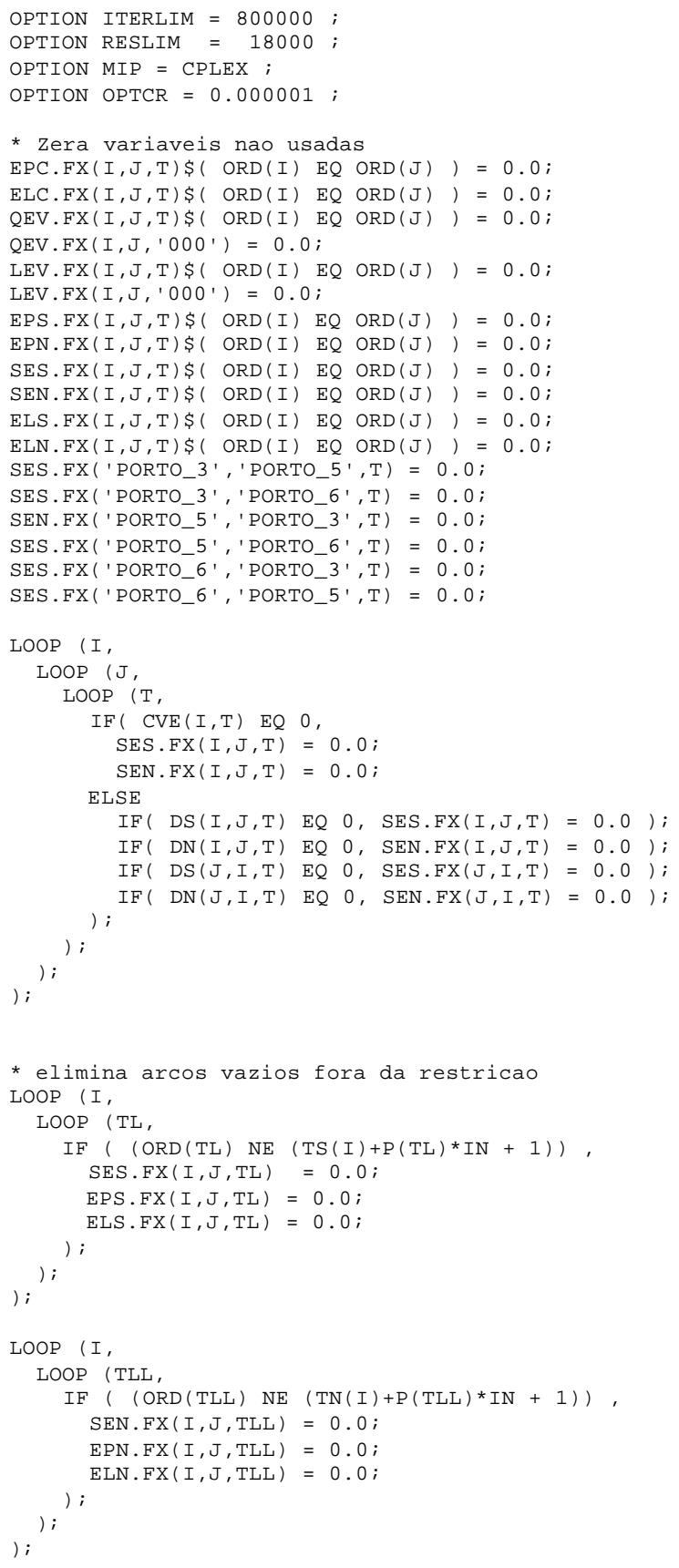

* Formatacao do arquivo de saida 


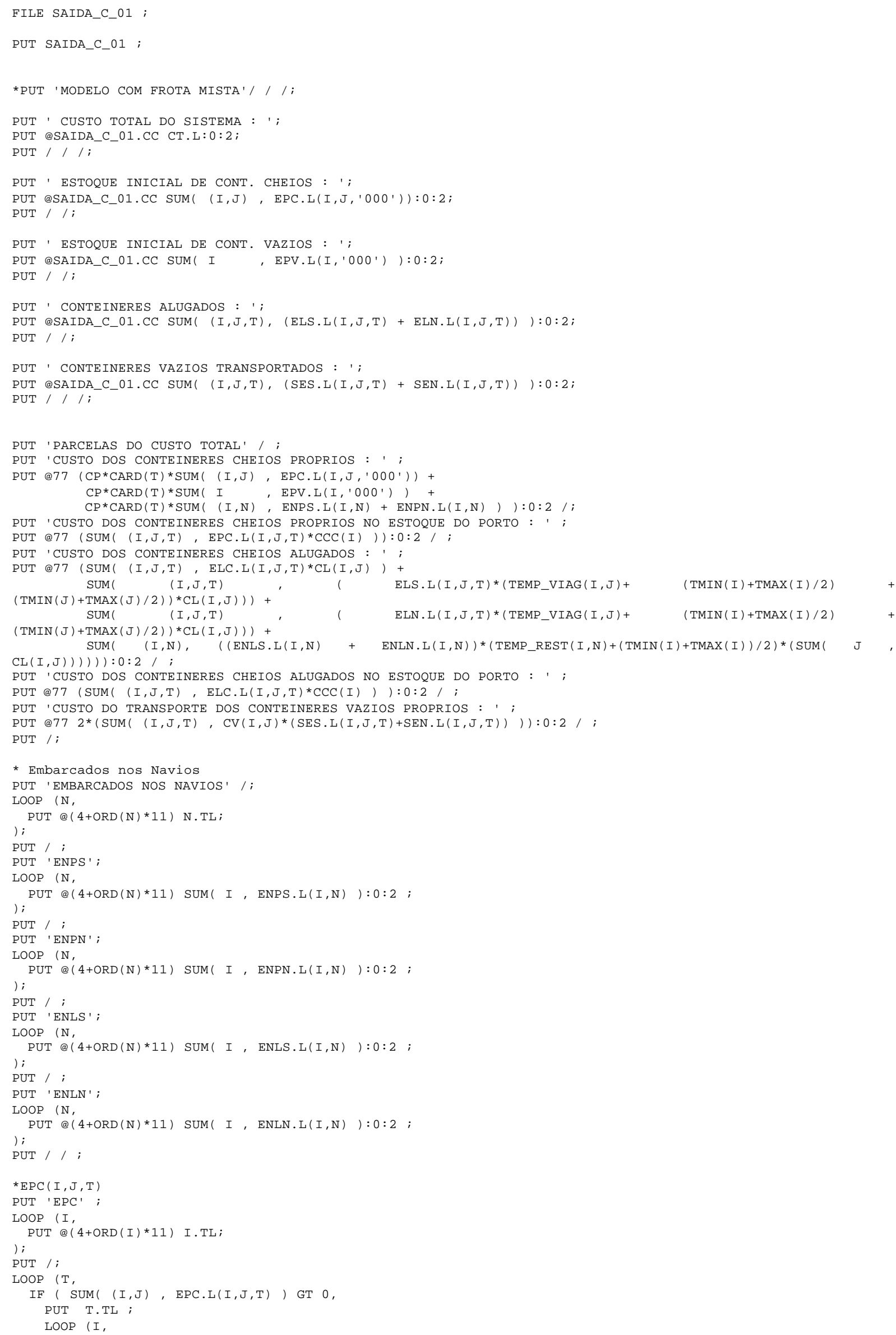




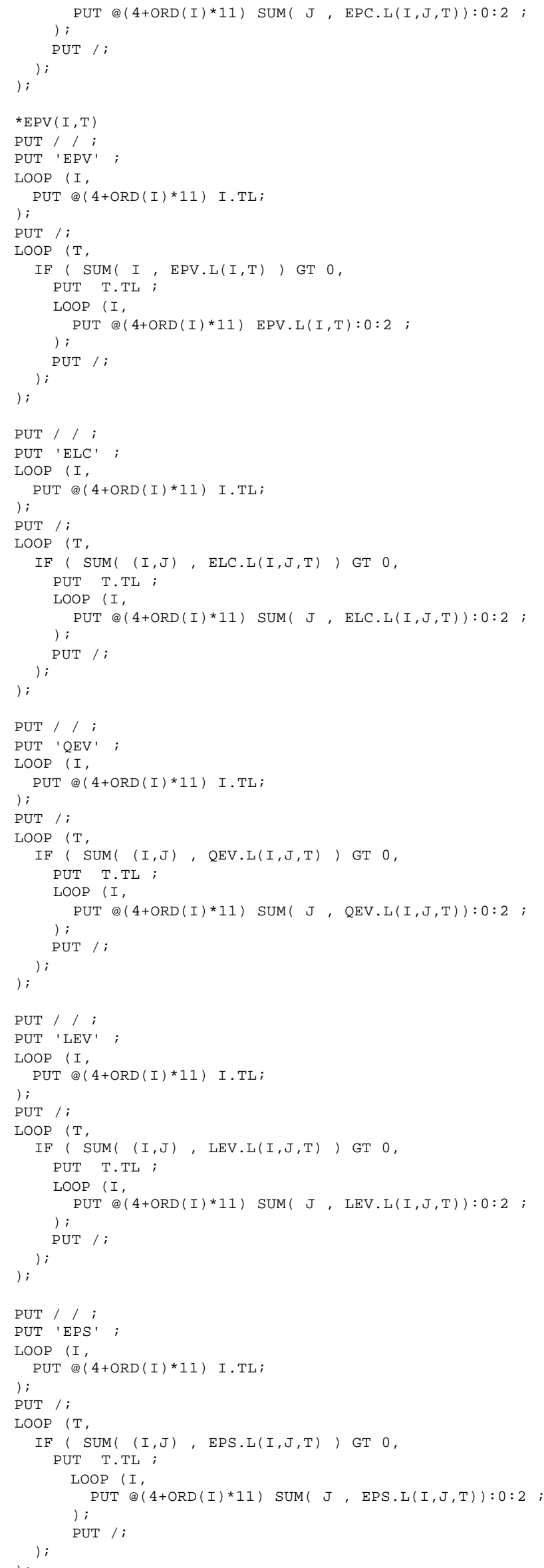




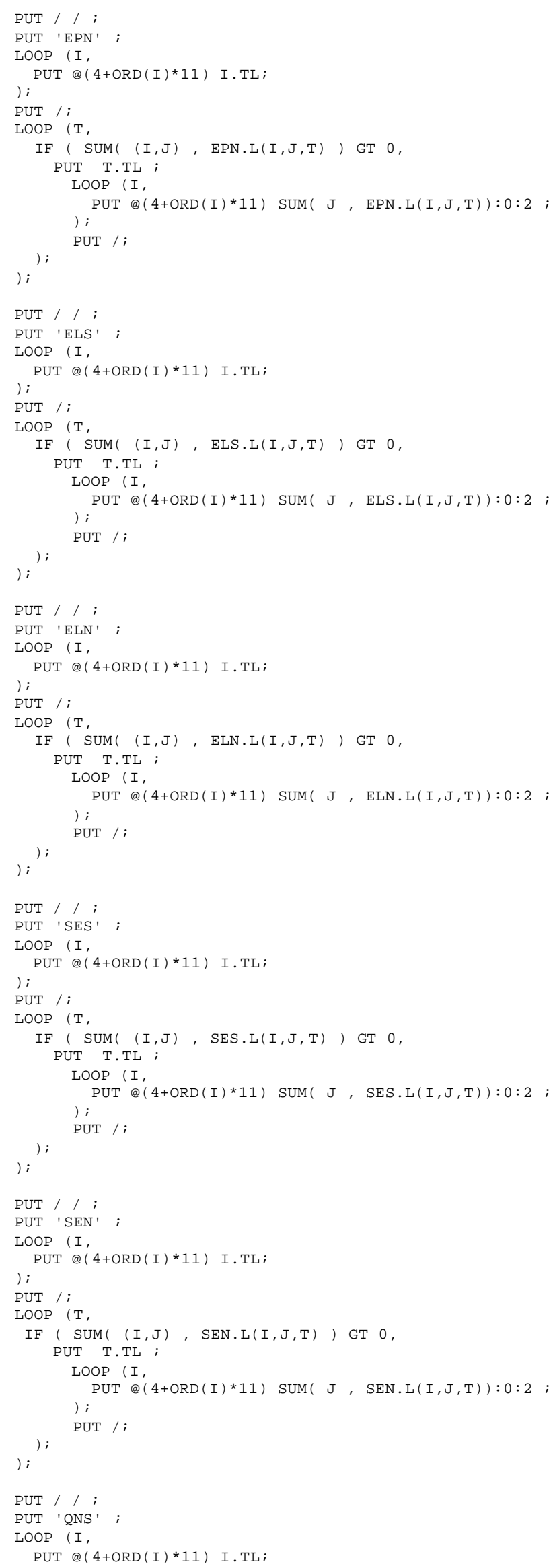




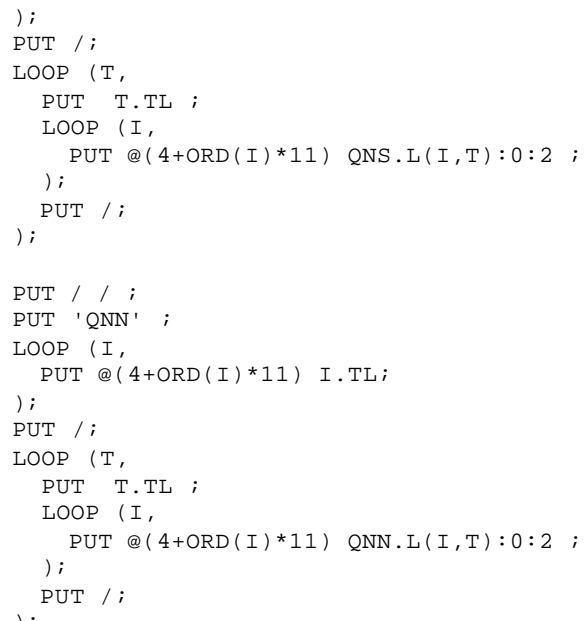




\section{ANEXO D}

\section{SAÍDA DO PROGRAMA REFERENTE AO CENÁRIO $V \_01$}

CUSTO TOTAL DO SISTEMA : 78686124.16

ESTOQUE INICIAL DE CONT. CHEIOS : 7170.52

ESTOQUE INICIAL DE CONT. VAZIOS : 4008.65

CONTEINERES ALUGADOS : 17789.14

CONTEINERES VAZIOS TRANSPORTADOS : 10414.67

PARCELAS DO CUSTO TOTAL

CUSTO DOS CONTEINERES CHEIOS PROPRIOS :

CUSTO DOS CONTEINERES CHEIOS PROPRIOS NO ESTOQUE DO PORTO :

CUSTO DOS CONTEINERES CHEIOS ALUGADOS :

CUSTO DOS CONTEINERES CHEIOS ALUGADOS NO ESTOQUE DO PORTO :

CUSTO DO TRANSPORTE DOS CONTEINERES VAZIOS PROPRIOS :

6911420.53

64765625.22

2095019.02

4909893.53

2082.93

EMBARCADOS NOS NAVIOS

\begin{tabular}{|c|c|c|c|c|c|}
\hline & N01 & N02 & N03 & N0 4 & N05 \\
\hline EMB_NP_S & 420.00 & 805.00 & 1080.00 & 930.00 & 765.00 \\
\hline EMB_NP_N & 475.00 & 190.00 & 90.00 & 45.00 & 375.00 \\
\hline EMB_NL_S & 0.00 & 0.00 & 0.00 & 0.00 & 0.00 \\
\hline EMB_NL_N & 0.00 & 0.00 & 0.00 & 0.00 & 0.00 \\
\hline EPC & PORTO_1 & PORTO_2 & PORTO_3 & PORTO_4 & PORTO_ \\
\hline 000 & 1344.95 & 658.02 & 934.06 & 626.45 & 874.64 \\
\hline 001 & 1019.95 & 658.02 & 889.06 & 626.45 & 784.64 \\
\hline 002 & 1019.95 & 658.02 & 659.06 & 626.45 & 784.64 \\
\hline 003 & 1019.95 & 658.02 & 659.06 & 626.45 & 619.64 \\
\hline 004 & 1019.95 & 658.02 & 659.06 & 626.45 & 619.64 \\
\hline 005 & 1019.95 & 658.02 & 659.06 & 626.45 & 619.64 \\
\hline 006 & 1019.95 & 348.02 & 659.06 & 331.45 & 619.64 \\
\hline 007 & 1019.95 & 348.02 & 659.06 & 331.45 & 619.64 \\
\hline 008 & 1020.60 & 348.64 & 659.61 & 332.04 & 620.15 \\
\hline 009 & 1022.88 & 350.81 & 661.54 & 334.11 & 621.93 \\
\hline 010 & 1027.75 & 355.46 & 665.66 & 338.53 & 625.76 \\
\hline 011 & 711.20 & 363.52 & 627.81 & 346.20 & 542.39 \\
\hline 012 & 723.88 & 375.61 & 408.54 & 357.71 & 552.33 \\
\hline 013 & 742.08 & 392.97 & 423.94 & 374.23 & 401.61 \\
\hline 014 & 764.83 & 414.67 & 443.19 & 394.88 & 419.46 \\
\hline 015 & 791.48 & 440.09 & 465.74 & 419.07 & 440.37 \\
\hline 016 & 821.05 & 158.30 & 490.76 & 150.91 & 463.58 \\
\hline 017 & 852.58 & 188.37 & 517.43 & 179.53 & 488.31 \\
\hline 018 & 885.16 & 219.37 & 544.93 & 209.03 & 513.81 \\
\hline 019 & 917.94 & 250.37 & 572.44 & 238.53 & 539.31 \\
\hline 020 & 951.04 & 281.37 & 600.06 & 268.03 & 564.81 \\
\hline 021 & 650.98 & 312.37 & 582.98 & 297.53 & 500.52 \\
\hline 022 & 685.04 & 343.37 & 381.38 & 327.03 & 526.76 \\
\hline 023 & 719.78 & 374.37 & 410.44 & 356.53 & 388.83 \\
\hline 024 & 755.08 & 405.37 & 440.16 & 386.03 & 416.94 \\
\hline 025 & 790.86 & 436.37 & 470.60 & 415.53 & 446.03 \\
\hline 026 & 827.00 & 157.25 & 501.52 & 150.03 & 476.19 \\
\hline 027 & 863.38 & 188.25 & 532.79 & 179.53 & 506.81 \\
\hline 028 & 899.88 & 219.25 & 564.32 & 209.03 & 537.53 \\
\hline 029 & 936.38 & 250.25 & 595.84 & 238.53 & 567.89 \\
\hline & 972.88 & 281.25 & 627.48 & 26803 & 597.75 \\
\hline
\end{tabular}

$765.00 \quad 615.00$
375.000

$0.00 \quad 0.00$

$0.00 \quad 0.00$

PORTO_6

$608.98 \quad 1094.68$

608.98

608.98

608.98

343.98

343.98

343.98

344.43

346.00

349.38

355.31

364.36

377.56

394.35

157.68

180.32

204.66

229.84

254.94

279.76

304.10

328.08

351.90

375.80

154.50

179.24

204.54

230.32

256.46

282.84
N06 107

$375.00 \quad 520.00$
PORTO_8

733.75

733.75

$1094.68 \quad 733.75$

$1094.68 \quad 733.75$

$1094.68 \quad 733.75$

$1094.68 \quad 733.75$

$1094.68 \quad 398.75$

$1094.68 \quad 398.75$

$1095.26 \quad 399.42$

$1097.33 \quad 401.77$

$1101.75 \quad 406.79$

$\begin{array}{ll}762.17 & 415.50\end{array}$

$773.68 \quad 428.57$

$790.20 \quad 447.33$

$810.85 \quad 470.78$

$835.04 \quad 498.25$

$861.88 \quad 169.25$

$890.50 \quad 201.75$

$920.00 \quad 235.25$

$949.50 \quad 268.75$

$979.00 \quad 302.25$

$704.42 \quad 335.75$

$733.92 \quad 369.25$

$763.42 \quad 402.83$

$792.92 \quad 436.61$

$822.42 \quad 470.71$

$851.92 \quad 168.13$

$881.42 \quad 203.19$

$910.92 \quad 238.93$

$940.42 \quad 275.23$

$969.92 \quad 312.01$ 


\begin{tabular}{|c|c|c|c|c|c|c|c|c|}
\hline 031 & 650.98 & 312.25 & 614.42 & 297.53 & 537.24 & 309.34 & 704.42 & 349.15 \\
\hline 032 & 687.48 & 343.25 & 381.38 & 327.03 & 566.43 & 335.84 & 733.92 & 386.53 \\
\hline 033 & 723.98 & 374.25 & 413.98 & 356.53 & 405.62 & 362.34 & 763.42 & 424.03 \\
\hline 034 & 760.48 & 405.25 & 446.82 & 386.03 & 435.33 & 388.84 & 792.92 & 461.53 \\
\hline 035 & 796.98 & 436.25 & 479.72 & 415.53 & 465.33 & 154.50 & 822.42 & 499.03 \\
\hline 036 & 833.48 & 157.25 & 512.43 & 150.03 & 495.39 & 181.00 & 851.92 & 168.13 \\
\hline 037 & 869.98 & 188.25 & 544.79 & 179.53 & 525.15 & 207.50 & 881.42 & 205.63 \\
\hline 038 & 906.48 & 219.25 & 576.86 & 209.03 & 554.43 & 234.00 & 910.92 & 243.13 \\
\hline 039 & 942.98 & 250.25 & 608.56 & 238.53 & 582.99 & 260.50 & 940.42 & 280.63 \\
\hline 040 & 979.48 & 281.25 & 640.20 & 268.03 & 611.19 & 287.00 & 969.92 & 318.13 \\
\hline 041 & 650.98 & 312.25 & 627.14 & 297.53 & 547.98 & 313.50 & 704.42 & 355.63 \\
\hline 042 & 687.48 & 343.25 & 381.38 & 327.03 & 576.36 & 340.00 & 733.92 & 393.13 \\
\hline 043 & 723.98 & 374.25 & 413.98 & 356.53 & 404.40 & 366.50 & 763.42 & 430.63 \\
\hline 044 & 760.48 & 405.25 & 446.82 & 386.03 & 433.98 & 393.00 & 792.92 & 468.13 \\
\hline 045 & 796.98 & 436.25 & 479.72 & 415.53 & 463.98 & 154.50 & 822.42 & 505.63 \\
\hline 046 & 833.48 & 157.25 & 512.43 & 150.03 & 494.04 & 181.00 & 851.92 & 168.13 \\
\hline 047 & 869.98 & 188.25 & 544.79 & 179.53 & 523.80 & 207.50 & 881.42 & 205.63 \\
\hline 048 & 906.48 & 219.25 & 576.86 & 209.03 & 553.08 & 234.00 & 910.92 & 243.13 \\
\hline 049 & 942.98 & 250.25 & 608.75 & 238.53 & 581.64 & 260.50 & 940.42 & 280.63 \\
\hline 050 & 979.48 & 281.25 & 641.06 & 268.03 & 609.99 & 287.00 & 969.92 & 318.13 \\
\hline 051 & 650.98 & 312.25 & 629.44 & 297.53 & 548.66 & 313.50 & 704.42 & 355.63 \\
\hline 052 & 687.48 & 343.25 & 386.18 & 327.03 & 578.16 & 340.18 & 733.92 & 393.13 \\
\hline 053 & 723.98 & 374.46 & 422.52 & 356.72 & 408.15 & 367.29 & 763.42 & 430.88 \\
\hline 054 & 760.48 & 406.18 & 460.69 & 386.92 & 440.75 & 395.11 & 792.92 & 469.25 \\
\hline 055 & 796.98 & 438.72 & 500.18 & 417.90 & 475.14 & 158.90 & 822.42 & 508.63 \\
\hline 056 & 833.48 & 162.40 & 540.51 & 154.98 & 510.69 & 188.83 & 851.92 & 174.38 \\
\hline 057 & 869.98 & 197.42 & 581.22 & 188.34 & 546.82 & 220.26 & 881.42 & 216.75 \\
\hline 058 & 906.72 & 234.18 & 622.15 & 223.38 & 583.11 & 252.91 & 911.12 & 261.2 \\
\hline 059 & 944.06 & 272.39 & 662.95 & 259.81 & 619.32 & 286.59 & 941.31 & 307.5 \\
\hline 060 & 982.38 & 311.84 & 703.80 & 297.43 & 655.31 & 321.05 & 972.28 & 355.2 \\
\hline 061 & 536.03 & 352.21 & 669.06 & 335.94 & 557.16 & 356.02 & 579.97 & 404.13 \\
\hline 062 & 577.24 & 393.20 & 340.52 & 375.04 & 593.77 & 391.24 & 613.30 & 453.75 \\
\hline 063 & 620.52 & 434.50 & 383.26 & 414.44 & 355.88 & 426.43 & 648.28 & 503.75 \\
\hline 064 & 665.49 & 475.80 & 426.53 & 453.76 & 394.62 & 461.65 & 684.64 & 553.75 \\
\hline 065 & 711.91 & 517.10 & 470.06 & 492.86 & 434.08 & 143.00 & 722.18 & 603.75 \\
\hline 066 & 759.42 & 143.91 & 513.34 & 137.15 & 473.89 & 178.24 & 760.60 & 153.7 \\
\hline 067 & 807.66 & 185.21 & 556.02 & 175.39 & 513.48 & 213.40 & 799.60 & 203.7 \\
\hline 068 & 856.26 & 226.51 & 598.13 & 213.03 & 552.36 & 248.31 & 838.90 & 253.75 \\
\hline 069 & 904.86 & 267.81 & 639.55 & 249.90 & 590.04 & 282.82 & 878.20 & 303.75 \\
\hline 070 & 953.46 & 309.11 & 680.74 & 286.09 & 627.00 & 316.74 & 917.50 & 353.75 \\
\hline 071 & 516.06 & 350.41 & 659.25 & 321.54 & 541.16 & 349.97 & 558.36 & 403.75 \\
\hline 072 & 564.66 & 391.71 & 336.16 & 356.13 & 577.96 & 382.30 & 597.66 & 453.75 \\
\hline 073 & 613.26 & 433.01 & 378.70 & 389.90 & 351.60 & 413.89 & 636.96 & 503.75 \\
\hline 074 & 661.86 & 474.31 & 421.78 & 423.01 & 389.52 & 444.85 & 676.26 & 553.75 \\
\hline 075 & 710.46 & 515.61 & 465.15 & 455.67 & 427.92 & 143.00 & 715.56 & 603.75 \\
\hline 076 & 759.06 & 143.91 & 508.34 & 137.15 & 466.40 & 173.16 & 754.86 & 153.75 \\
\hline 077 & 807.66 & 185.21 & 550.86 & 169.20 & 504.56 & 203.16 & 794.16 & 203.7 \\
\hline 078 & 856.26 & 226.51 & 592.50 & 201.50 & 541.84 & 233.16 & 833.46 & 253.7 \\
\hline 079 & 904.86 & 267.81 & 633.18 & 233.79 & 578.24 & 263.16 & 872.76 & 303.7 \\
\hline 080 & 953.46 & 309.11 & 673.38 & 265.90 & 613.68 & 293.16 & 912.06 & 353.75 \\
\hline 081 & 516.06 & 350.39 & 653.50 & 297.66 & 528.56 & 323.16 & 558.36 & 403.75 \\
\hline 082 & 564.66 & 391.55 & 336.16 & 329.13 & 563.20 & 353.16 & 597.66 & 453.75 \\
\hline 083 & 613.26 & 432.45 & 376.92 & 359.97 & 351.60 & 383.27 & 636.96 & 503.75 \\
\hline 084 & 661.86 & 472.94 & 417.91 & 390.45 & 386.48 & 413.64 & 676.26 & 553.7 \\
\hline 085 & 710.46 & 512.90 & 458.99 & 420.94 & 421.52 & 143.00 & 715.56 & 603.75 \\
\hline 086 & 759.06 & 143.91 & 499.75 & 137.15 & 456.88 & 174.18 & 754.86 & 153.7 \\
\hline 087 & 807.66 & 182.45 & 539.63 & 168.99 & 492.00 & 205.73 & 794.16 & 203.75 \\
\hline 088 & 856.26 & 220.35 & 578.63 & 201.69 & 526.96 & 237.71 & 833.46 & 253.75 \\
\hline 089 & 904.86 & 257.71 & 616.67 & 235.11 & 561.68 & 269.81 & 872.76 & 303.7 \\
\hline 090 & 953.46 & 294.68 & 654.16 & 268.81 & 596.16 & 301.78 & 912.06 & 353.75 \\
\hline 091 & 516.06 & 331.39 & 631.55 & 302.49 & 510.56 & 333.38 & 558.36 & 403.75 \\
\hline 092 & 564.66 & 367.99 & 336.16 & 335.88 & 545.42 & 364.60 & 597.66 & 453.75 \\
\hline 093 & 613.26 & 404.59 & 374.83 & 369.05 & 352.38 & 395.50 & 636.96 & 503.7 \\
\hline 094 & 661.86 & 441.19 & 414.55 & 402.02 & 389.12 & 426.24 & 676.26 & 553.7 \\
\hline 095 & 710.46 & 477.79 & 455.63 & 435.33 & 427.02 & 143.00 & 715.56 & 603.7 \\
\hline 096 & 759.06 & 143.91 & 497.84 & 137.15 & 466.40 & 174.38 & 754.86 & 153.7 \\
\hline 097 & 807.66 & 180.51 & 540.85 & 171.61 & 506.40 & 206.45 & 794.16 & 203.7 \\
\hline 098 & 856.26 & 217.11 & 584.22 & 206.74 & 546.65 & 239.41 & 833.46 & 253.75 \\
\hline 099 & 904.86 & 253.71 & 627.46 & 242.31 & 586.64 & 273.12 & 872.76 & 303.75 \\
\hline 100 & 953.46 & 290.21 & 670.39 & 278.05 & 625.93 & 307.47 & 912.06 & 353.75 \\
\hline 101 & 516.06 & 326.17 & 652.42 & 313.70 & 538.29 & 342.29 & 558.36 & 403.75 \\
\hline 102 & 564.66 & 361.23 & 337.04 & 349.08 & 575.98 & 377.33 & 597.66 & 453.75 \\
\hline 103 & 613.26 & 395.34 & 379.58 & 384.27 & 352.80 & 412.37 & 636.96 & 503.7 \\
\hline 104 & 661.86 & 428.65 & 422.49 & 419.42 & 390.94 & 447.25 & 676.26 & 553.7 \\
\hline 105 & 710.46 & 461.40 & 466.20 & 454.81 & 429.87 & 143.00 & 715.53 & 603.75 \\
\hline 106 & 759.06 & 126.90 & 510.13 & 137.15 & 470.22 & 177.62 & 754.35 & 153.75 \\
\hline 107 & 807.66 & 159.83 & 553.89 & 173.44 & 511.68 & 212.04 & 792.35 & 203.7 \\
\hline 108 & 856.26 & 193.86 & 597.44 & 210.22 & 553.80 & 246.61 & 829.45 & 253.75 \\
\hline 109 & 904.86 & 229.03 & 640.56 & 247.22 & 596.46 & 281.29 & 865.67 & 303.7 \\
\hline 110 & 953.46 & 265.17 & 683.08 & 284.22 & 639.42 & 316.12 & 901.16 & 353.75 \\
\hline 111 & 516.06 & 301.60 & 650.57 & 320.96 & 549.84 & 351.11 & 542.73 & 403.75 \\
\hline 112 & 564.66 & 337.80 & 335.26 & 357.15 & 592.68 & 386.25 & 577.59 & 453.75 \\
\hline 113 & 613.26 & 373.09 & 378.01 & 392.82 & 353.22 & 421.55 & 613.16 & 503.7 \\
\hline 114 & 661.86 & 407.34 & 421.12 & 428.09 & 396.24 & 456.85 & 649.54 & 553.75 \\
\hline 115 & 710.46 & 440.80 & 464.37 & 463.22 & 439.08 & 143.00 & 686.83 & 603.75 \\
\hline 116 & 759.06 & 98.32 & 507.43 & 122.42 & 481.64 & 178.30 & 725.02 & 153.75 \\
\hline
\end{tabular}




\begin{tabular}{|c|c|c|c|c|c|c|c|c|}
\hline 117 & 807.66 & 131.34 & 549.84 & 157.77 & 523.71 & 213.60 & 763.90 & 203.75 \\
\hline 118 & 856.26 & 165.39 & 591.52 & 193.86 & 565.39 & 249.08 & 802.80 & 254.00 \\
\hline 119 & 904.86 & 200.83 & 632.76 & 230.63 & 606.92 & 285.00 & 841.47 & 304.88 \\
\hline 120 & 953.46 & 237.23 & 674.32 & 268.19 & 648.59 & 321.64 & 879.92 & 356.75 \\
\hline 121 & 393.06 & 274.13 & 626.80 & 306.08 & 520.42 & 359.17 & 419.62 & 410.00 \\
\hline 122 & 441.66 & 311.03 & 215.88 & 344.01 & 563.59 & 397.62 & 457.62 & 464.88 \\
\hline 123 & 490.26 & 347.47 & 262.07 & 382.08 & 242.48 & 437.27 & 495.86 & 521.88 \\
\hline 124 & 538.86 & 383.10 & 309.82 & 419.86 & 287.99 & 477.84 & 534.29 & 580.63 \\
\hline 125 & 587.46 & 417.58 & 358.67 & 457.53 & 334.02 & 72.70 & 572.94 & 640.88 \\
\hline 126 & 636.06 & 48.85 & 407.87 & 41.29 & 380.07 & 114.11 & 611.82 & 77.25 \\
\hline 127 & 684.66 & 84.43 & 456.53 & 78.96 & 425.66 & 155.37 & 650.75 & 139.38 \\
\hline 128 & 733.51 & 121.84 & 504.28 & 117.59 & 470.05 & 196.43 & 689.45 & 201.88 \\
\hline 129 & 782.97 & 160.80 & 551.06 & 157.01 & 513.14 & 236.88 & 727.77 & 264.38 \\
\hline 130 & 833.41 & 200.67 & 597.50 & 196.76 & 555.25 & 276.49 & 766.01 & 326.88 \\
\hline 131 & 276.21 & 240.68 & 554.02 & 236.17 & 432.33 & 315.44 & 297.67 & 389.38 \\
\hline 132 & 329.61 & 279.55 & 176.82 & 274.80 & 473.58 & 353.13 & 336.77 & 451.88 \\
\hline 133 & 385.10 & 316.48 & 225.76 & 312.05 & 198.34 & 389.43 & 377.00 & 514.38 \\
\hline 134 & 442.31 & 350.77 & 276.11 & 347.74 & 240.14 & 424.54 & 418.95 & 576.88 \\
\hline 135 & 500.99 & 383.56 & 327.24 & 382.12 & 282.25 & 52.19 & 461.49 & 639.38 \\
\hline 136 & 560.78 & 50.58 & 378.60 & 41.36 & 324.62 & 86.35 & 503.63 & 76.88 \\
\hline 137 & 621.31 & 84.50 & 429.66 & 76.85 & 367.13 & 119.70 & 544.41 & 139.38 \\
\hline 138 & 682.22 & 120.75 & 479.66 & 114.25 & 409.70 & 154.76 & 583.41 & 201.88 \\
\hline 139 & 743.12 & 159.48 & 528.76 & 153.69 & 452.23 & 190.78 & 619.90 & 264.38 \\
\hline 140 & 804.02 & 200.37 & 577.16 & 194.89 & 494.73 & 227.87 & 654.48 & 326.88 \\
\hline 141 & 255.92 & 242.10 & 547.82 & 237.24 & 384.00 & 265.53 & 152.95 & 389.38 \\
\hline 142 & 316.82 & 283.34 & 172.62 & 279.58 & 427.57 & 303.33 & 188.38 & 451.88 \\
\hline 143 & 377.72 & 323.27 & 222.42 & 321.22 & 194.78 & 341.16 & 226.24 & 514.38 \\
\hline 144 & 438.62 & 361.40 & 273.71 & 362.12 & 239.98 & 378.32 & 266.68 & 576.88 \\
\hline 145 & 499.52 & 398.23 & 325.91 & 402.68 & 285.83 & 40.52 & 309.04 & 639.38 \\
\hline 146 & 560.42 & 54.18 & 378.50 & 37.59 & 332.58 & 78.11 & 351.86 & 76.88 \\
\hline 147 & 621.32 & 91.34 & 430.90 & 78.39 & 379.19 & 115.83 & 393.67 & 139.38 \\
\hline 148 & 682.22 & 130.20 & 482.60 & 120.30 & 425.16 & 155.42 & 433.60 & 201.88 \\
\hline 149 & 743.12 & 170.90 & 532.90 & 163.39 & 470.41 & 195.87 & 470.92 & 264.38 \\
\hline 150 & 804.02 & 213.43 & 582.16 & 206.92 & 514.72 & 236.92 & 506.66 & 326.88 \\
\hline 151 & 255.92 & 256.96 & 555.40 & 250.85 & 400.89 & 277.70 & 109.99 & 389.38 \\
\hline 152 & 316.82 & 300.48 & 153.56 & 294.89 & 444.41 & 318.12 & 146.99 & 451.88 \\
\hline 153 & 377.72 & 343.15 & 204.47 & 338.48 & 193.67 & 358.31 & 186.43 & 514.38 \\
\hline 154 & 438.62 & 384.78 & 257.18 & 381.68 & 238.63 & 397.96 & 228.60 & 576.88 \\
\hline 155 & 499.52 & 425.53 & 312.27 & 425.05 & 284.20 & 19.62 & 273.25 & 639.38 \\
\hline 156 & 560.42 & 63.38 & 368.62 & 23.38 & 330.98 & 60.42 & 319.02 & 76.88 \\
\hline 157 & 621.32 & 103.94 & 425.35 & 68.34 & 378.00 & 102.75 & 364.52 & 139.38 \\
\hline 158 & 682.22 & 145.70 & 481.42 & 114.61 & 424.36 & 146.92 & 408.82 & 201.88 \\
\hline 159 & 743.12 & 188.80 & 535.89 & 161.78 & 470.40 & 192.15 & 451.86 & 264.38 \\
\hline 160 & 804.02 & 232.97 & 588.50 & 209.33 & 516.47 & 237.83 & 493.69 & 326.88 \\
\hline 161 & 255.92 & 277.76 & 489.75 & 256.49 & 366.01 & 283.23 & 50.04 & 389.38 \\
\hline 162 & 316.82 & 322.48 & 119.10 & 302.94 & 413.55 & 327.55 & 92.85 & 451.88 \\
\hline 163 & 377.72 & 366.37 & 169.91 & 348.52 & 142.72 & 370.22 & 137.43 & 514.38 \\
\hline 164 & 438.62 & 409.25 & 221.35 & 393.31 & 194.40 & 411.59 & 183.75 & 576.88 \\
\hline 165 & 499.52 & 451.55 & 274.11 & 437.80 & 247.57 & 8.58 & 231.14 & 639.38 \\
\hline 166 & 560.42 & 45.34 & 327.40 & 37.51 & 301.37 & 49.48 & 278.87 & 76.87 \\
\hline 167 & 621.32 & 88.11 & 380.32 & 82.96 & 354.82 & 90.79 & 326.01 & 139.38 \\
\hline 168 & 682.22 & 132.44 & 432.44 & 129.78 & 406.85 & 133.47 & 371.60 & 201.88 \\
\hline 169 & 743.12 & 178.29 & 483.47 & 177.76 & 457.20 & 177.04 & 416.01 & 264.38 \\
\hline 170 & 804.02 & 225.37 & 533.94 & 226.28 & 505.90 & 220.87 & 460.19 & 326.88 \\
\hline 171 & 255.92 & 272.84 & 473.39 & 274.77 & 380.17 & 264.17 & 30.79 & 389.38 \\
\hline 172 & 316.82 & 319.96 & 119.27 & 322.57 & 428.35 & 305.85 & 77.46 & 451.88 \\
\hline 173 & 377.72 & 365.58 & 171.86 & 369.46 & 164.62 & 346.10 & 126.56 & 514.38 \\
\hline 174 & 438.62 & 409.59 & 226.45 & 415.29 & 215.46 & 385.01 & 177.77 & 576.88 \\
\hline 175 & 499.52 & 452.37 & 282.26 & 460.24 & 267.42 & 27.17 & 229.96 & 639.38 \\
\hline 176 & 560.42 & 16.03 & 338.48 & 45.51 & 320.12 & 65.40 & 281.49 & 76.87 \\
\hline 177 & 621.32 & 58.40 & 393.89 & 90.42 & 372.40 & 104.42 & 331.33 & 139.37 \\
\hline 178 & 682.22 & 102.24 & 448.20 & 136.66 & 423.79 & 145.53 & 379.00 & 202.12 \\
\hline 179 & 743.12 & 147.96 & 501.45 & 184.25 & 474.29 & 188.53 & 424.32 & 265.50 \\
\hline 180 & 804.02 & 195.13 & 553.85 & 232.71 & 523.95 & 233.21 & 468.21 & 329.87 \\
\hline 181 & 134.92 & 242.89 & 489.22 & 281.69 & 383.15 & 279.39 & 68.67 & 395.62 \\
\hline 182 & 195.82 & 290.29 & 54.84 & 330.44 & 434.14 & 325.96 & 114.21 & 463.00 \\
\hline 183 & 256.72 & 336.77 & 109.80 & 378.61 & 79.54 & 372.61 & 162.54 & 532.50 \\
\hline 184 & 317.62 & 382.03 & 166.64 & 425.35 & 134.32 & 418.91 & 213.46 & 603.75 \\
\hline 185 & 378.52 & 426.04 & 224.10 & 471.55 & 190.26 & 0.76 & 266.09 & 676.50 \\
\hline 186 & 439.42 & 0.15 & 281.92 & 0.19 & 246.43 & 46.82 & 319.00 & 0.37 \\
\hline 187 & 500.32 & 46.07 & 339.18 & 46.48 & 302.08 & 92.60 & 370.68 & 75.00 \\
\hline 188 & 561.46 & 94.63 & 395.61 & 93.68 & 356.19 & 140.53 & 420.01 & 150.00 \\
\hline 189 & 623.20 & 145.37 & 451.35 & 141.56 & 408.72 & 189.34 & 466.19 & 225.00 \\
\hline 190 & 685.92 & 197.17 & 507.11 & 189.96 & 459.67 & 238.35 & 510.45 & 300.00 \\
\hline 191 & 19.96 & 248.76 & 430.73 & 237.76 & 308.25 & 286.76 & 11.67 & 375.00 \\
\hline 192 & 85.58 & 298.53 & 15.73 & 284.89 & 359.09 & 333.37 & 57.09 & 450.00 \\
\hline 193 & 153.26 & 344.99 & 77.36 & 331.06 & 38.97 & 377.79 & 104.87 & 525.00 \\
\hline 194 & 222.63 & 388.02 & 141.97 & 376.67 & 91.78 & 418.84 & 155.85 & 600.00 \\
\hline 195 & 293.45 & 429.33 & 208.18 & 422.74 & 145.23 & 0.00 & 208.90 & 675.00 \\
\hline 196 & 365.36 & 0.00 & 274.98 & 0.00 & 199.43 & 39.13 & 262.16 & 0.00 \\
\hline 197 & 438.00 & 44.29 & 340.67 & 50.18 & 252.55 & 79.08 & 313.43 & 75.00 \\
\hline 198 & 511.00 & 92.25 & 404.17 & 103.10 & 304.42 & 121.99 & 361.62 & 150.00 \\
\hline 199 & 584.00 & 143.87 & 464.80 & 158.20 & 355.13 & 166.69 & 406.43 & 225.00 \\
\hline 200 & 657.00 & 197.97 & 523.03 & 214.26 & 405.20 & 212.63 & 448.87 & 300.00 \\
\hline 201 & 0.00 & 252.29 & 458.42 & 269.88 & 264.49 & 258.12 & 0.00 & 375.00 \\
\hline 202 & 73.00 & 304.33 & 10.45 & 323.47 & 316.10 & 301.91 & 44.13 & 450.00 \\
\hline
\end{tabular}




\begin{tabular}{|c|c|c|c|c|c|c|c|c|}
\hline 203 & 146.00 & 353.44 & 67.92 & 374.58 & 41.85 & 343.29 & 91.09 & $\begin{array}{l}525.00 \\
600.00\end{array}$ \\
\hline 204 & 219.00 & 399.22 & 128.27 & 423.58 & 100.55 & 382.58 & 140.70 & 600.00 \\
\hline 205 & 292.00 & 443.43 & 190.58 & 471.59 & 162.40 & 0.00 & 192.12 & 675.00 \\
\hline 206 & 365.00 & 0.00 & 254.15 & 0.00 & 226.59 & 39.85 & 243.71 & 0.00 \\
\hline 207 & 438.00 & 46.49 & 317.89 & 50.11 & 291.05 & 81.90 & 293.05 & 75.00 \\
\hline 208 & 511.00 & 96.25 & 380.62 & 103.18 & 353.40 & 127.58 & 340.14 & 150.00 \\
\hline 209 & 584.00 & 148.98 & 441.64 & 158.91 & 412.40 & 176.07 & 385.47 & 225.00 \\
\hline 210 & 657.00 & 203.79 & 500.33 & 216.19 & 467.04 & 226.49 & 430.59 & 300.00 \\
\hline 211 & 0.00 & 258.66 & 453.32 & 273.71 & 273.19 & 277.41 & 0.00 & 375.00 \\
\hline 212 & 73.00 & 311.79 & 11.60 & 329.90 & 323.21 & 327.91 & 49.60 & 450.00 \\
\hline 213 & 146.00 & 362.13 & 71.50 & 384.19 & 50.74 & 377.55 & 103.15 & 525.00 \\
\hline 214 & 219.00 & 409.91 & 134.96 & 436.44 & 105.17 & 426.15 & 159.59 & 600.00 \\
\hline 215 & 292.00 & 456.28 & 201.09 & 487.58 & 163.01 & 0.00 & 217.47 & 675.00 \\
\hline 216 & 365.00 & 0.00 & 269.21 & 0.00 & 224.44 & 48.79 & 274.58 & 0.00 \\
\hline 217 & 438.00 & 48.20 & 337.44 & 52.68 & 288.05 & 98.58 & 328.99 & 75.00 \\
\hline 218 & 511.00 & 99.36 & 403.67 & 107.95 & 351.85 & 150.02 & 380.64 & 150.00 \\
\hline 219 & 584.00 & 153.04 & 466.22 & 165.30 & 413.85 & 202.39 & 429.49 & 225.00 \\
\hline 220 & 657.00 & 207.88 & 524.80 & 223.86 & 473.22 & 255.21 & 476.80 & 300.00 \\
\hline 221 & 0.00 & 261.95 & 427.02 & 282.53 & 273.29 & 307.95 & 0.00 & 375.00 \\
\hline 222 & 73.00 & 313.74 & 13.30 & 340.00 & 329.78 & 360.58 & 48.89 & 450.00 \\
\hline 223 & 146.00 & 361.88 & 68.69 & 395.41 & 49.48 & 413.20 & 100.70 & 525.00 \\
\hline 224 & 219.00 & 406.92 & 127.96 & 448.67 & 108.87 & 465.89 & 154.81 & 600.00 \\
\hline 225 & 292.00 & 450.35 & 190.48 & 500.85 & 170.34 & 0.00 & 210.69 & 675.00 \\
\hline 226 & 365.00 & 0.00 & 255.49 & 0.00 & 233.30 & 54.88 & 267.41 & 0.00 \\
\hline 227 & 438.00 & 47.13 & 321.24 & 53.41 & 296.77 & 111.28 & 324.05 & 75.00 \\
\hline 228 & 511.00 & 98.74 & 385.44 & 108.90 & 359.80 & 169.12 & 379.91 & 150.00 \\
\hline 229 & 584.00 & 154.81 & 446.68 & 166.19 & 421.41 & 228.04 & 435.37 & 225.00 \\
\hline 230 & 657.00 & 213.54 & 504.19 & 224.38 & 480.95 & 287.68 & 491.44 & 300.00 \\
\hline 231 & 0.00 & 272.73 & 401.57 & 282.35 & 294.95 & 347.56 & 0.00 & 375.00 \\
\hline 232 & 73.00 & 330.22 & 15.66 & 338.67 & 353.85 & 407.11 & 58.56 & 450.00 \\
\hline 233 & 146.00 & 384.50 & 70.83 & 393.28 & 45.36 & 466.27 & 118.64 & 525.00 \\
\hline 234 & 219.00 & 435.04 & 130.72 & 446.03 & 108.36 & 525.03 & 180.05 & 600.00 \\
\hline 235 & 292.00 & 482.82 & 194.94 & 498.03 & 173.80 & 0.00 & 241.55 & 675.00 \\
\hline 236 & 365.00 & 0.00 & 263.44 & 0.00 & 240.95 & 58.04 & 301.42 & 0.00 \\
\hline 237 & 438.00 & 47.35 & 335.37 & 53.27 & 308.55 & 115.98 & 359.68 & 75.00 \\
\hline 238 & 511.00 & 96.63 & 409.40 & 108.57 & 375.34 & 174.26 & 416.64 & 150.00 \\
\hline 239 & 584.00 & 147.84 & 484.24 & 165.37 & 440.61 & 232.86 & 473.08 & 225.00 \\
\hline 240 & 657.00 & 200.90 & 558.36 & 223.19 & 503.68 & 291.86 & 530.01 & 300.00 \\
\hline 241 & 0.00 & 255.16 & 458.86 & 280.91 & 321.65 & 351.26 & 0.00 & 375.00 \\
\hline 242 & 73.00 & 309.88 & 19.00 & 338.16 & 382.85 & 411.05 & 61.73 & 450.00 \\
\hline 243 & 146.00 & 364.40 & 92.13 & 394.81 & 47.04 & 471.05 & 127.11 & 525.00 \\
\hline 244 & 219.00 & 418.91 & 165.98 & 451.02 & 110.91 & 531.05 & 195.14 & 600.00 \\
\hline 245 & 292.00 & 474.28 & 240.55 & 507.44 & 176.85 & 0.00 & 264.96 & 675.00 \\
\hline 246 & 365.00 & 0.00 & 315.93 & 0.00 & 245.07 & 60.00 & 335.81 & 0.00 \\
\hline 247 & 438.00 & 58.96 & 392.12 & 59.07 & 315.18 & 120.00 & 407.08 & 75.00 \\
\hline 248 & 511.00 & 119.55 & 468.56 & 120.02 & 386.33 & 179.70 & 478.38 & 149.63 \\
\hline 249 & 584.00 & 181.03 & 544.55 & 181.97 & 457.55 & 238.66 & 549.48 & 223.33 \\
\hline 250 & 657.00 & 242.13 & 619.39 & 244.15 & 527.89 & 296.42 & 620.94 & 295.56 \\
\hline 251 & 182.00 & 301.78 & 549.65 & 305.69 & 408.32 & 352.55 & 196.00 & 365.75 \\
\hline 252 & 255.00 & 358.87 & 197.18 & 365.87 & 475.99 & 406.74 & 269.33 & 433.54 \\
\hline 253 & 328.00 & 413.09 & 266.12 & 423.63 & 215.91 & 458.40 & 343.74 & 498.18 \\
\hline 254 & 401.00 & 465.05 & 333.04 & 479.08 & 280.14 & 507.97 & 418.69 & 560.23 \\
\hline 255 & 474.00 & 515.40 & 398.23 & 532.55 & 343.03 & 104.75 & 493.73 & 620.06 \\
\hline 256 & 547.00 & 106.49 & 462.13 & 100.98 & 404.93 & 151.19 & 568.41 & 113.22 \\
\hline 257 & 620.00 & 156.58 & 525.16 & 151.98 & 466.17 & 196.74 & 642.10 & 170.28 \\
\hline 258 & 692.64 & 207.41 & 587.67 & 202.48 & 526.93 & 241.84 & 714.59 & 226.78 \\
\hline 259 & 764.36 & 259.13 & 649.94 & 252.98 & 587.36 & 286.94 & 785.47 & 283.28 \\
\hline 260 & 834.63 & 311.44 & 711.83 & 303.48 & 647.26 & 332.04 & 854.69 & 339.78 \\
\hline 261 & 354.90 & 364.04 & 630.21 & 353.98 & 503.42 & 377.14 & 382.20 & 396.28 \\
\hline 262 & 420.80 & 416.64 & 254.98 & 404.48 & 561.70 & 422.24 & 448.07 & 452.78 \\
\hline 263 & 483.61 & 469.24 & 314.95 & 454.98 & 279.85 & 467.34 & 512.13 & 509.28 \\
\hline 264 & 543.87 & 521.84 & 374.26 & 505.48 & 336.06 & 512.44 & 574.71 & 565.78 \\
\hline 265 & 601.95 & 574.44 & 433.00 & 555.98 & 391.47 & 106.54 & 636.02 & 622.28 \\
\hline 266 & 658.38 & 107.01 & 491.32 & 101.48 & 446.27 & 151.64 & 696.37 & 113.78 \\
\hline 267 & 713.73 & 159.61 & 549.37 & 151.98 & 500.67 & 196.74 & 756.09 & 170.28 \\
\hline 268 & 768.53 & 212.21 & 607.27 & 202.48 & 554.87 & 241.84 & 815.49 & 226.77 \\
\hline 269 & 823.33 & 264.81 & 665.17 & 252.98 & 609.07 & 286.94 & 874.89 & 283.28 \\
\hline 270 & 878.13 & 317.41 & 723.07 & 303.48 & 663.27 & 332.04 & 934.29 & 339.78 \\
\hline 271 & 384.93 & 370.01 & 637.97 & 353.98 & 514.47 & 377.14 & 414.54 & 396.28 \\
\hline 272 & 439.73 & 422.61 & 259.87 & 404.48 & 568.67 & 422.24 & 473.94 & 452.77 \\
\hline 273 & 494.53 & 475.21 & 317.77 & 454.98 & 283.87 & 467.33 & 533.34 & 509.28 \\
\hline 274 & 549.33 & 527.81 & 375.67 & 505.48 & 338.07 & 512.43 & 592.74 & 565.78 \\
\hline 275 & 604.13 & 580.41 & 433.56 & 555.97 & 392.27 & 106.54 & 652.14 & 622.28 \\
\hline 276 & 658.93 & 107.01 & 491.46 & 101.47 & 446.47 & 151.64 & 711.54 & 113.77 \\
\hline 277 & 713.73 & 159.61 & 549.36 & 151.97 & 500.67 & 196.74 & 770.94 & 170.27 \\
\hline 278 & 768.53 & 212.21 & 607.27 & 202.47 & 554.87 & 241.84 & 830.34 & 226.77 \\
\hline 279 & 823.33 & 264.81 & 665.17 & 252.97 & 609.07 & 286.94 & 889.74 & 283.27 \\
\hline 280 & 878.13 & 317.41 & 723.07 & 303.47 & 663.27 & 332.04 & 949.14 & 339.78 \\
\hline 281 & 384.93 & 370.01 & 637.96 & 353.97 & 514.47 & 377.14 & 414.54 & 396.27 \\
\hline 282 & 439.73 & 422.61 & 259.86 & 404.47 & 568.67 & 422.24 & 473.94 & 452.77 \\
\hline 283 & 494.53 & 475.21 & 317.76 & 454.97 & 283.87 & 467.33 & 533.34 & 509.27 \\
\hline 284 & 549.33 & 527.81 & 375.66 & 505.47 & 338.07 & 512.43 & 592.74 & 565.77 \\
\hline 285 & 604.13 & 580.41 & 433.56 & 555.97 & 392.27 & 106.54 & 652.14 & 622.27 \\
\hline 286 & 658.93 & 107.01 & 491.46 & 101.47 & 446.47 & 151.64 & 711.54 & 113.77 \\
\hline 287 & 713.73 & 159.61 & 549.36 & 151.97 & 500.67 & 196.74 & 770.94 & 170.27 \\
\hline 288 & 768.53 & 212.21 & 607.26 & 202.47 & 554.87 & 241.84 & 830.34 & 226.77 \\
\hline
\end{tabular}




\begin{tabular}{|c|c|c|c|c|c|c|c|c|}
\hline 289 & 823.33 & 264.81 & 665.16 & 252.97 & 609.07 & 286.94 & 889.74 & $\begin{array}{l}283.27 \\
339.77\end{array}$ \\
\hline 290 & 878.13 & 317.41 & 723.07 & 303.47 & 663.27 & 332.04 & 949.14 & 339.77 \\
\hline 291 & 384.93 & 370.01 & 637.96 & 353.97 & 514.47 & 377.14 & 414.54 & 396.27 \\
\hline 292 & 439.73 & 422.61 & 259.86 & 404.47 & 568.67 & 422.23 & 473.94 & 452.77 \\
\hline 293 & 494.53 & 475.21 & 317.76 & 454.97 & 283.87 & 467.33 & 533.34 & 509.27 \\
\hline 294 & 549.33 & 527.81 & 375.66 & 505.47 & 338.07 & 512.43 & 592.74 & 565.77 \\
\hline 295 & 604.13 & 580.41 & 433.56 & 555.97 & 392.27 & 106.53 & 652.14 & 622.27 \\
\hline 296 & 658.93 & 107.01 & 491.46 & 101.47 & 446.47 & 151.63 & 711.54 & 113.77 \\
\hline 297 & 713.73 & 159.61 & 549.36 & 151.97 & 500.67 & 196.73 & 770.94 & 170.27 \\
\hline 298 & 768.53 & 212.21 & 607.26 & 202.47 & 554.87 & 241.83 & 830.34 & 226.77 \\
\hline 299 & 823.33 & 264.81 & 665.16 & 252.97 & 609.07 & 286.93 & 889.74 & 283.27 \\
\hline 300 & 878.13 & 317.41 & 723.06 & 303.47 & 663.27 & 332.04 & 949.14 & 339.77 \\
\hline 301 & 384.93 & 370.01 & 637.96 & 353.97 & 514.47 & 377.13 & 414.54 & 396.27 \\
\hline 302 & 439.73 & 422.61 & 259.86 & 404.47 & 568.67 & 422.23 & 473.94 & 452.77 \\
\hline 303 & 494.53 & 475.21 & 317.76 & 454.97 & 283.87 & 467.33 & 533.34 & 509.27 \\
\hline 304 & 549.33 & 527.81 & 375.66 & 505.47 & 338.07 & 512.43 & 592.74 & 565.77 \\
\hline 305 & 604.13 & 580.41 & 433.56 & 555.97 & 392.27 & 106.53 & 652.14 & 622.27 \\
\hline 306 & 658.93 & 107.01 & 491.46 & 101.47 & 446.47 & 151.63 & 711.54 & 113.77 \\
\hline 307 & 713.73 & 159.61 & 549.36 & 151.97 & 500.67 & 196.73 & 770.94 & 170.27 \\
\hline 308 & 768.53 & 211.86 & 606.97 & 202.13 & 554.64 & 241.53 & 830.34 & 226.39 \\
\hline 309 & 823.33 & 263.23 & 663.85 & 251.44 & 608.04 & 285.58 & 889.74 & 281.56 \\
\hline 310 & 878.13 & 313.19 & 719.56 & 299.39 & 660.53 & 328.41 & 949.14 & 335.21 \\
\hline 311 & 567.93 & 361.21 & 678.66 & 345.47 & 576.77 & 369.59 & 613.54 & 386.77 \\
\hline 312 & 622.73 & 406.95 & 440.87 & 389.34 & 626.52 & 408.80 & 672.94 & 435.86 \\
\hline 313 & 677.53 & 449.69 & 490.59 & 430.32 & 449.34 & 445.44 & 732.34 & 481.72 \\
\hline 314 & 732.33 & 489.97 & 538.27 & 468.92 & 495.56 & 479.97 & 791.74 & 524.92 \\
\hline 315 & 787.13 & 528.14 & 584.20 & 505.48 & 540.41 & 212.69 & 851.14 & 565.84 \\
\hline 316 & 841.93 & 214.72 & 628.82 & 205.51 & 584.24 & 244.05 & 910.54 & 230.05 \\
\hline 317 & 896.73 & 250.25 & 672.55 & 239.52 & 627.38 & 274.50 & 969.94 & 268.12 \\
\hline 318 & 951.16 & 285.25 & 715.76 & 273.02 & 670.04 & 304.50 & 1028.94 & 305.62 \\
\hline 319 & 1004.68 & 320.25 & 758.72 & 306.52 & 712.37 & 334.50 & 1086.95 & 343.12 \\
\hline 320 & 1056.74 & 355.25 & 801.30 & 340.02 & 754.15 & 364.50 & 1143.36 & 380.62 \\
\hline 321 & 741.78 & 390.25 & 748.35 & 373.52 & 660.18 & 394.50 & 802.59 & 418.12 \\
\hline 322 & 789.44 & 425.25 & 499.78 & 407.02 & 700.33 & 424.50 & 854.23 & 455.62 \\
\hline 323 & 833.99 & 460.25 & 540.39 & 440.52 & 514.32 & 454.50 & 902.48 & 493.12 \\
\hline 324 & 875.98 & 495.25 & 580.33 & 474.02 & 552.36 & 484.50 & 947.95 & 530.62 \\
\hline 325 & 915.78 & 530.25 & 619.70 & 507.52 & 589.58 & 214.50 & 991.04 & 568.12 \\
\hline 326 & 953.93 & 215.25 & 658.63 & 206.02 & 626.20 & 244.50 & 1032.33 & 230.62 \\
\hline 327 & 990.97 & 250.25 & 697.27 & 239.52 & 662.40 & 274.50 & 1072.42 & 268.12 \\
\hline 328 & 1027.47 & 285.25 & 735.77 & 273.02 & 698.40 & 304.50 & 1111.92 & 305.62 \\
\hline 329 & 1063.97 & 320.25 & 774.27 & 306.52 & 734.40 & 334.50 & 1151.42 & 343.12 \\
\hline 330 & 1100.47 & 355.25 & 812.77 & 340.02 & 770.40 & 364.50 & 1190.92 & 380.62 \\
\hline 331 & 771.97 & 390.25 & 756.27 & 373.52 & 671.40 & 394.50 & 835.42 & 418.12 \\
\hline 332 & 808.47 & 425.25 & 504.77 & 407.02 & 707.40 & 424.50 & 874.92 & 455.62 \\
\hline 333 & 844.98 & 460.25 & 543.27 & 440.52 & 518.40 & 454.50 & 914.42 & 493.12 \\
\hline 334 & 881.48 & 495.25 & 581.77 & 474.02 & 554.40 & 484.50 & 953.92 & 530.62 \\
\hline 335 & 917.98 & 530.25 & 620.27 & 507.52 & 590.40 & 214.50 & 993.42 & 568.12 \\
\hline 336 & 954.48 & 215.25 & 658.77 & 206.02 & 626.40 & 244.50 & 1032.92 & 230.62 \\
\hline 337 & 990.98 & 250.25 & 697.27 & 239.52 & 662.40 & 274.50 & 1072.42 & 268.12 \\
\hline 338 & 1027.47 & 285.25 & 735.77 & 273.02 & 698.40 & 304.50 & 1111.92 & 305.62 \\
\hline 339 & 1063.97 & 320.25 & 774.27 & 306.52 & 734.40 & 334.50 & 1151.42 & 343.12 \\
\hline 340 & 1100.47 & 355.25 & 812.77 & 340.02 & 770.40 & 364.50 & 1190.92 & 380.62 \\
\hline 341 & 771.97 & 390.25 & 756.27 & 373.52 & 671.40 & 394.50 & 835.42 & 418.12 \\
\hline 342 & 808.47 & 425.25 & 504.77 & 407.02 & 707.40 & 424.50 & 874.92 & 455.62 \\
\hline 343 & 844.98 & 460.25 & 543.27 & 440.52 & 518.40 & 454.50 & 914.42 & 493.12 \\
\hline 344 & 881.48 & 495.25 & 581.77 & 474.02 & 554.40 & 484.50 & 953.92 & 530.62 \\
\hline 345 & 917.98 & 530.25 & 620.27 & 507.52 & 590.40 & 214.50 & 993.42 & 568.12 \\
\hline 346 & 954.48 & 215.25 & 658.77 & 206.02 & 626.40 & 244.50 & 1032.92 & 230.62 \\
\hline 347 & 990.98 & 250.25 & 697.27 & 239.52 & 662.40 & 274.50 & 1072.42 & 268.12 \\
\hline 348 & 1027.47 & 285.25 & 735.77 & 273.02 & 698.40 & 304.50 & 1111.92 & 305.62 \\
\hline 349 & 1063.97 & 320.25 & 774.27 & 306.52 & 734.40 & 334.50 & 1151.42 & 343.12 \\
\hline 350 & 1100.47 & 355.25 & 812.77 & 340.02 & 770.40 & 364.50 & 1190.92 & 380.62 \\
\hline 351 & 771.97 & 390.25 & 756.27 & 373.52 & 671.40 & 394.50 & 835.42 & 418.12 \\
\hline 352 & 808.47 & 425.25 & 504.77 & 407.02 & 707.40 & 424.50 & 874.92 & 455.62 \\
\hline 353 & 844.98 & 460.25 & 543.27 & 440.52 & 518.40 & 454.50 & 914.42 & 493.12 \\
\hline 354 & 881.48 & 495.25 & 581.77 & 474.02 & 554.40 & 484.50 & 953.92 & 530.6 \\
\hline 355 & 917.98 & 530.25 & 620.27 & 507.52 & 590.40 & 214.50 & 993.42 & 568.12 \\
\hline 356 & 954.48 & 215.25 & 658.77 & 206.02 & 626.40 & 244.50 & 1032.92 & 230.62 \\
\hline 357 & 990.98 & 250.25 & 697.27 & 239.52 & 662.40 & 274.50 & 1072.42 & 268.12 \\
\hline 358 & 1027.47 & 285.25 & 735.77 & 273.02 & 698.40 & 304.50 & 1111.92 & 305.62 \\
\hline 359 & 1063.97 & 320.25 & 774.27 & 306.52 & 734.40 & 334.50 & 1151.42 & 343.12 \\
\hline 360 & 1100.47 & 355.25 & 812.77 & 340.02 & 770.40 & 364.50 & 1190.92 & 380.62 \\
\hline 361 & 771.97 & 390.25 & 756.27 & 373.52 & 671.40 & 394.50 & 835.42 & 418.1 \\
\hline 362 & 808.47 & 425.25 & 504.77 & 407.02 & 707.40 & 424.50 & 874.92 & 455.6 \\
\hline 363 & 844.98 & 460.25 & 543.27 & 440.52 & 518.40 & 454.50 & 914.42 & 493.1 \\
\hline 364 & 881.48 & 495.25 & 581.77 & 474.02 & 554.40 & 484.50 & 953.92 & 530.6 \\
\hline 365 & 917.98 & 530.25 & 620.27 & 507.52 & 590.40 & 214.50 & 993.42 & 568.12 \\
\hline 366 & 954.48 & 215.25 & 658.77 & 206.02 & 626.40 & 244.50 & 1032.92 & 230.62 \\
\hline 367 & 990.98 & 250.25 & 697.27 & 239.52 & 662.40 & 274.50 & 1072.42 & 268.12 \\
\hline 368 & 1027.47 & 284.55 & 735.19 & 272.35 & 697.95 & 303.90 & 1111.92 & 304.87 \\
\hline 369 & 1063.97 & 317.10 & 771.66 & 303.51 & 732.37 & 331.80 & 1151.42 & 339.75 \\
\hline 370 & 1100.47 & 346.85 & 805.81 & 331.98 & 765.00 & 357.30 & 1190.92 & 371.62 \\
\hline EPV & PORTO_1 & PORTO_2 & PORTO_3 & PORTO_4 & PORTO_5 & PORTO_6 & PORTO_7 & PORTO \\
\hline 000 & 314.25 & 876.78 & 372.75 & 479.22 & 486.90 & 361.00 & 616.75 & 501.00 \\
\hline
\end{tabular}




\begin{tabular}{|c|c|c|c|c|c|c|c|c|}
\hline 001 & 281.75 & 845.78 & 316.50 & 449.72 & 422.90 & 338.50 & 587.25 & 467.50 \\
\hline 002 & 249.25 & 814.78 & 232.75 & 420.22 & 397.40 & 316.00 & 557.75 & 434.00 \\
\hline 003 & 216.75 & 783.78 & 205.25 & 390.72 & 235.40 & 293.50 & 528.25 & 400.50 \\
\hline 004 & 184.25 & 752.78 & 177.75 & 361.22 & 209.90 & 267.00 & 498.75 & 367.00 \\
\hline 005 & 151.75 & 721.78 & 150.25 & 331.72 & 184.40 & 215.50 & 469.25 & 333.50 \\
\hline 006 & 119.25 & 690.78 & 122.75 & 302.22 & 158.90 & 189.00 & 439.75 & 300.00 \\
\hline 007 & 86.75 & 659.78 & 95.25 & 272.72 & 133.40 & 162.50 & 410.25 & 266.50 \\
\hline 008 & 60.55 & 628.78 & 74.45 & 243.22 & 114.00 & 136.00 & 386.75 & 233.00 \\
\hline 009 & 43.80 & 597.78 & 66.40 & 213.72 & 103.75 & 113.50 & 372.25 & 199.50 \\
\hline 010 & 36.50 & 566.78 & 72.45 & 184.22 & 107.25 & 91.00 & 366.75 & 166.00 \\
\hline 011 & 92.15 & 535.78 & 53.94 & 154.72 & 78.05 & 68.50 & 370.25 & 132.50 \\
\hline 012 & 96.60 & 504.78 & 38.50 & 125.22 & 110.60 & 52.50 & 379.75 & 99.00 \\
\hline 013 & 113.65 & 479.78 & 79.50 & 102.02 & 36.00 & 46.25 & 401.25 & 70.70 \\
\hline 014 & 121.25 & 463.78 & 115.85 & 88.27 & 72.60 & 45.75 & 413.75 & 50.20 \\
\hline 015 & 122.55 & 456.78 & 141.45 & 83.97 & 112.30 & 30.00 & 420.25 & 37.50 \\
\hline 016 & 114.40 & 458.78 & 154.30 & 89.12 & 135.95 & 45.75 & 417.75 & 155.60 \\
\hline 017 & 96.80 & 466.78 & 159.05 & 100.57 & 151.85 & 74.50 & 406.25 & 151.90 \\
\hline 018 & 75.05 & 486.78 & 156.40 & 124.62 & 162.30 & 93.50 & 391.75 & 158.60 \\
\hline 019 & 51.80 & 497.78 & 146.40 & 139.22 & 165.85 & 106.00 & 377.25 & 157.50 \\
\hline 020 & 36.50 & 502.78 & 146.45 & 147.52 & 176.25 & 108.75 & 371.75 & 151.20 \\
\hline 021 & 379.48 & 498.78 & 75.60 & 146.37 & 36.00 & 101.75 & 375.25 & 137.10 \\
\hline 022 & 377.43 & 485.78 & 100.50 & 135.77 & 62.55 & 91.50 & 384.75 & 115.20 \\
\hline 023 & 385.98 & 469.78 & 141.50 & 122.02 & 87.00 & 81.25 & 406.25 & 89.10 \\
\hline 024 & 386.58 & 453.78 & 177.85 & 108.27 & 128.10 & 80.75 & 418.75 & 60.60 \\
\hline 025 & 381.88 & 446.78 & 203.45 & 103.97 & 172.30 & 65.00 & 425.25 & 37.50 \\
\hline 026 & 369.23 & 448.78 & 216.30 & 109.12 & 200.45 & 80.75 & 422.75 & 229.80 \\
\hline 027 & 348.63 & 456.78 & 221.05 & 120.57 & 220.85 & 109.50 & 411.25 & 215.70 \\
\hline 028 & 324.18 & 476.78 & 218.40 & 144.62 & 231.30 & 128.50 & 396.75 & 208.80 \\
\hline 029 & 297.93 & 487.78 & 208.40 & 159.22 & 234.85 & 141.00 & 382.25 & 196.50 \\
\hline 030 & 277.83 & 492.78 & 208.45 & 167.52 & 245.25 & 143.75 & 376.75 & 180.60 \\
\hline 031 & 686.38 & 488.78 & 222.60 & 166.37 & 83.80 & 136.75 & 380.25 & 159.30 \\
\hline 032 & 676.53 & 475.78 & 162.50 & 155.77 & 110.35 & 126.50 & 389.75 & 132.60 \\
\hline 033 & 674.88 & 459.78 & 203.50 & 142.02 & 156.00 & 116.25 & 411.25 & 102.10 \\
\hline 034 & 667.08 & 443.78 & 239.85 & 128.27 & 197.10 & 115.75 & 423.75 & 68.60 \\
\hline 035 & 655.18 & 436.78 & 265.45 & 123.97 & 241.30 & 100.00 & 430.25 & 37.50 \\
\hline 036 & 637.13 & 438.78 & 278.30 & 129.12 & 269.45 & 115.75 & 427.75 & 459.07 \\
\hline 037 & 612.93 & 446.78 & 283.05 & 140.57 & 289.85 & 144.50 & 416.25 & 431.97 \\
\hline 038 & 586.68 & 466.78 & 280.40 & 164.62 & 300.30 & 163.50 & 401.75 & 408.07 \\
\hline 039 & 560.43 & 477.78 & 270.40 & 179.22 & 303.85 & 176.00 & 387.25 & 381.77 \\
\hline 040 & 540.33 & 482.78 & 270.45 & 187.52 & 314.25 & 178.75 & 381.75 & 353.87 \\
\hline 041 & 568.78 & 478.78 & 284.60 & 186.37 & 184.95 & 171.75 & 385.25 & 323.57 \\
\hline 042 & 558.93 & 465.78 & 214.90 & 175.77 & 211.50 & 161.50 & 394.75 & 290.87 \\
\hline 043 & 557.28 & 449.78 & 246.30 & 162.02 & 217.50 & 151.25 & 416.25 & 255.77 \\
\hline 044 & 549.48 & 433.78 & 273.05 & 148.27 & 251.10 & 150.75 & 428.75 & 218.27 \\
\hline 045 & 537.58 & 426.78 & 289.05 & 143.97 & 287.80 & 126.20 & 435.25 & 180.77 \\
\hline 046 & 519.53 & 418.48 & 292.30 & 139.22 & 308.45 & 133.15 & 432.75 & 487.50 \\
\hline 047 & 495.33 & 416.18 & 289.45 & 140.77 & 316.65 & 153.10 & 421.25 & 437.50 \\
\hline 048 & 467.18 & 425.88 & 279.20 & 154.92 & 321.60 & 163.30 & 406.75 & 387.50 \\
\hline 049 & 436.18 & 426.58 & 259.60 & 159.62 & 319.65 & 167.00 & 392.25 & 337.50 \\
\hline 050 & 408.48 & 421.28 & 250.05 & 158.02 & 324.55 & 160.95 & 386.75 & 287.50 \\
\hline 051 & 371.98 & 406.98 & 168.10 & 146.97 & 214.05 & 145.77 & 380.45 & 237.50 \\
\hline 052 & 337.68 & 383.68 & 181.90 & 126.47 & 230.10 & 126.72 & 380.15 & 187.50 \\
\hline 053 & 307.78 & 357.38 & 211.80 & 102.82 & 203.80 & 107.67 & 391.85 & 137.50 \\
\hline 054 & 274.58 & 331.08 & 237.05 & 79.17 & 234.40 & 98.37 & 394.55 & 87.50 \\
\hline 055 & 239.18 & 313.78 & 251.55 & 64.97 & 268.10 & 73.82 & 391.25 & 37.50 \\
\hline 056 & 200.48 & 305.48 & 253.30 & 60.22 & 285.75 & 80.77 & 378.95 & 493.20 \\
\hline 057 & 158.48 & 303.18 & 248.95 & 65.88 & 297.65 & 100.72 & 357.65 & 443.20 \\
\hline 058 & 117.42 & 312.88 & 237.20 & 84.73 & 299.60 & 110.92 & 333.35 & 393.20 \\
\hline 059 & 79.42 & 313.58 & 223.22 & 94.13 & 294.65 & 114.62 & 309.05 & 343.20 \\
\hline 060 & 47.77 & 308.28 & 212.17 & 97.23 & 296.55 & 113.87 & 293.75 & 293.20 \\
\hline 061 & 306.80 & 293.98 & 110.14 & 90.88 & 139.21 & 103.37 & 287.45 & 243.20 \\
\hline 062 & 285.75 & 270.68 & 115.02 & 75.08 & 155.26 & 89.62 & 287.15 & 193.20 \\
\hline 063 & 273.19 & 244.38 & 144.92 & 56.13 & 124.80 & 75.87 & 298.85 & 144.10 \\
\hline 064 & 254.27 & 218.08 & 170.17 & 45.50 & 155.40 & 71.87 & 301.55 & 96.37 \\
\hline 065 & 231.11 & 200.78 & 184.67 & 44.70 & 189.10 & 44.62 & 298.25 & 50.00 \\
\hline 066 & 201.59 & 192.48 & 186.42 & 44.70 & 214.75 & 56.87 & 285.95 & 452.09 \\
\hline 067 & 165.71 & 190.18 & 182.07 & 50.95 & 226.65 & 82.12 & 264.65 & 407.99 \\
\hline 068 & 126.45 & 199.88 & 170.32 & 69.80 & 228.60 & 97.62 & 240.35 & 365.70 \\
\hline 069 & 85.29 & 200.58 & 157.22 & 79.20 & 223.65 & 106.62 & 216.05 & 322.05 \\
\hline 070 & 48.60 & 195.28 & 154.17 & 82.30 & 225.55 & 105.87 & 200.75 & 277.49 \\
\hline 071 & 349.43 & 180.98 & 91.60 & 84.65 & 81.75 & 95.37 & 194.45 & 231.57 \\
\hline 072 & 320.18 & 157.68 & 57.02 & 77.55 & 105.80 & 81.88 & 194.15 & 184.29 \\
\hline 073 & 296.89 & 131.68 & 86.92 & 67.60 & 69.80 & 68.78 & 205.85 & 137.57 \\
\hline 074 & 269.13 & 107.05 & 112.17 & 53.00 & 100.40 & 65.82 & 208.55 & 92.35 \\
\hline 075 & 238.40 & 95.65 & 134.67 & 44.70 & 142.10 & 40.00 & 205.25 & 50.00 \\
\hline 076 & 203.20 & 93.70 & 144.42 & 46.30 & 167.75 & 48.64 & 192.95 & 413.30 \\
\hline 077 & 163.53 & 98.05 & 140.07 & 54.50 & 179.65 & 70.80 & 171.65 & 375.7 \\
\hline 078 & 122.92 & 115.00 & 128.76 & 75.90 & 182.50 & 84.62 & 147.93 & 342.00 \\
\hline 079 & 83.12 & 122.50 & 117.66 & 87.40 & 179.80 & 95.18 & 125.08 & 305.39 \\
\hline 080 & 48.60 & 123.70 & 118.62 & 92.30 & 185.30 & 95.60 & 112.10 & 266.87 \\
\hline 081 & 325.09 & 115.45 & 73.21 & 87.30 & 48.00 & 85.88 & 108.99 & 225.48 \\
\hline 082 & 299.37 & 97.75 & 51.30 & 81.10 & 77.90 & 73.48 & 112.46 & 181.2 \\
\hline 083 & 280.70 & 77.20 & 90.79 & 67.82 & 48.00 & 62.13 & 129.09 & 136.2 \\
\hline 084 & 256.74 & 57.10 & 126.77 & 50.92 & 78.90 & 61.97 & 135.85 & 91.51 \\
\hline 085 & 229.26 & 46.90 & 150.21 & 44.70 & 118.00 & 40.00 & 136.03 & 50.00 \\
\hline 086 & 196.51 & 46.60 & 159.34 & 44.70 & 139.70 & 53.19 & 126.34 & 405.21 \\
\hline
\end{tabular}




\begin{tabular}{|c|c|c|c|c|c|c|c|c|}
\hline 087 & 158.47 & 52.90 & 152.36 & 51.74 & 146.30 & 81.30 & 106.78 & $\begin{array}{l}369.00 \\
337.04\end{array}$ \\
\hline 088 & 119.24 & 72.40 & 136.41 & 77.56 & 143.48 & 98.22 & 84.53 & 337.04 \\
\hline 089 & 80.85 & 82.00 & 118.66 & 92.70 & 141.00 & 107.68 & 63.18 & 301.89 \\
\hline 090 & 48.60 & 85.00 & 118.62 & 100.72 & 151.56 & 105.95 & 52.60 & 264.62 \\
\hline 091 & 305.75 & 78.10 & 71.13 & 98.06 & 48.00 & 93.03 & 52.79 & 224.17 \\
\hline 092 & 283.72 & 61.30 & 51.30 & 84.72 & 88.82 & $\begin{array}{l}76.98 \\
61.83\end{array}$ & 60.16 & 180.54 \\
\hline 093 & 269.85 & 46.60 & 84.09 & 67.82 & 48.00 & 61.83 & 81.89 & 135.89 \\
\hline 094 & 249.86 & 46.60 & 113.37 & 50.92 & 93.16 & 58.77 & 92.85 & 91.32 \\
\hline 095 & 225.78 & 46.60 & 135.92 & 44.70 & 141.82 & 40.00 & 96.63 & 50.00 \\
\hline 096 & 195.57 & 46.60 & 145.05 & 44.70 & 175.91 & 57.09 & 89.64 & 481.31 \\
\hline 097 & 159.24 & 50.54 & 140.64 & 51.58 & 192.28 & 90.30 & 71.88 & 445.41 \\
\hline 098 & 120.64 & 68.40 & 133.65 & 72.70 & 195.58 & 111.42 & 52.60 & 413.86 \\
\hline 099 & 81.72 & 80.52 & 126.30 & 85.43 & 189.54 & 124.48 & 52.60 & 379.05 \\
\hline 100 & 48.60 & 85.68 & 123.10 & 93.45 & 192.28 & 125.45 & 52.60 & 342.07 \\
\hline 101 & 311.81 & 80.40 & 77.37 & 90.79 & 48.00 & 114.33 & 55.65 & 301.84 \\
\hline 102 & 288.38 & 64.68 & 51.30 & 77.45 & 73.29 & 99.18 & 66.40 & 258.35 \\
\hline 103 & 272.68 & 46.60 & 98.95 & 60.85 & 53.64 & 84.03 & 92.55 & 213.87 \\
\hline 104 & 251.18 & 46.60 & 141.65 & 44.70 & 104.03 & 80.97 & 107.15 & 169.55 \\
\hline 105 & 225.81 & 46.60 & 170.85 & 44.70 & 159.20 & 57.00 & 114.05 & 128.63 \\
\hline 106 & 194.63 & 46.60 & 185.20 & 46.11 & 193.92 & 74.09 & 109.40 & 515.73 \\
\hline 107 & 157.64 & 50.54 & 189.10 & 54.94 & 211.25 & 107.30 & 93.20 & 480.49 \\
\hline 108 & 118.98 & 73.10 & 183.89 & 78.61 & 215.93 & 128.42 & 73.15 & 449.78 \\
\hline 109 & 80.69 & 85.22 & 177.39 & 95.85 & 219.86 & 141.48 & 53.10 & 415.67 \\
\hline 110 & 48.60 & 90.38 & 183.55 & 105.67 & 228.14 & 142.45 & 52.60 & 379.30 \\
\hline 111 & 355.29 & 75.80 & 75.97 & 95.76 & 57.90 & 122.43 & 55.65 & 327.01 \\
\hline 112 & 333.51 & 50.78 & 96.23 & 74.72 & 83.69 & 98.38 & 65.90 & 271.32 \\
\hline 113 & 319.99 & 46.60 & 136.97 & 49.97 & 79.32 & 74.33 & 92.05 & 214.32 \\
\hline 114 & 300.27 & 46.60 & 172.25 & 44.70 & 124.37 & 66.17 & 106.65 & 157.06 \\
\hline 115 & 276.44 & 46.60 & 201.38 & 44.70 & 173.89 & 40.00 & 113.55 & 102.94 \\
\hline 116 & 246.41 & 46.60 & 216.56 & 44.70 & 209.95 & 48.19 & 108.90 & 534.56 \\
\hline 117 & 210.19 & 49.19 & 213.68 & 49.63 & 230.70 & 72.50 & 92.70 & 485.68 \\
\hline 118 & 171.53 & 66.70 & 201.68 & 69.40 & 238.62 & 91.42 & 72.65 & 440.98 \\
\hline 119 & 132.32 & 73.02 & 188.44 & 78.04 & 237.75 & 102.28 & 52.60 & 393.15 \\
\hline 120 & 98.74 & 71.88 & 188.31 & 79.26 & 245.93 & 101.05 & 52.60 & 343.22 \\
\hline 121 & 436.78 & 59.55 & 64.20 & 69.35 & 60.00 & 87.73 & 65.90 & 290.14 \\
\hline 122 & 400.29 & 58.40 & 85.14 & 55.80 & 93.47 & 70.38 & 66.75 & 233.93 \\
\hline 123 & 371.32 & 58.40 & 127.36 & 55.80 & 65.67 & 53.03 & 83.00 & 176.29 \\
\hline 124 & 336.71 & 58.40 & 162.98 & 55.80 & 119.66 & 50.00 & 87.70 & 118.10 \\
\hline 125 & 298.34 & 58.40 & 184.56 & 55.80 & 177.84 & 50.00 & 84.70 & 62.50 \\
\hline 126 & 254.34 & 58.40 & 199.32 & 55.80 & 214.69 & 58.19 & 70.15 & 541.36 \\
\hline 127 & 204.71 & 62.68 & 195.56 & 59.48 & 233.28 & 82.50 & 65.90 & 490.06 \\
\hline 128 & 153.88 & 82.40 & 182.23 & 85.20 & 238.58 & 94.72 & 65.90 & 442.22 \\
\hline 129 & 104.06 & 90.54 & 167.32 & 98.74 & 234.64 & 105.58 & 65.90 & 391.79 \\
\hline 130 & 60.90 & 90.96 & 166.04 & 104.16 & 239.71 & 104.35 & 65.90 & 339.63 \\
\hline 131 & 416.35 & 79.80 & 64.20 & 97.40 & 60.00 & 91.03 & 65.90 & 284.89 \\
\hline 132 & 384.27 & 66.86 & 64.20 & 78.46 & 94.41 & 74.56 & 66.75 & 227.56 \\
\hline 133 & 361.07 & 58.40 & 107.31 & 56.02 & 60.00 & 59.41 & 83.00 & 170.29 \\
\hline 134 & 331.21 & 58.40 & 144.10 & 55.80 & 96.29 & 57.67 & 87.70 & 114.41 \\
\hline 135 & 296.92 & 58.40 & 166.63 & 55.80 & 144.52 & 50.00 & 84.70 & 62.50 \\
\hline 136 & 255.97 & 58.40 & 172.21 & 55.80 & 181.25 & 58.11 & 70.15 & 505.02 \\
\hline 137 & 208.38 & 66.32 & 169.07 & 56.42 & 199.75 & 84.10 & 65.90 & 459.73 \\
\hline 138 & 157.94 & 90.80 & 156.57 & 86.90 & 206.00 & 96.68 & 65.90 & 419.73 \\
\hline 139 & 106.56 & 102.86 & 143.51 & 104.36 & 204.52 & 111.22 & 65.90 & 375.76 \\
\hline 140 & 60.90 & 106.64 & 145.39 & 113.14 & 213.53 & 113.95 & 65.90 & 329.14 \\
\hline 141 & 435.05 & 98.00 & 64.20 & 108.90 & 60.00 & 103.27 & 65.90 & 278.55 \\
\hline 142 & 398.91 & 76.94 & 64.20 & 91.64 & 100.82 & 88.82 & 72.21 & 224.00 \\
\hline 143 & 370.39 & 58.74 & 106.44 & 70.60 & 60.00 & 75.42 & 95.60 & 168.40 \\
\hline 144 & 336.15 & 58.40 & 142.91 & 55.80 & 103.19 & 76.48 & 106.18 & 113.25 \\
\hline 145 & 298.11 & 58.40 & 163.82 & 55.80 & 150.70 & 50.00 & 108.22 & 62.50 \\
\hline 146 & 254.35 & 58.40 & 169.06 & 55.80 & 191.86 & 62.66 & 97.45 & 493.87 \\
\hline 147 & 204.88 & 62.47 & 161.55 & 60.06 & 213.32 & 94.60 & 73.87 & 450.46 \\
\hline 148 & 154.10 & 89.50 & 151.46 & 82.80 & 221.53 & 112.08 & 65.90 & 412.93 \\
\hline 149 & 104.20 & 103.66 & 139.62 & 101.36 & 221.25 & 119.92 & 65.90 & 371.00 \\
\hline 150 & 60.90 & 109.24 & 142.31 & 113.50 & 233.15 & 115.06 & 65.90 & 326.12 \\
\hline 151 & 419.12 & 101.95 & 64.20 & 111.78 & 60.00 & 106.48 & 65.90 & 276.84 \\
\hline 152 & 386.82 & 81.79 & 64.20 & 96.20 & 90.28 & 92.23 & 65.90 & 223.16 \\
\hline 153 & 363.33 & 58.40 & 108.55 & 76.00 & 60.00 & 76.73 & 88.18 & 168.0 \\
\hline 154 & 333.23 & 58.40 & 149.39 & 55.80 & 112.78 & 74.42 & 102.96 & 113.03 \\
\hline 155 & 298.74 & 58.40 & 182.57 & 55.80 & 170.24 & 50.00 & 108.60 & 62.50 \\
\hline 156 & 257.64 & 58.40 & 197.25 & 55.80 & 210.26 & 57.18 & 108.03 & 496.10 \\
\hline 157 & 209.94 & 64.94 & 199.50 & 60.06 & 233.91 & 81.96 & 93.75 & 453.05 \\
\hline 158 & 159.25 & 89.40 & 190.98 & 89.50 & 245.86 & 93.54 & 75.34 & 415.97 \\
\hline 159 & 107.37 & 100.42 & 180.09 & 105.08 & 245.20 & 96.32 & 65.90 & 374.4 \\
\hline 160 & 60.90 & 102.48 & 182.60 & 111.42 & 253.54 & 98.41 & 65.90 & 329.8 \\
\hline 161 & 452.70 & 96.90 & 64.20 & 103.90 & 60.00 & 87.30 & 65.90 & 280.8 \\
\hline 162 & 415.25 & 77.88 & 83.61 & 82.52 & 82.66 & 72.58 & 65.90 & 227.30 \\
\hline 163 & 385.02 & 58.40 & 126.37 & 62.50 & 60.00 & 62.48 & 81.46 & 171.71 \\
\hline 164 & 349.37 & 58.40 & 161.08 & 55.80 & 105.03 & 70.05 & 92.79 & 115.28 \\
\hline 165 & 310.12 & 58.40 & 190.68 & 55.80 & 163.94 & 50.00 & 101.09 & 62.50 \\
\hline 166 & 265.46 & 58.40 & 201.90 & 55.80 & 199.57 & 62.34 & 95.02 & 574.24 \\
\hline 167 & 215.38 & 64.94 & 195.68 & 61.21 & 215.56 & 93.87 & 84.37 & 527.53 \\
\hline 168 & 162.93 & 89.40 & 185.69 & 92.16 & 227.93 & 116.80 & 75.05 & 485.68 \\
\hline 169 & 109.64 & 101.43 & 175.83 & 108.97 & 231.51 & 130.15 & 65.90 & 440.1 \\
\hline 170 & 60.90 & 109.29 & 183.15 & 116.38 & 246.30 & 129.11 & 65.90 & 392.2 \\
\hline 171 & 479.21 & 94.61 & 64.20 & 99.75 & 60.00 & 104.88 & 65.90 & 328.18 \\
\hline 172 & 438.08 & 66.49 & 82.96 & 84.00 & 85.99 & 76.37 & 69.05 & 260.47 \\
\hline
\end{tabular}




\begin{tabular}{|c|c|c|c|c|c|c|c|c|}
\hline 173 & 403.02 & 58.40 & 139.27 & 63.67 & 62.44 & 50.00 & 93.10 & 192.23 \\
\hline 174 & 363.41 & 58.40 & 188.05 & 55.80 & 119.92 & 50.00 & 102.60 & 125.02 \\
\hline 175 & 320.75 & 58.40 & 228.12 & 55.80 & 183.04 & 50.00 & 102.40 & 62.50 \\
\hline 176 & 273.54 & 58.40 & 247.98 & 55.80 & 232.17 & 55.63 & 87.65 & 596.65 \\
\hline 177 & 221.76 & 58.40 & 245.50 & 58.81 & 259.14 & 81.44 & 75.85 & 541.92 \\
\hline 178 & 171.18 & 76.81 & 231.84 & 80.90 & 270.09 & 99.12 & 65.90 & 493.43 \\
\hline 179 & 124.66 & 81.03 & 217.09 & 103.68 & 270.00 & 106.69 & 65.90 & 440.26 \\
\hline 180 & 86.78 & 75.79 & 219.48 & 116.92 & 281.03 & 99.13 & 65.90 & 383.97 \\
\hline 181 & 480.38 & 70.00 & 77.00 & 115.85 & 72.00 & 76.41 & 79.00 & 323.01 \\
\hline 182 & 444.79 & 70.00 & 97.29 & 100.47 & 114.08 & 68.07 & 79.00 & 257.37 \\
\hline 183 & 420.71 & 70.00 & 144.40 & 81.02 & 72.00 & 60.18 & 91.45 & 192.10 \\
\hline 184 & 387.99 & 70.00 & 184.49 & 69.62 & 119.59 & 74.16 & 89.35 & 129.76 \\
\hline 185 & 349.52 & 70.00 & 215.95 & 67.00 & 193.53 & 60.00 & 91.55 & 75.00 \\
\hline 186 & 302.42 & 70.00 & 226.17 & 67.00 & 241.03 & 60.09 & 84.51 & 533.10 \\
\hline 187 & 246.69 & 70.00 & 224.90 & 67.00 & 265.90 & 78.66 & 79.00 & 491.00 \\
\hline 188 & 187.21 & 82.79 & 211.30 & 87.04 & 278.47 & 83.37 & 79.00 & 459.01 \\
\hline 189 & 126.44 & 80.97 & 195.22 & 91.72 & 284.85 & 85.83 & 79.00 & 419.44 \\
\hline 190 & 73.00 & 87.41 & 209.54 & 101.16 & 302.64 & 82.55 & 79.00 & 374.81 \\
\hline 191 & 527.63 & 79.24 & 77.00 & 102.05 & 72.00 & 79.28 & 79.00 & 322.58 \\
\hline 192 & 486.42 & 76.07 & 96.03 & 88.77 & 96.68 & 72.99 & 79.00 & 262.76 \\
\hline 193 & 455.00 & 70.00 & 147.31 & 70.95 & 72.00 & 69.07 & 90.49 & 199.31 \\
\hline 194 & 416.23 & 70.00 & 194.72 & 67.00 & 120.91 & 81.41 & 88.58 & 134.19 \\
\hline 195 & 372.58 & 70.00 & 224.58 & 67.00 & 174.98 & 60.00 & 108.10 & 75.00 \\
\hline 196 & 321.59 & 70.00 & 233.42 & 67.00 & 202.32 & 70.42 & 113.24 & 585.80 \\
\hline 197 & 263.26 & 70.00 & 219.11 & 70.33 & 206.76 & 102.52 & 104.00 & 536.49 \\
\hline 198 & 200.45 & 87.72 & 206.96 & 95.30 & 216.53 & 118.36 & 90.85 & 495.09 \\
\hline 199 & 134.58 & 96.93 & 193.02 & 104.04 & 227.16 & 132.28 & 79.00 & 447.76 \\
\hline 200 & 73.00 & 106.85 & 208.23 & 114.96 & 265.35 & 133.04 & 79.00 & 396.48 \\
\hline 201 & 591.64 & 109.29 & 77.00 & 109.65 & 72.00 & 117.54 & 79.00 & 339.27 \\
\hline 202 & 537.19 & 96.25 & 97.68 & 93.65 & 102.53 & 99.16 & 79.00 & 276.13 \\
\hline 203 & 488.45 & 77.24 & 145.36 & 76.06 & 72.00 & 80.50 & 88.92 & 209.45 \\
\hline 204 & 435.43 & 70.00 & 184.91 & 67.00 & 127.21 & 86.45 & 91.33 & 140.43 \\
\hline 205 & 379.55 & 70.00 & 206.54 & 67.00 & 186.68 & 60.00 & 106.72 & 75.00 \\
\hline 206 & 319.40 & 70.00 & 206.83 & 67.00 & 218.07 & 76.29 & 106.79 & 640.49 \\
\hline 207 & 254.96 & 70.00 & 197.55 & 72.65 & 238.21 & 116.05 & 100.18 & 581.04 \\
\hline 208 & 190.61 & 80.79 & 184.09 & 100.65 & 241.58 & 138.21 & 89.05 & 526.38 \\
\hline 209 & 128.53 & 77.32 & 171.22 & 111.89 & 233.83 & 155.17 & 79.00 & 468.12 \\
\hline 210 & 73.00 & 71.24 & 193.32 & 118.59 & 257.77 & 159.98 & 79.00 & 407.48 \\
\hline 211 & 536.69 & 72.49 & 77.00 & 114.88 & 72.00 & 147.19 & 79.49 & 343.24 \\
\hline 212 & 492.08 & 70.00 & 93.77 & 103.41 & 106.97 & 129.20 & 91.16 & 275.42 \\
\hline 213 & 456.21 & 70.00 & 136.57 & 86.09 & 72.00 & 112.20 & 125.19 & 206.81 \\
\hline 214 & 413.79 & 70.00 & 171.05 & 68.36 & 133.55 & 101.80 & 142.45 & 138.80 \\
\hline 215 & 367.00 & 70.00 & 188.44 & 67.00 & 200.52 & 60.00 & 150.63 & 75.00 \\
\hline 216 & 313.65 & 70.00 & 193.08 & 67.00 & 240.92 & 80.60 & 148.94 & 626.05 \\
\hline 217 & 253.76 & 70.00 & 181.35 & 70.91 & 266.04 & 126.00 & 130.48 & 569.25 \\
\hline 218 & 191.53 & 91.54 & 164.54 & 96.64 & 279.99 & 152.80 & 106.95 & 518.04 \\
\hline 219 & 129.10 & 96.92 & 163.24 & 106.01 & 279.90 & 167.20 & 84.20 & 462.63 \\
\hline 220 & 73.00 & 93.79 & 185.78 & 117.46 & 291.05 & 163.00 & 79.00 & 404.43 \\
\hline 221 & 552.58 & 85.25 & 77.00 & 112.55 & 72.00 & 140.20 & 81.95 & 342.02 \\
\hline 222 & 507.05 & 78.56 & 103.02 & 100.28 & 100.27 & 111.20 & 79.00 & 275.42 \\
\hline 223 & 469.97 & 74.70 & 157.62 & 83.18 & 88.43 & 82.20 & 99.45 & 207.34 \\
\hline 224 & 426.54 & 71.15 & 203.20 & 67.00 & 142.58 & 77.98 & 129.35 & 139.13 \\
\hline 225 & 378.90 & 70.00 & 229.97 & 67.00 & 202.97 & 60.00 & 147.55 & 75.00 \\
\hline 226 & 324.91 & 70.00 & 234.19 & 67.00 & 235.44 & 80.60 & 148.20 & 596.71 \\
\hline 227 & 264.59 & 84.37 & 213.59 & 74.94 & 244.14 & 126.00 & 131.30 & 539.38 \\
\hline 228 & 200.74 & 120.70 & 179.75 & 105.94 & 245.04 & 152.80 & 108.55 & 487.48 \\
\hline 229 & 134.76 & 140.56 & 152.37 & 131.28 & 236.68 & 167.20 & 85.80 & 431.50 \\
\hline 230 & 73.00 & 149.44 & 142.99 & 146.46 & 234.01 & 163.00 & 79.00 & 372.80 \\
\hline 231 & 565.68 & 146.49 & 77.00 & 144.34 & 72.00 & 140.20 & 200.78 & 310.03 \\
\hline 232 & 510.94 & 130.43 & 79.52 & 124.93 & 75.97 & 110.12 & 197.83 & 243.18 \\
\hline 233 & 461.82 & 109.38 & 132.93 & 99.80 & 105.32 & 78.41 & 223.85 & 179.29 \\
\hline 234 & 408.49 & 81.08 & 178.86 & 74.72 & 131.42 & 63.68 & 235.75 & 121.87 \\
\hline 235 & 352.35 & 70.00 & 205.82 & 67.00 & 165.27 & 60.00 & 235.95 & 75.00 \\
\hline 236 & 291.99 & 70.00 & 210.48 & 86.45 & 177.30 & 73.56 & 218.60 & 323.30 \\
\hline 237 & 227.42 & 74.62 & 190.40 & 94.65 & 171.23 & 109.75 & 183.70 & 294.01 \\
\hline 238 & 166.68 & 102.20 & 153.90 & 125.99 & 149.95 & 128.97 & 142.95 & 278.78 \\
\hline 239 & 113.80 & 112.56 & 109.58 & 139.98 & 116.77 & 136.87 & 102.20 & 253.01 \\
\hline 240 & 73.00 & 124.35 & 77.00 & 142.40 & 87.73 & 127.79 & 79.00 & 220.20 \\
\hline 241 & 353.34 & 133.21 & 77.00 & 143.97 & 72.00 & 116.64 & 215.98 & 195.35 \\
\hline 242 & 332.66 & 124.85 & 92.92 & 128.17 & 75.55 & 97.43 & 213.03 & 159.94 \\
\hline 243 & 328.07 & 109.40 & 129.94 & 104.76 & 100.37 & 74.60 & 233.48 & 123.86 \\
\hline 244 & 311.42 & 82.10 & 163.27 & 78.58 & 120.64 & 65.14 & 236.38 & 92.03 \\
\hline 245 & 286.71 & 70.00 & 181.63 & 67.00 & 145.04 & 60.00 & 236.58 & 75.00 \\
\hline 246 & 249.93 & 73.08 & 183.06 & 70.01 & 151.46 & 72.81 & 219.23 & 118.77 \\
\hline 247 & 201.08 & 86.29 & 165.35 & 82.75 & 142.61 & 103.44 & 184.33 & 126.4 \\
\hline 248 & 150.66 & 119.74 & 135.58 & 114.95 & 122.34 & 120.70 & 143.50 & 153.7 \\
\hline 249 & 103.95 & 138.00 & 101.29 & 132.56 & 93.95 & 129.06 & 102.54 & 166.36 \\
\hline 250 & 73.00 & 146.15 & 77.00 & 140.44 & 72.00 & 124.05 & 79.00 & 169.07 \\
\hline 251 & 77.93 & 139.10 & 74.02 & 133.72 & 54.20 & 105.67 & 83.48 & 156.97 \\
\hline 252 & 91.46 & 116.88 & 84.11 & 112.41 & 61.22 & 83.13 & 99.58 & 130.07 \\
\hline 253 & 126.03 & 89.91 & 112.36 & 86.50 & 88.33 & 61.02 & 138.91 & 99.19 \\
\hline 254 & 144.82 & 63.42 & 137.99 & 61.00 & 110.24 & 52.70 & 160.82 & 69.73 \\
\hline 255 & 153.10 & 52.60 & 150.54 & 50.50 & 134.86 & 45.10 & 171.11 & 56.50 \\
\hline 256 & 145.61 & 57.45 & 148.48 & 55.00 & 142.68 & 59.77 & 163.98 & 86.79 \\
\hline 257 & 122.35 & 72.74 & 129.80 & 69.50 & 136.01 & 92.83 & 139.43 & 100.59 \\
\hline 258 & 94.13 & 108.92 & 102.90 & 104.00 & 120.91 & 112.10 & 109.27 & 136.03 \\
\hline
\end{tabular}




\begin{tabular}{|c|c|c|c|c|c|c|c|c|}
\hline 259 & 66.36 & 129.44 & 74.90 & 123.50 & 101.57 & 122.17 & 79.43 & $\begin{array}{l}155.25 \\
163.65\end{array}$ \\
\hline 260 & 54.80 & 139.51 & 57.90 & 133.00 & 92.09 & 118.45 & 67.31 & 163.65 \\
\hline 261 & 59.46 & 133.91 & 57.90 & 127.49 & 54.20 & 100.93 & 72.93 & 155.83 \\
\hline 262 & 74.93 & 112.65 & 70.71 & 106.99 & 71.49 & 81.07 & 90.36 & 131.78 \\
\hline 263 & 112.03 & 86.66 & 103.23 & 82.16 & 111.94 & 64.58 & 131.44 & 101.90 \\
\hline 264 & 132.91 & 61.42 & 129.08 & 58.33 & 144.08 & 65.26 & 154.79 & 71.40 \\
\hline 265 & 142.98 & 52.60 & 142.12 & 50.50 & 176.38 & 45.10 & 166.31 & 56.50 \\
\hline 266 & 136.83 & 60.20 & 139.64 & 58.67 & 189.72 & 74.39 & 160.11 & 105.95 \\
\hline 267 & 114.46 & 78.74 & 120.17 & 77.51 & 186.24 & 126.56 & 136.17 & 117.05 \\
\hline 268 & 87.68 & 119.16 & 95.45 & 117.68 & 173.85 & 161.57 & 105.66 & 148.95 \\
\hline 269 & 62.39 & 143.18 & 74.19 & 141.86 & 157.57 & 185.13 & 74.16 & 165.25 \\
\hline 270 & 54.80 & 156.24 & 70.35 & 155.36 & 156.17 & 191.53 & 59.40 & 171.15 \\
\hline 271 & 64.92 & 152.90 & 88.35 & 152.86 & 82.42 & 180.76 & 103.98 & 161.45 \\
\hline 272 & 86.84 & 133.13 & 122.32 & 134.37 & 118.33 & 164.39 & 117.12 & 136.15 \\
\hline 273 & 132.36 & 108.07 & 182.62 & 111.14 & 183.63 & 148.19 & 152.58 & 105.15 \\
\hline 274 & 160.18 & 83.27 & 230.89 & 88.83 & 240.05 & 149.33 & 171.30 & 73.40 \\
\hline 275 & 176.20 & 75.15 & 263.18 & 83.43 & 298.80 & 129.81 & 178.86 & 56.50 \\
\hline 276 & 174.51 & 83.71 & 275.03 & 94.94 & 333.18 & 159.85 & 169.68 & 126.08 \\
\hline 277 & 155.12 & 103.39 & 265.03 & 117.73 & 346.30 & 213.01 & 143.76 & 133.93 \\
\hline 278 & 129.53 & 145.31 & 245.94 & 163.06 & 344.20 & 248.83 & 111.38 & 161.58 \\
\hline 279 & 103.48 & 170.55 & 228.09 & 191.49 & 331.48 & 273.09 & 77.68 & 174.38 \\
\hline 280 & 94.68 & 184.67 & 231.08 & 208.64 & 330.14 & 280.01 & 59.40 & 177.28 \\
\hline 281 & 103.13 & 182.11 & 259.12 & 208.87 & 256.13 & 269.59 & 142.54 & 165.33 \\
\hline 282 & 123.08 & 162.87 & 305.83 & 192.20 & 289.17 & 252.49 & 149.96 & 138.53 \\
\hline 283 & 166.03 & 137.53 & 382.01 & 169.97 & 350.92 & 234.04 & 177.94 & 106.56 \\
\hline 284 & 191.73 & 111.38 & 446.92 & 147.87 & 405.86 & 231.58 & 190.50 & 74.27 \\
\hline 285 & 205.93 & 101.10 & 493.16 & 142.81 & 465.48 & 207.11 & 192.78 & 56.50 \\
\hline 286 & 202.88 & 106.69 & 516.33 & 154.79 & 500.98 & 231.30 & 179.64 & 137.88 \\
\hline 287 & 182.58 & 122.86 & 514.44 & 178.13 & 515.82 & 276.81 & 151.08 & 144.32 \\
\hline 288 & 156.53 & 160.19 & 498.82 & 224.19 & 515.68 & 306.33 & 116.58 & 170.12 \\
\hline 289 & 130.48 & 181.65 & 479.19 & 253.21 & 505.16 & 325.19 & 80.88 & 181.40 \\
\hline 290 & 121.68 & 192.53 & 476.72 & 270.87 & 504.89 & 328.06 & 59.40 & 183.00 \\
\hline 291 & 130.13 & 187.54 & 497.32 & 271.49 & 429.57 & 314.94 & 172.14 & 170.08 \\
\hline 292 & 150.08 & 166.68 & 535.33 & 255.07 & 462.51 & 296.49 & 174.36 & 142.63 \\
\hline 293 & 193.03 & 140.53 & 600.04 & 232.53 & 524.12 & 278.04 & 195.54 & 109.83 \\
\hline 294 & 218.73 & 114.38 & 655.89 & 209.33 & 578.89 & 275.58 & 202.50 & 76.28 \\
\hline 295 & 232.93 & 104.10 & 694.33 & 202.51 & 638.30 & 251.11 & 199.98 & 56.50 \\
\hline 296 & 229.88 & 109.69 & 711.73 & 212.07 & 673.62 & 275.30 & 183.24 & 61.49 \\
\hline 297 & 209.58 & 125.86 & 706.06 & 232.55 & 688.30 & 320.81 & 152.28 & 64.66 \\
\hline 298 & 182.59 & 163.19 & 688.14 & 274.87 & 688.05 & 350.33 & 116.58 & 86.19 \\
\hline 299 & 154.19 & 184.65 & 667.44 & 300.81 & 677.45 & 369.19 & 80.88 & 93.95 \\
\hline 300 & 141.63 & 195.53 & 662.97 & 315.83 & 677.14 & 372.06 & 59.40 & 92.53 \\
\hline 301 & 144.91 & 208.14 & 695.42 & 331.47 & 701.97 & 374.04 & 178.89 & 96.34 \\
\hline 302 & 158.75 & 204.88 & 744.78 & 330.73 & 746.31 & 370.69 & 181.11 & 86.38 \\
\hline 303 & 193.71 & 195.59 & 819.84 & 324.53 & 819.32 & 367.34 & 202.29 & 71.83 \\
\hline 304 & 212.83 & 185.19 & 886.79 & 318.33 & 885.49 & 379.98 & 209.25 & 57.28 \\
\hline 305 & 221.39 & 189.55 & 936.83 & 328.51 & 956.30 & 408.61 & 206.73 & 56.50 \\
\hline 306 & 214.11 & 208.67 & 966.58 & 355.07 & 1003.02 & 447.90 & 189.99 & 69.49 \\
\hline 307 & 190.99 & 237.63 & 974.01 & 392.55 & 1029.10 & 508.51 & 159.03 & 91.66 \\
\hline 308 & 162.19 & 286.27 & 969.20 & 451.87 & 1040.25 & 553.13 & 123.33 & 132.19 \\
\hline 309 & 132.79 & 320.15 & 961.25 & 494.81 & 1041.05 & 587.09 & 87.63 & 158.95 \\
\hline 310 & 118.63 & 344.19 & 968.42 & 526.83 & 1052.14 & 605.06 & 66.15 & 176.53 \\
\hline 311 & 138.01 & 353.47 & 1001.60 & 542.47 & 1083.77 & 607.04 & 78.79 & 180.34 \\
\hline 312 & 167.55 & 347.99 & 1050.95 & 541.73 & 1134.91 & 603.69 & 100.91 & 170.38 \\
\hline 313 & 217.41 & 337.19 & 1124.52 & 534.49 & 1214.72 & 600.34 & 141.99 & 155.83 \\
\hline 314 & 252.03 & 325.79 & 1191.09 & 525.69 & 1287.69 & 612.98 & 168.85 & 141.28 \\
\hline 315 & 276.49 & 328.55 & 1241.49 & 531.71 & 1365.30 & 641.61 & 186.23 & 140.50 \\
\hline 316 & 285.71 & 345.47 & 1272.71 & 552.55 & 1418.82 & 680.90 & 189.39 & 153.49 \\
\hline 317 & 279.69 & 371.83 & 1282.72 & 583.27 & 1451.70 & 741.51 & 178.33 & 175.66 \\
\hline 318 & 268.25 & 417.07 & 1281.60 & 633.75 & 1469.65 & 786.13 & 162.53 & 216.19 \\
\hline 319 & 256.30 & 448.15 & 1278.45 & 669.41 & 1477.25 & 820.09 & 146.73 & 242.95 \\
\hline 320 & 259.08 & 469.79 & 1290.42 & 695.19 & 1495.14 & 838.06 & 145.15 & 260.53 \\
\hline 321 & 276.59 & 477.27 & 1323.60 & 706.15 & 1526.77 & 840.04 & 157.79 & 264.34 \\
\hline 322 & 303.92 & 470.59 & 1372.95 & 702.29 & 1577.91 & 835.41 & 179.91 & 254.38 \\
\hline 323 & 350.89 & 458.33 & 1446.52 & 692.63 & 1657.72 & 828.86 & 220.99 & 239.37 \\
\hline 324 & 383.13 & 444.78 & 1513.09 & 681.68 & 1730.69 & 836.38 & 247.85 & 223.67 \\
\hline 325 & 405.55 & 444.10 & 1563.49 & 684.26 & 1808.30 & 857.97 & 265.23 & 221.05 \\
\hline 326 & 413.24 & 456.29 & 1594.71 & 700.37 & 1861.82 & 888.94 & 268.39 & 231.51 \\
\hline 327 & 406.20 & 477.06 & 1604.72 & 725.50 & 1894.70 & 938.67 & 257.33 & 250.69 \\
\hline 328 & 393.41 & 514.99 & 1602.94 & 768.67 & 1911.29 & 974.33 & 240.23 & 287.31 \\
\hline 329 & 379.36 & 540.05 & 1596.78 & 798.31 & 1915.49 & 1000.61 & 221.18 & 310.85 \\
\hline 330 & 378.78 & 556.53 & 1602.71 & 818.93 & 1927.94 & 1012.82 & 214.40 & 325.67 \\
\hline 331 & 391.67 & 560.14 & 1626.82 & 826.02 & 1952.09 & 1010.96 & 219.89 & 327.41 \\
\hline 332 & 413.54 & 550.88 & 1664.40 & 819.58 & 1994.39 & 1003.35 & 233.56 & 316.07 \\
\hline 333 & 453.37 & 536.87 & 1723.52 & 807.83 & 2062.64 & 994.15 & 263.59 & 299.55 \\
\hline 334 & 479.73 & 522.17 & 1773.91 & 794.88 & 2126.09 & 997.43 & 281.35 & 281.80 \\
\hline 335 & 497.11 & 519.65 & 1810.83 & 794.26 & 2195.54 & 1013.19 & 290.93 & 275.90 \\
\hline 336 & 501.02 & 529.31 & 1830.92 & 805.97 & 2242.94 & 1037.27 & 288.24 & 281.85 \\
\hline 337 & 491.46 & 547.09 & 1832.83 & 825.90 & 2271.74 & 1077.99 & 273.28 & 295.70 \\
\hline 338 & 476.81 & 581.11 & 1825.98 & 862.27 & 2284.59 & 1106.23 & 253.31 & 325.35 \\
\hline 339 & 461.26 & 602.95 & 1817.78 & 886.31 & 2284.54 & 1126.15 & 231.96 & 343.15 \\
\hline 340 & 458.28 & 616.67 & 1823.71 & 902.13 & 2288.49 & 1133.59 & 221.50 & 353.05 \\
\hline 341 & 467.87 & 618.21 & 1847.82 & 905.62 & 2299.04 & 1128.55 & 221.93 & 351.10 \\
\hline 342 & 485.84 & 607.57 & 1885.40 & 896.78 & 2323.49 & 1118.45 & 229.62 & 337.30 \\
\hline 343 & 520.57 & 592.31 & 1944.52 & 883.83 & 2367.94 & 1107.00 & 251.83 & 318.55 \\
\hline 344 & 542.73 & 576.21 & 1994.91 & 870.88 & 2408.44 & 1106.68 & 263.15 & 298.30 \\
\hline
\end{tabular}




\begin{tabular}{|c|c|c|c|c|c|c|c|c|}
\hline 345 & 556.51 & 571.45 & 2031.83 & 870.26 & 2453.24 & 1117.49 & 267.21 & 288.40 \\
\hline 346 & 557.72 & 578.03 & 2051.92 & 881.97 & 2481.09 & 1135.72 & 260.38 & 288.85 \\
\hline 347 & 546.36 & 592.17 & 2053.83 & 901.90 & 2494.59 & 1168.79 & 242.66 & 296.20 \\
\hline 348 & 530.81 & 621.43 & 2045.52 & 938.27 & 2497.24 & 1190.73 & 220.51 & 317.35 \\
\hline 349 & 515.26 & 639.35 & 2033.67 & 962.31 & 2492.09 & 1205.25 & 197.16 & 328.15 \\
\hline 350 & 512.28 & 649.71 & 2033.76 & 978.13 & 2492.89 & 1208.64 & 183.50 & 332.05 \\
\hline 351 & 521.87 & 648.73 & 2049.84 & 981.62 & 2501.94 & 1200.90 & 179.53 & 325.60 \\
\hline 352 & 539.84 & 636.41 & 2077.93 & 972.78 & 2523.99 & 1189.45 & 182.02 & 308.80 \\
\hline 353 & 574.57 & 620.31 & 2124.64 & 959.37 & 2565.14 & 1178.00 & 197.43 & 287.75 \\
\hline 354 & 596.73 & 604.21 & 2164.81 & 945.27 & 2601.74 & 1177.68 & 203.15 & 265.50 \\
\hline 355 & 610.51 & 599.45 & 2192.97 & 942.81 & 2641.44 & 1188.49 & 202.41 & 252.40 \\
\hline 356 & 611.72 & 606.03 & 2206.49 & 951.99 & 2665.09 & 1206.72 & 191.98 & 248.45 \\
\hline 357 & 600.36 & 620.17 & 2204.02 & 968.93 & 2674.99 & 1239.79 & 171.86 & 250.60 \\
\hline 358 & 583.85 & 649.43 & 2193.02 & 1001.39 & 2674.94 & 1261.73 & 148.51 & 264.95 \\
\hline 359 & 565.90 & 667.35 & 2179.92 & 1022.21 & 2667.99 & 1276.25 & 125.16 & 270.15 \\
\hline 360 & 559.08 & 677.71 & 2178.01 & 1035.27 & 2667.89 & 1279.64 & 111.50 & 269.25 \\
\hline 361 & 563.39 & 711.73 & 2220.34 & 1070.19 & 2699.44 & 1301.90 & 107.53 & 296.70 \\
\hline 362 & 575.12 & 734.41 & 2274.18 & 1093.47 & 2743.99 & 1320.45 & 110.02 & 315.00 \\
\hline 363 & 601.69 & 752.55 & 2345.64 & 1112.87 & 2807.64 & 1339.00 & 125.43 & 330.25 \\
\hline 364 & 617.13 & 769.55 & 2411.31 & 1132.27 & 2866.74 & 1368.68 & 131.15 & 345.50 \\
\hline 365 & 625.15 & 796.75 & 2465.47 & 1163.31 & 2928.94 & 1409.49 & 130.41 & 369.90 \\
\hline 366 & 622.04 & 834.15 & 2505.74 & 1205.99 & 2975.09 & 1457.72 & 119.98 & 403.45 \\
\hline 367 & 607.80 & 878.35 & 2530.77 & 1256.43 & 3007.49 & 1520.79 & 99.86 & 443.10 \\
\hline 368 & 589.45 & 936.15 & 2547.26 & 1322.39 & 3029.94 & 1572.73 & 76.51 & 494.95 \\
\hline 369 & 570.50 & 983.75 & 2561.26 & 1376.71 & 3045.49 & 1617.25 & 53.16 & 537.65 \\
\hline 370 & 562.08 & 1024.55 & 2585.31 & 1423.27 & 3067.89 & 1650.64 & 39.50 & 574.25 \\
\hline ELC & PORTO_1 & PORTO_2 & PORTO_3 & PORTO_4 & PORTO_5 & PORTO_6 & PORTO_7 & PORTO_ \\
\hline 000 & 78.00 & 64.48 & $228.0 \overline{9}$ & 64.60 & $228.1 \overline{7}$ & 60.03 & 150.18 & 40.00 \\
\hline 001 & 38.00 & 64.48 & 178.09 & 64.60 & 183.17 & 60.03 & 50.18 & 40.00 \\
\hline 002 & 38.00 & 64.48 & 118.09 & 64.60 & 183.17 & 60.03 & 50.18 & 40.00 \\
\hline 003 & 38.00 & 64.48 & 118.09 & 64.60 & 123.17 & 60.03 & 50.18 & 40.00 \\
\hline 004 & 38.00 & 64.48 & 118.09 & 64.60 & 123.17 & 60.03 & 50.18 & 40.00 \\
\hline 005 & 38.00 & 64.48 & 118.09 & 64.60 & 123.17 & 25.03 & 50.18 & 40.00 \\
\hline 006 & 38.00 & 24.48 & 118.09 & 24.60 & 123.17 & 25.03 & 50.18 & 0.00 \\
\hline 007 & 38.00 & 24.48 & 118.09 & 24.60 & 123.17 & 25.03 & 50.18 & 0.00 \\
\hline 008 & 38.08 & 24.56 & 118.31 & 24.68 & 123.38 & 25.17 & 50.38 & 0.08 \\
\hline 009 & 38.36 & 24.84 & 119.08 & 24.96 & 124.11 & 25.70 & 51.08 & 0.36 \\
\hline 010 & 38.96 & 25.44 & 120.73 & 25.56 & 125.69 & 26.83 & 52.58 & 0.96 \\
\hline 011 & 0.00 & 26.48 & 73.59 & 26.60 & 83.42 & 28.70 & 7.42 & 2.00 \\
\hline 012 & 1.56 & 28.04 & 17.88 & 28.16 & 87.51 & 31.34 & 11.32 & 3.56 \\
\hline 013 & 3.80 & 30.28 & 24.04 & 30.40 & 33.39 & 34.94 & 16.92 & 5.80 \\
\hline 014 & 6.60 & 33.08 & 31.74 & 33.20 & 40.74 & 39.15 & 23.92 & 8.60 \\
\hline 015 & 9.88 & 36.36 & 40.76 & 36.48 & 49.35 & 0.42 & 32.13 & 11.88 \\
\hline 016 & 13.52 & 0.00 & 50.77 & 0.12 & 58.91 & 5.09 & 41.23 & 0.00 \\
\hline 017 & 17.40 & 3.88 & 61.44 & 4.00 & 69.09 & 9.84 & 50.93 & 3.88 \\
\hline 018 & 21.32 & 7.88 & 72.44 & 8.00 & 79.59 & 14.66 & 60.93 & 7.88 \\
\hline 019 & 25.04 & 11.88 & 83.44 & 12.00 & 90.09 & 19.56 & 70.93 & 11.88 \\
\hline 020 & 28.44 & 15.88 & 94.32 & 16.00 & 100.59 & 24.74 & 80.93 & 15.88 \\
\hline 021 & 0.00 & 19.88 & 54.90 & 20.00 & 65.88 & 30.40 & 0.00 & 19.88 \\
\hline 022 & 2.44 & 23.88 & 5.00 & 24.00 & 75.65 & 36.42 & 10.00 & 23.88 \\
\hline 023 & 4.20 & 27.88 & 14.44 & 28.00 & 24.57 & 42.60 & 20.00 & 27.80 \\
\hline 024 & 5.40 & 31.88 & 23.22 & 32.00 & 32.46 & 48.70 & 30.00 & 31.52 \\
\hline 025 & 6.12 & 35.88 & 31.28 & 36.00 & 39.38 & 0.00 & 40.00 & 34.92 \\
\hline 026 & 6.48 & 0.00 & 38.86 & 0.00 & 45.21 & 5.26 & 50.00 & 0.00 \\
\hline 027 & 6.60 & 4.00 & 46.08 & 4.00 & 50.60 & 9.96 & 60.00 & 2.44 \\
\hline 028 & 6.60 & 8.00 & 53.06 & 8.00 & 55.88 & 14.18 & 70.00 & 4.20 \\
\hline 029 & 6.60 & 12.00 & 60.04 & 12.00 & 61.52 & 18.04 & 80.00 & 5.40 \\
\hline 030 & 6.60 & 16.00 & 66.90 & 16.00 & 67.65 & 21.66 & 90.00 & 6.12 \\
\hline 031 & 0.00 & 20.00 & 23.46 & 20.00 & 29.16 & 25.16 & 0.00 & 6.48 \\
\hline 032 & 0.00 & 24.00 & 5.00 & 24.00 & 35.97 & 28.66 & 10.00 & 6.60 \\
\hline 033 & 0.00 & 28.00 & 10.90 & 28.00 & 7.79 & 32.16 & 20.00 & 6.60 \\
\hline 034 & 0.00 & 32.00 & 16.56 & 32.00 & 14.07 & 35.66 & 30.00 & 6.60 \\
\hline 035 & 0.00 & 36.00 & 22.16 & 36.00 & 20.07 & 0.00 & 40.00 & 6.60 \\
\hline 036 & 0.00 & 0.00 & 27.94 & 0.00 & 26.01 & 3.50 & 50.00 & 0.00 \\
\hline 037 & 0.00 & 4.00 & 34.08 & 4.00 & 32.25 & 7.00 & 60.00 & 0.00 \\
\hline 038 & 0.00 & 8.00 & 40.52 & 8.00 & 38.97 & 10.50 & 70.00 & 0.00 \\
\hline 039 & 0.00 & 12.00 & 47.32 & 12.00 & 46.41 & 14.00 & 80.00 & 0.00 \\
\hline 040 & 0.00 & 16.00 & 54.18 & 16.00 & 54.21 & 17.50 & 90.00 & 0.00 \\
\hline 041 & 0.00 & 20.00 & 10.74 & 20.00 & 18.42 & 21.00 & 0.00 & 0.00 \\
\hline 042 & 0.00 & 24.00 & 5.00 & 24.00 & 26.04 & 24.50 & 10.00 & 0.00 \\
\hline 043 & 0.00 & 28.00 & 10.90 & 28.00 & 9.00 & 28.00 & 20.00 & 0.00 \\
\hline 044 & 0.00 & 32.00 & 16.56 & 32.00 & 15.42 & 31.50 & 30.00 & 0.00 \\
\hline 045 & 0.00 & 36.00 & 22.16 & 36.00 & 21.42 & 0.00 & 40.00 & 0.00 \\
\hline 046 & 0.00 & 0.00 & 27.94 & 0.00 & 27.36 & 3.50 & 50.00 & 0.00 \\
\hline 047 & 0.00 & 4.00 & 34.08 & 4.00 & 33.60 & 7.00 & 60.00 & 0.00 \\
\hline 048 & 0.00 & 8.00 & 40.52 & 8.00 & 40.32 & 10.50 & 70.00 & 0.00 \\
\hline 049 & 0.00 & 12.00 & 47.32 & 12.00 & 47.76 & 14.00 & 80.00 & 0.00 \\
\hline 050 & 0.00 & 16.00 & 54.18 & 16.00 & 55.56 & 17.50 & 90.00 & 0.00 \\
\hline 051 & 0.00 & 20.00 & 10.74 & 20.00 & 18.42 & 21.00 & 0.00 & 0.00 \\
\hline 052 & 0.00 & 24.00 & 5.00 & 24.00 & 26.04 & 24.52 & 10.00 & 0.00 \\
\hline 053 & 0.00 & 28.03 & 10.90 & 28.03 & 9.00 & 28.11 & 20.00 & 0.00 \\
\hline 054 & 0.00 & 32.12 & 16.60 & 32.12 & 15.33 & 31.79 & 30.00 & 0.00 \\
\hline 055 & 0.00 & 36.31 & 22.34 & 36.31 & 21.13 & 0.60 & 40.00 & 0.00 \\
\hline 056 & 0.00 & 0.65 & 28.38 & 0.65 & 26.83 & 4.57 & 50.00 & 0.00 \\
\hline
\end{tabular}




\begin{tabular}{|c|c|c|c|c|c|c|c|c|}
\hline 057 & 0.00 & 5.16 & 34.90 & 5.16 & 32.86 & 8.74 & 60.00 & 0.00 \\
\hline 058 & 0.00 & 9.88 & 41.85 & 9.88 & 39.48 & 13.09 & 70.07 & 0.00 \\
\hline 059 & 0.00 & 14.79 & 49.37 & 14.79 & 46.86 & 17.61 & 80.30 & 0.00 \\
\hline 060 & 0.00 & 19.86 & 57.11 & 19.86 & 55.05 & 22.25 & 90.79 & 0.00 \\
\hline 061 & 0.00 & 25.04 & 13.78 & 25.04 & 17.87 & 26.98 & 0.00 & 0.00 \\
\hline 062 & 0.00 & 30.30 & 5.66 & 30.30 & 26.51 & 31.76 & 11.29 & 0.00 \\
\hline 063 & 0.00 & 35.60 & 12.82 & 35.60 & 10.43 & 36.57 & 23.14 & 0.00 \\
\hline 064 & 0.00 & 40.90 & 19.89 & 40.99 & 18.33 & 41.35 & 35.45 & 0.00 \\
\hline 065 & 0.00 & 46.20 & 27.08 & 46.59 & 26.06 & 0.00 & 48.15 & 0.00 \\
\hline 066 & 0.00 & 0.00 & 34.81 & 0.00 & 33.85 & 4.76 & 61.15 & 0.00 \\
\hline 067 & 0.00 & 5.30 & 43.33 & 6.46 & 42.12 & 9.60 & 74.35 & 0.00 \\
\hline 068 & 0.00 & 10.60 & 52.52 & 13.51 & 51.24 & 14.69 & 87.66 & 0.00 \\
\hline 069 & 0.00 & 15.90 & 62.41 & 21.35 & 61.56 & 20.18 & 100.95 & 0.00 \\
\hline 070 & 0.00 & 21.20 & 72.51 & 29.85 & 72.60 & 26.26 & 114.26 & 0.00 \\
\hline 071 & 0.00 & 26.50 & 18.31 & 39.10 & 26.44 & 33.03 & 0.00 & 0.00 \\
\hline 072 & 0.00 & 31.80 & 6.70 & 49.22 & 37.64 & 40.70 & 13.30 & 0.00 \\
\hline 073 & 0.00 & 37.10 & 15.45 & 60.14 & 12.00 & 49.11 & 26.60 & 0.00 \\
\hline 074 & 0.00 & 42.40 & 23.68 & 71.74 & 22.08 & 58.15 & 39.90 & 0.00 \\
\hline 075 & 0.00 & 47.70 & 31.60 & 83.78 & 31.68 & 0.00 & 53.20 & 0.00 \\
\hline 076 & 0.00 & 0.00 & 39.72 & 0.00 & 41.20 & 9.84 & 66.50 & 0.00 \\
\hline 077 & 0.00 & 5.30 & 48.50 & 12.65 & 51.04 & 19.84 & 79.80 & 0.00 \\
\hline 078 & 0.00 & 10.60 & 58.16 & 25.05 & 61.76 & 29.84 & 93.10 & 0.00 \\
\hline 079 & 0.00 & 15.90 & 68.78 & 37.46 & 73.36 & 39.84 & 106.40 & 0.00 \\
\hline 080 & 0.00 & 21.20 & 79.88 & 50.05 & 85.92 & 49.84 & 119.70 & 0.00 \\
\hline 081 & 0.00 & 26.52 & 24.06 & 62.99 & 39.04 & 59.84 & 0.00 & 0.00 \\
\hline 082 & 0.00 & 31.96 & 6.70 & 76.21 & 52.40 & 69.84 & 13.30 & 0.00 \\
\hline 083 & 0.00 & 37.66 & 17.24 & 90.07 & 12.00 & 79.74 & 26.60 & 0.00 \\
\hline 084 & 0.00 & 43.77 & 27.54 & 104.29 & 25.12 & 89.36 & 39.90 & 0.00 \\
\hline 085 & 0.00 & 50.41 & 37.76 & 118.50 & 38.08 & 0.00 & 53.20 & 0.00 \\
\hline 086 & 0.00 & 0.00 & 48.30 & 0.00 & 50.72 & 8.82 & 66.50 & 0.00 \\
\hline 087 & 0.00 & 8.06 & 59.72 & 12.85 & 63.60 & 17.27 & 79.80 & 0.00 \\
\hline 088 & 0.00 & 16.76 & 72.02 & 24.85 & 76.64 & 25.29 & 93.10 & 0.00 \\
\hline 089 & 0.00 & 26.00 & 85.28 & 36.13 & 89.92 & 33.19 & 106.40 & 0.00 \\
\hline 090 & 0.00 & 35.63 & 99.10 & 47.13 & 103.44 & 41.22 & 119.70 & 0.00 \\
\hline 091 & 0.00 & 45.52 & 46.00 & 58.16 & 57.04 & 49.62 & 0.00 & 0.00 \\
\hline 092 & 0.00 & 55.52 & 6.70 & 69.46 & 70.18 & 58.40 & 13.30 & 0.00 \\
\hline 093 & 0.00 & 65.52 & 19.32 & 80.99 & 11.22 & 67.50 & 26.60 & 0.00 \\
\hline 094 & 0.00 & 75.52 & 30.90 & 92.73 & 22.48 & 76.76 & 39.90 & 0.00 \\
\hline 095 & 0.00 & 85.52 & 41.12 & 104.11 & 32.58 & 0.00 & 53.20 & 0.00 \\
\hline 096 & 0.00 & 0.00 & 50.22 & 0.00 & 41.20 & 8.62 & 66.50 & 0.00 \\
\hline 097 & 0.00 & 10.00 & 58.50 & 10.23 & 49.20 & 16.56 & 79.80 & 0.00 \\
\hline 098 & 0.00 & 20.00 & 66.43 & 19.80 & 56.95 & 23.59 & 93.10 & 0.00 \\
\hline 099 & 0.00 & 30.00 & 74.49 & 28.93 & 64.96 & 29.88 & 106.40 & 0.00 \\
\hline 100 & 0.00 & 40.10 & 82.87 & 37.89 & 73.67 & 35.53 & 119.70 & 0.00 \\
\hline 101 & 0.00 & 50.74 & 25.13 & 46.95 & 29.31 & 40.71 & 0.00 & 0.00 \\
\hline 102 & 0.00 & 62.28 & 5.81 & 56.27 & 39.62 & 45.67 & 13.30 & 0.00 \\
\hline 103 & 0.00 & 74.77 & 14.57 & 65.77 & 10.80 & 50.63 & 26.60 & 0.00 \\
\hline 104 & 0.00 & 88.06 & 22.97 & 75.32 & 20.66 & 55.75 & 39.90 & 0.00 \\
\hline 105 & 0.00 & 101.91 & 30.56 & 84.63 & 29.73 & 0.00 & 53.23 & 0.00 \\
\hline 106 & 0.00 & 17.01 & 37.93 & 0.00 & 37.38 & 5.38 & 67.01 & 0.00 \\
\hline 107 & 0.00 & 30.68 & 45.47 & 8.41 & 43.92 & 10.96 & 81.61 & 0.00 \\
\hline 108 & 0.00 & 43.25 & 53.21 & 16.33 & 49.80 & 16.39 & 97.11 & 0.00 \\
\hline 109 & 0.00 & 54.68 & 61.40 & 24.03 & 55.14 & 21.71 & 113.49 & 0.00 \\
\hline 110 & 0.00 & 65.14 & 70.17 & 31.72 & 60.18 & 26.88 & 130.60 & 0.00 \\
\hline 111 & 0.00 & 75.31 & 26.99 & 39.69 & 17.76 & 31.89 & 15.63 & 0.00 \\
\hline 112 & 0.00 & 85.71 & 7.60 & 48.20 & 22.92 & 36.75 & 33.37 & 0.00 \\
\hline 113 & 0.00 & 97.02 & 16.15 & 57.23 & 10.38 & 41.45 & 50.40 & 0.00 \\
\hline 114 & 0.00 & 109.37 & 24.33 & 66.66 & 15.36 & 46.15 & 66.62 & 0.00 \\
\hline 115 & 0.00 & 122.51 & 32.38 & 76.22 & 20.52 & 0.00 & 81.93 & 0.00 \\
\hline 116 & 0.00 & 45.59 & 40.62 & 14.73 & 25.96 & 4.70 & 96.34 & 0.00 \\
\hline 117 & 0.00 & 59.17 & 49.52 & 24.08 & 31.89 & 9.40 & 110.06 & 0.00 \\
\hline 118 & 0.00 & 71.95 & 59.33 & 32.90 & 38.36 & 14.12 & 123.76 & 0.00 \\
\hline 119 & 0.00 & 83.94 & 70.08 & 41.61 & 45.36 & 18.90 & 137.69 & 0.00 \\
\hline 120 & 0.00 & 95.91 & 81.29 & 50.42 & 52.81 & 23.76 & 151.84 & 0.00 \\
\hline 121 & 0.00 & 108.68 & 24.65 & 60.12 & 5.93 & 28.83 & 5.74 & 0.00 \\
\hline 122 & 0.00 & 122.98 & 6.70 & 71.22 & 13.68 & 34.28 & 20.34 & 0.00 \\
\hline 123 & 0.00 & 139.75 & 17.29 & 84.06 & 12.00 & 40.23 & 34.70 & 0.00 \\
\hline 124 & 0.00 & 158.98 & 27.71 & 98.75 & 19.74 & 46.66 & 48.87 & 0.00 \\
\hline 125 & 0.00 & 180.78 & 38.19 & 114.88 & 27.85 & 0.00 & 62.82 & 0.00 \\
\hline 126 & 0.00 & 22.85 & 49.21 & 27.93 & 36.63 & 7.69 & 76.54 & 0.00 \\
\hline 127 & 0.00 & 45.31 & 61.36 & 45.72 & 46.31 & 16.13 & 90.21 & 0.00 \\
\hline 128 & 0.00 & 66.30 & 74.77 & 62.89 & 57.51 & 25.07 & 104.37 & 0.00 \\
\hline 129 & 0.00 & 85.74 & 89.30 & 79.27 & 70.24 & 34.63 & 119.58 & 0.00 \\
\hline 130 & 0.00 & 104.27 & 104.43 & 95.32 & 84.30 & 45.01 & 135.94 & 0.00 \\
\hline 131 & 0.00 & 122.66 & 51.81 & 111.71 & 38.89 & 56.06 & 1.34 & 0.00 \\
\hline 132 & 0.00 & 142.19 & 7.32 & 128.88 & 54.90 & 68.37 & 20.03 & 0.00 \\
\hline 133 & 0.00 & 163.66 & 21.22 & 147.43 & 13.16 & 82.07 & 39.85 & 0.00 \\
\hline 134 & 0.00 & 187.77 & 34.14 & 167.54 & 30.01 & 96.96 & 59.81 & 0.00 \\
\hline 135 & 0.00 & 213.38 & 46.65 & 188.96 & 47.09 & 19.31 & 80.77 & 0.00 \\
\hline 136 & 0.00 & 20.76 & 59.21 & 27.52 & 64.32 & 35.15 & 103.33 & 0.00 \\
\hline 137 & 0.00 & 45.24 & 72.26 & 47.83 & 81.67 & 51.80 & 128.06 & 0.00 \\
\hline 138 & 0.00 & 67.39 & 86.46 & 66.23 & 99.10 & 66.74 & 154.95 & 0.00 \\
\hline 139 & 0.00 & 87.06 & 101.56 & 82.59 & 116.57 & 80.72 & 184.37 & 0.00 \\
\hline 140 & 0.00 & 104.57 & 117.36 & 97.19 & 134.07 & 93.63 & 215.68 & 0.00 \\
\hline 141 & 0.00 & 121.24 & 52.90 & 110.64 & 79.80 & 105.97 & 124.12 & 0.00 \\
\hline 142 & 0.00 & 138.40 & 8.30 & 124.10 & 96.23 & 118.17 & 154.59 & 0.00 \\
\hline
\end{tabular}




\begin{tabular}{|c|c|c|c|c|c|c|c|c|}
\hline 143 & 0.00 & 156.87 & 22.70 & 138.26 & 14.03 & 130.34 & 182.63 & 0.00 \\
\hline 144 & 0.00 & 177.14 & 35.61 & 153.16 & 28.82 & 143.18 & 208.08 & 0.00 \\
\hline 145 & 0.00 & 198.71 & 47.61 & 168.40 & 42.97 & 30.98 & 231.63 & 0.00 \\
\hline 146 & 0.00 & 17.16 & 59.22 & 31.29 & 56.22 & 43.39 & 254.71 & 0.00 \\
\hline 147 & 0.00 & 38.40 & 71.02 & 46.29 & 69.61 & 55.67 & 278.80 & 0.00 \\
\hline 148 & 0.00 & 57.94 & 83.52 & 60.18 & 83.64 & 66.08 & 304.77 & 0.00 \\
\hline 149 & 0.00 & 75.64 & 97.42 & 72.89 & 98.39 & 75.63 & 333.35 & 0.00 \\
\hline 150 & 0.00 & 91.51 & 112.36 & 85.16 & 114.08 & 84.58 & 363.51 & 0.00 \\
\hline 151 & 0.00 & 106.38 & 45.32 & 97.03 & 62.91 & 93.80 & 167.07 & 0.00 \\
\hline 152 & 0.00 & 121.26 & 27.35 & 108.79 & 79.39 & 103.38 & 195.98 & 0.00 \\
\hline 153 & 0.00 & 136.99 & 40.65 & 121.00 & 15.13 & 113.19 & 222.44 & 0.00 \\
\hline 154 & 0.00 & 153.76 & 52.14 & 133.60 & 30.17 & 123.54 & 246.16 & 0.00 \\
\hline 155 & 0.00 & 171.41 & 61.25 & 146.03 & 44.60 & 51.88 & 267.41 & 0.00 \\
\hline 156 & 0.00 & 7.96 & 69.10 & 45.50 & 57.82 & 61.08 & 287.54 & 0.00 \\
\hline 157 & 0.00 & 25.80 & 76.57 & 56.34 & 70.80 & 68.75 & 307.94 & 0.00 \\
\hline 158 & 0.00 & 42.44 & 84.70 & 65.87 & 84.44 & 74.58 & 329.55 & 0.00 \\
\hline 159 & 0.00 & 57.74 & 94.43 & 74.50 & 98.40 & 79.35 & 352.40 & 0.00 \\
\hline 160 & 0.00 & 71.97 & 106.02 & 82.75 & 112.33 & 83.67 & 376.48 & 0.00 \\
\hline 161 & 0.00 & 85.58 & 110.97 & 91.39 & 97.79 & 88.27 & 227.02 & 0.00 \\
\hline 162 & 0.00 & 99.26 & 61.82 & 100.74 & 110.25 & 93.95 & 250.11 & 0.00 \\
\hline 163 & 0.00 & 113.77 & 75.21 & 110.96 & 66.08 & 101.28 & 271.44 & 0.00 \\
\hline 164 & 0.00 & 129.29 & 87.97 & 121.97 & 74.40 & 109.91 & 291.02 & 0.00 \\
\hline 165 & 0.00 & 145.39 & 99.41 & 133.28 & 81.23 & 62.92 & 309.52 & 0.00 \\
\hline 166 & 0.00 & 26.00 & 110.32 & 31.37 & 87.43 & 72.02 & 327.70 & 0.00 \\
\hline 167 & 0.00 & 41.63 & 121.60 & 41.72 & 93.98 & 80.71 & 346.45 & 0.00 \\
\hline 168 & 0.00 & 55.70 & 133.68 & 50.70 & 101.95 & 88.03 & 366.76 & 0.00 \\
\hline 169 & 0.00 & 68.25 & 146.85 & 58.52 & 111.60 & 94.46 & 388.25 & 0.00 \\
\hline 170 & 0.00 & 79.57 & 160.58 & 65.80 & 122.90 & 100.63 & 409.97 & 0.00 \\
\hline 171 & 0.00 & 90.50 & 127.33 & 73.11 & 83.63 & 107.33 & 246.28 & 0.00 \\
\hline 172 & 0.00 & 101.78 & 61.65 & 81.11 & 95.45 & 115.65 & 265.50 & 0.00 \\
\hline 173 & 0.00 & 114.56 & 73.26 & 90.02 & 44.18 & 125.40 & 282.31 & 0.00 \\
\hline 174 & 0.00 & 128.95 & 82.87 & 99.99 & 53.34 & 136.49 & 296.99 & 0.00 \\
\hline 175 & 0.00 & 144.57 & 91.26 & 110.84 & 61.38 & 44.33 & 310.70 & 0.00 \\
\hline 176 & 0.00 & 55.31 & 99.24 & 23.37 & 68.68 & 56.10 & 325.08 & 0.00 \\
\hline 177 & 0.00 & 71.34 & 108.03 & 34.26 & 76.40 & 67.08 & 341.13 & 0.00 \\
\hline 178 & 0.00 & 86.13 & 118.12 & 44.05 & 85.16 & 76.17 & 359.36 & 0.00 \\
\hline 179 & 0.00 & 99.63 & 129.74 & 53.04 & 95.18 & 83.87 & 379.95 & 0.00 \\
\hline 180 & 0.00 & 112.59 & 142.97 & 62.06 & 106.65 & 90.69 & 401.96 & 0.00 \\
\hline 181 & 0.00 & 126.25 & 84.30 & 71.79 & 39.40 & 97.11 & 77.39 & 0.00 \\
\hline 182 & 0.00 & 141.77 & 6.62 & 83.21 & 51.33 & 104.44 & 97.75 & 0.00 \\
\hline 183 & 0.00 & 160.19 & 21.24 & 97.11 & 20.13 & 113.39 & 115.33 & 0.00 \\
\hline 184 & 0.00 & 181.45 & 35.32 & 114.01 & 30.60 & 124.09 & 130.30 & 0.00 \\
\hline 185 & 0.00 & 205.36 & 49.93 & 132.79 & 40.82 & 0.44 & 143.57 & 0.00 \\
\hline 186 & 0.00 & 0.19 & 65.04 & 0.15 & 51.47 & 13.48 & 156.57 & 0.00 \\
\hline 187 & 0.00 & 23.93 & 81.30 & 20.52 & 63.09 & 27.40 & 170.78 & 0.00 \\
\hline 188 & 0.00 & 45.37 & 98.73 & 40.32 & 76.58 & 39.47 & 187.62 & 0.00 \\
\hline 189 & 0.00 & 64.63 & 117.02 & 59.44 & 91.86 & 50.66 & 208.25 & 0.00 \\
\hline 190 & 0.00 & 82.83 & 135.54 & 78.04 & 109.08 & 61.65 & 231.86 & 0.00 \\
\hline 191 & 0.00 & 101.24 & 96.55 & 97.24 & 59.18 & 73.24 & 9.94 & 0.00 \\
\hline 192 & 0.00 & 121.47 & 6.60 & 117.11 & 77.59 & 86.63 & 35.53 & 0.00 \\
\hline 193 & 0.00 & 145.01 & 20.56 & 137.94 & 17.73 & 102.21 & 60.99 & 0.00 \\
\hline 194 & 0.00 & 171.98 & 31.99 & 159.33 & 35.57 & 121.16 & 85.08 & 0.00 \\
\hline 195 & 0.00 & 200.67 & 42.20 & 180.26 & 53.31 & 0.00 & 108.67 & 0.00 \\
\hline 196 & 0.00 & 0.00 & 52.11 & 0.00 & 70.70 & 20.87 & 133.23 & 0.00 \\
\hline 197 & 0.00 & 25.71 & 63.33 & 16.82 & 89.45 & 40.92 & 160.57 & 0.00 \\
\hline 198 & 0.00 & 47.75 & 76.83 & 30.90 & 109.58 & 58.01 & 191.38 & 0.00 \\
\hline 199 & 0.00 & 66.13 & 93.20 & 42.80 & 130.87 & 73.31 & 225.57 & 0.00 \\
\hline 200 & 0.00 & 82.03 & 111.97 & 53.74 & 152.80 & 87.37 & 262.13 & 0.00 \\
\hline 201 & 0.00 & 97.71 & 63.58 & 65.12 & 95.51 & 101.88 & 0.00 & 0.00 \\
\hline 202 & 0.00 & 115.67 & 8.55 & 78.53 & 115.90 & 118.09 & 34.87 & 0.00 \\
\hline 203 & 0.00 & 136.56 & 28.08 & 94.42 & 12.15 & 136.71 & 66.91 & 0.00 \\
\hline 204 & 0.00 & 160.78 & 44.73 & 112.42 & 25.45 & 157.42 & 96.30 & 0.00 \\
\hline 205 & 0.00 & 186.57 & 59.42 & 131.41 & 35.60 & 0.00 & 123.88 & 0.00 \\
\hline 206 & 0.00 & 0.00 & 72.85 & 0.00 & 43.41 & 20.15 & 151.29 & 0.00 \\
\hline 207 & 0.00 & 23.51 & 86.11 & 16.89 & 50.95 & 38.10 & 180.95 & 0.00 \\
\hline 208 & 0.00 & 43.75 & 100.38 & 30.82 & 60.60 & 52.42 & 212.86 & 0.00 \\
\hline 209 & 0.00 & 61.02 & 116.36 & 42.09 & 73.60 & 63.93 & 246.53 & 0.00 \\
\hline 210 & 0.00 & 76.21 & 134.67 & 51.81 & 90.96 & 73.51 & 280.41 & 0.00 \\
\hline 211 & 0.00 & 91.34 & 68.68 & 61.29 & 86.81 & 82.59 & 0.00 & 0.00 \\
\hline 212 & 0.00 & 108.21 & 7.40 & 72.10 & 108.79 & 92.09 & 29.40 & 0.00 \\
\hline 213 & 0.00 & 127.87 & 24.50 & 84.81 & 3.26 & 102.45 & 54.85 & 0.00 \\
\hline 214 & 0.00 & 150.09 & 38.04 & 99.56 & 20.83 & 113.85 & 77.41 & 0.00 \\
\hline 215 & 0.00 & 173.72 & 48.91 & 115.42 & 34.99 & 0.00 & 98.53 & 0.00 \\
\hline 216 & 0.00 & 0.00 & 57.79 & 0.00 & 45.56 & 11.21 & 120.42 & 0.00 \\
\hline 217 & 0.00 & 21.80 & 66.56 & 14.32 & 53.95 & 21.42 & 145.01 & 0.00 \\
\hline 218 & 0.00 & 40.64 & 77.33 & 26.05 & 62.15 & 29.98 & 172.36 & 0.00 \\
\hline 219 & 0.00 & 56.96 & 91.78 & 35.70 & 72.15 & 37.61 & 202.51 & 0.00 \\
\hline 220 & 0.00 & 72.12 & 110.20 & 44.14 & 84.78 & 44.79 & 234.20 & 0.00 \\
\hline 221 & 0.00 & 88.05 & 94.98 & 52.47 & 86.71 & 52.05 & 0.00 & 0.00 \\
\hline 222 & 0.00 & 106.26 & 5.70 & 62.00 & 102.22 & 59.42 & 30.11 & 0.00 \\
\hline 223 & 0.00 & 128.12 & 27.31 & 73.59 & 4.52 & 66.80 & 57.30 & 0.00 \\
\hline 224 & 0.00 & 153.08 & 45.04 & 87.33 & 17.13 & 74.11 & 82.19 & 0.00 \\
\hline 225 & 0.00 & 179.65 & 59.52 & 102.15 & 27.66 & 0.00 & 105.31 & 0.00 \\
\hline 226 & 0.00 & 0.00 & 71.51 & 0.00 & 36.70 & 5.12 & 127.59 & 0.00 \\
\hline 227 & 0.00 & 22.87 & 82.76 & 13.59 & 45.23 & 8.72 & 149.95 & 0.00 \\
\hline 228 & 0.00 & 41.26 & 95.56 & 25.10 & 54.20 & 10.88 & 173.09 & 0.00 \\
\hline
\end{tabular}




\begin{tabular}{|c|c|c|c|c|c|c|c|c|}
\hline 229 & 0.00 & 55.19 & 111.32 & 34.81 & 64.59 & 11.96 & 196.63 & 0.00 \\
\hline 230 & 0.00 & 66.46 & 130.81 & 43.62 & 77.05 & 12.32 & 219.56 & 0.00 \\
\hline 231 & 0.00 & 77.27 & 120.43 & 52.65 & 65.05 & 12.44 & 0.00 & 0.00 \\
\hline 232 & 0.00 & 89.78 & 3.34 & 63.33 & 78.15 & 12.89 & 20.44 & 0.00 \\
\hline 233 & 0.00 & 105.50 & 25.17 & 75.72 & 8.64 & 13.73 & 39.36 & 0.00 \\
\hline 234 & 0.00 & 124.96 & 42.28 & 89.97 & 17.64 & 14.97 & 56.95 & 0.00 \\
\hline 235 & 0.00 & 147.18 & 55.06 & 104.97 & 24.20 & 0.00 & 74.45 & 0.00 \\
\hline 236 & 0.00 & 0.00 & 63.56 & 0.00 & 29.05 & 1.96 & 93.58 & 0.00 \\
\hline 237 & 0.00 & 22.65 & 68.63 & 13.73 & 33.45 & 4.02 & 114.32 & 0.00 \\
\hline 238 & 0.00 & 43.37 & 71.60 & 25.43 & 38.66 & 5.74 & 136.37 & 0.00 \\
\hline 239 & 0.00 & 62.16 & 73.76 & 35.63 & 45.39 & 7.14 & 158.92 & 0.00 \\
\hline 240 & 0.00 & 79.10 & 76.64 & 44.81 & 54.32 & 8.14 & 180.99 & 0.00 \\
\hline 241 & 0.00 & 94.84 & 63.14 & 54.09 & 38.35 & 8.74 & 0.00 & 0.00 \\
\hline 242 & 0.00 & 110.12 & 0.00 & 63.84 & 49.15 & 8.95 & 17.27 & 0.00 \\
\hline 243 & 0.00 & 125.60 & 3.87 & 74.19 & 6.96 & 8.95 & 30.89 & 0.00 \\
\hline 244 & 0.00 & 141.09 & 7.02 & 84.98 & 15.09 & 8.95 & 41.86 & 0.00 \\
\hline 245 & 0.00 & 155.72 & 9.45 & 95.56 & 21.15 & 0.00 & 51.04 & 0.00 \\
\hline 246 & 0.00 & 0.00 & 11.07 & 0.00 & 24.93 & 0.00 & 59.19 & 0.00 \\
\hline 247 & 0.00 & 11.04 & 11.88 & 7.93 & 26.82 & 0.00 & 66.92 & 0.00 \\
\hline 248 & 0.00 & 20.11 & 12.15 & 13.65 & 27.45 & 0.00 & 74.62 & 0.00 \\
\hline 249 & 0.00 & 27.40 & 12.15 & 17.55 & 27.45 & 0.00 & 82.52 & 0.00 \\
\hline 250 & 0.00 & 33.70 & 12.15 & 19.89 & 27.45 & 0.00 & 90.06 & 0.00 \\
\hline 251 & 0.00 & 39.52 & 12.15 & 21.06 & 13.13 & 0.00 & 0.00 & 0.00 \\
\hline 252 & 0.00 & 45.65 & 0.00 & 21.45 & 13.13 & 0.00 & 5.67 & 0.00 \\
\hline 253 & 0.00 & 51.68 & 0.00 & 21.45 & 0.00 & 0.00 & 10.26 & 0.00 \\
\hline 254 & 0.00 & 57.54 & 0.00 & 21.45 & 0.00 & 0.00 & 14.31 & 0.00 \\
\hline 255 & 0.00 & 62.92 & 0.00 & 21.45 & 0.00 & 0.00 & 18.27 & 0.00 \\
\hline 256 & 0.00 & 0.00 & 0.00 & 0.00 & 0.00 & 0.00 & 22.59 & 0.00 \\
\hline 257 & 0.00 & 3.03 & 0.00 & 0.00 & 0.00 & 0.00 & 27.90 & 0.00 \\
\hline 258 & 0.00 & 4.80 & 0.00 & 0.00 & 0.00 & 0.00 & 34.02 & 0.00 \\
\hline 259 & 0.00 & 5.68 & 0.00 & 0.00 & 0.00 & 0.00 & 40.77 & 0.00 \\
\hline 260 & 0.00 & 5.97 & 0.00 & 0.00 & 0.00 & 0.00 & 47.61 & 0.00 \\
\hline 261 & 0.00 & 5.97 & 0.00 & 0.00 & 0.00 & 0.00 & 0.00 & 0.00 \\
\hline 262 & 0.00 & 5.97 & 0.00 & 0.00 & 0.00 & 0.00 & 5.49 & 0.00 \\
\hline 263 & 0.00 & 5.97 & 0.00 & 0.00 & 0.00 & 0.00 & 9.45 & 0.00 \\
\hline 264 & 0.00 & 5.97 & 0.00 & 0.00 & 0.00 & 0.00 & 12.15 & 0.00 \\
\hline 265 & 0.00 & 5.97 & 0.00 & 0.00 & 0.00 & 0.00 & 13.77 & 0.00 \\
\hline 266 & 0.00 & 0.00 & 0.00 & 0.00 & 0.00 & 0.00 & 14.58 & 0.00 \\
\hline 267 & 0.00 & 0.00 & 0.00 & 0.00 & 0.00 & 0.00 & 14.85 & 0.00 \\
\hline 268 & 0.00 & 0.00 & 0.00 & 0.00 & 0.00 & 0.00 & 14.85 & 0.00 \\
\hline 269 & 0.00 & 0.00 & 0.00 & 0.00 & 0.00 & 0.00 & 14.85 & 0.00 \\
\hline 270 & 0.00 & 0.00 & 0.00 & 0.00 & 0.00 & 0.00 & 14.85 & 0.00 \\
\hline QEV & PORTO_1 & PORTO_2 & PORTO_3 & PORTO_4 & PORTO_5 & PORTO_6 & PORTO_7 & PORTO_8 \\
\hline 001 & 32.50 & 31.00 & 27.50 & 29.50 & 25.50 & 22.50 & 29.50 & 33.50 \\
\hline 002 & 32.50 & 31.00 & 27.50 & 29.50 & 25.50 & 22.50 & 29.50 & 33.50 \\
\hline 003 & 32.50 & 31.00 & 27.50 & 29.50 & 25.50 & 22.50 & 29.50 & 33.50 \\
\hline 004 & 32.50 & 31.00 & 27.50 & 29.50 & 25.50 & 26.50 & 29.50 & 33.50 \\
\hline 005 & 32.50 & 31.00 & 27.50 & 29.50 & 25.50 & 26.50 & 29.50 & 33.50 \\
\hline 006 & 32.50 & 31.00 & 27.50 & 29.50 & 25.50 & 26.50 & 29.50 & 33.50 \\
\hline 007 & 32.50 & 31.00 & 27.50 & 29.50 & 25.50 & 26.50 & 29.50 & 33.50 \\
\hline 008 & 32.50 & 31.00 & 27.50 & 29.50 & 25.50 & 26.50 & 29.50 & 33.50 \\
\hline 009 & 32.50 & 31.00 & 27.50 & 29.50 & 25.50 & 22.50 & 29.50 & 33.50 \\
\hline 010 & 32.50 & 31.00 & 27.50 & 29.50 & 25.50 & 22.50 & 29.50 & 33.50 \\
\hline 011 & 36.50 & 31.00 & 27.50 & 29.50 & 25.50 & 22.50 & 29.50 & 33.50 \\
\hline 012 & 36.50 & 31.00 & 27.50 & 29.50 & 25.50 & 22.50 & 29.50 & 33.50 \\
\hline 013 & 36.50 & 31.00 & 33.50 & 29.50 & 25.50 & 22.50 & 29.50 & 33.50 \\
\hline 014 & 36.50 & 31.00 & 33.50 & 29.50 & 36.00 & 26.50 & 29.50 & 33.50 \\
\hline 015 & 36.50 & 31.00 & 33.50 & 29.50 & 36.00 & 26.50 & 29.50 & 33.50 \\
\hline 016 & 36.50 & 31.00 & 33.50 & 29.50 & 36.00 & 26.50 & 29.50 & 37.50 \\
\hline 017 & 36.50 & 31.00 & 27.50 & 29.50 & 30.00 & 26.50 & 29.50 & 37.50 \\
\hline 018 & 36.50 & 31.00 & 27.50 & 29.50 & 25.50 & 26.50 & 29.50 & 37.50 \\
\hline 019 & 36.50 & 31.00 & 33.50 & 29.50 & 25.50 & 26.50 & 29.50 & 37.50 \\
\hline 020 & 36.50 & 31.00 & 33.50 & 29.50 & 25.50 & 26.50 & 29.50 & 37.50 \\
\hline 021 & 36.50 & 31.00 & 33.50 & 29.50 & 31.50 & 26.50 & 29.50 & 37.50 \\
\hline 022 & 36.50 & 31.00 & 33.50 & 29.50 & 31.50 & 26.50 & 29.50 & 37.50 \\
\hline 023 & 36.50 & 31.00 & 33.50 & 29.50 & 31.50 & 26.50 & 29.50 & 37.50 \\
\hline 024 & 36.50 & 31.00 & 33.50 & 29.50 & 31.50 & 26.50 & 29.50 & 37.50 \\
\hline 025 & 36.50 & 31.00 & 33.50 & 29.50 & 31.50 & 26.50 & 29.50 & 37.50 \\
\hline 026 & 36.50 & 31.00 & 33.50 & 29.50 & 31.50 & 26.50 & 29.50 & 37.50 \\
\hline 027 & 36.50 & 31.00 & 27.50 & 29.50 & 25.50 & 26.50 & 29.50 & 37.50 \\
\hline 028 & 36.50 & 31.00 & 27.50 & 29.50 & 25.50 & 26.50 & 29.50 & 37.50 \\
\hline 029 & 36.50 & 31.00 & 33.50 & 29.50 & 25.50 & 26.50 & 29.50 & 37.50 \\
\hline 030 & 36.50 & 31.00 & 33.50 & 29.50 & 25.50 & 26.50 & 29.50 & 37.50 \\
\hline 031 & 36.50 & 31.00 & 33.50 & 29.50 & 31.50 & 26.50 & 29.50 & 37.50 \\
\hline 032 & 36.50 & 31.00 & 33.50 & 29.50 & 31.50 & 26.50 & 29.50 & 37.50 \\
\hline 033 & 36.50 & 31.00 & 33.50 & 29.50 & 31.50 & 26.50 & 29.50 & 37.50 \\
\hline 034 & 36.50 & 31.00 & 33.50 & 29.50 & 31.50 & 26.50 & 29.50 & 37.50 \\
\hline 035 & 36.50 & 31.00 & 33.50 & 29.50 & 31.50 & 26.50 & 29.50 & 37.50 \\
\hline 036 & 36.50 & 31.00 & 33.50 & 29.50 & 31.50 & 26.50 & 29.50 & 37.50 \\
\hline 037 & 36.50 & 31.00 & 27.50 & 29.50 & 25.50 & 26.50 & 29.50 & 37.50 \\
\hline 038 & 36.50 & 31.00 & 27.50 & 29.50 & 25.50 & 26.50 & 29.50 & 37.50 \\
\hline 039 & 36.50 & 31.00 & 33.50 & 29.50 & 25.50 & 26.50 & 29.50 & 37.50 \\
\hline 040 & 36.50 & 31.00 & 33.50 & 29.50 & 25.50 & 26.50 & 29.50 & 37.50 \\
\hline 041 & 36.50 & 31.00 & 33.50 & 29.50 & 31.50 & 26.50 & 29.50 & 37.50 \\
\hline
\end{tabular}




\begin{tabular}{|c|c|c|c|c|c|c|c|c|}
\hline 042 & 36.50 & 31.00 & 43.10 & 29.50 & 31.50 & 26.50 & 29.50 & 37.50 \\
\hline 043 & 36.50 & 31.00 & 43.10 & 29.50 & 39.00 & 26.50 & 29.50 & 37.50 \\
\hline 044 & 36.50 & 31.00 & 43.10 & 29.50 & 39.00 & 26.50 & 29.50 & 37.50 \\
\hline 045 & 36.50 & 31.00 & 43.10 & 29.50 & 39.00 & 35.30 & 29.50 & 37.50 \\
\hline 046 & 36.50 & 41.30 & 43.10 & 39.40 & 39.00 & 35.30 & 29.50 & 50.00 \\
\hline 047 & 36.50 & 41.30 & 35.10 & 39.40 & 37.70 & 35.30 & 29.50 & 50.00 \\
\hline 048 & 36.50 & 41.30 & 35.10 & 39.40 & 31.00 & 35.30 & 29.50 & 50.00 \\
\hline 049 & 36.50 & 41.30 & 43.10 & 39.40 & 31.00 & 35.30 & 29.50 & 50.00 \\
\hline 050 & 36.50 & 41.30 & 43.10 & 39.40 & 31.00 & 35.30 & 29.50 & 50.00 \\
\hline 051 & 48.60 & 41.30 & 44.60 & 39.40 & 42.00 & 34.68 & 39.30 & 50.00 \\
\hline 052 & 48.60 & 41.30 & 44.60 & 39.40 & 42.00 & 35.30 & 39.30 & 50.00 \\
\hline 053 & 48.60 & 41.30 & 44.60 & 39.40 & 42.00 & 35.30 & 39.30 & 50.00 \\
\hline 054 & 48.60 & 41.30 & 44.60 & 39.40 & 42.00 & 35.30 & 39.30 & 50.00 \\
\hline 055 & 48.60 & 41.30 & 44.60 & 39.40 & 42.00 & 35.30 & 39.30 & 50.00 \\
\hline 056 & 48.60 & 41.30 & 44.60 & 39.40 & 42.00 & 35.30 & 39.30 & 50.00 \\
\hline 057 & 48.60 & 41.30 & 36.60 & 35.29 & 34.00 & 35.30 & 39.30 & 50.00 \\
\hline 058 & 48.60 & 41.30 & 36.60 & 34.70 & 34.00 & 35.30 & 39.30 & 50.00 \\
\hline 059 & 48.60 & 41.30 & 37.48 & 34.70 & 34.00 & 35.30 & 39.30 & 50.00 \\
\hline 060 & 48.60 & 41.30 & 44.60 & 34.70 & 34.00 & 30.00 & 39.30 & 50.00 \\
\hline 061 & 48.60 & 41.30 & 44.60 & 34.70 & 34.00 & 30.00 & 39.30 & 50.00 \\
\hline 062 & 48.60 & 41.30 & 44.60 & 34.70 & 42.00 & 30.00 & 39.30 & 50.00 \\
\hline 063 & 48.60 & 41.30 & 44.60 & 34.70 & 42.00 & 30.00 & 39.30 & 50.00 \\
\hline 064 & 48.60 & 41.30 & 44.60 & 26.38 & 42.00 & 30.00 & 39.30 & 50.00 \\
\hline 065 & 48.60 & 41.30 & 44.60 & 26.00 & 42.00 & 30.00 & 39.30 & 50.00 \\
\hline 066 & 48.60 & 41.30 & 44.60 & 34.65 & 34.00 & 30.00 & 39.30 & 50.00 \\
\hline 067 & 48.60 & 41.30 & 36.60 & 34.70 & 34.00 & 30.00 & 39.30 & 50.00 \\
\hline 068 & 48.60 & 41.30 & 36.60 & 34.70 & 34.00 & 30.00 & 39.30 & 50.00 \\
\hline 069 & 48.60 & 41.30 & 36.60 & 34.70 & 34.00 & 30.00 & 39.30 & 50.00 \\
\hline 070 & 48.60 & 41.30 & 36.60 & 34.70 & 34.00 & 30.00 & 39.30 & 50.00 \\
\hline 071 & 48.60 & 41.30 & 44.60 & 26.00 & 34.00 & 30.00 & 39.30 & 50.00 \\
\hline 072 & 48.60 & 41.30 & 44.60 & 26.00 & 34.00 & 30.00 & 39.30 & 50.00 \\
\hline 073 & 48.60 & 41.30 & 44.60 & 26.00 & 34.00 & 30.00 & 39.30 & 50.00 \\
\hline 074 & 48.60 & 40.38 & 44.60 & 31.10 & 42.00 & 30.00 & 39.30 & 50.00 \\
\hline 075 & 48.60 & 36.60 & 36.60 & 34.70 & 34.00 & 30.00 & 39.30 & 50.00 \\
\hline 076 & 48.60 & 36.60 & 36.60 & 34.70 & 34.00 & 35.30 & 39.30 & 50.00 \\
\hline 077 & 48.60 & 36.60 & 36.60 & 34.70 & 34.00 & 35.30 & 39.30 & 50.00 \\
\hline 078 & 48.60 & 36.60 & 36.60 & 34.70 & 34.00 & 33.50 & 39.30 & 50.00 \\
\hline 079 & 48.60 & 36.60 & 36.60 & 34.70 & 34.00 & 30.00 & 39.30 & 50.00 \\
\hline 080 & 48.60 & 36.60 & 36.60 & 34.70 & 34.00 & 30.00 & 39.30 & 50.00 \\
\hline 081 & 48.60 & 36.60 & 36.60 & 34.70 & 34.00 & 30.00 & 39.30 & 50.00 \\
\hline 082 & 48.60 & 36.60 & 36.60 & 26.00 & 34.00 & 30.00 & 39.30 & 50.00 \\
\hline 083 & 48.60 & 36.60 & 44.60 & 30.30 & 34.00 & 30.00 & 39.30 & 50.00 \\
\hline 084 & 48.60 & 36.60 & 44.60 & 34.70 & 48.00 & 30.00 & 39.30 & 50.00 \\
\hline 085 & 48.60 & 36.60 & 44.60 & 34.70 & 42.00 & 30.00 & 39.30 & 50.00 \\
\hline 086 & 48.60 & 36.60 & 44.60 & 39.16 & 42.00 & 35.30 & 39.30 & 50.00 \\
\hline 087 & 48.60 & 36.60 & 44.60 & 39.24 & 42.00 & 35.30 & 39.30 & 50.00 \\
\hline 088 & 48.60 & 36.60 & 44.60 & 34.70 & 42.00 & 35.30 & 39.30 & 50.00 \\
\hline 089 & 48.60 & 36.60 & 44.60 & 34.70 & 36.22 & 35.30 & 39.30 & 50.00 \\
\hline 090 & 48.60 & 36.60 & 37.60 & 34.70 & 34.00 & 35.30 & 39.30 & 50.00 \\
\hline 091 & 48.60 & 36.60 & 36.60 & 34.70 & 34.00 & 35.30 & 39.30 & 50.00 \\
\hline 092 & 48.60 & 36.60 & 36.60 & 34.70 & 34.00 & 35.30 & 39.30 & 50.00 \\
\hline 093 & 48.60 & 31.56 & 51.30 & 34.70 & 34.00 & 35.30 & 39.30 & 50.00 \\
\hline 094 & 48.60 & 17.40 & 51.30 & 34.70 & 48.00 & 35.30 & 39.30 & 50.00 \\
\hline 095 & 48.60 & 27.84 & 45.49 & 34.70 & 48.00 & 30.10 & 39.30 & 50.00 \\
\hline 096 & 48.60 & 38.28 & 44.60 & 39.16 & 42.00 & 35.30 & 39.30 & 50.00 \\
\hline 097 & 48.60 & 41.30 & 42.03 & 39.40 & 42.00 & 35.30 & 39.30 & 50.00 \\
\hline 098 & 48.60 & 41.30 & 36.60 & 39.40 & 42.00 & 35.30 & 37.75 & 50.00 \\
\hline 099 & 48.60 & 36.60 & 36.60 & 37.11 & 42.00 & 35.30 & 19.25 & 50.00 \\
\hline 100 & 48.60 & 36.60 & 44.60 & 34.70 & 42.00 & 35.30 & 30.80 & 50.00 \\
\hline 101 & 48.60 & 36.60 & 44.60 & 34.70 & 42.00 & 35.30 & 39.30 & 50.00 \\
\hline 102 & 48.60 & 36.60 & 44.60 & 34.70 & 48.00 & 35.30 & 39.30 & 50.00 \\
\hline 103 & 48.60 & 35.48 & 44.60 & 34.70 & 42.00 & 35.30 & 39.30 & 50.00 \\
\hline 104 & 48.60 & 17.40 & 44.60 & 34.70 & 42.00 & 35.30 & 39.30 & 50.00 \\
\hline 105 & 48.60 & 27.84 & 44.60 & 29.68 & 42.00 & 35.30 & 39.30 & 50.00 \\
\hline 106 & 48.60 & 38.28 & 43.70 & 39.40 & 42.00 & 35.30 & 39.30 & 50.00 \\
\hline 107 & 48.60 & 41.30 & 36.60 & 39.40 & 42.00 & 35.30 & 39.30 & 50.00 \\
\hline 108 & 48.60 & 36.60 & 36.60 & 39.40 & 42.00 & 35.30 & 39.30 & 50.00 \\
\hline 109 & 48.60 & 36.60 & 36.60 & 34.70 & 34.00 & 35.30 & 39.30 & 50.00 \\
\hline 110 & 48.60 & 36.60 & 36.60 & 34.70 & 38.28 & 35.30 & 31.30 & 50.00 \\
\hline 111 & 48.60 & 45.90 & 54.40 & 43.30 & 49.50 & 44.20 & 39.30 & 62.50 \\
\hline 112 & 48.60 & 45.90 & 54.40 & 43.30 & 49.50 & 44.20 & 39.80 & 62.50 \\
\hline 113 & 48.60 & 22.08 & 54.40 & 43.30 & 49.50 & 44.20 & 39.30 & 62.50 \\
\hline 114 & 48.60 & 18.65 & 54.40 & 23.82 & 49.50 & 40.40 & 39.30 & 62.50 \\
\hline 115 & 48.60 & 29.84 & 46.71 & 29.68 & 49.50 & 37.50 & 39.30 & 62.50 \\
\hline 116 & 48.60 & 41.03 & 44.40 & 40.81 & 42.04 & 44.20 & 39.30 & 62.50 \\
\hline 117 & 48.60 & 45.90 & 44.40 & 43.30 & 39.50 & 44.20 & 39.30 & 62.50 \\
\hline 118 & 48.60 & 45.90 & 44.40 & 43.30 & 39.50 & 37.50 & 39.30 & 62.50 \\
\hline 119 & 48.60 & 45.90 & 44.40 & 43.30 & 39.50 & 37.50 & 39.30 & 62.50 \\
\hline 120 & 48.60 & 45.90 & 44.40 & 43.30 & 39.50 & 37.50 & 30.80 & 62.50 \\
\hline 121 & 60.90 & 45.90 & 45.90 & 43.30 & 42.50 & 37.50 & 29.05 & 62.50 \\
\hline 122 & 60.90 & 23.53 & 55.90 & 35.81 & 43.62 & 37.50 & 49.20 & 62.50 \\
\hline 123 & 60.90 & 18.91 & 55.90 & 19.25 & 42.50 & 37.50 & 49.20 & 62.50 \\
\hline 124 & 60.90 & 19.30 & 55.90 & 20.30 & 42.50 & 35.27 & 49.20 & 62.50 \\
\hline 125 & 60.90 & 30.88 & 55.90 & 32.48 & 42.50 & 2.33 & 49.20 & 62.50 \\
\hline 126 & 60.90 & 42.46 & 45.90 & 44.66 & 42.50 & 44.20 & 49.20 & 62.50 \\
\hline 127 & 60.90 & 45.90 & 45.90 & 49.10 & 42.50 & 44.20 & 27.35 & 62.50 \\
\hline
\end{tabular}




\begin{tabular}{|c|c|c|c|c|c|c|c|c|}
\hline 128 & 60.90 & 45.90 & 45.90 & 43.30 & 42.50 & 44.20 & 19.25 & 62.50 \\
\hline 129 & 60.90 & 45.90 & 45.90 & 43.30 & 42.50 & 37.50 & 19.25 & 62.50 \\
\hline 130 & 60.90 & 45.90 & 45.90 & 43.30 & 42.50 & 37.50 & 30.80 & 62.50 \\
\hline 131 & 60.90 & 45.90 & $\begin{array}{l}45.90 \\
55.87\end{array}$ & 43.30 & $\begin{array}{r}42.50 \\
42.50\end{array}$ & $\begin{array}{l}37.50 \\
37.50\end{array}$ & $\begin{array}{l}42.35 \\
49.20\end{array}$ & $\begin{array}{l}62.50 \\
62.50\end{array}$ \\
\hline 132 & 60.90 & 36.10 & 55.87 & 43.30 & 42.50 & 37.50 & 49.20 & $\begin{array}{l}62.50 \\
62.50\end{array}$ \\
\hline $\begin{array}{l}133 \\
134\end{array}$ & $\begin{array}{l}60.90 \\
60.90\end{array}$ & $\begin{array}{l}28.32 \\
20.70\end{array}$ & $\begin{array}{l}55.90 \\
55.90\end{array}$ & $\begin{array}{l}43.30 \\
21.92\end{array}$ & $\begin{array}{l}42.50 \\
60.00\end{array}$ & $\begin{array}{l}37.50 \\
37.50\end{array}$ & $\begin{array}{l}49.20 \\
49.20\end{array}$ & $\begin{array}{l}62.50 \\
62.50\end{array}$ \\
\hline 135 & 60.90 & 33.12 & 55.90 & 34.72 & 52.28 & 14.84 & 49.20 & 62.50 \\
\hline 136 & 60.90 & 45.54 & 55.90 & 47.74 & 42.50 & 50.00 & 49.20 & 62.50 \\
\hline 137 & 60.90 & 45.90 & 45.90 & 55.80 & 42.50 & 50.00 & 27.35 & 62.50 \\
\hline 138 & 60.90 & 45.90 & 45.90 & 43.30 & 42.50 & 50.00 & 20.09 & 62.50 \\
\hline 139 & 60.90 & 45.90 & 45.90 & 43.30 & 42.50 & 39.10 & 21.35 & 62.50 \\
\hline 140 & 60.90 & 45.90 & 45.90 & 43.30 & 42.50 & 37.50 & 34.16 & 62.50 \\
\hline 141 & 60.90 & 45.90 & 45.90 & 43.30 & 42.50 & 37.50 & 46.97 & 62.50 \\
\hline 142 & 60.90 & 45.90 & 45.90 & 43.30 & 42.50 & 37.50 & 49.20 & 62.50 \\
\hline 143 & 60.90 & 39.20 & 64.20 & 43.30 & 36.53 & 37.50 & 49.20 & 62.50 \\
\hline 144 & 60.90 & 21.79 & 64.20 & 37.90 & 60.00 & 37.50 & 49.20 & 62.50 \\
\hline 145 & 60.90 & 34.32 & 64.20 & 36.96 & 58.92 & 37.50 & 49.20 & 62.50 \\
\hline 146 & 60.90 & 47.19 & 61.69 & 50.82 & 42.50 & 50.00 & 49.20 & 62.50 \\
\hline 147 & 60.90 & 51.70 & 54.20 & 55.80 & 42.50 & 50.00 & 49.20 & 62.50 \\
\hline 148 & 60.90 & 45.90 & 45.90 & 55.80 & 42.50 & 50.00 & 29.92 & 62.50 \\
\hline 149 & 60.90 & 45.90 & 45.90 & 46.12 & 42.50 & 50.00 & 22.85 & 62.50 \\
\hline 150 & 60.90 & 45.90 & 45.90 & 43.30 & 42.50 & 48.24 & 36.56 & 62.50 \\
\hline 151 & 60.90 & 45.90 & 45.90 & 43.30 & 42.50 & 37.50 & 50.27 & 62.50 \\
\hline 152 & 60.90 & 45.90 & 45.90 & 43.30 & 60.00 & 37.50 & 59.41 & 62.50 \\
\hline 153 & 60.90 & 45.22 & 64.20 & 43.30 & 60.00 & 37.50 & 55.41 & 62.50 \\
\hline 154 & 60.90 & 22.40 & 62.59 & 43.30 & 60.00 & 37.50 & 49.20 & 62.50 \\
\hline 155 & 60.90 & 35.84 & 54.20 & 36.96 & 60.00 & 30.80 & 49.20 & 62.50 \\
\hline 156 & 60.90 & 49.28 & 54.20 & 50.82 & 52.50 & 50.00 & 41.70 & 62.50 \\
\hline 157 & 60.90 & 51.70 & 45.90 & 55.80 & 47.50 & 50.00 & 41.70 & 62.50 \\
\hline 158 & 60.90 & 51.70 & 45.90 & 49.10 & 42.50 & 50.00 & 41.70 & 62.50 \\
\hline 159 & 60.90 & 51.70 & 45.90 & 49.10 & 42.50 & 50.00 & 33.40 & 62.50 \\
\hline 160 & 60.90 & 51.70 & 45.90 & 49.10 & 42.50 & 37.50 & 38.34 & 62.50 \\
\hline 161 & 60.90 & 45.90 & 45.90 & 49.10 & 42.50 & 37.50 & 52.71 & 62.50 \\
\hline 162 & 60.90 & 45.90 & 64.20 & 49.10 & 60.00 & 37.50 & 62.30 & 62.50 \\
\hline 163 & 60.90 & 41.88 & 64.20 & 43.30 & 56.25 & 34.08 & 65.90 & 62.50 \\
\hline 164 & 60.90 & 22.40 & 64.20 & 30.24 & 60.00 & 30.80 & 55.77 & 62.50 \\
\hline 165 & 60.90 & 35.84 & 54.20 & 37.67 & 52.50 & 30.80 & 49.20 & 62.50 \\
\hline 166 & 60.90 & 49.28 & 54.20 & 51.79 & 52.50 & 50.00 & 49.20 & 62.50 \\
\hline 167 & 60.90 & 51.70 & 51.56 & 55.80 & 52.50 & 50.00 & 39.40 & 62.50 \\
\hline 168 & 60.90 & 51.70 & 45.90 & 49.10 & 42.50 & 44.20 & 33.40 & 62.50 \\
\hline 169 & 60.90 & 50.69 & 45.90 & 49.10 & 42.50 & 44.20 & 33.40 & 62.50 \\
\hline 170 & 60.90 & 45.90 & 45.90 & 49.10 & 42.50 & 44.20 & 38.80 & 62.50 \\
\hline 171 & 60.90 & 55.00 & 53.50 & 59.00 & 48.00 & 53.00 & 53.35 & 75.00 \\
\hline 172 & 60.90 & 55.00 & 73.80 & 44.00 & 67.50 & 53.00 & 59.90 & 75.00 \\
\hline 173 & 60.90 & 30.99 & 61.80 & 44.00 & 67.50 & 51.61 & 58.40 & 75.00 \\
\hline 174 & 60.90 & 23.65 & 61.80 & 31.72 & 60.00 & 40.38 & 58.40 & 75.00 \\
\hline 175 & 60.90 & 37.84 & 53.50 & 38.16 & 60.00 & 13.53 & 58.40 & 75.00 \\
\hline 176 & 60.90 & 52.03 & 53.50 & 52.47 & 48.00 & 60.00 & 58.40 & 75.00 \\
\hline 177 & 60.90 & 61.49 & 53.50 & 59.00 & 48.00 & 60.00 & 40.90 & 75.00 \\
\hline 178 & 60.90 & 62.00 & 53.50 & 59.00 & 48.00 & 53.00 & 34.20 & 75.00 \\
\hline 179 & 60.90 & 62.00 & 53.50 & 44.00 & 48.00 & 53.00 & 24.25 & 75.00 \\
\hline 180 & 60.90 & 62.00 & 53.50 & 44.00 & 48.00 & 53.00 & 38.80 & 75.00 \\
\hline 181 & 73.00 & 48.36 & 51.86 & 44.00 & 51.00 & 53.00 & 40.25 & 75.00 \\
\hline 182 & 73.00 & 28.38 & 77.00 & 44.00 & 53.38 & 32.73 & 63.05 & 75.00 \\
\hline 183 & 73.00 & 23.93 & 77.00 & 44.00 & 51.00 & 31.00 & 70.00 & 75.00 \\
\hline 184 & 73.00 & 24.35 & 76.28 & 37.00 & 72.00 & 23.00 & 70.00 & 75.00 \\
\hline 185 & 73.00 & 38.96 & 67.00 & 43.58 & 51.00 & 15.00 & 56.00 & 75.00 \\
\hline 186 & 73.00 & 53.57 & 67.00 & 56.32 & 51.00 & 60.00 & 50.69 & 75.00 \\
\hline 187 & 73.00 & 63.31 & 55.00 & 66.56 & 51.00 & 60.00 & 34.61 & 75.00 \\
\hline 188 & 73.00 & 70.00 & 55.00 & 67.00 & 47.02 & 60.00 & 24.14 & 75.00 \\
\hline 189 & 73.00 & 70.00 & 55.00 & 67.00 & 42.00 & 53.00 & 23.97 & 75.00 \\
\hline 190 & 73.00 & 52.00 & 41.00 & 52.00 & 42.00 & 44.88 & 38.35 & 75.00 \\
\hline 191 & 73.00 & 52.00 & 41.00 & 45.19 & 42.00 & 31.00 & 52.73 & 75.00 \\
\hline 192 & 73.00 & 32.39 & 77.00 & 44.00 & 72.00 & 31.00 & 62.31 & 75.00 \\
\hline 193 & 73.00 & 31.00 & 71.33 & 44.00 & 66.84 & 31.00 & 70.00 & 75.00 \\
\hline 194 & 73.00 & 25.80 & 67.00 & 31.00 & 72.00 & 31.00 & 69.02 & 75.00 \\
\hline 195 & 73.00 & 41.28 & 67.00 & 43.28 & 72.00 & 31.00 & 38.00 & 75.00 \\
\hline 196 & 73.00 & 56.76 & 67.00 & 59.51 & 72.00 & 60.00 & 38.00 & 75.00 \\
\hline 197 & 73.00 & 67.08 & 67.00 & 67.00 & 72.00 & 60.00 & 38.00 & 75.00 \\
\hline 198 & 73.00 & 70.00 & 53.00 & 67.00 & 51.00 & 60.00 & 38.00 & 75.00 \\
\hline 199 & 73.00 & 63.03 & 53.00 & 67.00 & 40.00 & 51.09 & 38.00 & 75.00 \\
\hline 200 & 73.00 & 52.00 & 41.00 & 54.00 & 25.20 & 48.00 & 41.85 & 75.00 \\
\hline 201 & 73.00 & 44.00 & 41.00 & 54.00 & 18.00 & 48.00 & 57.54 & 75.00 \\
\hline 202 & 73.00 & 44.00 & 77.00 & 48.46 & 72.00 & 46.37 & 68.00 & 75.00 \\
\hline 203 & 73.00 & 44.00 & 77.00 & 45.00 & 72.00 & 48.00 & 79.00 & 75.00 \\
\hline 204 & 73.00 & 31.00 & 77.00 & 37.00 & 72.00 & 41.00 & 70.83 & 75.00 \\
\hline 205 & 73.00 & 38.02 & 77.00 & 44.71 & 72.00 & 41.00 & 47.38 & 75.00 \\
\hline 206 & 73.00 & 52.28 & 77.00 & 61.47 & 72.00 & 60.00 & 47.00 & 75.00 \\
\hline 207 & 73.00 & 61.78 & 63.00 & 67.00 & 59.00 & 60.00 & 38.00 & 75.00 \\
\hline 208 & 73.00 & 70.00 & 54.61 & 67.00 & 59.00 & 60.00 & 38.00 & 75.00 \\
\hline 209 & 73.00 & 70.00 & 51.00 & 67.00 & 59.00 & 53.47 & 38.00 & 75.00 \\
\hline 210 & 73.00 & 63.11 & 32.00 & 60.37 & 41.15 & 48.00 & 44.72 & 75.00 \\
\hline 211 & 73.00 & 41.53 & 23.00 & 54.00 & 28.00 & 48.00 & 61.00 & 75.00 \\
\hline 212 & 73.00 & 31.00 & 77.00 & 45.00 & 72.00 & 48.00 & 61.00 & 75.00 \\
\hline 213 & 73.00 & 25.03 & 77.00 & 45.00 & 72.00 & 48.00 & 61.00 & 75.00 \\
\hline
\end{tabular}




\begin{tabular}{|c|c|c|c|c|c|c|c|c|}
\hline 214 & 73.00 & 26.92 & 77.00 & 45.00 & 72.00 & 60.00 & 61.00 & 75.00 \\
\hline 215 & 73.00 & 43.08 & 77.00 & 45.00 & 72.00 & 60.00 & 58.90 & 75.00 \\
\hline 216 & 73.00 & 59.23 & 69.20 & 60.00 & 69.06 & 60.00 & 52.00 & 75.00 \\
\hline 217 & 73.00 & 70.00 & 63.00 & 67.00 & 59.00 & 60.00 & 52.00 & 75.00 \\
\hline 218 & 73.00 & 70.00 & 57.54 & 67.00 & 51.00 & 60.00 & 52.00 & 75.00 \\
\hline 219 & 73.00 & 70.00 & 42.00 & 67.00 & 51.00 & 60.00 & 52.00 & 75.00 \\
\hline 220 & 73.00 & 67.75 & 36.86 & 54.00 & 51.00 & 60.00 & 52.00 & 75.00 \\
\hline 221 & 73.00 & 57.00 & 23.00 & 54.00 & 51.00 & 60.00 & 61.40 & 75.00 \\
\hline 222 & 73.00 & 39.00 & 77.00 & 45.00 & 72.00 & 60.00 & 79.00 & 75.00 \\
\hline 223 & 73.00 & 31.00 & 77.00 & 45.00 & 72.00 & 60.00 & 79.00 & 75.00 \\
\hline 224 & 73.00 & 31.00 & 77.00 & 45.00 & 72.00 & 53.82 & 52.00 & 75.00 \\
\hline 225 & 73.00 & 45.07 & 77.00 & 46.12 & 72.00 & 53.00 & 52.00 & 75.00 \\
\hline 226 & 73.00 & 60.39 & 77.00 & 63.41 & 72.00 & 60.00 & 52.00 & 75.00 \\
\hline 227 & 73.00 & 57.00 & 77.00 & 67.00 & 72.00 & 60.00 & 52.00 & 75.00 \\
\hline 228 & 73.00 & 57.00 & 77.00 & 67.00 & 59.00 & 60.00 & 52.00 & 75.00 \\
\hline 229 & 73.00 & 57.00 & 68.00 & 55.37 & 51.00 & 60.00 & 52.00 & 75.00 \\
\hline 230 & 73.00 & 57.00 & 68.00 & 54.00 & 51.00 & 60.00 & 53.60 & 75.00 \\
\hline 231 & 73.00 & 52.36 & 68.00 & 54.00 & 51.00 & 60.00 & 79.00 & 75.00 \\
\hline 232 & 73.00 & 49.00 & 77.00 & 54.00 & 72.00 & 60.00 & 79.00 & 75.00 \\
\hline 233 & 73.00 & 49.00 & 77.00 & 54.00 & 72.00 & 60.00 & 73.43 & 75.00 \\
\hline 234 & 73.00 & 57.00 & 77.00 & 54.00 & 72.00 & 60.00 & 70.00 & 75.00 \\
\hline 235 & 73.00 & 57.00 & 77.00 & 54.00 & 72.00 & 60.00 & 70.00 & 75.00 \\
\hline 236 & 73.00 & 63.14 & 77.00 & 67.00 & 72.00 & 60.00 & 70.00 & 75.00 \\
\hline 237 & 73.00 & 70.00 & 77.00 & 67.00 & 72.00 & 60.00 & 70.00 & 75.00 \\
\hline 238 & 73.00 & 70.00 & 77.00 & 67.00 & 72.00 & 60.00 & 70.00 & 75.00 \\
\hline 239 & 73.00 & 70.00 & 77.00 & 67.00 & 72.00 & 60.00 & 70.00 & 75.00 \\
\hline 240 & 73.00 & 57.09 & 77.00 & 67.00 & 72.00 & 60.00 & 70.00 & 75.00 \\
\hline 241 & 73.00 & 42.80 & 62.60 & 50.50 & 60.90 & 45.10 & 79.00 & 56.50 \\
\hline 242 & 73.00 & 42.80 & 62.60 & 50.50 & 60.90 & 45.10 & 79.00 & 56.50 \\
\hline 243 & 73.00 & 42.80 & 62.60 & 50.50 & 60.90 & 45.10 & 79.00 & 56.50 \\
\hline 244 & 73.00 & 52.60 & 62.60 & 50.50 & 60.90 & 45.10 & 79.00 & 56.50 \\
\hline 245 & 73.00 & 52.60 & 62.60 & 50.50 & 60.90 & 45.10 & 70.00 & 56.50 \\
\hline 246 & 73.00 & 52.60 & 62.60 & 50.50 & 60.90 & 45.10 & 70.00 & 56.50 \\
\hline 247 & 73.00 & 52.60 & 62.60 & 50.50 & 60.90 & 45.10 & 70.00 & 56.50 \\
\hline 248 & 73.00 & 52.60 & 62.60 & 50.50 & 60.90 & 45.10 & 70.00 & 56.50 \\
\hline 249 & 73.00 & 52.60 & 62.60 & 50.50 & 60.90 & 45.10 & 70.00 & 56.50 \\
\hline 250 & 73.00 & 52.60 & 62.60 & 50.50 & 60.90 & 45.10 & 70.00 & 56.50 \\
\hline 251 & 54.80 & 52.60 & 57.90 & 50.50 & 54.20 & 45.10 & 59.40 & 56.50 \\
\hline 252 & 54.80 & 52.60 & 57.90 & 50.50 & 54.20 & 45.10 & 59.40 & 56.50 \\
\hline 253 & 54.80 & 52.60 & 57.90 & 50.50 & 54.20 & 45.10 & 59.40 & 56.50 \\
\hline 254 & 54.80 & 52.60 & 57.90 & 50.50 & 54.20 & 45.10 & 59.40 & 56.50 \\
\hline 255 & 54.80 & 52.60 & 57.90 & 50.50 & 54.20 & 45.10 & 59.40 & 56.50 \\
\hline 256 & 54.80 & 52.60 & 57.90 & 50.50 & 54.20 & 45.10 & 59.40 & 56.50 \\
\hline 257 & 54.80 & 52.60 & 57.90 & 50.50 & 54.20 & 45.10 & 59.40 & 56.50 \\
\hline 258 & 54.80 & 52.60 & 57.90 & 50.50 & 54.20 & 45.10 & 59.40 & 56.50 \\
\hline 259 & 54.80 & 52.60 & 57.90 & 50.50 & 54.20 & 45.10 & 59.40 & 56.50 \\
\hline 260 & 54.80 & 52.60 & 57.90 & 50.50 & 54.20 & 45.10 & 59.40 & 56.50 \\
\hline 261 & 54.80 & 52.60 & 57.90 & 50.50 & 54.20 & 45.10 & 59.40 & 56.50 \\
\hline 262 & 54.80 & 52.60 & 57.90 & 50.50 & 54.20 & 45.10 & 59.40 & 56.50 \\
\hline 263 & 54.80 & 52.60 & 57.90 & 50.50 & 54.20 & 45.10 & 59.40 & 56.50 \\
\hline 264 & 54.80 & 52.60 & 57.90 & 50.50 & 54.20 & 45.10 & 59.40 & 56.50 \\
\hline 265 & 54.80 & 52.60 & 57.90 & 50.50 & 54.20 & 45.10 & 59.40 & 56.50 \\
\hline 266 & 54.80 & 52.60 & 57.90 & 50.50 & 54.20 & 45.10 & 59.40 & 56.50 \\
\hline 267 & 54.80 & 52.60 & 57.90 & 50.50 & 54.20 & 45.10 & 59.40 & 56.50 \\
\hline 268 & 54.80 & 52.60 & 57.90 & 50.50 & 54.20 & 45.10 & 59.40 & 56.50 \\
\hline 269 & 54.80 & 52.60 & 57.90 & 50.50 & 54.20 & 45.10 & 59.40 & 56.50 \\
\hline 270 & 54.80 & 52.60 & 57.90 & 50.50 & 54.20 & 45.10 & 59.40 & 56.50 \\
\hline 271 & 54.80 & 52.60 & 57.90 & 50.50 & 54.20 & 45.10 & 59.40 & 56.50 \\
\hline 272 & 54.80 & 52.60 & 57.90 & 50.50 & 54.20 & 45.10 & 59.40 & 56.50 \\
\hline 273 & 54.80 & 52.60 & 57.90 & 50.50 & 54.20 & 45.10 & 59.40 & 56.50 \\
\hline 274 & 54.80 & 52.60 & 57.90 & 50.50 & 54.20 & 45.10 & 59.40 & 56.50 \\
\hline 275 & 54.80 & 52.60 & 57.90 & 50.50 & 54.20 & 45.10 & 59.40 & 56.50 \\
\hline 276 & 54.80 & 52.60 & 57.90 & 50.50 & 54.20 & 45.10 & 59.40 & 56.50 \\
\hline 277 & 54.80 & 52.60 & 57.90 & 50.50 & 54.20 & 45.10 & 59.40 & 56.50 \\
\hline 278 & 54.80 & 52.60 & 57.90 & 50.50 & 54.20 & 45.10 & 59.40 & 56.50 \\
\hline 279 & 54.80 & 52.60 & 57.90 & 50.50 & 54.20 & 45.10 & 59.40 & 56.50 \\
\hline 280 & 54.80 & 52.60 & 57.90 & 50.50 & 54.20 & 45.10 & 59.40 & 56.50 \\
\hline 281 & 54.80 & 52.60 & 57.90 & 50.50 & 54.20 & 45.10 & 59.40 & 56.50 \\
\hline 282 & 54.80 & 52.60 & 57.90 & 50.50 & 54.20 & 45.10 & 59.40 & 56.50 \\
\hline 283 & 54.80 & 52.60 & 57.90 & 50.50 & 54.20 & 45.10 & 59.40 & 56.50 \\
\hline 284 & 54.80 & 52.60 & 57.90 & 50.50 & 54.20 & 45.10 & 59.40 & 56.50 \\
\hline 285 & 54.80 & 52.60 & 57.90 & 50.50 & 54.20 & 45.10 & 59.40 & 56.50 \\
\hline 286 & 54.80 & 52.60 & 57.90 & 50.50 & 54.20 & 45.10 & 59.40 & 56.50 \\
\hline 287 & 54.80 & 52.60 & 57.90 & 50.50 & 54.20 & 45.10 & 59.40 & 56.50 \\
\hline 288 & 54.80 & 52.60 & 57.90 & 50.50 & 54.20 & 45.10 & 59.40 & 56.50 \\
\hline 289 & 54.80 & 52.60 & 57.90 & 50.50 & 54.20 & 45.10 & 59.40 & 56.50 \\
\hline 290 & 54.80 & 52.60 & 57.90 & 50.50 & 54.20 & 45.10 & 59.40 & 56.50 \\
\hline 291 & 54.80 & 52.60 & 57.90 & 50.50 & 54.20 & 45.10 & 59.40 & 56.50 \\
\hline 292 & 54.80 & 52.60 & 57.90 & 50.50 & 54.20 & 45.10 & 59.40 & 56.50 \\
\hline 293 & 54.80 & 52.60 & 57.90 & 50.50 & 54.20 & 45.10 & 59.40 & 56.50 \\
\hline 294 & 54.80 & 52.60 & 57.90 & 50.50 & 54.20 & 45.10 & 59.40 & 56.50 \\
\hline 295 & 54.80 & 52.60 & 57.90 & 50.50 & 54.20 & 45.10 & 59.40 & 56.50 \\
\hline 296 & 54.80 & 52.60 & 57.90 & 50.50 & 54.20 & 45.10 & 59.40 & 56.50 \\
\hline 297 & 54.80 & 52.60 & 57.90 & 50.50 & 54.20 & 45.10 & 59.40 & 56.50 \\
\hline 298 & 54.80 & 52.60 & 57.90 & 50.50 & 54.20 & 45.10 & 59.40 & 56.50 \\
\hline 299 & 54.80 & 52.60 & 57.90 & 50.50 & 54.20 & 45.10 & 59.40 & 56.50 \\
\hline
\end{tabular}




\begin{tabular}{|c|c|c|c|c|c|c|c|c|}
\hline 300 & 54.80 & 52.60 & 57.90 & 50.50 & 54.20 & 45.10 & 59.40 & 56.50 \\
\hline 301 & 54.80 & 35.00 & 43.30 & 33.50 & 42.80 & 30.00 & 59.40 & 37.50 \\
\hline 302 & 54.80 & 35.00 & 43.30 & 33.50 & 42.80 & 30.00 & 59.40 & 37.50 \\
\hline 303 & 54.80 & 35.00 & 43.30 & 33.50 & 42.80 & 30.00 & 59.40 & 37.50 \\
\hline 304 & 54.80 & 35.00 & 43.30 & 33.50 & 42.80 & 30.00 & 59.40 & 37.50 \\
\hline 305 & 54.80 & 35.00 & 43.30 & 33.50 & 42.80 & 30.00 & 59.40 & 37.50 \\
\hline 306 & 54.80 & 35.00 & 43.30 & 33.50 & 42.80 & 30.00 & 59.40 & 37.50 \\
\hline 307 & 54.80 & 35.00 & 43.30 & 33.50 & 42.80 & 30.00 & 59.40 & 37.50 \\
\hline 308 & 54.80 & 35.00 & 43.30 & 33.50 & 42.80 & 30.00 & 59.40 & 37.50 \\
\hline 309 & 54.80 & 35.00 & 43.30 & 33.50 & 42.80 & 30.00 & 59.40 & 37.50 \\
\hline 310 & 54.80 & 35.00 & 43.30 & 33.50 & 42.80 & 30.00 & 59.40 & 37.50 \\
\hline 311 & 36.50 & 35.00 & 38.50 & 33.50 & 36.00 & 30.00 & 39.50 & 37.50 \\
\hline 312 & 36.50 & 35.00 & 38.50 & 33.50 & 36.00 & 30.00 & 39.50 & 37.50 \\
\hline 313 & 36.50 & 35.00 & 38.50 & 33.50 & 36.00 & 30.00 & 39.50 & 37.50 \\
\hline 314 & 36.50 & 35.00 & 38.50 & 33.50 & 36.00 & 30.00 & 39.50 & 37.50 \\
\hline 315 & 36.50 & 35.00 & 38.50 & 33.50 & 36.00 & 30.00 & 39.50 & 37.50 \\
\hline 316 & 36.50 & 35.00 & 38.50 & 33.50 & 36.00 & 30.00 & 39.50 & 37.50 \\
\hline 317 & 36.50 & 35.00 & 38.50 & 33.50 & 36.00 & 30.00 & 39.50 & 37.50 \\
\hline 318 & 36.50 & 35.00 & 38.50 & 33.50 & 36.00 & 30.00 & 39.50 & 37.50 \\
\hline 319 & 36.50 & 35.00 & 38.50 & 33.50 & 36.00 & 30.00 & 39.50 & 37.50 \\
\hline 320 & 36.50 & 35.00 & 38.50 & 33.50 & 36.00 & 30.00 & 39.50 & 37.50 \\
\hline 321 & 36.50 & 35.00 & 38.50 & 33.50 & 36.00 & 30.00 & 39.50 & 37.50 \\
\hline 322 & 36.50 & 35.00 & 38.50 & 33.50 & 36.00 & 30.00 & 39.50 & 37.50 \\
\hline 323 & 36.50 & 35.00 & 38.50 & 33.50 & 36.00 & 30.00 & 39.50 & 37.50 \\
\hline 324 & 36.50 & 35.00 & 38.50 & 33.50 & 36.00 & 30.00 & 39.50 & 37.50 \\
\hline 325 & 36.50 & 35.00 & 38.50 & 33.50 & 36.00 & 30.00 & 39.50 & 37.50 \\
\hline 326 & 36.50 & 35.00 & 38.50 & 33.50 & 36.00 & 30.00 & 39.50 & 37.50 \\
\hline 327 & 36.50 & 35.00 & 38.50 & 33.50 & 36.00 & 30.00 & 39.50 & 37.50 \\
\hline 328 & 36.50 & 35.00 & 38.50 & 33.50 & 36.00 & 30.00 & 39.50 & 37.50 \\
\hline 329 & 36.50 & 35.00 & 38.50 & 33.50 & 36.00 & 30.00 & 39.50 & 37.50 \\
\hline 330 & 36.50 & 35.00 & 38.50 & 33.50 & 36.00 & 30.00 & 39.50 & 37.50 \\
\hline 331 & 36.50 & 35.00 & 38.50 & 33.50 & 36.00 & 30.00 & 39.50 & 37.50 \\
\hline 332 & 36.50 & 35.00 & 38.50 & 33.50 & 36.00 & 30.00 & 39.50 & 37.50 \\
\hline 333 & 36.50 & 35.00 & 38.50 & 33.50 & 36.00 & 30.00 & 39.50 & 37.50 \\
\hline 334 & 36.50 & 35.00 & 38.50 & 33.50 & 36.00 & 30.00 & 39.50 & 37.50 \\
\hline 335 & 36.50 & 35.00 & 38.50 & 33.50 & 36.00 & 30.00 & 39.50 & 37.50 \\
\hline 336 & 36.50 & 35.00 & 38.50 & 33.50 & 36.00 & 30.00 & 39.50 & 37.50 \\
\hline 337 & 36.50 & 35.00 & 38.50 & 33.50 & 36.00 & 30.00 & 39.50 & 37.50 \\
\hline 338 & 36.50 & 35.00 & 38.50 & 33.50 & 36.00 & 30.00 & 39.50 & 37.50 \\
\hline 339 & 36.50 & 35.00 & 38.50 & 33.50 & 36.00 & 30.00 & 39.50 & 37.50 \\
\hline 340 & 36.50 & 35.00 & 38.50 & 33.50 & 36.00 & 30.00 & 39.50 & 37.50 \\
\hline 341 & 36.50 & 35.00 & 38.50 & 33.50 & 36.00 & 30.00 & 39.50 & 37.50 \\
\hline 342 & 36.50 & 35.00 & 38.50 & 33.50 & 36.00 & 30.00 & 39.50 & 37.50 \\
\hline 343 & 36.50 & 35.00 & 38.50 & 33.50 & 36.00 & 30.00 & 39.50 & 37.50 \\
\hline 344 & 36.50 & 35.00 & 38.50 & 33.50 & 36.00 & 30.00 & 39.50 & 37.50 \\
\hline 345 & 36.50 & 35.00 & 38.50 & 33.50 & 36.00 & 30.00 & 39.50 & 37.50 \\
\hline 346 & 36.50 & 35.00 & 38.50 & 33.50 & 36.00 & 30.00 & 39.50 & 37.50 \\
\hline 347 & 36.50 & 35.00 & 38.50 & 33.50 & 36.00 & 30.00 & 39.50 & 37.50 \\
\hline 348 & 36.50 & 35.00 & 38.50 & 33.50 & 36.00 & 30.00 & 39.50 & 37.50 \\
\hline 349 & 36.50 & 35.00 & 38.50 & 33.50 & 36.00 & 30.00 & 39.50 & 37.50 \\
\hline 350 & 36.50 & 35.00 & 38.50 & 33.50 & 36.00 & 30.00 & 39.50 & 37.50 \\
\hline 351 & 36.50 & 35.00 & 38.50 & 33.50 & 36.00 & 30.00 & 39.50 & 37.50 \\
\hline 352 & 36.50 & 35.00 & 38.50 & 33.50 & 36.00 & 30.00 & 39.50 & 37.50 \\
\hline 353 & 36.50 & 35.00 & 38.50 & 33.50 & 36.00 & 30.00 & 39.50 & 37.50 \\
\hline 354 & 36.50 & 35.00 & 38.50 & 33.50 & 36.00 & 30.00 & 39.50 & 37.50 \\
\hline 355 & 36.50 & 35.00 & 38.50 & 33.50 & 36.00 & 30.00 & 39.50 & 37.50 \\
\hline 356 & 36.50 & 35.00 & 38.50 & 33.50 & 36.00 & 30.00 & 39.50 & 37.50 \\
\hline 357 & 36.50 & 35.00 & 38.50 & 33.50 & 36.00 & 30.00 & 39.50 & 37.50 \\
\hline 358 & 36.50 & 35.00 & 38.50 & 33.50 & 36.00 & 30.00 & 39.50 & 37.50 \\
\hline 359 & 36.50 & 35.00 & 38.50 & 33.50 & 36.00 & 30.00 & 39.50 & 37.50 \\
\hline 360 & 36.50 & 35.00 & 38.50 & 33.50 & 36.00 & 30.00 & 39.50 & 37.50 \\
\hline 361 & 36.50 & 0.00 & 9.50 & 0.00 & 13.50 & 0.00 & 39.50 & 0.00 \\
\hline 362 & 36.50 & 0.00 & 9.50 & 0.00 & 13.50 & 0.00 & 39.50 & 0.00 \\
\hline 363 & 36.50 & 0.00 & 9.50 & 0.00 & 13.50 & 0.00 & 39.50 & 0.00 \\
\hline 364 & 36.50 & 0.00 & 9.50 & 0.00 & 13.50 & 0.00 & 39.50 & 0.00 \\
\hline 365 & 36.50 & 0.00 & 9.50 & 0.00 & 13.50 & 0.00 & 39.50 & 0.00 \\
\hline 366 & 36.50 & 0.00 & 9.50 & 0.00 & 13.50 & 0.00 & 39.50 & 0.00 \\
\hline 367 & 36.50 & 0.00 & 9.50 & 0.00 & 13.50 & 0.00 & 39.50 & 0.00 \\
\hline 368 & 36.50 & 0.00 & 9.50 & 0.00 & 13.50 & 0.00 & 39.50 & 0.00 \\
\hline 369 & 36.50 & 0.00 & 9.50 & 0.00 & 13.50 & 0.00 & 39.50 & 0.00 \\
\hline 370 & 36.50 & 0.00 & 9.50 & 0.00 & 13.50 & 0.00 & 39.50 & 0.00 \\
\hline LEV & PORTO_1 & PORTO_2 & PORTO_3 & PORTO_4 & PORTO_5 & PORTO_6 & PORTO_7 & PORTO_ \\
\hline 001 & 4.00 & 4.00 & 11.00 & 4.00 & 10.50 & 7.50 & 10.00 & 4.00 \\
\hline 002 & 4.00 & 4.00 & 11.00 & 4.00 & 10.50 & 7.50 & 10.00 & 4.00 \\
\hline 003 & 4.00 & 4.00 & 11.00 & 4.00 & 10.50 & 7.50 & 10.00 & 4.00 \\
\hline 004 & 4.00 & 4.00 & 11.00 & 4.00 & 10.50 & 3.50 & 10.00 & 4.00 \\
\hline 005 & 4.00 & 4.00 & 11.00 & 4.00 & 10.50 & 3.50 & 10.00 & 4.00 \\
\hline 006 & 4.00 & 4.00 & 11.00 & 4.00 & 10.50 & 3.50 & 10.00 & 4.00 \\
\hline 007 & 4.00 & 4.00 & 11.00 & 4.00 & 10.50 & 3.50 & 10.00 & 4.00 \\
\hline 008 & 4.00 & 4.00 & 11.00 & 4.00 & 10.50 & 3.50 & 10.00 & 4.00 \\
\hline 009 & 4.00 & 4.00 & 11.00 & 4.00 & 10.50 & 7.50 & 10.00 & 4.00 \\
\hline 010 & 4.00 & 4.00 & 11.00 & 4.00 & 10.50 & 7.50 & 10.00 & 4.00 \\
\hline 011 & 0.00 & 4.00 & 11.00 & 4.00 & 10.50 & 7.50 & 10.00 & 4.00 \\
\hline 012 & 0.00 & 4.00 & 11.00 & 4.00 & 10.50 & 7.50 & 10.00 & 4.00 \\
\hline
\end{tabular}




\begin{tabular}{|c|c|c|c|c|c|c|c|c|}
\hline 013 & 0.00 & 4.00 & 5.00 & 4.00 & 10.50 & 7.50 & 10.00 & 4.00 \\
\hline 014 & 0.00 & 4.00 & 5.00 & 4.00 & 0.00 & 3.50 & 10.00 & 4.00 \\
\hline 015 & 0.00 & 4.00 & 5.00 & 4.00 & 0.00 & 3.50 & 10.00 & 4.00 \\
\hline 016 & 0.00 & 4.00 & 5.00 & 4.00 & 0.00 & 3.50 & 10.00 & 0.00 \\
\hline 017 & 0.00 & 4.00 & 11.00 & 4.00 & 6.00 & 3.50 & 10.00 & 0.00 \\
\hline 018 & 0.00 & 4.00 & 11.00 & 4.00 & 10.50 & 3.50 & 10.00 & 0.00 \\
\hline 019 & 0.00 & 4.00 & 5.00 & 4.00 & 10.50 & 3.50 & 10.00 & 0.00 \\
\hline 020 & 0.00 & 4.00 & 5.00 & 4.00 & 10.50 & 3.50 & 10.00 & 0.00 \\
\hline 021 & 0.00 & 4.00 & 5.00 & 4.00 & 4.50 & 3.50 & 10.00 & 0.00 \\
\hline 022 & 0.00 & 4.00 & 5.00 & 4.00 & 4.50 & 3.50 & 10.00 & 0.00 \\
\hline 023 & 0.00 & 4.00 & 5.00 & 4.00 & 4.50 & 3.50 & 10.00 & 0.00 \\
\hline 024 & 0.00 & 4.00 & 5.00 & 4.00 & 4.50 & 3.50 & 10.00 & 0.00 \\
\hline 025 & 0.00 & 4.00 & 5.00 & 4.00 & 4.50 & 3.50 & 10.00 & 0.00 \\
\hline 026 & 0.00 & 4.00 & 5.00 & 4.00 & 4.50 & 3.50 & 10.00 & 0.00 \\
\hline 027 & 0.00 & 4.00 & 11.00 & 4.00 & 10.50 & 3.50 & 10.00 & 0.00 \\
\hline 028 & 0.00 & 4.00 & 11.00 & 4.00 & 10.50 & 3.50 & 10.00 & 0.00 \\
\hline 029 & 0.00 & 4.00 & 5.00 & 4.00 & 10.50 & 3.50 & 10.00 & 0.00 \\
\hline 030 & 0.00 & 4.00 & 5.00 & 4.00 & 10.50 & 3.50 & 10.00 & 0.00 \\
\hline 031 & 0.00 & 4.00 & 5.00 & 4.00 & 4.50 & 3.50 & 10.00 & 0.00 \\
\hline 032 & 0.00 & 4.00 & 5.00 & 4.00 & 4.50 & 3.50 & 10.00 & 0.00 \\
\hline 033 & 0.00 & 4.00 & 5.00 & 4.00 & 4.50 & 3.50 & 10.00 & 0.00 \\
\hline 034 & 0.00 & 4.00 & 5.00 & 4.00 & 4.50 & 3.50 & 10.00 & 0.00 \\
\hline 035 & 0.00 & 4.00 & 5.00 & 4.00 & 4.50 & 3.50 & 10.00 & 0.00 \\
\hline 036 & 0.00 & 4.00 & 5.00 & 4.00 & 4.50 & 3.50 & 10.00 & 0.00 \\
\hline 037 & 0.00 & 4.00 & 11.00 & 4.00 & 10.50 & 3.50 & 10.00 & 0.00 \\
\hline 038 & 0.00 & 4.00 & 11.00 & 4.00 & 10.50 & 3.50 & 10.00 & 0.00 \\
\hline 039 & 0.00 & 4.00 & 5.00 & 4.00 & 10.50 & 3.50 & 10.00 & 0.00 \\
\hline 040 & 0.00 & 4.00 & 5.00 & 4.00 & 10.50 & 3.50 & 10.00 & 0.00 \\
\hline 041 & 0.00 & 4.00 & 5.00 & 4.00 & 4.50 & 3.50 & 10.00 & 0.00 \\
\hline 042 & 0.00 & 4.00 & 5.00 & 4.00 & 4.50 & 3.50 & 10.00 & 0.00 \\
\hline 043 & 0.00 & 4.00 & 5.00 & 4.00 & 4.50 & 3.50 & 10.00 & 0.00 \\
\hline 044 & 0.00 & 4.00 & 5.00 & 4.00 & 4.50 & 3.50 & 10.00 & 0.00 \\
\hline 045 & 0.00 & 4.00 & 5.00 & 4.00 & 4.50 & 4.70 & 10.00 & 0.00 \\
\hline 046 & 0.00 & 5.30 & 5.00 & 5.30 & 4.50 & 4.70 & 10.00 & 0.00 \\
\hline 047 & 0.00 & 5.30 & 13.00 & 5.30 & 5.80 & 4.70 & 10.00 & 0.00 \\
\hline 048 & 0.00 & 5.30 & 13.00 & 5.30 & 12.50 & 4.70 & 10.00 & 0.00 \\
\hline 049 & 0.00 & 5.30 & 5.00 & 5.30 & 12.50 & 4.70 & 10.00 & 0.00 \\
\hline 050 & 0.00 & 5.30 & 5.00 & 5.30 & 12.50 & 4.70 & 10.00 & 0.00 \\
\hline 051 & 0.00 & 5.30 & 6.70 & 5.30 & 6.00 & 5.32 & 13.30 & 0.00 \\
\hline 052 & 0.00 & 5.30 & 6.70 & 5.30 & 6.00 & 4.70 & 13.30 & 0.00 \\
\hline 053 & 0.00 & 5.30 & 6.70 & 5.30 & 6.00 & 4.70 & 13.30 & 0.00 \\
\hline 054 & 0.00 & 5.30 & 6.70 & 5.30 & 6.00 & 4.70 & 13.30 & 0.00 \\
\hline 055 & 0.00 & 5.30 & 6.70 & 5.30 & 6.00 & 4.70 & 13.30 & 0.00 \\
\hline 056 & 0.00 & 5.30 & 6.70 & 5.30 & 6.00 & 4.70 & 13.30 & 0.00 \\
\hline 057 & 0.00 & 5.30 & 14.70 & 9.41 & 14.00 & 4.70 & 13.30 & 0.00 \\
\hline 058 & 0.00 & 5.30 & 14.70 & 10.00 & 14.00 & 4.70 & 13.30 & 0.00 \\
\hline 059 & 0.00 & 5.30 & 13.82 & 10.00 & 14.00 & 4.70 & 13.30 & 0.00 \\
\hline 060 & 0.00 & 5.30 & 6.70 & 10.00 & 14.00 & 10.00 & 13.30 & 0.00 \\
\hline 061 & 0.00 & 5.30 & 6.70 & 10.00 & 14.00 & 10.00 & 13.30 & 0.00 \\
\hline 062 & 0.00 & 5.30 & 6.70 & 10.00 & 6.00 & 10.00 & 13.30 & 0.00 \\
\hline 063 & 0.00 & 5.30 & 6.70 & 10.00 & 6.00 & 10.00 & 13.30 & 0.00 \\
\hline 064 & 0.00 & 5.30 & 6.70 & 18.32 & 6.00 & 10.00 & 13.30 & 0.00 \\
\hline 065 & 0.00 & 5.30 & 6.70 & 18.70 & 6.00 & 10.00 & 13.30 & 0.00 \\
\hline 066 & 0.00 & 5.30 & 6.70 & 10.05 & 14.00 & 10.00 & 13.30 & 0.00 \\
\hline 067 & 0.00 & 5.30 & 14.70 & 10.00 & 14.00 & 10.00 & 13.30 & 0.00 \\
\hline 068 & 0.00 & 5.30 & 14.70 & 10.00 & 14.00 & 10.00 & 13.30 & 0.00 \\
\hline 069 & 0.00 & 5.30 & 14.70 & 10.00 & 14.00 & 10.00 & 13.30 & 0.00 \\
\hline 070 & 0.00 & 5.30 & 14.70 & 10.00 & 14.00 & 10.00 & 13.30 & 0.00 \\
\hline 071 & 0.00 & 5.30 & 6.70 & 18.70 & 14.00 & 10.00 & 13.30 & 0.00 \\
\hline 072 & 0.00 & 5.30 & 6.70 & 18.70 & 14.00 & 10.00 & 13.30 & 0.00 \\
\hline 073 & 0.00 & 5.30 & 6.70 & 18.70 & 14.00 & 10.00 & 13.30 & 0.00 \\
\hline 074 & 0.00 & 6.22 & 6.70 & 13.60 & 6.00 & 10.00 & 13.30 & 0.00 \\
\hline 075 & 0.00 & 10.00 & 14.70 & 10.00 & 14.00 & 10.00 & 13.30 & 0.00 \\
\hline 076 & 0.00 & 10.00 & 14.70 & 10.00 & 14.00 & 4.70 & 13.30 & 0.00 \\
\hline 077 & 0.00 & 10.00 & 14.70 & 10.00 & 14.00 & 4.70 & 13.30 & 0.00 \\
\hline 078 & 0.00 & 10.00 & 14.70 & 10.00 & 14.00 & 6.50 & 13.30 & 0.00 \\
\hline 079 & 0.00 & 10.00 & 14.70 & 10.00 & 14.00 & 10.00 & 13.30 & 0.00 \\
\hline 080 & 0.00 & 10.00 & 14.70 & 10.00 & 14.00 & 10.00 & 13.30 & 0.00 \\
\hline 081 & 0.00 & 10.00 & 14.70 & 10.00 & 14.00 & 10.00 & 13.30 & 0.00 \\
\hline 082 & 0.00 & 10.00 & 14.70 & 18.70 & 14.00 & 10.00 & 13.30 & 0.00 \\
\hline 083 & 0.00 & 10.00 & 6.70 & 14.40 & 14.00 & 10.00 & 13.30 & 0.00 \\
\hline 084 & 0.00 & 10.00 & 6.70 & 10.00 & 0.00 & 10.00 & 13.30 & 0.00 \\
\hline 085 & 0.00 & 10.00 & 6.70 & 10.00 & 6.00 & 10.00 & 13.30 & 0.00 \\
\hline 086 & 0.00 & 10.00 & 6.70 & 5.54 & 6.00 & 4.70 & 13.30 & 0.00 \\
\hline 087 & 0.00 & 10.00 & 6.70 & 5.46 & 6.00 & 4.70 & 13.30 & 0.00 \\
\hline 088 & 0.00 & 10.00 & 6.70 & 10.00 & 6.00 & 4.70 & 13.30 & 0.00 \\
\hline 089 & 0.00 & 10.00 & 6.70 & 10.00 & 11.78 & 4.70 & 13.30 & 0.00 \\
\hline 090 & 0.00 & 10.00 & 13.70 & 10.00 & 14.00 & 4.70 & 13.30 & 0.00 \\
\hline 091 & 0.00 & 10.00 & 14.70 & 10.00 & 14.00 & 4.70 & 13.30 & 0.00 \\
\hline 092 & 0.00 & 10.00 & 14.70 & 10.00 & 14.00 & 4.70 & 13.30 & 0.00 \\
\hline 093 & 0.00 & 15.04 & 0.00 & 10.00 & 14.00 & 4.70 & 13.30 & 0.00 \\
\hline 094 & 0.00 & 29.20 & 0.00 & 10.00 & 0.00 & 4.70 & 13.30 & 0.00 \\
\hline 095 & 0.00 & 18.76 & 5.81 & 10.00 & 0.00 & 9.90 & 13.30 & 0.00 \\
\hline 096 & 0.00 & 8.32 & 6.70 & 5.54 & 6.00 & 4.70 & 13.30 & 0.00 \\
\hline 097 & 0.00 & 5.30 & 9.27 & 5.30 & 6.00 & 4.70 & 13.30 & 0.00 \\
\hline 098 & 0.00 & 5.30 & 14.70 & 5.30 & 6.00 & 4.70 & 14.85 & 0.00 \\
\hline
\end{tabular}




\begin{tabular}{|c|c|c|c|c|c|c|c|c|}
\hline 099 & 0.00 & 10.00 & 14.70 & 7.59 & 6.00 & 4.70 & 33.35 & 0.00 \\
\hline 100 & 0.00 & 10.00 & 6.70 & 10.00 & 6.00 & 4.70 & 21.80 & 0.00 \\
\hline 101 & 0.00 & 10.00 & 6.70 & 10.00 & 6.00 & 4.70 & 13.30 & 0.00 \\
\hline 102 & 0.00 & 10.00 & 6.70 & 10.00 & 0.00 & 4.70 & 13.30 & 0.00 \\
\hline 103 & 0.00 & 11.12 & 6.70 & 10.00 & 6.00 & 4.70 & 13.30 & 0.00 \\
\hline 104 & 0.00 & 29.20 & 6.70 & 10.00 & 6.00 & 4.70 & 13.30 & 0.00 \\
\hline 105 & 0.00 & 18.76 & 6.70 & 15.02 & 6.00 & 4.70 & 13.30 & 0.00 \\
\hline 106 & 0.00 & 8.32 & 7.60 & 5.30 & 6.00 & 4.70 & 13.30 & 0.00 \\
\hline 107 & 0.00 & 5.30 & 14.70 & 5.30 & 6.00 & 4.70 & 13.30 & 0.00 \\
\hline 108 & 0.00 & 10.00 & 14.70 & 5.30 & 6.00 & 4.70 & 13.30 & 0.00 \\
\hline 109 & 0.00 & 10.00 & 14.70 & 10.00 & 14.00 & 4.70 & 13.30 & 0.00 \\
\hline 110 & 0.00 & 10.00 & 14.70 & 10.00 & 9.72 & 4.70 & 21.30 & 0.00 \\
\hline 111 & 0.00 & 12.50 & 6.70 & 12.50 & 6.00 & 5.80 & 13.30 & 0.00 \\
\hline 112 & 0.00 & 12.50 & 6.70 & 12.50 & 6.00 & 5.80 & 12.80 & 0.00 \\
\hline 113 & 0.00 & 36.32 & 6.70 & 12.50 & 6.00 & 5.80 & 13.30 & 0.00 \\
\hline 114 & 0.00 & 39.75 & 6.70 & 31.98 & 6.00 & 9.60 & 13.30 & 0.00 \\
\hline 115 & 0.00 & 28.56 & 14.39 & 26.12 & 6.00 & 12.50 & 13.30 & 0.00 \\
\hline 116 & 0.00 & 17.37 & 16.70 & 14.99 & 13.46 & 5.80 & 13.30 & 0.00 \\
\hline 117 & 0.00 & 12.50 & 16.70 & 12.50 & 16.00 & 5.80 & 13.30 & 0.00 \\
\hline 118 & 0.00 & 12.50 & 16.70 & 12.50 & 16.00 & 12.50 & 13.30 & 0.00 \\
\hline 119 & 0.00 & 12.50 & 16.70 & 12.50 & 16.00 & 12.50 & 13.30 & 0.00 \\
\hline 120 & 0.00 & 12.50 & 16.70 & 12.50 & 16.00 & 12.50 & 21.80 & 0.00 \\
\hline 121 & 0.00 & 12.50 & 18.30 & 12.50 & 17.50 & 12.50 & 36.85 & 0.00 \\
\hline 122 & 0.00 & 34.87 & 8.30 & 19.99 & 16.38 & 12.50 & 16.70 & 0.00 \\
\hline 123 & 0.00 & 39.49 & 8.30 & 36.55 & 17.50 & 12.50 & 16.70 & 0.00 \\
\hline 124 & 0.00 & 39.10 & 8.30 & 35.50 & 17.50 & 14.73 & 16.70 & 0.00 \\
\hline 125 & 0.00 & 27.52 & 8.30 & 23.32 & 17.50 & 47.67 & 16.70 & 0.00 \\
\hline 126 & 0.00 & 15.94 & 18.30 & 11.14 & 17.50 & 5.80 & 16.70 & 0.00 \\
\hline 127 & 0.00 & 12.50 & 18.30 & 6.70 & 17.50 & 5.80 & 38.55 & 0.00 \\
\hline 128 & 0.00 & 12.50 & 18.30 & 12.50 & 17.50 & 5.80 & 46.65 & 0.00 \\
\hline 129 & 0.00 & 12.50 & 18.30 & 12.50 & 17.50 & 12.50 & 46.65 & 0.00 \\
\hline 130 & 0.00 & 12.50 & 18.30 & 12.50 & 17.50 & 12.50 & 35.10 & 0.00 \\
\hline 131 & 0.00 & 12.50 & 18.30 & 12.50 & 17.50 & 12.50 & 23.55 & 0.00 \\
\hline 132 & 0.00 & 22.30 & 8.33 & 12.50 & 17.50 & 12.50 & 16.70 & 0.00 \\
\hline 133 & 0.00 & 30.08 & 8.30 & 12.50 & 17.50 & 12.50 & 16.70 & 0.00 \\
\hline 134 & 0.00 & 37.70 & 8.30 & 33.88 & 0.00 & 12.50 & 16.70 & 0.00 \\
\hline 135 & 0.00 & 25.28 & 8.30 & 21.08 & 7.72 & 35.16 & 16.70 & 0.00 \\
\hline 136 & 0.00 & 12.86 & 8.30 & 8.06 & 17.50 & 0.00 & 16.70 & 0.00 \\
\hline 137 & 0.00 & 12.50 & 18.30 & 0.00 & 17.50 & 0.00 & 38.55 & 0.00 \\
\hline 138 & 0.00 & 12.50 & 18.30 & 12.50 & 17.50 & 0.00 & 45.81 & 0.00 \\
\hline 139 & 0.00 & 12.50 & 18.30 & 12.50 & 17.50 & 10.90 & 44.55 & 0.00 \\
\hline 140 & 0.00 & 12.50 & 18.30 & 12.50 & 17.50 & 12.50 & 31.74 & 0.00 \\
\hline 141 & 0.00 & 12.50 & 18.30 & 12.50 & 17.50 & 12.50 & 18.93 & 0.00 \\
\hline 142 & 0.00 & 12.50 & 18.30 & 12.50 & 17.50 & 12.50 & 16.70 & 0.00 \\
\hline 143 & 0.00 & 19.20 & 0.00 & 12.50 & 23.47 & 12.50 & 16.70 & 0.00 \\
\hline 144 & 0.00 & 36.61 & 0.00 & 17.90 & 0.00 & 12.50 & 16.70 & 0.00 \\
\hline 145 & 0.00 & 24.08 & 0.00 & 18.84 & 1.08 & 12.50 & 16.70 & 0.00 \\
\hline 146 & 0.00 & 11.21 & 2.51 & 4.98 & 17.50 & 0.00 & 16.70 & 0.00 \\
\hline 147 & 0.00 & 6.70 & 10.00 & 0.00 & 17.50 & 0.00 & 16.70 & 0.00 \\
\hline 148 & 0.00 & 12.50 & 18.30 & 0.00 & 17.50 & 0.00 & 35.98 & 0.00 \\
\hline 149 & 0.00 & 12.50 & 18.30 & 9.68 & 17.50 & 0.00 & 43.05 & 0.00 \\
\hline 150 & 0.00 & 12.50 & 18.30 & 12.50 & 17.50 & 1.76 & 29.34 & 0.00 \\
\hline 151 & 0.00 & 12.50 & 18.30 & 12.50 & 17.50 & 12.50 & 15.63 & 0.00 \\
\hline 152 & 0.00 & 12.50 & 18.30 & 12.50 & 0.00 & 12.50 & 6.49 & 0.00 \\
\hline 153 & 0.00 & 13.18 & 0.00 & 12.50 & 0.00 & 12.50 & 10.49 & 0.00 \\
\hline 154 & 0.00 & 36.00 & 1.61 & 12.50 & 0.00 & 12.50 & 16.70 & 0.00 \\
\hline 155 & 0.00 & 22.56 & 10.00 & 18.84 & 0.00 & 19.20 & 16.70 & 0.00 \\
\hline 156 & 0.00 & 9.12 & 10.00 & 4.98 & 7.50 & 0.00 & 24.20 & 0.00 \\
\hline 157 & 0.00 & 6.70 & 18.30 & 0.00 & 12.50 & 0.00 & 24.20 & 0.00 \\
\hline 158 & 0.00 & 6.70 & 18.30 & 6.70 & 17.50 & 0.00 & 24.20 & 0.00 \\
\hline 159 & 0.00 & 6.70 & 18.30 & 6.70 & 17.50 & 0.00 & 32.50 & 0.00 \\
\hline 160 & 0.00 & 6.70 & 18.30 & 6.70 & 17.50 & 12.50 & 27.56 & 0.00 \\
\hline 161 & 0.00 & 12.50 & 18.30 & 6.70 & 17.50 & 12.50 & 13.19 & 0.00 \\
\hline 162 & 0.00 & 12.50 & 0.00 & 6.70 & 0.00 & 12.50 & 3.60 & 0.00 \\
\hline 163 & 0.00 & 16.52 & 0.00 & 12.50 & 3.75 & 15.92 & 0.00 & 0.00 \\
\hline 164 & 0.00 & 36.00 & 0.00 & 25.56 & 0.00 & 19.20 & 10.13 & 0.00 \\
\hline 165 & 0.00 & 22.56 & 10.00 & 18.13 & 7.50 & 19.20 & 16.70 & 0.00 \\
\hline 166 & 0.00 & 9.12 & 10.00 & 4.01 & 7.50 & 0.00 & 16.70 & 0.00 \\
\hline 167 & 0.00 & 6.70 & 12.64 & 0.00 & 7.50 & 0.00 & 26.50 & 0.00 \\
\hline 168 & 0.00 & 6.70 & 18.30 & 6.70 & 17.50 & 5.80 & 32.50 & 0.00 \\
\hline 169 & 0.00 & 7.71 & 18.30 & 6.70 & 17.50 & 5.80 & 32.50 & 0.00 \\
\hline 170 & 0.00 & 12.50 & 18.30 & 6.70 & 17.50 & 5.80 & 27.10 & 0.00 \\
\hline 171 & 0.00 & 15.00 & 20.30 & 8.00 & 19.50 & 7.00 & 12.55 & 0.00 \\
\hline 172 & 0.00 & 15.00 & 0.00 & 23.00 & 0.00 & 7.00 & 6.00 & 0.00 \\
\hline 173 & 0.00 & 39.01 & 12.00 & 23.00 & 0.00 & 8.39 & 7.50 & 0.00 \\
\hline 174 & 0.00 & 46.35 & 12.00 & 35.28 & 7.50 & 19.62 & 7.50 & 0.00 \\
\hline 175 & 0.00 & 32.16 & 20.30 & 28.84 & 7.50 & 46.47 & 7.50 & 0.00 \\
\hline 176 & 0.00 & 17.97 & 20.30 & 14.53 & 19.50 & 0.00 & 7.50 & 0.00 \\
\hline 177 & 0.00 & 8.51 & 20.30 & 8.00 & 19.50 & 0.00 & 25.00 & 0.00 \\
\hline 178 & 0.00 & 8.00 & 20.30 & 8.00 & 19.50 & 7.00 & 31.70 & 0.00 \\
\hline 179 & 0.00 & 8.00 & 20.30 & 23.00 & 19.50 & 7.00 & 41.65 & 0.00 \\
\hline 180 & 0.00 & 8.00 & 20.30 & 23.00 & 19.50 & 7.00 & 27.10 & 0.00 \\
\hline 181 & 0.00 & 21.64 & 25.14 & 23.00 & 21.00 & 7.00 & 38.75 & 0.00 \\
\hline 182 & 0.00 & 41.62 & 0.00 & 23.00 & 18.62 & 27.27 & 15.95 & 0.00 \\
\hline 183 & 0.00 & 46.07 & 0.00 & 23.00 & 21.00 & 29.00 & 9.00 & 0.00 \\
\hline 184 & 0.00 & 45.65 & 0.72 & 30.00 & 0.00 & 37.00 & 9.00 & 0.00 \\
\hline
\end{tabular}




\begin{tabular}{|c|c|c|c|c|c|c|c|c|}
\hline 185 & 0.00 & 31.04 & 10.00 & 23.42 & 21.00 & 45.00 & 23.00 & 0.00 \\
\hline 186 & 0.00 & 16.43 & 10.00 & 10.68 & 21.00 & 0.00 & 28.31 & 0.00 \\
\hline 187 & 0.00 & 6.69 & 22.00 & 0.44 & 21.00 & 0.00 & 44.39 & 0.00 \\
\hline 188 & 0.00 & 0.00 & 22.00 & 0.00 & 24.98 & 0.00 & 54.86 & 0.00 \\
\hline 189 & 0.00 & 0.00 & 22.00 & 0.00 & 30.00 & 7.00 & 55.03 & 0.00 \\
\hline 190 & 0.00 & 18.00 & 36.00 & 15.00 & 30.00 & 15.12 & 40.65 & 0.00 \\
\hline 191 & 0.00 & 18.00 & 36.00 & 21.81 & 30.00 & 29.00 & 26.27 & 0.00 \\
\hline 192 & 0.00 & 37.61 & 0.00 & 23.00 & 0.00 & 29.00 & 16.69 & 0.00 \\
\hline 193 & 0.00 & 39.00 & 5.67 & 23.00 & 5.16 & 29.00 & 9.00 & 0.00 \\
\hline 194 & 0.00 & 44.20 & 10.00 & 36.00 & 0.00 & 29.00 & 9.98 & 0.00 \\
\hline 195 & 0.00 & 28.72 & 10.00 & 23.72 & 0.00 & 29.00 & 41.00 & 0.00 \\
\hline 196 & 0.00 & 13.24 & 10.00 & 7.49 & 0.00 & 0.00 & 41.00 & 0.00 \\
\hline 197 & 0.00 & 2.92 & 10.00 & 0.00 & 0.00 & 0.00 & 41.00 & 0.00 \\
\hline 198 & 0.00 & 0.00 & 24.00 & 0.00 & 21.00 & 0.00 & 41.00 & 0.00 \\
\hline 199 & 0.00 & 6.97 & 24.00 & 0.00 & 32.00 & 8.91 & 41.00 & 0.00 \\
\hline 200 & 0.00 & 18.00 & 36.00 & 13.00 & 46.80 & 12.00 & 37.15 & 0.00 \\
\hline 201 & 0.00 & 26.00 & 36.00 & 13.00 & 54.00 & 12.00 & 21.46 & 0.00 \\
\hline 202 & 0.00 & 26.00 & 0.00 & 18.54 & 0.00 & 13.63 & 11.00 & 0.00 \\
\hline 203 & 0.00 & 26.00 & 0.00 & 22.00 & 0.00 & 12.00 & 0.00 & 0.00 \\
\hline 204 & 0.00 & 39.00 & 0.00 & 30.00 & 0.00 & 19.00 & 8.17 & 0.00 \\
\hline 205 & 0.00 & 31.98 & 0.00 & 22.29 & 0.00 & 19.00 & 31.62 & 0.00 \\
\hline 206 & 0.00 & 17.72 & 0.00 & 5.53 & 0.00 & 0.00 & 32.00 & 0.00 \\
\hline 207 & 0.00 & 8.22 & 14.00 & 0.00 & 13.00 & 0.00 & 41.00 & 0.00 \\
\hline 208 & 0.00 & 0.00 & 22.39 & 0.00 & 13.00 & 0.00 & 41.00 & 0.00 \\
\hline 209 & 0.00 & 0.00 & 26.00 & 0.00 & 13.00 & 6.53 & 41.00 & 0.00 \\
\hline 210 & 0.00 & 6.89 & 45.00 & 6.63 & 30.85 & 12.00 & 34.28 & 0.00 \\
\hline 211 & 0.00 & 28.47 & 54.00 & 13.00 & 44.00 & 12.00 & 18.00 & 0.00 \\
\hline 212 & 0.00 & 39.00 & 0.00 & 22.00 & 0.00 & 12.00 & 18.00 & 0.00 \\
\hline 213 & 0.00 & 44.97 & 0.00 & 22.00 & 0.00 & 12.00 & 18.00 & 0.00 \\
\hline 214 & 0.00 & 43.08 & 0.00 & 22.00 & 0.00 & 0.00 & 18.00 & 0.00 \\
\hline 215 & 0.00 & 26.92 & 0.00 & 22.00 & 0.00 & 0.00 & 20.10 & 0.00 \\
\hline 216 & 0.00 & 10.77 & 7.80 & 7.00 & 2.94 & 0.00 & 27.00 & 0.00 \\
\hline 217 & 0.00 & 0.00 & 14.00 & 0.00 & 13.00 & 0.00 & 27.00 & 0.00 \\
\hline 218 & 0.00 & 0.00 & 19.46 & 0.00 & 21.00 & 0.00 & 27.00 & 0.00 \\
\hline 219 & 0.00 & 0.00 & 35.00 & 0.00 & 21.00 & 0.00 & 27.00 & 0.00 \\
\hline 220 & 0.00 & 2.25 & 40.14 & 13.00 & 21.00 & 0.00 & 27.00 & 0.00 \\
\hline 221 & 0.00 & 13.00 & 54.00 & 13.00 & 21.00 & 0.00 & 17.60 & 0.00 \\
\hline 222 & 0.00 & 31.00 & 0.00 & 22.00 & 0.00 & 0.00 & 0.00 & 0.00 \\
\hline 223 & 0.00 & 39.00 & 0.00 & 22.00 & 0.00 & 0.00 & 0.00 & 0.00 \\
\hline 224 & 0.00 & 39.00 & 0.00 & 22.00 & 0.00 & 6.18 & 27.00 & 0.00 \\
\hline 225 & 0.00 & 24.93 & 0.00 & 20.88 & 0.00 & 7.00 & 27.00 & 0.00 \\
\hline 226 & 0.00 & 9.61 & 0.00 & 3.59 & 0.00 & 0.00 & 27.00 & 0.00 \\
\hline 227 & 0.00 & 13.00 & 0.00 & 0.00 & 0.00 & 0.00 & 27.00 & 0.00 \\
\hline 228 & 0.00 & 13.00 & 0.00 & 0.00 & 13.00 & 0.00 & 27.00 & 0.00 \\
\hline 229 & 0.00 & 13.00 & 9.00 & 11.63 & 21.00 & 0.00 & 27.00 & 0.00 \\
\hline 230 & 0.00 & 13.00 & 9.00 & 13.00 & 21.00 & 0.00 & 25.40 & 0.00 \\
\hline 231 & 0.00 & 17.64 & 9.00 & 13.00 & 21.00 & 0.00 & 0.00 & 0.00 \\
\hline 232 & 0.00 & 21.00 & 0.00 & 13.00 & 0.00 & 0.00 & 0.00 & 0.00 \\
\hline 233 & 0.00 & 21.00 & 0.00 & 13.00 & 0.00 & 0.00 & 5.57 & 0.00 \\
\hline 234 & 0.00 & 13.00 & 0.00 & 13.00 & 0.00 & 0.00 & 9.00 & 0.00 \\
\hline 235 & 0.00 & 13.00 & 0.00 & 13.00 & 0.00 & 0.00 & 9.00 & 0.00 \\
\hline 236 & 0.00 & 6.86 & 0.00 & 0.00 & 0.00 & 0.00 & 9.00 & 0.00 \\
\hline 237 & 0.00 & 0.00 & 0.00 & 0.00 & 0.00 & 0.00 & 9.00 & 0.00 \\
\hline 238 & 0.00 & 0.00 & 0.00 & 0.00 & 0.00 & 0.00 & 9.00 & 0.00 \\
\hline 239 & 0.00 & 0.00 & 0.00 & 0.00 & 0.00 & 0.00 & 9.00 & 0.00 \\
\hline 240 & 0.00 & 12.91 & 0.00 & 0.00 & 0.00 & 0.00 & 9.00 & 0.00 \\
\hline 241 & 0.00 & 9.80 & 0.00 & 0.00 & 0.00 & 0.00 & 0.00 & 0.00 \\
\hline 242 & 0.00 & 9.80 & 0.00 & 0.00 & 0.00 & 0.00 & 0.00 & 0.00 \\
\hline 243 & 0.00 & 9.80 & 0.00 & 0.00 & 0.00 & 0.00 & 0.00 & 0.00 \\
\hline 245 & 0.00 & 0.00 & 0.00 & 0.00 & 0.00 & 0.00 & 9.00 & 0.00 \\
\hline 246 & 0.00 & 0.00 & 0.00 & 0.00 & 0.00 & 0.00 & 9.00 & 0.00 \\
\hline 247 & 0.00 & 0.00 & 0.00 & 0.00 & 0.00 & 0.00 & 9.00 & 0.00 \\
\hline 248 & 0.00 & 0.00 & 0.00 & 0.00 & 0.00 & 0.00 & 9.00 & 0.00 \\
\hline 249 & 0.00 & 0.00 & 0.00 & 0.00 & 0.00 & 0.00 & 9.00 & 0.00 \\
\hline 250 & 0.00 & 0.00 & 0.00 & 0.00 & 0.00 & 0.00 & 9.00 & 0.00 \\
\hline EMBPS & PORTO_1 & PORTO_2 & PORTO_3 & PORTO_4 & PORTO_5 & PORTO_6 & PORTO_7 & PORTO_ \\
\hline 001 & 325.00 & 0.00 & 0.00 & 0.00 & 90.00 & 0.00 & 295.00 & 0.00 \\
\hline 002 & 0.00 & 0.00 & 230.00 & 0.00 & 0.00 & 0.00 & 0.00 & 0.00 \\
\hline 005 & 0.00 & 0.00 & 0.00 & 0.00 & 0.00 & 265.00 & 0.00 & 0.00 \\
\hline 006 & 0.00 & 310.00 & 0.00 & 295.00 & 0.00 & 0.00 & 0.00 & 0.00 \\
\hline 011 & 325.00 & 0.00 & 0.00 & 0.00 & 90.00 & 0.00 & 347.25 & 0.00 \\
\hline 012 & 0.00 & 0.00 & 230.00 & 0.00 & 0.00 & 0.00 & 0.00 & 0.00 \\
\hline 015 & 0.00 & 0.00 & 0.00 & 0.00 & 0.00 & 256.68 & 0.00 & 0.00 \\
\hline 016 & 0.00 & 310.00 & 0.00 & 295.00 & 0.00 & 0.00 & 0.00 & 0.00 \\
\hline 021 & 333.60 & 0.00 & 0.00 & 0.00 & 90.00 & 0.00 & 304.08 & 0.00 \\
\hline 022 & 0.00 & 0.00 & 230.00 & 0.00 & 0.00 & 0.00 & 0.00 & 0.00 \\
\hline 025 & 0.00 & 0.00 & 0.00 & 0.00 & 0.00 & 245.48 & 0.00 & 0.00 \\
\hline 026 & 0.00 & 310.12 & 0.00 & 295.00 & 0.00 & 0.00 & 0.00 & 0.00 \\
\hline 031 & 358.40 & 0.00 & 0.00 & 0.00 & 90.00 & 0.00 & 295.00 & 0.00 \\
\hline 032 & 0.00 & 0.00 & 265.28 & 0.00 & 0.00 & 0.00 & 0.00 & 0.00 \\
\hline 035 & 0.00 & 0.00 & 0.00 & 0.00 & 0.00 & 260.84 & 0.00 & 0.00 \\
\hline 036 & 0.00 & 310.00 & 0.00 & 295.00 & 0.00 & 0.00 & 0.00 & 0.00 \\
\hline 041 & 365.00 & 0.00 & 0.00 & 0.00 & 91.35 & 0.00 & 295.00 & 0.00 \\
\hline 042 & 0.00 & 0.00 & 278.00 & 0.00 & 0.00 & 0.00 & 0.00 & 0.00 \\
\hline
\end{tabular}




\begin{tabular}{|c|c|c|c|c|c|c|c|c|}
\hline 045 & 0.00 & 0.00 & 0.00 & 0.00 & 0.00 & 265.00 & 0.00 & 0.00 \\
\hline 046 & 0.00 & 310.00 & 0.00 & 295.00 & 0.00 & 0.00 & 0.00 & 0.00 \\
\hline 051 & 365.00 & 0.00 & 0.00 & 0.00 & 90.00 & 0.00 & 295.00 & 0.00 \\
\hline 052 & 0.00 & 0.00 & 278.00 & 0.00 & 0.00 & 0.00 & 0.00 & 0.00 \\
\hline 055 & 0.00 & 0.00 & 0.00 & 0.00 & 0.00 & 265.00 & 0.00 & 0.00 \\
\hline 056 & 0.00 & 310.00 & 0.00 & 295.00 & 0.00 & 0.00 & 0.00 & 0.00 \\
\hline 061 & 486.00 & 0.00 & 0.00 & 0.00 & 134.25 & 0.00 & 424.35 & 0.00 \\
\hline 062 & 0.00 & 0.00 & 370.54 & 0.00 & 0.00 & 0.00 & 0.00 & 0.00 \\
\hline 065 & 0.00 & 0.00 & 0.00 & 0.00 & 0.00 & 353.87 & 0.00 & 0.00 \\
\hline 066 & 0.00 & 414.50 & 0.00 & 394.46 & 0.00 & 0.00 & 0.00 & 0.00 \\
\hline 071 & 486.00 & 0.00 & 0.00 & 0.00 & 122.48 & 0.00 & 398.45 & 0.00 \\
\hline 072 & 0.00 & 0.00 & 365.02 & 0.00 & 0.00 & 0.00 & 0.00 & 0.00 \\
\hline 075 & 0.00 & 0.00 & 0.00 & 0.00 & 0.00 & 332.32 & 0.00 & 0.00 \\
\hline 076 & 0.00 & 413.00 & 0.00 & 350.67 & 0.00 & 0.00 & 0.00 & 0.00 \\
\hline 081 & 486.00 & 0.00 & 0.00 & 0.00 & 120.00 & 0.00 & 393.00 & 0.00 \\
\hline 082 & 0.00 & 0.00 & 357.62 & 0.00 & 0.00 & 0.00 & 0.00 & 0.00 \\
\hline 085 & 0.00 & 0.00 & 0.00 & 0.00 & 0.00 & 301.40 & 0.00 & 0.00 \\
\hline 086 & 0.00 & 408.30 & 0.00 & 314.84 & 0.00 & 0.00 & 0.00 & 0.00 \\
\hline 091 & 486.00 & 0.00 & 0.00 & 0.00 & 120.12 & 0.00 & 393.00 & 0.00 \\
\hline 092 & 0.00 & 0.00 & 333.20 & 0.00 & 0.00 & 0.00 & 0.00 & 0.00 \\
\hline 095 & 0.00 & 0.00 & 0.00 & 0.00 & 0.00 & 314.14 & 0.00 & 0.00 \\
\hline 096 & 0.00 & 370.48 & 0.00 & 332.08 & 0.00 & 0.00 & 0.00 & 0.00 \\
\hline 101 & 486.00 & 0.00 & 0.00 & 0.00 & 126.00 & 0.00 & 393.00 & 0.00 \\
\hline 102 & 0.00 & 0.00 & 357.76 & 0.00 & 0.00 & 0.00 & 0.00 & 0.00 \\
\hline 105 & 0.00 & 0.00 & 0.00 & 0.00 & 0.00 & 338.98 & 0.00 & 0.00 \\
\hline 106 & 0.00 & 366.78 & 0.00 & 353.52 & 0.00 & 0.00 & 0.00 & 0.00 \\
\hline 111 & 486.00 & 0.00 & 0.00 & 0.00 & 132.60 & 0.00 & 393.00 & 0.00 \\
\hline 112 & 0.00 & 0.00 & 357.62 & 0.00 & 0.00 & 0.00 & 0.00 & 0.00 \\
\hline 115 & 0.00 & 0.00 & 0.00 & 0.00 & 0.00 & 349.15 & 0.00 & 0.00 \\
\hline 116 & 0.00 & 375.08 & 0.00 & 376.06 & 0.00 & 0.00 & 0.00 & 0.00 \\
\hline 121 & 609.00 & 0.00 & 0.00 & 0.00 & 170.28 & 0.00 & 498.59 & 0.00 \\
\hline 122 & 0.00 & 0.00 & 454.98 & 0.00 & 0.00 & 0.00 & 0.00 & 0.00 \\
\hline 125 & 0.00 & 0.00 & 0.00 & 0.00 & 0.00 & 446.38 & 0.00 & 0.00 \\
\hline 126 & 0.00 & 403.20 & 0.00 & 453.41 & 0.00 & 0.00 & 0.00 & 0.00 \\
\hline 131 & 609.00 & 0.00 & 0.00 & 0.00 & 164.42 & 0.00 & 506.89 & 0.00 \\
\hline 132 & 0.00 & 0.00 & 424.86 & 0.00 & 0.00 & 0.00 & 0.00 & 0.00 \\
\hline 135 & 0.00 & 0.00 & 0.00 & 0.00 & 0.00 & 406.70 & 0.00 & 0.00 \\
\hline 136 & 0.00 & 365.57 & 0.00 & 375.10 & 0.00 & 0.00 & 0.00 & 0.00 \\
\hline 141 & 609.00 & 0.00 & 0.00 & 0.00 & 153.58 & 0.00 & 535.68 & 0.00 \\
\hline 142 & 0.00 & 0.00 & 423.99 & 0.00 & 0.00 & 0.00 & 0.00 & 0.00 \\
\hline 145 & 0.00 & 0.00 & 0.00 & 0.00 & 0.00 & 374.88 & 0.00 & 0.00 \\
\hline 146 & 0.00 & 380.33 & 0.00 & 405.13 & 0.00 & 0.00 & 0.00 & 0.00 \\
\hline 151 & 609.00 & 0.00 & 0.00 & 0.00 & 157.50 & 0.00 & 432.23 & 0.00 \\
\hline 152 & 0.00 & 0.00 & 451.38 & 0.00 & 0.00 & 0.00 & 0.00 & 0.00 \\
\hline 155 & 0.00 & 0.00 & 0.00 & 0.00 & 0.00 & 418.19 & 0.00 & 0.00 \\
\hline 156 & 0.00 & 402.11 & 0.00 & 445.74 & 0.00 & 0.00 & 0.00 & 0.00 \\
\hline 161 & 609.00 & 0.00 & 0.00 & 0.00 & 197.10 & 0.00 & 485.27 & 0.00 \\
\hline 162 & 0.00 & 0.00 & 421.26 & 0.00 & 0.00 & 0.00 & 0.00 & 0.00 \\
\hline 165 & 0.00 & 0.00 & 0.00 & 0.00 & 0.00 & 443.74 & 0.00 & 0.00 \\
\hline 166 & 0.00 & 447.96 & 0.00 & 445.08 & 0.00 & 0.00 & 0.00 & 0.00 \\
\hline 171 & 609.00 & 0.00 & 0.00 & 0.00 & 173.74 & 0.00 & 474.29 & 0.00 \\
\hline 172 & 0.00 & 0.00 & 405.33 & 0.00 & 0.00 & 0.00 & 0.00 & 0.00 \\
\hline 175 & 0.00 & 0.00 & 0.00 & 0.00 & 0.00 & 396.03 & 0.00 & 0.00 \\
\hline 176 & 0.00 & 478.12 & 0.00 & 459.16 & 0.00 & 0.00 & 0.00 & 0.00 \\
\hline 181 & 730.00 & 0.00 & 0.00 & 0.00 & 190.72 & 0.00 & 443.46 & 0.00 \\
\hline 182 & 0.00 & 0.00 & 487.81 & 0.00 & 0.00 & 0.00 & 0.00 & 0.00 \\
\hline 185 & 0.00 & 0.00 & 0.00 & 0.00 & 0.00 & 464.26 & 0.00 & 0.00 \\
\hline 186 & 0.00 & 469.97 & 0.00 & 517.21 & 0.00 & 0.00 & 0.00 & 0.00 \\
\hline 191 & 730.00 & 0.00 & 0.00 & 0.00 & 201.90 & 0.00 & 542.52 & 0.00 \\
\hline 192 & 0.00 & 0.00 & 474.16 & 0.00 & 0.00 & 0.00 & 0.00 & 0.00 \\
\hline 195 & 0.00 & 0.00 & 0.00 & 0.00 & 0.00 & 458.23 & 0.00 & 0.00 \\
\hline 196 & 0.00 & 471.08 & 0.00 & 470.26 & 0.00 & 0.00 & 0.00 & 0.00 \\
\hline 201 & 730.00 & 0.00 & 0.00 & 0.00 & 190.98 & 0.00 & 491.15 & 0.00 \\
\hline 202 & 0.00 & 0.00 & 504.42 & 0.00 & 0.00 & 0.00 & 0.00 & 0.00 \\
\hline 205 & 0.00 & 0.00 & 0.00 & 0.00 & 0.00 & 421.37 & 0.00 & 0.00 \\
\hline 206 & 0.00 & 487.68 & 0.00 & 519.72 & 0.00 & 0.00 & 0.00 & 0.00 \\
\hline 211 & 730.00 & 0.00 & 0.00 & 0.00 & 245.45 & 0.00 & 477.28 & 0.00 \\
\hline 212 & 0.00 & 0.00 & 499.88 & 0.00 & 0.00 & 0.00 & 0.00 & 0.00 \\
\hline 215 & 0.00 & 0.00 & 0.00 & 0.00 & 0.00 & 474.58 & 0.00 & 0.00 \\
\hline 216 & 0.00 & 502.50 & 0.00 & 538.72 & 0.00 & 0.00 & 0.00 & 0.00 \\
\hline 221 & 730.00 & 0.00 & 0.00 & 0.00 & 257.49 & 0.00 & 524.01 & 0.00 \\
\hline 222 & 0.00 & 0.00 & 468.47 & 0.00 & 0.00 & 0.00 & 0.00 & 0.00 \\
\hline 225 & 0.00 & 0.00 & 0.00 & 0.00 & 0.00 & 519.26 & 0.00 & 0.00 \\
\hline 226 & 0.00 & 494.39 & 0.00 & 553.19 & 0.00 & 0.00 & 0.00 & 0.00 \\
\hline 231 & 730.00 & 0.00 & 0.00 & 0.00 & 244.62 & 0.00 & 548.67 & 0.00 \\
\hline 232 & 0.00 & 0.00 & 440.11 & 0.00 & 0.00 & 0.00 & 0.00 & 0.00 \\
\hline 235 & 0.00 & 0.00 & 0.00 & 0.00 & 0.00 & 583.45 & 0.00 & 0.00 \\
\hline 236 & 0.00 & 529.45 & 0.00 & 550.28 & 0.00 & 0.00 & 0.00 & 0.00 \\
\hline 241 & 730.00 & 0.00 & 0.00 & 0.00 & 243.60 & 0.00 & 588.78 & 0.00 \\
\hline 242 & 0.00 & 0.00 & 512.90 & 0.00 & 0.00 & 0.00 & 0.00 & 0.00 \\
\hline 245 & 0.00 & 0.00 & 0.00 & 0.00 & 0.00 & 591.05 & 0.00 & 0.00 \\
\hline 246 & 0.00 & 531.40 & 0.00 & 564.86 & 0.00 & 0.00 & 0.00 & 0.00 \\
\hline 251 & 548.00 & 0.00 & 0.00 & 0.00 & 188.68 & 0.00 & 497.28 & 0.00 \\
\hline 252 & 0.00 & 0.00 & 423.85 & 0.00 & 0.00 & 0.00 & 0.00 & 0.00 \\
\hline 255 & 0.00 & 0.00 & 0.00 & 0.00 & 0.00 & 451.00 & 0.00 & 0.00 \\
\hline 256 & 0.00 & 458.88 & 0.00 & 483.55 & 0.00 & 0.00 & 0.00 & 0.00 \\
\hline
\end{tabular}




\begin{tabular}{|c|c|c|c|c|c|c|c|c|}
\hline 261 & 548.00 & 0.00 & 0.00 & 0.00 & 203.00 & 0.00 & 540.00 & 0.00 \\
\hline 262 & 0.00 & 0.00 & 436.00 & 0.00 & 0.00 & 0.00 & 0.00 & 0.00 \\
\hline 265 & 0.00 & 0.00 & 0.00 & 0.00 & 0.00 & 451.00 & 0.00 & 0.00 \\
\hline 266 & 0.00 & 520.03 & 0.00 & 505.00 & 0.00 & 0.00 & 0.00 & 0.00 \\
\hline 271 & 548.00 & 0.00 & 0.00 & 0.00 & 203.00 & 0.00 & 579.15 & 0.00 \\
\hline 272 & 0.00 & 0.00 & 436.00 & 0.00 & 0.00 & 0.00 & 0.00 & 0.00 \\
\hline 275 & 0.00 & 0.00 & 0.00 & 0.00 & 0.00 & 451.00 & 0.00 & 0.00 \\
\hline 276 & 0.00 & 526.00 & 0.00 & 505.00 & 0.00 & 0.00 & 0.00 & 0.00 \\
\hline 281 & 548.00 & 0.00 & 0.00 & 0.00 & 203.00 & 0.00 & 594.00 & 0.00 \\
\hline 282 & 0.00 & 0.00 & 436.00 & 0.00 & 0.00 & 0.00 & 0.00 & 0.00 \\
\hline 285 & 0.00 & 0.00 & 0.00 & 0.00 & 0.00 & 451.00 & 0.00 & 0.00 \\
\hline 286 & 0.00 & 526.00 & 0.00 & 505.00 & 0.00 & 0.00 & 0.00 & 0.00 \\
\hline 291 & 548.00 & 0.00 & 0.00 & 0.00 & 203.00 & 0.00 & 594.00 & 0.00 \\
\hline 292 & 0.00 & 0.00 & 436.00 & 0.00 & 0.00 & 0.00 & 0.00 & 0.00 \\
\hline 295 & 0.00 & 0.00 & 0.00 & 0.00 & 0.00 & 451.00 & 0.00 & 0.00 \\
\hline 296 & 0.00 & 526.00 & 0.00 & 505.00 & 0.00 & 0.00 & 0.00 & 0.00 \\
\hline 301 & 548.00 & 0.00 & 0.00 & 0.00 & 203.00 & 0.00 & 594.00 & 0.00 \\
\hline 302 & 0.00 & 0.00 & 436.00 & 0.00 & 0.00 & 0.00 & 0.00 & 0.00 \\
\hline 305 & 0.00 & 0.00 & 0.00 & 0.00 & 0.00 & 451.00 & 0.00 & 0.00 \\
\hline 306 & 0.00 & 526.00 & 0.00 & 505.00 & 0.00 & 0.00 & 0.00 & 0.00 \\
\hline 311 & 365.00 & 0.00 & 0.00 & 0.00 & 135.00 & 0.00 & 395.00 & 0.00 \\
\hline 312 & 0.00 & 0.00 & 290.00 & 0.00 & 0.00 & 0.00 & 0.00 & 0.00 \\
\hline 315 & 0.00 & 0.00 & 0.00 & 0.00 & 0.00 & 300.00 & 0.00 & 0.00 \\
\hline 316 & 0.00 & 350.00 & 0.00 & 335.00 & 0.00 & 0.00 & 0.00 & 0.00 \\
\hline 321 & 365.00 & 0.00 & 0.00 & 0.00 & 135.00 & 0.00 & 395.00 & 0.00 \\
\hline 322 & 0.00 & 0.00 & 290.00 & 0.00 & 0.00 & 0.00 & 0.00 & 0.00 \\
\hline 325 & 0.00 & 0.00 & 0.00 & 0.00 & 0.00 & 300.00 & 0.00 & 0.00 \\
\hline 326 & 0.00 & 350.00 & 0.00 & 335.00 & 0.00 & 0.00 & 0.00 & 0.00 \\
\hline 331 & 365.00 & 0.00 & 0.00 & 0.00 & 135.00 & 0.00 & 395.00 & 0.00 \\
\hline 332 & 0.00 & 0.00 & 290.00 & 0.00 & 0.00 & 0.00 & 0.00 & 0.00 \\
\hline 335 & 0.00 & 0.00 & 0.00 & 0.00 & 0.00 & 300.00 & 0.00 & 0.00 \\
\hline 336 & 0.00 & 350.00 & 0.00 & 335.00 & 0.00 & 0.00 & 0.00 & 0.00 \\
\hline 341 & 365.00 & 0.00 & 0.00 & 0.00 & 135.00 & 0.00 & 395.00 & 0.00 \\
\hline 342 & 0.00 & 0.00 & 290.00 & 0.00 & 0.00 & 0.00 & 0.00 & 0.00 \\
\hline 345 & 0.00 & 0.00 & 0.00 & 0.00 & 0.00 & 300.00 & 0.00 & 0.00 \\
\hline 346 & 0.00 & 350.00 & 0.00 & 335.00 & 0.00 & 0.00 & 0.00 & 0.00 \\
\hline 351 & 365.00 & 0.00 & 0.00 & 0.00 & 135.00 & 0.00 & 395.00 & 0.00 \\
\hline 352 & 0.00 & 0.00 & 290.00 & 0.00 & 0.00 & 0.00 & 0.00 & 0.00 \\
\hline 355 & 0.00 & 0.00 & 0.00 & 0.00 & 0.00 & 300.00 & 0.00 & 0.00 \\
\hline 356 & 0.00 & 350.00 & 0.00 & 335.00 & 0.00 & 0.00 & 0.00 & 0.00 \\
\hline 361 & 365.00 & 0.00 & 0.00 & 0.00 & 135.00 & 0.00 & 395.00 & 0.00 \\
\hline 362 & 0.00 & 0.00 & 290.00 & 0.00 & 0.00 & 0.00 & 0.00 & 0.00 \\
\hline 365 & 0.00 & 0.00 & 0.00 & 0.00 & 0.00 & 300.00 & 0.00 & 0.00 \\
\hline 366 & 0.00 & 350.00 & 0.00 & 335.00 & 0.00 & 0.00 & 0.00 & 0.00 \\
\hline EMBPN & PORTO_1 & PORTO_2 & PORTO_3 & PORTO_4 & PORTO_5 & PORTO_6 & PORTO_7 & PORTO_8 \\
\hline 001 & 0.00 & 0.00 & 45.00 & 0.00 & 0.00 & 0.00 & 0.00 & 0.00 \\
\hline 003 & 0.00 & 0.00 & 0.00 & 0.00 & 165.00 & 0.00 & 0.00 & 0.00 \\
\hline 006 & 0.00 & 0.00 & 0.00 & 0.00 & 0.00 & 0.00 & 0.00 & 335.00 \\
\hline 011 & 0.00 & 0.00 & 45.00 & 0.00 & 0.00 & 0.00 & 0.00 & 0.00 \\
\hline 013 & 0.00 & 0.00 & 0.00 & 0.00 & 165.00 & 0.00 & 0.00 & 0.00 \\
\hline 016 & 0.00 & 0.00 & 0.00 & 0.00 & 0.00 & 0.00 & 0.00 & 359.48 \\
\hline 021 & 0.00 & 0.00 & 45.00 & 0.00 & 0.00 & 0.00 & 0.00 & 0.00 \\
\hline 023 & 0.00 & 0.00 & 0.00 & 0.00 & 165.00 & 0.00 & 0.00 & 0.00 \\
\hline 026 & 0.00 & 0.00 & 0.00 & 0.00 & 0.00 & 0.00 & 0.00 & 337.12 \\
\hline 031 & 0.00 & 0.00 & 45.00 & 0.00 & 0.00 & 0.00 & 0.00 & 0.00 \\
\hline 033 & 0.00 & 0.00 & 0.00 & 0.00 & 190.26 & 0.00 & 0.00 & 0.00 \\
\hline 036 & 0.00 & 0.00 & 0.00 & 0.00 & 0.00 & 0.00 & 0.00 & 368.40 \\
\hline 041 & 0.00 & 0.00 & 45.00 & 0.00 & 0.00 & 0.00 & 0.00 & 0.00 \\
\hline 043 & 0.00 & 0.00 & 0.00 & 0.00 & 201.00 & 0.00 & 0.00 & 0.00 \\
\hline 046 & 0.00 & 0.00 & 0.00 & 0.00 & 0.00 & 0.00 & 0.00 & 375.00 \\
\hline 051 & 0.00 & 0.00 & 45.00 & 0.00 & 0.00 & 0.00 & 0.00 & 0.00 \\
\hline 053 & 0.00 & 0.00 & 0.00 & 0.00 & 201.00 & 0.00 & 0.00 & 0.00 \\
\hline 056 & 0.00 & 0.00 & 0.00 & 0.00 & 0.00 & 0.00 & 0.00 & 375.00 \\
\hline 061 & 0.00 & 0.00 & 76.15 & 0.00 & 0.00 & 0.00 & 0.00 & 0.00 \\
\hline 063 & 0.00 & 0.00 & 0.00 & 0.00 & 275.70 & 0.00 & 0.00 & 0.00 \\
\hline 066 & 0.00 & 0.00 & 0.00 & 0.00 & 0.00 & 0.00 & 0.00 & 500.00 \\
\hline 071 & 0.00 & 0.00 & 62.80 & 0.00 & 0.00 & 0.00 & 0.00 & 0.00 \\
\hline 073 & 0.00 & 0.00 & 0.00 & 0.00 & 263.56 & 0.00 & 0.00 & 0.00 \\
\hline 076 & 0.00 & 0.00 & 0.00 & 0.00 & 0.00 & 0.00 & 0.00 & 500.00 \\
\hline 081 & 0.00 & 0.00 & 60.00 & 0.00 & 0.00 & 0.00 & 0.00 & 0.00 \\
\hline 083 & 0.00 & 0.00 & 0.00 & 0.00 & 246.24 & 0.00 & 0.00 & 0.00 \\
\hline 086 & 0.00 & 0.00 & 0.00 & 0.00 & 0.00 & 0.00 & 0.00 & 500.00 \\
\hline 091 & 0.00 & 0.00 & 60.00 & 0.00 & 0.00 & 0.00 & 0.00 & 0.00 \\
\hline 093 & 0.00 & 0.00 & 0.00 & 0.00 & 228.72 & 0.00 & 0.00 & 0.00 \\
\hline 096 & 0.00 & 0.00 & 0.00 & 0.00 & 0.00 & 0.00 & 0.00 & 500.00 \\
\hline 101 & 0.00 & 0.00 & 60.60 & 0.00 & 0.00 & 0.00 & 0.00 & 0.00 \\
\hline 103 & 0.00 & 0.00 & 0.00 & 0.00 & 260.86 & 0.00 & 0.00 & 0.00 \\
\hline 106 & 0.00 & 0.00 & 0.00 & 0.00 & 0.00 & 0.00 & 0.00 & 500.00 \\
\hline 111 & 0.00 & 0.00 & 74.58 & 0.00 & 0.00 & 0.00 & 0.00 & 0.00 \\
\hline 113 & 0.00 & 0.00 & 0.00 & 0.00 & 282.24 & 0.00 & 0.00 & 0.00 \\
\hline 116 & 0.00 & 0.00 & 0.00 & 0.00 & 0.00 & 0.00 & 0.00 & 500.00 \\
\hline 121 & 0.00 & 0.00 & 90.10 & 0.00 & 0.00 & 0.00 & 0.00 & 0.00 \\
\hline 123 & 0.00 & 0.00 & 0.00 & 0.00 & 365.69 & 0.00 & 0.00 & 0.00 \\
\hline 126 & 0.00 & 0.00 & 0.00 & 0.00 & 0.00 & 0.00 & 0.00 & 625.00 \\
\hline
\end{tabular}




\begin{tabular}{|c|c|c|c|c|c|c|c|c|}
\hline 131 & 0.00 & 0.00 & 90.20 & 0.00 & 0.00 & 0.00 & 0.00 & 0.00 \\
\hline 133 & 0.00 & 0.00 & 0.00 & 0.00 & 316.63 & 0.00 & 0.00 & 0.00 \\
\hline 136 & 0.00 & 0.00 & 0.00 & 0.00 & 0.00 & 0.00 & 0.00 & 625.00 \\
\hline 141 & 0.00 & 0.00 & 77.64 & 0.00 & 0.00 & 0.00 & 0.00 & 0.00 \\
\hline 143 & 0.00 & 0.00 & 0.00 & 0.00 & 277.18 & 0.00 & 0.00 & 0.00 \\
\hline 146 & 0.00 & 0.00 & 0.00 & 0.00 & 0.00 & 0.00 & 0.00 & 625.00 \\
\hline 151 & 0.00 & 0.00 & 75.75 & 0.00 & 0.00 & 0.00 & 0.00 & 0.00 \\
\hline 153 & 0.00 & 0.00 & 0.00 & 0.00 & 294.80 & 0.00 & 0.00 & 0.00 \\
\hline 156 & 0.00 & 0.00 & 0.00 & 0.00 & 0.00 & 0.00 & 0.00 & 625.00 \\
\hline 161 & 0.00 & 0.00 & 149.97 & 0.00 & 0.00 & 0.00 & 0.00 & 0.00 \\
\hline 163 & 0.00 & 0.00 & 0.00 & 0.00 & 320.00 & 0.00 & 0.00 & 0.00 \\
\hline 166 & 0.00 & 0.00 & 0.00 & 0.00 & 0.00 & 0.00 & 0.00 & 625.00 \\
\hline 171 & 0.00 & 0.00 & 110.94 & 0.00 & 0.00 & 0.00 & 0.00 & 0.00 \\
\hline 173 & 0.00 & 0.00 & 0.00 & 0.00 & 312.71 & 0.00 & 0.00 & 0.00 \\
\hline 176 & 0.00 & 0.00 & 0.00 & 0.00 & 0.00 & 0.00 & 0.00 & 625.00 \\
\hline 181 & 0.00 & 0.00 & 117.18 & 0.00 & 0.00 & 0.00 & 0.00 & 0.00 \\
\hline 183 & 0.00 & 0.00 & 0.00 & 0.00 & 407.32 & 0.00 & 0.00 & 0.00 \\
\hline 186 & 0.00 & 0.00 & 0.00 & 0.00 & 0.00 & 0.00 & 0.00 & 750.00 \\
\hline 191 & 0.00 & 0.00 & 133.46 & 0.00 & 0.00 & 0.00 & 0.00 & 0.00 \\
\hline 193 & 0.00 & 0.00 & 0.00 & 0.00 & 371.79 & 0.00 & 0.00 & 0.00 \\
\hline 196 & 0.00 & 0.00 & 0.00 & 0.00 & 0.00 & 0.00 & 0.00 & 750.00 \\
\hline 201 & 0.00 & 0.00 & 121.50 & 0.00 & 0.00 & 0.00 & 0.00 & 0.00 \\
\hline 203 & 0.00 & 0.00 & 0.00 & 0.00 & 328.65 & 0.00 & 0.00 & 0.00 \\
\hline 206 & 0.00 & 0.00 & 0.00 & 0.00 & 0.00 & 0.00 & 0.00 & 750.00 \\
\hline 211 & 0.00 & 0.00 & 104.93 & 0.00 & 0.00 & 0.00 & 0.00 & 0.00 \\
\hline 213 & 0.00 & 0.00 & 0.00 & 0.00 & 323.01 & 0.00 & 0.00 & 0.00 \\
\hline 216 & 0.00 & 0.00 & 0.00 & 0.00 & 0.00 & 0.00 & 0.00 & 750.00 \\
\hline 221 & 0.00 & 0.00 & 153.75 & 0.00 & 0.00 & 0.00 & 0.00 & 0.00 \\
\hline 223 & 0.00 & 0.00 & 0.00 & 0.00 & 336.93 & 0.00 & 0.00 & 0.00 \\
\hline 226 & 0.00 & 0.00 & 0.00 & 0.00 & 0.00 & 0.00 & 0.00 & 750.00 \\
\hline 231 & 0.00 & 0.00 & 157.41 & 0.00 & 0.00 & 0.00 & 0.00 & 0.00 \\
\hline 233 & 0.00 & 0.00 & 0.00 & 0.00 & 368.70 & 0.00 & 0.00 & 0.00 \\
\hline 236 & 0.00 & 0.00 & 0.00 & 0.00 & 0.00 & 0.00 & 0.00 & 750.00 \\
\hline 241 & 0.00 & 0.00 & 172.81 & 0.00 & 0.00 & 0.00 & 0.00 & 0.00 \\
\hline 243 & 0.00 & 0.00 & 0.00 & 0.00 & 397.61 & 0.00 & 0.00 & 0.00 \\
\hline 246 & 0.00 & 0.00 & 0.00 & 0.00 & 0.00 & 0.00 & 0.00 & 750.00 \\
\hline 251 & 0.00 & 0.00 & 143.00 & 0.00 & 0.00 & 0.00 & 0.00 & 0.00 \\
\hline 253 & 0.00 & 0.00 & 0.00 & 0.00 & 325.87 & 0.00 & 0.00 & 0.00 \\
\hline 256 & 0.00 & 0.00 & 0.00 & 0.00 & 0.00 & 0.00 & 0.00 & 565.00 \\
\hline 261 & 0.00 & 0.00 & 143.00 & 0.00 & 0.00 & 0.00 & 0.00 & 0.00 \\
\hline 263 & 0.00 & 0.00 & 0.00 & 0.00 & 339.00 & 0.00 & 0.00 & 0.00 \\
\hline 266 & 0.00 & 0.00 & 0.00 & 0.00 & 0.00 & 0.00 & 0.00 & 565.00 \\
\hline 271 & 0.00 & 0.00 & 143.00 & 0.00 & 0.00 & 0.00 & 0.00 & 0.00 \\
\hline 273 & 0.00 & 0.00 & 0.00 & 0.00 & 339.00 & 0.00 & 0.00 & 0.00 \\
\hline 276 & 0.00 & 0.00 & 0.00 & 0.00 & 0.00 & 0.00 & 0.00 & 565.00 \\
\hline 281 & 0.00 & 0.00 & 143.00 & 0.00 & 0.00 & 0.00 & 0.00 & 0.00 \\
\hline 283 & 0.00 & 0.00 & 0.00 & 0.00 & 339.00 & 0.00 & 0.00 & 0.00 \\
\hline 286 & 0.00 & 0.00 & 0.00 & 0.00 & 0.00 & 0.00 & 0.00 & 565.00 \\
\hline 291 & 0.00 & 0.00 & 143.00 & 0.00 & 0.00 & 0.00 & 0.00 & 0.00 \\
\hline 293 & 0.00 & 0.00 & 0.00 & 0.00 & 339.00 & 0.00 & 0.00 & 0.00 \\
\hline 296 & 0.00 & 0.00 & 0.00 & 0.00 & 0.00 & 0.00 & 0.00 & 565.00 \\
\hline 301 & 0.00 & 0.00 & 143.00 & 0.00 & 0.00 & 0.00 & 0.00 & 0.00 \\
\hline 303 & 0.00 & 0.00 & 0.00 & 0.00 & 339.00 & 0.00 & 0.00 & 0.00 \\
\hline 306 & 0.00 & 0.00 & 0.00 & 0.00 & 0.00 & 0.00 & 0.00 & 565.00 \\
\hline 311 & 0.00 & 0.00 & 95.00 & 0.00 & 0.00 & 0.00 & 0.00 & 0.00 \\
\hline 313 & 0.00 & 0.00 & 0.00 & 0.00 & 225.00 & 0.00 & 0.00 & 0.00 \\
\hline 316 & 0.00 & 0.00 & 0.00 & 0.00 & 0.00 & 0.00 & 0.00 & 375.00 \\
\hline 321 & 0.00 & 0.00 & 95.00 & 0.00 & 0.00 & 0.00 & 0.00 & 0.00 \\
\hline 323 & 0.00 & 0.00 & 0.00 & 0.00 & 225.00 & 0.00 & 0.00 & 0.00 \\
\hline 326 & 0.00 & 0.00 & 0.00 & 0.00 & 0.00 & 0.00 & 0.00 & 375.00 \\
\hline 331 & 0.00 & 0.00 & 95.00 & 0.00 & 0.00 & 0.00 & 0.00 & 0.00 \\
\hline 333 & 0.00 & 0.00 & 0.00 & 0.00 & 225.00 & 0.00 & 0.00 & 0.00 \\
\hline 336 & 0.00 & 0.00 & 0.00 & 0.00 & 0.00 & 0.00 & 0.00 & 375.00 \\
\hline 341 & 0.00 & 0.00 & 95.00 & 0.00 & 0.00 & 0.00 & 0.00 & 0.00 \\
\hline 343 & 0.00 & 0.00 & 0.00 & 0.00 & 225.00 & 0.00 & 0.00 & 0.00 \\
\hline 346 & 0.00 & 0.00 & 0.00 & 0.00 & 0.00 & 0.00 & 0.00 & 375.00 \\
\hline 351 & 0.00 & 0.00 & 95.00 & 0.00 & 0.00 & 0.00 & 0.00 & 0.00 \\
\hline 353 & 0.00 & 0.00 & 0.00 & 0.00 & 225.00 & 0.00 & 0.00 & 0.00 \\
\hline 356 & 0.00 & 0.00 & 0.00 & 0.00 & 0.00 & 0.00 & 0.00 & 375.00 \\
\hline 361 & 0.00 & 0.00 & 95.00 & 0.00 & 0.00 & 0.00 & 0.00 & 0.00 \\
\hline 363 & 0.00 & 0.00 & 0.00 & 0.00 & 225.00 & 0.00 & 0.00 & 0.00 \\
\hline 366 & 0.00 & 0.00 & 0.00 & 0.00 & 0.00 & 0.00 & 0.00 & 375.00 \\
\hline EMBLS & PORTO_1 & PORTO_2 & PORTO_3 & PORTO_4 & PORTO_5 & PORTO_6 & PORTO_7 & PORTO_8 \\
\hline 001 & $40.00^{-}$ & 0.00 & 0.00 & 0.00 & $45.00^{-}$ & 0.00 & 100.00 & 0.00 \\
\hline 002 & 0.00 & 0.00 & 60.00 & 0.00 & 0.00 & 0.00 & 0.00 & 0.00 \\
\hline 005 & 0.00 & 0.00 & 0.00 & 0.00 & 0.00 & 35.00 & 0.00 & 0.00 \\
\hline 006 & 0.00 & 40.00 & 0.00 & 40.00 & 0.00 & 0.00 & 0.00 & 0.00 \\
\hline 011 & 40.00 & 0.00 & 0.00 & 0.00 & 45.00 & 0.00 & 47.75 & 0.00 \\
\hline 012 & 0.00 & 0.00 & 60.00 & 0.00 & 0.00 & 0.00 & 0.00 & 0.00 \\
\hline 015 & 0.00 & 0.00 & 0.00 & 0.00 & 0.00 & 43.32 & 0.00 & 0.00 \\
\hline 016 & 0.00 & 40.00 & 0.00 & 40.00 & 0.00 & 0.00 & 0.00 & 0.00 \\
\hline 021 & 31.40 & 0.00 & 0.00 & 0.00 & 45.00 & 0.00 & 90.93 & 0.00 \\
\hline 022 & 0.00 & 0.00 & 60.00 & 0.00 & 0.00 & 0.00 & 0.00 & 0.00 \\
\hline 025 & 0.00 & 0.00 & 0.00 & 0.00 & 0.00 & 54.52 & 0.00 & 0.00 \\
\hline
\end{tabular}




\begin{tabular}{|c|c|c|c|c|c|c|c|c|}
\hline 026 & 0.00 & 39.88 & 0.00 & 40.00 & 0.00 & 0.00 & 0.00 & 0.00 \\
\hline 031 & 6.60 & 0.00 & 0.00 & 0.00 & 45.00 & 0.00 & 100.00 & 0.00 \\
\hline 032 & 0.00 & 0.00 & 24.72 & 0.00 & 0.00 & 0.00 & 0.00 & 0.00 \\
\hline 035 & 0.00 & 0.00 & 0.00 & 0.00 & 0.00 & 39.16 & 0.00 & 0.00 \\
\hline 036 & 0.00 & 40.00 & 0.00 & 40.00 & 0.00 & 0.00 & 0.00 & 0.00 \\
\hline 041 & 0.00 & 0.00 & 0.00 & 0.00 & 43.65 & 0.00 & 100.00 & 0.00 \\
\hline 042 & 0.00 & 0.00 & 12.00 & 0.00 & 0.00 & 0.00 & 0.00 & 0.00 \\
\hline 045 & 0.00 & 0.00 & 0.00 & 0.00 & 0.00 & 35.00 & 0.00 & 0.00 \\
\hline 046 & 0.00 & 40.00 & 0.00 & 40.00 & 0.00 & 0.00 & 0.00 & 0.00 \\
\hline 051 & 0.00 & 0.00 & 0.00 & 0.00 & 45.00 & 0.00 & 100.00 & 0.00 \\
\hline 052 & 0.00 & 0.00 & 12.00 & 0.00 & 0.00 & 0.00 & 0.00 & 0.00 \\
\hline 055 & 0.00 & 0.00 & 0.00 & 0.00 & 0.00 & 35.00 & 0.00 & 0.00 \\
\hline 056 & 0.00 & 40.00 & 0.00 & 40.00 & 0.00 & 0.00 & 0.00 & 0.00 \\
\hline 061 & 0.00 & 0.00 & 0.00 & 0.00 & 45.75 & 0.00 & 101.65 & 0.00 \\
\hline 062 & 0.00 & 0.00 & 15.46 & 0.00 & 0.00 & 0.00 & 0.00 & 0.00 \\
\hline 065 & 0.00 & 0.00 & 0.00 & 0.00 & 0.00 & 46.13 & 0.00 & 0.00 \\
\hline 066 & 0.00 & 51.50 & 0.00 & 52.54 & 0.00 & 0.00 & 0.00 & 0.00 \\
\hline 071 & 0.00 & 0.00 & 0.00 & 0.00 & 57.53 & 0.00 & 127.55 & 0.00 \\
\hline 072 & 0.00 & 0.00 & 20.98 & 0.00 & 0.00 & 0.00 & 0.00 & 0.00 \\
\hline 075 & 0.00 & 0.00 & 0.00 & 0.00 & 0.00 & 67.68 & 0.00 & 0.00 \\
\hline 076 & 0.00 & 53.00 & 0.00 & 96.33 & 0.00 & 0.00 & 0.00 & 0.00 \\
\hline 081 & 0.00 & 0.00 & 0.00 & 0.00 & 60.00 & 0.00 & 133.00 & 0.00 \\
\hline 082 & 0.00 & 0.00 & 28.38 & 0.00 & 0.00 & 0.00 & 0.00 & 0.00 \\
\hline 085 & 0.00 & 0.00 & 0.00 & 0.00 & 0.00 & 98.61 & 0.00 & 0.00 \\
\hline 086 & 0.00 & 57.70 & 0.00 & 132.16 & 0.00 & 0.00 & 0.00 & 0.00 \\
\hline 091 & 0.00 & 0.00 & 0.00 & 0.00 & 59.88 & 0.00 & 133.00 & 0.00 \\
\hline 092 & 0.00 & 0.00 & 52.80 & 0.00 & 0.00 & 0.00 & 0.00 & 0.00 \\
\hline 095 & 0.00 & 0.00 & 0.00 & 0.00 & 0.00 & 85.86 & 0.00 & 0.00 \\
\hline 096 & 0.00 & 95.52 & 0.00 & 114.92 & 0.00 & 0.00 & 0.00 & 0.00 \\
\hline 101 & 0.00 & 0.00 & 0.00 & 0.00 & 54.00 & 0.00 & 133.00 & 0.00 \\
\hline 102 & 0.00 & 0.00 & 28.24 & 0.00 & 0.00 & 0.00 & 0.00 & 0.00 \\
\hline 105 & 0.00 & 0.00 & 0.00 & 0.00 & 0.00 & 61.02 & 0.00 & 0.00 \\
\hline 106 & 0.00 & 99.22 & 0.00 & 93.48 & 0.00 & 0.00 & 0.00 & 0.00 \\
\hline 111 & 0.00 & 0.00 & 0.00 & 0.00 & 47.40 & 0.00 & 133.00 & 0.00 \\
\hline 112 & 0.00 & 0.00 & 28.38 & 0.00 & 0.00 & 0.00 & 0.00 & 0.00 \\
\hline 115 & 0.00 & 0.00 & 0.00 & 0.00 & 0.00 & 50.85 & 0.00 & 0.00 \\
\hline 116 & 0.00 & 90.92 & 0.00 & 70.94 & 0.00 & 0.00 & 0.00 & 0.00 \\
\hline 121 & 0.00 & 0.00 & 0.00 & 0.00 & 54.72 & 0.00 & 160.41 & 0.00 \\
\hline 122 & 0.00 & 0.00 & 29.02 & 0.00 & 0.00 & 0.00 & 0.00 & 0.00 \\
\hline 125 & 0.00 & 0.00 & 0.00 & 0.00 & 0.00 & 53.62 & 0.00 & 0.00 \\
\hline 126 & 0.00 & 180.80 & 0.00 & 104.59 & 0.00 & 0.00 & 0.00 & 0.00 \\
\hline 131 & 0.00 & 0.00 & 0.00 & 0.00 & 60.58 & 0.00 & 152.11 & 0.00 \\
\hline 132 & 0.00 & 0.00 & 59.14 & 0.00 & 0.00 & 0.00 & 0.00 & 0.00 \\
\hline 135 & 0.00 & 0.00 & 0.00 & 0.00 & 0.00 & 93.30 & 0.00 & 0.00 \\
\hline 136 & 0.00 & 218.43 & 0.00 & 182.90 & 0.00 & 0.00 & 0.00 & 0.00 \\
\hline 141 & 0.00 & 0.00 & 0.00 & 0.00 & 71.42 & 0.00 & 123.32 & 0.00 \\
\hline 142 & 0.00 & 0.00 & 60.01 & 0.00 & 0.00 & 0.00 & 0.00 & 0.00 \\
\hline 145 & 0.00 & 0.00 & 0.00 & 0.00 & 0.00 & 125.12 & 0.00 & 0.00 \\
\hline 146 & 0.00 & 203.67 & 0.00 & 152.87 & 0.00 & 0.00 & 0.00 & 0.00 \\
\hline 151 & 0.00 & 0.00 & 0.00 & 0.00 & 67.50 & 0.00 & 226.77 & 0.00 \\
\hline 152 & 0.00 & 0.00 & 32.62 & 0.00 & 0.00 & 0.00 & 0.00 & 0.00 \\
\hline 155 & 0.00 & 0.00 & 0.00 & 0.00 & 0.00 & 81.81 & 0.00 & 0.00 \\
\hline 156 & 0.00 & 181.89 & 0.00 & 112.26 & 0.00 & 0.00 & 0.00 & 0.00 \\
\hline 161 & 0.00 & 0.00 & 0.00 & 0.00 & 27.90 & 0.00 & 173.73 & 0.00 \\
\hline 162 & 0.00 & 0.00 & 62.74 & 0.00 & 0.00 & 0.00 & 0.00 & 0.00 \\
\hline 165 & 0.00 & 0.00 & 0.00 & 0.00 & 0.00 & 56.26 & 0.00 & 0.00 \\
\hline 166 & 0.00 & 136.04 & 0.00 & 112.92 & 0.00 & 0.00 & 0.00 & 0.00 \\
\hline 171 & 0.00 & 0.00 & 0.00 & 0.00 & 51.26 & 0.00 & 184.71 & 0.00 \\
\hline 172 & 0.00 & 0.00 & 78.67 & 0.00 & 0.00 & 0.00 & 0.00 & 0.00 \\
\hline 175 & 0.00 & 0.00 & 0.00 & 0.00 & 0.00 & 103.97 & 0.00 & 0.00 \\
\hline 176 & 0.00 & 105.88 & 0.00 & 98.84 & 0.00 & 0.00 & 0.00 & 0.00 \\
\hline 181 & 0.00 & 0.00 & 0.00 & 0.00 & 79.28 & 0.00 & 346.54 & 0.00 \\
\hline 182 & 0.00 & 0.00 & 92.19 & 0.00 & 0.00 & 0.00 & 0.00 & 0.00 \\
\hline 185 & 0.00 & 0.00 & 0.00 & 0.00 & 0.00 & 135.74 & 0.00 & 0.00 \\
\hline 186 & 0.00 & 230.03 & 0.00 & 152.79 & 0.00 & 0.00 & 0.00 & 0.00 \\
\hline 191 & 0.00 & 0.00 & 0.00 & 0.00 & 68.10 & 0.00 & 247.48 & 0.00 \\
\hline 192 & 0.00 & 0.00 & 105.84 & 0.00 & 0.00 & 0.00 & 0.00 & 0.00 \\
\hline 195 & 0.00 & 0.00 & 0.00 & 0.00 & 0.00 & 141.77 & 0.00 & 0.00 \\
\hline 196 & 0.00 & 228.92 & 0.00 & 199.74 & 0.00 & 0.00 & 0.00 & 0.00 \\
\hline 201 & 0.00 & 0.00 & 0.00 & 0.00 & 79.02 & 0.00 & 298.85 & 0.00 \\
\hline 202 & 0.00 & 0.00 & 75.58 & 0.00 & 0.00 & 0.00 & 0.00 & 0.00 \\
\hline 205 & 0.00 & 0.00 & 0.00 & 0.00 & 0.00 & 178.63 & 0.00 & 0.00 \\
\hline 206 & 0.00 & 212.32 & 0.00 & 150.28 & 0.00 & 0.00 & 0.00 & 0.00 \\
\hline 211 & 0.00 & 0.00 & 0.00 & 0.00 & 24.55 & 0.00 & 312.72 & 0.00 \\
\hline 212 & 0.00 & 0.00 & 80.12 & 0.00 & 0.00 & 0.00 & 0.00 & 0.00 \\
\hline 215 & 0.00 & 0.00 & 0.00 & 0.00 & 0.00 & 125.42 & 0.00 & 0.00 \\
\hline 216 & 0.00 & 197.50 & 0.00 & 131.28 & 0.00 & 0.00 & 0.00 & 0.00 \\
\hline 221 & 0.00 & 0.00 & 0.00 & 0.00 & 12.51 & 0.00 & 265.99 & 0.00 \\
\hline 222 & 0.00 & 0.00 & 111.53 & 0.00 & 0.00 & 0.00 & 0.00 & 0.00 \\
\hline 225 & 0.00 & 0.00 & 0.00 & 0.00 & 0.00 & 80.74 & 0.00 & 0.00 \\
\hline 226 & 0.00 & 205.61 & 0.00 & 116.81 & 0.00 & 0.00 & 0.00 & 0.00 \\
\hline 231 & 0.00 & 0.00 & 0.00 & 0.00 & 25.38 & 0.00 & 241.33 & 0.00 \\
\hline 232 & 0.00 & 0.00 & 139.89 & 0.00 & 0.00 & 0.00 & 0.00 & 0.00 \\
\hline 235 & 0.00 & 0.00 & 0.00 & 0.00 & 0.00 & 16.55 & 0.00 & 0.00 \\
\hline 236 & 0.00 & 170.55 & 0.00 & 119.72 & 0.00 & 0.00 & 0.00 & 0.00 \\
\hline 241 & 0.00 & 0.00 & 0.00 & 0.00 & 26.40 & 0.00 & 201.22 & 0.00 \\
\hline
\end{tabular}




\begin{tabular}{|c|c|c|c|c|c|c|c|c|}
\hline 242 & 0.00 & 0.00 & 67.10 & 0.00 & 0.00 & 0.00 & 0.00 & 0.00 \\
\hline 245 & 0.00 & 0.00 & 0.00 & 0.00 & 0.00 & 8.95 & 0.00 & 0.00 \\
\hline 246 & 0.00 & 168.60 & 0.00 & 105.14 & 0.00 & 0.00 & 0.00 & 0.00 \\
\hline 251 & 0.00 & 0.00 & 0.00 & 0.00 & 14.32 & 0.00 & 96.72 & 0.00 \\
\hline 252 & 0.00 & 0.00 & 12.15 & 0.00 & 0.00 & 0.00 & 0.00 & 0.00 \\
\hline 256 & 0.00 & 67.12 & 0.00 & 21.45 & 0.00 & 0.00 & 0.00 & 0.00 \\
\hline 261 & 0.00 & 0.00 & 0.00 & 0.00 & 0.00 & 0.00 & 54.00 & 0.00 \\
\hline 266 & 0.00 & 5.97 & 0.00 & 0.00 & 0.00 & 0.00 & 0.00 & 0.00 \\
\hline 271 & 0.00 & 0.00 & 0.00 & 0.00 & 0.00 & 0.00 & 14.85 & 0.00 \\
\hline EMBLN & PORTO_1 & PORTO_2 & PORTO_3 & PORTO_4 & PORTO_5 & PORTO_6 & PORTO_7 & PORTO_8 \\
\hline 001 & 0.00 & 0.00 & 50.00 & 0.00 & 0.00 & 0.00 & 0.00 & 0.00 \\
\hline 003 & 0.00 & 0.00 & 0.00 & 0.00 & 60.00 & 0.00 & 0.00 & 0.00 \\
\hline 006 & 0.00 & 0.00 & 0.00 & 0.00 & 0.00 & 0.00 & 0.00 & 40.00 \\
\hline 011 & 0.00 & 0.00 & 50.00 & 0.00 & 0.00 & 0.00 & 0.00 & 0.00 \\
\hline 013 & 0.00 & 0.00 & 0.00 & 0.00 & 60.00 & 0.00 & 0.00 & 0.00 \\
\hline 016 & 0.00 & 0.00 & 0.00 & 0.00 & 0.00 & 0.00 & 0.00 & 15.52 \\
\hline 021 & 0.00 & 0.00 & 50.00 & 0.00 & 0.00 & 0.00 & 0.00 & 0.00 \\
\hline 023 & 0.00 & 0.00 & 0.00 & 0.00 & 60.00 & 0.00 & 0.00 & 0.00 \\
\hline 026 & 0.00 & 0.00 & 0.00 & 0.00 & 0.00 & 0.00 & 0.00 & 37.88 \\
\hline 031 & 0.00 & 0.00 & 50.00 & 0.00 & 0.00 & 0.00 & 0.00 & 0.00 \\
\hline 033 & 0.00 & 0.00 & 0.00 & 0.00 & 34.74 & 0.00 & 0.00 & 0.00 \\
\hline 036 & 0.00 & 0.00 & 0.00 & 0.00 & 0.00 & 0.00 & 0.00 & 6.60 \\
\hline 041 & 0.00 & 0.00 & 50.00 & 0.00 & 0.00 & 0.00 & 0.00 & 0.00 \\
\hline 043 & 0.00 & 0.00 & 0.00 & 0.00 & 24.00 & 0.00 & 0.00 & 0.00 \\
\hline 051 & 0.00 & 0.00 & 50.00 & 0.00 & 0.00 & 0.00 & 0.00 & 0.00 \\
\hline 053 & 0.00 & 0.00 & 0.00 & 0.00 & 24.00 & 0.00 & 0.00 & 0.00 \\
\hline 061 & 0.00 & 0.00 & 50.85 & 0.00 & 0.00 & 0.00 & 0.00 & 0.00 \\
\hline 063 & 0.00 & 0.00 & 0.00 & 0.00 & 24.30 & 0.00 & 0.00 & 0.00 \\
\hline 071 & 0.00 & 0.00 & 64.20 & 0.00 & 0.00 & 0.00 & 0.00 & 0.00 \\
\hline 073 & 0.00 & 0.00 & 0.00 & 0.00 & 36.44 & 0.00 & 0.00 & 0.00 \\
\hline 081 & 0.00 & 0.00 & 67.00 & 0.00 & 0.00 & 0.00 & 0.00 & 0.00 \\
\hline 083 & 0.00 & 0.00 & 0.00 & 0.00 & 53.76 & 0.00 & 0.00 & 0.00 \\
\hline 091 & 0.00 & 0.00 & 67.00 & 0.00 & 0.00 & 0.00 & 0.00 & 0.00 \\
\hline 093 & 0.00 & 0.00 & 0.00 & 0.00 & 71.28 & 0.00 & 0.00 & 0.00 \\
\hline 101 & 0.00 & 0.00 & 66.40 & 0.00 & 0.00 & 0.00 & 0.00 & 0.00 \\
\hline 103 & 0.00 & 0.00 & 0.00 & 0.00 & 39.14 & 0.00 & 0.00 & 0.00 \\
\hline 111 & 0.00 & 0.00 & 52.42 & 0.00 & 0.00 & 0.00 & 0.00 & 0.00 \\
\hline 113 & 0.00 & 0.00 & 0.00 & 0.00 & 17.76 & 0.00 & 0.00 & 0.00 \\
\hline 121 & 0.00 & 0.00 & 67.90 & 0.00 & 0.00 & 0.00 & 0.00 & 0.00 \\
\hline 123 & 0.00 & 0.00 & 0.00 & 0.00 & 9.31 & 0.00 & 0.00 & 0.00 \\
\hline 131 & 0.00 & 0.00 & 67.80 & 0.00 & 0.00 & 0.00 & 0.00 & 0.00 \\
\hline 133 & 0.00 & 0.00 & 0.00 & 0.00 & 58.37 & 0.00 & 0.00 & 0.00 \\
\hline 141 & 0.00 & 0.00 & 80.36 & 0.00 & 0.00 & 0.00 & 0.00 & 0.00 \\
\hline 143 & 0.00 & 0.00 & 0.00 & 0.00 & 97.82 & 0.00 & 0.00 & 0.00 \\
\hline 151 & 0.00 & 0.00 & 82.25 & 0.00 & 0.00 & 0.00 & 0.00 & 0.00 \\
\hline 153 & 0.00 & 0.00 & 0.00 & 0.00 & 80.20 & 0.00 & 0.00 & 0.00 \\
\hline 161 & 0.00 & 0.00 & 8.03 & 0.00 & 0.00 & 0.00 & 0.00 & 0.00 \\
\hline 163 & 0.00 & 0.00 & 0.00 & 0.00 & 55.00 & 0.00 & 0.00 & 0.00 \\
\hline 171 & 0.00 & 0.00 & 47.06 & 0.00 & 0.00 & 0.00 & 0.00 & 0.00 \\
\hline 173 & 0.00 & 0.00 & 0.00 & 0.00 & 62.29 & 0.00 & 0.00 & 0.00 \\
\hline 181 & 0.00 & 0.00 & 72.82 & 0.00 & 0.00 & 0.00 & 0.00 & 0.00 \\
\hline 183 & 0.00 & 0.00 & 0.00 & 0.00 & 42.68 & 0.00 & 0.00 & 0.00 \\
\hline 191 & 0.00 & 0.00 & 56.54 & 0.00 & 0.00 & 0.00 & 0.00 & 0.00 \\
\hline 193 & 0.00 & 0.00 & 0.00 & 0.00 & 78.21 & 0.00 & 0.00 & 0.00 \\
\hline 201 & 0.00 & 0.00 & 68.50 & 0.00 & 0.00 & 0.00 & 0.00 & 0.00 \\
\hline 203 & 0.00 & 0.00 & 0.00 & 0.00 & 121.35 & 0.00 & 0.00 & 0.00 \\
\hline 211 & 0.00 & 0.00 & 85.07 & 0.00 & 0.00 & 0.00 & 0.00 & 0.00 \\
\hline 213 & 0.00 & 0.00 & 0.00 & 0.00 & 126.99 & 0.00 & 0.00 & 0.00 \\
\hline 221 & 0.00 & 0.00 & 36.25 & 0.00 & 0.00 & 0.00 & 0.00 & 0.00 \\
\hline 223 & 0.00 & 0.00 & 0.00 & 0.00 & 113.07 & 0.00 & 0.00 & 0.00 \\
\hline 231 & 0.00 & 0.00 & 32.59 & 0.00 & 0.00 & 0.00 & 0.00 & 0.00 \\
\hline 233 & 0.00 & 0.00 & 0.00 & 0.00 & 81.30 & 0.00 & 0.00 & 0.00 \\
\hline 241 & 0.00 & 0.00 & 17.19 & 0.00 & 0.00 & 0.00 & 0.00 & 0.00 \\
\hline 243 & 0.00 & 0.00 & 0.00 & 0.00 & 52.39 & 0.00 & 0.00 & 0.00 \\
\hline 253 & 0.00 & 0.00 & 0.00 & 0.00 & 13.13 & 0.00 & 0.00 & 0.00 \\
\hline SES & PORTO_1 & PORTO_2 & PORTO_3 & PORTO_4 & PORTO_5 & PORTO_6 & PORTO_7 & PORTO_8 \\
\hline 001 & 0.00 & 0.00 & 0.00 & 0.00 & 38.50 & 0.00 & 0.00 & 0.00 \\
\hline 002 & 0.00 & 0.00 & 56.25 & 0.00 & 0.00 & 0.00 & 0.00 & 0.00 \\
\hline 005 & 0.00 & 0.00 & 0.00 & 0.00 & 0.00 & 25.00 & 0.00 & 0.00 \\
\hline 011 & 0.00 & 0.00 & 0.00 & 0.00 & 48.75 & 0.00 & 0.00 & 0.00 \\
\hline 012 & 0.00 & 0.00 & 46.34 & 0.00 & 0.00 & 0.00 & 0.00 & 0.00 \\
\hline 015 & 0.00 & 0.00 & 0.00 & 0.00 & 0.00 & 25.00 & 0.00 & 0.00 \\
\hline 021 & 0.00 & 0.00 & 0.00 & 0.00 & 153.80 & 0.00 & 0.00 & 0.00 \\
\hline 025 & 0.00 & 0.00 & 0.00 & 0.00 & 0.00 & 25.00 & 0.00 & 0.00 \\
\hline 031 & 0.00 & 0.00 & 0.00 & 0.00 & 175.00 & 0.00 & 0.00 & 0.00 \\
\hline 032 & 0.00 & 0.00 & 85.00 & 0.00 & 0.00 & 0.00 & 0.00 & 0.00 \\
\hline 035 & 0.00 & 0.00 & 0.00 & 0.00 & 0.00 & 25.00 & 0.00 & 0.00 \\
\hline 041 & 0.00 & 0.00 & 0.00 & 0.00 & 142.85 & 0.00 & 0.00 & 0.00 \\
\hline 042 & 0.00 & 0.00 & 85.00 & 0.00 & 0.00 & 0.00 & 0.00 & 0.00 \\
\hline 045 & 0.00 & 0.00 & 0.00 & 0.00 & 0.00 & 25.00 & 0.00 & 0.00 \\
\hline 051 & 0.00 & 0.00 & 0.00 & 0.00 & 113.55 & 0.00 & 0.00 & 0.00 \\
\hline 055 & 0.00 & 0.00 & 0.00 & 0.00 & 0.00 & 25.00 & 0.00 & 0.00 \\
\hline
\end{tabular}




\begin{tabular}{|c|c|c|c|c|c|c|c|c|}
\hline 061 & 0.00 & 0.00 & 0.00 & 0.00 & 168.39 & 0.00 & 0.00 & 0.00 \\
\hline 062 & 0.00 & 0.00 & 8.92 & 0.00 & 0.00 & 0.00 & 0.00 & 0.00 \\
\hline 065 & 0.00 & 0.00 & 0.00 & 0.00 & 0.00 & 33.00 & 0.00 & 0.00 \\
\hline 071 & 0.00 & 0.00 & 0.00 & 0.00 & 154.85 & 0.00 & 0.00 & 0.00 \\
\hline 072 & 0.00 & 0.00 & 48.38 & 0.00 & 0.00 & 0.00 & 0.00 & 0.00 \\
\hline 075 & 0.00 & 0.00 & 0.00 & 0.00 & 0.00 & 33.00 & 0.00 & 0.00 \\
\hline 081 & 0.00 & 0.00 & 0.00 & 0.00 & 153.30 & 0.00 & 0.00 & 0.00 \\
\hline 082 & 0.00 & 0.00 & 51.52 & 0.00 & 0.00 & 0.00 & 0.00 & 0.00 \\
\hline 085 & 0.00 & 0.00 & 0.00 & 0.00 & 0.00 & 33.00 & 0.00 & 0.00 \\
\hline 091 & 0.00 & 0.00 & 0.00 & 0.00 & 127.79 & 0.00 & 0.00 & 0.00 \\
\hline 092 & 0.00 & 0.00 & 49.44 & 0.00 & 0.00 & 0.00 & 0.00 & 0.00 \\
\hline 095 & 0.00 & 0.00 & 0.00 & 0.00 & 0.00 & 33.00 & 0.00 & 0.00 \\
\hline 101 & 0.00 & 0.00 & 0.00 & 0.00 & 158.86 & 0.00 & 0.00 & 0.00 \\
\hline 102 & 0.00 & 0.00 & 53.92 & 0.00 & 0.00 & 0.00 & 0.00 & 0.00 \\
\hline 105 & 0.00 & 0.00 & 0.00 & 0.00 & 0.00 & 33.00 & 0.00 & 0.00 \\
\hline 111 & 0.00 & 0.00 & 0.00 & 0.00 & 179.02 & 0.00 & 0.00 & 0.00 \\
\hline 115 & 0.00 & 0.00 & 0.00 & 0.00 & 0.00 & 33.00 & 0.00 & 0.00 \\
\hline 121 & 0.00 & 0.00 & 0.00 & 0.00 & 203.23 & 0.00 & 0.00 & 0.00 \\
\hline 125 & 0.00 & 0.00 & 0.00 & 0.00 & 0.00 & 42.00 & 0.00 & 0.00 \\
\hline 131 & 0.00 & 0.00 & 0.00 & 0.00 & 196.86 & 0.00 & 0.00 & 0.00 \\
\hline 132 & 0.00 & 0.00 & 21.72 & 0.00 & 0.00 & 0.00 & 0.00 & 0.00 \\
\hline 135 & 0.00 & 0.00 & 0.00 & 0.00 & 0.00 & 42.00 & 0.00 & 0.00 \\
\hline 141 & 0.00 & 0.00 & 0.00 & 0.00 & 176.10 & 0.00 & 0.00 & 0.00 \\
\hline 142 & 0.00 & 0.00 & 37.68 & 0.00 & 0.00 & 0.00 & 0.00 & 0.00 \\
\hline 145 & 0.00 & 0.00 & 0.00 & 0.00 & 0.00 & 42.00 & 0.00 & 0.00 \\
\hline 151 & 0.00 & 0.00 & 0.00 & 0.00 & 200.76 & 0.00 & 0.00 & 0.00 \\
\hline 152 & 0.00 & 0.00 & 39.47 & 0.00 & 0.00 & 0.00 & 0.00 & 0.00 \\
\hline 155 & 0.00 & 0.00 & 0.00 & 0.00 & 0.00 & 42.00 & 0.00 & 0.00 \\
\hline 161 & 0.00 & 0.00 & 0.00 & 0.00 & 214.53 & 0.00 & 0.00 & 0.00 \\
\hline 165 & 0.00 & 0.00 & 0.00 & 0.00 & 0.00 & 42.00 & 0.00 & 0.00 \\
\hline 171 & 0.00 & 0.00 & 0.00 & 0.00 & 210.63 & 0.00 & 0.00 & 0.00 \\
\hline 175 & 0.00 & 0.00 & 0.00 & 0.00 & 0.00 & 42.00 & 0.00 & 0.00 \\
\hline 181 & 0.00 & 0.00 & 0.00 & 0.00 & 232.03 & 0.00 & 0.00 & 0.00 \\
\hline 185 & 0.00 & 0.00 & 0.00 & 0.00 & 0.00 & 50.00 & 0.00 & 0.00 \\
\hline 191 & 0.00 & 0.00 & 0.00 & 0.00 & 263.67 & 0.00 & 0.00 & 0.00 \\
\hline 195 & 0.00 & 0.00 & 0.00 & 0.00 & 0.00 & 50.00 & 0.00 & 0.00 \\
\hline 201 & 0.00 & 0.00 & 0.00 & 0.00 & 255.33 & 0.00 & 0.00 & 0.00 \\
\hline 205 & 0.00 & 0.00 & 0.00 & 0.00 & 0.00 & 50.00 & 0.00 & 0.00 \\
\hline 211 & 0.00 & 0.00 & 0.00 & 0.00 & 240.88 & 0.00 & 0.00 & 0.00 \\
\hline 215 & 0.00 & 0.00 & 0.00 & 0.00 & 0.00 & 50.00 & 0.00 & 0.00 \\
\hline 221 & 0.00 & 0.00 & 0.00 & 0.00 & 245.56 & 0.00 & 0.00 & 0.00 \\
\hline 225 & 0.00 & 0.00 & 0.00 & 0.00 & 0.00 & 33.18 & 0.00 & 0.00 \\
\hline 231 & 0.00 & 0.00 & 0.00 & 0.00 & 168.72 & 0.00 & 0.00 & 0.00 \\
\hline 232 & 0.00 & 0.00 & 22.81 & 0.00 & 0.00 & 0.00 & 0.00 & 0.00 \\
\hline 235 & 0.00 & 0.00 & 0.00 & 0.00 & 0.00 & 5.92 & 0.00 & 0.00 \\
\hline 241 & 0.00 & 0.00 & 0.00 & 0.00 & 4.61 & 0.00 & 0.00 & 0.00 \\
\hline 245 & 0.00 & 0.00 & 0.00 & 0.00 & 0.00 & 9.04 & 0.00 & 0.00 \\
\hline 251 & 0.00 & 0.00 & 0.00 & 0.00 & 11.30 & 0.00 & 0.00 & 0.00 \\
\hline 255 & 0.00 & 0.00 & 0.00 & 0.00 & 0.00 & 13.08 & 0.00 & 0.00 \\
\hline 261 & 0.00 & 0.00 & 0.00 & 0.00 & 40.41 & 0.00 & 0.00 & 0.00 \\
\hline 265 & 0.00 & 0.00 & 0.00 & 0.00 & 0.00 & 38.00 & 0.00 & 0.00 \\
\hline 271 & 0.00 & 0.00 & 0.00 & 0.00 & 90.31 & 0.00 & 0.00 & 0.00 \\
\hline 275 & 0.00 & 0.00 & 0.00 & 0.00 & 0.00 & 38.00 & 0.00 & 0.00 \\
\hline 281 & 0.00 & 0.00 & 0.00 & 0.00 & 87.50 & 0.00 & 0.00 & 0.00 \\
\hline 285 & 0.00 & 0.00 & 0.00 & 0.00 & 0.00 & 38.00 & 0.00 & 0.00 \\
\hline 291 & 0.00 & 0.00 & 0.00 & 0.00 & 88.75 & 0.00 & 0.00 & 0.00 \\
\hline 295 & 0.00 & 0.00 & 0.00 & 0.00 & 0.00 & 38.00 & 0.00 & 0.00 \\
\hline SEN & PORTO_1 & PORTO_2 & PORTO_3 & PORTO_4 & PORTO_5 & PORTO_6 & PORTO_7 & PORTO_8 \\
\hline 001 & 0.00 & 0.00 & 28.75 & 0.00 & 0.00 & 0.00 & 0.00 & 0.00 \\
\hline 003 & 0.00 & 0.00 & 0.00 & 0.00 & 136.50 & 0.00 & 0.00 & 0.00 \\
\hline 011 & 0.00 & 0.00 & 38.66 & 0.00 & 0.00 & 0.00 & 0.00 & 0.00 \\
\hline 013 & 0.00 & 0.00 & 0.00 & 0.00 & 126.25 & 0.00 & 0.00 & 0.00 \\
\hline 021 & 0.00 & 0.00 & 85.00 & 0.00 & 0.00 & 0.00 & 0.00 & 0.00 \\
\hline 023 & 0.00 & 0.00 & 0.00 & 0.00 & 21.20 & 0.00 & 0.00 & 0.00 \\
\hline 043 & 0.00 & 0.00 & 0.00 & 0.00 & 32.15 & 0.00 & 0.00 & 0.00 \\
\hline 051 & 0.00 & 0.00 & 85.00 & 0.00 & 0.00 & 0.00 & 0.00 & 0.00 \\
\hline 053 & 0.00 & 0.00 & 0.00 & 0.00 & 61.45 & 0.00 & 0.00 & 0.00 \\
\hline 061 & 0.00 & 0.00 & 105.08 & 0.00 & 0.00 & 0.00 & 0.00 & 0.00 \\
\hline 063 & 0.00 & 0.00 & 0.00 & 0.00 & 65.61 & 0.00 & 0.00 & 0.00 \\
\hline 071 & 0.00 & 0.00 & 65.62 & 0.00 & 0.00 & 0.00 & 0.00 & 0.00 \\
\hline 073 & 0.00 & 0.00 & 0.00 & 0.00 & 79.15 & 0.00 & 0.00 & 0.00 \\
\hline 081 & 0.00 & 0.00 & 62.48 & 0.00 & 0.00 & 0.00 & 0.00 & 0.00 \\
\hline 083 & 0.00 & 0.00 & 0.00 & 0.00 & 80.70 & 0.00 & 0.00 & 0.00 \\
\hline 091 & 0.00 & 0.00 & 64.56 & 0.00 & 0.00 & 0.00 & 0.00 & 0.00 \\
\hline 093 & 0.00 & 0.00 & 0.00 & 0.00 & 106.21 & 0.00 & 0.00 & 0.00 \\
\hline 101 & 0.00 & 0.00 & 60.08 & 0.00 & 0.00 & 0.00 & 0.00 & 0.00 \\
\hline 103 & 0.00 & 0.00 & 0.00 & 0.00 & 75.14 & 0.00 & 0.00 & 0.00 \\
\hline 111 & 0.00 & 0.00 & 114.00 & 0.00 & 0.00 & 0.00 & 0.00 & 0.00 \\
\hline 113 & 0.00 & 0.00 & 0.00 & 0.00 & 54.98 & 0.00 & 0.00 & 0.00 \\
\hline 121 & 0.00 & 0.00 & 141.00 & 0.00 & 0.00 & 0.00 & 0.00 & 0.00 \\
\hline 123 & 0.00 & 0.00 & 0.00 & 0.00 & 87.77 & 0.00 & 0.00 & 0.00 \\
\hline 131 & 0.00 & 0.00 & 119.28 & 0.00 & 0.00 & 0.00 & 0.00 & 0.00 \\
\hline 133 & 0.00 & 0.00 & 0.00 & 0.00 & 94.14 & 0.00 & 0.00 & 0.00 \\
\hline 141 & 0.00 & 0.00 & 103.32 & 0.00 & 0.00 & 0.00 & 0.00 & 0.00 \\
\hline
\end{tabular}




\begin{tabular}{|c|c|c|c|c|c|c|c|c|}
\hline 143 & 0.00 & 0.00 & 0.00 & 0.00 & 114.90 & 0.00 & 0.00 & 0.00 \\
\hline 151 & 0.00 & 0.00 & 101.53 & 0.00 & 0.00 & 0.00 & 0.00 & 0.00 \\
\hline 153 & 0.00 & 0.00 & 0.00 & 0.00 & 90.24 & 0.00 & 0.00 & 0.00 \\
\hline 161 & 0.00 & 0.00 & 141.00 & 0.00 & 0.00 & 0.00 & 0.00 & 0.00 \\
\hline 163 & 0.00 & 0.00 & 0.00 & 0.00 & 76.47 & 0.00 & 0.00 & 0.00 \\
\hline 171 & 0.00 & 0.00 & 141.00 & 0.00 & 0.00 & 0.00 & 0.00 & 0.00 \\
\hline 173 & 0.00 & 0.00 & 0.00 & 0.00 & 80.37 & 0.00 & 0.00 & 0.00 \\
\hline 181 & 0.00 & 0.00 & 170.00 & 0.00 & 0.00 & 0.00 & 0.00 & 0.00 \\
\hline 183 & 0.00 & 0.00 & 0.00 & 0.00 & 117.97 & 0.00 & 0.00 & 0.00 \\
\hline 191 & 0.00 & 0.00 & 170.00 & 0.00 & 0.00 & 0.00 & 0.00 & 0.00 \\
\hline 193 & 0.00 & 0.00 & 0.00 & 0.00 & 86.33 & 0.00 & 0.00 & 0.00 \\
\hline 201 & 0.00 & 0.00 & 170.00 & 0.00 & 0.00 & 0.00 & 0.00 & 0.00 \\
\hline 203 & 0.00 & 0.00 & 0.00 & 0.00 & 94.67 & 0.00 & 0.00 & 0.00 \\
\hline 211 & 0.00 & 0.00 & 170.00 & 0.00 & 0.00 & 0.00 & 0.00 & 0.00 \\
\hline 213 & 0.00 & 0.00 & 0.00 & 0.00 & 105.11 & 0.00 & 0.00 & 0.00 \\
\hline 221 & 0.00 & 0.00 & 170.00 & 0.00 & 0.00 & 0.00 & 0.00 & 0.00 \\
\hline 223 & 0.00 & 0.00 & 0.00 & 0.00 & 73.18 & 0.00 & 0.00 & 0.00 \\
\hline 231 & 0.00 & 0.00 & 81.35 & 0.00 & 0.00 & 0.00 & 0.00 & 0.00 \\
\hline 241 & 0.00 & 0.00 & 0.95 & 0.00 & 0.00 & 0.00 & 0.00 & 0.00 \\
\hline NAVIO_SUL & PORTO_1 & PORTO_2 & PORTO_3 & PORTO_4 & PORTO_5 & PORTO_6 & PORTO_7 & PORTO_8 \\
\hline 000 & 0.00 & 0.00 & 0.00 & 0.00 & 0.00 & 0.00 & 0.00 & 0.00 \\
\hline 001 & 365.00 & 0.00 & 0.00 & 0.00 & 173.50 & 0.00 & 395.00 & 0.00 \\
\hline 002 & 0.00 & 0.00 & 346.25 & 0.00 & 0.00 & 0.00 & 0.00 & 0.00 \\
\hline 003 & 0.00 & 0.00 & 0.00 & 0.00 & 0.00 & 0.00 & 0.00 & 0.00 \\
\hline 004 & 0.00 & 0.00 & 0.00 & 0.00 & 0.00 & 0.00 & 0.00 & 0.00 \\
\hline 005 & 0.00 & 0.00 & 0.00 & 0.00 & 0.00 & 458.50 & 0.00 & 0.00 \\
\hline 006 & 0.00 & 670.00 & 0.00 & 636.25 & 0.00 & 0.00 & 0.00 & 0.00 \\
\hline 007 & 0.00 & 0.00 & 0.00 & 0.00 & 0.00 & 0.00 & 0.00 & 0.00 \\
\hline 008 & 0.00 & 0.00 & 0.00 & 0.00 & 0.00 & 0.00 & 0.00 & 0.00 \\
\hline 009 & 0.00 & 0.00 & 0.00 & 0.00 & 0.00 & 0.00 & 0.00 & 0.00 \\
\hline 010 & 0.00 & 0.00 & 0.00 & 0.00 & 0.00 & 0.00 & 0.00 & 0.00 \\
\hline 011 & 410.00 & 0.00 & 0.00 & 0.00 & 685.00 & 0.00 & 768.50 & 0.00 \\
\hline 012 & 0.00 & 0.00 & 871.34 & 0.00 & 0.00 & 0.00 & 0.00 & 0.00 \\
\hline 013 & 0.00 & 0.00 & 0.00 & 0.00 & 0.00 & 0.00 & 0.00 & 0.00 \\
\hline 014 & 0.00 & 0.00 & 0.00 & 0.00 & 0.00 & 0.00 & 0.00 & 0.00 \\
\hline 015 & 0.00 & 0.00 & 0.00 & 0.00 & 0.00 & 865.00 & 0.00 & 0.00 \\
\hline 016 & 0.00 & 670.00 & 0.00 & 1081.34 & 0.00 & 0.00 & 0.00 & 0.00 \\
\hline 017 & 0.00 & 0.00 & 0.00 & 0.00 & 0.00 & 0.00 & 0.00 & 0.00 \\
\hline 018 & 0.00 & 0.00 & 0.00 & 0.00 & 0.00 & 0.00 & 0.00 & 0.00 \\
\hline 019 & 0.00 & 0.00 & 0.00 & 0.00 & 0.00 & 0.00 & 0.00 & 0.00 \\
\hline 020 & 0.00 & 0.00 & 0.00 & 0.00 & 0.00 & 0.00 & 0.00 & 0.00 \\
\hline 021 & 510.00 & 0.00 & 0.00 & 0.00 & 1065.14 & 0.00 & 1085.00 & 0.00 \\
\hline 022 & 0.00 & 0.00 & 825.00 & 0.00 & 0.00 & 0.00 & 0.00 & 0.00 \\
\hline 023 & 0.00 & 0.00 & 0.00 & 0.00 & 0.00 & 0.00 & 0.00 & 0.00 \\
\hline 024 & 0.00 & 0.00 & 0.00 & 0.00 & 0.00 & 0.00 & 0.00 & 0.00 \\
\hline 025 & 0.00 & 0.00 & 0.00 & 0.00 & 0.00 & 1155.14 & 0.00 & 0.00 \\
\hline 026 & 0.00 & 715.00 & 0.00 & 1035.00 & 0.00 & 0.00 & 0.00 & 0.00 \\
\hline 027 & 0.00 & 0.00 & 0.00 & 0.00 & 0.00 & 0.00 & 0.00 & 0.00 \\
\hline 028 & 0.00 & 0.00 & 0.00 & 0.00 & 0.00 & 0.00 & 0.00 & 0.00 \\
\hline 029 & 0.00 & 0.00 & 0.00 & 0.00 & 0.00 & 0.00 & 0.00 & 0.00 \\
\hline 030 & 0.00 & 0.00 & 0.00 & 0.00 & 0.00 & 0.00 & 0.00 & 0.00 \\
\hline 031 & 510.00 & 0.00 & 0.00 & 0.00 & 1040.00 & 0.00 & 1295.14 & 0.00 \\
\hline 032 & 0.00 & 0.00 & 910.00 & 0.00 & 0.00 & 0.00 & 0.00 & 0.00 \\
\hline 033 & 0.00 & 0.00 & 0.00 & 0.00 & 0.00 & 0.00 & 0.00 & 0.00 \\
\hline 034 & 0.00 & 0.00 & 0.00 & 0.00 & 0.00 & 0.00 & 0.00 & 0.00 \\
\hline 035 & 0.00 & 0.00 & 0.00 & 0.00 & 0.00 & 1130.00 & 0.00 & 0.00 \\
\hline 036 & 0.00 & 715.00 & 0.00 & 1120.00 & 0.00 & 0.00 & 0.00 & 0.00 \\
\hline 037 & 0.00 & 0.00 & 0.00 & 0.00 & 0.00 & 0.00 & 0.00 & 0.00 \\
\hline 038 & 0.00 & 0.00 & 0.00 & 0.00 & 0.00 & 0.00 & 0.00 & 0.00 \\
\hline 039 & 0.00 & 0.00 & 0.00 & 0.00 & 0.00 & 0.00 & 0.00 & 0.00 \\
\hline 040 & 0.00 & 0.00 & 0.00 & 0.00 & 0.00 & 0.00 & 0.00 & 0.00 \\
\hline 041 & 825.00 & 0.00 & 0.00 & 0.00 & 1092.85 & 0.00 & 1270.00 & 0.00 \\
\hline 042 & 0.00 & 0.00 & 910.00 & 0.00 & 0.00 & 0.00 & 0.00 & 0.00 \\
\hline 043 & 0.00 & 0.00 & 0.00 & 0.00 & 0.00 & 0.00 & 0.00 & 0.00 \\
\hline 044 & 0.00 & 0.00 & 0.00 & 0.00 & 0.00 & 0.00 & 0.00 & 0.00 \\
\hline 045 & 0.00 & 0.00 & 0.00 & 0.00 & 0.00 & 1182.85 & 0.00 & 0.00 \\
\hline 046 & 0.00 & 955.00 & 0.00 & 1120.00 & 0.00 & 0.00 & 0.00 & 0.00 \\
\hline 047 & 0.00 & 0.00 & 0.00 & 0.00 & 0.00 & 0.00 & 0.00 & 0.00 \\
\hline 048 & 0.00 & 0.00 & 0.00 & 0.00 & 0.00 & 0.00 & 0.00 & 0.00 \\
\hline 049 & 0.00 & 0.00 & 0.00 & 0.00 & 0.00 & 0.00 & 0.00 & 0.00 \\
\hline 050 & 0.00 & 0.00 & 0.00 & 0.00 & 0.00 & 0.00 & 0.00 & 0.00 \\
\hline 051 & 905.00 & 0.00 & 0.00 & 0.00 & 1063.55 & 0.00 & 1322.85 & 0.00 \\
\hline 052 & 0.00 & 0.00 & 825.00 & 0.00 & 0.00 & 0.00 & 0.00 & 0.00 \\
\hline 053 & 0.00 & 0.00 & 0.00 & 0.00 & 0.00 & 0.00 & 0.00 & 0.00 \\
\hline 054 & 0.00 & 0.00 & 0.00 & 0.00 & 0.00 & 0.00 & 0.00 & 0.00 \\
\hline 055 & 0.00 & 0.00 & 0.00 & 0.00 & 0.00 & 1153.55 & 0.00 & 0.00 \\
\hline 056 & 0.00 & 995.00 & 0.00 & 1170.00 & 0.00 & 0.00 & 0.00 & 0.00 \\
\hline 057 & 0.00 & 0.00 & 0.00 & 0.00 & 0.00 & 0.00 & 0.00 & 0.00 \\
\hline 058 & 0.00 & 0.00 & 0.00 & 0.00 & 0.00 & 0.00 & 0.00 & 0.00 \\
\hline 059 & 0.00 & 0.00 & 0.00 & 0.00 & 0.00 & 0.00 & 0.00 & 0.00 \\
\hline 060 & 0.00 & 0.00 & 0.00 & 0.00 & 0.00 & 0.00 & 0.00 & 0.00 \\
\hline 061 & 1066.00 & 0.00 & 0.00 & 0.00 & 1078.39 & 0.00 & 1424.55 & 0.00 \\
\hline 062 & 0.00 & 0.00 & 929.92 & 0.00 & 0.00 & 0.00 & 0.00 & 0.00 \\
\hline 063 & 0.00 & 0.00 & 0.00 & 0.00 & 0.00 & 0.00 & 0.00 & 0.00 \\
\hline
\end{tabular}




\begin{tabular}{|c|c|c|c|c|c|c|c|c|}
\hline 064 & 0.00 & 0.00 & 0.00 & 0.00 & 0.00 & 0.00 & 0.00 & 0.00 \\
\hline 065 & 0.00 & 0.00 & 0.00 & 0.00 & 0.00 & 1308.39 & 0.00 & 0.00 \\
\hline 066 & 0.00 & 1217.00 & 0.00 & 1371.92 & 0.00 & 0.00 & 0.00 & 0.00 \\
\hline 067 & 0.00 & 0.00 & 0.00 & 0.00 & 0.00 & 0.00 & 0.00 & 0.00 \\
\hline 068 & 0.00 & 0.00 & 0.00 & 0.00 & 0.00 & 0.00 & 0.00 & 0.00 \\
\hline 069 & 0.00 & 0.00 & 0.00 & 0.00 & 0.00 & 0.00 & 0.00 & 0.00 \\
\hline 070 & 0.00 & 0.00 & 0.00 & 0.00 & 0.00 & 0.00 & 0.00 & 0.00 \\
\hline 071 & 1081.00 & 0.00 & 0.00 & 0.00 & 1221.77 & 0.00 & 1505.39 & 0.00 \\
\hline 072 & 0.00 & 0.00 & 1146.38 & 0.00 & 0.00 & 0.00 & 0.00 & 0.00 \\
\hline 073 & 0.00 & 0.00 & 0.00 & 0.00 & 0.00 & 0.00 & 0.00 & 0.00 \\
\hline 074 & 0.00 & 0.00 & 0.00 & 0.00 & 0.00 & 0.00 & 0.00 & 0.00 \\
\hline 075 & 0.00 & 0.00 & 0.00 & 0.00 & 0.00 & 1416.77 & 0.00 & 0.00 \\
\hline 076 & 0.00 & 1217.00 & 0.00 & 1562.38 & 0.00 & 0.00 & 0.00 & 0.00 \\
\hline 077 & 0.00 & 0.00 & 0.00 & 0.00 & 0.00 & 0.00 & 0.00 & 0.00 \\
\hline 078 & 0.00 & 0.00 & 0.00 & 0.00 & 0.00 & 0.00 & 0.00 & 0.00 \\
\hline 079 & 0.00 & 0.00 & 0.00 & 0.00 & 0.00 & 0.00 & 0.00 & 0.00 \\
\hline 080 & 0.00 & 0.00 & 0.00 & 0.00 & 0.00 & 0.00 & 0.00 & 0.00 \\
\hline 081 & 1114.00 & 0.00 & 0.00 & 0.00 & 1353.68 & 0.00 & 1583.77 & 0.00 \\
\hline 082 & 0.00 & 0.00 & 1149.52 & 0.00 & 0.00 & 0.00 & 0.00 & 0.00 \\
\hline 083 & 0.00 & 0.00 & 0.00 & 0.00 & 0.00 & 0.00 & 0.00 & 0.00 \\
\hline 084 & 0.00 & 0.00 & 0.00 & 0.00 & 0.00 & 0.00 & 0.00 & 0.00 \\
\hline 085 & 0.00 & 0.00 & 0.00 & 0.00 & 0.00 & 1518.68 & 0.00 & 0.00 \\
\hline 086 & 0.00 & 1232.00 & 0.00 & 1565.52 & 0.00 & 0.00 & 0.00 & 0.00 \\
\hline 087 & 0.00 & 0.00 & 0.00 & 0.00 & 0.00 & 0.00 & 0.00 & 0.00 \\
\hline 088 & 0.00 & 0.00 & 0.00 & 0.00 & 0.00 & 0.00 & 0.00 & 0.00 \\
\hline 089 & 0.00 & 0.00 & 0.00 & 0.00 & 0.00 & 0.00 & 0.00 & 0.00 \\
\hline 090 & 0.00 & 0.00 & 0.00 & 0.00 & 0.00 & 0.00 & 0.00 & 0.00 \\
\hline 091 & 1114.00 & 0.00 & 0.00 & 0.00 & 1331.31 & 0.00 & 1659.68 & 0.00 \\
\hline 092 & 0.00 & 0.00 & 1147.44 & 0.00 & 0.00 & 0.00 & 0.00 & 0.00 \\
\hline 093 & 0.00 & 0.00 & 0.00 & 0.00 & 0.00 & 0.00 & 0.00 & 0.00 \\
\hline 094 & 0.00 & 0.00 & 0.00 & 0.00 & 0.00 & 0.00 & 0.00 & 0.00 \\
\hline 095 & 0.00 & 0.00 & 0.00 & 0.00 & 0.00 & 1496.31 & 0.00 & 0.00 \\
\hline 096 & 0.00 & 1232.00 & 0.00 & 1563.44 & 0.00 & 0.00 & 0.00 & 0.00 \\
\hline 097 & 0.00 & 0.00 & 0.00 & 0.00 & 0.00 & 0.00 & 0.00 & 0.00 \\
\hline 098 & 0.00 & 0.00 & 0.00 & 0.00 & 0.00 & 0.00 & 0.00 & 0.00 \\
\hline 099 & 0.00 & 0.00 & 0.00 & 0.00 & 0.00 & 0.00 & 0.00 & 0.00 \\
\hline 100 & 0.00 & 0.00 & 0.00 & 0.00 & 0.00 & 0.00 & 0.00 & 0.00 \\
\hline 101 & 1219.00 & 0.00 & 0.00 & 0.00 & 1360.30 & 0.00 & 1637.31 & 0.00 \\
\hline 102 & 0.00 & 0.00 & 1151.92 & 0.00 & 0.00 & 0.00 & 0.00 & 0.00 \\
\hline 103 & 0.00 & 0.00 & 0.00 & 0.00 & 0.00 & 0.00 & 0.00 & 0.00 \\
\hline 104 & 0.00 & 0.00 & 0.00 & 0.00 & 0.00 & 0.00 & 0.00 & 0.00 \\
\hline 105 & 0.00 & 0.00 & 0.00 & 0.00 & 0.00 & 1525.30 & 0.00 & 0.00 \\
\hline 106 & 0.00 & 1312.00 & 0.00 & 1567.92 & 0.00 & 0.00 & 0.00 & 0.00 \\
\hline 107 & 0.00 & 0.00 & 0.00 & 0.00 & 0.00 & 0.00 & 0.00 & 0.00 \\
\hline 108 & 0.00 & 0.00 & 0.00 & 0.00 & 0.00 & 0.00 & 0.00 & 0.00 \\
\hline 109 & 0.00 & 0.00 & 0.00 & 0.00 & 0.00 & 0.00 & 0.00 & 0.00 \\
\hline 110 & 0.00 & 0.00 & 0.00 & 0.00 & 0.00 & 0.00 & 0.00 & 0.00 \\
\hline 111 & 1245.00 & 0.00 & 0.00 & 0.00 & 1384.94 & 0.00 & 1666.30 & 0.00 \\
\hline 112 & 0.00 & 0.00 & 1098.00 & 0.00 & 0.00 & 0.00 & 0.00 & 0.00 \\
\hline 113 & 0.00 & 0.00 & 0.00 & 0.00 & 0.00 & 0.00 & 0.00 & 0.00 \\
\hline 114 & 0.00 & 0.00 & 0.00 & 0.00 & 0.00 & 0.00 & 0.00 & 0.00 \\
\hline 115 & 0.00 & 0.00 & 0.00 & 0.00 & 0.00 & 1549.94 & 0.00 & 0.00 \\
\hline 116 & 0.00 & 1325.00 & 0.00 & 1559.00 & 0.00 & 0.00 & 0.00 & 0.00 \\
\hline 117 & 0.00 & 0.00 & 0.00 & 0.00 & 0.00 & 0.00 & 0.00 & 0.00 \\
\hline 118 & 0.00 & 0.00 & 0.00 & 0.00 & 0.00 & 0.00 & 0.00 & 0.00 \\
\hline 119 & 0.00 & 0.00 & 0.00 & 0.00 & 0.00 & 0.00 & 0.00 & 0.00 \\
\hline 120 & 0.00 & 0.00 & 0.00 & 0.00 & 0.00 & 0.00 & 0.00 & 0.00 \\
\hline 121 & 1381.00 & 0.00 & 0.00 & 0.00 & 1400.23 & 0.00 & 1823.94 & 0.00 \\
\hline 122 & 0.00 & 0.00 & 1196.00 & 0.00 & 0.00 & 0.00 & 0.00 & 0.00 \\
\hline 123 & 0.00 & 0.00 & 0.00 & 0.00 & 0.00 & 0.00 & 0.00 & 0.00 \\
\hline 124 & 0.00 & 0.00 & 0.00 & 0.00 & 0.00 & 0.00 & 0.00 & 0.00 \\
\hline 125 & 0.00 & 0.00 & 0.00 & 0.00 & 0.00 & 1675.23 & 0.00 & 0.00 \\
\hline 126 & 0.00 & 1551.00 & 0.00 & 1753.00 & 0.00 & 0.00 & 0.00 & 0.00 \\
\hline 127 & 0.00 & 0.00 & 0.00 & 0.00 & 0.00 & 0.00 & 0.00 & 0.00 \\
\hline 128 & 0.00 & 0.00 & 0.00 & 0.00 & 0.00 & 0.00 & 0.00 & 0.00 \\
\hline 129 & 0.00 & 0.00 & 0.00 & 0.00 & 0.00 & 0.00 & 0.00 & 0.00 \\
\hline 130 & 0.00 & 0.00 & 0.00 & 0.00 & 0.00 & 0.00 & 0.00 & 0.00 \\
\hline 131 & 1396.00 & 0.00 & 0.00 & 0.00 & 1542.86 & 0.00 & 1907.23 & 0.00 \\
\hline 132 & 0.00 & 0.00 & 1398.72 & 0.00 & 0.00 & 0.00 & 0.00 & 0.00 \\
\hline 133 & 0.00 & 0.00 & 0.00 & 0.00 & 0.00 & 0.00 & 0.00 & 0.00 \\
\hline 134 & 0.00 & 0.00 & 0.00 & 0.00 & 0.00 & 0.00 & 0.00 & 0.00 \\
\hline 135 & 0.00 & 0.00 & 0.00 & 0.00 & 0.00 & 1782.86 & 0.00 & 0.00 \\
\hline 136 & 0.00 & 1551.00 & 0.00 & 1927.72 & 0.00 & 0.00 & 0.00 & 0.00 \\
\hline 137 & 0.00 & 0.00 & 0.00 & 0.00 & 0.00 & 0.00 & 0.00 & 0.00 \\
\hline 138 & 0.00 & 0.00 & 0.00 & 0.00 & 0.00 & 0.00 & 0.00 & 0.00 \\
\hline 139 & 0.00 & 0.00 & 0.00 & 0.00 & 0.00 & 0.00 & 0.00 & 0.00 \\
\hline 140 & 0.00 & 0.00 & 0.00 & 0.00 & 0.00 & 0.00 & 0.00 & 0.00 \\
\hline 141 & 1430.00 & 0.00 & 0.00 & 0.00 & 1640.82 & 0.00 & 1984.86 & 0.00 \\
\hline 142 & 0.00 & 0.00 & 1414.68 & 0.00 & 0.00 & 0.00 & 0.00 & 0.00 \\
\hline 143 & 0.00 & 0.00 & 0.00 & 0.00 & 0.00 & 0.00 & 0.00 & 0.00 \\
\hline 144 & 0.00 & 0.00 & 0.00 & 0.00 & 0.00 & 0.00 & 0.00 & 0.00 \\
\hline 145 & 0.00 & 0.00 & 0.00 & 0.00 & 0.00 & 1850.82 & 0.00 & 0.00 \\
\hline 146 & 0.00 & 1566.00 & 0.00 & 1943.68 & 0.00 & 0.00 & 0.00 & 0.00 \\
\hline 147 & 0.00 & 0.00 & 0.00 & 0.00 & 0.00 & 0.00 & 0.00 & 0.00 \\
\hline 148 & 0.00 & 0.00 & 0.00 & 0.00 & 0.00 & 0.00 & 0.00 & 0.00 \\
\hline 149 & 0.00 & 0.00 & 0.00 & 0.00 & 0.00 & 0.00 & 0.00 & 0.00 \\
\hline
\end{tabular}




\begin{tabular}{|c|c|c|c|c|c|c|c|c|}
\hline 150 & 0.00 & 0.00 & 0.00 & 0.00 & 0.00 & 0.00 & 0.00 & 0.00 \\
\hline 151 & 1430.00 & 0.00 & 0.00 & 0.00 & 1681.44 & 0.00 & 2024.82 & 0.00 \\
\hline 152 & 0.00 & 0.00 & 1416.47 & 0.00 & 0.00 & 0.00 & 0.00 & 0.00 \\
\hline 153 & 0.00 & 0.00 & 0.00 & 0.00 & 0.00 & 0.00 & 0.00 & 0.00 \\
\hline 154 & 0.00 & 0.00 & 0.00 & 0.00 & 0.00 & 0.00 & 0.00 & 0.00 \\
\hline 155 & 0.00 & 0.00 & 0.00 & 0.00 & 0.00 & 1891.44 & 0.00 & 0.00 \\
\hline 156 & 0.00 & 1566.00 & 0.00 & 1945.47 & 0.00 & 0.00 & 0.00 & 0.00 \\
\hline 157 & 0.00 & 0.00 & 0.00 & 0.00 & 0.00 & 0.00 & 0.00 & 0.00 \\
\hline 158 & 0.00 & 0.00 & 0.00 & 0.00 & 0.00 & 0.00 & 0.00 & 0.00 \\
\hline 159 & 0.00 & 0.00 & 0.00 & 0.00 & 0.00 & 0.00 & 0.00 & 0.00 \\
\hline 160 & 0.00 & 0.00 & 0.00 & 0.00 & 0.00 & 0.00 & 0.00 & 0.00 \\
\hline 161 & 1535.00 & 0.00 & 0.00 & 0.00 & 1697.00 & 0.00 & 2065.44 & 0.00 \\
\hline 162 & 0.00 & 0.00 & 1377.00 & 0.00 & 0.00 & 0.00 & 0.00 & 0.00 \\
\hline 163 & 0.00 & 0.00 & 0.00 & 0.00 & 0.00 & 0.00 & 0.00 & 0.00 \\
\hline 164 & 0.00 & 0.00 & 0.00 & 0.00 & 0.00 & 0.00 & 0.00 & 0.00 \\
\hline 165 & 0.00 & 0.00 & 0.00 & 0.00 & 0.00 & 1907.00 & 0.00 & 0.00 \\
\hline 166 & 0.00 & 1646.00 & 0.00 & 1906.00 & 0.00 & 0.00 & 0.00 & 0.00 \\
\hline 167 & 0.00 & 0.00 & 0.00 & 0.00 & 0.00 & 0.00 & 0.00 & 0.00 \\
\hline 168 & 0.00 & 0.00 & 0.00 & 0.00 & 0.00 & 0.00 & 0.00 & 0.00 \\
\hline 169 & 0.00 & 0.00 & 0.00 & 0.00 & 0.00 & 0.00 & 0.00 & 0.00 \\
\hline 170 & 0.00 & 0.00 & 0.00 & 0.00 & 0.00 & 0.00 & 0.00 & 0.00 \\
\hline 171 & 1563.00 & 0.00 & 0.00 & 0.00 & 1653.63 & 0.00 & 2081.00 & 0.00 \\
\hline 172 & 0.00 & 0.00 & 1377.00 & 0.00 & 0.00 & 0.00 & 0.00 & 0.00 \\
\hline 173 & 0.00 & 0.00 & 0.00 & 0.00 & 0.00 & 0.00 & 0.00 & 0.00 \\
\hline 174 & 0.00 & 0.00 & 0.00 & 0.00 & 0.00 & 0.00 & 0.00 & 0.00 \\
\hline 175 & 0.00 & 0.00 & 0.00 & 0.00 & 0.00 & 1863.63 & 0.00 & 0.00 \\
\hline 176 & 0.00 & 1660.00 & 0.00 & 1951.00 & 0.00 & 0.00 & 0.00 & 0.00 \\
\hline 177 & 0.00 & 0.00 & 0.00 & 0.00 & 0.00 & 0.00 & 0.00 & 0.00 \\
\hline 178 & 0.00 & 0.00 & 0.00 & 0.00 & 0.00 & 0.00 & 0.00 & 0.00 \\
\hline 179 & 0.00 & 0.00 & 0.00 & 0.00 & 0.00 & 0.00 & 0.00 & 0.00 \\
\hline 180 & 0.00 & 0.00 & 0.00 & 0.00 & 0.00 & 0.00 & 0.00 & 0.00 \\
\hline 181 & 1698.00 & 0.00 & 0.00 & 0.00 & 1720.03 & 0.00 & 2168.63 & 0.00 \\
\hline 182 & 0.00 & 0.00 & 1473.00 & 0.00 & 0.00 & 0.00 & 0.00 & 0.00 \\
\hline 183 & 0.00 & 0.00 & 0.00 & 0.00 & 0.00 & 0.00 & 0.00 & 0.00 \\
\hline 184 & 0.00 & 0.00 & 0.00 & 0.00 & 0.00 & 0.00 & 0.00 & 0.00 \\
\hline 185 & 0.00 & 0.00 & 0.00 & 0.00 & 0.00 & 2040.03 & 0.00 & 0.00 \\
\hline 186 & 0.00 & 1882.00 & 0.00 & 2144.00 & 0.00 & 0.00 & 0.00 & 0.00 \\
\hline 187 & 0.00 & 0.00 & 0.00 & 0.00 & 0.00 & 0.00 & 0.00 & 0.00 \\
\hline 188 & 0.00 & 0.00 & 0.00 & 0.00 & 0.00 & 0.00 & 0.00 & 0.00 \\
\hline 189 & 0.00 & 0.00 & 0.00 & 0.00 & 0.00 & 0.00 & 0.00 & 0.00 \\
\hline 190 & 0.00 & 0.00 & 0.00 & 0.00 & 0.00 & 0.00 & 0.00 & 0.00 \\
\hline 191 & 1713.00 & 0.00 & 0.00 & 0.00 & 1899.67 & 0.00 & 2301.03 & 0.00 \\
\hline 192 & 0.00 & 0.00 & 1650.00 & 0.00 & 0.00 & 0.00 & 0.00 & 0.00 \\
\hline 193 & 0.00 & 0.00 & 0.00 & 0.00 & 0.00 & 0.00 & 0.00 & 0.00 \\
\hline 194 & 0.00 & 0.00 & 0.00 & 0.00 & 0.00 & 0.00 & 0.00 & 0.00 \\
\hline 195 & 0.00 & 0.00 & 0.00 & 0.00 & 0.00 & 2184.67 & 0.00 & 0.00 \\
\hline 196 & 0.00 & 1882.00 & 0.00 & 2295.00 & 0.00 & 0.00 & 0.00 & 0.00 \\
\hline 197 & 0.00 & 0.00 & 0.00 & 0.00 & 0.00 & 0.00 & 0.00 & 0.00 \\
\hline 198 & 0.00 & 0.00 & 0.00 & 0.00 & 0.00 & 0.00 & 0.00 & 0.00 \\
\hline 199 & 0.00 & 0.00 & 0.00 & 0.00 & 0.00 & 0.00 & 0.00 & 0.00 \\
\hline 200 & 0.00 & 0.00 & 0.00 & 0.00 & 0.00 & 0.00 & 0.00 & 0.00 \\
\hline 201 & 1746.00 & 0.00 & 0.00 & 0.00 & 1985.33 & 0.00 & 2415.67 & 0.00 \\
\hline 202 & 0.00 & 0.00 & 1650.00 & 0.00 & 0.00 & 0.00 & 0.00 & 0.00 \\
\hline 203 & 0.00 & 0.00 & 0.00 & 0.00 & 0.00 & 0.00 & 0.00 & 0.00 \\
\hline 204 & 0.00 & 0.00 & 0.00 & 0.00 & 0.00 & 0.00 & 0.00 & 0.00 \\
\hline 205 & 0.00 & 0.00 & 0.00 & 0.00 & 0.00 & 2240.33 & 0.00 & 0.00 \\
\hline 206 & 0.00 & 1897.00 & 0.00 & 2295.00 & 0.00 & 0.00 & 0.00 & 0.00 \\
\hline 207 & 0.00 & 0.00 & 0.00 & 0.00 & 0.00 & 0.00 & 0.00 & 0.00 \\
\hline 208 & 0.00 & 0.00 & 0.00 & 0.00 & 0.00 & 0.00 & 0.00 & 0.00 \\
\hline 209 & 0.00 & 0.00 & 0.00 & 0.00 & 0.00 & 0.00 & 0.00 & 0.00 \\
\hline 210 & 0.00 & 0.00 & 0.00 & 0.00 & 0.00 & 0.00 & 0.00 & 0.00 \\
\hline 211 & 1746.00 & 0.00 & 0.00 & 0.00 & 1970.88 & 0.00 & 2445.33 & 0.00 \\
\hline 212 & 0.00 & 0.00 & 1650.00 & 0.00 & 0.00 & 0.00 & 0.00 & 0.00 \\
\hline 213 & 0.00 & 0.00 & 0.00 & 0.00 & 0.00 & 0.00 & 0.00 & 0.00 \\
\hline 214 & 0.00 & 0.00 & 0.00 & 0.00 & 0.00 & 0.00 & 0.00 & 0.00 \\
\hline 215 & 0.00 & 0.00 & 0.00 & 0.00 & 0.00 & 2225.88 & 0.00 & 0.00 \\
\hline 216 & 0.00 & 1897.00 & 0.00 & 2295.00 & 0.00 & 0.00 & 0.00 & 0.00 \\
\hline 217 & 0.00 & 0.00 & 0.00 & 0.00 & 0.00 & 0.00 & 0.00 & 0.00 \\
\hline 218 & 0.00 & 0.00 & 0.00 & 0.00 & 0.00 & 0.00 & 0.00 & 0.00 \\
\hline 219 & 0.00 & 0.00 & 0.00 & 0.00 & 0.00 & 0.00 & 0.00 & 0.00 \\
\hline 220 & 0.00 & 0.00 & 0.00 & 0.00 & 0.00 & 0.00 & 0.00 & 0.00 \\
\hline 221 & 1851.00 & 0.00 & 0.00 & 0.00 & 1975.56 & 0.00 & 2430.88 & 0.00 \\
\hline 222 & 0.00 & 0.00 & 1650.00 & 0.00 & 0.00 & 0.00 & 0.00 & 0.00 \\
\hline 223 & 0.00 & 0.00 & 0.00 & 0.00 & 0.00 & 0.00 & 0.00 & 0.00 \\
\hline 224 & 0.00 & 0.00 & 0.00 & 0.00 & 0.00 & 0.00 & 0.00 & 0.00 \\
\hline 225 & 0.00 & 0.00 & 0.00 & 0.00 & 0.00 & 2213.74 & 0.00 & 0.00 \\
\hline 226 & 0.00 & 1977.00 & 0.00 & 2295.00 & 0.00 & 0.00 & 0.00 & 0.00 \\
\hline 227 & 0.00 & 0.00 & 0.00 & 0.00 & 0.00 & 0.00 & 0.00 & 0.00 \\
\hline 228 & 0.00 & 0.00 & 0.00 & 0.00 & 0.00 & 0.00 & 0.00 & 0.00 \\
\hline 229 & 0.00 & 0.00 & 0.00 & 0.00 & 0.00 & 0.00 & 0.00 & 0.00 \\
\hline 230 & 0.00 & 0.00 & 0.00 & 0.00 & 0.00 & 0.00 & 0.00 & 0.00 \\
\hline 231 & 1877.00 & 0.00 & 0.00 & 0.00 & 1898.72 & 0.00 & 2282.31 & 0.00 \\
\hline 232 & 0.00 & 0.00 & 1672.81 & 0.00 & 0.00 & 0.00 & 0.00 & 0.00 \\
\hline 233 & 0.00 & 0.00 & 0.00 & 0.00 & 0.00 & 0.00 & 0.00 & 0.00 \\
\hline 234 & 0.00 & 0.00 & 0.00 & 0.00 & 0.00 & 0.00 & 0.00 & 0.00 \\
\hline 235 & 0.00 & 0.00 & 0.00 & 0.00 & 0.00 & 2109.63 & 0.00 & 0.00 \\
\hline
\end{tabular}




\begin{tabular}{|c|c|c|c|c|c|c|c|c|}
\hline 236 & 0.00 & 1990.00 & 0.00 & 2340.00 & 0.00 & 0.00 & 0.00 & 0.00 \\
\hline 237 & 0.00 & 0.00 & 0.00 & 0.00 & 0.00 & 0.00 & 0.00 & 0.00 \\
\hline 238 & 0.00 & 0.00 & 0.00 & 0.00 & 0.00 & 0.00 & 0.00 & 0.00 \\
\hline 239 & 0.00 & 0.00 & 0.00 & 0.00 & 0.00 & 0.00 & 0.00 & 0.00 \\
\hline 240 & 0.00 & 0.00 & 0.00 & 0.00 & 0.00 & 0.00 & 0.00 & 0.00 \\
\hline 241 & 1890.00 & 0.00 & 0.00 & 0.00 & 1734.61 & 0.00 & 2163.00 & 0.00 \\
\hline 242 & 0.00 & 0.00 & 1650.00 & 0.00 & 0.00 & 0.00 & 0.00 & 0.00 \\
\hline 243 & 0.00 & 0.00 & 0.00 & 0.00 & 0.00 & 0.00 & 0.00 & 0.00 \\
\hline 244 & 0.00 & 0.00 & 0.00 & 0.00 & 0.00 & 0.00 & 0.00 & 0.00 \\
\hline 245 & 0.00 & 0.00 & 0.00 & 0.00 & 0.00 & 1963.65 & 0.00 & 0.00 \\
\hline 246 & 0.00 & 1990.00 & 0.00 & 2340.00 & 0.00 & 0.00 & 0.00 & 0.00 \\
\hline 247 & 0.00 & 0.00 & 0.00 & 0.00 & 0.00 & 0.00 & 0.00 & 0.00 \\
\hline 248 & 0.00 & 0.00 & 0.00 & 0.00 & 0.00 & 0.00 & 0.00 & 0.00 \\
\hline 249 & 0.00 & 0.00 & 0.00 & 0.00 & 0.00 & 0.00 & 0.00 & 0.00 \\
\hline 250 & 0.00 & 0.00 & 0.00 & 0.00 & 0.00 & 0.00 & 0.00 & 0.00 \\
\hline 251 & 1708.00 & 0.00 & 0.00 & 0.00 & 1674.30 & 0.00 & 1957.65 & 0.00 \\
\hline 252 & 0.00 & 0.00 & 1506.00 & 0.00 & 0.00 & 0.00 & 0.00 & 0.00 \\
\hline 253 & 0.00 & 0.00 & 0.00 & 0.00 & 0.00 & 0.00 & 0.00 & 0.00 \\
\hline 254 & 0.00 & 0.00 & 0.00 & 0.00 & 0.00 & 0.00 & 0.00 & 0.00 \\
\hline 255 & 0.00 & 0.00 & 0.00 & 0.00 & 0.00 & 1778.38 & 0.00 & 0.00 \\
\hline 256 & 0.00 & 1656.00 & 0.00 & 2053.00 & 0.00 & 0.00 & 0.00 & 0.00 \\
\hline 257 & 0.00 & 0.00 & 0.00 & 0.00 & 0.00 & 0.00 & 0.00 & 0.00 \\
\hline 258 & 0.00 & 0.00 & 0.00 & 0.00 & 0.00 & 0.00 & 0.00 & 0.00 \\
\hline 259 & 0.00 & 0.00 & 0.00 & 0.00 & 0.00 & 0.00 & 0.00 & 0.00 \\
\hline 260 & 0.00 & 0.00 & 0.00 & 0.00 & 0.00 & 0.00 & 0.00 & 0.00 \\
\hline 261 & 1686.00 & 0.00 & 0.00 & 0.00 & 1483.41 & 0.00 & 1814.38 & 0.00 \\
\hline 262 & 0.00 & 0.00 & 1239.00 & 0.00 & 0.00 & 0.00 & 0.00 & 0.00 \\
\hline 263 & 0.00 & 0.00 & 0.00 & 0.00 & 0.00 & 0.00 & 0.00 & 0.00 \\
\hline 264 & 0.00 & 0.00 & 0.00 & 0.00 & 0.00 & 0.00 & 0.00 & 0.00 \\
\hline 265 & 0.00 & 0.00 & 0.00 & 0.00 & 0.00 & 1664.41 & 0.00 & 0.00 \\
\hline 266 & 0.00 & 1656.00 & 0.00 & 1826.00 & 0.00 & 0.00 & 0.00 & 0.00 \\
\hline 267 & 0.00 & 0.00 & 0.00 & 0.00 & 0.00 & 0.00 & 0.00 & 0.00 \\
\hline 268 & 0.00 & 0.00 & 0.00 & 0.00 & 0.00 & 0.00 & 0.00 & 0.00 \\
\hline 269 & 0.00 & 0.00 & 0.00 & 0.00 & 0.00 & 0.00 & 0.00 & 0.00 \\
\hline 270 & 0.00 & 0.00 & 0.00 & 0.00 & 0.00 & 0.00 & 0.00 & 0.00 \\
\hline 271 & 1637.00 & 0.00 & 0.00 & 0.00 & 1391.31 & 0.00 & 1701.81 & 0.00 \\
\hline 272 & 0.00 & 0.00 & 1239.00 & 0.00 & 0.00 & 0.00 & 0.00 & 0.00 \\
\hline 273 & 0.00 & 0.00 & 0.00 & 0.00 & 0.00 & 0.00 & 0.00 & 0.00 \\
\hline 274 & 0.00 & 0.00 & 0.00 & 0.00 & 0.00 & 0.00 & 0.00 & 0.00 \\
\hline 275 & 0.00 & 0.00 & 0.00 & 0.00 & 0.00 & 1617.31 & 0.00 & 0.00 \\
\hline 276 & 0.00 & 1634.00 & 0.00 & 1826.00 & 0.00 & 0.00 & 0.00 & 0.00 \\
\hline 277 & 0.00 & 0.00 & 0.00 & 0.00 & 0.00 & 0.00 & 0.00 & 0.00 \\
\hline 278 & 0.00 & 0.00 & 0.00 & 0.00 & 0.00 & 0.00 & 0.00 & 0.00 \\
\hline 279 & 0.00 & 0.00 & 0.00 & 0.00 & 0.00 & 0.00 & 0.00 & 0.00 \\
\hline 280 & 0.00 & 0.00 & 0.00 & 0.00 & 0.00 & 0.00 & 0.00 & 0.00 \\
\hline 281 & 1637.00 & 0.00 & 0.00 & 0.00 & 1388.50 & 0.00 & 1651.31 & 0.00 \\
\hline 282 & 0.00 & 0.00 & 1239.00 & 0.00 & 0.00 & 0.00 & 0.00 & 0.00 \\
\hline 283 & 0.00 & 0.00 & 0.00 & 0.00 & 0.00 & 0.00 & 0.00 & 0.00 \\
\hline 284 & 0.00 & 0.00 & 0.00 & 0.00 & 0.00 & 0.00 & 0.00 & 0.00 \\
\hline 285 & 0.00 & 0.00 & 0.00 & 0.00 & 0.00 & 1614.50 & 0.00 & 0.00 \\
\hline 286 & 0.00 & 1634.00 & 0.00 & 1826.00 & 0.00 & 0.00 & 0.00 & 0.00 \\
\hline 287 & 0.00 & 0.00 & 0.00 & 0.00 & 0.00 & 0.00 & 0.00 & 0.00 \\
\hline 288 & 0.00 & 0.00 & 0.00 & 0.00 & 0.00 & 0.00 & 0.00 & 0.00 \\
\hline 289 & 0.00 & 0.00 & 0.00 & 0.00 & 0.00 & 0.00 & 0.00 & 0.00 \\
\hline 290 & 0.00 & 0.00 & 0.00 & 0.00 & 0.00 & 0.00 & 0.00 & 0.00 \\
\hline 291 & 1482.00 & 0.00 & 0.00 & 0.00 & 1389.75 & 0.00 & 1614.50 & 0.00 \\
\hline 292 & 0.00 & 0.00 & 1239.00 & 0.00 & 0.00 & 0.00 & 0.00 & 0.00 \\
\hline 293 & 0.00 & 0.00 & 0.00 & 0.00 & 0.00 & 0.00 & 0.00 & 0.00 \\
\hline 294 & 0.00 & 0.00 & 0.00 & 0.00 & 0.00 & 0.00 & 0.00 & 0.00 \\
\hline 295 & 0.00 & 0.00 & 0.00 & 0.00 & 0.00 & 1615.75 & 0.00 & 0.00 \\
\hline 296 & 0.00 & 1516.00 & 0.00 & 1826.00 & 0.00 & 0.00 & 0.00 & 0.00 \\
\hline 297 & 0.00 & 0.00 & 0.00 & 0.00 & 0.00 & 0.00 & 0.00 & 0.00 \\
\hline 298 & 0.00 & 0.00 & 0.00 & 0.00 & 0.00 & 0.00 & 0.00 & 0.00 \\
\hline 299 & 0.00 & 0.00 & 0.00 & 0.00 & 0.00 & 0.00 & 0.00 & 0.00 \\
\hline 300 & 0.00 & 0.00 & 0.00 & 0.00 & 0.00 & 0.00 & 0.00 & 0.00 \\
\hline 301 & 1442.00 & 0.00 & 0.00 & 0.00 & 1301.00 & 0.00 & 1609.00 & 0.00 \\
\hline 302 & 0.00 & 0.00 & 1239.00 & 0.00 & 0.00 & 0.00 & 0.00 & 0.00 \\
\hline 303 & 0.00 & 0.00 & 0.00 & 0.00 & 0.00 & 0.00 & 0.00 & 0.00 \\
\hline 304 & 0.00 & 0.00 & 0.00 & 0.00 & 0.00 & 0.00 & 0.00 & 0.00 \\
\hline 305 & 0.00 & 0.00 & 0.00 & 0.00 & 0.00 & 1489.00 & 0.00 & 0.00 \\
\hline 306 & 0.00 & 1496.00 & 0.00 & 1760.00 & 0.00 & 0.00 & 0.00 & 0.00 \\
\hline 307 & 0.00 & 0.00 & 0.00 & 0.00 & 0.00 & 0.00 & 0.00 & 0.00 \\
\hline 308 & 0.00 & 0.00 & 0.00 & 0.00 & 0.00 & 0.00 & 0.00 & 0.00 \\
\hline 309 & 0.00 & 0.00 & 0.00 & 0.00 & 0.00 & 0.00 & 0.00 & 0.00 \\
\hline 310 & 0.00 & 0.00 & 0.00 & 0.00 & 0.00 & 0.00 & 0.00 & 0.00 \\
\hline 311 & 1239.00 & 0.00 & 0.00 & 0.00 & 1233.00 & 0.00 & 1410.00 & 0.00 \\
\hline 312 & 0.00 & 0.00 & 1093.00 & 0.00 & 0.00 & 0.00 & 0.00 & 0.00 \\
\hline 313 & 0.00 & 0.00 & 0.00 & 0.00 & 0.00 & 0.00 & 0.00 & 0.00 \\
\hline 314 & 0.00 & 0.00 & 0.00 & 0.00 & 0.00 & 0.00 & 0.00 & 0.00 \\
\hline 315 & 0.00 & 0.00 & 0.00 & 0.00 & 0.00 & 1268.00 & 0.00 & 0.00 \\
\hline 316 & 0.00 & 1160.00 & 0.00 & 1467.00 & 0.00 & 0.00 & 0.00 & 0.00 \\
\hline 317 & 0.00 & 0.00 & 0.00 & 0.00 & 0.00 & 0.00 & 0.00 & 0.00 \\
\hline 318 & 0.00 & 0.00 & 0.00 & 0.00 & 0.00 & 0.00 & 0.00 & 0.00 \\
\hline 319 & 0.00 & 0.00 & 0.00 & 0.00 & 0.00 & 0.00 & 0.00 & 0.00 \\
\hline 320 & 0.00 & 0.00 & 0.00 & 0.00 & 0.00 & 0.00 & 0.00 & 0.00 \\
\hline 321 & 1216.00 & 0.00 & 0.00 & 0.00 & 1008.00 & 0.00 & 1254.00 & 0.00 \\
\hline
\end{tabular}




\begin{tabular}{|c|c|c|c|c|c|c|c|c|}
\hline 322 & 0.00 & 0.00 & 825.00 & 0.00 & 0.00 & 0.00 & 0.00 & 0.00 \\
\hline 323 & 0.00 & 0.00 & 0.00 & 0.00 & 0.00 & 0.00 & 0.00 & 0.00 \\
\hline 324 & 0.00 & 0.00 & 0.00 & 0.00 & 0.00 & 0.00 & 0.00 & 0.00 \\
\hline 325 & 0.00 & 0.00 & 0.00 & 0.00 & 0.00 & 1096.00 & 0.00 & 0.00 \\
\hline 326 & 0.00 & 1160.00 & 0.00 & 1239.00 & 0.00 & 0.00 & 0.00 & 0.00 \\
\hline 327 & 0.00 & 0.00 & 0.00 & 0.00 & 0.00 & 0.00 & 0.00 & 0.00 \\
\hline 328 & 0.00 & 0.00 & 0.00 & 0.00 & 0.00 & 0.00 & 0.00 & 0.00 \\
\hline 329 & 0.00 & 0.00 & 0.00 & 0.00 & 0.00 & 0.00 & 0.00 & 0.00 \\
\hline 330 & 0.00 & 0.00 & 0.00 & 0.00 & 0.00 & 0.00 & 0.00 & 0.00 \\
\hline 331 & 1165.00 & 0.00 & 0.00 & 0.00 & 865.00 & 0.00 & 1128.00 & 0.00 \\
\hline 332 & 0.00 & 0.00 & 825.00 & 0.00 & 0.00 & 0.00 & 0.00 & 0.00 \\
\hline 333 & 0.00 & 0.00 & 0.00 & 0.00 & 0.00 & 0.00 & 0.00 & 0.00 \\
\hline 334 & 0.00 & 0.00 & 0.00 & 0.00 & 0.00 & 0.00 & 0.00 & 0.00 \\
\hline 335 & 0.00 & 0.00 & 0.00 & 0.00 & 0.00 & 998.00 & 0.00 & 0.00 \\
\hline 336 & 0.00 & 1137.00 & 0.00 & 1239.00 & 0.00 & 0.00 & 0.00 & 0.00 \\
\hline 337 & 0.00 & 0.00 & 0.00 & 0.00 & 0.00 & 0.00 & 0.00 & 0.00 \\
\hline 338 & 0.00 & 0.00 & 0.00 & 0.00 & 0.00 & 0.00 & 0.00 & 0.00 \\
\hline 339 & 0.00 & 0.00 & 0.00 & 0.00 & 0.00 & 0.00 & 0.00 & 0.00 \\
\hline 340 & 0.00 & 0.00 & 0.00 & 0.00 & 0.00 & 0.00 & 0.00 & 0.00 \\
\hline 341 & 1165.00 & 0.00 & 0.00 & 0.00 & 865.00 & 0.00 & 1070.00 & 0.00 \\
\hline 342 & 0.00 & 0.00 & 825.00 & 0.00 & 0.00 & 0.00 & 0.00 & 0.00 \\
\hline 343 & 0.00 & 0.00 & 0.00 & 0.00 & 0.00 & 0.00 & 0.00 & 0.00 \\
\hline 344 & 0.00 & 0.00 & 0.00 & 0.00 & 0.00 & 0.00 & 0.00 & 0.00 \\
\hline 345 & 0.00 & 0.00 & 0.00 & 0.00 & 0.00 & 998.00 & 0.00 & 0.00 \\
\hline 346 & 0.00 & 1137.00 & 0.00 & 1239.00 & 0.00 & 0.00 & 0.00 & 0.00 \\
\hline 347 & 0.00 & 0.00 & 0.00 & 0.00 & 0.00 & 0.00 & 0.00 & 0.00 \\
\hline 348 & 0.00 & 0.00 & 0.00 & 0.00 & 0.00 & 0.00 & 0.00 & 0.00 \\
\hline 349 & 0.00 & 0.00 & 0.00 & 0.00 & 0.00 & 0.00 & 0.00 & 0.00 \\
\hline 350 & 0.00 & 0.00 & 0.00 & 0.00 & 0.00 & 0.00 & 0.00 & 0.00 \\
\hline 351 & 1005.00 & 0.00 & 0.00 & 0.00 & 865.00 & 0.00 & 1070.00 & 0.00 \\
\hline 352 & 0.00 & 0.00 & 825.00 & 0.00 & 0.00 & 0.00 & 0.00 & 0.00 \\
\hline 353 & 0.00 & 0.00 & 0.00 & 0.00 & 0.00 & 0.00 & 0.00 & 0.00 \\
\hline 354 & 0.00 & 0.00 & 0.00 & 0.00 & 0.00 & 0.00 & 0.00 & 0.00 \\
\hline 355 & 0.00 & 0.00 & 0.00 & 0.00 & 0.00 & 998.00 & 0.00 & 0.00 \\
\hline 356 & 0.00 & 1015.00 & 0.00 & 1239.00 & 0.00 & 0.00 & 0.00 & 0.00 \\
\hline 357 & 0.00 & 0.00 & 0.00 & 0.00 & 0.00 & 0.00 & 0.00 & 0.00 \\
\hline 358 & 0.00 & 0.00 & 0.00 & 0.00 & 0.00 & 0.00 & 0.00 & 0.00 \\
\hline 359 & 0.00 & 0.00 & 0.00 & 0.00 & 0.00 & 0.00 & 0.00 & 0.00 \\
\hline 360 & 0.00 & 0.00 & 0.00 & 0.00 & 0.00 & 0.00 & 0.00 & 0.00 \\
\hline 361 & 965.00 & 0.00 & 0.00 & 0.00 & 865.00 & 0.00 & 1070.00 & 0.00 \\
\hline 362 & 0.00 & 0.00 & 825.00 & 0.00 & 0.00 & 0.00 & 0.00 & 0.00 \\
\hline 363 & 0.00 & 0.00 & 0.00 & 0.00 & 0.00 & 0.00 & 0.00 & 0.00 \\
\hline 364 & 0.00 & 0.00 & 0.00 & 0.00 & 0.00 & 0.00 & 0.00 & 0.00 \\
\hline 365 & 0.00 & 0.00 & 0.00 & 0.00 & 0.00 & 998.00 & 0.00 & 0.00 \\
\hline 366 & 0.00 & 995.00 & 0.00 & 1170.00 & 0.00 & 0.00 & 0.00 & 0.00 \\
\hline 367 & 0.00 & 0.00 & 0.00 & 0.00 & 0.00 & 0.00 & 0.00 & 0.00 \\
\hline 368 & 0.00 & 0.00 & 0.00 & 0.00 & 0.00 & 0.00 & 0.00 & 0.00 \\
\hline 369 & 0.00 & 0.00 & 0.00 & 0.00 & 0.00 & 0.00 & 0.00 & 0.00 \\
\hline 370 & 0.00 & 0.00 & 0.00 & 0.00 & 0.00 & 0.00 & 0.00 & 0.00 \\
\hline NAVIO_NORTE & PORTO_1 & PORTO_2 & PORTO_3 & PORTO_4 & PORTO_5 & PORTO_6 & PORTO_7 & PORTO_8 \\
\hline 000 & 0.00 & 0.00 & 0.00 & 0.00 & 0.00 & 0.00 & 0.00 & 0.00 \\
\hline 001 & 0.00 & 0.00 & 123.75 & 0.00 & 0.00 & 0.00 & 0.00 & 0.00 \\
\hline 002 & 0.00 & 0.00 & 0.00 & 0.00 & 0.00 & 0.00 & 0.00 & 0.00 \\
\hline 003 & 0.00 & 0.00 & 0.00 & 0.00 & 361.50 & 0.00 & 0.00 & 0.00 \\
\hline 004 & 0.00 & 0.00 & 0.00 & 0.00 & 0.00 & 0.00 & 0.00 & 0.00 \\
\hline 005 & 0.00 & 0.00 & 0.00 & 0.00 & 0.00 & 0.00 & 0.00 & 0.00 \\
\hline 006 & 0.00 & 0.00 & 0.00 & 0.00 & 0.00 & 0.00 & 0.00 & 725.00 \\
\hline 007 & 0.00 & 0.00 & 0.00 & 0.00 & 0.00 & 0.00 & 0.00 & 0.00 \\
\hline 008 & 0.00 & 0.00 & 0.00 & 0.00 & 0.00 & 0.00 & 0.00 & 0.00 \\
\hline 009 & 0.00 & 0.00 & 0.00 & 0.00 & 0.00 & 0.00 & 0.00 & 0.00 \\
\hline 010 & 0.00 & 0.00 & 0.00 & 0.00 & 0.00 & 0.00 & 0.00 & 0.00 \\
\hline 011 & 0.00 & 0.00 & 430.16 & 0.00 & 0.00 & 0.00 & 0.00 & 0.00 \\
\hline 012 & 0.00 & 0.00 & 0.00 & 0.00 & 0.00 & 0.00 & 0.00 & 0.00 \\
\hline 013 & 0.00 & 0.00 & 0.00 & 0.00 & 351.25 & 0.00 & 0.00 & 0.00 \\
\hline 014 & 0.00 & 0.00 & 0.00 & 0.00 & 0.00 & 0.00 & 0.00 & 0.00 \\
\hline 015 & 0.00 & 0.00 & 0.00 & 0.00 & 0.00 & 0.00 & 0.00 & 0.00 \\
\hline 016 & 0.00 & 0.00 & 0.00 & 0.00 & 0.00 & 0.00 & 0.00 & 955.00 \\
\hline 017 & 0.00 & 0.00 & 0.00 & 0.00 & 0.00 & 0.00 & 0.00 & 0.00 \\
\hline 018 & 0.00 & 0.00 & 0.00 & 0.00 & 0.00 & 0.00 & 0.00 & 0.00 \\
\hline 019 & 0.00 & 0.00 & 0.00 & 0.00 & 0.00 & 0.00 & 0.00 & 0.00 \\
\hline 020 & 0.00 & 0.00 & 0.00 & 0.00 & 0.00 & 0.00 & 0.00 & 0.00 \\
\hline 021 & 0.00 & 0.00 & 466.25 & 0.00 & 0.00 & 0.00 & 0.00 & 0.00 \\
\hline 022 & 0.00 & 0.00 & 0.00 & 0.00 & 0.00 & 0.00 & 0.00 & 0.00 \\
\hline 023 & 0.00 & 0.00 & 0.00 & 0.00 & 801.20 & 0.00 & 0.00 & 0.00 \\
\hline 024 & 0.00 & 0.00 & 0.00 & 0.00 & 0.00 & 0.00 & 0.00 & 0.00 \\
\hline 025 & 0.00 & 0.00 & 0.00 & 0.00 & 0.00 & 0.00 & 0.00 & 0.00 \\
\hline 026 & 0.00 & 0.00 & 0.00 & 0.00 & 0.00 & 0.00 & 0.00 & 1130.00 \\
\hline 027 & 0.00 & 0.00 & 0.00 & 0.00 & 0.00 & 0.00 & 0.00 & 0.00 \\
\hline 028 & 0.00 & 0.00 & 0.00 & 0.00 & 0.00 & 0.00 & 0.00 & 0.00 \\
\hline 029 & 0.00 & 0.00 & 0.00 & 0.00 & 0.00 & 0.00 & 0.00 & 0.00 \\
\hline 030 & 0.00 & 0.00 & 0.00 & 0.00 & 0.00 & 0.00 & 0.00 & 0.00 \\
\hline 031 & 0.00 & 0.00 & 686.20 & 0.00 & 0.00 & 0.00 & 0.00 & 0.00 \\
\hline 032 & 0.00 & 0.00 & 0.00 & 0.00 & 0.00 & 0.00 & 0.00 & 0.00 \\
\hline 033 & 0.00 & 0.00 & 0.00 & 0.00 & 950.00 & 0.00 & 0.00 & 0.00 \\
\hline
\end{tabular}




\begin{tabular}{|c|c|c|c|c|c|c|c|c|}
\hline 034 & 0.00 & 0.00 & 0.00 & 0.00 & 0.00 & 0.00 & 0.00 & 0.00 \\
\hline 035 & 0.00 & 0.00 & 0.00 & 0.00 & 0.00 & 0.00 & 0.00 & 0.00 \\
\hline 036 & 0.00 & 0.00 & 0.00 & 0.00 & 0.00 & 0.00 & 0.00 & 1140.00 \\
\hline 037 & 0.00 & 0.00 & 0.00 & 0.00 & 0.00 & 0.00 & 0.00 & 0.00 \\
\hline 038 & 0.00 & 0.00 & 0.00 & 0.00 & 0.00 & 0.00 & 0.00 & 0.00 \\
\hline 039 & 0.00 & 0.00 & 0.00 & 0.00 & 0.00 & 0.00 & 0.00 & 0.00 \\
\hline 040 & 0.00 & 0.00 & 0.00 & 0.00 & 0.00 & 0.00 & 0.00 & 0.00 \\
\hline 041 & 0.00 & 0.00 & 785.00 & 0.00 & 0.00 & 0.00 & 0.00 & 0.00 \\
\hline 042 & 0.00 & 0.00 & 0.00 & 0.00 & 0.00 & 0.00 & 0.00 & 0.00 \\
\hline 043 & 0.00 & 0.00 & 0.00 & 0.00 & 1007.15 & 0.00 & 0.00 & 0.00 \\
\hline 044 & 0.00 & 0.00 & 0.00 & 0.00 & 0.00 & 0.00 & 0.00 & 0.00 \\
\hline 045 & 0.00 & 0.00 & 0.00 & 0.00 & 0.00 & 0.00 & 0.00 & 0.00 \\
\hline 046 & 0.00 & 0.00 & 0.00 & 0.00 & 0.00 & 0.00 & 0.00 & 1161.64 \\
\hline 047 & 0.00 & 0.00 & 0.00 & 0.00 & 0.00 & 0.00 & 0.00 & 0.00 \\
\hline 048 & 0.00 & 0.00 & 0.00 & 0.00 & 0.00 & 0.00 & 0.00 & 0.00 \\
\hline 049 & 0.00 & 0.00 & 0.00 & 0.00 & 0.00 & 0.00 & 0.00 & 0.00 \\
\hline 050 & 0.00 & 0.00 & 0.00 & 0.00 & 0.00 & 0.00 & 0.00 & 0.00 \\
\hline 051 & 0.00 & 0.00 & 1002.15 & 0.00 & 0.00 & 0.00 & 0.00 & 0.00 \\
\hline 052 & 0.00 & 0.00 & 0.00 & 0.00 & 0.00 & 0.00 & 0.00 & 0.00 \\
\hline 053 & 0.00 & 0.00 & 0.00 & 0.00 & 1011.45 & 0.00 & 0.00 & 0.00 \\
\hline 054 & 0.00 & 0.00 & 0.00 & 0.00 & 0.00 & 0.00 & 0.00 & 0.00 \\
\hline 055 & 0.00 & 0.00 & 0.00 & 0.00 & 0.00 & 0.00 & 0.00 & 0.00 \\
\hline 056 & 0.00 & 0.00 & 0.00 & 0.00 & 0.00 & 0.00 & 0.00 & 1140.00 \\
\hline 057 & 0.00 & 0.00 & 0.00 & 0.00 & 0.00 & 0.00 & 0.00 & 0.00 \\
\hline 058 & 0.00 & 0.00 & 0.00 & 0.00 & 0.00 & 0.00 & 0.00 & 0.00 \\
\hline 059 & 0.00 & 0.00 & 0.00 & 0.00 & 0.00 & 0.00 & 0.00 & 0.00 \\
\hline 060 & 0.00 & 0.00 & 0.00 & 0.00 & 0.00 & 0.00 & 0.00 & 0.00 \\
\hline 061 & 0.00 & 0.00 & 1058.53 & 0.00 & 0.00 & 0.00 & 0.00 & 0.00 \\
\hline 062 & 0.00 & 0.00 & 0.00 & 0.00 & 0.00 & 0.00 & 0.00 & 0.00 \\
\hline 063 & 0.00 & 0.00 & 0.00 & 0.00 & 1112.25 & 0.00 & 0.00 & 0.00 \\
\hline 064 & 0.00 & 0.00 & 0.00 & 0.00 & 0.00 & 0.00 & 0.00 & 0.00 \\
\hline 065 & 0.00 & 0.00 & 0.00 & 0.00 & 0.00 & 0.00 & 0.00 & 0.00 \\
\hline 066 & 0.00 & 0.00 & 0.00 & 0.00 & 0.00 & 0.00 & 0.00 & 1381.00 \\
\hline 067 & 0.00 & 0.00 & 0.00 & 0.00 & 0.00 & 0.00 & 0.00 & 0.00 \\
\hline 068 & 0.00 & 0.00 & 0.00 & 0.00 & 0.00 & 0.00 & 0.00 & 0.00 \\
\hline 069 & 0.00 & 0.00 & 0.00 & 0.00 & 0.00 & 0.00 & 0.00 & 0.00 \\
\hline 070 & 0.00 & 0.00 & 0.00 & 0.00 & 0.00 & 0.00 & 0.00 & 0.00 \\
\hline 071 & 0.00 & 0.00 & 1097.86 & 0.00 & 0.00 & 0.00 & 0.00 & 0.00 \\
\hline 072 & 0.00 & 0.00 & 0.00 & 0.00 & 0.00 & 0.00 & 0.00 & 0.00 \\
\hline 073 & 0.00 & 0.00 & 0.00 & 0.00 & 1104.15 & 0.00 & 0.00 & 0.00 \\
\hline 074 & 0.00 & 0.00 & 0.00 & 0.00 & 0.00 & 0.00 & 0.00 & 0.00 \\
\hline 075 & 0.00 & 0.00 & 0.00 & 0.00 & 0.00 & 0.00 & 0.00 & 0.00 \\
\hline 076 & 0.00 & 0.00 & 0.00 & 0.00 & 0.00 & 0.00 & 0.00 & 1457.00 \\
\hline 077 & 0.00 & 0.00 & 0.00 & 0.00 & 0.00 & 0.00 & 0.00 & 0.00 \\
\hline 078 & 0.00 & 0.00 & 0.00 & 0.00 & 0.00 & 0.00 & 0.00 & 0.00 \\
\hline 079 & 0.00 & 0.00 & 0.00 & 0.00 & 0.00 & 0.00 & 0.00 & 0.00 \\
\hline 080 & 0.00 & 0.00 & 0.00 & 0.00 & 0.00 & 0.00 & 0.00 & 0.00 \\
\hline 081 & 0.00 & 0.00 & 1086.64 & 0.00 & 0.00 & 0.00 & 0.00 & 0.00 \\
\hline 082 & 0.00 & 0.00 & 0.00 & 0.00 & 0.00 & 0.00 & 0.00 & 0.00 \\
\hline 083 & 0.00 & 0.00 & 0.00 & 0.00 & 1289.70 & 0.00 & 0.00 & 0.00 \\
\hline 084 & 0.00 & 0.00 & 0.00 & 0.00 & 0.00 & 0.00 & 0.00 & 0.00 \\
\hline 085 & 0.00 & 0.00 & 0.00 & 0.00 & 0.00 & 0.00 & 0.00 & 0.00 \\
\hline 086 & 0.00 & 0.00 & 0.00 & 0.00 & 0.00 & 0.00 & 0.00 & 1507.00 \\
\hline 087 & 0.00 & 0.00 & 0.00 & 0.00 & 0.00 & 0.00 & 0.00 & 0.00 \\
\hline 088 & 0.00 & 0.00 & 0.00 & 0.00 & 0.00 & 0.00 & 0.00 & 0.00 \\
\hline 089 & 0.00 & 0.00 & 0.00 & 0.00 & 0.00 & 0.00 & 0.00 & 0.00 \\
\hline 090 & 0.00 & 0.00 & 0.00 & 0.00 & 0.00 & 0.00 & 0.00 & 0.00 \\
\hline 091 & 0.00 & 0.00 & 1226.26 & 0.00 & 0.00 & 0.00 & 0.00 & 0.00 \\
\hline 092 & 0.00 & 0.00 & 0.00 & 0.00 & 0.00 & 0.00 & 0.00 & 0.00 \\
\hline 093 & 0.00 & 0.00 & 0.00 & 0.00 & 1371.21 & 0.00 & 0.00 & 0.00 \\
\hline 094 & 0.00 & 0.00 & 0.00 & 0.00 & 0.00 & 0.00 & 0.00 & 0.00 \\
\hline 095 & 0.00 & 0.00 & 0.00 & 0.00 & 0.00 & 0.00 & 0.00 & 0.00 \\
\hline 096 & 0.00 & 0.00 & 0.00 & 0.00 & 0.00 & 0.00 & 0.00 & 1519.00 \\
\hline 097 & 0.00 & 0.00 & 0.00 & 0.00 & 0.00 & 0.00 & 0.00 & 0.00 \\
\hline 098 & 0.00 & 0.00 & 0.00 & 0.00 & 0.00 & 0.00 & 0.00 & 0.00 \\
\hline 099 & 0.00 & 0.00 & 0.00 & 0.00 & 0.00 & 0.00 & 0.00 & 0.00 \\
\hline 100 & 0.00 & 0.00 & 0.00 & 0.00 & 0.00 & 0.00 & 0.00 & 0.00 \\
\hline 101 & 0.00 & 0.00 & 1286.29 & 0.00 & 0.00 & 0.00 & 0.00 & 0.00 \\
\hline 102 & 0.00 & 0.00 & 0.00 & 0.00 & 0.00 & 0.00 & 0.00 & 0.00 \\
\hline 103 & 0.00 & 0.00 & 0.00 & 0.00 & 1340.14 & 0.00 & 0.00 & 0.00 \\
\hline 104 & 0.00 & 0.00 & 0.00 & 0.00 & 0.00 & 0.00 & 0.00 & 0.00 \\
\hline 105 & 0.00 & 0.00 & 0.00 & 0.00 & 0.00 & 0.00 & 0.00 & 0.00 \\
\hline 106 & 0.00 & 0.00 & 0.00 & 0.00 & 0.00 & 0.00 & 0.00 & 1519.00 \\
\hline 107 & 0.00 & 0.00 & 0.00 & 0.00 & 0.00 & 0.00 & 0.00 & 0.00 \\
\hline 108 & 0.00 & 0.00 & 0.00 & 0.00 & 0.00 & 0.00 & 0.00 & 0.00 \\
\hline 109 & 0.00 & 0.00 & 0.00 & 0.00 & 0.00 & 0.00 & 0.00 & 0.00 \\
\hline 110 & 0.00 & 0.00 & 0.00 & 0.00 & 0.00 & 0.00 & 0.00 & 0.00 \\
\hline 111 & 0.00 & 0.00 & 1334.14 & 0.00 & 0.00 & 0.00 & 0.00 & 0.00 \\
\hline 112 & 0.00 & 0.00 & 0.00 & 0.00 & 0.00 & 0.00 & 0.00 & 0.00 \\
\hline 113 & 0.00 & 0.00 & 0.00 & 0.00 & 1319.98 & 0.00 & 0.00 & 0.00 \\
\hline 114 & 0.00 & 0.00 & 0.00 & 0.00 & 0.00 & 0.00 & 0.00 & 0.00 \\
\hline 115 & 0.00 & 0.00 & 0.00 & 0.00 & 0.00 & 0.00 & 0.00 & 0.00 \\
\hline 116 & 0.00 & 0.00 & 0.00 & 0.00 & 0.00 & 0.00 & 0.00 & 1519.00 \\
\hline 117 & 0.00 & 0.00 & 0.00 & 0.00 & 0.00 & 0.00 & 0.00 & 0.00 \\
\hline 118 & 0.00 & 0.00 & 0.00 & 0.00 & 0.00 & 0.00 & 0.00 & 0.00 \\
\hline 119 & 0.00 & 0.00 & 0.00 & 0.00 & 0.00 & 0.00 & 0.00 & 0.00 \\
\hline
\end{tabular}




\begin{tabular}{|c|c|c|c|c|c|c|c|c|}
\hline 120 & 0.00 & 0.00 & 0.00 & 0.00 & 0.00 & 0.00 & 0.00 & 0.00 \\
\hline 121 & 0.00 & 0.00 & 1371.98 & 0.00 & 0.00 & 0.00 & 0.00 & 0.00 \\
\hline 122 & 0.00 & 0.00 & 0.00 & 0.00 & 0.00 & 0.00 & 0.00 & 0.00 \\
\hline 123 & 0.00 & 0.00 & 0.00 & 0.00 & 1427.77 & 0.00 & 0.00 & 0.00 \\
\hline 124 & 0.00 & 0.00 & 0.00 & 0.00 & 0.00 & 0.00 & 0.00 & 0.00 \\
\hline 125 & 0.00 & 0.00 & 0.00 & 0.00 & 0.00 & 0.00 & 0.00 & 0.00 \\
\hline 126 & 0.00 & 0.00 & 0.00 & 0.00 & 0.00 & 0.00 & 0.00 & 1762.00 \\
\hline 127 & 0.00 & 0.00 & 0.00 & 0.00 & 0.00 & 0.00 & 0.00 & 0.00 \\
\hline 128 & 0.00 & 0.00 & 0.00 & 0.00 & 0.00 & 0.00 & 0.00 & 0.00 \\
\hline 129 & 0.00 & 0.00 & 0.00 & 0.00 & 0.00 & 0.00 & 0.00 & 0.00 \\
\hline 130 & 0.00 & 0.00 & 0.00 & 0.00 & 0.00 & 0.00 & 0.00 & 0.00 \\
\hline 131 & 0.00 & 0.00 & 1437.05 & 0.00 & 0.00 & 0.00 & 0.00 & 0.00 \\
\hline 132 & 0.00 & 0.00 & 0.00 & 0.00 & 0.00 & 0.00 & 0.00 & 0.00 \\
\hline 133 & 0.00 & 0.00 & 0.00 & 0.00 & 1434.14 & 0.00 & 0.00 & 0.00 \\
\hline 134 & 0.00 & 0.00 & 0.00 & 0.00 & 0.00 & 0.00 & 0.00 & 0.00 \\
\hline 135 & 0.00 & 0.00 & 0.00 & 0.00 & 0.00 & 0.00 & 0.00 & 0.00 \\
\hline 136 & 0.00 & 0.00 & 0.00 & 0.00 & 0.00 & 0.00 & 0.00 & 1840.00 \\
\hline 137 & 0.00 & 0.00 & 0.00 & 0.00 & 0.00 & 0.00 & 0.00 & 0.00 \\
\hline 138 & 0.00 & 0.00 & 0.00 & 0.00 & 0.00 & 0.00 & 0.00 & 0.00 \\
\hline 139 & 0.00 & 0.00 & 0.00 & 0.00 & 0.00 & 0.00 & 0.00 & 0.00 \\
\hline 140 & 0.00 & 0.00 & 0.00 & 0.00 & 0.00 & 0.00 & 0.00 & 0.00 \\
\hline 141 & 0.00 & 0.00 & 1427.46 & 0.00 & 0.00 & 0.00 & 0.00 & 0.00 \\
\hline 142 & 0.00 & 0.00 & 0.00 & 0.00 & 0.00 & 0.00 & 0.00 & 0.00 \\
\hline 143 & 0.00 & 0.00 & 0.00 & 0.00 & 1641.90 & 0.00 & 0.00 & 0.00 \\
\hline 144 & 0.00 & 0.00 & 0.00 & 0.00 & 0.00 & 0.00 & 0.00 & 0.00 \\
\hline 145 & 0.00 & 0.00 & 0.00 & 0.00 & 0.00 & 0.00 & 0.00 & 0.00 \\
\hline 146 & 0.00 & 0.00 & 0.00 & 0.00 & 0.00 & 0.00 & 0.00 & 1890.00 \\
\hline 147 & 0.00 & 0.00 & 0.00 & 0.00 & 0.00 & 0.00 & 0.00 & 0.00 \\
\hline 148 & 0.00 & 0.00 & 0.00 & 0.00 & 0.00 & 0.00 & 0.00 & 0.00 \\
\hline 149 & 0.00 & 0.00 & 0.00 & 0.00 & 0.00 & 0.00 & 0.00 & 0.00 \\
\hline 150 & 0.00 & 0.00 & 0.00 & 0.00 & 0.00 & 0.00 & 0.00 & 0.00 \\
\hline 151 & 0.00 & 0.00 & 1584.43 & 0.00 & 0.00 & 0.00 & 0.00 & 0.00 \\
\hline 152 & 0.00 & 0.00 & 0.00 & 0.00 & 0.00 & 0.00 & 0.00 & 0.00 \\
\hline 153 & 0.00 & 0.00 & 0.00 & 0.00 & 1675.24 & 0.00 & 0.00 & 0.00 \\
\hline 154 & 0.00 & 0.00 & 0.00 & 0.00 & 0.00 & 0.00 & 0.00 & 0.00 \\
\hline 155 & 0.00 & 0.00 & 0.00 & 0.00 & 0.00 & 0.00 & 0.00 & 0.00 \\
\hline 156 & 0.00 & 0.00 & 0.00 & 0.00 & 0.00 & 0.00 & 0.00 & 1901.00 \\
\hline 157 & 0.00 & 0.00 & 0.00 & 0.00 & 0.00 & 0.00 & 0.00 & 0.00 \\
\hline 158 & 0.00 & 0.00 & 0.00 & 0.00 & 0.00 & 0.00 & 0.00 & 0.00 \\
\hline 159 & 0.00 & 0.00 & 0.00 & 0.00 & 0.00 & 0.00 & 0.00 & 0.00 \\
\hline 160 & 0.00 & 0.00 & 0.00 & 0.00 & 0.00 & 0.00 & 0.00 & 0.00 \\
\hline 161 & 0.00 & 0.00 & 1641.24 & 0.00 & 0.00 & 0.00 & 0.00 & 0.00 \\
\hline 162 & 0.00 & 0.00 & 0.00 & 0.00 & 0.00 & 0.00 & 0.00 & 0.00 \\
\hline 163 & 0.00 & 0.00 & 0.00 & 0.00 & 1661.47 & 0.00 & 0.00 & 0.00 \\
\hline 164 & 0.00 & 0.00 & 0.00 & 0.00 & 0.00 & 0.00 & 0.00 & 0.00 \\
\hline 165 & 0.00 & 0.00 & 0.00 & 0.00 & 0.00 & 0.00 & 0.00 & 0.00 \\
\hline 166 & 0.00 & 0.00 & 0.00 & 0.00 & 0.00 & 0.00 & 0.00 & 1901.00 \\
\hline 167 & 0.00 & 0.00 & 0.00 & 0.00 & 0.00 & 0.00 & 0.00 & 0.00 \\
\hline 168 & 0.00 & 0.00 & 0.00 & 0.00 & 0.00 & 0.00 & 0.00 & 0.00 \\
\hline 169 & 0.00 & 0.00 & 0.00 & 0.00 & 0.00 & 0.00 & 0.00 & 0.00 \\
\hline 170 & 0.00 & 0.00 & 0.00 & 0.00 & 0.00 & 0.00 & 0.00 & 0.00 \\
\hline 171 & 0.00 & 0.00 & 1652.47 & 0.00 & 0.00 & 0.00 & 0.00 & 0.00 \\
\hline 172 & 0.00 & 0.00 & 0.00 & 0.00 & 0.00 & 0.00 & 0.00 & 0.00 \\
\hline 173 & 0.00 & 0.00 & 0.00 & 0.00 & 1665.37 & 0.00 & 0.00 & 0.00 \\
\hline 174 & 0.00 & 0.00 & 0.00 & 0.00 & 0.00 & 0.00 & 0.00 & 0.00 \\
\hline 175 & 0.00 & 0.00 & 0.00 & 0.00 & 0.00 & 0.00 & 0.00 & 0.00 \\
\hline 176 & 0.00 & 0.00 & 0.00 & 0.00 & 0.00 & 0.00 & 0.00 & 1901.00 \\
\hline 177 & 0.00 & 0.00 & 0.00 & 0.00 & 0.00 & 0.00 & 0.00 & 0.00 \\
\hline 178 & 0.00 & 0.00 & 0.00 & 0.00 & 0.00 & 0.00 & 0.00 & 0.00 \\
\hline 179 & 0.00 & 0.00 & 0.00 & 0.00 & 0.00 & 0.00 & 0.00 & 0.00 \\
\hline 180 & 0.00 & 0.00 & 0.00 & 0.00 & 0.00 & 0.00 & 0.00 & 0.00 \\
\hline 181 & 0.00 & 0.00 & 1717.37 & 0.00 & 0.00 & 0.00 & 0.00 & 0.00 \\
\hline 182 & 0.00 & 0.00 & 0.00 & 0.00 & 0.00 & 0.00 & 0.00 & 0.00 \\
\hline 183 & 0.00 & 0.00 & 0.00 & 0.00 & 1777.97 & 0.00 & 0.00 & 0.00 \\
\hline 184 & 0.00 & 0.00 & 0.00 & 0.00 & 0.00 & 0.00 & 0.00 & 0.00 \\
\hline 185 & 0.00 & 0.00 & 0.00 & 0.00 & 0.00 & 0.00 & 0.00 & 0.00 \\
\hline 186 & 0.00 & 0.00 & 0.00 & 0.00 & 0.00 & 0.00 & 0.00 & 2142.00 \\
\hline 187 & 0.00 & 0.00 & 0.00 & 0.00 & 0.00 & 0.00 & 0.00 & 0.00 \\
\hline 188 & 0.00 & 0.00 & 0.00 & 0.00 & 0.00 & 0.00 & 0.00 & 0.00 \\
\hline 189 & 0.00 & 0.00 & 0.00 & 0.00 & 0.00 & 0.00 & 0.00 & 0.00 \\
\hline 190 & 0.00 & 0.00 & 0.00 & 0.00 & 0.00 & 0.00 & 0.00 & 0.00 \\
\hline 191 & 0.00 & 0.00 & 1807.97 & 0.00 & 0.00 & 0.00 & 0.00 & 0.00 \\
\hline 192 & 0.00 & 0.00 & 0.00 & 0.00 & 0.00 & 0.00 & 0.00 & 0.00 \\
\hline 193 & 0.00 & 0.00 & 0.00 & 0.00 & 1746.33 & 0.00 & 0.00 & 0.00 \\
\hline 194 & 0.00 & 0.00 & 0.00 & 0.00 & 0.00 & 0.00 & 0.00 & 0.00 \\
\hline 195 & 0.00 & 0.00 & 0.00 & 0.00 & 0.00 & 0.00 & 0.00 & 0.00 \\
\hline 196 & 0.00 & 0.00 & 0.00 & 0.00 & 0.00 & 0.00 & 0.00 & 2218.00 \\
\hline 197 & 0.00 & 0.00 & 0.00 & 0.00 & 0.00 & 0.00 & 0.00 & 0.00 \\
\hline 198 & 0.00 & 0.00 & 0.00 & 0.00 & 0.00 & 0.00 & 0.00 & 0.00 \\
\hline 199 & 0.00 & 0.00 & 0.00 & 0.00 & 0.00 & 0.00 & 0.00 & 0.00 \\
\hline 200 & 0.00 & 0.00 & 0.00 & 0.00 & 0.00 & 0.00 & 0.00 & 0.00 \\
\hline 201 & 0.00 & 0.00 & 1776.33 & 0.00 & 0.00 & 0.00 & 0.00 & 0.00 \\
\hline 202 & 0.00 & 0.00 & 0.00 & 0.00 & 0.00 & 0.00 & 0.00 & 0.00 \\
\hline 203 & 0.00 & 0.00 & 0.00 & 0.00 & 1938.67 & 0.00 & 0.00 & 0.00 \\
\hline 204 & 0.00 & 0.00 & 0.00 & 0.00 & 0.00 & 0.00 & 0.00 & 0.00 \\
\hline 205 & 0.00 & 0.00 & 0.00 & 0.00 & 0.00 & 0.00 & 0.00 & 0.00 \\
\hline
\end{tabular}




\begin{tabular}{|c|c|c|c|c|c|c|c|c|}
\hline 206 & 0.00 & 0.00 & 0.00 & 0.00 & 0.00 & 0.00 & 0.00 & 2268.00 \\
\hline 207 & 0.00 & 0.00 & 0.00 & 0.00 & 0.00 & 0.00 & 0.00 & 0.00 \\
\hline 208 & 0.00 & 0.00 & 0.00 & 0.00 & 0.00 & 0.00 & 0.00 & 0.00 \\
\hline 209 & 0.00 & 0.00 & 0.00 & 0.00 & 0.00 & 0.00 & 0.00 & 0.00 \\
\hline 210 & 0.00 & 0.00 & 0.00 & 0.00 & 0.00 & 0.00 & 0.00 & 0.00 \\
\hline 211 & 0.00 & 0.00 & 1920.67 & 0.00 & 0.00 & 0.00 & 0.00 & 0.00 \\
\hline 212 & 0.00 & 0.00 & 0.00 & 0.00 & 0.00 & 0.00 & 0.00 & 0.00 \\
\hline 213 & 0.00 & 0.00 & 0.00 & 0.00 & 2005.11 & 0.00 & 0.00 & 0.00 \\
\hline 214 & 0.00 & 0.00 & 0.00 & 0.00 & 0.00 & 0.00 & 0.00 & 0.00 \\
\hline 215 & 0.00 & 0.00 & 0.00 & 0.00 & 0.00 & 0.00 & 0.00 & 0.00 \\
\hline 216 & 0.00 & 0.00 & 0.00 & 0.00 & 0.00 & 0.00 & 0.00 & 2280.00 \\
\hline 217 & 0.00 & 0.00 & 0.00 & 0.00 & 0.00 & 0.00 & 0.00 & 0.00 \\
\hline 218 & 0.00 & 0.00 & 0.00 & 0.00 & 0.00 & 0.00 & 0.00 & 0.00 \\
\hline 219 & 0.00 & 0.00 & 0.00 & 0.00 & 0.00 & 0.00 & 0.00 & 0.00 \\
\hline 220 & 0.00 & 0.00 & 0.00 & 0.00 & 0.00 & 0.00 & 0.00 & 0.00 \\
\hline 221 & 0.00 & 0.00 & 1970.11 & 0.00 & 0.00 & 0.00 & 0.00 & 0.00 \\
\hline 222 & 0.00 & 0.00 & 0.00 & 0.00 & 0.00 & 0.00 & 0.00 & 0.00 \\
\hline 223 & 0.00 & 0.00 & 0.00 & 0.00 & 1973.18 & 0.00 & 0.00 & 0.00 \\
\hline 224 & 0.00 & 0.00 & 0.00 & 0.00 & 0.00 & 0.00 & 0.00 & 0.00 \\
\hline 225 & 0.00 & 0.00 & 0.00 & 0.00 & 0.00 & 0.00 & 0.00 & 0.00 \\
\hline 226 & 0.00 & 0.00 & 0.00 & 0.00 & 0.00 & 0.00 & 0.00 & 2280.00 \\
\hline 227 & 0.00 & 0.00 & 0.00 & 0.00 & 0.00 & 0.00 & 0.00 & 0.00 \\
\hline 228 & 0.00 & 0.00 & 0.00 & 0.00 & 0.00 & 0.00 & 0.00 & 0.00 \\
\hline 229 & 0.00 & 0.00 & 0.00 & 0.00 & 0.00 & 0.00 & 0.00 & 0.00 \\
\hline 230 & 0.00 & 0.00 & 0.00 & 0.00 & 0.00 & 0.00 & 0.00 & 0.00 \\
\hline 231 & 0.00 & 0.00 & 1874.53 & 0.00 & 0.00 & 0.00 & 0.00 & 0.00 \\
\hline 232 & 0.00 & 0.00 & 0.00 & 0.00 & 0.00 & 0.00 & 0.00 & 0.00 \\
\hline 233 & 0.00 & 0.00 & 0.00 & 0.00 & 1900.00 & 0.00 & 0.00 & 0.00 \\
\hline 234 & 0.00 & 0.00 & 0.00 & 0.00 & 0.00 & 0.00 & 0.00 & 0.00 \\
\hline 235 & 0.00 & 0.00 & 0.00 & 0.00 & 0.00 & 0.00 & 0.00 & 0.00 \\
\hline 236 & 0.00 & 0.00 & 0.00 & 0.00 & 0.00 & 0.00 & 0.00 & 2280.00 \\
\hline 237 & 0.00 & 0.00 & 0.00 & 0.00 & 0.00 & 0.00 & 0.00 & 0.00 \\
\hline 238 & 0.00 & 0.00 & 0.00 & 0.00 & 0.00 & 0.00 & 0.00 & 0.00 \\
\hline 239 & 0.00 & 0.00 & 0.00 & 0.00 & 0.00 & 0.00 & 0.00 & 0.00 \\
\hline 240 & 0.00 & 0.00 & 0.00 & 0.00 & 0.00 & 0.00 & 0.00 & 0.00 \\
\hline 241 & 0.00 & 0.00 & 1720.95 & 0.00 & 0.00 & 0.00 & 0.00 & 0.00 \\
\hline 242 & 0.00 & 0.00 & 0.00 & 0.00 & 0.00 & 0.00 & 0.00 & 0.00 \\
\hline 243 & 0.00 & 0.00 & 0.00 & 0.00 & 1900.00 & 0.00 & 0.00 & 0.00 \\
\hline 244 & 0.00 & 0.00 & 0.00 & 0.00 & 0.00 & 0.00 & 0.00 & 0.00 \\
\hline 245 & 0.00 & 0.00 & 0.00 & 0.00 & 0.00 & 0.00 & 0.00 & 0.00 \\
\hline 246 & 0.00 & 0.00 & 0.00 & 0.00 & 0.00 & 0.00 & 0.00 & 2280.00 \\
\hline 247 & 0.00 & 0.00 & 0.00 & 0.00 & 0.00 & 0.00 & 0.00 & 0.00 \\
\hline 248 & 0.00 & 0.00 & 0.00 & 0.00 & 0.00 & 0.00 & 0.00 & 0.00 \\
\hline 249 & 0.00 & 0.00 & 0.00 & 0.00 & 0.00 & 0.00 & 0.00 & 0.00 \\
\hline 250 & 0.00 & 0.00 & 0.00 & 0.00 & 0.00 & 0.00 & 0.00 & 0.00 \\
\hline 251 & 0.00 & 0.00 & 1673.00 & 0.00 & 0.00 & 0.00 & 0.00 & 0.00 \\
\hline 252 & 0.00 & 0.00 & 0.00 & 0.00 & 0.00 & 0.00 & 0.00 & 0.00 \\
\hline 253 & 0.00 & 0.00 & 0.00 & 0.00 & 1789.00 & 0.00 & 0.00 & 0.00 \\
\hline 254 & 0.00 & 0.00 & 0.00 & 0.00 & 0.00 & 0.00 & 0.00 & 0.00 \\
\hline 255 & 0.00 & 0.00 & 0.00 & 0.00 & 0.00 & 0.00 & 0.00 & 0.00 \\
\hline 256 & 0.00 & 0.00 & 0.00 & 0.00 & 0.00 & 0.00 & 0.00 & 1921.00 \\
\hline 257 & 0.00 & 0.00 & 0.00 & 0.00 & 0.00 & 0.00 & 0.00 & 0.00 \\
\hline 258 & 0.00 & 0.00 & 0.00 & 0.00 & 0.00 & 0.00 & 0.00 & 0.00 \\
\hline 259 & 0.00 & 0.00 & 0.00 & 0.00 & 0.00 & 0.00 & 0.00 & 0.00 \\
\hline 260 & 0.00 & 0.00 & 0.00 & 0.00 & 0.00 & 0.00 & 0.00 & 0.00 \\
\hline 261 & 0.00 & 0.00 & 1594.00 & 0.00 & 0.00 & 0.00 & 0.00 & 0.00 \\
\hline 262 & 0.00 & 0.00 & 0.00 & 0.00 & 0.00 & 0.00 & 0.00 & 0.00 \\
\hline 263 & 0.00 & 0.00 & 0.00 & 0.00 & 1789.00 & 0.00 & 0.00 & 0.00 \\
\hline 264 & 0.00 & 0.00 & 0.00 & 0.00 & 0.00 & 0.00 & 0.00 & 0.00 \\
\hline 265 & 0.00 & 0.00 & 0.00 & 0.00 & 0.00 & 0.00 & 0.00 & 0.00 \\
\hline 266 & 0.00 & 0.00 & 0.00 & 0.00 & 0.00 & 0.00 & 0.00 & 1806.00 \\
\hline 267 & 0.00 & 0.00 & 0.00 & 0.00 & 0.00 & 0.00 & 0.00 & 0.00 \\
\hline 268 & 0.00 & 0.00 & 0.00 & 0.00 & 0.00 & 0.00 & 0.00 & 0.00 \\
\hline 269 & 0.00 & 0.00 & 0.00 & 0.00 & 0.00 & 0.00 & 0.00 & 0.00 \\
\hline 270 & 0.00 & 0.00 & 0.00 & 0.00 & 0.00 & 0.00 & 0.00 & 0.00 \\
\hline 271 & 0.00 & 0.00 & 1594.00 & 0.00 & 0.00 & 0.00 & 0.00 & 0.00 \\
\hline 272 & 0.00 & 0.00 & 0.00 & 0.00 & 0.00 & 0.00 & 0.00 & 0.00 \\
\hline 273 & 0.00 & 0.00 & 0.00 & 0.00 & 1515.00 & 0.00 & 0.00 & 0.00 \\
\hline 274 & 0.00 & 0.00 & 0.00 & 0.00 & 0.00 & 0.00 & 0.00 & 0.00 \\
\hline 275 & 0.00 & 0.00 & 0.00 & 0.00 & 0.00 & 0.00 & 0.00 & 0.00 \\
\hline 276 & 0.00 & 0.00 & 0.00 & 0.00 & 0.00 & 0.00 & 0.00 & 1732.00 \\
\hline 277 & 0.00 & 0.00 & 0.00 & 0.00 & 0.00 & 0.00 & 0.00 & 0.00 \\
\hline 278 & 0.00 & 0.00 & 0.00 & 0.00 & 0.00 & 0.00 & 0.00 & 0.00 \\
\hline 279 & 0.00 & 0.00 & 0.00 & 0.00 & 0.00 & 0.00 & 0.00 & 0.00 \\
\hline 280 & 0.00 & 0.00 & 0.00 & 0.00 & 0.00 & 0.00 & 0.00 & 0.00 \\
\hline 281 & 0.00 & 0.00 & 1392.00 & 0.00 & 0.00 & 0.00 & 0.00 & 0.00 \\
\hline 282 & 0.00 & 0.00 & 0.00 & 0.00 & 0.00 & 0.00 & 0.00 & 0.00 \\
\hline 283 & 0.00 & 0.00 & 0.00 & 0.00 & 1430.00 & 0.00 & 0.00 & 0.00 \\
\hline 284 & 0.00 & 0.00 & 0.00 & 0.00 & 0.00 & 0.00 & 0.00 & 0.00 \\
\hline 285 & 0.00 & 0.00 & 0.00 & 0.00 & 0.00 & 0.00 & 0.00 & 0.00 \\
\hline 286 & 0.00 & 0.00 & 0.00 & 0.00 & 0.00 & 0.00 & 0.00 & 1715.00 \\
\hline 287 & 0.00 & 0.00 & 0.00 & 0.00 & 0.00 & 0.00 & 0.00 & 0.00 \\
\hline 288 & 0.00 & 0.00 & 0.00 & 0.00 & 0.00 & 0.00 & 0.00 & 0.00 \\
\hline 289 & 0.00 & 0.00 & 0.00 & 0.00 & 0.00 & 0.00 & 0.00 & 0.00 \\
\hline 290 & 0.00 & 0.00 & 0.00 & 0.00 & 0.00 & 0.00 & 0.00 & 0.00 \\
\hline 291 & 0.00 & 0.00 & 1332.00 & 0.00 & 0.00 & 0.00 & 0.00 & 0.00 \\
\hline
\end{tabular}




\begin{tabular}{|c|c|c|c|c|c|c|c|c|}
\hline 292 & 0.00 & 0.00 & 0.00 & 0.00 & 0.00 & 0.00 & 0.00 & 0.00 \\
\hline 293 & 0.00 & 0.00 & 0.00 & 0.00 & 1430.00 & 0.00 & 0.00 & 0.00 \\
\hline 294 & 0.00 & 0.00 & 0.00 & 0.00 & 0.00 & 0.00 & 0.00 & 0.00 \\
\hline 295 & 0.00 & 0.00 & 0.00 & 0.00 & 0.00 & 0.00 & 0.00 & 0.00 \\
\hline 296 & 0.00 & 0.00 & 0.00 & 0.00 & 0.00 & 0.00 & 0.00 & 1715.00 \\
\hline 297 & 0.00 & 0.00 & 0.00 & 0.00 & 0.00 & 0.00 & 0.00 & 0.00 \\
\hline 298 & 0.00 & 0.00 & 0.00 & 0.00 & 0.00 & 0.00 & 0.00 & 0.00 \\
\hline 299 & 0.00 & 0.00 & 0.00 & 0.00 & 0.00 & 0.00 & 0.00 & 0.00 \\
\hline 300 & 0.00 & 0.00 & 0.00 & 0.00 & 0.00 & 0.00 & 0.00 & 0.00 \\
\hline 301 & 0.00 & 0.00 & 1295.00 & 0.00 & 0.00 & 0.00 & 0.00 & 0.00 \\
\hline 302 & 0.00 & 0.00 & 0.00 & 0.00 & 0.00 & 0.00 & 0.00 & 0.00 \\
\hline 303 & 0.00 & 0.00 & 0.00 & 0.00 & 1430.00 & 0.00 & 0.00 & 0.00 \\
\hline 304 & 0.00 & 0.00 & 0.00 & 0.00 & 0.00 & 0.00 & 0.00 & 0.00 \\
\hline 305 & 0.00 & 0.00 & 0.00 & 0.00 & 0.00 & 0.00 & 0.00 & 0.00 \\
\hline 306 & 0.00 & 0.00 & 0.00 & 0.00 & 0.00 & 0.00 & 0.00 & 1715.00 \\
\hline 307 & 0.00 & 0.00 & 0.00 & 0.00 & 0.00 & 0.00 & 0.00 & 0.00 \\
\hline 308 & 0.00 & 0.00 & 0.00 & 0.00 & 0.00 & 0.00 & 0.00 & 0.00 \\
\hline 309 & 0.00 & 0.00 & 0.00 & 0.00 & 0.00 & 0.00 & 0.00 & 0.00 \\
\hline 310 & 0.00 & 0.00 & 0.00 & 0.00 & 0.00 & 0.00 & 0.00 & 0.00 \\
\hline 311 & 0.00 & 0.00 & 1247.00 & 0.00 & 0.00 & 0.00 & 0.00 & 0.00 \\
\hline 312 & 0.00 & 0.00 & 0.00 & 0.00 & 0.00 & 0.00 & 0.00 & 0.00 \\
\hline 313 & 0.00 & 0.00 & 0.00 & 0.00 & 1316.00 & 0.00 & 0.00 & 0.00 \\
\hline 314 & 0.00 & 0.00 & 0.00 & 0.00 & 0.00 & 0.00 & 0.00 & 0.00 \\
\hline 315 & 0.00 & 0.00 & 0.00 & 0.00 & 0.00 & 0.00 & 0.00 & 0.00 \\
\hline 316 & 0.00 & 0.00 & 0.00 & 0.00 & 0.00 & 0.00 & 0.00 & 1349.00 \\
\hline 317 & 0.00 & 0.00 & 0.00 & 0.00 & 0.00 & 0.00 & 0.00 & 0.00 \\
\hline 318 & 0.00 & 0.00 & 0.00 & 0.00 & 0.00 & 0.00 & 0.00 & 0.00 \\
\hline 319 & 0.00 & 0.00 & 0.00 & 0.00 & 0.00 & 0.00 & 0.00 & 0.00 \\
\hline 320 & 0.00 & 0.00 & 0.00 & 0.00 & 0.00 & 0.00 & 0.00 & 0.00 \\
\hline 321 & 0.00 & 0.00 & 1166.00 & 0.00 & 0.00 & 0.00 & 0.00 & 0.00 \\
\hline 322 & 0.00 & 0.00 & 0.00 & 0.00 & 0.00 & 0.00 & 0.00 & 0.00 \\
\hline 323 & 0.00 & 0.00 & 0.00 & 0.00 & 1316.00 & 0.00 & 0.00 & 0.00 \\
\hline 324 & 0.00 & 0.00 & 0.00 & 0.00 & 0.00 & 0.00 & 0.00 & 0.00 \\
\hline 325 & 0.00 & 0.00 & 0.00 & 0.00 & 0.00 & 0.00 & 0.00 & 0.00 \\
\hline 326 & 0.00 & 0.00 & 0.00 & 0.00 & 0.00 & 0.00 & 0.00 & 1234.00 \\
\hline 327 & 0.00 & 0.00 & 0.00 & 0.00 & 0.00 & 0.00 & 0.00 & 0.00 \\
\hline 328 & 0.00 & 0.00 & 0.00 & 0.00 & 0.00 & 0.00 & 0.00 & 0.00 \\
\hline 329 & 0.00 & 0.00 & 0.00 & 0.00 & 0.00 & 0.00 & 0.00 & 0.00 \\
\hline 330 & 0.00 & 0.00 & 0.00 & 0.00 & 0.00 & 0.00 & 0.00 & 0.00 \\
\hline 331 & 0.00 & 0.00 & 1166.00 & 0.00 & 0.00 & 0.00 & 0.00 & 0.00 \\
\hline 332 & 0.00 & 0.00 & 0.00 & 0.00 & 0.00 & 0.00 & 0.00 & 0.00 \\
\hline 333 & 0.00 & 0.00 & 0.00 & 0.00 & 1035.00 & 0.00 & 0.00 & 0.00 \\
\hline 334 & 0.00 & 0.00 & 0.00 & 0.00 & 0.00 & 0.00 & 0.00 & 0.00 \\
\hline 335 & 0.00 & 0.00 & 0.00 & 0.00 & 0.00 & 0.00 & 0.00 & 0.00 \\
\hline 336 & 0.00 & 0.00 & 0.00 & 0.00 & 0.00 & 0.00 & 0.00 & 1158.00 \\
\hline 337 & 0.00 & 0.00 & 0.00 & 0.00 & 0.00 & 0.00 & 0.00 & 0.00 \\
\hline 338 & 0.00 & 0.00 & 0.00 & 0.00 & 0.00 & 0.00 & 0.00 & 0.00 \\
\hline 339 & 0.00 & 0.00 & 0.00 & 0.00 & 0.00 & 0.00 & 0.00 & 0.00 \\
\hline 340 & 0.00 & 0.00 & 0.00 & 0.00 & 0.00 & 0.00 & 0.00 & 0.00 \\
\hline 341 & 0.00 & 0.00 & 958.00 & 0.00 & 0.00 & 0.00 & 0.00 & 0.00 \\
\hline 342 & 0.00 & 0.00 & 0.00 & 0.00 & 0.00 & 0.00 & 0.00 & 0.00 \\
\hline 343 & 0.00 & 0.00 & 0.00 & 0.00 & 950.00 & 0.00 & 0.00 & 0.00 \\
\hline 344 & 0.00 & 0.00 & 0.00 & 0.00 & 0.00 & 0.00 & 0.00 & 0.00 \\
\hline 345 & 0.00 & 0.00 & 0.00 & 0.00 & 0.00 & 0.00 & 0.00 & 0.00 \\
\hline 346 & 0.00 & 0.00 & 0.00 & 0.00 & 0.00 & 0.00 & 0.00 & 1140.00 \\
\hline 347 & 0.00 & 0.00 & 0.00 & 0.00 & 0.00 & 0.00 & 0.00 & 0.00 \\
\hline 348 & 0.00 & 0.00 & 0.00 & 0.00 & 0.00 & 0.00 & 0.00 & 0.00 \\
\hline 349 & 0.00 & 0.00 & 0.00 & 0.00 & 0.00 & 0.00 & 0.00 & 0.00 \\
\hline 350 & 0.00 & 0.00 & 0.00 & 0.00 & 0.00 & 0.00 & 0.00 & 0.00 \\
\hline 351 & 0.00 & 0.00 & 898.00 & 0.00 & 0.00 & 0.00 & 0.00 & 0.00 \\
\hline 352 & 0.00 & 0.00 & 0.00 & 0.00 & 0.00 & 0.00 & 0.00 & 0.00 \\
\hline 353 & 0.00 & 0.00 & 0.00 & 0.00 & 950.00 & 0.00 & 0.00 & 0.00 \\
\hline 354 & 0.00 & 0.00 & 0.00 & 0.00 & 0.00 & 0.00 & 0.00 & 0.00 \\
\hline 355 & 0.00 & 0.00 & 0.00 & 0.00 & 0.00 & 0.00 & 0.00 & 0.00 \\
\hline 356 & 0.00 & 0.00 & 0.00 & 0.00 & 0.00 & 0.00 & 0.00 & 1140.00 \\
\hline 357 & 0.00 & 0.00 & 0.00 & 0.00 & 0.00 & 0.00 & 0.00 & 0.00 \\
\hline 358 & 0.00 & 0.00 & 0.00 & 0.00 & 0.00 & 0.00 & 0.00 & 0.00 \\
\hline 359 & 0.00 & 0.00 & 0.00 & 0.00 & 0.00 & 0.00 & 0.00 & 0.00 \\
\hline 360 & 0.00 & 0.00 & 0.00 & 0.00 & 0.00 & 0.00 & 0.00 & 0.00 \\
\hline 361 & 0.00 & 0.00 & 860.00 & 0.00 & 0.00 & 0.00 & 0.00 & 0.00 \\
\hline 362 & 0.00 & 0.00 & 0.00 & 0.00 & 0.00 & 0.00 & 0.00 & 0.00 \\
\hline 363 & 0.00 & 0.00 & 0.00 & 0.00 & 950.00 & 0.00 & 0.00 & 0.00 \\
\hline 364 & 0.00 & 0.00 & 0.00 & 0.00 & 0.00 & 0.00 & 0.00 & 0.00 \\
\hline 365 & 0.00 & 0.00 & 0.00 & 0.00 & 0.00 & 0.00 & 0.00 & 0.00 \\
\hline 366 & 0.00 & 0.00 & 0.00 & 0.00 & 0.00 & 0.00 & 0.00 & 1140.00 \\
\hline 367 & 0.00 & 0.00 & 0.00 & 0.00 & 0.00 & 0.00 & 0.00 & 0.00 \\
\hline 368 & 0.00 & 0.00 & 0.00 & 0.00 & 0.00 & 0.00 & 0.00 & 0.00 \\
\hline 369 & 0.00 & 0.00 & 0.00 & 0.00 & 0.00 & 0.00 & 0.00 & 0.00 \\
\hline 370 & 0.00 & 0.00 & 0.00 & 0.00 & 0.00 & 0.00 & 0.00 & 0.00 \\
\hline
\end{tabular}




\section{LISTA DE REFERÊNCIAS}

BOWERSOX, D.J., CLOSS, D.J. Logística Empresarial - O Processo de Integração da Cadeia de Suprimento. Ed. Atlas. São Paulo. 2001.

CHOONG, S.T., COLE, M.H., KUTANOGLU, E. Empty container management for container-on-barge (COB) transportation: planning horizon effects on empty container management in a multi-modal transportation network. 2001.

CRAINIC, T.G., GENDREAU, M., DEJAX, P. Dynamic and stochastic models for the allocation of empty containers. 1993.

FAGERHOLT, K. Optimal fleet design in a ship routing problem 1999.

GAO, Q. An operational approach container control in liner shipping. 1994.

GERTSBACH, I., GUREVICH, Y. Constructing an optimal fleet for a transportation schedule. 1977.

GLICKMAN, T.S., SHERALI, H.D. Large-scale network distribution of pooled empty freight cars over time, with limited substitution and equitable benefits. 1985. 
IMAI, A., RIVERA, F. Strategic fleet size planning for maritime refrigerated containers . 2001.

MENDIRATTA, V.B., TURNQUIST, M.A. Model for management of empty freight cars . 1982.

SHERALI, H.D., TUNCBILEK, C.H. Static and dynamic time-space strategic models and algorithms for multilevel rail-car fleet management. 1997.

TURNQUIST, M.A., JORDAN, W.C. Fleet sizing under production cycles and uncertain travel times. 1986.

UNCTAD. Review of Maritime Transport. Geneva: United Nations, 2003. 